\title{
VI. Rechtspflege und organisierte außernormative Gewalt: das Verhältnis der Justiz zu SS und Polizei
}

\section{Die Justiz und die Reichstagsbrandverordnung vom 28. Februar 1933 als Rechtsgrundlage für die Gestapotätigkeit}

Rechtsgrundlage für die nicht an gesetzliche Schranken gebundene Tätigkeit der Polizei war die „Verordnung des Reichspräsidenten zum Schutz von Volk und Staat“ vom 28. Februar $1933^{1}$, die am Tage nach dem Brand des Reichstagsgebäudes aufgrund des Artikels 48 Absatz 2 der Weimarer Verfassung erlassen wurde. Ob hinter dem gefaßten Brandstifter van der Lubbe tatsächlich andere Urheber standen bzw. an der Tat beteiligt waren oder nicht ${ }^{2}$ : der Brand wurde jedenfalls sofort und ohne das Ergebnis der Untersuchung abzuwarten den Kommunisten angelastet und dazu benutzt, die konservativen Mitglieder des Kabinetts und Hindenburg zur Unterzeichnung der Notverordnung zu bewegen. An der Abfassung des noch in den Morgenstunden des 28. Februar ausgearbeiteten Entwurfs hat Gürtner nicht teilgenommen, zu den Initiatoren dieser Verordnung gehörte er nicht. ${ }^{3}$ Als Frick am Vormittag den Entwurf im Kabinett verlas und Göring angebliche kommunistische Terrorabsichten wie Brand- und Sprengstoffanschläge, Vergiftung öffentlicher Küchen, Geiselnahmen usw. aufzählte, die sich aus beschlagnahmtem KPD-Material ergeben haben sollten, führte Gürtner lediglich aus, daß dann ,in den Entwurf auch noch die besonderen Tatbestände des Komplotts, des Gebrauchs des Giftes als Terrormittel sowie die Vorbereitung des Mordes Aufnahme finden müßten“". Es sei dahingestellt, ob Hitler, Göring und Frick an eine bevorstehende Aktion der Kommunisten glaubten oder die

1 RGBl. I, S.83.

2 Die Frage ist bis heute umstritten. Die These von der Alleintāterschaft van der Lubbes, die F. Tobias, Der Reichstagsbrand. Legende und Wirklichkeit, Rastatt 1962, mit beachtlichen Gründen vertritt, wird bestritten von W. Hofer, E. Calic, K. Stephan, F. Zipfel (Hrsg.), Der Reichstagsbrand. Eine wissenschaftliche Dokumentation, Bd. I, Berlin 1972, Bd. II, München 1978. Die Qualität dieser Dokumentation wird wiederum verneint in: U. Backes, K.-H. Janßen, E. Jesse, H. Köhler, H. Mommsen, F. Tobias, Reichstagsbrand - Aufklärung einer historischen Legende, München 1986.

3 Vgl. H. Mommsen, Der Reichstagsbrand und seine politischen Folgen (VfZ 1964, S. 351 ff.), S. 399. M. - Anhänger der These von der Alleintäterschaft van der Lubbes - sucht trotz der schlechten Aktenlage die Genesis der ReichstagsbrandVO zu erhellen.

4 Vgl. Niederschr. der Ministerbespr. am 28.2.33, vorm. 11 Uhr (Akten der Reichskanzlei, Die Regierung Hitler, Teil I: 1933/34, Band 1 [s. Anm. 3 in Kapitel I], Dok. Nr. 32, S. 128 ff.); ferner die kurze Schilderung der Sitzung bei M. Broszat, Zum Streit um den Reichstagsbrand (VfZ 1960, S. 275 ff.). 
nichtnationalsozialistischen Kabinettsmitglieder nur von der Notwendigkeit der vorgeschlagenen Maßnahmen „für eine rücksichtslose Auseinandersetzung mit der $\mathrm{KPD}^{\text {“s }}$ überzeugen wollten; jedenfalls fiel unter diesen Umständen der Vorschlag einer derartigen Verordnung, die laut Präambel ausdrücklich „zur Abwehr kommunistischer staatsgefährdender Gewaltakte" erlassen werden sollte, bei den konservativen Ministern auf fruchtbaren Boden. Als Frick in der Nachmittagssitzung des Kabinetts die endgültige Fassung des Entwurfs vortrug, waren Gürtners Anregungen berücksichtigt worden, indem $\S 5$ der Verordnung die Todes- und schwere Zuchthausstrafen für jene Straftaten vorsah, die Göring den Kommunisten unterstellte. In dieser Sitzung, in der die Reichsregierung die Verordnung billigte, waren weder Gürtner noch ein anderer Vertreter des Reichsjustizministeriums anwesend. ${ }^{6}$

Die wichtigsten Bestimmungen der Verordnung waren im $\S 1$ enthalten, der die hauptsächlichsten Grundrechte der Weimarer Verfassung „bis auf weiteres“ außer Kraft setzte und damit die Beschränkung der persönlichen Freiheit, des Rechts der freien Meinungsäußerung einschließlich der Pressefreiheit, des Vereins- und Versammlungsrechts und außerdem Eingriffe in das Brief-, Post-, Telegrafen- und Fernsprechgeheimnis, Anordnungen von Haussuchungen sowie Beschlagnahmen und Beschränkungen des Eigentums „auch außerhalb der sonst hierfür bestimmten gesetzlichen Grenzen“ für zulässig erklärte. Im $\S 2$ wurde die Reichsregierung ermächtigt, alle „zur Wiederherstellung der öffentlichen Sicherheit und Ordnung nötigen Maßnahmen" zu treffen und auch in den Ländern durchzusetzen, die zu diesem Zeitpunkt noch nicht gleichgeschaltet waren. Damit war in Deutschland der zivile Ausnahmezustand geschaffen, der bis zum Ende des Regimes 1945 aufrechterhalten blieb, war zugleich auch die verfassungsrechtliche Grundlage für die durch Gesetze nicht beschränkte Tätigkeit der Polizei gegeben - und zwar nicht nur zur Abwehr staatsgefährdender Akte. In der späteren Entwicklung der nationalsozialistischen Diktatur sollte sich die Gestapo als wichtigstes Organ des Maßnahmenstaates allerdings nicht mehr auf die Reichstagsbrandverordnung stützen, sondern ihre unbeschränkten Befugnisse aus dem „politischen Gesamtauftrag" herleiten, den sie von der Führung bekommen habe. ${ }^{7}$ In einem Runderlaß des Reichssicherheitshauptamtes von 1940 hieß es:

„Die Rechtsgültigkeit staatspolizeilicher Anordnungen ist nicht davon abhängig, daß die Verordnung des Reichspräsidenten zum Schutz von Volk und Staat vom 28. Februar 1933 als Rechtsgrundlage für diese Anordnungen angezogen wird, da sich die Befugnis der Geheimen Staatspolizei zur Durchführung aller Maßnahmen, die zur Erfüllung ihrer Aufgaben erforderlich sind, nicht aus einzelnen Gesetzen und Verordnungen, sondern aus dem Gesamtauftrag herleitet,

s So Hitler im Kabinett (Niederschrift a.a.O.).

6 Vgl. Niederschr. der Ministerbespr. am 28.2.33, nachm. 4.15 Uhr (a.a.O., Dok. Nr. 34, S. 132 f). Gürtner hatte jedoch die VO mit zu unterzeichnen, da in den $\S \S 4$ u. 5 sein Geschäftsbereich berührt war. Zum $\S 5$ der VO vgl. Kapitel VII.3.a., S. 823.

7 Vgl. H. Himmler, Aufgaben und Aufbau der Polizei des Dritten Reiches (in: Dr. Wilhelm Frick und sein Ministerium, München 1937, S.125ff.) S.128: „Die nationalsozialistische Polizei leitet ihre Befugnisse zum Vollzug des Willens der Staatsführung [d.h. nicht nur zur Gefahrenabwehr!] und zur Sicherung des Volkes und des Staates nicht aus Einzelgesetzen, sondern aus der Wirklichkeit des nationalsozialistischen Führerstaates und aus den ihr von der Führung gestellten Aufgaben her. Ihre Befugnisse dürfen deshalb nicht durch formale Schranken gehemmt werden, ...“. Zur pol. Polizei als Kern einer "politischen Verwaltung“ vgl. H. Buchheim, Die SS - das Herrschaftsinstrument (Anatomie des SS-Staates, Bd. I, Olten u. Freiburg i. Br. 1965), S. $96 \mathrm{ff}$. 
der der Deutschen Polizei im allgemeinen und der Geheimen Staatspolizei im besonderen im Zuge des Neuaufbaues des nationalsozialistischen Staates erteilt worden ist." ${ }^{\text {" }}$

Im Jahre 1933 jedoch stellte die Reichstagsbrandverordnung zunächst die Rechtsgrundlage für die Verhängung der polizeilichen Schutzhaft dar, die sehr bald nicht nur zur Bekämpfung „kommunistischer Staatsfeinde“, sondern als zentrales Zwangsmittel gegen Opposition von jeder Seite eingesetzt wurde. Aufgrund $\S 1$ der Verordnung, auf die sich die ausgestellten Schutzhaftbefehle ausdrücklich bezogen, konnte die Polizei nunmehr Personen verhaften, ohne an die zeitlichen und verfahrensrechtlichen Beschränkungen gebunden zu sein, die die $\$ \S 112 \mathrm{ff}$. StPO und die landesrechtlichen Regelungen der polizeilichen „Verwahrung“ - in Preußen $\S 15$ des Polizeiverwaltungsgesetzes $^{9}$ - hinsichtlich der Vorführung vor den Richter bzw. der Wiederentlassung aus der Haft aufstellten.

Da die Gestapobehörden bei ihrer Tätigkeit insoweit nicht mehr an die Gesetze gebunden waren, entzogen sich ihre Maßnahmen der Nachprüfung durch die Gerichte. Die Rechtsprechung der Verwaltungsgerichte, die der Justiz nicht unterstanden ${ }^{10}$, war in dieser Hinsicht nur noch ein Rückzugsgefecht: sie erkannten diesen Grundsatz schließlich an $^{11}$, noch bevor ihnen der $\S 7$ des preußischen Gesetzes über die Geheime Staatspolizei vom 10. Februar $1936^{12}$, das im ganzen Reich angewendet wurde, die Nachprüfung ausdrücklich entzog. Auf die Dauer hätten sie sich wohl auch ohne dieses Gesetz der herrschenden nationalsozialistischen Staatsauffassung nicht entziehen können ${ }^{13}$, daß Gesetzgebung, Verwaltung und Justiz nur verschiedene Tätigkeiten

${ }^{8}$ RdErl. des RSHA v. 15.4 .40 betr. Rechtsgrundlage für staatspolizeiliche Anordnungen (Allg. Erlaßsammlung 2 F I, S.6f., Arch. des IfZ, Sign. Dc 15.21).

9 PolizeiverwaltungsG v. 1.6.31 (preuß. GS 1931, S.77). Bereits die VO des Reichspräsidenten zum Schutze des deutschen Volkes v. 4.2.33 (RGBI. I, S. 35) hatte in $\$ 22$ eine erweiterte Polizeihaft bis zu drei Monaten, aber nur bei Verdacht strafbarer Handlungen (Hoch- und Landesverrat, bewaffnete Delikte) vorgesehen. Die Einordnung dieser Ermāchtigung unter den Abschnitt "Strafbestimmungen“ und vor allem die Zulassung der Anrufung des Amtsrichters, nach dessen verneinender Entscheidung über den dringenden Tatverdacht die Polizeihaft aufzuheben war, lassen erkennen, daß es sich noch um eine Maßnahme strafrechtlicher Art handelte.

10 Zum Aufbau u. Verfahren der damaligen Verw.Gerichte, die außer der obersten Rechtsstufe der Verw.Organisation ein- oder angegliedert waren, vgl. J. Danckwerts, Die Verwaltungsgerichtsbarkeit im nationalsozialistischen Staate (H. Frank, Deutsches Verwaltungsrecht, München 1937, S. 99 ff.); A. Wagner, Die Umgestaltung der Gerichtsverfassung und des Verfahrens- und Richterrechts in nationalsozialistischen Staat (Die deutsche Justiz und der Nationalsozialismus, Teil I, Stuttgart 1968), S. 332 ff.; W. Kohl, Reichsverwaltungsgericht (1991).

${ }^{11}$ Während z. B. das preuß. OVG in seiner Entsch. v.25.10.34 (WW 1935, S.1272) die Nachprüfbarkeit noch bejahte, vertrat es mit seiner Entsch. v. 2.5.35 die These, daß das Geheime Staatspolizeiamt (Gestapa) als "Sonderpolizeibehörde" nicht zu denjenigen im preuß. PolVerwG aufgeführten Polizeibehörden gehöre, deren Akte nach dem in Preußen bestehenden Enumerationsprinzip einer verwaltungsgerichtl. Nachprüfung unterlagen (ReichsVerwBl. 1935, S. 577). Vgl. dazu W. Hempfer, Die nationalsozialistische Staatsauffassung in der Rechtsprechung des Preußischen Oberverwaltungsgerichts, Berlin 1974, S.162 ff.; R. Echterhölter, Das öffentliche Recht im nationalsozialistischen Staat (Die deutsche Justiz und der Nationalsozialismus, Teil II, Stuttgart 1970), S. 100 ff.; E. Fraenkel, Der Doppelstaat, Frankfurt a. M.-Köln 1974, S. 52 ff.; W. Spohr, Recht der Schutzhaft, Berlin 1937, S. 73 ff.

12 Preuß. GS 1936, S.21, Berichtigung S. 28.

${ }^{13}$ Echterhölter (a.a.O., S. 100 f.) meint, daß das preuß. OVG statt der Entsch. v. 2.5.35 (Anm. 11) eine juristisch durchaus vertretbare Entsch. für eine weitere Nachprüfbarkeit hätte fällen können. Er läßt dabei den historischen Hintergrund u. die Tatsache unberücksichtigt, daß es die Führung in der Hand hatte, jederzeit auf gesetzgeberischem Wege eine Nachprüfung auszuschließen (vgl. Hempfer, a.a.O., S.164). In Sachsen z.B. wurde die Anfechtbarkeit poliz. Verfügungen, soweit sie aufgrund der ReichstagsbrandVO erlassen wurden, bereits durch das vom sächs. Gesamtministerium erlassene G. zur Änderung des G. über die Verwaltungsrechtspflege v. 14.12.33 (Sächs. GBI., S. 194) beseitigt. 
desselben Organismus seien, daher die Justiz nicht unter dem Blickpunkt einer anderen Betrachtungsweise verneinen könne, was die Exekutive als politische Handlung vornehme, und daß sich folglich die Gerichte nicht „auf das Gebiet der Staatspolizei begeben und möglicherweise im Einzelfall behördliche Maßnahmen staatspolitischer Natur durchkreuzen und aufheben" könnten. ${ }^{14}$ Am 30. April 1936 erfuhr der zuständige Referent im Reichsjustizministerium aus einem zwei Tage vorher in der Zeitung „Germania“ erschienenen Artikel von einem Beschluß des Preußischen Oberverwaltungsgerichts vom 19. März, daß nicht nur die Verfügungen der Gestapodienststellen, sondern nunmehr in bestimmten Fällen auch diejenigen der ordentlichen Polizeibehörden im Verwaltungsstreitverfahren unanfechtbar seien. Das Ministerium forderte daraufhin die Entscheidung beim Oberverwaltungsgericht an, und seine Angehörigen konnten in der übersandten Abschrift nachlesen, daß tatsächlich

„diejenigen Anordnungen sachlichen Inhalts der ordentlichen (Kreis- und Orts-)Polizeibehörden der Anfechtung entzogen [sind], die diese in ihrer Eigenschaft als Hilfsorgane der Geheimen Staatspolizei ... in einer Angelegenheit der Geheimen Staatspolizei getroffen haben“.

Die Verfügungen brauchten nur ,nach Anlaß und Ziel sich selbst als zum Schutze der Staatssicherheit bestimmt kennzeichnen“, um sie der richterlichen Nachprüfung zu entziehen. ${ }^{15}$

Der von den Verwaltungsgerichten anerkannte Rechtszustand ermöglichte es den Gestapobehörden und den in deren Aufgabenbereich handelnden ordentlichen Polizeibehörden, über die Schranken von $\S 14$ des preußischen Polizeiverwaltungsgesetzes hinaus tätig zu werden. Dieser Paragraph hatte die Aufgabe der Polizei dahin bestimmt, daß sie „im Rahmen der geltenden Gesetze die nach pflichtmäßigem Ermessen notwendigen Maßnahmen“ treffen könne, „um von der Allgemeinheit oder dem einzelnen Gefahren abzuwehren, durch die die öffentliche Sicherheit oder Ordnung bedroht wird“. ${ }^{16}$ Nunmehr konnte die politische Polizei die Reichstagsbrandverordnung nicht nur zur Gefahrenabwebr - von der die Präambel der Verordnung sprach -, sondern zu jedem Zweck anwenden: durch die Aufhebung der erwähnten Schranken war z.B. auch „die Verhängung von Schutzhaft nicht nur gegen aktive Staatsfeinde, sondern z. B. auch aus erzieherischen Gründen, gegen Kritiker der Regierung der nationalen Erhebung, gegen Miesmacher usw. zulässig, auch wenn sie nicht die öffentliche Sicherheit (i.S. $\S \S 14$ und 41 PVG) gefährden". ${ }^{17}$

Auch die ordentlichen Gerichte sollten der Gestapo in dieser Hinsicht die Beseitigung verfassungsrechtlicher, gesetzlicher und polizeirechtlicher Schranken bescheini-

14 Urt. des Hamburg. VerwGs v. 7.10.35, vgl. (auch allgemein) v. Voß, Verwaltungsgerichtsbarkeit (1988), S.131 ff., 137.

15 Das OVG hielt die Nachprüfbarkeit nur dann für gegeben, wenn sich die Verf. außerhalb des Zuständigkeitsbereichs der Gestapo bewege (Beschl. des preuß. OVG v. 19.3.36, Art. der "Germania" v. 28.4.36 u. Korrespondenz vgl. Akten des RJM, BA, Sign. R 22/1462). Der Beschl. des preuß. OVG wurde dann auch in der Jurist. Wochenschrift vom 1.8.36 (JW 1936, S.2189) veröffentlicht.

16 Preuß. PVG v. 1.6.31 (preuß. GS 1931, S.77). Die fast wörtlich aus dem Allg. Preuß. Landrecht (10 II 17) von 1794 übernommenen Bestimmungen des $\S 14$ galten kraft gewohnheitsrechtlicher Úbung seit vielen Jahrzehnten in ganz Deutschland. Gemäß $\S 41$ waren polizeil. Verfügungen, die nicht aufgrund eines besonderen Gesetzes oder einer PolizeiVO erlassen wurden, nur gültig, soweit sie zur Beseitigung einer Störung oder zur Abwehr einer bevorstehenden Gefahr für die öffentl. Sicherheit oder Ordnung erforderlich waren.

17 So die Ansicht der Gestapo, vertreten durch W. Spohr, Das Recht der Schutzhaft (Dj, Nr. v. 12.1.34, S. 59); vgl. demgegenüber den im April 1934 unternommenen Vetsuch des RMdI, die Befugnis durch neue Schutzhaftbestimmungen einzuschrānken (s. Kapitel VI.2.a., S.548f.). Zur Einführung der polizeilichen Vorbeugungshaft gegen unpolitische Kriminelle durch Görings Erl. v. 13.11.33, die gleichfalls auf der ReichstagsbrandVO und der Lösung der Polizei vom PVG beruhte, s. Kapitel VI.8.a., S.719f. 
gen, wenn auch nicht ohne anfängliche Schwierigkeiten. Sie waren insofern zuständig, als $\S 4$ der Reichstagsbrandverordnung denjenigen mit Strafen bedrohte, der den von der Reichsregierung, den obersten Landesregierungen oder den ihnen nachgeordneten Behörden zur Durchführung der Verordnung erlassenen Anordnungen zuwiderhandelte oder dazu aufforderte. Die Gerichte vertraten nun bei Strafprozessen verschiedentlich die Auffassung, daß auf die Reichstagsbrandverordnung gestützte Anordnungen der Gestapo rechtswidrig seien, da sie nicht der - in der Präambel ausgesprochenen - Zielsetzung der „Abwehr kommunistischer staatsgefährdender Gewaltakte" dienten. ${ }^{18} \mathrm{Um}$ dieser - der Führung höchst ungelegenen - engen Auslegung der Verordnung vorzubeugen, hatte Ministerialdirektor Crohne vom preußischen Justizministerium bereits in einem Artikel der Septemberausgabe 1933 der „Deutschen Justiz" - ohne die Verordnung dabei zu nennen - ausgeführt:

„Ebenso verfehlt, wie geistlose Wortklauberei, ist aber auch die Auslegungsweise, die sich an die Überschrift eines Gesetzes klammert. Diese will nur die Veranlassung des Gesetzes bezeichnen, kann aber nie wesentlicher Bestandteil des Gesetzestextes selbst werden, vor allem wenn die Gesetzesworte selbst einen Begriff, den die Überschrift bringt, nicht enthalten. “19

Seine verkappte Mahnung wurde jedoch nicht überall beherzigt. So stellte z.B. das Schöffengericht in Neuwied Ende November 1934 das Verfahren gegen einen evangelischen Missionar ein, der als Anhänger der Bekennenden Kirche den Konfirmanden Briefe mit nach Hause gegeben hatte, in denen er gegen die örtliche Kirchenleitung der Deutschen Christen angegangen war. Ihm wurde zur Last gelegt, damit gegen die staatspolizeiliche Anordnung des Oberpräsidenten der Rheinprovinz vom 12. Juni 1934 verstoßen zu haben, die ,jede unsachliche Polemik bei der Erörterung und Wiedergabe kirchenpolitischer Fragen" untersagte. Das Gericht erklärte diese Anordnung jedoch für ungültig, da es sich bei der Bekennenden Kirche „nicht um einen Zusammenschluß von Anhängern der ehemaligen kommunistischen Partei“ handele und die Anordnung daher nicht dem Anwendungsgebiet der Reichstagsbrandverordnung entspreche: „Auch selbst die weiteste Auslegung des Begriffs ,Abwehr kommunistischer staatsgefährdender Gewaltakte', wonach etwa kommunistische Gewaltakte nur mittelbar herbeigeführt werden könnten“, sei gegenüber dieser Bewegung nicht anwendbar. $^{20}$

Als ein weiteres Beispiel sei der Beschluß des Amtsgerichts in Siegburg vom Mai 1935 angeführt, das die Eröffnung des Hauptverfahrens gegen einen Schneider ablehnte, der als Führer eines katholischen Jugendverbandes mit seiner Gruppe eine Wanderung mit Geländespielen veranstaltet hatte: die staatspolizeiliche Anordnung des Regierungspräsidenten in Köln vom 21. Mai 1934, die das öffentliche Auftreten konfessioneller Jugendverbände verbot und gegen die der Schneider verstoßen haben

${ }^{18} \mathrm{Vgl}$. demgegenüber die Feststellung im RdSchr. des oldenburg. MdI v. 2.8.33 (Niedersächs. StArch. Olden-

burg, Sign. Best. 136, (Nr. 2889): „Die Verordnung richtet sich ... gegen alles, was die kommunistische Bewegung auch nur mittelbar fördert. ... Alles was das Ansehen der Regierung und die Wirkung ihrer Maßnahmen herabzusetzen geeignet ist, hindert den neuen Staat an der Bekämpfung des Kommunismus und dient daher mittelbar zur Förderung kommunistischer staatsfeindlicher Bestrebungen“; auch W. Hamel, Wesen und Rechtsgrundlagen der Polizei im nationalsozialistischen Staate (H. Frank, Deutsches Verwaltungsrecht, München 1937), S. 386 f.: Die Präambel könne "nicht dahin verstanden werden, daß die Behörden nur in diesem Kampfe von den liberalen Fesseln frei sind: die liberalen Grenzen dürfen nicht nur durch Maßnahmen durcbbrocben werden, sondern sie sind vorbehaltlos niedergelegt“" (Hervorheb. im Original).

19 W. Crohne, Bedeutung und Aufgaben der Sondergerichte (DJ 1933, S.385).

${ }^{20}$ Urt. des SchöffenG Neuwied v. 29.11.34 (Akten des RJM, BA, Sign. R 22/1496). 
sollte, sei nicht rechtswirksam, da sie über den Rahmen der Reichstagsbrandverordnung hinausgehe: „Aber selbst bei weitester Auslegung wird man nicht sagen können, daß Zweck, Ziel und Betätigung der konfessionellen, also der kath. und evangelischen Jugend- und Standesverbände mit kommunistischen Bestrebungen irgend etwas zu tun haben." ${ }^{21}$

Die Strafrechtspflegeabteilung des Reichsjustizministeriums unter Freisler stellte sich entschieden gegen eine solche einschränkende Auslegung der Reichstagsbrandverordnung, die auch nur von einer Minderheit der Gerichte vertreten wurde. ${ }^{22}$ Als sich Mitte April 1935 das Geheime Staatspolizeiamt, das sich von seinen Dienststellen über die Rechtsprechung berichten ließ, bei Freisler über derartige Entscheidungen beschwerte, antwortete Abteilungsleiter Crohne, ihm seien Gerichtsentscheidungen mit ,irrtümlicher, den Zweck der genannten Verordnung verkennender Auslegung ... in letzter Zeit nur vereinzelt aufgefallen“. Er habe aber dann fast stets die Staatsanwaltschaft angewiesen,

„durch Einlegung etwa möglicher Rechtsmittel die fehlerhafte Entscheidung revidieren zu lassen und im übrigen durch nachdrückliche Hervorhebung einerseits der die Bekämpfung jeglichen staatsfeindlichen Zusammenschlusses bezweckenden Absicht des Gesetzgebers, andererseits der Bedeutungslosigkeit der Überschrift der genannten Verordnung für den Umfang ihrer Anwendungsmöglichkeit künftigen Fehlentscheidungen der Gerichte nach Möglichkeit zu begegnen “". 23

In der Tat zeitigte diese „Lenkung über den Staatsanwalt“ bei den Revisionsgerichten Erfolge, auch in den genannten beiden Fällen: das Kammergericht, das die Lehre von der "mittelbaren kommunistischen Gefahr" entwickelt hatte, hob das Urteil des Schöffengerichts Neuwied im Mai 1935 mit der Begründung auf, zum Einschreiten aufgrund der Verordnung genüge

„schon die mittelbare Gefahr, die für den Staat durch die Verbreitung als Ausdruck der Unzufriedenheit mit der neuen Ordnung der Dinge sich kennzeichnender und damit dem Wiederauftauchen kommunistischer Bestrebungen den Boden bereitender Meinungen entsteht ${ }^{\text {. }}{ }^{24}$

Ebenso wurde der erwähnte Beschluß des Amtsgerichts Siegburg, gegen den der Oberstaatsanwalt in Bonn am 20. Mai 1935 Beschwerde einlegte, schon am nächsten Tag durch den Beschluß der 2. Strafkammer des Landgerichts Bonn aufgehoben, der besagte, daß mit den Eingangsworten der Reichstagsbrandverordnung "nur der nächstliegende Zweck bezeichnet sein [solle], ohne eine Beschränkung der Anwendung dieser VO. auf die Abwehr ausschließlich kommunistischer Gewaltakte etc. auszudrücken“. Das Schöffengericht mußte nunmehr das Verfahren durchführen und verurteilte den Angeklagten zu einer Geldstrafe. ${ }^{25}$ Das Geheime Staatspolizeiamt beobachtete die Rechtssprechung der Gerichte in dieser Hinsicht auch weiterhin genau:

21 Beschl. des SchöffenG Siegburg v. 7.5.35 (a.a.O.).

22 Beispiele aus der Mehrheit der Urteile: Urt. des LG Berlin v. 1.11.33 (DJ 1934, S.63 f.): „Uberdies werden alle gegen die öffentliche Sicherheit und Ordnung als gegen den Bestand des Staates gerichtete Angriffe als kommunistische im weitesten Sinne [?] aufzufassen sein“; ferner Urt. des SG Hamburg v. 15.3.35 (JW 1935, S. 2989).

${ }^{23}$ Schr. des RJM (I.V. Crohne für den in Urlaub befindl. Freisler) v. 29.4.35 (Akten des RJM, BA, Sign. R 22/1496).

24 Urt. des KG v. 17.5.35 (a.a.O. und DJ 1935, S. 1831 f.; dort irrtüml. nach dem Tag der Verhandl. mit 3.5.35 datiert).

25 Akten des RJM (BA, Sign. R 22/1496). Der Beschl. des LG Bonn v. 21.5.35 stützte sich auf ein Urt. des RG v. 23.1.34 (JW 1934, S. 767). Weitere einschläg. Urt. des RG, des KG, des OLG München u. a. bei Fraenkel, a.a.O., S. 43 ff., 59 . 
noch im September 1935 forderte es alle Staatspolizeistellen auf, sofort zu berichten, wenn Gerichte die Verordnung etwa in anderem Sinne auslegten. ${ }^{26}$

Auch aus anderen Gründen erklärten Gerichte polizeiliche Anordnungen, die aufgrund der Reichstagsbrandverordnung ergangen waren, für nichtig. Die Verordnung hatte die Polizeibehörden zwar von den inhaltlichen Schranken des preußischen Polizeiverwaltungsgesetzes befreit, dennoch blieben ihre Anordnungen entweder Polizeiverordnungen oder Polizeiverfügungen im Sinne der Paragraphen 24 und 40 dieses Gesetzes und "daher auch in formeller Beziehung den dafür geltenden Vorschriften“ unterworfen. ${ }^{27}$ Das Sondergericht Altona sprach z. B. im April 1935 Ernste Bibelforscher wegen Rechtsungültigkeit des Verbots ihrer Vereinigung durch den preußischen Innenminister vom 24. Juni 1933 frei, weil es als Rechtsverordnung - d.h. als ein für eine unbestimmte Zahl von Fällen an einen unbestimmten Personenkreis gerichtetes Verbot - nicht in der Preußischen Gesetzsammlung veröffentlicht worden war, wie es $\S 35$ des Polizeiverwaltungsgesetzes vorschrieb. Als eine Polizeiverfügung aber könne es sich nur auf eine bestimmte Person oder einen bestimmten Personenkreis beziehen, d.h. auf die Internationale Bibelforschervereinigung e.V. in Magdeburg, deren Mitgliederzahl satzungsgemäß auf zwölf Personen beschränkt sei. Die übrigen Anhänger seien von dem Verbot dagegen nicht erfaßt worden, weil sie organisatorisch nicht zu einem bestimmten Personenkreis zusammengefaßt seien und den einzelnen eine polizeiliche Verbotsverfügung nicht zugestellt worden sei. Das Urteil bewirkte, daß der Oberstaatsanwalt in Altona Anklagen in gleichliegenden Fällen vorerst zurücknahm. ${ }^{28}$ Als das Sondergericht Breslau ein gleiches Urteil fältte, nahm Ministerialdirektor Crohne Verbindung mit dem Reichsinnenministerium auf. Es stellte sich heraus, daß die Veröffentlichung der Anordnung vom 24. Juni 1933 vergessen worden war. ${ }^{29}$ Das Innenministerium vertrat jedoch die Ansicht, es müsse

„von der unbestreitbaren Tatsache ausgegangen werden, daß sich in mehr als zweijähriger Verwaltungsübung auf der Grundlage der VO. zum Schutze von Volk und Staat auf Grund revolutionären Rechts die Rechtsfigur der, staatspolitischen Anordnungen' entwickelt habe, die sowohl nach Inhalt und Form als auch nach der Art der Verkündung nicht an den Maßstäben der geltenden Polizeigesetze gemessen werden könne“.

Das Innenministerium würde es daher begrüßen, wenn „in geeigneter Form der ... unrichtigen Rechtsauffassung der Sondergerichte Altona und Breslau entgegengetreten würde“. 30

Crohne sah abermals einen Artikel in der „Deutschen Justiz“ als die geeignete Form der Urteilskritik an. Er rügte darin, „daß Richter aus derart formellen Gründen freisprechen“ und mit ihrem Urteil eine „Mißachtung des ausdrücklich kundgetanen Willens der nationalsozialistischen Staatsführung“ zum Ausdruck brächten. Er legte die

26 Erl. des Gestapa v. 19.9.35 (Staatsarch. Düsseldorf, Sign. RW 18, Nr. 4).

27 So ausdrücklich noch im Erl. des preuß. MdI v. 3.3.33 (MBliV I, S. 233).

28 Urt. des SG Altona v. 3.4 .35 (vgl. Diensttageb. des RJM, Bd.3, Eintr. v. 18.5.35, BA, Sign. R 22/1056). Crohne mußte durch RV v. 5.6.35 alle preuß. GStAe anweisen, bis zur Klärung der Frage „von Anklageerhebungen abzusehen und bereits festgesetzte Hauptverhandlungstermine aufheben zu lassen“ (Akten des RJM, BA, R 22/953).

29 Vgl. Diensttageb. des RJM, Eintr. v. 17.6.35 (a.a.O., Sign. R 22/1056). Die preuß. Anordn. v. 24.6.33 war am 13.9.34 durch einen Erl. des RuPrMdI auf Reichsebene ersetzt worden.

30 Vgl. Diensttageb. des RJM, Eintr. v. 29.6.35 (a.a.O.). Die Abt. V (öffentl. Recht) des RJM faßte die ReichstagsbrandVO dahin auf, „daß sie zwar für die Polizei keine neuen Befugnisse geschaffen habe [!], daß sie jedoch die Polizei von der Einhaltung der Formvorschriften befreie“ (Eintr. v. 17.6.35, a.a.O.). 
These des Innenministeriums von der in der Praxis entwickelten Rechtsfigur der „staatspolizeilichen Anordnung“ dar, die auch nach Art der Verkündung nicht an den Polizeigesetzen der Länder gemessen werden könne. Vor allem könne sie „nicht in das hergebrachte Schema ,Polizeiverordnung' oder ,Polizeiverfügung' gepreßt werden, weil es sich um ein eigenartiges, aus den politischen Bedürfnissen einer Übergangszeit geborenes Gebilde handelt ${ }^{\text {“. }}{ }^{31}$ Kurze Zeit später mußte Crohne jedoch selbst das „hergebrachte Schema“ gegenüber der Gestapo verteidigen. Im September 1935 beschwerte sich das Geheime Staatspolizeiamt unter Hinweis auf eine Reihe bekanntgewordener Fälle, daß verschiedene Staatsanwaltschaften die Strafverfolgung von Zuwiderhandlungen gegen staatspolizeiliche Verfügungen mit der Begründung ablehnten, daß eine Bestrafung gemäß $\S 4$ der Reichstagsbrandverordnung nur erfolgen könne, wenn es sich um eine aufgrund dieser Verordnung ergangene Rechtsverordnung der Gestapo handele. Das Geheime Staatspolizeiamt äußerte die gegenteilige Ansicht, daß der im $\S 4$ gebrauchte Ausdruck „Anordnungen“ einen Oberbegriff darstelle, der Polizeiverordnungen und -verfügungen umfasse, weshalb auch Verstöße gegen staatspolizeiliche Verfügungen von der Justiz verfolgt werden müßten. ${ }^{32}$ Demgegenüber vertrat Crohne im Auftrag des Ministeriums den vom Innenministerium unterstützten Standpunkt, daß mit dem Wort „Anordnungen“ im $\S 4$ der Reichstagsbrandverordnung schon deshalb nur allgemeine Anordnungen, die sich an einen unbestimmten Personenkreis richteten, gemeint sein könnten, weil die dort angedrohten Mindeststrafen von einem Monat Gefängnis oder einer Geldstrafe von 150 bis 15000 Reichsmark für die Nichtbefolgung polizeilicher Verfügungen ungewöhnlich hoch seien. Der Gesetzgeber habe schließlich generell den Ungehorsam gegen polizeiliche Verfügungen straflos gelassen, weil zur Erreichung des erstrebten Zieles die Anwendung des Verwaltungszwanges - in Preußen die Androhung von Zwangsgeld, unmittelbarem Zwang und Zwangshaft nach dem Polizeiverwaltungsgesetz - genüge und ein Einschreiten mit Mitteln des Strafrechts überflüssig mache; soweit in Einzelfällen gesetzlich Strafe angedroht werde, handele es sich nur um Übertretungsstrafen. Hinzu komme, daß die Verfügungen der Gestapo nicht mit Rechtsmitteln, sondern nur mit der Dienstaufsichtsbeschwerde angefochten werden könnten ${ }^{33}$; da die Dienstaufsichtsbeschwerde jedoch keine aufschiebende Wirkung habe, sei - vom Standpunkt der Gestapo aus die Strafe für eine Zuwiderhandlung gegen eine Verfügung selbst dann verwirkt, wenn die Aufsichtsbehörde die Verfügung später mißbillige und aufhebe. Crohne hob aber hervor, daß die Verbote bestimmter Vereinigungen im Einklang mit seinen Ausführungen in der „Deutschen Justiz“ auf jeden Fall als allgemeine Anordnungen und Verstöße gegen sie als nach $\S 4$ der Reichstagsbrandverordnung strafbar angesehen würden. Bei jenen Fällen jedoch, die die Beschwerde der Gestapo veranlaßt hätten, sehe sich das Ministerium zu einer Änderung seiner Auffassung nicht in der Lage. ${ }^{34}$ Als

31 Crohne, Die Verbote der Internationalen Bibelforschervereinigung sind rechtsgültig (DJ, Ausgabe v. 9.8.35, S. $1144 \mathrm{f}$.$) .$

32 Schr. des Gestapa an das RJM v. 13.9.35 (Akten des RJM, BA, Sign. R 22/1496).

$33 \mathrm{Vgl}$. Urt. des preuß. OVG v. 2.5.35 (Anm. 11), K. Lauer, Die polizeirechtliche Bedeutung der Verordnung zum Schutze von Volk und Staat (RVerwBl. 1935, S.168ff.), S. 171, auch schon: W. Spohr, Das Recht der Schutzhaft (DJ 1934, S. 58 ff.), S. 59.

${ }^{34}$ Schr. des RJM (I. A. Crohne) an das Gestapa v. 10.1.36; Schr. des RJM an das RuPrMdI v. 9. 10.35 u. Antw. v. 14.12.35 (Akten des RJM, a.a.O.). 
Folge dieser Auffassung genossen auch weiterhin nur allgemeine staatspolizeiliche Anordnungen den strafrechtlichen Schutz des $\S 4$ der Verordnung vom 28. Februar 1933; da zu ihnen aber auf jeden Fall das Verbot der Bibelforschervereinigung gezählt wurde, wurde es von der Rechtsprechung nunmehr generell anerkannt.

Auch die Frage, ob die durch die Reichstagsbrandverordnung nicht ausdrücklich suspendierten Grundrechte der Weimarer Verfassung noch fortgalten, haben Gerichte verschiedentlich noch bejaht. So vertrat das Sondergericht Darmstadt im März 1934 die Ansicht, daß die in der Verordnung nicht aufgezählten Art. 135 (Glaubensfreiheit) und 137 (Freiheit der Vereinigung zu Religionsgesellschaften) der Reichsverfassung noch in Kraft seien, da überdies ihre Suspension in Art. 48 Abs. 2 - auf dem die Notverordnung vom 28. Februar 1933 beruhte - überhaupt nicht vorgesehen war. Diese Meinung hatte im Januar 1934 auch das Reichsgericht geäußert. ${ }^{35}$ Das Sondergericht sprach daraufhin Ernste Bibelforscher frei, die das Verbot ihrer Religionsgesellschaft mißachtet hatten. Bereits ein Jahr später änderte das Sondergericht jedoch seine Rechtsprechung. ${ }^{36}$ Das Reichsgericht behielt zwar seine Ansicht von der Weitergeltung des Art. 137 bei, erklärte aber das Verbot für zulässig, wenn es nicht wegen der Eigenschaft als Religionsgesellschaft, sondern aus anderen Gründen erfolgte; etwa wenn die Ziele der Gesellschaft "mit der Ordnung des Staatswesens unvereinbar" und darauf gerichtet waren, „den Bestand des Staates zu vernichten oder auch nur zu schwächen" ${ }^{37}$ Die Justiz konnte die Gestapo nicht mehr daran hindern, mit ihren Anordnungen auch in die „diktaturfesten“ Grundrechte einzugreifen. Diese hilflosen Versuche der Gerichte, die Tätigkeit der Gestapo am positiven Recht zu messen und dabei doch dem Willen der politischen Führung gerecht zu werden, hat der Leiter der Abteilung Verwaltung und Recht im Geheimen Staatspolizeiamt, Werner Best, treffend charakterisiert: sie versuchten „sich durch eine gewaltsam erweiterte Auslegung des Begriffes der Gefahrenabwehr zu helfen, die manchmal geradezu zu innerer Unwahrheit der Begründungen“ führe. Diesen untauglichen Versuchen sollte nach seiner Meinung durch die Anerkennung des neuen Polizeirechts ein Ende bereitet werden, das die Gestapo - kraft ihres von der Führung erteilten Auftrags - in der Form von Einzelregelungen und Dienstanweisungen schaffe, und das keiner Kontrolle durch die Justiz mehr bedürfe. ${ }^{38}$

Trotz der willfährigen Rechtsprechung versuchte daher die Polizeiführung, der Justiz die Zuständigkeit für die Ahndung von Verstößen gegen Polizeiverordnungen, die aufgrund der Reichstagsbrandverordnung erlassen worden waren, abzusprechen. Als z.B. der Oberstaatsanwalt in Breslau bei der dortigen Staatspolizeistelle anfragte, warum Zuwiderhandlungen gegen die preußische Polizeiverordnung gegen konfessionelle Jugendverbände vom 23. Juli 1935 von der Polizei nicht zur Aburteilung durch das Sondergericht abgegeben, sondern durch eigene Maßnahmen bestraft würden, er-

35 Urt. v. 23.1.34 (JW 1934, S.767).

${ }^{36}$ Urt. des SG Darmstadt v. 26.3.34 (WW 1934, S. 1747) u. nichtveröffentl. Urt. v. 29.4.35 SM 20/35 (erwähnt DJ 1935, S. 1145).

37 Urt. des RG v. 24.9.35 (JW 1935, S.3377).

${ }^{38}$ W. Best, Werdendes Polizeirecht (DR 1938, S.224ff.), S.226: „Der Eindruck eines Rechtszwiespaltes“ werde allein dadurch verursacht, daß die Gerichte unter Nichtbeachtung des von der Gestapo geschaffenen neuen Rechts „Entscheidungen fällen, die dann durch polizeiliche Maßnahmen wieder unschädlich gemacht werden müssen“: „Die aus dieser Divergenz etwa entspringende Ansehensminderung trifft dabei bestimmt nicht die Geheime Staatspolizei, deren Maßnahme als letzte immer recht behält.“ 
hielt er zur Antwort, daß die Gerichte dafür nicht zuständig seien, weil $\S 3$ der von Heydrich gezeichneten Polizeiverordnung eigene polizeiliche Strafbestimmungen vorsehe. Auch die Staatspolizeistelle Oppeln berief sich dem Oberstaatsanwalt gegenüber auf eine Anweisung des Geheimen Staatspolizeiamts, „derzufolge Verstöße gegen die genannte Pol. Verordnung allein im Wege polizeilichen Zwanges und schließlich im Wege der Schutzhaft geahndet werden" sollten. Auf Bitte des Oberstaatsanwalts um Weisung erhob das Reichsjustizministerium bei der Gestapoführung dagegen rechtliche Bedenken: Da sich die Polizeiverordnung ausdrücklich auf die Reichstagsbrandverordnung stütze, gelte für sie auch deren $\S 4$, der als allgemeine Rahmenbestimmung „die Zuwiderhandlungen gegen sämtliche Rechtsverordnungen unter Strafe stellt, die auf Grund der VO vom 28.2.33 erlassen werden". Weil diese Rechtsauffassung auch von der Rechtsprechung vertreten werde, bitte das Justizministerium, die Staatspolizeistellen anzuweisen, ,ihren gegenteiligen Standpunkt fallen zu lassen“. ${ }^{39}$ Daraufhin hob die Gestapoführung den fraglichen $\S 3$ der Polizeiverordnung tatsächlich auf. ${ }^{40}$

Blieben die ordentlichen Gerichte auf dem Umweg über Strafverfahren somit weiterhin für die Nachprüfung allgemeiner Anordnungen der Gestapo zuständig, so waren deren Verfügungen im Einzelfall ihrer Nachprüfung entzogen, da sie - wie dargelegt - nicht mit Rechtsmitteln, sondern nur mit der Dienstaufsichtsbeschwerde anfechtbar waren. Zu ihnen gehörte die schärfste Waffe der Gestapo: die Schutzhaft. ${ }^{41}$ Zu einer Überprüfung der Rechtmäßigkeit und Zweckmäßigkeit bei der Anwendung der Schutzhaft waren die ordentlichen Gerichte mangels gesetzlicher Grundlage auch nicht auf dem Umweg über eine Schadensersatzklage wegen Amtspflichtverletzung nach § 839 BGB im Zusammenhang mit dem nicht außer Kraft gesetzten Artikel 131 der Weimarer Verfassung über Staatshaftung für Beamte befugt. ${ }^{42}$ Durch die Aufhebung der Gesetzmäßigkeit der Exekutive auf diesem Gebiet entwickelte sich die politische Polizei zu einem Verfolgungsinstrument, das zwar von der Justiz unabhängig tätig wurde, mit dem die Justiz wegen der engen Verwandtschaft der Aufgaben aber dennoch auf verschiedene Art und Weise in konfliktträchtige Berührung kam.

39 Vgl. dazu Schr. des OStA Breslau an das RJM v. 26.2.36 nebst Anl.; Schr. des RJM an das Gestapa v. 10.6.36 (Akten des RJM, a.a.O.).

40 Schr. des Gestapa an das RJM v. 30.10 .36 (a.a.O.) u. PolizeiVO v. 19.10.36 zur Änderung der PolizeiVO gegen die konfessionellen Jugendverbände (Preuß.GS, S. 159).

${ }^{4} \mathrm{Im}$ Hinblick auf eine stets erhoffte generelle Neuregelung des Gesamtkomplexes hielt die Justizverw. noch 1938 theoretisch den Anspruch aufrecht, Schutzhaft bei „der Erörterung (und Ahndung) einer strafbaren Handlung“ nachprüfen zu können, wenn „offensichtlicher Ermessensmißbrauch oder Willkür“ vorlägen. Vgl. die Kritik des Generalref. für politische Strafsachen OStA Klemm an der Schrift von O. Geigenmüller, Die politische Schutzhaft im nationalsozialistischen Staat, Würzburg 1937 (DJ v. 15.7.38, S. 1135). Klemm fuhr allerdings fort: "Wenn es sich insoweit auch nur um theoretische Erwägungen handelt (die Praxis hatte noch keinen Anlaß, dazu Stellung nehmen zu müssen), so ist es mit Rücksicht auf die zukünftige Regelung [!] notwendig", diesen Grundsatz aufrechtzuerhalten.

42 Vgl. z. B. Beschl. des LG Tübingen v. 25.1.34 (JW 1934, S.627f.); Beschl. des OLG München v. 31.10 .36 (JW 1937, S. 243f.): „Die Verhängung und Ausführung der Schutzhaft als solche ist im Deutschen Reiche nach der hierüber erlassenen VO v. 28. Febr. 1933 (RGBl I, 83) ausschließlich eine Maßnahme der politischen Polizei. Zur Nachprüfung solcher rein politischen Akte können aber die Verwaltungsrichter und die bürgerlichen Gerichte im Deutschen Reiche auch auf dem Umweg einer Schadensersatzklage nicht veranlaßt werden. Diese Rechtswege sind vielmehr nach dem Inhalte, Sinn und Zwecke der gesetzlichen Vorschriften über die Schutzhaft für die Beteiligten geschlossen.“ 


\section{Die Bemühungen der Justiz um eine „Verrechtlichung“ der Schutzhaft}

Eines der wichtigsten Instrumente für die Errichtung und Aufrechterhaltung der nationalsozialistischen Diktatur war die Schutzhaft und ihr Vollzug im Konzentrationslager. Das Institut der Schutzhaft war zwar nicht neu ${ }^{1}$, nahm aber durch seinen Masseneinsatz und die Beseitigung rechtsstaatlicher Beschränkungen einen anderen Chrakter an. Obgleich die Justiz die unheilvolle Entwicklung, die das Schutzhaftwesen ohne ihre unmittelbare Beteiligung nahm, keineswegs begrüßte, haben die Anhänger eines autoritären Staates in der Justizleitung, wie z.B. Gürtner, die vorübergehende Verwendung der Polizeihaft zum Zwecke der Überwindung der politischen, vor allem der linken, Opposition sowie der inneren Festigung des „nationalen“ Regimes - weniger dagegen als vorbeugendes Mittel zur Bekämpfung der Kriminalität ${ }^{1 a}$ - aus Überzeugung bejaht: als Verächter jenes „liberalistischen“ Begriffs der Rechtssicherheit, der die unverbrüchliche Garantie des einzelnen gegen Übergriffe eines Staates beinhaltete, dessen Gerichte ohne Ausnahme auch „schützen, was sie hassen“" Juristen die Berechtigung außerordentlicher Maßnahmen der Staatsgewalt für politische Ziele an. Nur sollte nach ihren Vorstellungen auch dieser, nicht durch die Justiz, sondern durch die Exekutive (Polizei) angeordnete Freiheitsentzug in „rechtlich“ geregelten Bahnen vor sich gehen - weniger um der Gerechtigkeit, als vielmehr sachlicher Berechenbarkeit willen - und keinesfalls die Verfolgung strafrechtlicher Delikte bezwecken, für die die Justiz als allein zuständig angesehen wurde. Dem Reichsjustizministerium schien diese Beschränkung des Schutzhaftwesens auf seine eigentlichen

${ }^{1}$ Die beiden preußischen Gesetze „zum Schutze der persönlichen Freiheit“ v. 24.9.1848 und 12.2.1850 gestatteten „Personen in polizeiliche Verwahrung zu nehmen, wenn der eigene Schutz dieser Person oder die Aufrechterhaltung der öffentlichen Sittlichkeit, Sicherheit und Ruhe diese Maßregel dringend erfordern" ( $(\S 6$ des G.v. 12.2.1850). Die Festgenommenen mußten aber spätestens am übernächsten Tage freigelassen oder dem Gericht bzw. einer Irrenanstalt, einem Armen- oder Siechenhaus o.ä. überwiesen werden. Das G. von 1850 wurde durch das Preußische PolizeiverwaltungsG v. 1.6.1931 (preuß. GS, S.77, s. dazu Kapitel VI.1., S. 537 und Anm.9) ersetzt. Die anderen deutschen Gliedstaaten besaßen ähnliche Regelungen. Neben dieser ordentlichen polizeilichen Verwahrung gab es die außerordentliche polizeiliche Verwahrung aufgrund des Ausnahmezustandes: Als bei Ausbruch des Ersten Weltkrieges die vollziehende Gewalt auf die Militärbefehlshaber überging, konnten sie aufgrund des Preußischen Gesetzes über den Belagerungszustand v. 4.6.1851 (preuß. GS, S. 451) den Art. 5 der Preußischen Verfassung, der die Freiheit der Person gewährleistete, außer Kraft setzen und Verhaftungen vornehmen. Nach Beschwerden und Petitionen an den Bundesrat und den Reichstag wurde ein eigenes G. „betreffend die Verhaftung und Aufenthaltsbeschränkung auf Grund des Kriegszustandes und des Belagerungszustandes“ v.4.12.1916 (RGBI., S. 1329) erlassen, das die Haft „zur Abwendung einer Gefahr für die Sicherheit des Reichs“ ermöglichte, aber schriftlichen Haftbefehl mit Gründen, richterliche Vernehmung am folgenen Tag über Einwendungen des Verhafteten, Beschwerderecht an das Reichsmilitärgericht, Recht auf einen Verteidiger und Haftprüfung nach drei Monaten vorschrieb. Wenngleich sich der Ausdruck „Schutzhaft“ in keinem der genannten Gesetze findet, bürgerte er sich im Sprachgebrauch für diese Haftart ein. Vgl. dazu O. Geigenmüller, Die politische Schutzhaft im nationalsozialistischen Deutschland, Würzburg 1937, S. 7 ff. Soweit in der Weimarer Zeit bei Erklärung des Ausnahmezustandes nach Art. 48 Abs. 2 der Reichsverfassung die persönliche Freiheit beschränkt wurde, war das G. v.4.12.16 „entsprechend anzuwenden“; vgl. z.B. $\S 5$ der VO des Reichspräsidenten betreffend die zur Wiederherstellung der öffentlichen Sicherheit und Ordnung im Reichsgebiet mit Ausnahme von Bayern, Sachsen, Württemberg und Baden und der von ihnen umschlossenen Gebiete nötigen Maßnahmen v. 13.1 .20 (RGBI. S. 207).

1a Vgl. dazu Kapitel VI.8.a., S.721 ff.

2 Treffender Ausdruck bei E. Fraenkel, „Rule of Law“ in einer sich wandelnden Welt, in: Reformismus und Pluralismus, Hamburg 1973, S. 274. 
Ziele am besten gewahrt werden zu können, wenn die Zuständigkeit für die polizeiliche Schutzhaft nach Überwindung der revolutionären Phase der nationalsozialistischen Machtergreifung wieder voll dem Innenministerium zugesprochen wurde und nicht endgültig in die Hände der SS-Führung überging. Der Gedanke, das Schutzhaftund Konzentrationslagerwesen nach einer Stabilisierung des Regimes überhaupt wieder abzuschaffen, ist bei verschiedenen leitenden Juristen lebendig geblieben ${ }^{3}$; jedoch gibt es keine Beweise, daß sie sich für diesen Gedanken etwa bei Hitler entschieden eingesetzt hätten. In seinen Memoiren berichtet Hans Frank, er habe im März 1934 in seiner Eigenschaft als Reichsjustizkommissar „einen direkten Vorstoß bei Hitler" gemacht und "eine Gesamtaussprache über dieses dringende Problem“ der Schutzhaft beantragt, die schließlich im April unter Beteiligung Himmlers, Gürtners und anderer mit Hitler in der Reichskanzlei stattgefunden habe:

„Ich trug meine Argumente an Hand eines reichen Materials vor. Ich beantragte, daß ein Endzeitpunkt für dieses ganze, System 'bestimmt werden müsse, der so nahe wie möglich zu liegen hätte und daß ab sofort sämtliche Weiterverhaftungen einzustellen und alle bisher vorgenommenen und aufrechterhaltenen Inhaftierungen ... juristisch, also durch die ordentlichen Gerichte nachgeprüft werden sollten. Reichsjustizminister Dr. Gürtner stimmte mir in ernsten Worten zu, aber er und ich blieben allein."

Hitler habe diese Maßnahmen angesichts der innenpolitischen Lage als „verfrüht“ bezeichnet, sie würden vom Gegner lediglich als Schwächezeichen gedeutet werden. ${ }^{4}$ Die Darstellung Franks ist dokumentarisch nirgends belegt. ${ }^{5}$ Himmler bestätigt lediglich in einer Rede vom März 1936, daß im Jahre 1934 neben einem Abbau des Konzentrationslagerwesens „sogar der Gedanke erwogen wurde, ob man nicht die Politischen Polizeien auflösen könnte und sie in die übrige Verwaltung restlos wieder eingliedern könne". ${ }^{6}$ Nachdem aber Hitler zur Beibehaltung der Institution der Schutzhaft und der Gestapo als eigenständiger Organisation entschlossen war, unterstützte die Justiz das Innenministerium bei dem Bestreben, durch eindeutige Bestimmungen eine materielle Ausgestaltung der Schutzhaft zu erreichen, die Mißbrauch nach Möglichkeit ausschloß, und die politische Polizei hinsichtlich der Einhaltung der Bestimmungen zu überwachen. Wenn dabei die Einhaltung im Einzelfall auch nicht durch die ordentlichen Gerichte nachgeprüft werden konnte, so sollten die Interessen der Schutzhäftlinge gegenüber den Gestapobehörden wenigstens durch Rechtsanwälte vertreten werden können. Zu dieser Vorstellung von einer institutionalisierten Schutz-

${ }^{3}$ Vgl. z. B. die Einleitung zu Fricks RdErl. v. 12.4.34 (Kapitel VI.2.a., S. 548 f.). Bei der Behandlung der Zulässigkeit der Polizeiaufsicht in der Sitzung der amtlichen Strafrechtskommission am 2.3.34 äußerte Gürtner: „Die völlige Aufhebung der persönlichen Freiheit wird nicht von Dauer sein. Der Zeitpunkt bis zur nächsten Habeascorpusakte wird um so näher gerückt, je länger die Aufhebung der persönlichen Freiheit rechtens ist. Da die Aufhebung der persönlichen Freiheit im praktischen Vollzug gewisse Kritik herausfordert, müssen sowohl die Schutzhaft wie die polizeilichen Befugnisse gegenüber dem einzelnen irgendwie in Normen gegossen werden“ (Strafrechtskommission, 18. Sitzung, 2. März 1934, Schubert, Quellen II.2.1, S. 473).

${ }^{4} \mathrm{H}$. Frank, Im Angesicht des Galgens. Deutung Hitlers und seiner Zeit auf Grund eigener Erlebnisse und Erkenntnisse, München-Gräfelfing 1953, S. 160 f.

5 Eine regelrechte Kabinettssitzung bzw. Ministerbespr. fand im April 1934 nicht statt (vgl. Úberblick über die Sitzungen des Reichskabinetts, Arch. des IfZ, Sign. Fa 203/4).

6 Eigenhänd. korrig. Manuskr. der Rede Himmlers vor den preuß. Staatsräten im Haus der Flieger am 5.3.36 (IfZ, Sign. MA 311); H. bezeichnete diese Absicht als „einen der schwersten politischen Fehler", den der NSStaat hätte begehen können, er habe geglaubt, "vor solchen Gedankengängen eindringlich warnen zu müssen“. Zu den Versuchen Fricks, sich die Gestapo im Zuge der Verreichlichung zu unterstellen, s. Kapitel
VI.2.a., S. $552 \mathrm{ff}$. 
haft gehörte auch, daß sich die Behandlung der Gefangenen während des Vollzugs in den Polizeigefängnissen und Konzentrationslagern - analog dem Vollzug in den Justizgefängnissen - innerhalb der Sphäre des Rechts bewegte, d.h. Mißhandlung oder Tötung von Häftlingen strafrechtliche Delikte darstellten. Die mit Ausnahmen erfolglosen Versuche der Justiz, derartige Delikte in der revolutionären Phase zu verfolgen, sind bereits dargestellt worden; sehr viel mehr Erfolg sollte ihren Bemühungen auch gegenüber den bürokratisch-organisierten Untaten in Himmlers Konzentrationslagersystem nicht beschieden sein. Die Bestrebungen der Justiz, eine Verwischung der Funktionen von Polizei und Justiz zu verhindern, ihr Bemühen um eine klare Trennung von Polizeimaßnahmen und gerichtlicher Tätigkeit und um eine „Verrechtlichung" der Schutzhaft im Verein mit dem Innenministerium, ihre Auseinandersetzung mit Himmlers Polizeiapparat - der sich in dieser Zeit gegenüber dem Innenministerium verselbständigte - über Eingriffe in die Strafrechtspflege, über Korrekturen der Gerichtsurteile durch polizeiliche Schritte und andere Probleme, die die Abgrenzung der beiderseitigen Funktionen aufwarf, sollen im folgenden behandelt werden.

\section{a. Bemübungen um den Erlaß und die Einhaltung von Schutzhaftbestimmungen zur Abgrenzung der Gestapotätigkeit von der Rechtspflege}

Die Anstrengungen der Justiz, die Schutzhaft als Instrument der Verfolgung strafrechtlicher Handlungen auszuschalten, für die allein die Gerichte zuständig bleiben sollten, vereinigten sich mit dem Bestreben der inneren Verwaltung, das ausufernde Schutzhaftwesen durch eindeutige Bestimmungen und strengere Kontrolle in den Griff zu bekommen.' Gürtner fand daher bei Göring und Frick Unterstützung. In einem Runderlaß an die Landesregierungen vom 9. Januar 1934 stellte Frick fest, er könne sich „des Eindrucks nicht erwehren, daß von der Schutzhaft in manchen Fällen ein mit ihrem Zweck nicht vereinbarer Gebrauch gemacht" werde, und wies darauf hin, sie dürfe vor allem

„nicht als ,Strafe“ d.h. als Ersatz für eine gerichtliche oder polizeiliche Strafe, zudem mit von vornherein begrenzter Dauer verhängt werden. Es ist daher grundsätzlich nicht angängig, daß an Stelle der Einleitung eines Strafverfahrens Schutzhaft angeordnet wird.“8

7 Die wichtigsten Vorschriften betr. Organisation u. Zuständigkeit der Gestapo bis März 1934 waren in PreuBen: VO des preuß. MdI v. 2.3.33 (GS, S.33), RdErl. des preuß. MdI v. 3.3.33 (MBliV. I, S. 233), G. v. 26.4.33 (GS, S. 122), RdErl. des preuß. MdI v. 26. 4.33 (MBliV. I, S. 503), 28.4.33 (a.a.O., S. 510), 14.10.33 (Arch. des IfZ, Sign. Fa 183/1, Bl. 284), G. v. 30.11 .33 (GS, S.413). Im RdErl. des preuß. MinPräs/Gestapo v. 16.1.34 (Arch. des IfZ, a.a.O., Bl.297) hieß es bezeichnend: „Diese meine Anordnungen sind bisher nicht überall so beachtet worden, wie ich es erwartet und gewünscht hätte. Konnte in der ersten Zeit nach der Machtübernahme auch darüber hinweggesehen werden, weil die Sicherung des Staates gegen Anschläge und Umtriebe seiner Feinde damals schnelle, durch formale Vorschriften nicht behinderte Maßnahmen erforderte, so müssen heute die ergangenen Bestimmungen genau beobachtet werden ... Zuwiderhandelnde setzen sich der Gefahr aus, wegen Amtsmißbrauchs und Freiheitsberaubung zur Verantwortung gezogen zu werden“; VO v. 8.3.34 (GS, S. 143), RdErl. des MinPräs/Chef der Gestapo v. 8.3.34 u. 14.3.34 (MBliV. I, S. 469 u. 471). In Bayern: Bekanntm. des StMdI v. 4.4.33 (GuVOBl. S.85), Anordn. des StMdI v. 1.4.33 (a.a.O., S.95), RdErl. des StMdI v. 10.4.33 (BayerHStArch., Sign. MJu 12202); durch eine Dienstanweisung des OSAF v. 1.9.33 wurde in Bayern den Sonderbevollmächtigten $\mathbf{u}$. Sonderbeauftragten der SA die Befugnis zur Schutzhaftverhängung entzogen und die ausschließl. Zuständigkeit der politischen Polizei anerkannt (RdErl. des StMdI/ Polit.Pol. Kommandeur Bayerns v. 8.1.34, a.a.O., Bl.294), die jedoch zahlreiche Verhaftungen „auf Antrag“ von Stellen der Bewegung vornahm.

${ }^{8}$ RdErl. des RMdI an die Landesreg. v. 9.1.34 (Arch. des IfZ, Sign. Fa 183/1 (a), Bl. 295). 
Bezeichnenderweise gab Heydrich im Auftrag des Politischen Polizeikommandeurs in Bayern diesen Erlaß seinen nachgeordneten Behörden mit dem vielsagenden Hinweis bekannt, „daß bei Gefahr im Verzuge nach wie vor rasches und scharfes Eingreifen geboten" sei." Im bayerischen Kabinett rügte Justizminister Frank, der sich seit April 1933 vergeblich für ein streng geregeltes Schutzhaftverfahren eingesetzt hatte, die Praxis der politischen Polizei: „die Verhaftungen in dem gegenwärtigen Ausmaß mit den vielfach unzureichenden Begründungen seien nicht tragbar". Er drang aber mit seinem Vorschlag, daß der Innenminister die Anordnung der Schutzhaft selbst treffen solle, nicht durch. ${ }^{10}$ In Preußen hielt es Göring als Chef der dortigen Gestapo für notwendig, in einem Erlaß vom 11. März 1934 seine Beobachtung mitzuteilen, daß die Stapostellen teilweise Schutzhaftmaßnahmen ergriffen hätten, „die als Mißbrauch der gesetzlichen Handhaben bezeichnet werden" müßten, und ordnete an:

„Wird die Schutzhaft als provisorische Maßnahme wegen des Verdachts einer strafbaren Handlung angeordnet, so ist unverzüglich die Entscheidung des Gerichts über die Verhängung der gerichtlichen Untersuchungshaft herbeizuführen und im Falle der Ablehnung eines richterlichen Haftbefehls auch die polizeiliche Maßnahme außer Kraft zu setzen, sofern nicht ausnahmsweise ihre Aufrechterhaltung aus anderen Gründen begründet erscheint.“

In diesen Fällen sollte der richterliche Haftbefehl „unter allen Umständen binnen 24 Stunden" herbeigeführt werden; war er innerhalb dieser Frist nicht zu erlangen, war der Betroffene sofort zu entlassen. Sollte die Schutzhaft aus anderen Gründen aufrechterhalten werden, so war dem Ministerpräsidenten binnen 24 Stunden telegrafisch zu berichten und die Maßnahme genau zu begründen. Ordnete der Ministerpräsident die Fortdauer der Schutzhaft nicht an, so sollte sie spätestens am 8. Tage automatisch außer Kraft treten. Göring drohte an, die mißbräuchliche Schutzhaft künftig „unnachsichtlich" ahnden zu lassen. Die Justiz hielt diesen Erlaß für so wichtig, daß sie ihn in ihrem Ministerialblatt veröffentlichte. ${ }^{11}$

Im April 1934 suchte das Reichsinnenministerium den Auswüchsen der Schutzhaft durch einheitliche Bestimmungen für das ganze Reich Herr zu werden. ${ }^{12}$ Es ist bemerkenswert, daß der grundlegende Runderlaß des Reichsinnenministers an die Landesregierungen und Reichsstatthalter vom 12. April 1934 - er wurde am 26. April um einige Bestimmungen ergänzt - noch von der Vorstellung ausging, die auch Gürtner teilte und die in der Rechtsprechung selbst des Reichsgerichts verschiedentlich zum Ausdruck gekommen war ${ }^{13}$ : daß Ausnahmezustand und Schutzhaftwesen vorübergehende Erscheinungen seien. In der Einleitung wurde festgestellt, daß das Recht der

9 RdErl. des bayer. StMdI/Polit.Pol.Kommandeur Bayerns v. 25.1.34 (a.a.O., Bl. 296).

${ }^{10}$ Vgl. Niederschr. der Ministerratssitzung v. 27.2.34 (BayerHStArch., Sign. MA 99 525); vgl. auch schon Niederschr. der Sitzung v. 7.4 .33 (a.a.O., Sign. MA 99 526): „Es sei ein förmliches Verfahren einzurichten, das die Zuständigkeit regele und den Verhafteten gewisse Sicherungen und Beschwerdemöglichkeiten biete."

11 Erl. des Preuß. MinPräs/Gestapo v. 11.3.34, veröffentl. durch die AV des preuß. JM v. 15.3.34 (DJ 1934, S. 341). In dem Erl. hob Göring ferner die Zuständigkeit der Kreispolizeibehörden für Schutzhaft auf und wiederholte die Unzuständigkeit von Dienststellen der Bewegung.

12 RdErl. des RMdI v. 12./26.4.34 (Akten des RJM, BA, Sign. R 22/1467). M. Broszat, Nationalsozialistische Konzentrationslager 1933-1945 (Anatomie des SS-Staates, Bd. II, Olten u. Freiburg i. Br. 1965), S. 38, charakterisiert diesen Schutzhafterlaß treffend als „Ausdruck des von der inneren Verwaltung ausgehenden Strebens nach Normalisierung und möglichst gar völligem Abbau der außerordentlichen Einrichtung der Schutzhaft und der Konzentrationslager, das damals auch vor allem von seiten der Justiz unterstützt wurde“.

13 Vgl. Urt. des RG v. 22.10.34: Die Eigentumsgarantie des Art. 153 der Reichsverf. sei durch die RTBr VO außer Kraft gesetzt mit der „Maßgabe, daß dies nur bis auf weiteres zu gelten habe“ (Akten des RJM, BA, Sign. R 22/1496, veröffentl. in Entsch. des RG in Zivilsachen 145, S.373f.). 
Freiheit der Person „zur Abwehr der durch den Reichstagsbrand vom 27. Februar 1933 angekündigten staats- und volksfeindlichen Umsturzbestrebungen" durch die Notverordnung vom 28. Februar 1933 „zeitweilig aufgehoben“ worden sei. Da aber "die Zeit für die völlige Beseitigung der Schutzhaft noch nicht reif“" sei, diese Maßnahme aber vielfach mißbräuchlich angewendet worden sei, würden nunmehr einheitliche Schutzhaftbestimmungen erlassen, die künftig strengstens zu beachten seien. Der Erlaß enthielt eine genaue Zuständigkeitsregelung ${ }^{14}$, die den „Stellen der NSDAP und der SA (Kreisleiter, Gauleiter, SA-Führer)" die Befugnis zur Inschutzhaftnahme absprach, und bedrohte jeden, der ohne Zuständigkeit verhaftete, „rücksichtslos“ mit Strafverfolgung wegen Freiheitsberaubung. Dem Häftling sollte künftig innerhalb 24 Stunden ein mit Gründen versehener Schutzhaftbefehl ausgehändigt werden; er durfte nur noch in staatlichen Gefangenenanstalten oder Konzentrationslagern verwahrt werden. Die Schutzhaft wurde nur für zulässig erklärt entweder „zum eigenen Schutze des Häftlings“ oder wenn er "durch sein Verhalten, insbesondere durch staatsfeindliche Betätigung, die öffentliche Sicherheit und Ordnung unmittelbar gefährdet“. Sofern nicht zugleich eine dieser beiden Voraussetzungen vorlag, sollte die Verhängung von Schutzhaft u. a. nicht zulässig sein ,gegen Personen, die lediglich von einem ihnen nach bürgerlichem oder öffentlichem Recht zustehenden Anspruch (z. B. Anzeige, Klage, Beschwerde) Gebrauch machen“, sowie "gegen Rechtsanwälte wegen Vertretung von Interessen ihrer Klienten". Diese Unzulässigkeitsbestimmungen waren auf Drängen der Justiz aufgenommen worden ${ }^{15}$; der für sie wichtigste Passus aber lautete:

„Die Verhängung von Schutzhaft ist ferner nicht zulässig zur Ahndung strafbarer oder zwar nicht strafbarer, aber sonst verwerflicher Handlungen. Strafbare Handlungen sind durch die Gerichte abzuurteilen. Für die Verhaftung von Angeschuldigten gelten die Vorschriften der Strafprozeßordnung ( $\S \S 112 \mathrm{ff}$.). Auch ohne richterlichen Haftbefehl ist eine vorläufige Festnahme nach $\S 127$ Abs. 2 der Strafprozeßordnung zulässig (Polizeihaft). ${ }^{16}$ Nur in besonderen Ausnahmefällen kann danach bei strafbaren Tatbeständen die Verhängung von Schutzhaft gerechtfertigt erscheinen. In diesen Fällen ist schleunigst auf den Erlaß eines richterlichen Haftbefehls hinzuwirken.“

Auch „als Ersatzstrafe auf bestimmte Zeit“ sollte Schutzhaft nicht verhängt werden dürfen. ${ }^{17}$

14 Für Schutzhaft waren danach zuständig in Preußen: das Gestapa, die Ober- u. Reg.Präs., der PolPräs. in Berlin u. die Stapostellen; in den übrigen Ländern die von der LReg. bestimmten Behörden. Dazu wurden in Bayern bestimmt: die BPP, die Pol.Direktionen u. Stapoämter, die Bezirksämter u. deren Vorstände als Stadtkommissäre (RdErl. des bayer. StMdI v. 2.5.34, Arch. des IfZ, Sign. Fa 183/1(a), Bl.316 ff.). Stellen der Bewegung konnten Schutzhaft lediglich bei den zuständ. Stellen anregen; eine Ausnahme machten die Gauleiter/RStH: Fricks Ergänzungserl. v. 26.4.34 (Akten des RJM, a.a.O.) sah vor, daß die Oberste Landesbehörde einem Ersuchen des RStH um Schutzhaftverhängung entsprechen mußte, der dann die alleinige Verantwortung trug u. zur Entlassung seine Zustimmung geben mußte. Durch RdErl. v. 10.7.34 (a.a.O.) erinnerte Frick als Reaktion auf die abgeschlossene Röhm-Aktion, daß zu den „Stellen, die zur Inschutzhaftnahme nicht befugt sind, auch die Stellen der SS. zu rechnen sind“.

15 Vgl. dazu Kapitel VI.7.a. Ferner war Schutzhaft unzulässig wegen persönlicher Angelegenheiten (z. B. Beleidigungen) u. wegen wirtschaftlicher Maßnahmen (Lohnfragen, Entlassung von Arbeitnehmern usw.).

${ }^{16} \S 127$ Abs. 1 StPO gibt jedermann das Recht zur vorläufigen Festnahme eines Menschen, den er auf frischer Tat antrifft oder verfolgt, wenn er der Flucht verdächtig ist oder seine Persönlichkeit nicht sofort festgestellt werden kann. Abs. 2 befugt die StAschaft u. die Polizei zur vorläufigen Festnahme, wenn die Voraussetzungen eines richterl. Haftbefehls vorliegen und Gefahr im Verzug obwaltet.

17 Die Schutzhaftdauer war wie in Görings Erl. v. 11.3.34 geregelt: wurde die Schutzhaft nicht von der Obersten Landesbehörde selbst angeordnet, war an diese sofort zu berichten und der Häftling spätestens am 8. Tage der Haft zu entlassen, sofern die Oberste Landesbehörde bis dahin den Haftbefehl nicht bestätigt hatte. Neu war, daß die Oberste Landesbehörde alle drei Monate die Frage der Entlassung zu prüfen hatte. 
Mit diesem Erlaß schien die präventive Tätigkeit der Gestapo bzw. politischen Polizei, die hier nochmals - aller Konkurrenten entledigt - für die Schutzhaft allein zuständig erklärt wurde, von der Tätigkeit der Justiz deutlich getrennt und abgegrenzt worden zu sein. Es sollte sich jedoch erweisen, daß die Gestapo nach der Übernahme der politischen Polizeien der Länder und des Geheimen Staatspolizeiamtes durch Himmler und Heydrich, die noch im selben Monat erfolgte, erst recht nicht daran dachte, sich an diese Abgrenzung zu halten, obgleich selbst Hitler - wohl auf Veranlassung des Innenministers - im August 1934 nach der Röhm-Affäre nochmals anordnete, daß Fricks Erlaß „von allen Stellen genau beachtet" werde. ${ }^{18}$

Das Reichsinnenministerium sah sich nicht mehr in der Lage, die Schutzhaftpraxis der politischen Polizei und ihre Eingriffe in die Justiz auf dem Wege über die Reichsstatthalter zu kontrollieren oder gar zu korrigieren. In Bayern endete ein solcher Versuch kläglich: Am 20. März 1934 hatte Reichsstatthalter von Epp in einer langen Beschwerdeschrift ihm bekanntgewordene Begründungen für die Schutzhaft - „Trunksucht, Mißhandlung der Ehefrau, Fangen von Singvögeln, Holzfrevel, Unterschlagung von Organisationsgeldern, unsittlicher Lebenswandel, grober Unfug, Arbeitsscheue u.a." - gerügt und gefordert, daß Strafsachen vor den Richter gehörten. Die nationalsozialistische Strafgesetzgebung habe neue strafrechtliche Tatbestände geschaffen, die eine Schutzhaft in vielen Fällen entbehrlich machten, und durch die Einrichtung der Sondergerichte mit ihrem vereinfachten Verfahren sei auch eine rasche Aburteilung gewährleistet. Er forderte daher eine Aufstellung der in Bayern festgehaltenen Schutzhäftlinge mit genauer Angabe der Gründe. ${ }^{19}$ Sie wurde ihm von Innenminister Wagner verweigert, da ihre Anforderung eine Kontrolle und Aufsicht über Beamte seines Geschäftsbereichs bedeute und lediglich beweise, „daß die Reichsstatthalterei der Behandlung der Schutzhaftfälle durch sein Ministerium das nötige Vertrauen nicht entgegenbringt “. Er gab offen zu, daß die Schutzhaft wegen der kritisierten Begründungen „nicht ganz den Buchstaben der geltenden Bestimmungen entspricht. Wohl aber entspricht sie dem nationalsozialistischen Empfinden“. Wagners Ausführungen gipfelten in der Behauptung, daß die Schutzhaft zur Korrektur der Justiz notwendig sei:

„Tatsache ist jedenfalls, daß die Inschutzhaftnahme von Personen wegen oben angeführter krimineller Delikte zweifellos wesentlichen Anteil an dem Rückgang der Kriminalität in Bayern hat. Die Furcht vor Inschutzhaftnahme hält zahlreiche Gewohnheitsverbrecher, die gerade auf den Lücken der Rechtsmittel ihre Tätigkeit aufbauten, davon ab, ihren bisherigen Lebenswandel fortzusetzen ... Es ist in der Praxis unrichtig, wenn die Behauptung aufgestellt wird, daß ,asozialem Verhalten` auf Grund der gegenwärtigen gesetzlichen Bestimmungen auch mit der nötigen Schärfe und Schnelligkeit begegnet werden kann. Hier hatten die Sachbearbeiter des Staatsministeriums mehrfach Gelegenheit mit maßgebenden Juristen der Justiz gerade diese Tatsache festzustellen ... Ich bitte daher aus der Tatsache, daß häufig auch bei kriminellen Dingen Schutzhaft verhängt werden muß, einmal nicht, wie bisher zur Regel wurde, ein Versagen der mir unterstellten Dienststellen zu sehen, sondern darin den Beweis zu sehen, daß wirklich die Rechtsmittel zur schnellen richterlichen Aburteilung dieser Fälle nicht vorhanden sind. Die Abstellung dieser Fehler liegt aber nicht im Machtbereich meines Ministeriums, sondern wäre durch den Herrn Reichsstatthalter als Vertreter der Reichsgewalt beim Reichsjustizministerium zur Änderung zu bringen ... Ich glaube, daß bei Abstellung dieser Mängel viel eher die Notwendigkeit zur Verfügung der Schutzhaft eingeschränkt wird, als durch eine immer wiederkehrende Kontrolle der Schutzhaftfälle und der Handhabung der Schutzhaft an sich."

18 Erl. Hitlers an den RMdI, die RStH u. LandesReg. v. 7.8.34 (Arch. des IfZ, Sign. Fa 183/1, Bl. 324).

19 Schr. des RStH an den bayer. MinPräs. v. 20.3.34, von diesem abschriftl. an Himmler als Polit.Pol.Kommandeur zur Stellungnahme weitergereicht (Akten der Reichskanzlei, BA, Sign. R 43 II/398). 
Gerade Fricks Schutzhafterlaß habe neuerlich wieder „klar die Notwendigkeit der Beibehaltung der Schutzhaft erwiesen" ${ }^{20}$ Epp, der die gewünschte Aufstellung trotz mehrmaliger Aufforderung nicht erhielt, konnte nur resigniert feststellen, daß das Verhalten des Innenministers in dieser Frage „eine sachliche Behandlung unmöglich machte“ und sich die Angriffe Wagners „in gleicher Weise gegen den Herrn Reichsminister des Innern richten". ${ }^{21}$ Auch Frick drang in Bayern nicht mehr durch, auf seine Ersuchen um Berichte in Schutzhaftsachen bekam er nur die Antwort, dem Politischen Polizeikommandeur der Länder sei darüber bereits ausführlich berichtet worden. ${ }^{22}$

Bei dem Kampf um die Schutzhaftpraxis hatte somit die Justiz im Innenministerium nur einen schwachen Verbündeten. Ebensowenig richtete sie selbst gegen die Gestapo aus. Das preußische Justizministerium suchte zu erreichen, daß Fricks Runderlaß vom 12./26. April 1934, der als innerdienstlicher Erlaß nicht veröffentlicht worden war, in der „Deutschen Justiz“ publiziert werden konnte. Hatte sich doch die Veröffentlichung des nunmehr aufgehobenen Göring-Erlasses vom 11. März insofern als hilfreich erwiesen, als sich dadurch Betroffene oder deren Rechtsanwälte in Schutzhaftsachen gegenüber Gestapostellen auf seine Bestimmungen - teilweise mit Erfolg ${ }^{23}$ - hatten berufen können. Heydrich lehnte jedoch ab: die Veröffentlichung von Anordnungen über die Gestaltung der Schutzhaft, selbst eine Bekanntmachung der Aufhebung bisher geltender Bestimmungen, werde „z.Zt. nicht für angebracht gehalten ". ${ }^{24}$ In den folgenden Jahren bemühte sich das Reichsjustizministerium immer wieder vergeblich, entweder die April-Bestimmungen oder neue, zusammen mit dem Innenministerium und der Gestapo auszuarbeitende Schutzhaftbestimmungen zu veröffentlichen. Es wurde dabei verschiedentlich mit dem Hinweis auf ein Reichspolizeiverwaltungsgesetz vertröstet, das im Innenministerium bearbeitet werde und „auch das Schutzhaftproblem regeln" solle. ${ }^{25}$ Die Angelegenheit kam nicht voran, weil die Gestapo nicht daran dachte, ihre Tätigkeit einem Gesetz zu unterwerfen, auf das sich Außenstehende hätten berufen können.

Unterdessen war sich das Innenministerium darüber klargeworden, daß es durch gelegentliche Rügen von Einzelfällen auf die Schutzhaftpraxis keinen Einfluß mehr nehmen konnte, und daß die Bestimmungen seines Erlasses vom April 1934 durch die Praxis überholt worden waren. Am 9. März 1935 gestand der Leiter der Polizeiabtei-

${ }^{20}$ Schr. des bayer. StMdI Wagner an den RStH v. 13.4.34 (a.a.O.).

${ }^{21}$ Aufz. der RStHalterei (undat., jedoch nach dem 3.7.34, Arch. des IfZ, Sign. Fa 183/1, Bl. 327 ff.). Epp drang mit seiner Forderung, „er wolle in der Verhängung der Schutzhaft in Zukunft gehört werden und behalte sich die Entscheidung der Verhängung vor", auch in einer Bespr. mit den Mitgl. der bayer. Landesreg. am 25.4.35 nicht mehr durch: sie werde "weder vom Standpunkte des Gesetzes, noch vom Standpunkt der Stellung des Reichsstatthalters für zweckmäßig“ gehalten (Aufz. des bayer. MinPräs. v. 25.4.35, BayerHStArch., Sign. MA 105 499). Gleichfalls im Frühjahr 1935 scheiterte auch ein Versuch Fricks, eine Aufstellung über die bayer. Schutzhäftlinge mit Haftgründen zu erhalten, vgl. M. Broszat, Nationalsozialistische Konzentrationslager 1933-1945, a.a.O., S. 45.

${ }^{22}$ Vgl. Fricks Beschwerde an die bayer. StKanzlei v. 29.5.35 (BayerHStArch., Sign. MA 106301), er erhielt darauf Antwort von Himmler.

${ }^{23}$ Vgl. V.2.b., S. $564 \mathrm{f}$.

${ }^{24}$ Schr. des preuß. JM an den preuß. MinPräs/Chef der Gestapo v. 26.6.34, Antw. Heydrichs v. 20.7.34 (Akten des preuß. JM, GehStArch. Berlin, Sign. Rep. 84a/3715).

${ }^{25}$ Aktenverm. v. 15.3.35 (a.a.O.); Verm. v. 27.7.36: „Wann und in welcher Form eine neue Regelung des Problems erfolgen wird, läßt sich z.Zt. nicht übersehen. Vor der Vereinheitlichung der Polizei unter dem Reichsführer SS dachte man im M.d.I. zuletzt an ,Richtlinien', die zwischen dem M.D.I., R.Just.Min. und Geh.St.Pol. vereinbart werden sollten" (a.a.O.). 
lung im Reichs- und Preußischen Innenministerium, Regierungsrat Gisevius, einem Leipziger Rechtsanwalt - der wegen einer Schutzhaftsache gegen evangelische Pfarrer vorsprach - offen ein, daß diese Bestimmungen „praktisch längst außer Kraft gesetzt“ seien. Irritiert berichtete der Anwalt an das Reichsjustizministerium, es fehle „dann überhaupt an jeder einigermaßen konkreten Bestimmung über Voraussetzungen der Schutzhaft und über das Schutzhaftverfahren".26

Gisevius legte um diese Zeit in einer Denkschrift den für das Innenministerium unhaltbaren Zustand dar, der eine grundsätzliche Klärung der Zuständigkeiten in Polizeiangelegenheiten erfordere. Sein Ministerium erhalte von zahlreichen Vorgängen „überhaupt erst durch die Beschwerde Kenntnis“, Beschwerdeführer könnten aber nicht beschieden werden, wenn kein Verlaß auf die Durchführung der bestehenden Bestimmungen im Lande mehr bestehe. Es müsse unbedingt geklärt werden,

„nach welchen Richtlinien über Begründung, Dauer und Art der Vollstreckung von Schutzhaft verfahren werden soll... Beteiligte und Angehörige finden sich mit der Tatsache der Schutzhaft ab, nicht aber mit der vollkommenen Unsicherheit darüber, aus welchen Gründen nun eigentlich Schutzhaft verhängt werden kann oder nicht. Diese fraglose Recbtsunsicherbeit schafft Unruhe und Verbitterung ... Ich schlage vor, daß grundsätzlich geklärt wird, wer in allen Dingen der politischen Polizei nicht nur die Verantwortung der Richtlinien sondern auch für die Durchführung dieser Richtlinien trägt.

Entweder trägt diese Verantwortung der Reichsminister des Innern. Dann muß er in einem ganz anderen Maße in die Lage versetzt werden, in den Fragen politisch-polizeilicher Art befehlen zu dürfen.

Oder diese Verantwortung übernimmt nunmehr in allen Konsequenzen der Reichsführer SS, der ja bereits faktisch die Führung der politischen Polizei im Reich für sich in Anspruch nimmt. ${ }^{\text {"27 }}$

Diese Vorgänge müssen auf dem breiteren Hintergrund des Kampfes um die Polizeigewalt im Reich gesehen werden. Seit Mai 1933 waren alle Vorstöße Fricks, die Polizeigewalt zu „verreichlichen“ und dem Reichsinnenministerium zu unterstellen ${ }^{28}$, um die Gestapo möglichst in einen normalen Zweig der Verwaltung zurückverwandeln zu können ${ }^{29}$ - Bestrebungen, von denen sich Gürtner eine rechtliche Normierung der Schutzhaft erhoffte -, durch Göring und Himmler vereitelt worden, die sich auf die den Ländern verbliebenen Polizeibefugnisse stützten. Als Frick Anfang Mai 1934 von Göring das preußische Innenministerium übernahm, bekam er die aus der inneren Verwaltung herausgenommene und Göring als Ministerpräsidenten unterstellte Gestapo nicht in die Hand, sondern nur einen politisch entmachteten Polizeiapparat. Mit der Betrauung des Reichsführers-SS als stellvertretenden Chef und Inspekteur der preußischen Gestapo im April 1934 hatte Göring offensichtlich einen Verbündeten sowohl gegen Fricks Bestrebungen als auch für die drohende Auseinandersetzung mit Röhms SA gesucht. Allein die Ereignisse am 30. Juni, als Göring mit seiner Sonderpolizeitruppe und Himmler mit SS und Gestapo zuschlugen, während

26 Schr. des RA an das RJM v. 10.5.35 (Akten des RJM, BA, Sign. R 22/1467).

27 Undat. Denkschr. des Leiters der Pol.Abt. im RuPrMdI (Nürnbg. Dok. PS-775).

28 Vgl. dazu S. Aronson, Reinhard Heydrich und die Frühgeschichte von Gestapo und SD, Stuttgart 1971, S.80f., 89, 172, 189, 218 f., ferner C. Graf, Politische Polizei zwischen Demokratie und Diktatur. Die Entwicklung der preußischen Politischen Polizei vom Staatsschutzorgan der Weimarer Republik zum Geheimen Staatspolizeiamt des Dritten Reiches, Berlin 1983, S. $153 \mathrm{ff}$.

29 Zu Fricks Versuch v. Oktober 1933, auf den Göring mit dem GestapoG v. 30.11.33 reagierte, vgl. G. Plum, Staatspolizei und innere Verwaltung 1934-1936 (VfZ 1965, S.191 ff.), S. 193. 
Frick von den Ereignissen völlig überrascht wurde, zeigten, wer die eigentliche Polizeigewalt besaß. In dieser Komplizenschaft bei der Röhm-Affäre, aber auch in den allgemeinen Zentralisierungsbestrebungen der Polizei lag begründet, daß Göring am 20. November 1934 Himmler als den Kommandeur der politischen Polizeien fast aller deutscher Länder mit seiner Vertretung in allen Gestaposachen beauftragte, die bisher der Staatssekretär im preußischen Staatsministerium wahrgenommen hatte. ${ }^{30}$

Als einen erneuten Vorstoß in diesem Kampf übermittelte das Reichsinnenministerium dem Justizministerium Ende Juli 1935 den Entwurf eines Gesetzes zur Überleitung der Polizei der Länder auf das Reich „mit der Bitte, die Bestrebungen nach Verreichlichung der staatlichen Polizei, insbesondere im Hinblick auf die Zusammenhänge von Justiz und Polizei, zu unterstützen". ${ }^{31}$ Mit ihm sollten zumindest die organisatorischen und haushaltsrechtlichen Zuständigkeiten der staatlichen Polizei einschließlich der Politischen Polizei (= Geheime Staatspolizei) auf das Reichsinnenministerium übergehen. Um die Justiz als Bundesgenossen brauchte Frick nicht lange zu werben: das Reichsjustizministerium unterstützte den Entwurf durch Mitarbeit in $\mathrm{Re}$ ferentenbesprechungen trotz der Widerstände, die sich „besonders im Preußischen Kabinett" dagegen regten. Frick beabsichtigte, die Frage der Verreichlichung in einer der seltenen Sitzungen des Reichskabinetts am 13. Dezember 1935 zur Sprache zu bringen. ${ }^{32}$ Offenbar stieß er mit seiner Absicht auf so massive Ablehnung, daß die Vorlage des Gesetzentwurfs unterblieb. ${ }^{33}$

Erfolgreicher war sein Gegenspieler Himmler, der bereits Anfang Mai 1935 Göring den Entwurf eines Gesetzes über die Geheime Staatspolizei zur Verabschiedung durch das preußische Kabinett vorgelegt hatte, um in Preußen hinsichtlich des Aufgabenbereichs der Gestapo vollendete Tatsachen zu schaffen und damit eine etwaige Reichsregelung von vornherein zu präjudizieren. An diesem Entwurf sollte sich die Auseinandersetzung zwischen Justiz und Gestapo über die strittigen Probleme der Schutzhaft mit aller Deutlichkeit entzünden. Der Gesetzentwurf, der dem Reichsjustizministerium am 3. Mai zugestellt wurde, definierte als Aufgabe der Gestapo ziemlich global,

„alle staatsgefährlichen Bestrebungen im gesamten Staatsgebiet zu erforschen und zu bekämpfen, das Ergebnis der Erhebungen zu sammeln und auszuwerten, die Staatsregierung zu unterrichten und die übrigen Behörden über für sie wichtige Feststellungen auf dem laufenden zu halten und mit Anregungen zu versehen. Welche Geschäfte im einzelnen auf die Geheime Staatspolizei übergehen, bestimmt der Chef der Geheimen Staatspolizei.“

Der letzte Satz $^{34}$ bedeutete nichts weniger als die allgemeine Kompetenz-Kompetenz des Gestapochefs - nominell Göring, für den aber nach dem Entwurf Himmler

30 Erl. des preuß. MinPräs/Chef der Gestapo v. 20.11.34 (Arch. des IfZ, Sign. MA 433), aller Schriftwechsel war nunmehr an das Gestapa zu richten. Vordem hatte sich die Vertretung nach $\S 1$ Abs. 2 des $G$. v. 30.11 .33 (GS, S.413) geregelt.

31 Schr. des RuPrMdI an das RJM v. 26.7.35 u. weitere Akten mit Entw. für G. u. DurchfVO (Akten des RJM, BA, Sign. R 22/1457).

32 Aktenverm. v. 29.11.35 über die Referentenbespr. im MdI (a.a.O.).

33 In der Niederschr. über die Sitzung des Reichskabinetts v. 13.12.35 (Akten der RK, Regierung Hitler, Bd. II.2, Dok. Nr. 282, S.988) ist der Entw. als Beratungsgegenstand nirgends erwähnt. Wahrscheinlich hat Himmler das Vorhaben durch seine Einwirkung auf Hitler zu Fall gebracht, mit dem er am 1.11.35 Gestapound Schutzhaftfragen erörterte (vgl. im folgenden S. 559 und Anm. 54).

${ }^{34}$ Dieser Satz war aus $\S 2$ des G. v. 30.11.33 (GS, S. 413) übernommen, hatte aber dort seinen spezif. Sinn, da durch das G. die Gestapo aus der inner. Verw. herausgenommen worden war. Die Aufgabenumschreibung im Entw. weist Ähnlichkeit mit der im Erl. des preuß. MdI v. 26.4.33 (MBliV.I, S. 503) auf. 
als Stellvertretender Chef die Dienstgeschäfte führen sollte -, der auch allein die Ausführungsbestimmungen zu diesem Gesetz erlassen sollte. Gleichzeitig sollte das Geheime Staatspolizeiamt zu einem Ministerium, d.h. zu einer Zentralbehörde mit allen Auswirkungen auf dem Gebiet des Beamtenrechts, der Einleitung von Disziplinarverfahren usw. erhoben werden. Damit mußte eine spätere Rückgliederung der Gestapo in die innere Verwaltung unmöglich gemacht werden: das Gesetz bezweckte, die Gestapo für immer von der inneren Verwaltung zu trennen und als einen besonderen Zweig der Staatsverwaltung weiter auszubauen. ${ }^{35}$

Da der Entwurf auf die Tagesordnung der nächsten Sitzung des preußischen Ministerrates gesetzt werden sollte, arbeiteten die Abteilungen II (Strafgesetzgebung) und V (Öffentliches Recht) des Reichsjustizministeriums im Auftrag Gürtners eine Stellungnahme aus. Ihre Kritik konzentrierte sich vor allem gegen die unbestimmt gehaltene Aufgabenstellung der Gestapo; nach dem Entwurf könnten der Gestapo Angelegenheiten übertragen werden, die weit über polizeiliche Aufgaben gemäß $\S 14$ des Polizeiverwaltungsgesetzes hinausgingen, da ein „Bekämpfen staatsfeindlicher Bestrebungen" nicht nur durch Abwehr drohender Gefahren zu erfolgen brauche:

„Ein Kampfmittel ist auch die Strafe. Tatsächlich verhängen ja auch schon jetzt die Behörden der GehStP. ,Schutzhaftstrafen“ von einer im voraus bestimmten Dauer zur Ahndung einzelner, oft weit zurückliegender Taten. Das Geheime Staatspolizeiamt will ferner, wie sich in einer Besprechung über ein Reichspolizeigesetz ergab, nicht nur die Abwehr der dem Staat in seiner gegenwärtigen Form drohenden Gefahren für sich in Anspruch nehmen, sondern auch die Richtung der staatlichen Entwicklung beeinflußen [!] können.“

Demgegenüber forderten die Referenten des Justizministeriums, daß das Gesetz eine Einschränkung der Gestapo auf polizeiliche Aufgaben und eine eindeutige „Abgrenzung von den Aufgaben der Justiz und eine Klarstellung des Verhältnisses der GehStPol. und ihrer Staatspolizeistellen zur Staatsanwaltschaft" enthalten solle. Vor allem aber müsse zugleich mit einer neuen Regelung der Organisation der Gestapo auch eine endgültige „Regelung des materiellen Rechts (Zulässigkeit bestimmter Maßnahmen insbesondere der Anordnung von Schutzhaft, Rechtsmittel usw.)" erfolgen. ${ }^{36}$

In der Sitzung des preußischen Kabinetts am 27. Juni 1935, zu der auch Himmler zugezogen worden war, wurde $z$ war ,festgestellt, daß bis auf weiteres das besondere, zur Bekämpfung des Staatsfeindes geschaffene Instrument der Geheimen Staatspolizei nicht entbehrt werden " könne, Himmlers Entwurf wurde in der vorliegenden Fassung aber nicht angenommen. Vielmehr sollten die strittigen Punkte zwischen Himmler und Frick unmittelbar geklärt werden. Frick suchte eine stärkere Einflußnahme der inneren Verwaltung auf die Tätigkeit der Gestapostellen durch deren Unterstellung unter die Regierungspräsidenten zu erreichen. „Auf die mehrfach“ - offensichtlich neben Gürtner auch von dem mit der Führung des preußischen Wirtschaftsministeriums beauftragten Schacht - „vorgebrachte Anregung, aus innen- und außenpolitischen Gründen eine klare Verfahrens- insbesondere Rechtsmittelregelung für Maßnahmen der Geheimen Staatspolizei zu schaffen“, bemerkte Frick, „daß an einem entsprechenden Entwurf im Reichsministerium des Innern schon gearbeitet werde". ${ }^{37}$ In dieser

${ }^{35}$ G.Entw. mit Schr. des preuß. MinPräs. an die preuß. StMin. v. 3.5. 35 (Akten des RJM, BA, Sign. R 22/1462). Das RJM blieb auf Wunsch Görings nach der Übernahme des preuß. JM an der preuß. Gesetzgebung beteiligt. Gürtner nahm daher auch an den Sitzungen des preuß. Kabinetts teil (vgl. dazu Kapitel II.6., S. 120).

${ }^{36}$ Verm. v. 3.6.35 zur Kabinettsvorlage, auch von Freisler u. Schlegelberger abgezeichnet (a.a.O.).

${ }^{37}$ Auszug aus der Niederschr. über die Sitzung des preuß. Ministerrats v. 27.6.35 (Akten des RJM, a.a.O.). 
Richtung erreichte Gürtner wenigstens das Einverständnis des Kabinetts darüber, daß „jedenfalls für Preußen“ folgende Schutzhaftmaßnahmen unzulässig sein sollten:

„a) Schutzhaft auf Zeit,

b) Schutzhaft an Stelle strafrechtlicher Verurteilung,

c) jegliche Verhinderung der Vertretung in Schutzhaftsachen durch Rechtsanwälte,

d) Schutzhaft gegen Beamte ohne Zustimmung der vorgesetzten Dienststelle.“

Es sollte sich jedoch erweisen, daß die Gestapo diesen Beschluß der preußischen Staatsregierung in der Praxis mißachtete. Auf der Sitzung kam es schließlich noch zu einer einschneidenden Zuständigkeitsabgrenzung: während für Schutzhaftsachen in Preußen künftig „ausschließlich der Chef der Geheimen Staatspolizei“ zuständig sein sollte, sollten „für Schutzhaftsachen außerpreußischer Länder ... die Reichsressorts mit dem Herrn Reichsminister des Innern in Verbindung " treten. ${ }^{38}$ Das bedeutete, daß Frick aus den Erfahrungen bei der Kontrolle der Schutzhaftpraxis wenigstens teilweise die Konsequenzen zog und sein Ministerium als Aufsichts- und Beschwerdestelle für Schutzhaftsachen in Preußen praktisch zugunsten Himmlers verzichtete. ${ }^{39}$ Damit nahm gleichzeitig die „Methode Gisevius“ ein Ende, Schutzhaftbeschwerden, die dem preußischen Innenministerium zu Gehör kamen, dort aber wegen der Unterstellung unter den preußischen Ministerpräsidenten nicht bearbeitet werden konnten, ins Reichsinnenministerium zu übernehmen und dort beim Geheimen Staatspolizeiamt Sachberichte anzufordern. ${ }^{40}$

Am 27. Juli 1935 ging dem Reichsjustizministerium die zweite Fassung des Gesetzentwurfs zu, auf die sich Gestapo und Innenministerium "geeinigt" hatten. Nunmehr sollten die Aufgaben der Gestapo im einzelnen sowie die Durchführungsbestimmungen zum Gesetz vom Gestapochef „im Einvernehmen mit dem Reichs- und Preußischen Minister des Innern“ bestimmt werden. Das Geheime Staatspolizeiamt erhielt nicht die Stellung eines Ministeriums, sondern einer „Obersten Landesbehörde“. Die Staatspolizeistellen sollten nunmehr ,gleichzeitig“ den zuständigen Regierungspräsidenten unterstellt sein und deren Weisungen entsprechen. Da die Leiter der Staatspolizeistellen, die der Befehlsgewalt Heydrichs im Geheimen Staatspolizeiamt unterstanden, zugleich die politischen Sachbearbeiter der Regierungspräsidenten sein sollten, mußte sich dieser Kompromiß im Konfliktfall stets zugunsten der Gestapo auswirken: wenn die Weisungen der Regierungspräsidenten den Gestapobefehlen widersprachen, hatten die Staatspolizeistellen die Entscheidung des Geheimen Staatspolizeiamtes einzuholen. $^{41}$

Auch der neue Entwurf enthielt kein Wort über die Abgrenzung der Gestapotätigkeit gegenüber der Justiz, geschweige denn eine materielle Regelung der Schutzhaft mit jenen Punkten, über die Gürtner das Einverständnis des preußischen Kabinetts erwirkt hatte. Statt dessen war als neuer $\S 7$ die Bestimmung aufgenommen worden,

38 Verm. Gürtners v. 1.7.35 über die Sitzung des preuß. StMin. am 27.6.35 (Akten des RJM, BA, Sign. R 22/1467).

39 Vgl. den bezeichnenden Verm. MinRat Kritzingers über die Notwendigkeit, diese Neuregelung im RJM durch Hausverf. bekanntzugeben: die Vereinbarung bedeute, „daß der Reichsminister des Innern sich mit Angelegenheiten der Gestapo in Preußen nicht mehr befassen will [!] und demnach - mangels einer zuständigen Reichsbehörde - der PrMinPräs im Reich die oberste zuständige Behörde ist“ (a.a.O.).

40 Zur Ausnützung dieses Kompetenzwirrwarrs vgl. H. B. Gisevius, Bis zum bittern Ende, Bd. I, Zürich 1946, S. 211.

41 So bereits in Görings Erl. v. 6.7.34 geregelt, vgl. G. Plum, a.a.O., S. 208. 
daß Verfügungen in Angelegenheiten der Gestapo nicht der Nachprüfung der Verwaltungsgerichte unterliegen sollten. ${ }^{42}$ Da Gürtner kurz nach der Kabinettssitzung nach Hahnenklee (Harz) gefahren war, um sich als Vorsitzender der amtlichen Strafrechtskommission an den Arbeiten für ein neues Strafgesetzbuch zu beteiligen, bat das Ministerium beim preußischen Staatsministerium um Fristenverlängerung und meldete seine Bedenken gegen den Gesetzentwurf im Auftrage Gürtners einstweilen mündlich an. ${ }^{43}$ Gürtner nahm erst am 10. August in einem ausführlichen Schreiben Stellung. Er halte die Frage des Aufgabenbereichs der Gestapo, die in die Zuständigkeitsverteilung $\mathbf{z w i s c h e n}$ Polizei und den übrigen Zweigen der Staatsverwaltung eingreife, für so bedeutsam, daß er vorschlage, diese Frage unbeschadet der landesrechtlichen Organisation der Gestapo schon jetzt auf Reichsebene zu regeln. Einer landesrechtlichen Regelung, wie sie der Entwurf enthalte, würde er nur dann zustimmen,

„wenn durch einen Zusatz klargestellt würde, daß die Ahndung strafbarer Handlungen und sonstige Aufgaben der Rechtspflege nicht zum Aufgabenkreis der Geheimen Staatspolizei gehören. Ich lege auf diese Klarstellung Wert wegen der Zweifel, die sich in der Vergangenheit insbesondere bei der Frage des Verhältnisses der Schutzhaft zu strafrechtlichen Maßnahmen ergeben haben. Dabei darf ich Bezug nehmen, daß in der Sitzung des Ministerrats vom 27. Juni 1935 Einigkeit darüber bestand, daß Schutzhaft als Strafe nicht verhängt werden und den Charakter einer Strafe nicht annehmen dürfe.“

Wie er bereits in der Kabinettssitzung ausgeführt habe, sei eine ausdrückliche Aufnahme der Bestimmung über den Ausschluß der verwaltungsgerichtlichen Nachprüfung wegen seiner negativen Wirkung auf das Ausland bedenklich. Unausgesprochen hielt Gürtner die Festschreibung dieser Bestimmung vor allem in Hinblick auf die von Frick angekündigte Regelung des Rechtsmittelzuges für Gestapoverfügungen auf Reichsebene, auf die er immer noch hoffte, für schädlich. Er schrieb:

„Ich bin der Auffassung, daß die Frage des Rechtsmittelzugs gegen Entscheidungen der Geheimen Staatspolizei ebenfalls schon jetzt reichsrechtlich geregelt werden könnte, zumal der Entwurf eines solchen Gesetzes im Reichsministerium des Innern nach den Erklärungen im Ministerrat vom 27. Juni bereits in Bearbeitung ist. Meine sachliche Stellungnahme darf ich mir für diese Regelung vorbehalten."

Gürtner beantragte, die Bestimmung des $\S 7$ zu streichen, da ihr Inhalt nach der Rechtsprechung des Preußischen Oberverwaltungsgerichts ohnehin dem gegenwärtigen Rechtszustand entspräche und daher für Preußen entbehrlich sei. Wegen der besonderen Bedeutung des Gesetzes regte er ferner an, vor einer endgültigen Verabschiedung auch jene Reichsminister zu beteiligen, die nicht zugleich Mitglieder des preußischen Kabinetts seien. ${ }^{44}$

Schützenhilfe bekam die Justiz durch Schacht, der gegen den vorliegenden Entwurf erhebliche Einwände erhob. Schacht war wegen der ständigen Eingriffe der Gestapo in die Wirtschaft aufgebracht, die das Mindestmaß an Rechtssicherheit und Berechenbarkeit gefährdeten, das für eine Stabilisierung in diesem Bereich notwendig war. Er forderte, daß die Aufgaben der Gestapo nicht nur im Einvernehmen mit dem Innenminister, sondern auch mit den sonst betroffenen Fachministern bestimmt werden müßten; ebenso müßten alle Ausführungsbestimmungen zu dem Gesetz dem preußischen

42 Entw. mit Schr. des preuß. MinPräs. an die preuß. StMin. v. 27.7.35 (Akten des RJM, BA, Sign. R 22/1462).

43 Verm. v. 2.8. u. 9.8.35 (a.a.O.).

${ }^{44}$ Schr. Gürtners an den preuß. MinPräs. v. 10.8.35 (a.a.O.). 
Kabinett unterbreitet werden. Auch seine Bedenken richteten sich besonders gegen den $\S 7$, wobei er die Rechtsprechung des Preußischen Oberverwaltungsgerichts völlig ignorierte: er halte diese Bestimmung „mit den allgemeinen Grundsätzen eines Rechtsstaates für unvereinbar“ und vermöge die bloße Dienstaufsichtsbeschwerde „als ausreichenden Rechtsschutz nicht anzusehen":

„Ich muß vielmehr darauf bestehen, daß gegen die Verfügungen der Geheimen Staatspolizei ein Rechtszug an die Verwaltungsgerichte eröffnet wird. Soweit diese Verfügungen in Inhaftierungen bestehen, halte ich es für erforderlich, den 9. Abschnitt der Strafprozeßordnung über ,Verhaftung und vorläufige Festnahme' ( $\$ 112 \mathrm{ff}$.) zur Anwendung zu bringen. Alsdann wäre die Geheime Staatspolizei unter den Voraussetzungen der $\S \S 127,128$ StPO zur vorläufigen Festnahme ebenso wie die allgemeinen Polizeibehörden berechtigt, während die Verhaftung gemäß 114 StPO nur auf Grund eines richterlichen Haftbefehls erfolgen könnte.“ “5

Die Einwände des Reichsjustizministeriums wurden am 24. August zwischen Ministerialdirektor Neumann vom preußischen Staatsministerium und Gürtner besprochen. Es stellte sich heraus, daß die von Gürtner geforderte Aufnahme einer Abgrenzung der Tätigkeit der Gestapo von der Rechtspflege in das Gesetz besonders „große Schwierigkeiten“ bereitete, deren Gründe für Gürtner „nicht klar ersichtlich“ waren. ${ }^{46}$ Das Staatsministerium glaubte die Forderung der Justiz schließlich durch die Einfügung der Formel befriedigen zu können: „Die Zuständigkeit der Gerichte und Staatsanwaltschaften wird durch das Gesetz nicht berührt." Das Justizministerium lehnte aber diese vage Formulierung sofort ab: Ministerialrat Kritzinger, Referent für Staatsund Verwaltungsrecht und Kompetenzkonflikte, erklärte dem Staatsministerium,

„es handle sich nicht darum, daß die Behörden der Geheimen Staatspolizei den Justizbehörden ihre Zuständigkeit bestritten hätten, sondern darum, daß sie neben den Justizbehörden ihrerseits Maßnahmen träfen, die zu den Aufgaben der Justizbehörden gehörten, z. B. zur Ahndung strafbarer Handlungen ,Schutzhaftstrafen" verhängten“.

Deshalb müsse das Justizministerium auf der von ihm vorgeschlagenen Fassung bestehen: „Die Ahndung strafbarer Handlungen und sonstige Aufgaben der Rechtspflege gehören nicht zum Aufgabenkreis der Geheimen Staatspolizei." Obwohl auch der zuständige Referent des Staatsministeriums erklärte, „die Berechtigung der vom Reichsjustizministerium vorgeschlagenen Fassung einzusehen ${ }^{407}$, blieb das Problem wegen des Widerstandes Himmlers zunächst offen.

Gürtner mochte schon in der Sitzung des preußischen Kabinetts am 27. Juni 1935 erkannt haben, daß die Aufnahme einer materiellen Regelung der Schutzhaft in das Gesetz bzw. eine reichsgesetzliche Ordnung dieser Materie Schwierigkeiten oder zumindest Verzögerung verursachen würde. Um so dringlicher war es für ihn, jenes „Einverständnis“ des Kabinetts über die Unzulässigkeit der Schutzhaft in bestimmten - vor allen strafrechtlichen - Fällen auszunutzen und praktisch wirksam zu machen. Noch aus Hahnenklee ließ er Kritzinger durch seinen persönlichen Referenten von Dohnanyi anweisen, zwei gleichlautende Schreiben an Göring und Frick als die für Schutzhaftsachen in Preußen bzw. in den außerpreußischen Ländern zuständigen In-

4 Schr. des RuPrWirtschMin. (mit der Führung der Geschäfte beauftragt: Schacht) an den preuß. MinPräs. v. 31.7.35, am 8.8.35 dem RJM zugesandt (a.a.O.). Zu § 127 StPO s. voranstehende Anm. 16. Nach $\S 128$ war der vorläuf. Festgenommene „unverzüglich“ dem Amtsrichter vorzuführen, der ihn spätestens am Tage nach der Vorführung zu vernehmen $u$. über den Haftbefehl zu entscheiden hatte. $\S 114$ regelte die Verhaftung aufgrund bereits vorliegenden Haftbefehls wegen strafbarer Handlung.

46 Verm. Gürtners v. 25.8.35 (a.a.O.).

47 Verm. Kritzingers v. 11.9.35, von Freisler u. Schlegelberger abgezeichnet (a.a.O.). 
stanzen auszuarbeiten und vorzulegen. Darin wurde auf den Kabinettsbeschluß verwiesen und die Bitte ausgesprochen, „das Weitere zu veranlassen und mir von dem Veranlaßten Kenntnis zu geben “ ${ }^{48}$ Erst Anfang September übersandte Frick schließlich als Antwort seine bisherigen Schutzhafterlasse vom 12./26. April 1934 und erklärte in einem Begleitschreiben, daß diese für das ganze Reichsgebiet erlassenen Richtlinien „vom Führer und Reichskanzler gebilligt worden sind und unverändert weiterbestehen “ ${ }^{49}$ Mit dieser an der Realität vorbeigehenden und daher unzureichenden Reaktion auf sein Ersuchen gab sich Gürtner nicht zufrieden. Er antwortete, aus zahlreichen bis in die jüngste Zeit aufgetretenen Schutzhaftfällen gehe hervor, daß die Richtlinien vom April 1934 überholt seien. Sogar in der Presse seien Verhaftungen wegen wirtschaftlicher Maßnahmen, Lohnfragen usw. bekanntgegeben worden. Die Richtlinien stimmten ferner nicht mit Hitlers Proklamation vom 11. September $1935^{50}$ überein, daß sich die Regierung im Falle ungesetzlicher Preissteigerungen nicht scheuen werde, die Schuldigen „durch das Konzentrationslager dem nationalen Gesamtinteresse gleichzuschalten“. Für den Regierungsstil im Führerstaat war es immerhin bezeichnend, daß ein Minister grundlegende Absichten des Regierungschefs einer auf dem Reichsparteitag verlesenen öffentlichen Proklamation entnehmen mußte. Gürtner fuhr fort:

„Ich muß vom Standpunkt meines Geschäftsbereichs Wert darauf legen, daß über die Zulässigkeit von Schutzhaft und das dabei zu beachtende Verfahren bei den nachgeordneten Behörden und in der Öffentlichkeit Klarheit herrscht. Wenn die politische Notwendigkeit zu einer weiteren Anwendung von Schutzhaft zwingt, wie dies jetzt der Führer und Reichskanzler ausdrücklich erklärt hat, so muß das auch mit aller Klarheit in den Verwaltungsanordnungen für die nachgeordneten Behörden zum Ausdruck kommen. Sonst ergeben sich für diese Behörden ständig Schwierigkeiten, und im Volk wird der Eindruck erweckt, als ob die untergeordneten Behörden ohne Rücksicht auf die ihnen erteilten Anweisungen willkürlich verführen. Besonders bedenklich muß sich eine unklare Rechtslage auswirken, wenn die ordentlichen Gerichte infolge von Strafanzeigen oder bei der Geltendmachung von Schadensersatzansprüchen die Zulässigkeit von Schutzhaftmaßnahmen nachprüfen müssen." ${ }^{\text {.51 }}$

Vom preußischen Gestapochef, sprich Himmler, hatte Gürtner auf sein Schreiben vom 4. Juli überhaupt keine Antwort erhalten. Himmler war entschlossen, sich jeder Festlegung in der Schutzhaftfrage zu entziehen und das Gestapo-Gesetz in der von ihm gewünschten Form über Hitler durchzusetzen. Hatte doch Hitler in der erwähnten September-Proklamation unmißverständlich zum Ausdruck gebracht, daß das Regime entschlossen sei, jeden Widerstand gegen seine Politik „schon im Keime zu ersticken“ und diese Aufgabe, für die der normale Staatsapparat „- weil seinem innersten Wesen fremd - nicht geeignet ist, auf dem Wege der Gesetzgebung den Einrich-

${ }^{48}$ Schr. Gürtners an den PrMinPräs/Chef der Gestapo und an den RuPrMdI v. 4.7.35, letzteres mit dem Zusatz, er gehe davon aus, daß die im preuß. Kabinett vereinbarten Grundsätze auch für die außerpreuß. Gebiete zu gelten hätten. Dazu Schr. Dohnanyis an Kritzinger aus Hahnenklee v. 1.7.35 (Akten des RJM, BA, Sign. R 22/1467).

49 Schr. Fricks an das RJM v. 5.9 .35 (a.a.O.), beigelegt waren ferner: sein Erl. v. 10.7.34, daß die SS zur Inschutzhaftnahme nicht berechtigt sei, u. Erl. v. 29.4.35, daß die Inschutzhaftnahme von Geistlichen seiner Zustimmung bedürfe.

so Von Gauleiter Adolf Wagner auf dem Reichsparteitag verlesen (VB v. 12.9.35, Münchn. Ausg. Nr.255, S.1f.).

s1 Schr. Gürtners an den RuPrMdI v. 24.9.35 (Akten des RJM, a.a.O.). Gürtner hielt hier aus taktischen Gründen einen Nachprüfungsanspruch aufrecht, der jedoch von der Rechtspr. selbst aufgegeben wurde; vgl. Kapitel VI.1, S. $538 \mathrm{ff}$. 
tungen zu übertragen, die für die Lösung einer solchen Aufgabe besser geeignet erscheinen". 52 Während sich Himmler in den folgenden Monaten jeder Erörterung der schwebenden Fragen im preußischen Kabinett oder mit Gürtner entzog ${ }^{53}$, hatte er am 1. November eine Aussprache mit Hitler über Gestapo- und Schutzhaftfragen, bei der er Hitlers Unterstützung für seine Ansichten ${ }^{54}$, vermutlich auch für das beabsichtigte Gesetz, fand. Jedenfalls wurde am 10. Februar 1936 das Gesetz über die Geheime Staatspolizei von Göring und Frick im wesentlichen in der Fassung unterzeichnet und verkündet, die dem Reichsjustizministerium am 27. Juli 1935 zugegangen war. Die Einwände Gürtners waren ignoriert worden; mit der bloßen Zufügung des Satzes: „Die Zuständigkeit der Organe der ordentlichen Rechtspflege bleibt unberührt" war den Wünschen des Ministeriums in keiner Weise Rechnung getragen. Eine rechtliche Regelung der Schutzhaft fehlte nach wie vor. ${ }^{55}$

Die Hoffnung des Justizministeriums auf eine solche Regelung schwand noch mehr, als Himmler im Juni 1936 nach monatelangen Verhandlungen über die Verreichlichung der Polizei - bei denen er und Heydrich mit offenkundiger Unterstützung Hitlers alle Versuche Fricks vereitelten, Himmler als „Leiter der Polizeiabteilung" in die Behördenorganisation des Reichsinnenministeriums ein- und unterzuordnen ${ }^{56}$ - als „Reichsführer SS und Chef der Deutschen Polizei im Reichsministerium des Innern" mit der Führung der gesamten Polizei im Reich betraut wurde. Weder der von Frick erstrittene, die Zugehörigkeit zu seinem Ministerium bezeichnende Zusatz „im Reichsministerium des Innern“ noch die Formel, daß ihm der Polizeichef „persönlich und unmittelbar unterstellt" sei ${ }^{57}$, konnten verhindern, daß die Polizei nunmehr der Verfügung des Innenministers entzogen war: da der Reichsführer-SS, der mit dem Chef der Polizei institutionell eine Einheit bildete, als politisches Führungsorgan Hitler direkt unterstand, konnte Frick bei Konflikten gegenüber dem ihm nicht objektiv-geschäftsmäßig, sondern eben nur „persönlich und unmittelbar“ unterstellten Himmler weder eine sachliche Zuständigkeit noch die eigene Autorität ins Feld führen, weil er damit gegen die höhere Autorität Hitlers aufgetreten wäre. ${ }^{58}$ Bald waren

32 Proklamation v. 11.9.35 (VB v. 12.9.35, Münchn. Ausg. Nr. 255, S.2).

33 Vgl. Gürtners Schr. an Himmler v. 23.12.35 u. 17.1.36 (Akten des RJM, a.a.O.).

$54 \mathrm{Vgl}$. Schr. Himmlers an Gürtner v. 6.11.35 (Akten des RJM, a.a.O.).

55 G. über die Geheime Staatspolizei u. AusfVO v. 10.2.36 (GS, S. 21 ff.); der Zusatz erfolgte als Abs. 2 zum $§ 1$ des G. Zu den $\S \S 1$ u. 12 der AusfVO (Ermittlungstätigkeit der Gestapo u. Verhältnis zur StAschaft) vgl. Kapitel VI.3.a., S. 584. In der AusfVO hatte Frick einwilligen müssen, daß die Ober- u. Reg.Präs. dem Gestapa in Gestapoangelegenheiten unterstellt wurden.

${ }^{56} \mathrm{Zu}$ den Vorverhandlungen vgl. H.-J. Neufeldt, J. Huck, G. Tessin, Zur Geschichte der Ordnungspolizei 1936-1945 (Schriften des Bundesarchivs 3, als Manuskript gedruckt, Koblenz 1957), S. 12 ff.

57 Erl. über die Einsetzung eines Chefs der Deutschen Polizei im Reichsministerium des Innern v. 17.6.36 (RGBl. I, S.487), von Hitler u. Frick unterzeichnet. Himmler nahm nunmehr an den Sitzungen des Reichskabinetts teil, soweit sein Geschäftsbereich berührt wurde. Nach dieser „Verreichlichung“ der Befehlsführung konnte auch die haushaltsmäßige erfolgen: durch das G. v. 19.3.37 (RGBl. I, S.325) wurden die Vollzugspol. und die Gestapo, durch das G. v. 28.3.40 (RGBl. I, S.613) die bisher noch auf den Länderhaushalten verbliebenen PolVerwaltungsbeamten in den unmittelbaren Reichsdienst übernommen (beide Entw. mit Begründ. in den Akten des RJM, BA, Sign. R 22/1457).

38 Dazu eingehend H. Buchheim, Die SS in der Verfassung des Dritten Reiches (VfZ 1955, S. $132 \mathrm{ff}$.). Vgl. Aussage Lammers' im Nürnbg. Prozeß am 8.4.46: „Die Unterstellung im Innenministerium ist daher beinahe gegenstandslos geworden ... Als der Reichsminister Frick darüber eine Beschwerde bei mir anbrachte, die ich an den Führer bringen sollte, da hat mir der Führer gesagt: Ubermitteln Sie Herrn Frick, er möchte den Himmler als Chef der Polizei nicht zu sehr einschränken, die Polizei ist bei ihm gut aufgehoben, er solle ihm möglichst freie Hand lassen." Normalerweise habe Hitler Weisungen auch direkt an Himmler gegeben (IMG, Bd.XI, S.71). 
alle Zweifel behoben, daß Himmler innerhalb seines Geschäftsbereichs als ständiger Vertreter Fricks Entscheidungen treffen konnte, die laut Gesetz dem Minister vorbehalten waren..$^{59}$ Bei Frick verblieben zwar gewisse verwaltungs- und beamtenrechtliche Zuständigkeiten der Polizei, auch eine sekundäre Verfügungsgewalt für „unpolitische“ Zwecke, die er aber im Gegensatz zu Himmler nur im Einklang mit den bestehenden Rechtsnormen ausüben konnte. Mit der der SS institutionell verbundenen, auch personell weitgehend verschmolzenen ${ }^{60}$ und verfassungsorganisatorisch „entstaatlichten " Polizei $^{61}$ war ein außernormativer Exekutivapparat entstanden, mit dem die Justiz alle strittigen Probleme nunmehr direkt ausfechten mußte. Ihr Hauptgegner blieb das Geheime Staatspolizeiamt, das nun die Führungszentrale für die einheitlich organisierte Gestapo im ganzen Reich darstellte, nachdem Himmler diese Behörde mit der Wahrnehmung der Angelegenheiten des Politischen Polizeikommandeurs der Länder betraut hatte. ${ }^{62}$

Bereits im August 1936 trat das Reichsjustizministerium an Himmler in dessen neuer Eigenschaft als Reichspolizeichef mit dem Ersuchen heran, die Schutzhaft durch eindeutige Bestimmungen von der Tätigkeit der Rechtspflege abzugrenzen, da die Richtlinien vom April 1934 in der Praxis nicht mehr beachtet würden. Best antwortete am 7. Oktober, er

„bearbeite z.Zt. eine grundsätzliche allgemeine Neuregelung der Schutzhaft, um die Schwierigkeiten, die sich bei der Anwendung des Erlasses des Reichsministers des Innern vom 12.4.1934 ergeben haben, zu beseitigen. Dabei wird auch die Zulässigkeit der Verhängung der Schutzhaft beim Vorliegen strafbarer Tatbestände genau abgegrenzt und ein Zusammenarbeiten mit den Justizbehörden sichergestellt werden."

Sobald der Entwurf der neuen Schutzhaftbestimmungen fertiggestellt sei, werde er ihn dem Justizministerium vorlegen, um Referentenbesprechungen vorzubereiten. Best wies jedoch darauf hin, daß auch nach den ,jetzt geltenden [!] Richtlinien des Reichsministers des Innern vom 12.4.1934“ die Schutzhaftverhängung bei strafbaren Tatbeständen in Ausnahmefällen zulässig sei ${ }^{63}$, und begründete die Notwendigkeit für diese Ausnahme:

„Von dieser Möglichkeit muß von den Behörden der Geheimen Staatspolizei in den Fällen Gebrauch gemacht werden, in denen die Erörterungen gegen eine große Anzahl Beschuldigter wegen staatsfeindlicher Betätigung infolge der notwendigen Gegenüberstellungen längere Zeit in Anspruch nehmen. Eine unverzügliche Zuführung einzelner Festgenommener an die Staatsanwaltschaft gemäß $\S 128$ StPO vor Abschluß der gesamten Erörterungen würde ein unvollständiges Bild geben und es wäre dann zu befürchten, daß richterlicher Haftbefehl nicht ergeht. Durch die vorzeitige Freilassung einzelner Beschuldigter würden jedoch die Gesamtermittlungen erheblich gefährdet oder sogar unmöglich gemacht werden.“

59 RdErl. des RuPrMdI v. 15.5.37 über die Rechtsstellung des RFSSuChdDtPol. im RMdI (MBliV., S. 788).

$60 \mathrm{Vgl}$. H. Buchheim, Die SS - Das Herrschaftsinstrument (Anatomie des SS-Staates, Bd. I, Olten und Freiburg i. Br. 1965), S.118ff.

61 So plastisch, wenn auch in staatsrechtl. Hinsicht überspitzt: H. Buchheim, Die SS in der Verfassung des Dritten Reiches, a.a.O. (Anm. 58), S. 136.

62 RdErl. des RuPrMdI v. 20.9.36 (RMBliV, S. 1343); durch den RdErl. des RFSSuChdDtPol. im RMdI v. 28.8.36 (a.a.O., S.1344) hatten die Gestapodienststellen im Reich die einheitl. Bezeichnungen „Staatspolizeileitstelle“ bzw. „Staatspolizeistelle“ erhalten.

${ }^{63}$ Vgl. Fricks Erl. v. 12.4.34 (voranstehend S.549), Ziff. III Abs. 3 Satz 3: „Nur in besonderen Ausnahmefällen kann danach bei strafbaren Tatbeständen die Verhängung von Schutzhaft gerechtfertigt erscheinen.“ 
In einzelnen Fällen hätten Staatsanwälte sogar von sich aus angeregt, die Verhafteten dem Gericht erst nach Abschluß der Gesamtuntersuchung zuzuführen und zunächst Schutzhaftbefehl gegen sie zu erlassen. ${ }^{64}$

Anfang November informierte Bests Sachbearbeiter den Generalreferenten für politische Strafsachen in der Strafrechtspflegeabteilung des Justizministeriums, Erster Staatsanwalt Klemm, vertraulich über die Grundgedanken des Entwurfs. Klemm notierte:

„Danach soll die Schutzhaft wieder die Schutzhaft in ihrer ursprünglichsten Bedeutung werden, daneben ist eine Verwahrungshaft geplant, die entweder vorbeugenden Charakters ist oder in besonders umfangreichen Verfahren lediglich den Charakter der Verwahrungshaft hat. Es sollen bestimmte Einzelvorschriften eingebaut werden, die einen Mißbrauch durch untere oder nebengeordnete Behörden ausschließen.“

Das Reichsjustizministerium sollte den Entwurf zur Stellungnahme erhalten, sobald er von Heydrich gebilligt worden war. ${ }^{65}$ Bei der Gestapo bereitete die Fertigstellung offenbar Schwierigkeiten, da das Justizministerium in den folgenden Monaten auf wiederholte Anfragen nur hinhaltende Antworten erhielt. ${ }^{66}$ In welcher Form das Ministerium nochmals beteiligt worden ist, geht aus den Akten nicht hervor: jedenfalls wurden die im „Amt Verwaltung und Recht“ (Best) des „Hauptamtes Sicherheitspolizei“ (Heydrich) ausgearbeiteten neuen Schutzhaftbestimmungen von Frick am 25. Januar 1938 herausgegeben. ${ }^{67}$ Gemäß den Bestrebungen der Gestapoführung waren die Voraussetzungen für die Schutzhaftverhängung gegenüber den Bestimmungen vom April 1934 erweitert worden. Schutzhaft konnte laut $§ 1$,zur Abwehr aller volks- und staatsfeindlichen Bestrebungen gegen Personen angeordnet werden, die durch ihr Verhalten den Bestand und die Sicherheit des Volkes und Staates gefährden“. Dafür war sie von der Funktion der Justiz eindeutig abgegrenzt worden: „Die Schutzhaft darf nicht zu Strafzwecken oder als Ersatz für Strafhaft angeordnet werden. Strafbare Handlungen sind durch die Gerichte abzuurteilen." Nur das Geheime Staatspolizeiamt war zur Anordnung der Schutzhaft befugt ${ }^{68}$, die nachgeordneten Staatspolizeileit- bzw. Staatspolizeistellen mußten die Verhängung dort beantragen. Von der Schutzhaft, die grundsätzlich in staatlichen Konzentrationslagern vollstreckt werden sollte, wurde die „vorläufige Festnahme“ unterschieden, die unter den Voraussetzungen des $\S 1$ von allen Gestapostellen angeordnet werden konnte, „wenn zu besorgen ist, daß die Freiheit zu staatsfeindlicher Betätigung mißbraucht" wurde, ferner wenn Verdunkelungsgefahr oder Fluchtverdacht vorlag; sie wurde im Polizeigefängnis vollstreckt. Eine vorläufig festgenommene Person war spätestens nach Ablauf von zehn Tagen zu entlassen,

${ }^{64}$ Schr. des RFSSuChdDtPol. im RMdI (I.V. Best) an das RJM v. 7.10.36 als Antw. auf das Schr. des RJM v. 22.8.36 (Akten des RJM, BA, Sign. R 22/1467).

${ }^{65}$ Verm. Klemms v. 5.11 .36 (a.a.O.). Der spätere Sts. Klemm war Dezernent für polit. Straf- u. Gnadensachen u. persönl. Referent beim sächs. JM Thierack gewesen u. nach der Verreichlichung am 1.4.35 ins RJM übernommen worden (Personalunterlagen DC Berlin).

${ }^{66}$ Vgl. fortlaufende Verm. bis 3.5.37 u. Mahnschr. v. 16.7.37 (Akten des RJM, a.a.O.).

${ }^{67}$ Geh. RdErl. des RMdI v. 25.1.38 - Pol. S-V 1 Nr. 70/37-179-g. - (Akten des RJM, a.a.O.), gedruckt in der Allg. Erl. Sammlung des RSHA, 2 F VIII a, S. 3 (Arch. des IfZ, Sign. Dc 15.21). Ausf.bestimmungen dazu erließ nur der Chef der Sipo.

68 RStH, Landesreg., Ober- u. Regpräs. konnten durch Stapostellen vorläufige Festnahmen durchführen lassen, über die endgültige Anordn. der Schutzhaft entschied nichtsdestoweniger das Gestapa nach seinen reichseinheitlichen Grundsätzen. 
wenn nicht unterdessen das Geheime Staatspolizeiamt Schutzhaft angeordnet hatte. ${ }^{69}$ In einem ergänzenden Runderlaß vom selben Tage machte Frick ,nochmals darauf aufmerksam, daß die Schutzhaft ausschließlich ein Mittel zur Bekämpfung volks- und staatsfeindlicher Bestrebungen ist und nicht zu Strafzwecken oder zur Erreichung irgendwelcher anderer Zwecke angewandt werden" dürfe. Sie solle nur dann verhängt werden, wenn der Widerstand gegen behördliche Maßnahmen mit anderen Mitteln nicht zu überwinden war, denn nur, wenn dieses Instrument „auf das im Reichsinteresse unbedingt notwendige Maß “ beschränkt werde, könne es „wirksam bleiben und seine innere Berechtigung und das Verständnis des Deutschen Volkes behalten".70

Damit hatte die Justiz nach jahrelangen Bemühungen erreicht, daß der Gestapo zumindest durch innerdienstliche Bestimmungen - die auch von der Stelle autorisiert waren, die ihre Einhaltung tatsächlich überwachen konnte - Übergriffe auf das Gebiet der Rechtspflege untersagt waren. Nicht erreicht hatte sie dagegen eine „Verrechtlichung" der Schutzhaft durch öffentlich verkündete Normen über Zulässigkeit und Verfahren sowie durch unabhängige gerichtliche Nachprüfung der Schutzhaftmaßnahmen. Weil aber die Gestapo Richter in eigener Sache blieb, sollten vom Geheimen Staatspolizeiamt gedeckte Eingriffe in die Rechtspflege auch nach dem Erlaß der neuen Bestimmungen an der Tagesordnung bleiben. Die Polizeiführung hielt an dem Grundsatz fest, daß das Handeln der Polizei durch ungeschriebenes Polizeirecht bestimmt werde. In einem Vortrag vor dem Ausschuß für Polizeirecht der Akademie für Deutsches Recht im Oktober 1936 stellte Himmler rückblickend fest:

„Wir Nationalsozialisten haben uns dann [1933] - es mag absonderlich klingen, wenn ich das in der Akademie für Deutsches Recht sage, aber Sie werden das verstehen - nicht ohne Recht, das wir in uns trugen, wohl aber ohne Gesetz an die Arbeit gemacht. Ich habe mich dabei von vornherein auf den Standpunkt gestellt, ob ein Paragraph unserem Handeln entgegensteht, ist mir völlig gleichgültig; ... Ob die anderen Leute über die ,Brechung der Gesetze jammerten, war in diesen Monaten und Jahren, in denen es um Leben und Sterben des deutschen Volkes ging, gänzlich gleichgültig. Das Ausland - nicht am wenigsten genährt durch zahlreiche Kräfte des Inlandes - sprach natürlich von einem rechtlosen Zustand in der Polizei und damit im Staate."71

Diese Auffassung blieb auch in den folgenden Jahren bestimmend. Im Juli 1938 schrieb Best als Vorsitzender des erwähnten Polizeirechtsausschusses offen, daß die Bestrebungen, ein neues Polizeirecht zu kodifizieren, bei den Mitarbeitern der Polizei „mit gemischten Gefühlen“ betrachtet würden und „die Gedanken an die Auswirkungen einer solchen Kodifikation einiges Unbehagen" verursachten. Es sei besser, noch zu warten, bis sich Theorie und Rechtsprechung „so weit im Sinne des neuen Rechtsdenkens weiter entwickelt hätten, daß der Erlaß eines grundlegenden Gesetzes die

69 Vom April-Erl. 1934 wurden ferner die Bestimmungen über Aushändigung des begründeten Schutzhaftbefehls u. über vierteljährl. Prüfung der Entlassungsfrage durch das Gestapa übernommen. Die 10-Tage-Frist wurde nach Kriegsausbruch durch RdErl. des RMdI v. 4.10.39 (Allg. Erl. Sammlung des RSHA, 2 F VIII a, S.7, a.a.O.) auf 3 Wochen verlängert: wegen der „höheren Festnahmetätigkeit“, u. um den Leitern der Stapo(leit)stellen „Festnahmen vorbeugenden und erzieherischen Charakters“ bis zu drei Wochen ohne Beantragung von Schutzhaft zu ermöglichen.

70 RdErl. des RuPrMdI v. 25.1.38 an die RStH, LandesReg., preuß. Ober- u. Reg.Präs. u. den PolPräs. in Berlin (Akten des RJM, BA, Sign. R 22/1469).

7 Frank-Himmler-Best-Höhn, Grundfragen der deutschen Polizei. Bericht über die konstituierende Sitzung des Ausschusses für Polizeirecht der Akademie für Deutsches Recht am 11. Oktober 1936, Hamburg 1937, S. $11 \mathrm{f}$. 
künftige Rechtsentwicklung nicht mehr beeinträchtigen "könne. ${ }^{72}$ Ein geschriebenes Reichs-Polizeirecht, das die Aufgaben und Tätigkeiten der Polizei abschließend regelte, kam daher auch nicht zustande. Der Grundsatz, daß die Polizei alle Aufgaben durchführen durfte, mit der die politische Führung sie betraut wissen wollte, und daß sie dabei nicht an die Gesetze gebunden war, sollte bis zum Ende des Dritten Reiches gelten $^{73}$, insbesondere bei der Anwendung der Schutzhaft. Er war die Grundursache dafür, daß vor wie nach der Schutzhaftregelung vom Januar 1938 zwischen Justiz und Gestapo Reibereien auftraten. Den Oberlandesgerichtspräsidenten und Generalstaatsanwälten umschrieb Gürtner diesen Zustand auf einer Tagung im Reichsjustizministerium im Juni 1937 so:

„Wir können hier offen reden. Wir haben in Deutschland die Schutzhaft auch heute noch ohne ausgesprochene rechtliche Basis. Das ist die Quelle gewisser Anwendungsformen, die auf die Dauer nicht erhalten werden können. Es ist vielfach vorgekommen, daß die Schutzhaft nicht zu Präventivmaßnahmen verwendet worden ist, sondern z.B. um jemanden vergleichsbereit zu machen oder einen Freigesprochenen oder zu gering Bestraften noch festzuhalten. ${ }^{174}$

$\mathrm{Zu}$ denjenigen leitenden Juristen, die die grundsätzliche Gefahr, die von der rechtlich nicht geregelten Aktivität der Gestapo für die Justiz ausging, klar erkannten und in Berichten an das Reichsjustizministerium auch mahnend aussprachen, gehörte der Hamburger Oberlandesgerichtspräsident Rothenberger, der später als Staatssekretär dieses Ministeriums durch sein Engagement für die Ressortinteressen der Justiz in Gegensatz zu Himmler geraten und unter anderem deshalb Ende 1943 nach sechzehnmonatiger Amtszeit wieder abgelöst werden sollte. ${ }^{75}$ Sein Lagebericht vom 8. Juli 1938 gibt das Problem präzise wieder:

„Es besteht die begründete Befürchtung, daß die Geheime Staatspolizei allgemein als Generalsicherheitsorgan des Staates [?] auch auf den der Justiz vorbehaltenen Gebieten funktionell kontrollierend eingreift, ohne daß es sich dabei etwa um Angriffe gegen den Bestand des Staates, die nach dem Recht des Staatsnotstandes zu beurteilen wären, handelt. Wenn die Geheime Staatspolizei grundsätzlich sich für befugt hält, gerichtliche Entscheidungen zu ignorieren und zu korrigieren und wenn sie einen Rechtsbegriff aufstellt, nach dem das von der Führung geschaffene Recht so weit geht, wie die Polizei ihre Maßnahmen ausdehnt, so bedeutet das einen grundsätzlichen Eingriff in das ureigenste Gebiet der Gerichte, die nach dem Willen des Führers auf diesen Gebieten seine ausschließlichen Beauftragten und Funktionsträger sind. Es scheint mir wirklich an der Zeit zu sein, daß endlich einmal von autoritativster Stelle diese ausschließliche Funktionszuständigkeit der Justiz mit aller Entschiedenheit betont und gegen die Korrekturen und Kontrollmaßnahmen ... der Geheimen Staatspolizei Widerspruch erhoben wird. Ein starker Staat, der der Justiz und dem Richter bestimmte Funktionen übertragen hat, darf nicht zulassen, daß die Stellung des Richters auf Grund einzelner Entscheidungen, die objektiv gesehen Fehlentscheidungen sein mögen, allgemein dadurch geschwächt wird, daß in solchen Fällen ein unzuständiger Funktionsträger eingreift. Ich bitte Sie, Herr Reichsminister, dieser Frage Ihre ganze Aufmerksamkeit zu widmen ... Es handelt sich hier um ganz grundsätzliche Fragen, die man nicht

72 SS-Oberführer Ministerialdirigent Dr. Werner Best, Vorsitzender des Ausschusses für Polizeirecht der Akademie für Deutsches Recht, Berlin: Werdendes Polizeirecht (DR 1938, S. 224 ff.), S. 226.

${ }^{73}$ Vgl. Kapitel VI.1, S. 536 f., u. W. Best, Die deutsche Polizei, Darmstadt 1940, S. 20: „Die ,Polizei“ handelt nie ,rechtlos' oder ,rechtswidrig', soweit sie nach den ihr von ihren Vorgesetzten - bis zur Obersten Führung gesetzten Regeln handelt ...; wird der Wille der Führung übertreten, so handelt nicht mehr die ,Polizei“, sondern begeht ein Angehöriger der Polizei ein Dienstvergehen."

74 Bespr. mit den OLGPräs. u. GStAen im RJM am 18.6.37 vormittags (Akten des RJM, BA, Sign. R 22/4277).

$75 \mathrm{Vgl}$. Rothenbergers autobiograph. Aufz. v. 4.4.44 (Nürnbg. Dok. NG-866). 
... mit der Behauptung abtun kann, es gehe hier nur um eine die Lebenstatbestände außer Acht lassende, auf Ressortegoismus beruhende(n) Prinzipienreiterei. ${ }^{476}$

Gerade die Bemühungen Gürtners, die hier geforderte klare Funktionstrennung durch eine „autoritative“ Normierung der Gestapotätigkeit zu erreichen, waren aber in den vorangegangenen Jahren bereits gescheitert und hatten seit dem wachsenden Einfluß Himmlers und der Gestapo erst recht keine Aussichten auf Erfolg mehr.

\section{b. Bemühungen um die Zulassung von Rechtsanwälten in Schutzhaftangelegenbeiten}

$\mathrm{Da}$ eine gerichtliche Nachprüfung von Gestapo-Maßnahmen ausgeschlossen war, kam der Vertretung von Schutzhäftlingen gegenüber den Dienststellen der Staatspolizei durch Rechtsanwälte eine um so größere Bedeutung zu. Dabei konnte es allerdings nur darum gehen, im Rahmen der allein zulässigen formlosen Dienstaufsichtsbeschwerde Verstöße gegen die Schutzhaftbestimmungen - soweit diese Vorschriften veröffentlicht waren - zu beanstanden bzw. nachzuweisen. Den Bemühungen der Anwälte kam dabei die bereits geschilderte Tendenz der inneren Verwaltung entgegen, im Verein mit dem Justizministerium wenigstens die Auswüchse im Schutzhaftwesen zu beschneiden. Daß einem geschickten Anwalt dabei gelegentlich Erfolg beschieden war, zeigt der Fall eines Maurermeisters in Groß-Solschen (Regierungsbezirk Hildesheim), der am 20. Januar 1934 mit der Begründung in Schutzhaft genommen worden war, er habe zum Schaden des Reichs unkorrekte Rechnungen ausgestellt „und damit Sabotage des Arbeitsbeschaffungswerkes verübt", ferner habe er früher mit der SPD sympathisiert. Auf die Beschwerde seines Anwalts, daß hier der Verdacht einer strafbaren Handlung vorliege und daher ein richterlicher Haftbefehl hätte erwirkt und der Beschuldigte gegebenenfalls in die Untersuchungshaft der Justiz hätte überführt werden müssen, antwortete der Regierungspräsident von Hildesheim/Staatspolizei, die Verhängung von Schutzhaft sei nicht vom Vorliegen einer strafbaren Handlung abhängig, es genüge vielmehr, "daß politische Gründe diese Maßnahme rechtfertigten“".77 Als die Justizbehörden das Strafverfahren gegen den Beschuldigten einstellten, verwies der Rechtsanwalt die Staatspolizeibehörde auf den in Form einer Allgemeinverfügung des preußischen Justizministeriums veröffentlichten Erlaß des preußischen Ministerpräsidenten als Chef der Gestapo vom 11. März 1934, wonach bei Schutzhaft wegen Verdachts einer strafbaren Handlung der Gefangene freizulassen sei, wenn ein unverzüglich zu beantragender richterlicher Haftbefehl abgelehnt werde. Er bat daher um Auskunft, welches Verhalten seines Mandanten die fortdauernde Schutzhaft begründe. ${ }^{78} \mathrm{Da}$ dem Maurermeister keine staatsfeindliche Betätigung nachgewiesen werden konnte, verfiel die Staatspolizei auf den Gedanken, die Zulässigkeit der Schutzhaft mit der Behauptung zu begründen, „die Erregung der Bevölkerung über das Verhalten“ des Gefangenen sei „noch so groß, daß seine Festhaltung in der Schutzhaft zu seinem eigenen Schutze dringend erforderlich" sei. Deshalb sei die weitere Schutzhaft

76 Auszugsweise Abschr. aus dem Lageber. des OLGPräs. Hamburg an das RJM v. 8.7.38 (Akten des RJM, BA, Sign. R 22/1462).

77 Schr. des RegPräs. Hildesheim an den RA v. 15.2.34 (Arch. des IfZ, Sign. MA 198/2).

78 Schr. des RA an den Reg.Präs. Hildesheim v. 30.4 .34 (a.a.O.). Zu Görings Erl. v. 11.3.34 vgl. Kapitel VI.2.a., S. 548, u. Anm. 11. 
den Vorschriften gemäß beim Geheimen Staatspolizeiamt beantragt worden. ${ }^{79}$ Der gewitzte Anwalt erkundigte sich jedoch beim Gemeindevorsteher und beim Landjäger des Heimatortes seines Mandanten und erfuhr, daß für den Maurermeister im Falle seiner Rückkehr nicht die geringste Gefahr bestehe. Am 4. Juni schickte er eine entsprechende Bescheinigung des Gemeindeschulzen - der Landjäger hatte eine schriftliche Bestätigung aus Furcht verweigert - an den Regierungspräsidenten und fragte an, welche Instanz die Notwendigkeit der weiteren Haft seines Mandanten festgestellt habe; ferner sandte er den gesamten bisherigen Schriftwechsel beschwerdeführend an das preußische Innenministerium. ${ }^{80}$ Die Folge war, daß der Maurermeister am 27. Juni 1934 - nach mehr als sechsmonatiger Haft - aus dem Konzentrationslager entlassen wurde. Die Angelegenheit hatte ein Nachspiel: das preußische Innenministerium fragte beim Regierungspräsidenten in Hildesheim an, warum der Häftling erst so spät nach Einstellung des Strafverfahrens entlassen worden sei und ob die Schutzhaftbestimmungen des Reichsinnenministers vom 12. April beachtet worden seien. In der Antwort wurde ein Verstoß gegen die Bestimmungen abgestritten: die Entlassung sei lediglich deshalb nicht früher erfolgt, ,weil der Landrat in Peine aus Gründen der örtlichen Sicherheit und Ordnung die Rückkehr für untragbar hielt“ ${ }^{81}$

Bei den Unannehmlichkeiten, die die Rechtsanwälte der Gestapo bereiteten, war es nicht verwunderlich, daß die Staatspolizeistellen eine Anwaltsvertretung in Schutzhaftsachen zu untersagen suchten und darüber mit der Justiz in Konflikt gerieten. Anstoß dazu gab der Bericht eines Bezirksfachgruppenleiters der Berufsgruppe Rechtsanwälte und Notare aus dem BNSDJ-Gau Hamm vom 10. Oktober 1934 an den Reichsjustizminister, daß die Staatspolizeistelle Münster einem Anwalt die Wahrnehmung der Interessen eines Schutzhäftlings verboten habe. Da ihm ein entsprechendes gesetzliches Verbot nicht bekannt sei, bat der Fachgruppenleiter, beim Innenministerium zu erwirken, daß die Polizeistellen über die Zulässigkeit der Anwaltsvertretung unterrichtet würden. Schließlich könne es die Staatspolizei nur begrüßen, wenn ein Schutzhäftling seine Stellungnahme zu ihren Maßnahmen „in sachlicher und angemessener Form durch einen Anwalt" vortrage. ${ }^{82}$ Das Justizministerium sandte dieses Schreiben zustimmend an den Reichs- und Preußischen Innenminister, der in seiner Antwort vom 17. Januar 1935 gleichfalls dem BNSDJ-Vertreter beipflichtete und fortfuhr: „Ein Ausschluß von Rechtsanwälten in der Vertretung von Rechtsangelegenheiten kann nur insoweit anerkannt werden, als es ausdrücklich festgelegt ist." Diese Antwort reichte der Reichsjustizminister an den Bezirksfachgruppenleiter mit der Bemerkung weiter, daß auch er dieser Auffassung beitrete. ${ }^{83} \mathrm{Um}$ die Stellungnahme der beiden Ministerien den Anwälten bekanntzugeben, wählte die BNSDJ-Reichsfachgruppe der Rechtsanwälte den Weg, den Schriftwechsel am 9. März in ihrem Organ ,Juristische Wochenschrift" zu veröffentlichen. Im begleitenden Kommentar verkündete sie dabei als nunmehr feststehend, daß ein Anwalt von der Vertretung eines Schutzhäft-

79 Schr. des RegPräs. Hildesheim an den RA v. 18.5.34 (a.a.O.). Zur Begründung der Schutzhaft mit dem „eigenen Schutze des Häftlings" im Erl. des RMdI v. 12.4.34 vgl. Kapitel VI.2.a., S. 548f. u. Anm.12.

${ }_{80} \mathrm{Schr}$. des RA an den RegPräs. Hildesheim v. 4.6.34 u. an das preuß. MdI v. 5.6.34 (a.a.O.).

81 Schr. des preuß. MdI v. 5.7.34 u. Antwort des RegPräs. Hildesheim v. 19.7.34 (a. a. O.).

${ }^{82}$ Schr. des Bezirksfachgruppenleiters im LG-Bez. Münster i. W. v. 10.10.34 (Akten des RJM, BA, Sign. R 22/1467)

${ }^{83}$ Schr. des Reichs- u. Preuß. MdI an das RJM v. 17.1.35 u. Schr. des RJM v. 31.1.35 (a.a.O.). 
lings "grundsätzlich nicht ausgeschlossen werden“ könne. ${ }^{84}$ Reichsfachgruppe und Gauführungen des BNSDJ sowie die Anwaltskammern machten in Rundschreiben nochmals auf diese Stellungnahmen aufmerksam. ${ }^{85}$

Hatte das Innenministerium somit die Lage hinsichtlich des positiven Rechts geklärt, so vermochte es jedoch längst nicht mehr, bei dem von Himmler bzw. Heydrich geführten Geheimen Staatspolizeiamt eine entsprechende Anordnung für die nachgeordneten Dienststellen durchzusetzen. Vielmehr erließ der stellvertretende Chef und Inspekteur der Gestapo am 11. April 1935 einen geheimen Erlaß an die Staatspolizeistellen, daß ein Rechtsanwalt zwar wie jeder andere Staatsbürger schriftliche Gesuche zugunsten eines Schutzhäftlings einreichen könne, daß dagegen Einsichtnahme in die Akten und Mitteilung politisch-polizeilicher Vorgänge grundsätzlich verboten und die Erteilung einer Sprecherlaubnis zu versagen sei, ,wenn dadurch der politisch-polizeiliche Zweck der Schutzhaft gefährdet wird“" ${ }^{86}$ Die Kommandanturen der Konzentrationslager waren bereits durch einen Befehl des Politischen Polizeikommandeurs der Länder vom 28. Januar 1935 informiert worden, daß es für Schutzhaft „kein formelles Beschwerderecht, sohin auch keine Vertretung durch Rechtsanwälte gibt" ${ }^{\text {" }}{ }^{77}$

Als Folge dieser gegensätzlichen Auffassung von Gestapo und Justiz wurden verschiedentlich Rechtsanwälte in Schutzhaft genommen, die sich energisch gegen eine Behinderung bei der Vertretung eines Schutzhäftlings wehrten, so z. B. ein Wittenberger Anwalt, der geäußert hatte, „daß selbst während des Ruhreinbruchs die Franzosen es nicht gewagt hätten, dem Verteidiger den Besuch eines Beschuldigten zu verbieten“ ${ }^{88}$ Das Reichsjustizministerium wurde mit Eingaben und Berichten von Anwälten überhäuft, die sich darüber beschwerten, daß ihre an Schutzhäftlinge gesandten Vollmachtsformulare von den Gestapobehörden ununterschrieben zurückgeschickt wurden, daß sie keine Sprecherlaubnis, aber auch keine Auskunft über den betreffenden Fall erhielten und grundsätzlich dahin beschieden wurden, daß eine Anwaltsvertretung in Schutzhaftsachen nicht zugelassen sei. ${ }^{89}$ Sie baten das Ministerium um Abhilfe. Rechtsanwalt Rudolf Dix, der bis Mai 1933 Präsident des ehemaligen Deutschen Anwaltvereins gewesen war, wies in seiner Eingabe besonders auf die Notwendigkeit der Sprecherlaubnis hin, ohne die eine anwaltliche Vertretung schlechterdings unmöglich sei. Aus zwei Gründen sei „die unmittelbare Information durch den Klienten eine nicht entbehrliche Erkenntnisquelle für den Verteidiger": einmal sei die vom Beschuldigten isoliert erfolgende Sammlung von Entlastungsmaterial keinesfalls sachdienlich und könne auch für den Verteidiger ,im höchsten Maße gefährlich“ werden,

84 JW 1935 H. 10, S.759.

85 Vgl. z. B. RdSchr. des Reichsfachgruppenleiters Nr. 18/1935; Gaunachrichten des Gaues KG-Bez. v. 18.4.35 u. der Hanseat. Anwaltskammer v. 28.3.35 (sämtl. erwähnt in den Korrespondenzen des RJM, BA, Sign. R 22/1467).

${ }^{86}$ Erl. in den Akten des RJM (BA, R 22/5032).

${ }^{87}$ Gleichlautende Zitate aus den Schr. der Lagerkommandanten Fuhlsbüttel (März 1935) u. Sachsenburg (25.4.35) an RAe unter Bezugnahme auf die Verf. des Polit.Pol.Kammandeurs v. 28.1.35 - II $1 \mathrm{~A} / \mathrm{III}$ - (Akten des RJM, BA, Sign. R 22/1467 u. Diensttageb. des RJM, Bd.3, Eintr. v. 7. u. 10.5.35 - BA, Sign. R 22/1056).

${ }^{88}$ Ber. des Gestapa an das RJM v. 26.4.35 (Diensttageb. des RJM, a.a.O., Eintr. v. 6. 5.35).

89 Charakteristisch die Eingabe eines Berliner RA, er befinde sich "durchaus in Ubereinstimmung mit anderen Kollegen“, wenn er die „unwürdige Behandlung, die den Rechtsanwälten bei der Stapo zuteil wird, als zur sachlichen Förderung und Aufklärung ungeeignet bezeichne“. In den Vorzimmern der Gestapo bekomme man nur abfällige Bemerkungen über die Arbeit der Justiz zu hören. „Daß der Besitz der Freiheit ein sehr hohes persönliches Gut sei, scheint nicht hinreichend gewürdigt zu werden“ (Diensttageb. des RJM, a.a.O.). 
zum anderen würden Auskünfte von seiten der Staatspolizei „immer mit der Begründung der Verpflichtung zur Geheimhaltung zurückgehalten“. Deshalb komme die gegenwärtige Handhabung einem Ausschluß der Anwaltsvertretung gleich und sei eine lex imperfecta. Mit folgenden Worten setzte sich Dix für eine gewisse „Verrechtlichung" des Schutzhaftverfahrens ein:

„Es entzieht sich der Zuständigkeit meiner Beurteilung, ob die politische Lage die Notwendigkeit eines geheimen inquisitorischen Verfahrens erfordert ... Ist es jedoch politisch zu verantworten, den Rechtsgrundsatz auch in Schutzhaftsachen in Geltung zu lassen, daß jeder deutsche Volksgenosse und jeder der deutschen Staatshoheit Unterworfene sich anwaltschaftlichen Beistandes erfreuen darf, so muß dem Anwalt grundsätzlich das Recht zugestanden werden, ... [sich] ehest möglich entsprechend der Übung im ordentlichen Strafverfabren über die Einzelheiten des Ermittlungsstandes Kenntnis zu verschaffen." ${ }^{\text {90 }}$

Die beschwerdeführenden Anwälte hatten bei den Staatspolizeistellen und teilweise sogar im Geheimen Staatspolizeiamt vorgesprochen und dort mitgeteilt erhalten, daß die in der "Juristischen Wochenschrift" veröffentlichte Stellungnahme der beiden Reichsministerien „von falschen Voraussetzungen ausgehe ${ }^{\text {" } 91}$ : eine Vertretung von Schutzhäftlingen sei äußerstenfalls in vermögensrechtlichen Angelegenheiten erlaubt. Einem Anwalt wurde sogar die Mitteilung gemacht, „die gegenteilige Ansicht des Herrn Reichsjustizministers habe man zur Stellungnahme dem Herrn Minister des Innern [!] unterbreitet. Von dort sei jedoch eine endgültige Entscheidung noch nicht erfolgt" ${ }^{.92}$ Schließlich wandte sich auch die Reichs-Rechtsanwaltskammer unter Beifügung von Berichtsmaterial an das Justizministerium mit der Bitte, er möge doch beim Innenminister erreichen, daß seine bereits getroffene und veröffentlichte Entscheidung ,auch von den ihm unterstellten [?] Behörden beachtet" werde. ${ }^{93}$ Hinter diesen Forderungen der Anwaltschaft standen auch handfeste materielle Interessen, da mit einem Vertretungsverbot Verluste an Honoraren verbunden waren. ${ }^{94}$ Daß sich der Bund National-Sozialistischer Deutscher Juristen in dieser Situation als berufsständische Interessen vertretende Organisation erwies und zusammen mit dem Reichsjustizministerium gegen die Gestapo Front machte, ist ein Beispiel dafür, wie sich auch unter dem NS-Regime - selbst in überwiegend staatspolitischen Fragen - die gesellschaftlichen Gegebenheiten durchsetzten. Der Stellvertreter des Reichsrechtsführers und Leiter des Amtes für Rechtsbetreuung im Reichsrechtsamt der NSDAP Raeke machte Gürtner am 10. Mai 1935 „auf die bedenklichen Folgen“ der von der Gestapo eingenommenen Haltung aufmerksam und bat, dahin zu wirken, daß „die in einem

90 Schr. RA Dix an das RJM v. 10.5.35 (Akten des RJM, BA, Sign. R 22/1467). Hervorheb. v. Verf.

91 Schr. eines Berliner RA an die Anwaltskammer Berlin v. 31.5.35 (a.a.O.).

92 Ber. eines Berliner RA an die Anwaltskammer Berlin v. 15.5.35 (a.a.O.). Zur Vertretung von Häftlingen in anderen Angelegenheiten berichtete E. Fraenkel, „daß ein Mann aus dem Konzentrationslager heraus erfolgreich seine Steuerbeschwerden bearbeiten konnte. Der politische Maßnahmen-Staat sperrte ihn ein, der technische Normen-Staat prüft seine Steuerbeschwerden, als ob nichts geschehen sei, als ob wir in einem Rechtsstaat lebten ...“ (E. Fraenkel, Das Dritte Reich als Doppelstaat, unter dem Pseudonym C. Jürges veröffentl. in Sozialistische Warte Jg. 1937, Wiederabdruck in: Reformismus und Pluralismus, Hamburg 1973, S. 234).

93 Schr. v. 20.5.35, weitere Schr. mit Material v. 22.5. u. 3.6.35 (Akten des RJM, a.a.O.).

$94 \mathrm{Vgl}$. Schr. eines Berliner Anwalts an den Gau KG-Bezirk des BNSDJ v. 10.5.35: „In der heutigen Zeit, in der das Arbeitsgebiet der Anwälte derartig beschränkt ist, muß der Gau mit aller Entschiedenheit darauf hinwirken, daß die Tätigkeit der Anwälte auf dem Gebiete der Schutzhaftsachen keiner Beschränkung unterliegt" (a.a.O.). 
Rechtsstaat allein mögliche Auffassung " des Reichsjustizministeriums in dieser Frage von den Staatspolizeistellen respektiert werde. ${ }^{95}$

Das war leichter gesagt als getan. Gürtner setzte dort an, wo es ihm zunächst möglich war: im preußischen Kabinett. Wie bereits in anderem Zusammenhang geschildert, erreichte er anläßlich der Beratung über Himmlers Entwurf eines Gestapo-Gesetzes in der Sitzung des Preußischen Staatsministeriums vom 27. Juni 1935 ein Einverständnis u.a. darüber, daß ,jegliche Verhinderung der Vertretung in Schutzhaftsachen durch Rechtsanwälte" unzulässig sei. ${ }^{96}$ Damit war allerdings noch wenig gewonnen. Am 4. Juli übersandte daher das Reichsjustizministerium dem preußischen Gestapochef - nominell Göring, in der Realität Himmler - und dem Reichsminister des Innern eine Reihe der eingegangenen Berichte der Rechtsanwälte und bat unter Bezug. nahme auf das Ergebnis der Kabinettssitzung, Anordnungen über die Zulassung der Anwaltsvertretung ergehen zu lassen und ihm darüber zu berichten. ${ }^{97}$ Bis September hörte das Ministerium daraufhin nichts mehr. Unterdessen mahnten sowohl das Präsidium der Reichs-Rechtsanwaltskammer, das dringend „eine baldige gesetzliche Regelung“ der Angelegenheit wünschte ${ }^{98}$, wie auch die Führung des BNSDJ, die „ernste Besorgnis um den Bestand der Rechtssicherheit in Deutschland“ hegte. Der stellvertretende Reichsjuristenführer hielt den seit Monaten anhaltenden ungeklärten $\mathrm{Zu}$ stand für äußerst bedenklich. Zudem sei es „eine erhebliche rechtspolitische Belastung" und die Erziehungsarbeit des BNSDJ an den deutschen Anwälten werde erheblich erschwert, wenn der Eindruck entstehe, daß die Gestapo der maßgeblich niedergelegten gemeinsamen Auffassung der zuständigen Reichsminister ungehindert zuwiderhandeln könne. Raeke machte dabei Ausführungen, die Bemerkenswertes über die grundsätzliche Auffassung der NS-Juristen von der Institution der Schutzhaft offenbaren:

„Darüber hinaus möchte ich in dem Bewußtsein, eine vielfach geäußerte Auffassung des Reichsjuristenführers Reichsminister Dr. Frank zu vertreten, darauf hinweisen, daß die Verweigerung des rechtlichen Beistandes in Schutzhaftsachen mit dem nationalsozialistischen Begriff der Rechtssicherheit vollkommen unvereinbar und ... umso bedenklicher ist, als die Herausarbeitung des Begriffs der Rechtssicherheit in der nationalsozialistischen Auffassung sowohl in der Idee als auch in der Praxis insbesondere international einer der Brennpunkte im Kampfe für das Verständnis unserer Weltanschauung sein dürfte ... Während also der Liberalismus in Maßnahmen wie in der durch die Geheime Staatspolizei verhängten Schutzhaft eine außerhalb der Rechtssphäre liegende Willkür erblickte, die nach seiner Weltanschauung zu verwerfen war ..., sieht der Nationalsozialismus derartige Maßnahmen als berechtigt und notwendig an und erklärt sie damit ... zu staatlichen Rechtsmaßnabmen besonderer Art, welche die ordentliche Rechtspflegetätigkeit des Staates notwendig ergänzen. Wenn also die Schutzhaft eine staatliche Einrichtung ist, die innerhalb der Sphäre des Rechts liegt, so ergibt sich daraus, daß auf dieses Rechtsinstitut die allgemein nicht nur im deutschen, sondern überhaupt im germanischen Rechtsbewußtsein verankerten Rechtsgrundsätze Anwendung finden müssen ... Diese allgemeinen Rechtsgrundsätze gehen einmal dahin, daß jeder Volksgenosse und Schutzbefohlene durch außerordentliche Rechtsmaß-

95 Schr. v. 10.5 .35 (a.a.O.). Mit Schr. v. 22.6.35 erinnerte Raeke an die Lösung dieser äußerst wichtigen Frage, „damit weiteren unbegründeten Angriffen dahingehend, daß in Deutschland keine Rechtssicherheit mehr bestehe, nach Möglichkeit der Boden entzogen" werde (a.a.O.).

96 Verm. Gürtners v. 1.7.35 (a.a.O.), vgl. dazu Kapitel VI.2.a., S. 555.

97 Beide Schr. v. 4.7 .35 (a.a.O.). Im Schr. an das RMdI fügte Gürtner hinzu, er gehe davon aus, daß die im preuß. Kabinett beschlossenen Grundsätze auch für die außerpreuß. Gebiete zu gelten hätten.

98 Schr. v. 21.8.35 (Akten des RJM, a.a.O., u. Diensttageb. des RJM, Bd.4, Eintr. v. 23.8.35, BA, Sign. R 22/1059). 
nahmen des Staates, wie die Schutzhaft, nur insoweit erfaßt werden darf, als außerordentliche $\mathrm{Zu}$ stände - wie Gefahr für die öffentliche Sicherheit oder Gefahr für die Sicherheit des Betreffenden - dies rechtfertigen, daß er aber nach Behebung des außerordentlichen Zustandes entweder wieder in Freiheit zu setzen oder dem ordentlichen Richter zuzuführen ist. Diesem allgemeinen Rechtsgrundsatz ist durch die [zu ergänzen: normative] Ausgestaltung der Schutzhaft Rechnung getragen. Der weitere allgemeine Rechtsgrundsatz ist der, daß der von der außerordentlichen Rechtsmaßnahme des Staates Erfaßte wie jeder Volksgenosse oder Schutzbefohlene sich eines Rechtsbeistandes bedienen kann, da er ... immer noch Volksgenosse oder Schutzbefohlener bleibt und ihm daher die Möglichkeit offengehalten bleiben muß, seine Unschuld darzutun ... Die Tatsache, daß es im Schutzhaftverfahren keine Beschwerdemöglichkeit gibt, was sich aus der außerordentlichen Natur dieser Rechtseinrichtung ohne weiteres erklärt, ändert also nichts daran, daß die Möglichkeit eines rechtlichen Beistandes gegeben sein muß, während andererseits die Zurückweisung rechtlichen Beistandes ... gerade wegen der Verankerung dieses Rechtsgefühls im Volksbewußtsein in bedenklichem Maße einer böswilligen Verleumdung und Hetze des Inhalts Vorschub leistet, daß die Tätigkeit der Geheimen Staatspolizei - wie die der russischen Tscheka - außerhalb der Rechtssphäre steht und reine Willkür sei. Demgemäß ist auch bei den Verhandlungen einer Sektion des internationalen Strafrechtskongresses ${ }^{99}$ von belgischer Seite der allerdings von dem Vertreter des B.N.S.D.J. mit Erfolg abgewehrte Versuch gemacht worden, eine ,wissenschaftliche' Erörterung über die Frage aufzurollen, daß und in welchem Umfang in die Strafrechtspflege des neuen deutschen Reiches durch die Maßnahmen der Geheimen Staatspolizei die Gesichtspunkte der Rache, der Willkür und der völligen Schutzlosigkeit hineingetragen worden seien!

Raeke schloß, die Beseitigung des, in einem autoritären Staat besonders peinlichen Widerspruchs“ zwischen Justiz und Gestapo zugunsten des vom Reichsjustizministerium eingenommenen Standpunktes sei "für das Ansehen der Rechtssicherheit in Deutschland und der nationalsozialistischen Rechtspflege" von so ausschlaggebender Bedeutung, daß sich „die Herbeiführung einer persönlichen Entscheidung des Führers und Reichskanzlers rechtfertigen dürfte“. ${ }^{\text {(00 }}$

Nach Eingang dieser Mahnungen der Reichs-Rechtsanwaltskammer und des BNSDJ hatte das Reichsjustizministerium eben ein Erinnerungsschreiben an den preußischen Gestapochef und an Fricks Ministerium entworfen, als am 5. September 1935 die Antwort Fricks einlief, die jedoch lediglich in der Übersendung seiner bereits früher erlassenen Schutzhaftbestimmungen bestand. ${ }^{101}$ In seiner Erwiderung stellte Gürtner fest, daß die übermittelten Erlasse „über die Frage der Anwaltsvertretung keinerlei Anordnungen“ enthielten, und bat angesichts der ungünstigen Beurteilung, die der gegenwärtige Zustand auch im Ausland finden könne, nochmals um den Erlaß eindeutiger Vorschriften, „um in der Angelegenheit zu klaren Verhältnissen zu kommen“. Die gleiche Aufforderung wurde an den preußischen Ministerpräsidenten und Gestapochef gerichtet. ${ }^{102}$ Außerdem ließ Gürtner das Thema erneut auf die Tagesord-

99 In diesen Tagen (18.-24.8.35) fand in Berlin der XI. Internationale Strafrechts- und Gefängniskongreß statt.

100 Streng vertraul. Schr. des Stellv. des Reichsrechtsführers an Gürtner v. 22.8.35, Hervorheb. im Original. In einer Anlage zu einem weiteren Schr. v. 12.12.35 forderte ein BNSDJ-Funktionär aus dem Gau Berlin sogar, die Einleitung eines Dienststrafverfahrens wegen Rechtsverweigerung gegen einen Gestapo-Beamten zu betreiben, der eine Anwaltsvertretung abgelehnt hatte (Akten des RJM, a.a.O.).

101 Entw. des RJM und Schr. Fricks mit den RdErl. v. 12./26.4.34, 10.7.34 u. 29.4.35 (a.a.O.).

102 Beide Schr. v. 24.9.35 (a.a.O.). Dem Schr. an Frick legte Gürtner Material über die Verhaftung eines Münchener RAs bei, dem die BPP vorwarf, daß er die Vertretung eines Schutzhäftlings übernommen habe, obwohl ihm bekannt gewesen sei (!), daß es ein Rechtsmittel in Schutzhaftsachen nicht gebe; vgl. dazu Schr. des RJM an das RMdI v. 4.11 .35 (a.a.O.). 
nung der nächsten Sitzung des preußischen Kabinetts am 11. Oktober 1935 setzen; die Sitzung wurde jedoch abgesagt. ${ }^{103}$

Da sich das Innenministerium als ohnmächtig erwies und auch Göring als preußischer Ministerpräsident Himmler in Gestapo-Angelegenheiten das Feld überlassen hatte, mußte das Reichsjustizministerium wohl oder übel direkt an das Geheime Staatspolizeiamt herantreten. Der Leiter der Strafrechtspflegeabteilung Ministerialdirektor Crohne und der Referent für Staats- und Verwaltungsrecht in der Abteilung V (Öffentliches Recht u.a.) Ministerialrat Kritzinger nahmen mit Oberregierungsrat Best, dem Leiter der Abteilung Verwaltung und Recht im Geheimen Staatspolizeiamt, Gespräche auf. Best lehnte jedoch ab, den Anwälten bei der Wahrnehmung der Interessen von Schutzhäftlingen mehr Rechte einzuräumen, als sie anderen Personen zustanden. Eine Anwaltsvertretung, argumentierte Best, würde nur „dazu führen, daß bemittelte Personen oder solche, hinter denen weitere Kreise stünden (Kommunisten), sich Anwälte nehmen könnten, andere aber nicht“. Außerdem komme es den Anwälten, wie sich ihren Eingaben „unzweideutig“ entnehmen lasse, „im wesentlichen auf wirtschaftliche Vorteile an“. Die Vertreter der Justiz räumten ein, daß bei der Anwaltsvertretung in Schutzhaftsachen im Vergleich zum Strafverfahren „gewisse Einschränkungen notwendig“ seien, und baten, von der Gestapo beabsichtigte Richtlinien dem Justizministerium mitzuteilen, damit darüber verhandelt werden könne. ${ }^{104}$

Unterdessen hatte Himmler selbst die Initiative ergriffen, um den Bestrebungen der Justiz ein für allemal einen Riegel vorzuschieben. Am 6. November 1935 sandte er in seiner Eigenschaft als stellvertretender Chef und Inspekteur der preußischen Gestapo folgendes kurzes Schreiben an Gürtner:

„Ich habe in der Angelegenheit des an uns herangetragenen Wunsches, betr. die Erteilung der Genehmigung, bei Schutzhaftfällen Rechtsanwälte einzuschalten, dem Führer am 1.11.1935 Vortrag gehalten.

Der Führer hat die Hinzuziehung von Rechtsanwälten verboten und mich beauftragt, Ihnen seine Entscheidung zur Kenntnis zu bringen." ${ }^{\text {105 }}$

Damit schien endgültig entschieden zu sein, daß jede Mitwirkung der Anwaltschaft bei Schutzhaftsachen unterbleiben sollte. Aber Gürtner suchte nach einem Weg, um nicht nur jene Befugnisse für die Anwälte zu retten, die ihnen die Gestapo mit ihrem Erlaß vom 11. April $1935^{106}$ zugestanden hatte und die an sich jeder Staatsbürger - Verwandter oder Freund eines Schutzhäftlings - geltend machen konnte, sondern ihnen darüber hinaus doch noch erweiterte Befugnisse zu verschaffen. Er wußte aus Erfahrung, daß mancher rasch eingeholte Führerentscheid - der oftmals zugunsten dessen ausfiel, der durch leichteren Zugang zu Hitler seine Argumente zuerst unterbreiten konnte - wieder umgestoßen oder zumindest bei der Realisierung durch die zuständigen Stellen abgeändert werden konnte. ${ }^{107}$ Um Zeit zu gewinnen, lehnte er

\footnotetext{
103 Verm. v. 9. u. 11.10.35 (Akten des RJM, a.a.O.).

104 Verm. Kritzingers v. 5.11 .35 (a.a.O.).

105 Akten des RJM (a.a.O.).

$106 \mathrm{Vgl}$. voranstehend S. 566 und Anm. 86.

107 Vgl. zu diesem Problem L. Gruchmann, Die „Reichsregierung“ im Führerstaat. Stellung und Funktion des Kabinetts im nationalsozialistischen Herrschaftssystem (in: Klassenjustiz und Pluralismus. Festschrift für Ernst Fraenkel zum 75. Geburtstag, Hamburg 1973, S. 187 ff.), S. 199; ein besonders deutliches Beispiel ist die Korrektur der von Ley bei Hitler erreichten VO über die DAF v. 24.10.34 durch ministerielle Ausführungsbestimmungen, vgl. M. Broszat, Der Staat Hitlers. Grundlegung und Entwicklung seiner inneren Verfassung, München 1969, S.201.
} 
vorerst die Bekanntgabe der Entscheidung an die Anwaltschaft mit dem Argument ab, sie „könnte im Ausland stimmungsmäßig in unerwünschter Weise verwertet werden“. ${ }^{108} \mathrm{Da}$ die Angelegenheit dennoch möglichst bald geklärt werden mußte, um weitere Zusammenstöße zwischen Anwälten und Gestapostellen zu vermeiden, beabsichtigte er, sie mit Göring, Frick und Himmler gelegentlich einer Sitzung des preußischen Kabinetts zu besprechen, wo er der Unterstützung Fricks und vielleicht auch Görings als des nominellen Chefs der preußischen Gestapo sicher sein konnte. Deshalb gab er Himmlers Brief zunächst nur dem Büro des preußischen Ministerpräsidenten abschriftlich zur Kenntnis. ${ }^{109}$ Unterdessen suchte das Innenministerium, das von Himmler eine Abschrift des Briefes erhalten hatte, beim stellvertretenden Gestapochef vorsichtig zu erkunden, ob Hitlers Verbot so verstanden werde, daß der Anwaltschaft nunmehr jede Tätigkeit in Schutzhaftsachen untersagt sei, oder dahingehend, daß „die Bemühungen der Anwaltschaft, ihre Befugnisse über den in der Verfügung vom 11. April 1935 gezogenen Rahmen hinaus auszudehnen, abgewiesen" seien. ${ }^{110}$ Da sich Gürtners Absicht einer Aussprache mit Himmler im Rahmen einer Kabinettssitzung bis Jahresende nicht verwirklichen ließ - Himmler blieb im November und Dezember den Sitzungen fern -, schlug er ihm am 23. Dezember vor, die Angelegenheit im Januar direkt und persönlich zu erörtern, um ,vielleicht doch eine andere Regelung der Frage" zu finden. Ihm schwebe vor, ähnlich wie beim Volksgerichtshof zu verfahren, wo die Wahl des Verteidigers durch den Vorsitzenden genehmigt werden mußte ${ }^{111}$ : dort würden nach Fühlungnahme mit der Reichs-Rechtsanwaltskammer zwei Listen der als Pflichtverteidiger in Frage kommenden Rechtsanwälte aufgestellt, wobei eine Liste jene Anwälte enthielte, „die als politisch unbedingt zuverlässig für die besonders vertraulichen Fälle geeignet" seien. Wenn durch eine ähnliche Auswahl geeigneter Anwälte ,eine korrekte und vertrauliche Behandlung der einzelnen Schutzhaftfälle gewährleistet würde“, könnten vielleicht die Bedenken der Gestapo wesentlich verringert werden. Anfang Januar äußerte sich Himmler - ,immer noch krank" - aus Tegernsee, daß er Gürtners Vorschlag für eine annehmbare Lösung halte. ${ }^{112}$ Unterdessen bekam auch das Innenministerium vom stellvertretenden $\mathrm{Ge}$ stapochef den Bescheid, daß Hitlers Entscheidung nicht als totales Verbot für die Mitwirkung von Anwälten in Schutzhaftsachen ausgelegt werde, sondern alle politischen Polizeien der Länder bereits Ende November informiert worden seien, daß der Erlaß vom 11. April 1935 weiterhin Grundlage für die Beteiligung der Anwälte bleibe. ${ }^{13}$ Endlich im März 1936 - die Begegnung war durch Himmlers Krankheit verzögert worden - einigten sich Gürtner und der Reichsführer-SS, daß die Reichs-Rechtsan-

${ }^{108}$ So in seinem späteren Schr. an Himmler v. 23.12.35 (vgl. folgendes).

109 Schr. Gürtners an das preuß. StMin. v. 14.11.35 (a.a.O.). Himmler hatte Göring allerdings bereits eine Abschrift übersandt.

110 Schr. des RuPreußMdI v. 6.12.35 (Akten des RJM, BA, Sign. R 22/5032).

111 Vgl. Art. IV $\S 3$ des G. zur Änderung von Vorschriften des Strafrechts und Strafverfahrens v. 24.4.34 (RGBl. I, S.341).

112 Schr. Gürtners an Himmler v. 23.12.35, Himmlers Antwort v. 6.1.36 u. Gürtners Bestätigungsschr. v. 17.1.36 (Akten des RJM, BA, Sign. R 22/1467).

113 Schr. des stellv. Chefs der preuß. Gestapo an das RuPreußMdI v. 29.2.36, Ber. des RuPreußMdI an das RJM v. 10.3.36 (Akten des RJM, BA, Sign. R 22/5032). Daß der Erl. v. 11.4.35 tatsächlich weiter befolgt wurde, beweist das Ablehnungsschr. des Kommandanten $\mathrm{KZ}$ Fuhlsbüttel v. 6.5 .36 an einen Hamburger RA (Schr. des NSRB-Gauführers an den Präs. des Hanseat.OLG v. 14.7.36, Akten des RJM, BA, Sign. R $22 / 1467)$. 
waltskammer im Benehmen mit dem Geheimen Staatspolizeiamt eine Liste von vertretungsberechtigten Anwälten aufstellen sollte. ${ }^{114}$ Obwohl das Justizministerium die Reichs-Rechtsanwaltskammer daraufhin ersuchte, deswegen mit der Gestapo in Verbindung zu treten, kam die Angelegenheit in den folgenden Monaten nicht voran. Dafür gab es mehrere Gründe. Einmal lag der Gestapo wenig an einer Änderung des Status quo, der ihr ermöglichte, die Mitwirkung von Anwälten zu verhindern. $\mathrm{Da}$ die Gestapo aufgrund des fortgeltenden Erlasses vom 11. April 1935 auch „ausgewählten“ Anwälten keine Vorrechte einzuräumen brauchte, dürfte auch die Anwaltskammer an der Aufstellung einer solchen Liste kein großes Interesse gehabt haben: die geforderte Auswahl unterwarf die Kammervorstände nur der peinlichen Aufgabe, über ihre Kollegen politische Urteile abgeben zu müssen ${ }^{115}$, ohne etwas anderes zu bringen als eine Schlechterstellung der nicht-ausgewählten Anwälte gegenüber jedem Staatsbürger, der - nicht von Berufs wegen - die „Rechte“ eines Schutzhäftlings wahrnehmen konnte. Auch die grundsätzlichen gegenseitigen Ressentiments zwischen SS/Gestapo und Anwaltschaft - die sich im Laufe der Jahre verstärkten und später darin gipfeln sollten, daß das Presseorgan der Reichsführung-SS, „Das Schwarze Korps“, den Anwaltsstand als „Gilde der kleinen Dreckaufwirbler und Kloakentiere" diffamierte ${ }^{116}$ und die Gestapo dem Präsidenten der Reichs-Rechtsanwaltskammer Neubert ein Landesverratsverfahren wegen Verletzung der Geheimhaltungspflicht anhängen wollte ${ }^{117}$ - dürften dazu beigetragen haben, daß Gürtners Vorstellungen nicht verwirklicht wurden. Schließlich nahm die Justizverwaltung die Sache selbst in die Hand: am 31. Januar 1938 wurden die Oberlandesgerichtspräsidenten vertraulich angewiesen, in ihren Bezirken für die Vertretung von Schutzhäftlingen geeignete Anwälte auszusuchen. Dabei sollte der Beitritt zur Partei nach dem 30. Januar 1933 „für sich allein das erforderliche $\mathrm{Maß}$ an Zuverlässigkeit in aller Regel noch nicht gewährleisten“, andererseits sollten aber auch Nichtparteigenossen nicht von vornherein ausgeschlossen bleiben. Ausschlaggebend sollte allein sein, daß die Auszuwählenden ,mit den politischen Bestrebungen des Staates und den weltanschaulichen Zielen der Bewegung voll übereinstimmen“. Die benannten Anwälte - im allgemeinen nur Strafverteidiger - sollten in

114 Ber. Gürtners an das RuPreußMdI v. 27.3.36 (Akten des RJM, BA, Sign. R 22/5032). Das RJM gab daraufhin z.B. am 8.8.36 an den Präs. des Hanseat.OLG die Auskunft:- „Die Frage der Anwaltsvertretung in Schutzhaftsachen wird z.Zt. zwischen den zuständigen Stellen erörtert [!“" (Akten des RJM, BA, Sign. R 22/1467).

115 Als z.B. das badische JM 1934 die Anwaltskammer Karlsruhe um eine Liste von i.S. des NS „zuverlässigen“ Anwälten für Fiskal- u. Behördenprozesse bitten wollte, unterblieb diese Maßnahme mit der Begründung, der Kammervorstand „käme dadurch in die Lage, Werturteile über die Mitglieder der Kammer stellen zu müssen“; sie wurde statt dessen vom BNSDJ aufgestellt (Diensttageb. des RJM, Bd.9, Eintr. v. 8.12.36, BA, Sign. R 22/930).

${ }^{116} \mathrm{Vgl}$. Artikel „Das muß aufhören!“ (Titelseite 8.Jg. 25. Folge v. 18.6.42); dagegen Erwiderung Hans Franks in seiner Rede in München am 20.7.42, der diesen Angriff „als der deutschen Volksgemeinschaft abträglich" bezeichnete (D. Willoweit, Das völkische Recht (1994) S.283), u. des Präs. der RRAK Neubert in seinem Aufruf in den Mitteilungen der RRAK 1942, S. 49 (Arch. des IfZ, Sign. Da 31.01): Wo die Kritik „sich in üblen Schimpfereien austobt, fehlt die Möglichkeit einer Auseinandersetzung. Hier müssen die für die Erziehung und Wahrnehmung der Ehre in Presse und Partei zuständigen Stellen sprechen. Das Ansehen der Anwaltschaft kann auf diese Weise nicht beeinträchtigt werden!“. Zu den Angriffen des „Schwarzen Korps" auf die RAe seit 1935 vgl. Weinkauff, a.a.O., S.123, 132, 139, 163, 326; F. Ostler, Die deutschen Rechtsanwälte 1871-1971, Essen 1971, S.241, 280, 296; dazu die zahlreichen Richtigstellungen und Erwiderungen in den Mitteilungen der RRAK (a.a.O.).

117 Schr. des Chefs Sipo u. SD an das RJM v. 17.11.42; Einstellungsverm. v. 20.3.43 in den Akten des RJM (BA, Sign. R 22/20028). 
eine nach Staatspolizeistellen gegliederte Liste aufgenommen und ihre Eignung vom Präsidenten der Reichs-Rechtsanwaltskammer vertraulich begutachtet werden; andere Stellen außerhalb der Justizverwaltung sollten dagegen nicht gehört werden. Zusammen mit der Liste sollten dem Ministerium Personal- und Befähigungsnachweise eingereicht werden, in denen nach Möglichkeit auch darzulegen war, „ob Grund zu der Annahme besteht, daß der Anwalt das Vertrauen der Staatspolizeistelle genießt".118

Aus der einleitenden Formulierung dieser Rundverfügung: - die Aktion erfolge „zur Vorbereitung einer Entschließung des Herrn Reichsführers-SS und Chefs der Deutschen Polizei darüber, ob einzelnen Rechtsanwälten die Übernahme der Vertretung von Schutzhäftlingen allgemein gestattet werden kann“ - geht hervor, daß Gürtner immer noch hoffte, Himmler durch ein Angebot „zuverlässiger“ Rechtsanwälte zur Gewährung erweiterter Vertretungsbefugnisse bewegen zu können. Diese Hoffnung sollte jedoch enttäuscht und durch die wachsende Macht der Gestapo nach Kriegsausbruch völlig zerstört werden: im November 1941 wies der Präsident der Reichs-Rechtsanwaltskammer aufgrund vielfacher Anfragen die Anwälte darauf hin, daß ihr Auftreten in Gestapo-Angelegenheiten „bisher noch nicht abschließend geregelt worden“ sei, „daß der Rechtsanwalt als Vertreter eines Beschuldigten in einem Verfahren bei der Geheimen Staatspolizei z.Zt. nicht die Stellung eines Strafverteidigers hat und daß ein Anspruch des Rechtsanwalts auf Zulassung als Vertreter des Beschuldigten nicht zuerkannt wird“. ${ }^{19}$ Obwohl die Liste mit geeigneten Rechtsanwälten der Reichsführung-SS schließlich übersandt worden war, mußte das Ministerium noch ein Jahr später feststellen, daß die Anwaltsvertretung von Schutzhäftlingen bis auf Ausnahmen durch örtliche Staatspolizeistellen nicht zugelassen wurde. ${ }^{120}$ Der Versuch des Reichsjustizministeriums, die Schutzhaft von dieser Seite her zu ,verrechtlichen“, war gescheitert. Gestützt auf Hitlers Autorität hatte die Gestapo auch auf diesem Sektor alle Absichten abgewehrt, die ihr außernormatives Handeln auch nur im geringsten hätten beeinträchtigen können.

\section{c. Auseinandersetzung über die Bebandlung von Scbutzbäftlingen in Justizgefängnissen}

Ein Reibungspunkt zwischen Justiz und Gestapo war die Unterbringung und Behandlung von Schutzhäftlingen in justizeigenen Vollzugsanstalten. Dieses Problem spielte nicht nur in der Zeit der frühen Verhaftungswellen von 1933, sondern auch noch später eine Rolle.

Als in Bayern im März 1933 die Massenverhaftung politischer Gegner einsetzte und das Konzentrationslager Dachau noch im Aufbau begriffen war, wurden die Schutzhäftlinge zunächst in die örtlichen Gerichtsgefängnisse und die Strafanstalten eingeliefert. ${ }^{21}$ Am 21. April beschwerte sich daher Justizminister Frank bei Innenminister Wagner, daß die Arbeit der Justiz durch die Überfüllung ihrer Gefängnisse beeinträch-

\footnotetext{
118 Streng vertraul. RV des RJM an die OLGPräs. v. 31.1.38 (Akten des RJM, BA, Sign. R 22/1467).

119 Anordn. des Prās. der RRAK Nr.60/41 (Mitteilungen der RRAK 1941, Nr. 10/11 v. 20.11.41, Arch. des IfZ, Sign. Da 31.01).

120 Verm. des Leiters der Abt. I (Personal- u. Organisationssachen) MinDir. Letz für den neuen Sts Rothenberger v. 14.9. 42 (Akten des RJM, BA, Sign. R 22/5029).

121 Schon am 7.4.33 wies Frank im bayer. Ministerrat auf die Úberfüllung der Gefängnisse hin; am 1.4.33 habe die Zahl der Schutzhäftlinge in Bayern 5000 betragen u. werde demnächst auf 6-7000 steigen (Niederschr. der Sitzung v. 7.4.33, BayerHStArch., Sign. MA 99526 ).
} 
tigt werde. Die Zusammendrängung der Gefangenen gefährde die körperliche Gesundheit und führe zu schweren Haftpsychosen; zudem könnten sie mit dem vorhandenen Personal nur ungenügend beaufsichtigt werden. Vor allem aber habe die Überbelegung zur Folge,

„daß der Strafvollzug in beträchtlichem Umfange lahmgelegt ist. Wie ich bereits in meinem Schreiben vom 11. April 1933 Nr.IV 11302 a mitgeteilt habe, mußte schon in vielen Fällen die Vollstreckung von Freiheitsstrafen aufgeschoben werden. Aus dem gleichen Grunde konnten und können Beschuldigte, gegen die zwecks unbehinderter Klärung der Sachlage Untersuchungshaft zu verhängen wäre, nicht in Haft genommen werden. Die gegenwärtigen Zustände verhindern also die Durchführung einer geordneten Rechtspflege und gefährden damit lebenswichtige Interessen des Staates und Volkes. Sie sind für die Justizverwaltung unerträglich und können nicht weiter verantwortet werden. Ich muß deshalb dringend ersuchen, anzuordnen, daß die Strafanstalten und Gerichtsgefängnisse umgehend von allen Schutzhaftgefangenen entlastet werden. ${ }^{“ 122}$

Die Innenministerien der Länder suchten diese keineswegs auf Bayern beschränkten Unzuträglichkeiten ${ }^{123}$ durch den Ausbau staatlicher Konzentrationslager zu beseitigen, in denen Schutzhäftlinge grundsätzlich untergebracht werden sollten. Soweit sie aber den Polizeibehörden für Ermittlungszwecke jederzeit zur Verfügung stehen mußten oder ihre Verhaftung nur für kurze Zeit beabsichtigt war, sollten sie in staatlichen oder kommunalen Polizeigefängnissen festgehalten werden. Da die kleinen Polizeigefängnisse dafür nicht hinreichend ausgestattet waren, bereitete den Polizeibehörden die Unterbringung dieser Schutzhaftgefangenen Schwierigkeiten. Im Land Braunschweig z. B., das kein eigenes Konzentrationslager eingerichtet hatte, mußte die Polizei in starkem Maße auf Justizgefängnisse zurückgreifen, weil eine Überführung von Schutzhäftlingen in die entfernt liegenden Lager anderer Länder nur bei längerer Haftdauer in Frage kam. ${ }^{124}$ In Preußen, wo jede Inanspruchnahme von Anstalten der Justizverwaltung für diesen Zweck ab Jahresende 1933 der Genehmigung des Innenministeriums bedurfte ${ }^{125}$, wurde Anfang 1935 zwischen Innen- und Justizministerium über die Unterbringung von Schutzhäftlingen vereinbart,

„daß diese Personen in einem Justizgefängnis untergebracht werden, wenn sich an dem Ort der Verwahrung oder in dessen Nähe kein geeignetes Polizeigefängnis befindet. Welche Gefängnisse für die Aufnahme in Frage kommen, bestimmt der Generalstaatsanwalt. Dieser hat auch zu entscheiden, ob infolge der Belegung eine Aufnahme von Schutzhäftlingen möglich ist. Von den kommunalen Polizeiverwaltungen sind der Justizverwaltung die Haftkosten nach den allgemeinen Sätzen zu erstatten. ${ }^{\text {} 126}$

Solange es keine Konzentrationslager für Frauen gab ${ }^{127}$, mußten weibliche Schutzhaftgefangene generell anderweitig untergebracht werden: während Frauen aus PreuBen und Mitteldeutschland in das Provinzialwerkhaus Moringen (Reg. Bez. Hildes-

122 Schr. Franks an das bayer. StMdI v. 21.4.33 (BA, Sammlung Schumacher/271, Kopie im Arch. des IfZ, Sign. Fa 183/1, Bl.270f.). Zu den Verhaftungswellen 1933 vgl. M. Broszat, Nationalsozialistische Konzentrationslager (Anatomie des SS-Staates, Bd. II, Olten u. Freiburg i. Br. 1965), S. $14 \mathrm{ff} ., 23 \mathrm{ff}$.

$123 \mathrm{Vgl.} \mathrm{z.B.} \mathrm{die} \mathrm{Ausführungen} \mathrm{zu} \mathrm{Hamburg-Fuhlsbüttel,} \mathrm{Kapitel} \mathrm{IV.3,} \mathrm{S.374f.}$

124 Vgl. Schr. des GStA Braunschweig an das RJM v. 23.11.35 (Akten des RJM, BA, Sign. R 22/1333).

125 RdErl. des preuß. MdI v. 14.10.33 an die RegPräs. und das Gestapa (StArch. Düsseldorf, Best. $R$ W 18, Nr. 2).

126 Erl. des RuPrMdI v. 7.2.35, durch RdErl. Heydrichs v. 21.3.35 allen Stapostellen z. K. gegeben (a.a.O.). Der Tagessatz der Haftkosten betrug 1.50 RM (RdErl. des preuß. MdI v. 20.5.33, MBliV I, S. 594)

127 Zur Errichtung der Frauen-KZ Lichtenburg (1937) und Ravensbrück (1939) vgl. I. Arndt, Das Frauenkonzentrationslager Ravensbrück (in: Studien zur Geschichte der Konzentrationslager, Stuttgart 1970), S.99 ff. 
heim) gebracht wurden, verwahrten die süddeutschen Länder ihre weiblichen Schutzhäftlinge in den dortigen Justizanstalten, Bayern z. B. in der Frauenabteilung des Strafvollstreckungsgefängnisses Stadelheim und im Landgerichtsgefängnis Landshut. ${ }^{128}$

Bei der unterschiedlichen Arbeitsweise von Justiz und Gestapo ging die Verwahrung der Schutzhäftlinge in den Gerichtsgefängnissen nicht ohne Reibereien ab. Als z. B. für einen am 18. August 1935 in das Amtsgerichtsgefängnis Alsfeld (Oberhessen) eingelieferten Schutzhäftling im Widerspruch zu den Schutzhaftbestimmungen des Reichsinnenministeriums nach Ablauf von über 24 Stunden noch kein Schutzhaftbefehl vorlag, ordnete der Oberamtsrichter am 20. August kurzerhand die Entlassung des Gefangenen an, obwohl ihm die Polizei die telefonische Bestätigung der Schutzhaft durch das Geheime Staatspolizeiamt Darmstadt mitgeteilt hatte. Diese Handlungsweise, die einer Nachprüfung der Einhaltung der Schutzhaftbestimmungen durch die Justiz gleichkam, konnte die Gestapo nicht unwidersprochen hinnehmen. Das Staatspolizeiamt in Darmstadt beschwerte sich beim dortigen Oberlandesgerichtspräsidenten mit einer Begründung, die ein bezeichnendes Licht auf die Einstellung der Gestapo zu den Schutzhaftbestimmungen Fricks und deren Handhabung wirft: Die vom Amtsgericht Alsfeld angeführte Bestimmung könne

„keineswegs dahin ausgelegt werden, daß eine längere Inhaftnahme als 24 Stunden unbedingt den Erlaß eines Schutzhaftbefehls zur Voraussetzung habe. Es kann sich hier vielmehr nur um eine grundsätzliche Dienstanweisung handeln, denn etwas anderes widerspräche der Natur der polizeilichen Aufgaben ... Es ist vollkommen unmöglich, wenn irgendwo im Schutzgebiet auf telefonische Anweisung hin eine Inschutzhaftnahme erfolgt, binnen 24 Stunden einen Schutzhaftbefehl vorzulegen, es sei denn, daß dieser lediglich die Tatsache der Inhaftnahme ohne jede Begründung enthält. ${ }^{\text {"129 }}$

In seiner Antwort verteidigte der Oberlandesgerichtspräsident das korrekte Verhalten des Oberamtsrichters: er sehe in der Anordnung des Reichsministers des Innern eine zwingende Vorschrift, „deren Anwendung nicht in das Ermessen der die Schutzhaft anordnenden Behörde gestellt" sei, und schließe das daraus, daß der Innenminister in seinem Erlaß ausdrücklich Bestrafung wegen Freiheitsberaubung und rücksichtslose Strafverfolgung für denjenigen angedroht habe, der einen Menschen ohne Befugnis einsperre. Da er sich der Ansicht der Gestapo über die Art und Weise der Handhabung der Schutzhaft nicht anschließen könne, werde er die Vorgänge dem Reichsjustizministerium unterbreiten, nicht zuletzt deshalb, „weil die Auswirkungen der Inschutzhaftnahme in Fällen, in denen die Schutzhaft in Gerichtsgefängnissen ohne Schutzhaftbefehl vollstreckt wird, auf die Justiz zurückfallen“. ${ }^{130}$

In seinem Bericht an das Ministerium meldete der Oberlandesgerichtspräsident gleichzeitig einen weiteren Fall, der sich beim Amtsgericht Reinheim (Odenwald) zugetragen hatte, wo ein Schutzhäftling fünf Tage ohne Schutzhaftbefehl inhaftiert gewesen war. Auf telefonische Anfrage habe das Darmstädter Geheime Staatspolizeiamt

$128 \mathrm{Vgl}$. Schr. Heydrichs an das RJM v. 21.1.36 (Akten des RJM, BA, Sign. R 22/1333). Wegen der begrenzten Aufnahmemöglichkeit war dazu für Landshut die Genehmigung des OStA beim LG erforderlich (RdErl. der BPP v. 25.11.35, Arch. des IfZ, Sign. Fa 183/1, Bl.347), für Stadelheim die des GStA München (RdErl. der BPP v. 13.2.36, a.a.O., Bl.354).

129 Schr. des Gestapa Darmstadt an den OLGPräs v. 28.8.35 (Akten des RJM, BA, Sign. R 22/1467), Hervorheb. im Original.

130 Schr. des OLGPräs. Darmstadt an das Gestapa Darmstadt v. 4.9 .35 (a.a.O.). 
lediglich erklärt, „die Prüfung dieser Frage gehöre nicht zur Zuständigkeit der Gerichte“. Demgegenüber vertrete er die Ansicht, ein Gefängnisvorsteher sei

„dafür verantwortlich, daß kein Volksgenosse durch Einlieferung in eine Gefangenenanstalt seiner Freiheit außer in den gesetzlich vorgesehenen Fällen beraubt wird. So wie der Vorsteher der Gefangenenanstalt keinen Untersuchungsgefangenen ohne Prüfung der formellen Voraussetzungen (vorläufiger Aufnahmeschein/Haftbefehl) aufnehmen bzw. behalten darf, so ist er auch verpflichtet, bei einem Schutzhäftling die formellen Voraussetzungen für die Entziehung der Freiheit zu prüfen."

Da das Staatspolizeiamt eine Behebung des formellen Mangels nicht einmal in Aussicht gestellt habe, habe der Gefängnisvorsteher den Schutzhäftling nicht länger zurückbehalten können, ohne sich selbst strafbar zu machen. Aus diesem Grunde und „aus der Erwägung, daß die Justizverwaltung letztenendes als verantwortlich für jeglichen Akt der behördlichen Freiheitsentziehung angesehen" werde, habe er beim dienstaufsichtsführenden Richter die sofortige Entlassung des Schutzhäftlings veranlaßt. Da die Zahl der Schutzhäftlinge verhältnismäßig groß und deshalb mit Wiederholungen des Konflikts zu rechnen sei, halte er es für geboten, daß der einheitliche Vollzug der Schutzhaft durch eine nochmalige Anweisung geregelt werde. ${ }^{131}$

Das Reichsjustizministerium unterbreitete diesen Bericht dem Reichsminister des Innern „als ein Beispiel für die Reibungen, die sich aus der Divergenz zwischen den erlassenen Richtlinien und der Praxis im einzelnen ergeben“, und bat, über das gültige Verfahren bei der Schutzhaft eindeutige Klarheit zu schaffen. ${ }^{132}$ Doch Frick konnte offenbar auch weiterhin nur den Standpunkt vertreten, daß seine für das ganze Reichsgebiet erlassenen Richtlinien vom April 1934 „unverändert weiterbestehen“133; ihre Einhaltung konnte er bei Himmler und Heydrich nicht mehr durchsetzen.

Auf einer Besprechung Gürtners mit den Generalstaatsanwälten im Reichsjustizministerium am 23. September 1935 kamen weitere Probleme zur Sprache, die die Aufnahme und Behandlung der Schutzhäftlinge in Gerichtsgefängnissen mit sich brachten. Der Generalstaatsanwalt Naumburg trug vor, daß ihm die Gestapo vor drei Monaten die bevorstehende Verhaftung von 300-400 Personen angekündigt habe, die alle in dafür ungeeignete kleine Amtsgerichte eingeliefert werden sollten. Sein Gegenvorschlag, die zu Verhaftenden im Konzentrationslager Lichtenburg unterzubringen, sei mit der Begründung abgelehnt worden, daß die Betroffenen für Ermittlungen zur Verfügung stehen müßten. Er bat das Ministerium, beim Geheimen Staatspolizeiamt zu erreichen, daß bei derartigen Massenaktionen wenigstens die große Menge der Mitläufer im Konzentrationslager aufgenommen würde. Der Generalstaatsanwalt Braunschweig warf die Frage auf, ob Schutzhäftlinge hinsichtlich der seelsorgerischen Betreuung der Gefängnisordnung unterständen, $d . h$. von Geistlichen besucht werden dürften, oder ob dafür die Weisungen der politischen Polizei maßgebend seien. Er sehe die Aufnahme von Schutzhäftlingen als einen Akt der Rechtshilfe an, so daß für sie die Gefängnisordnung gelte und folglich die Polizei keine Anordnungen treffen könne. Daran anknüpfend berichtete der Generalstaatsanwalt Karlsruhe, daß das dortige Geheime Staatspolizeiamt bei ihm beantragt habe, zukünftig alle in den Justizgefängnissen verwahrten Schutzhäftlinge wie Strafgefangene zu behandeln; er habe aber

${ }^{131}$ Schr. des OLGPräs. Darmstadt an das RJM v. 4.9 .35 (a.a.O.).

132 Schr. des RJM an den RuPrMdI v. 24.9.35 (a.a.O.).

${ }^{133}$ So in anderem Zusammenhang schon im Schr. an das RJM v. 5.9 .35 (a.a.O.). 
zunächst das Badische Innenministerium um Stellungnahme ersucht. $\mathrm{Zu}$ diesen Fragen äußerte Gürtner:

„Bei der Verwahrung von Schutzhaftgefangenen in Gefängnissen darf meiner Meinung nach ein Unterschied gegenüber den Untersuchungsgefangenen nicht gemacht werden. Es gelten für sie nur die Regeln unserer Gefängnisse, da auch wir die Verantwortung tragen. Gegen eine Gleichstellung der Schutzhäftlinge mit Strafgefangenen habe ich schwere Bedenken.“

Freisler kritisierte, daß die Anregung der badischen Staatspolizei als politische Frage von allgemeiner Bedeutung nicht der Landesregierung, sondern dem Reichsjustizministerium hätte vorgelegt werden müssen, um regional unterschiedliche Regelungen zu vermeiden. Auch er äußerte die Ansicht, daß die Schutzhäftlinge nach den Grundsätzen der Justiz behandelt werden müßten; als Parallele für die Schutzhaft komme nur die Untersuchungshaft in Frage: „so stellt ja auch der Führer die Schutzhaft der Untersuchungshaft gleich“" ${ }^{134}$ Falls die Polizeibehörden einmal verlangen sollten, für Schutzhäftlinge Räume ohne Justizpersonal zur Verfügung zu stellen, sei sofort an das Ministerium zu berichten. ${ }^{135}$

Unterdessen begann die Gestapo, den Justizgefängnissen bei der Einlieferung von Schutzhäftlingen bestimmte Anordnungen über die Art und Weise des Haftvollzugs zu erteilen. Am 24. Oktober 1935 berichtete z. B. der Generalstaatsanwalt Hamburg, das Geheime Staatspolizeiamt in Lübeck habe für eine wegen „rassenschänderischen Verhaltens" in die Frauenanstalt Lübeck-Lauerhof eingewiesene Schutzhaftgefangene angeordnet, daß sie innerhalb von zwei Wochen an sieben Tagen nur mit Wasser und Brot verpflegt werden sollte. Die Maßnahme sei zwar durchgeführt worden, die Gefangene jedoch anschließend auf Weisung der Anstaltsärztin ins Lazarett überführt worden. Eine vierzehnjährige Schutzhaftgefangene, die kommunistische Zeitschriften verteilt hatte, sollte überhaupt nur Wasser und Brot als Verpflegung erhalten. Diese Anordnung wurde jedoch nicht befolgt, weil das unterernährte Mädchen, Tochter einer wegen offener Tuberkulose im Krankenhaus liegenden Frau, laut anstaltsärztlichem Gutachten tuberkuloseempfänglich war. Die von der Gestapo vorgeschriebene Schreibbeschränkung für eine weitere Schutzhaftgefangene sei von der Anstalt jedoch eingehalten worden. Der Generalstaatsanwalt bat um baldige Übersendung der auf der September-Besprechung im Reichsjustizministerium angekündigten Weisung, wie sich die Anstaltsleiter gegenüber derartigen Verfügungen der Gestapo verhalten sollten. ${ }^{136}$ Als der Generalstaatsanwalt bei einem Besuch des Lübecker Marstall-Gefängnisses - gemäß den mündlichen Ausführungen Gürtners in der erwähnten Besprechung - anordnete, daß Schutzhäftlinge grundsätzlich wie Untersuchungsgefangene zu behandeln seien, protestierte das Geheime Staatspolizeiamt Lübeck bei ihm, weil die politische Polizei für die Schutzhaft allein zuständig und zu ihrer Verschärfung ausdrücklich ermächtigt sei. Durch die Weisung des Generalstaatsanwalts an die Vollzugsanstalt sei „der Zweck, für den die Schutzhaft gedacht ist, in keiner Weise mehr gegeben“. Das Staatspolizeiamt bat den Generalstaatsanwalt um den Wortlaut der ein-

134 Gemeint war Hitlers Entsch. vom Juni 1935, daß die Schutzhaft wie eine Untersuchungshaft auf die Strafzeit angerechnet werden könne. Vgl. Kapitel VI.3.c., S.605.

135 Vgl. ursprüngl. Fassung der Niederschr. über die Bespr. mit dem OReiA u. den GStAen am 23.9.35 (Akten des RJM, BA, Sign. R 22/1333).

136 Schr. des GStA Hamburg an das RJM v. 24.10.35 (a.a.O.). 
schlägigen Weisung des Reichsjustizministers, um eine grundsätzliche Regelung der Frage in Berlin zu erreichen. ${ }^{137}$

Das Reichsjustizministerium hatte unterdessen den Bericht des Generalstaatsanwalts vom 24. Oktober zum Anlaß genommen, um von sich aus an das Geheime Staatspolizeiamt in Berlin heranzutreten. In seinem Schreiben schilderte das Ministerium die drei Lübecker Fälle und fuhr fort:

„Ob Anordnungen, wie sie in den Fällen ... hinsichtlich der Verpflegung getroffen worden sind, im Vollzuge der Schutzhaft unter irgendwelchen Umständen überhaupt gerechtfertigt sein können, muß ich dortiger Entscheidung überlassen. Insoweit zum Vollzuge von Schutzhaft Vollzugsanstalten meines Geschäftsbereiches in Anspruch genommen werden, muß ich darauf bestehen, daß der Vollzug sich grundsätzlich nach den für die anderen Gefangenen dieser Anstalt geltenden Bestimmungen richtet. ${ }^{138}$ Jedoch bin ich damit einverstanden, daß über die Überwachung des Schriftverkehrs, Zulassung einer bestimmten Person zum Besuch und Mitüberwachung der Besucher besondere Vereinbarungen getroffen werden."

Im übrigen müsse das Justizministerium betonen, daß Schutzhäftlinge wegen des starken Eigenbedarfs an Haftraum immer nur vorübergehend aufgenommen werden könnten. So würden sich künftig wohl auch Einlieferungen in die Anstalt LübeckLauerhof vermeiden lassen, da der Gestapo in Hamburg-Fuhlsbüttel Haftraum zur Verfügung stehe. Deshalb werde auch gebeten, die in der Lübecker Anstalt noch vorhandenen Schutzhaftgefangenen nach dort zu überführen.

Eine auszugsweise Abschrift dieses Schreibens wurde allen Generalstaatsanwälten am 19. November 1935 in Form einer Rundverfügung „zur Kenntnisnahme und Beachtung " zugeleitet. ${ }^{139}$ Bei der Bekanntgabe dieser Rundverfügung an die Strafanstalten wiesen die Generalstaatsanwälte mit besonderem Nachdruck auf den Passus hin, daß Schutzhäftlinge nur vorübergehend aufgenommen werden sollten. Der Generalstaatsanwalt München bestimmte durch eine ergänzende Verfügung, in Fällen längerer Verwahrung seien bei den Polizeibehörden unter Bezugnahme auf die Rundverfügung Vorstellungen zu erheben, in der Regel dann, wenn die Dauer der Schutzhaft drei Monate übersteige. ${ }^{140}$ Diese Regelung bereitete der politischen Polizei besonders im süddeutschen Raum bei der Unterbringung weiblicher Schutzhaftgefangener Schwierigkeiten; so widerrief $z$. B. der Oberstaatsanwalt in Landshut seine Genehmigung, Elisabeth Salm - in deren Wohnung seinerzeit Horst Wessel ermordet worden war und die sich seit 1933 in Haft befand - weiter im Landgerichtsgefängnis zu verwahren. ${ }^{141}$

Am 21. Januar 1936 reagierte endlich auch Heydrich, nachdem er die Stellungnahme des Geheimen Staatspolizeiamtes Lübeck zu jenen Vorfällen eingeholt hatte, die das Reichsjustizministerium zu der Rundverfügung veranlaßt hatten. Er teilte mit,

137 Schr. des Gestapa Lübeck an den GStA Hamburg v. 16.11.35. Der GStA übersandte das Schr. mit seiner Antw. am 19.11.35 dem RJM (a.a.O.).

${ }^{138}$ Die schärfere Formulierung im Entw.: „daß Anordnungen der Geheimen Staatspolizei, die den Vollzug betreffen, überhaupt grundsätzlich unterblieben“, wurde v. Leiter der Abt.III (u.a. Strafvollzugsverwaltung), MinDir. Crohne, gemildert.

139 Schr. des RJM u. RV v. 19.11.35 (a.a.O.). Der GStA Hamburg wurde zusātzl. auf die $\$ \S 615$ f. der Hamburger Dienst- u. VollzO hingewiesen, wonach in Schutzhaft genommene Personen als Polizeigefangene der Strafgewalt der Anstalt unterstanden u. den zu einfacher Haft Verurteilten gleichgestellt waren. Für den Vollzug galten zu dieser Zeit noch die Vorschr. der Länder.

140 Verf. des GStA München v. 2.12.35 (a.a.O.).

141 Vgl. Schr. des Polit.Pol.Komm. der Länder (I. V. Heydrich) an das RJM v. 21.1 .36 (a.a.O.). 
daß er alle nachgeordneten Dienststellen auf die „unstatthaften Anordnungen“ der Lübecker Staatspolizei hingewiesen und "Wiederholungen untersagt" habe. Bedauerlicherweise hätten die Generalstaatsanwälte die Rundverfügung dazu benutzt, ihre Strafanstalten anzuweisen, Schutzhäftlinge nicht mehr länger als drei Monate zu verwahren. Obwohl gerade bei Frauen „ein besonders strenger Maßstab engster Auslegung der geltenden Schutzhaftbestimmungen geübt" werde, gebe es auch hier Fälle mit jahrelanger Haft. Er sei zwar bereit, weibliche Schutzhäftlinge mit längerer Haftzeit grundsätzlich nach Moringen zu überführen, bitte aber um Einverständnis, daß einzelne Frauen im Benehmen mit dem Generalstaatsanwalt München von dort nach Landshut gebracht würden, wenn die "Wahrung der Autorität und Ordnung in den einzelnen Anstalten" einen Aufenthaltswechsel erforderlich mache. ${ }^{142} \mathrm{Da}$ der Oberstaatsanwalt Landshut die Zahl der dort einsitzenden weiblichen Schutzhäftlinge bis Jahresende 1935 auf drei reduziert hatte ${ }^{143}$, erklärte sich das Justizministerium mit der vorgeschlagenen Regelung für Ausnahmefälle einverstanden, solange es die Belegungsverhältnisse gestatteten. Viel wichtiger war für das Ministerium, daß sich die Gestapoführung mit der Behandlung der eingewiesenen Schutzhäftlinge nach den Justizvorschriften einverstanden erklärt hatte: es ließ sich nochmals bestätigen, daß die politischen Polizeibehörden mit der Weisung versehen seien, in dieser Hinsicht eigene Anordnungen zu unterlassen. ${ }^{144}$

Die Frage, ob Schutzhäftlinge im Justizgewahrsam nach den Vorschriften für Untersuchungs- oder für Strafgefangene zu behandeln waren, sollte trotz Gürtners in der September-Besprechung eindeutig erfolgten Stellungnahme weiter erörtert werden. In der Tat ließ die Formulierung in der Rundverfügung vom 19. November 1935, daß sich die Behandlung "nach den für die anderen Gefangenen dieser Anstalt geltenden Bestimmungen richtet“, diese Frage - wenn auch unbeabsichtigt - offen: mit Recht vermerkte der Generalreferent für Strafvollzug im Ministerium, was denn dieser Passus bedeute, wenn Schutzhäftlinge z.B. in Zuchthäusern untergebracht würden. ${ }^{145}$ Kurz nach Eingang der Rundverfügung schrieb der Generalstaatsanwalt in Braunschweig, er erkenne in Übereinstimmung mit der dortigen politischen Polizei - die mangels eines eigenen oder nahegelegenen Konzentrationslagers besondere Schwierigkeiten habe - einerseits an, „daß Schutzhäftlinge, die wegen groben volks- und gemeinschaftsschädlichen Verhaltens notgedrungen für eine kurze Zeit von etwa 1-3 Wochen in Schutzhaft genommen werden müssen, die bevorzugte Behandlung eines Untersuchungsgefangenen nicht verdienen“. Andererseits sei es genauso problematisch, Personen, die nicht wegen einer strafbaren Handlung verfolgt würden, wie zu Gefängnisstrafen Verurteilte zu behandeln, nur weil die politische Polizei es wünsche. ${ }^{146}$ Der Generalstaatsanwalt Karlsruhe hatte bereits auf der September-Besprechung im Ministerium von der Forderung der badischen Staatspolizei berichtet, die

142 a.a.O. Im Erl. v. 13.2.36 teilte die BPP ihren Dienststellen mit, daß künftig auch aus Bayern weibl. Schutzhäftlinge mit Haftzeit von über 3 Monaten nach Moringen gebracht werden könnten (Arch. des IfZ, Sign. Fa 183/1, Bl.353).

143 Zahl der weibl. Schutzhäftlinge im OLGBez. München am 31.12.35: Stadelheim = 32, Landsberg = 8, Landshut $=3$. Entspr. Zahlen am 31.10.35: 32; 7; 14 (Verm. v. 31.1.36, Akten des RJM, BA, Sign. R 22/1333)

144 Vgl. Schr. des RJM an den Polit.Pol.Komm. d. Länder v. 6.2.36 u. Antw. v. 12.3.36 (a.a.O.).

145 Aktenverm. v. 26.11.35 (a.a.O.).

146 Schr. des GStA Braunschweig an das RJM v. 23.11 .35 (a.a.O.). 
bisher in den Bezirksgefängnissen wie Untersuchungsgefangene behandelten Schutzhäftlinge zukünftig den Bestimmungen der badischen Vollzugsordnung für Strafgefangene zu unterwerfen ${ }^{147}$ und entgegen diesen Bestimmungen für die Besuchs- und Sprecherlaubnis ausschließlich die Zuständigkeit der Staatspolizei anzuerkennen. Er meldete nunmehr, daß sich der badische Innenminister den Forderungen der Gestapo angeschlossen habe und das Reichsjustizministerium um Genehmigung dieser Regelung bitte. In seinen ergänzenden Erläuterungen erhob der Generalstaatsanwalt gegen die Gestapo-Forderung Einwände, die die spezifische Problematik der vorgeschlagenen Lösung für die Justiz beleuchten: Bei einer erheblichen Anzahl von Fällen, in denen die Gestapo Personen auf Verdacht hin verhaftet habe, habe die Untersuchung als ergebnislos eingestellt und die Schutzhaft als gegenstandslos aufgehoben werden müssen. Er könne sich

„keinen einleuchtenden Grund denken, warum in solchen Fällen Schutzhäftlinge schlechter als Untersuchungsgefangene behandelt werden sollten. Unter Umständen wäre die unliebsame Folge, daß Schutzhaftgefangenen, gegen die zunächst kein dringender Verdacht vorlag, die den Untersuchungsgefangenen zukommenden Vergünstigungen und Erleichterungen erst in dem Augenblick erfahren würden, zu dem der Verdacht eines verbrecherischen Verhaltens sich so verdichtet hätte, daß Haftbefehl ergehen müßte." ${ }^{\text {148 }}$

In einer am 26. November 1935 stattfindenden Besprechung der zuständigen Referenten des Reichsjustizministeriums wurde trotz allem nicht ausgeschlossen, daß für Schutzhäftlinge im Justizgewahrsam statt der bislang angewendeten einfachen $\mathrm{Haft}^{149}$ - die sich von der Untersuchungshaft nicht wesentlich unterschied - die Vorschriften über den Vollzug der Gefängnisstrafe eingeführt werden könnten. Es wurde dabei allerdings betont, daß eine solche Regelung vor allem in den Fällen auf größte Bedenken stoßen müsse, in denen die Verhaftung zum Schutze der eigenen Person erfolgte. ${ }^{150}$ Das Grundproblem lag in der Unvereinbarkeit der unterschiedlichen Arbeitsweise von Justiz und Gestapo: da die Gestapo bei der Verhängung der Schutzhaft weder die Nachprüfung des „Tatbestandes“ noch seine Einordnung in ein normatives System abgestufter Freiheitsentziehung kannte, mußte jede Entscheidung der Justiz über eine einheitliche Behandlung von Schutzhaftgefangenen in ihrem Gewahrsam im Einzelfall „ungerecht“ sein. Für sie konnte daher die einzige „gerechte“ Art des Freiheitsentzugs für diesen Personenkreis nur die Untersuchungshaft sein, die zunächst von der Schuldlosigkeit des Verhafteten ausging. Daher blieb es schließlich auch bei der durch Gürtner von Anfang an vertretenen Lösung: der Vorschlag des badischen Innenministeriums, die Schutzhaftgefangenen wie Strafgefangene zu behandeln, wurde abgelehnt. ${ }^{151}$ Ebenso wurde der vom sächsischen Innenminister vorgelegte

147 Die bad. Dienst- u. VollzO bestimmte an sich in $\S 384$, daß vorläufig Festgenommene, in Polizeigewahrsam oder in Schutzhaft befindl. Personen den U-Gefangenen gleich zu behandeln seien; nur die bei U-Gefangenen dem Richter zustehenden Entscheidungen (Sprecherlaubnis, Schriftverkehr) sollten bei ihnen vom Anstaltsvorstand getroffen werden.

148 Schr. des GStA Karlsruhe an das RJM v. 22.11.35 nebst Schr. des Gestapa Karlsruhe v. 19.9.35 u. des bad. MdI v. 4.11.35 an den GStA (Akten des RJM, a.a.O.).

$149 \mathrm{Vgl}$. Preuß. Dienst- u. VollzO, $\S 151$ Ziff. 2: „Die in Schutzhaft oder in polizeiliche Verwahrung genommenen Personen ... sind Polizeigefangene. Die Hausstrafgewalt hat der Vorsteher; die Behandlung richtet sich nach den Bestimmungen über einfache Haft, soweit nicht eine andere Regelung getroffen ist“ (zit. in den Akten des RJM, a.a.O.).

150 Referentenverm. v. 27.11.35 (Akten des RJM, a.a.O.).

151 Schr. des RJM an den GStA Karlsruhe v. 12.8.36 (a.a.O.). 
Entwurf einer „Verordnung über die Behandlung von in Polizei- oder Justizgefängnissen verwahrten Schutzhäftlingen" zurückgewiesen, da er in wesentlichen Punkten von der sächsischen Strafvollzugsordnung abwich. ${ }^{152}$

Dagegen wurde die Überwachung des Schriftverkehrs der Schutzhäftlinge, die Erlaubnis zum Besuch und dessen Überwachung den haftanordnenden Gestapobehörden durch örtliche Vereinbarungen übertragen ${ }^{153}$, die die Rundverfügung des Ministeriums vom 19. November zugelassen hatte. Verschiedentlich behielten sich dabei aber die Anstaltsleiter vor, Anordnungen der Gestapo, die die Ordnung und Sicherheit in den Anstalten beeinträchtigten, zu beanstanden und ihre Durchführung bis zu einer Einigung mit der anordnenden Stelle auszusetzen. ${ }^{154}$

Das Problem der Aufnahme und Behandlung von Schutzhäftlingen wiederholte sich nach dem Anschluß Österreichs für die dortigen Justizbehörden. Die Gerichtsgefängnisse weigerten sich hier zunächst verschiedentlich, von der Gestapo verhaftete Personen überhaupt aufzunehmen, da nach dem bisherigen österreichischen Recht

„Personen, die wegen Verdachtes einer Verwaltungsübertretung oder sonst aus irgendeinem Grund polizeilich festgenommen wurden, nicht in gerichtlichen Gefangenhäusern angehalten werden [dürfen], weil die Verwahrung solcher Personen nicht in den gesetzmäßigen Wirkungskreis der Gerichte fällt". ${ }^{\text {"155 }}$

Der Beauftragte des Reichsministers der Justiz in Wien, Minister Hueber, legte daher dem Reichsjustizministerium am 30. Mai 1938 entsprechende Erlaßentwürfe für die Oberlandesgerichtspräsidenten und Oberstaatsanwaltschaften in Wien, Graz und Innsbruck vor. Danach sollten von der Gestapo eingelieferte Personen aufgenommen und zur ausschließlichen Verfügung der Polizei gehalten werden; aber auch diejenigen Personen, die von ihr wegen Verdachts einer strafbaren Handlung eingewiesen wurden, für die aber das Gericht keinen Grund zur weiteren Verwahrung fand, sollten gegen den Willen der Gestapo nicht freigelassen werden. Obwohl das Reichsjustizministerium bereits am 18. Juni den beabsichtigten Erlassen zustimmte und Hueber über die im Altreich geltenden Regelungen informierte ${ }^{156}$, beschwerte sich Best eine Woche später, daß die Unterbringung von Gestapohäftlingen in den österreichischen Gerichtsgefängnissen wegen der Haltung der Bezirksgerichte Schwierigkeiten bereite. ${ }^{157}$ Es stellte sich heraus, daß die Abteilung Österreich des Reichsjustizministeriums in Wien die Erlasse wegen Abwesenheit Huebers noch nicht herausgegeben hatte; es geschah erst am 12. Juli. ${ }^{158}$ Bests Beschwerde konnte sich jedoch kaum auf den Oberlandesgerichtsbezirk Wien bezogen haben, wo sich schon Anfang Mai 2074 Schutzhäftlinge in Gerichtsgefängnissen befanden. ${ }^{159}$

Auch im angegliederten Österreich gab der Versuch justizfremder Stellen, auf die Behandlung der Schutzhäftlinge in Justizgewahrsam Einfluß zu nehmen, den Anstoß

152 Schr. des GStA Dresden an das RJM v. 26.2.36 mit beigel. Entw.; Antwort des RJM v. 6.3.36 (a.a.O.).

153 Vgl. z. B. Verf. des GStA Darmstadt v. 11.2.36 (a.a.O.). Für Preußen galt bereits diese Regelung in der RV v. 7.12.33 (a.a.O.).

154 So z.B. Verf. des GStA Karlsruhe v. 9.12.36 (a.a.O.).

155 Ber. des Beauftr. des RJM Wien an das RJM v. 30.5 .38 mit Erl.Entw. (Akten des RJM, BA, Sign. R 22/1462).

156 Schr. des RJM an den Beauftr. des RJM in Wien v. 18.6.38 (a.a.O.).

157 Schr. des RFSSuChdDtPol an das RJM v. 27.6.38 (Akten des RJM, BA Sign. R 22/1333).

158 Verm. v. 11.7.38 (a.a.O.) u. Schr. Huebers an das RJM v. 12.7.38 (Akten des RJM, BA, Sign. R 22/1462).

159 Verm. v. 6.7 .38 (Akten des RJM, BA, Sign. R 22/1333). 
zu einer generellen Weisung der Justizverwaltung über den Vollzug. Als die Kreisleitung der NSDAP in Krems für die Behandlung von 26 jüdischen Schutzhaftgefangenen, die im dortigen Landgerichtsgefängnis einsaßen, Vorschriften machen wollte, instruierte die Abteilung Österreich das Präsidium des Landgerichts, daß die Gefangenen ausschließlich nach der Gefängnis-Hausordnung zu behandeln seien und der Partei darauf kein Einfluß zustehe. Die Abteilung Österreich bat das Reichsjustizministerium um die Erlaubnis, diesen Bescheid auch in Form einer allgemeinen Weisung herausgeben zu dürfen. Das Reichsjustizministerium erklärte sich unter Hinweis auf seine eigene Rundverfügung vom 19. November 1935 einverstanden. ${ }^{160}$ Daraufhin erließ die Abteilung Österreich am 4. Februar 1939 eine Rundverfügung an alle Land- und Amtsgerichte, denen Gefängnisse angeschlossen waren, daß Schutzhaft grundsätzlich nach den Justizbestimmungen, und zwar nach $\S 2$ Absatz 2 der Hausordnung für gerichtliche Gefangenenhäuser zu vollziehen und lediglich Anordnungen über den Schrift- und Besuchsverkehr „auf Antrag oder im Benehmen mit der einweisenden Gestapostelle zu treffen" waren. ${ }^{161}$

Die Gestapo ließ jedoch in dieser Frage keine Ruhe. Im Frühjahr 1939 ersuchte die Staatspolizeileitstelle Karlsruhe den dortigen Generalstaatsanwalt erneut, auf Schutzhäftlinge die Bestimmungen für Strafgefangene anzuwenden, da die Vollzugsbestimmung der Justiz „nicht mehr dem Wesen der heutigen Schutzhaft als einer nach der nationalsozialistischen Machtergreifung geschaffenen neuen Art von politischer Haft entspricht, die vorwiegend gegen politische Verbrecher zu Vorbeugungs- und Besserungszwecken verwendet wird“" ${ }^{162}$ Das Reichsjustizministerium wies daraufhin den Generalstaatsanwalt an, der Staatspolizeistelle anheimzugeben, ihre Vorschläge dem Geheimen Staatspolizeiamt in Berlin zu unterbreiten, damit die Gestapoführung gegebenenfalls wegen einer neuen reichseinheitlichen Regelung an das Justizministerium herantreten könne. Möglicherweise dadurch wurden Verhandlungen veranlaßt, in denen das Justizministerium jedoch trotz der Ansicht der Gestapo vom veränderten Charakter der Schutzhaft seinen Standpunkt behaupten konnte: in einer am 7. Juli 1939 erlassenen grundlegenden Rundverfügung wurde jedenfalls eindeutig festgelegt, daß sich die Vollstreckung von Schutzhaft in Justizvollzugsanstalten ,nach den Vorschriften für den Vollzug von Untersuchungshaft" richtete. Die vorübergehende und nur nach vorherigem schriftlichen Ersuchen der Polizei mögliche Unterbringung durfte jetzt nur noch ,so lange dauern, bis der Abtransport in ein Polizeigefängnis oder in ein Schutzhaftlager" möglich sei. Sollten bei unangemessener Verzögerung Verhandlungen mit den Polizeibehörden erfolglos bleiben, war an das Ministerium zu berichten. In unmittelbarem Anschluß an Untersuchungshaft oder an richterlich erkannte Strafhaft sollte Schutzhaft in Justizvollzugsanstalten nicht zulässig sein. Wie die Untersuchungsgefangenen sollten die Schutzhäftlinge der Arbeitspflicht unterlie-

160 Schr. des RJM, Abt. Österreich, an das RJM v. 30.11 .38 u. Antw. des RJM v. 15.12.38 (a.a.O.).

${ }_{161}$ RV des RJM, Abt. Österreich, v. 4.2.39 (a.a.O.). $§ 2$ Abs. 2 der HausO betraf „Gefangene, die nur zum Zwecke des Vollzugs einer im Verfahren wegen bürgerlicher Rechtsangelegenheiten oder im Strafverfahren verhängten Ordnungs-, Mutwillens- oder Ungehorsamsstrafe angehalten werden, sowie Gefangene, an denen eine Haft vollzogen wird, die im Verfahren wegen bürgerlicher Rechtsangelegenheiten als Sicherungs- oder Zwangsmittel verhängt wurde"; sie wurden von den Straf- und Untersuchungsgefangenen getrennt untergebracht, konnten sich auf eigene Kosten Bequemlichkeiten verschaffen, verköstigen $u$. eigene Kleidung tragen (Aktenverm. v. 10.12.38, a.a.O.).

162 Zit. im Schr. des GStA Karlsruhe an das RJM v. 2.6.39 (a.a.O.) 
gen, sofern die Polizeibehörde im Einzelfall nicht widersprach. Auch die Hausstrafgewalt über Schutzhäftlinge stand dem Anstaltsvorstand zu, der jedoch erkannte Hausstrafen der einweisenden Polizeibehörde mitzuteilen hatte. „Sonstige Entscheidungen, die bei Untersuchungsgefangenen dem Richter zustehen würden (Erteilung von Sprecherlaubnis, Zulassung eigener Bücher, Zeitungen und Zeitschriften, Überwachung des Schriftverkehrs und der Besuche usw.)“, waren dagegen der einweisenden Polizeibehörde vorbehalten, soweit sie nicht zugunsten des Anstaltsvorstandes darauf verzichtete. ${ }^{163}$

Durch den Ausbau des Konzentrationslagerwesens und die Einrichtung von Frauenschutzhaftlagern hatte sich die Mitwirkung der Justiz beim Vollzug der Schutzhaft bis zum letzten Friedensjahr 1939 weitgehend reduziert - freilich um den Preis, daß bisher von ihr verwahrte Häftlinge in den inhumanen Vollzug der Konzentrationslager gerieten. Aber die Justizverwaltung sah diese Mitwirkung stets als eine fremde, außerhalb ihres Aufgabenbereiches stehende und vorübergehende Angelegenheit an, der sie sich nach Möglichkeit zu entziehen trachtete. ${ }^{164}$ Wenn sie diese Absicht auch nicht verwirklichen konnte, so gelang es ihr immerhin, die ureigenste Domäne des Haftvollzugs in ihren Anstalten von der Einwirkung der Gestapo abzuschirmen und die Behandlung der Schutzhäftlinge nach den Bestimmungen für Untersuchungsgefangene beizubehalten. Auch als die Justiz unter den veränderten Verhältnissen des Krieges von der Gestapo wieder stärker zur Vollzugshilfe herangezogen wurde - z. B. in den Schutzhaftfällen wegen Arbeitsverweigerung -, blieben die Bestimmungen der Rundverfügung vom 7. Juli 1939 für die Behandlung der Schutzhaftgefangenen maßgebend. ${ }^{165}$ Eine Ausnahme sollte hier allerdings für polnische Arbeitsverweigerer geschaffen werden, für die ab Juli 1941 auf Ersuchen der Gestapo der „verschärfte Vollzug" zugelassen wurde: er bestand in hartem Lager und Beschränkung der Mittagskost auf Wasser und Brot für mindestens einen und höchstens drei Tage in der Woche. ${ }^{166}$

\section{Die Schutzhaft als Mittel der Korrektur und Ergänzung der Rechtspflege durch die Polizei}

Von Anfang an verstand sich die Sicherheitspolizei nicht nur als ein von der Justiz getrennt wirkendes Instrument zur Ausschaltung politischer Gegner auf außernormativem Wege, sondern auch als ein Instrument zur Korrektur der Rechtspflege, die in ih-

163 RV des RJM an die GStAe v. 7.7.39 (Akten des RJM, BA, Sign. R 22/1421), zur Arbeitspflicht von U-Gefangenen s. AV des RJM v. 23.3.38 (DJ 1938, S. 447).

164 In einem Schr. des RJM an den RFSSuChdDtPol wegen der Auslagenerstattung zwischen Justiz- u. Pol.Behörden v. 1.12.38 (Akten des RJM, BA, Sign. R 22/1333) heißt es z. B. hierzu: „Hinsichtlich der Schutzhaft muß eine besondere Erörterung vorbehalten bleiben: sie ist eine außerhalb der Aufgaben der Justizverwaltung liegende Angelegenheit, bei ihrer Vollziehung wirkt die Justiz nur auf Grund einer vorläufigen Regelung mit; ob diese weiterbestehen soll, wird noch zu klären sein."

$165 \mathrm{Vgl}$. Schr. des RJM an den GStA Breslau v. 8.6.42: „Der verschärfte Vollzug von Schutzhaft ist durch die RV v. 19. November 1935 - III s ${ }^{1} 1340 / 35$ - abgelehnt. Auch in der RV vom 7. Juli $1939-4405$ III a ${ }^{1} 884$ - ist betont, daß der Vollzug von Schutzhaft sich nach den Vorschriften für den Vollzug von Untersuchungshaft richtet" (a.a.O.).

$166 \mathrm{Vgl}$. RV des RJM an die GStAe v. 30.7.41 in Verb. m. d. RV v. 8.10.40 (Arch. des IfZ, Sign. Fa 195). 
ren Augen das Gebot der Stunde nicht begriff und den Wünschen der Führung bei der Verwirklichung politischer Ziele nicht gerecht wurde: nicht nur deshalb, weil die Justiz bei ihrer Tätigkeit an „unzureichende“ Normen gebunden war, deren Anpassung den Ereignissen und Forderungen stets hinterherhinkte, sondern weil sie die Gesetze vielfach noch ohne Ansehen der Person anwandte, ohne zwischen Anhängern und Gegnern des Regimes zu unterscheiden, und die Gesetze nicht so auslegte, daß sie der politischen Zielsetzung entsprachen. Die Gestapo setzte zum Zwecke der Verschärfung gerichtlicher Strafurteile bedenkenlos die Schutzhaft ein, obwohl die grundsätzlichen Schutzhaftbestimmungen von 1934 und 1938 ihre Anwendung zur Ahndung von Straftaten untersagten. Jene Juristen, die den scheinbar zeitlich begrenzten außernormativen Maßnahmen der Gestapo gegen politische "Staatsfeinde“ mit Sympathie oder zumindest Duldung zugesehen hatten, mußten bald erkennen, daß hier ein polizeiliches Verfolgungssystem aufgebaut wurde, das sich ebenso gegen unpolitische Straftaten einsetzen ließ. Als die Sicherheitspolizei immer stärker korrigierend in ihren ureigensten Bereich eingriff, begannen sie den aussichtslosen Versuch, diese Praxis wieder abzuschaffen oder zumindest einzudämmen.

\section{a. Schutzhaft anstelle von Untersuchungshaft und die Auseinandersetzung um die Abgabe politischer Strafsachen an die Staatsanwaltschaft}

Ein Hauptgegenstand der Kontroverse zwischen Justiz und Gestapo war das Verfahren, polizeilich ermittelte Strafsachen vor der Abgabe an die Staatsanwaltschaft zu „sieben“ und die Schutzhaft zur Ahndung strafbarer Handlungen einzusetzen. Ermöglicht wurde dieses Verfahren dadurch, daß die Gestapo bei der Verbrechensbekämpfung gemäß dem allgemeinen Auftrag aus $\S 163 \mathrm{StPO}^{1}$ die kriminalpolizeilichen Ermittlungen für politische Straftaten zugewiesen bekommen hatte. Dazu zählten Hoch-, Landesverrats- und Sprengstoffsachen sowie schließlich ,sonstige strafbare Angriffe auf Partei und Staat". ${ }^{2}$ Die Gestapo konnte jedoch die Bearbeitung auch jeder unpolitischen Straftat an sich ziehen, wenn der Tatbestand ein politisches Element enthielt oder wenn Motiv bzw. Zweck als politisch angesehen wurde. Durch diese Ermittlungszuständigkeit hatte die Gestapo von den meisten einschlägigen Straftaten vor der Staatsanwaltschaft Kenntnis. Sie hatte daher u.a. die Möglichkeit, Straftaten nicht an die Staatsanwaltschaft weiterzugeben, entweder um unliebsame Prozesse z. B. gegen Angehörige der Bewegung zu verhindern, oder um die Straftat durch Schutzhaft selbst zu ahnden. Häufig wurde die Justiz erst eingeschaltet, nachdem die Verdächtigen einige Zeit in Schutzhaft verbracht hatten. Die Vorschrift des $\S 114 \mathrm{~b}$ der StPO, wonach ein Beschuldigter unverzüglich, spätestens am folgenden Tag, dem Richter vorgeführt werden sollte, war damit insoweit außer Kraft gesetzt worden. In anderen Fällen erfolgte die Schutzhaftverhängung, nachdem der Beschuldigte zwar dem Richter vorgeführt worden war, dieser aber einen Haftbefehl abgelehnt oder - teilweise nach Ein-

1 Laut $\S 163$ StPO hatten die Beamten der Polizei „strafbare Handlungen zu erforschen und alle keinen Aufschub gestattenden Anordnungen zu treffen, um die Verdunkelung der Sache zu verhüten. Sie übersenden ihre Verhandlungen ohne Verzug der Staatsanwaltschaft ......

2 Vgl. Erl. des preuß. MdI betr. Neuorganisation der polit. Pol. v. 26.4.33 (MBliV I, S. 503); AusfVO zum GestapoG v. 10.2.36 (GS, S.22); ferner die Aufzählung der polit. Straftaten (Stand 1940) bei W. Best, Die deutsche Polizei, Darmstadt 1940, S. 34 ff. 
stellung des Verfahrens - wieder aufgehoben hatte. ${ }^{3}$ Im Frühjahr 1935 klagte Heydrich darüber, daß den Gerichten übergebene Staatsfeinde häufig wieder freigelassen worden seien, obwohl die Voraussetzungen für einen Haftbefehl „durchaus gegeben“ gewesen seien, und stellte entrüstet fest: „Auch bei Kommunisten, die überführt und geständig waren, illegal für die KPD sich betätigt [zu] haben, wurde schon der Haftbefehl abgelehnt. “4 Als Gegenmaßnahme erließ das Geheime Staatspolizeiamt im März die Weisung, politischer Straftaten Verdächtige, die vor der Hauptverhandlung vom Richter aus der Untersuchungshaft entlassen wurden, „unbeschadet dieses Richterspruches“ weiterhin in Schutzhaft zu nehmen. Begründet wurde diese Maßnahme damit, „daß die vom Richter vor Abhaltung des Hauptverhandlungstermins angeordnete Aufhebung des Haftbefehls ... den wirklichen Erfordernissen zur vollkommenen Aufklärung des Sachverhalts nicht gerecht" werde. ${ }^{5}$

Die Tatsache, daß Beschuldigte, gegen die ein Strafverfahren durchgeführt werden sollte, statt in Untersuchungshaft in Schutzhaft kamen, warf für die Justiz Probleme auf: da die Beschuldigten häufig keine oder nur unter Aufsicht eines Gestapobeamten Sprecherlaubnis erhielten und erst zum Hauptverhandlungstermin in das Gerichtsgefängnis überführt wurden, waren die Verteidiger an der Wahrnehmung ihres gesetzlichen Anspruchs gemäß $\S 148$ StPO gehindert, den „verhafteten oder einstweilig untergebrachten Beschuldigten“ zumindest nach Eröffnung des Hauptverfahrens unbeaufsichtigt zu sprechen. ${ }^{6}$ Daß die Gestapo oft gerade diese Absicht mit der Schutzhaftverhängung verfolgte, geht z.B. daraus hervor, daß sie die Verhaftung und Überführung von Beschuldigten einer Hamburger Devisenstrafsache ins Konzentrationslager Fuhlsbüttel anordnete, ,um einer Verdunkelung vorzubeugen, die durch das Zwischentreten von Rechtsanwälten ... im Falle einer Festsetzung im Untersuchungsgefängnis $\mathrm{zu}$ befürchten ist“" ?

Es kam aber auch vor, daß die Gestapo z. B. Beschuldigte, die unter dem Verdacht hochverräterischer Umtriebe in Schutzhaft genommen worden waren, vor der Einleitung des Strafverfahrens mit der Erklärung entließ, „daß das Vorgefallene als erledigt angesehen und ihnen nunmehr Gelegenheit gegeben werde, sich wieder in die deutsche Volksgemeinschaft einzuordnen". Als die Beschuldigten nach Erhebung der An-

3 Zahlreiche Fälle aus den Jahren 1934-36 finden sich z.B. in den Akten der Bayer. StKanzlei (BayerHStArch., Sign. MA 106301); gemäß RdEntschl. der BPP v. 26.6.35 u. 19.5.37 war diese Handhabung grundsätzlich vorgeschrieben bei aktiven Anhängern der Bibelforschervereinigung (Arch. des IfZ, Sign. Fa 183/1, Bl.363, 374).

4 Erl. des Gestapa (Heydrich) an alle preuß. Stapostellen v. 26.4.35 (StArch. Düsseldorf, Sign. Best RW 18, Nr.4).

5 Schnellbrief des Gestapa an die preuß. Stapostellen u. Polit. Pol. der Länder v. 19.3.35 (a.a.O.), Nr. 2. Die Begründung mit häufiger Flucht war dabei nicht völlig aus der Luft gegriffen: in einer Bespr. über HV-Sachen mit Richtern u. StAen im RJM am 11./12.11.36 führte Crohne aus, es sei „wiederholt vorgekommen, daß bei verhältnismäßig schwerer Tat trotz Anklageerhebung kein Haftbefehl beantragt worden ist mit dem Erfolg, daß der Angeklagte flüchtig ging“. Bei der Höhe der zu erwartenden Strafe müsse i. d. Regel Haftbefehl erlassen werden, auch wenn der Beschuldigte während des Ermittlungsverfahrens auf freiem Fuß gelassen werden konnte (Vortr. Unterlagen, Akten des RJM, BA, Sign. R 22/5004).

6 Vgl. z. B. Korresp. zwischen einem RA, Justiz- u. Gestapostellen in Stuttgart v. Dez. 1938-März 1939 wegen eines Tübinger Falles. Auf Bitte des RA setzte sich das RJM beim Gestapa dafür ein, daß der Angeklagte spätestens 3 Tage vor einem neu anberaumten Hauptverhandlungstermin ins Gerichtsgefängnis überführt u. von der Stapoleitstelle Stuttgart Sprecherlaubnis ohne Aufsicht erhielt (Akten des RJM, BA, Sign. R 22/1467).

7 Aktenverm. der Gestapo im Verfahren $11 \mathrm{Js}$. 1640/37, Aufz. des OLGPräs. Hamburg für eine Bespr. im RJM v. Januar 1939 (Forschungsstelle für d. Gesch. des NS in Hamburg, Sign. Best 3305). 
klage in Untersuchungshaft genommen werden sollten, kam es zu Auseinandersetzungen mit Gestapo und Parteistellen, da die Wiederaufnahme der Vorgänge mit den Erklärungen in Widerspruch stand, die diese Stellen gegenüber den Betroffenen bei der Freilassung abgegeben hatten. Mit Recht beklagte sich der Generalstaatsanwalt des Kammergerichtsbezirks, „daß es der Staatsautorität abträglich“ sei, „wenn derselbe Sachverhalt von den Organen der Verwaltung und der Justiz unterschiedlich beurteilt und behandelt" werde. ${ }^{8}$ Der Protest des Justizministeriums führte zu der Zusage des Geheimen Staatspolizeiamtes, seine Dienststellen anzuweisen, in derartigen Fällen vor Entlassung aus der Schutzhaft mit den zuständigen Strafverfolgungsbehörden in Verbindung zu treten, damit gegebenenfalls vorher ein richterlicher Haftbefehl erlassen werden konnte.

Nach Ansicht der Justiz ersetzte die Schutzhaft, auf deren Verhängung und Dauer sie selbst keinen Einfluß nehmen konnte, eine notwendige richterliche Untersuchungshaft auch dann nicht, wenn der Beschuldigte in polizeilicher Einzelhaft gehalten und den Justizbehörden jederzeit zur Vernehmung vorgeführt wurde. Als ein Amtsrichter in einem solchen Fall auf Erlaß des Haftbefehls deshalb verzichtete, weil Fluchtverdacht und Verdunkelungsgefahr in der Einzel-Schutzhaft nicht gegeben seien, wurde er vom zuständigen Generalstaatsanwalt wegen völliger Verkennung seiner richterlichen Aufgabe zurechtgewiesen: Nach dem Gesetz sei in erster Linie der Richter dazu berufen, über die Freiheitsentziehung zu entscheiden. Er dürfe sich dabei keinesfalls auf Stellen verlassen, die Verhaftung und Entlassung ohne Rücksicht auf die Strafprozeßordnung handhabten; darin liege „ein völliger, dem Recht und Gesetz widersprechender Verzicht auf die richterliche Gewalt", der schließlich die einschlägigen strafprozessualen Vorschriften gegenstandslos machen würde. ${ }^{9}$

In einem Bericht an das Reichsjustizministerium über eine Reihe bayerischer Fälle, in denen Schutzhaft zur Ahndung strafbarer Handlungen angewendet worden war, führte Hans Frank im Januar 1934 aus, diese Maßnahmen würden von den politischen Stellen damit begründet, daß die Bevölkerung und als deren Sachwalter die Polizei "von den Justizbehörden eine rasche und nachhaltige Bestrafung der Täter nicht erwarte und daher auf dem Umwege über die Schutzhaft zu einer Art Selbsthilfe greifen müsse“. Frank wandte sich entschieden dagegen, daß die Schutzhaft mißbraucht werde, ,um einem ordentlichen mit Rechtsgarantien ausgestatteten Verfahren vorzugreifen“ und „nach dem Gesetz berufene Organe der Rechtspflege in der Wahrnehmung ihrer Obliegenheiten" $\mathrm{zu}$ hemmen. ${ }^{10}$ Aber auch nachdem Franks Bitte an das Reichsjustizministerium, bei den „zuständigen Stellen“ Mißbrauch ausschließende Anordnungen zu erwirken, durch Fricks Schutzhaftbestimmungen vom April 1934 erfüllt war, hörten die Übergriffe nicht auf. Folglich mußte die Justiz darangehen, dem Übel nach Möglichkeit durch - wenn auch kompromißhaltige - Vereinbarungen zu steuern, gegebenenfalls durch Absprachen zwischen Justizbehörden und Gestapostel-

8 Ber. des GStA beim KG an das preuß. JM v. 12.5.34 (Akten des preuß. JM, GehStArch. Berlin, Sign. Rep. 84a/7953), dort auch das anschl. Schr. des JM an das Gestapa v. 23.5.34 u. Antw. v. 22.8.34.

9 Verm. des GStA Düsseldorf v. 28.10.38 (Akten des RJM, BA, Sign. R 22 Gr. 5/A 10).

10 Schr. Franks an das RJM v. 24.1.34 (BayerHStArch., Sign. MJu 12003), vgl. auch schon seine Beschw. an Innenminister Wagner v. 28.9.33 (a.a.O.) u. Epps Protest in der Sitzung des bayer. MinRats v. 5.10.33 (BayerHStArch., Sign. MA 105 257). 
len auf regionaler Ebene. Dabei ging es um die Regelung folgender vier Hauptprobleme:

1. Die Justiz suchte zu erreichen, daß die Gestapo alle polizeilich ermittelten Straftaten zur strafrechtlichen Verfolgung an sie abgab, und zwar möglichst ohne Verzögerung. Wegen dieses Anspruchs war 1933/34 schon Hans Frank auf bayerischer Ebene mit der politischen Polizei in Konflikt geraten. ${ }^{11}$

2. Andererseits war die Gestapo daran interessiert, von allen bei der Justiz anhängigen „politischen“ Strafverfahren, die durch Anzeigen oder auf anderem Wege unmittelbar bei der Staatsanwaltschaft in Gang gekommen waren, Kenntnis zu erhalten.

3. Die Justiz forderte, daß Beschuldigte, die wegen einer Straftat in Schutzhaft genommen worden waren, gegen die aber richterlicher $\mathrm{Haftbefehl}$ erlassen wurde, in Untersuchungshaft überführt werden sollten, da die Schutzhaft andernfalls ,Justizcharakter" angenommen hätte. Wurde in einem solchen Fall trotz Eröffnung des Verfahrens kein Haftbefehl erlassen, so hatte die Justiz ein Interesse daran, über den Aufenthalt bzw. die Entlassung des Beschuldigten aus der Schutzhaft informiert zu werden.

4. Die Gestapo wollte sich die Möglichkeit sichern, sowohl aus der Schutzhaft in die Untersuchungshaft Überführte, wie auch Beschuldigte, die vorher nicht in Schutzhaft gewesen waren, im Falle einer Aufhebung des richterlichen Haftbefehls - weil das Verfahren eingestellt oder eine weitere Untersuchungshaft im Verlauf des Verfahrens nicht mehr für notwendig erachtet wurde - anschließend in Schutzhaft nehmen zu können.

Für die Lösung des vierten Problems hatte der nationalsozialistische Justizminister Preußens, Hanns Kerrl, im Jahre 1933 bereits Vorleistungen erbracht. Im Mai hatte er in einer Rundverfügung an die preußischen Justizbehörden gerügt, daß wiederholt staatsfeindlich eingestellte Personen aus der Untersuchungshaft entlassen worden waren, weil sie nach dem Stand der Ermittlungen nicht überführt werden konnten und daher ein dringender Tatverdacht verneint werden mußte:

„Ein derartiges Verfahren widerspricht unter den derzeitigen besonderen Verhältnissen vielfach dringenden Interessen des Staates und der Rechtspflege. Es gestattet aktiven volksschädlichen Elementen, ihr staatsgefährliches"zersetzendes Treiben ungestört fortzusetzen, und ermöglicht außerdem den Entlassenen, Spuren der Tat zu verwischen oder sich für den Fall späterer Verdichtung des Verdachts weiterer Strafverfolgung durch die Flucht zu entziehen.“

Daher sollten die Staatsanwaltschaften in solchen Fällen die Haftfrage besonders sorgfältig prüfen und bei einer Entlassung aus der Untersuchungshaft rechtzeitig die Polizei benachrichtigen, damit sie gegebenenfalls Schutzhaft verhängen könne. Fehle hierzu die Zeit, so werde „in Erwägung zu ziehen sein, ob der Beschuldigte nach Beendigung der Untersuchungshaft der Polizeibehörde unmittelbar zuzuführen " sei. ${ }^{12}$

11 Vgl. Kapitel IV.4.d., S. 405.

12 RV des preuß. JM an die OLGPräs., GStAe u. Präs. der Strafvollzugsämter v. 6.5.33 (Akten des preuß. JM, GehStArch. Berlin, Sign. Rep. 84a/8828). Ihr lag u.a. ein Schr. des Essener Gauleiters Terboven an Kerrl v. 12.4.33 mit einer Beschwerde des Pol.Präs. von Oberhausen (Rhld) vom Vortage zu Grunde, daß die Gerichte gegen korruptionsverdächtige Kommunalbeamte keinen Haftbefehl erließen u. sie auf freien Fuß setzten, obwohl die Pol. um vorherige Benachrichtigung gebeten hatte. Während der PolPräs. von einer „Vertrauenskrise zur Justiz“ sprach und „die vorübergehende Außerkraftsetzung der Bestimmungen über Haftprüfungsverfahren“ u. der entsprechenden AusfVO aus der Weimarer Zeit forderte, schrieb Terboven: „Bislang haben wir uns in den besonders krassen Fällen damit geholfen, die Leute nach ihrer Entlassung durch den Richter in politische Schutzhaft zu nehmen“ (a.a.O.). 
Im Dezember 1933 ersuchte der preußische Justizminister die Provinzialjustizbehörden, mit den regionalen Staatspolizeistellen zu erörtern, ob und unter welchen Umständen vor allem des Landesverrats verdächtige Untersuchungshäftlinge, „bei denen ein zur Verurteilung ausreichender Verdacht sich nicht begründen ließ", der Gestapo übergeben werden sollten. ${ }^{13}$ Daraufhin kam es z.B. im Oberlandesgerichtsbezirk Naumburg (Saale) zu der Vereinbarung, die Entlassung von Landesverratsverdächtigen aus der Untersuchungshaft rechtzeitig der Gestapo mitzuteilen, ihr bei Zeitdruck den Betroffenen sogar ,zuzuführen“ und die Akten zu übergeben. ${ }^{14}$

Nicht in allen preußischen Oberlandesgerichtsbezirken wurde dieses Problem zur Zufriedenheit der Gestapo gehandhabt. Im Dezember 1934 reichte das Geheime Staatspolizeiamt beim Reichs- und Preußischen Justizministerium eine Beschwerde der Staatspolizeistelle Düsseldorf ein, daß die Vorführungsrichter in Düsseldorf, Wuppertal und Oberhausen der illegalen Betätigung überführte Kommunisten nach $\mathrm{Ab}$ lehnung eines Haftbefehls freigelassen hatten, da „die Beschuldigten geständig seien und somit keine Verdunkelungsgefahr mehr vorläge“. Durch diese Behandlung von Hochverratsfällen, rügte die Gestapoführung, werde „die illegale Weisung der KPD., gefährdete Kommunisten unter falschen Namen sofort in andere Betriebe zu versetzen, geradezu gefördert" ${ }^{15}$ Gürtner, der seinen Richtern die Entscheidungsfreiheit hinsichtlich der Haft im Einzelfall nicht nehmen konnte, ordnete daraufhin durch eine Rundverfügung an, der Richter habe bei der Ablehnung eines Haftbefehls

„gegen einen wegen Hoch- oder Landesverrats oder ähnlicher staatsgefährlicher Verbrechen von der Polizei vorläufig festgenommenen und ihm vorgeführten Täter ... vor der Entlassung des Täters die vorführende Polizeibehörde von seinem Beschluß zu verständigen und ihr Gelegenheit zu geben, selbst Verwahrungsmaßnahmen zu treffen“.

Erwäge der Richter in einer solchen Strafsache die Aufhebung eines bestehenden Haftbefehls, so sollte die Staatsanwaltschaft, die nach $\S \S 33$ bzw. $124 \mathrm{StPO}$ vor der Entlassung des Beschuldigten zu hören war, „die zuständige Polizeistelle und, wenn diese eine weitere Festhaltung des Beschuldigten von sich aus veranlassen will, das zuständige Gerichtsgefängnis" verständigen. In seinem Antwortschreiben an das $\mathrm{Ge}-$ heime Staatspolizeiamt forderte das Justizministerium, daß im letzteren Falle „die sofortige Abholung des aus der Untersuchungshaft zu Entlassenden unmittelbar nach Aufhebung des Haftbefehls sichergestellt" werden müsse. ${ }^{16}$ Auch in den vom Reichsjustizministerium im April 1935 herausgegebenen einheitlichen „Richtlinien zum Strafverfahren“ wurde die Praxis auf eine Mitteilungspflicht an die Polizeibehörde beschränkt. Diese Richtlinien, die nach der Verreichlichung der Justizverwaltung an die Stelle der zahlreichen Anweisungen der früheren Landesjustizverwaltungen für die Strafverfolgungsbehörden traten, bestimmten, daß der Staatsanwalt bei der Entlassung eines Beschuldigten aus der Untersuchungshaft, „an dessen weiterem Verbleib die Polizeibehörde ein Interesse hat, (z. B. ein Ausländer, ein Zigeuner oder eine staatsfeind-

13 RV des preuß. JM an die Provinzialjustizbehörden v. 20.12 .33 (a.a.O., Sign. Rep. 84a/3715).

14 Gemeinsame geh. RV des OLGPräs. u. GStA Naumburg an die nachgeordneten JBehörden v. 5.1.34 über ihre Vereinbarung mit den Leitern der Stapostellen Halle, Magdeburg u. Erfurt (a.a.O.).

15 Schr. des Gestapa an das RJM v. 18.12.34 nebst Schr. der Stapostelle Düsseldorf v. 8.12.34 (Akten des RJM, BA, Sign. R 22/953).

is RV des RJM v. 5.1.35 u. Schr. des RJM an das Gestapa v. 12.1.35, Hervorh. im Original (a.a.O.). 
liche Person)“, dieser Behörde so rechtzeitig Kenntnis zu geben habe, „daß sie ihrerseits die etwa erforderlichen Maßnahmen treffen kann". ${ }^{17}$

Während Kerrls Verfügungen von dem Gedanken geprägt waren, den Beschuldigten der Gestapo wegen einer nicht nachgewiesenen Straftat zu übergeben, wurde in der Reichsregelung von 1935 das präventiv-staatspolizeiliche Interesse der Gestapo an der weiteren Festhaltung des Betroffenen in den Vordergrund gestellt. Gewiß war das Entgegenkommen der Justiz, das der Gestapo die weitere Kontrolle über den Entlassenen sicherte, eine wesentliche Voraussetzung für die Erreichung des Zieles, daß die Gestapo ihrerseits alle Straftaten an die Gerichte abgab. Die Justiz nahm dabei aber zwangsläufig in Kauf, daß der Beschuldigte gerade wegen jener Verdächtigungen in Schutzhaft genommen wurde, die durch ihr Ermittlungsergebnis zerstreut worden waren - daß die Gestapo also durch Ausübung von „Polizeijustiz“ die Arbeit der Rechtspflege korrigierte. Sie konnte sich freilich ebensogut einreden, daß die Schutzhaftverhängung lediglich aus staatspolizeilichen, $d$. h. politischen Gründen erfolgte, die mit der von ihr behandelten Strafsache nichts zu tun hatten: es lag ohnehin nicht in ihrer Macht, darüber zu entscheiden und eine entsprechende Behauptung der Gestapo zu widerlegen. Die Gestapo wiederum begründete eine Wiederverhaftung den Justizbehörden gegenüber wohl auch in den wenigsten Fällen damit, daß der Verdächtigte ihrer Ansicht nach durch die Maschen des Gesetzes geschlüpft und unverdientermaßen seiner Bestrafung entgangen sei - selbst dann nicht, wenn es ihr eigentliches Motiv war. Nach außen stellte sie das politisch-präventive Motiv in den Vordergrund. Laut Runderlaß der Bayerischen Politischen Polizei vom November 1935 sollte die Rückübernahme eines Häftlings ausschließlich deshalb erfolgen, weil „das politische Vorleben und die Wesensart des Häftlings die Annahme berechtigt, daß er sich nach ... Aufhebung des Haftbefehls in Freiheit wieder staatsabträglich betätigen würde“.18

Im Sommer 1936 kamen in Sachsen Verhandlungen über die Zusammenarbeit von Staatsanwaltschaft und Gestapo in Gang, die das dritte der erwähnten Probleme - die Überführung von Schutzhaft in Untersuchungshaft - einbezogen. Das Ergebnis der Verhandlungen wurde als Vorbild für eine reichsrechtliche Regelung angesehen. Den Anstoß dazu gaben die Beobachtungen, die der Referent des Reichsjustizministeriums für politische Einzelstrafsachen in den außerpreußischen Gebieten machte, als er zusammen mit dem Generalstaatsanwalt Dresden einem Prozeßtag des Sondergerichts Freiberg (Sachsen) beiwohnte. Dabei mußte er feststellen,

„daß eine in der Bibelforschersache Angeklagte seit 6 Monaten und ein in ganz geringfügiger Heimtückesache Angeklagter seit 8 Monaten im Zusammenhang mit der Straftat in Schutzhaft saßen! Anscheinend war bei der Stapo-Stelle im Hinblick auf das durchzuführende Gerichtsverfahren eine ordnungsgemäße Haftkontrolle unterblieben; andrerseits war die StA [Staatsanwaltschaft] über die Schutzhaftlage nicht unterrichtet“. ${ }^{19}$

17 Nr. 81 (Entlassung aus der Untersuchungshaft) der Richtlinien, AV des RJM v. 13.4.35 (Amtl. Sonderveröffentl. der DJ Nr.7, S.39). Mit diesen Richtlinien verloren allein in Preußen über 300 Einzelverfügungen an StAe und Gerichte ihre Bedeutung. Für die Entlassung von Zigeunern hatte in Preußen schon seit der Weimarer Zeit eine Vorschr. zur Benachrichtigung der Polizei bestanden (AV des preuß. JM v. 17. 12.27, JMBI., S.432). Hinsichtl. der „staatsfeindl. Personen“ konnte die Mitteilungspflicht immerhin so ausgelegt werden, daß die Gestapo ihr Interesse von sich aus bekundet haben mußte.

18 RdEntschl. der BPP v. 25.11.35, I. V. Stepp (Arch. des IfZ, Sign. Fa 183/1, B1.346).

19 Ber. des Referenten v. 25.5. 36 (Akten des RJM, BA, Sign. R 22/1467). 
Aus diesem Anlaß wurde der Generalstaatsanwalt beauftragt, mit dem Präsidenten des Sächsischen Staatspolizeiamtes die Frage einer besseren Zusammenarbeit zu erörtern. Die Verhandlungen führten zu folgender Vereinbarung: War ein Beschuldigter im Zuge der Ermittlungen einer Straftat in Schutzhaft genommen worden, sollte der Staatsanwalt „nach Eingang der Sache“ die Frage einer Untersuchungshaft prüfen. (Einfluß darauf, ob und wann ihr eine Strafsache übergeben wurde, hatte die Justiz damit allerdings noch nicht.) Erging kein Haftbefehl und blieb der Beschuldigte weiter in Schutzhaft, so war die Gestapobehörde verpflichtet, die Staatsanwaltschaft über die weitere Entwicklung der Schutzhaft und rechtzeitig über eine Aufhebung des Schutzhaftbefehls zu unterrichten, und zwar unter Mitteilung der Entlassungsadresse des Beschuldigten. Die Staatsanwaltschaft sollte diese Fälle mit derselben Beschleunigung bearbeiten wie normale Haftsachen. Wurde dagegen richterlicher Haftbefehl erlassen, so sollte die Gestapo dem Ersuchen um Überführung des Beschuldigten in die Untersuchungshaft grundsätzlich entsprechen. Allerdings setzte die Gestapo hier Ausnahmen durch: hielt „aus ganz besonderen Gründen die Staatspolizei in Einzelfällen“ (!) die Schutzhaft weiterhin für erforderlich, so mußte sie den zuständigen Oberstaatsanwalt verständigen und das Bestehen eines richterlichen Haftbefehls bei sich notieren, so daß bei einer Aufhebung der Schutzhaft die Überführung in die Untersuchungshaft gesichert war. Alle im Laufe des Strafverfahrens ermittelten Umstände, die für eine Beendigung der Schutzhaft bedeutsam sein konnten, waren der Gestapo mitzuteilen, ebenso die Einstellung des Strafverfahrens. Wurde andererseits ein Beschuldigter, gegen den vorher Schutzhaftbefehl bestanden hatte, aus der Untersuchungshaft entlassen, so war der Gestapo - im Einklang mit den erwähnten „Richtlinien“ des Reichsjustizministeriums vom April 1935 - Mitteilung zu machen. Die Behandlung von einschlägig Beschuldigten, die aus der Untersuchungshaft entlassen wurden, ohne vorher Schutzhäftlinge gewesen zu sein, wurde in der sächsischen Vereinbarung nicht erwähnt; die Erfassung dieser Kategorie durch die Gestapo war jedoch bereits durch die Mitteilungspflicht der Staatsanwaltschaft gemäß den „Richtlinien“ weitgehend gesichert.

Der Generalstaatsanwalt Dresden bat das Reichsjustizministerium, die Abmachungen als „Plattform für eine gedeihliche Zusammenarbeit“ mit der Gestapo zu genehmigen. ${ }^{20}$ Die Sachbearbeiter des Ministeriums hoben hervor, daß die Brauchbarkeit der vorgesehenen Regelung davon abhänge, was die Gestapo unter den „ganz besonderen Gründen" verstand, die der Überführung eines Schutzhäftlings in Untersuchungshaft im Wege stehen sollten: wurde dieser Begriff extensiv ausgelegt, so mußte die Vereinbarung ein Zurückstecken seitens des Justizministeriums gegenüber den Schutzhaftbestimmungen vom April 1934 bedeuten, die die Schutzhaft bei strafbaren Handlungen grundsätzlich ausgeschlossen und „besondere Ausnahmefälle“ nur unter der Voraussetzung zugelassen hatten, daß schleunigst richterlicher Haftbefehl und damit Úbernahme in die Untersuchungshaft erwirkt wurde. ${ }^{21} \mathrm{Da}$ aber die Gestapo die April-Bestimmungen in dieser Hinsicht ohnehin mißachtete, stellte die vorgesehene Regelung „zweifellos einen Fortschritt“ dar. Ministerialrat Kritzinger empfahl sogar, an den Chef der Deutschen Polizei wegen der Einführung einer gleichen oder ähnli-

20 Ber. des GStA Dresden an das RJM v. 26.6.36 (a.a.O.).

21 Vgl. Kapitel VI.2.a., S.549. 
chen reichseinheitlichen Regelung heranzutreten, um Schwierigkeiten in den anderen Oberlandesgerichtsbezirken auszuräumen. ${ }^{22}$ Am 22. August 1936 führte daher das Reichsjustizministerium in einem Schreiben an Himmler aus, daß sich „in der Praxis vielfach Schwierigkeiten und Meinungsverschiedenheiten zwischen den Justiz- und den Polizeibehörden ergeben" hätten, da trotz der anderslautenden Bestimmungen vom April 1934 „Personen viele Monate im Zusammenhang mit einer verhältnismäBig geringfügigen Straftat in Schutzhaft gehalten worden sind“. Deshalb sei eine nähere Regelung der Haftfrage besonders dringlich, wobei das Verbleiben eines Beschuldigten in Schutzhaft "nur ausnahmsweise“ in Frage kommen könne, z. B. „wenn ein gefährlicher Staatsfeind ohne Rücksicht auf die von den Justizbehörden verfolgte, vielleicht unpolitische Straftat in Schutzhaft" sei. Die vom Generalstaatsanwalt Dresden erzielte Vereinbarung über die Zusammenarbeit in politischen Strafsachen halte das Ministerium für geeignet und „die Einführung einer solchen Regelung für das ganze Reich ... für erwünscht". ${ }^{23}$

Eine Regelung auf Reichsebene kam in der Folgezeit jedoch offenbar deshalb nicht zustande, da sie in die Vorbereitung neuer Schutzhaftbestimmungen durch die Gestapo mündete, die zugleich das „Zusammenarbeiten mit den Justizbehörden“ ordnen sollten $^{24}$, aber bis Januar 1938 auf sich warten ließen. Die grundlegende Bestimmung im Erlaß vom Januar 1938, daß die Schutzhaft nicht Strafzwecken dienen sollte - die übrigens das praktische Problem der geforderten lückenlosen Abgabe aller Straftaten an die Justiz nicht löste -, bewirkte offenbar, daß die Überführung von Schutzhäftlingen in jenen Fällen zufriedenstellend gehandhabt wurde, in denen eine Abgabe der Sache an die Staatsanwaltschaft erfolgt war und die Justizbehörden die Überführung daraufhin beantragten. Als das Reichssicherheitshauptamt diese Materie im August 1943 erstmals einheitlich regelte, wurde festgelegt, „daß derartigen Ersuchen an sich grundsätzlich stattzugeben“ sei. Stand dem „ein besonderes staatspolizeiliches Interesse im Einzelfall“ entgegen, so entschied die einweisende Stelle oder auf deren Antrag das Reichssicherheitshauptamt. In allen Fällen, in denen mit der Überstellung an die Justiz nicht gleichzeitig die Schutzhaft aufgehoben wurde, sollte bei der Übergabe ein Rückführungsantrag gestellt werden. ${ }^{25}$ Nach diesem Modell hatten die Gestapobehörden die Überstellung offenbar schon in den vorangegangenen Jahren gehandhabt. Wie z.B. aus den Berichten der Oberlandesgerichtspräsidenten und Generalstaatsanwälte für das Jahr 1938 hervorgeht, wurde die Rücküberführung von der Gestapo häufig beantragt. Der Oberlandesgerichtspräsident Hamm berichtete als bemerkenswerte Folge, daß sich Richter in Zweifelsfällen für einen Haftbefehl entschieden und Vertei-

22 Aktenverm. der Abt. III (Strafrechtspflege) u. V (Öffentl. Recht) v. Juli 1936 (a.a.O.).

${ }^{23}$ Schr. des RJM (I. V. Freisler) an den RFSSuChdDtPol. im RMdI v. 22.8. 36 (a.a.O.).

24 Zum Werdegang des Schutzhaft-Erl. v. 25.1 .38 vgl. Kapitel VI.2.a., S. 560 f. Reichseinheitlich geregelt wurde durch Erl. des Chefs Sipo/SD v. 26.3.38 (Arch. des IfZ, Sign. Fa 506/12, B1. 258) lediglich die Überführung von KZ-Insassen zu gerichtlichen Vernehmungen als Zeugen, Beschuldigte sowie Kläger oder Beklagte in Privakklageverfahren: sie wurde grundsätzlich zugelassen; litt jedoch die Lagerdisziplin darunter, sollte die Lagerleitung das betr. Gericht bitten, die Vernehmung durch das zuständige AG im Lager vornehmen zu lassen.

25 RdErl. des RSHA an alle Sipo-Dienststellen betr. Ùberstellung von Schutzhaft- u. Vorbeugungshäftlingen aus den KL. auf Ersuchen der JBehörden v. 17.8.43 (a.a.O., Bl. 259). 
diger eine Haftbeschwerde unterließen, um dem Beschuldigten die Schutzhaft zu ersparen. $^{26}$

Zentral geregelt wurde hingegen noch 1937 das zweite der erwähnten Probleme: die Unterrichtung der Gestapobehörden über alle bei der Justiz anfallenden politischen Strafsachen. Ende November 1936 ließ Best dem Reichsjustizministerium den Entwurf eines Runderlasses an die Staatspolizeistellen zugehen, in dem die Orts- und Kreispolizeibehörden angewiesen wurden, ,alle Vorgänge in Angelegenheiten der Geheimen Staatspolizei“, die der Staatsanwaltschaft vorgelegt werden sollten, grundsätzlich über die zuständige Staatspolizeistelle zu leiten. Nur in eiligen Haftsachen sollten die Akten - nach vorheriger telefonischer Unterrichtung der Staatspolizeistelle - unmittelbar an die Staatsanwaltschaft gegeben werden können; in diesem Fall war der Staatspolizeistelle sofort ein Durchschlag der polizeilichen Vernehmungsprotokolle zu übersenden. Best bat das Reichsjustizministerium um Einverständnis und um eine Weisung an die Staatsanwälte, alle Ermittlungsersuchen an die Orts- und Kreispolizeibehörden, die durch ihnen unmittelbar zugegangene Anzeigen politischen Inhalts ausgelöst wurden, gleichfalls über die zuständige Staatspolizeistelle laufen zu lassen. Dafür sollten die Staatspolizeistellen durch den vorgesehenen Runderlaß verpflichtet werden, „die bei ihnen durchlaufenden Vorgänge schnellstens auszuwerten und ohne Verzug weiterzuleiten“. ${ }^{27}$

Der Vorschlag berührte aufs engste das Interesse der Justizleitung an einer schnellen und vor allem lückenlosen Abgabe aller politischen Strafsachen an die Justiz durch die Gestapo. In ihrer Antwort betonte sie daher, es sei ,nicht zu verkennen, daß die Anordnungen dieser Rundverfügung im Widerspruch mit der gesetzlichen Regelung des $\S 163$ Abs. II StPO stehen können, nach der die polizeilichen Vorgänge, ohne Verzug' der Staatsanwaltschaft zuzuleiten" seien. Wenn das Reichsjustizministerium trotzdem zustimme, so gehe es davon aus, daß durch diese Anordnungen in der Abgabe des Verfahrens an die Staatsanwaltschaft keine wesentliche Verzögerung eintrete und

„daß die Staatspolizeistellen in diesem Verfahrensabschnitt lediglich Durchgangsstellen sind, deren Aufgabe ausschließlich die Unterrichtung über das Verfahren ist, nicht aber die Entscheidung über die Notwendigkeit weiterer Ermittlungen oder etwa über die Frage, ob überhaupt eine Abgabe der Sache an die Staatsanwaltschaft erfolgen [!] soll“".

Deshalb werde das Ministerium die Auswirkungen der beabsichtigten Regelung besonders aufmerksam beobachten und bei auftretenden Mißständen um Abänderung des Runderlasses bitten. Bei der Staatsanwaltschaft gingen gelegentlich aber auch Fälle ein, in denen der Sachverhalt bereits vollständig ermittelt sei und nur noch Beschuldigte oder Zeugen ohne weitere Einschaltung der Polizei durch den Staatsanwalt vernommen werden müßten. Da diese Fälle durch das geplante Verfahren nicht erfaßt

26 Vgl. Bespr. im RJM mit den Chefpräs. am 24.1. u. den GStAen am 23.1.39 (Akten des RJM, BA, Sign. R 22/1467).

27 Schr. des RFSSuChdDtPol. im RMdI (I. A. Best) an das RJM v. 27.11.36 nebst Entw. (Akten des RJM, BA, Sign. R 22/1462). Vorausgegangen war eine Beschwerde des RJM, daß sich die Stapostelle Potsdam durch eine Verf. v. 1.7.36 vorbehalten hatte, über die Abgabe von Vorgängen der örtl. Pol.Behörden an die StAschaft selbst zu entscheiden. Das Gestapa ließ diese Verf. aufheben u. bereits die hier vorgeschlagene direkte Abgabe „über die Stapostelle“ einführen (a.a.O.). 
seien, werde diese Informationslücke durch entsprechende Bestimmungen in der erbetenen Weisung des Ministeriums an die Staatsanwälte geschlossen werden. ${ }^{28}$

Den von Best am 18. Februar 1937 herausgegebenen Runderlaß ${ }^{29}$ brachte das Reichsjustizministerium den Generalstaatsanwälten gleichzeitig mit der angekündigten eigenen Rundverfügung vom 10. März zur Kenntnis. Die Staatsanwaltschaften wurden darin angewiesen, alle Ermittlungsersuchen in politischen Strafsachen über die zuständige Staatspolizeistelle zu leiten, diese Stelle aber auch über alle unmittelbar einlaufenden einschlägigen Anzeigen zu informieren und ihr diese Vorgänge zur Kenntnisnahme zuzuleiten. Sei eine Übersendung der Akten wegen der Eilbedürftigkeit nicht möglich, so sei die Gestapo zumindest von der Einleitung des Verfahrens, gegebenenfalls unter Beifügung der Anklageschrift zu unterrichten. Das Ministerium sprach auch in dieser Rundverfügung die Erwartung aus, daß die Abgabe des Verfahrens an die Staatsanwaltschaft durch die Einschaltung der Staatspolizeistellen nicht verzögert oder gar verhindert würde, und bat, etwaige Beobachtungen in dieser Hinsicht zu berichten. ${ }^{30}$

Für derartige Berichte sollte allerdings auch in der Folgezeit noch genügend Veranlassung gegeben sein. Das wichtigste Problem für die Justiz blieb nach wie vor bestehen: die fehlende Sicherheit für die Abgabe sämtlicher Straftaten an die Justiz. Im September 1935 waren die Generalstaatsanwälte in einer Besprechung im Reichsjustizministerium ausdrücklich ermahnt worden, daß sich die Staatsanwaltschaft ,ihre Initiative nicht von der Polizei vorschreiben lassen“ dürfe. Es sei untragbar, daß z. B. nach einem großen öffentlichen Krawall, bei dem die Polizei Täter verhaftet habe, die Staatsanwaltschaft nicht einschreite, weil

„die Staatspolizei erklärt, es sei eine politische Sache und es stehe in ihrem Ermessen, wie weit sie der Staatsanwaltschaft Kenntnis gebe. Die Staatsanwaltschaft handelt pflichtwidrig, wenn sie auf solche dienstlichen Meldungen wartet und nicht bei jedem, auch außerdienstlich bekanntgewordenen Anhaltspunkt ( $\S 152^{2}$ StPO) einschreitet. ${ }^{\text {"31 }}$

Bei weniger spektakulären Vorfällen kamen die Staatsanwälte jedoch nur selten und mehr oder weniger zufällig darauf, daß ihnen Strafsachen von der Gestapo vorenthalten wurden. Als z. B. im Dezember 1936 ein Hauseigentümer von Parteigenossen der Ortsgruppe Bremen-Harstedt wegen „unsozialen Verhaltens“ gegenüber seinen Mietern aus der Wohnung geholt und schwer mißhandelt wurde, erfuhr der Oberstaatsanwalt Bremen erst durch die Anzeige der Tochter des Mißhandelten am 20. Januar 1937 von der Straftat, obwohl die Gestapo die Ermittlungen längst abgeschlossen, aber zu den Akten gelegt hatte. ${ }^{32}$

28 Schr. des RJM (l.A. Crohne) an den RFSSuChdDtPol. im RMdI v. 30.12 .36 (a.a.O.). Darin bat das RJM ferner um Mitteilung, ob sich durch die vorgesehene RV der RdErl. der BPP v. 21.7.36 erledige, der die bayer. Polizeistellen verpflichtete, die Vorgänge über politische Straftaten von Angehörigen der NSDAP, SA, SS u. HJ einschl. JV, BDM u. Jungmädel abschriftlich an die BPP abzugeben (vgl. dazu Kapitel IV.4.d., S.411, Anm. 128). Best antwortete am 30.1.37, daß dieser RdErl. von der beabsichtigten RV „nicht berührt“ werde; er blieb folglich bestehen (a.a.O.).

29 An alle Stapo(leit)stellen (a.a.O.), vgl. auch Diensttageb. des RJM, Bd.10, Eintr. v. 24.2.37 (BA, Sign. R 22/706).

30 RV des RJM an die GStAe v. 10.3.37 (Akten des RJM, BA, Sign. R 22/1462).

31 Bespr. mit dem OReiA u. den GStAen im RJM am 23.9.35 (a.a.O., Sign. R 22/4277).

32 Ber. des OStA Bremen v. 20.2.37 (Diensttageb. des RJM, Bd. 10, Eintr. v. 25. 2.37, BA, Sign. R 22/706). 
Neben diesen Eigenmächtigkeiten der Gestapo, die einer Ausschaltung der Staatsanwaltschaft gleichkamen, blieb die erheblich verzögerte Abgabe der Strafsachen ein ständiger Grund für Mißhelligkeiten. Im April 1936 beschwerte sich Ministerialdirektor Crohne bei der Gestapo, „daß die polizeilichen Ermittlungsakten in Hamburger Hochverratssachen zumeist erst 6 bis 8 Monate nach der vorläufigen Festnahme der Beschuldigten an den Reichsanwalt bei dem Volksgerichtshof vorgelegt" wurden. Falls die Gestapo damit etwa den Gedanken verfolge, daß die Beschuldigten zwecks wirksamer Abschreckung zunächst längere Zeit in Schutzhaft verbleiben sollten, so würde dieser Zweck deshalb nicht erzielt, da die Gerichte an die Stelle der Untersuchungshaft tretende Schutzhaft auf die Strafe anrechneten: im Falle einer Zuchthausstrafe könne dadurch sogar - meinte Crohne, die Verhältnisse in den Konzentrationslagern ignorierend - „eine gewisse Besserstellung [!] des Verurteilten eintreten“. Crohne wies eindringlich darauf hin, daß nur die möglichst baldige Vorführung vor den Ermittlungsrichter und Vorlage der Akten ein ordnungsgemäßes Strafverfahren gewährleisten könnten. Das gelte insbesondere dann, wenn der Beschuldigte Ausländer sei: in Hamburg sei ein amerikanischer Staatsbürger erst nach mehr als sieben Monaten Schutzhaft dem Ermittlungsrichter vorgeführt worden. Die Ansicht des Leiters der Hamburger Gestapo, daß auf das Ausland keine besondere Rücksicht genommen werden brauche, teile das Reichsjustizministerium nicht. Gerade bei Ausländern sei vielmehr „eine besonders rasche, den Bestimmungen der Strafprozeßordnung entsprechende Durchführung des Ermittlungsverfahrens unumgänglich nötig “. ${ }^{33}$

In einem Lagebericht vom September 1936 gab der Generalstaatsanwalt Köln als Ursache für die Verschleppungen an, daß die Staatspolizeistellen in allen wichtigeren Sachen erst ihrer vorgesetzten Dienststelle über den Ausgang der Ermittlungen berichteten und deren Entscheidung abwarteten, ob die Vorgänge an die Staatsanwaltschaft abzugeben seien. Da über das Vorliegen einer strafbaren Handlung aber ausschließlich der Staatsanwalt zu entscheiden habe, sei dieses Verfahren unzulässig. ${ }^{34}$ Der Generalreferent für politische Strafsachen Klemm setzte sich deswegen mit dem Sachbearbeiter im Geheimen Staatspolizeiamt in Verbindung, der um Vorlage der Einzelfälle bat. Vom Ministerium aufgefordert, reichte der Generalstaatsanwalt Unterlagen über vier beim Sondergericht Köln anhängige Fälle ein, in denen Verzögerungen von drei bis vier Monaten, in einer Sache sogar von anderthalb Jahren aufgetreten waren. Crohne gab die Fälle an die Gestapoführung weiter ${ }^{35}$, wo sie auf die Herausgabe des erwähnten Runderlasses Bests vom 18. Februar 1937 beschleunigend gewirkt haben dürften. Der vom Generalstaatsanwalt Köln angegebene Grund für die Verzögerungen hätte an sich durch die in diesem Runderlaß ausgesprochene Verpflichtung zur unverzüglichen Weiterleitung aller „durchlaufenden“ Vorgänge beseitigt sein müssen; dennoch hielten die Verzögerungen weiter an. Eine Ursache dafür war, daß die Gestapo ihre Ermittlungsakten der Staatsanwaltschaft oftmals schon deshalb nicht unmittelbar und urschriftlich übergeben konnte, weil sie Vorgänge enthielten, die die

${ }_{33}$ Schr. des RJM (I.A. Crohne) an das Gestapa v. 27.4.36 (Akten des RJM, BA, Sign. R 22/1462). Das Gestapa entschuldigte die Verzögerung im Schr. v. 11.6.36 mit dem großen Umfang der Hochverratskomplexe u. mit Arbeitsüberlastung (a.a.O.).

34 Auszug aus dem Lageber. des GStA Köln v. 20.9 .36 (a.a.O.); vgl. dazu die Verf. der Stapostelle Potsdam v. 1.7.36 (Anm. 27). Da den GStAen für ihre Lageber. ausdrücklich Vertraulichkeit zugesichert war, mußte für d. Weitergabe eines Ber.Auszugs an den Chef der Sipo die Genehmigung des GStA Köln eingeholt werden.

35 Ber. des GStA Köln v. 28. 12.36; Schr. des RJM an den Chef der Sipo v. 15.1.37 (a.a.O.). 
Gestapo nicht zum Gegenstand der Hauptverhandlung gemacht sehen wollte und die auch dem Verteidiger nicht vorgelegt werden sollten. Heydrich rügte Ende 1938 die sächsischen Gestapostellen, die darauf nicht geachtet hatten, und wies sie an, absolut unvermeidliche Mitteilungen dieser Art an die Justizbehörden ,gesondert unter Hinweis auf die Notwendigkeit vertraulicher Behandlung und Aufnahme in die Handakten der Staatsanwaltschaft zu machen". ${ }^{36}$ Ein plastisches Beispiel für das fortdauernde verschleppende und eigenmächtige Handeln der Gestapo ist der Bericht des Generalstaatsanwalts Naumburg vom Mai 1939 über eine Reihe von Fällen, in denen die Gestapo

„nicht nur Ermittlungsersuchen der Staatsanwaltschaft äußerst säumig erledigt und von ihr selbständig bearbeitete Verfahren sehr verspätet an die Staatsanwaltschaft abgegeben, sondern sich auch derartig als Herr des Verfahrens gefühlt hat, daß sie, ohne Verbindung mit dem zuständigen Staatsanwalt zu nehmen, selbständig in dessen Ermittlungen eingriff, die Herausgabe der Vorgänge längere Zeit hindurch verweigerte und von der Weitergabe an die Staatsanwaltschaft ganz absah, wenn sie es für angebracht hielt“.

Drei im einzelnen dargelegte Fälle, die die Gestapo überhaupt nicht weitergeleitet hatte, kommentierte der Generalstaatsanwalt mit der zutreffenden Schlußfolgerung:

„Da Fälle dieser Art nur ausnahmsweise und zufällig zur Kenntnis der Justizbehörden gelangen, erscheint der Schluß gerechtfertigt, daß die Geheime Staatspolizei in einer weit größeren Anzahl von Fällen die Abgabe an die Staatsanwaltschaft pflichtwidrig unterlassen hat."

Aus einer beigelegten genauen Übersichtstabelle für das Jahr 1938 ergab sich zwischen dem Abschluß der staatspolizeilichen Ermittlungen und dem Eingang der Sache bei der Staatsanwaltschaft ein Zeitraum zwischen ein und fünf Monaten. Der Generalstaatsanwalt schloß seinen Bericht mit der Feststellung, daß das Verhalten der Gestapo „mit den Grundsätzen einer raschen und energischen Strafverfolgung unvereinbar ist und die Einschaltung der Geh. Staatspolizei in vielen Fällen unerwünscht erscheinen läßt". ${ }^{37}$

In dieser Zeit - Sommer 1939 - war jedoch das Justizministerium mit generellen Vorstößen in dieser Sache bei der Gestapoführung zurückhaltend geworden. Ministerialdirektor Crohne vermerkte auf dem Bericht, daß er zur Weitergabe an die Gestapo nicht geeignet sei, da er „unnötige Schärfen“ enthalte. Der Generalstaatsanwalt wurde zunächst um Mitteilung gebeten, ob er schon mit dem Leiter der zuständigen Staatspolizeistelle in Verbindung getreten sei, um die aufgetretenen Mängel zu beheben. Dieses „Durchwursteln“ auf unterer Ebene schien die einzig noch mögliche Methode zu sein, die Mißstände in Grenzen zu halten. Aber der Generalstaatsanwalt ließ sich den Schwarzen Peter nicht zuschieben: er verneinte die Frage mit der Begründung, daß die Mißstände nicht „auf örtliche Unzuträglichkeiten“, sondern auf die Gesamtorganisation und die zentralen Direktiven der Gestapo zurückzuführen seien; sie könnten daher auch nur von der Zentrale her behoben werden, und zwar durch die Beschränkung der Gestapo-Aufgaben „auf rein politische Sachen“.38 Das Ministerium begnügte sich jedoch damit, die einzelnen Fälle von seinem Referenten mit dem

36 Erl. Heydrichs an die sächs. Stapo(leit)stellen v. 14.12.38 (a.a.O.).

37 Ber. des GStA Naumburg (Saale) an das RJM v. 25.5.39 (a.a.O.). Vgl. auch Ber. des GStA Karlsruhe v. 27.7.38 (Verbot weiterer Ermittlungen) (a.a.O., Sign. R 22/3136) u. v. 20.1.39 (Verzögerungen) u. des OStA Freiburg i. Br. v. 2.2.39 (versuchte Ausschaltung der StAschaft bei der Verfolgung der Erpressung durch einen Ortsgruppenleiter der NSDAP) (a.a.O., Sign. R 22/1463).

38 Antw.Schr. des GStA Naumburg v. 10.7.39 auf das Schr. des RJM v. 29.6.39 (a.a.O., Sign. R 22/1462). 
Sachbearbeiter der Gestapo durchsprechen zu lassen, wobei die Gestapo allerlei Rechtfertigungen und Entschuldigungen vorbrachte. Bevor ein genereller Vorstoß bei der Gestapoführung unternommen werden sollte, beabsichtigte Crohne die Beschwerden des Generalstaatsanwalts auf der nächsten Zusammenkunft der Generalstaatsanwälte zu behandeln, um die Erfahrungen aus anderen Bezirken zu sammeln, aus denen offensichtlich Mißstände nicht in diesem massiven Ausmaß gemeldet worden waren. ${ }^{39}$ Als sich jedoch die Verhältnisse im Oberlandesgerichtsbezirk Naumburg in den nächsten Monaten - vorübergehend - wieder besserten, sah Crohne von der Erörterung dieses Themas auf der Tagung der Generalstaatsanwälte 1940 ab. $^{40}$ Die Justizleitung hatte sich damit abgefunden, daß sie das Problem nicht mehr grundsätzlich zu ihren Gunsten werde lösen können; sie beschränkte sich darauf, der Gestapo besonders krasse Fälle zur Kenntnis zu bringen und Einzelkonflikte beizulegen. ${ }^{41}$ Dabei war sie jedoch stets darauf bedacht, der Gestapo niemals formell das Recht zur Ausschaltung der Staatsanwaltschaft in politischen Strafsachen zuzugestehen. Als nach dem Anschluß Österreichs der Leiter der Staatspolizeistelle Klagenfurt den dortigen Landgerichtspräsidenten aufforderte, seine nachgeordneten Behörden anzuweisen, „daß eine staatsanwaltschaftliche oder gerichtliche Behandlung politischer Vorfälle erst nach formell erfolgter Abgabe durch die Staatspolizeistelle" erfolgen dürfe ${ }^{42}$, lehnte die Abteilung Österreich des Reichsjustizministeriums dieses Ansinnen strikt ab, da es dem österreichischen Strafverfahrensrecht widerspreche. Die Befugnis der Staatsanwaltschaften und Gerichte, bei Verdacht einer strafbaren Handlung auch in politischen Vorfällen von sich aus einzuschreiten, sei durch die Zweite Verordnung zum Gesetz über die Wiedervereinigung Österreichs mit dem Deutschen Reich vom 18. März $1938^{43}$ nicht berührt worden, wonach der Reichsführer-SS und Chef der Deutschen Polizei und jene Stellen, denen er seine Befugnisse übertragen habe, Maßnahmen zur Aufrechterhaltung der Sicherheit und Ordnung auch außerhalb der sonst hierfür bestimmten gesetzlichen Grenzen treffen konnte. ${ }^{44}$ Das Reichsjustizministerium in Berlin stellte sich hinter diese Entscheidung mit der Begründung, daß „für die Rechtsverhältnisse zwischen Justiz und Polizei in Deutsch-Österreich gleiche Rechtsgrundsätze herrschen wie im alten Reiche“ ${ }^{45} \mathrm{Da}$ der Leiter der Klagenfurter Gestapo seine Forderung gerade damit begründet hatte, daß er damit „die für das alte Reich geltenden Grundsätze [!] in der staatspolizeilichen Arbeit" auf seinen neuen Wirkungsbereich anwenden wolle, wird bei dieser Gelegenheit die unterschiedliche Auffassung von Justiz und Gestapo in dieser Frage besonders deutlich. Oberreichsanwalt Parey konnte die Wiener Gestapoführung erst durch eine Besprechung im Juli 1938 von dem ungesetzlichen Verfahren abbringen,

39 Schr. Crohnes an den GStA Naumburg v. 8.8.39 (a.a.O.).

40 Ber. des GStA Naumburg v. 26.6.40 u. Verm. Crohnes v. 4.7.40 (a.a.O.).

4 Vgl. z. B. die Intervention Freislers beim RFSSuChdDtPol. wegen zweier Lüneburger Fälle, Schr. v. 16.6.41 u. Antw. v. 26.7.41 (a.a.O., Sign. R 22/1463). Einblick in die nicht nur durch Sachdifferenzen, sondern auch durch persönl. Querelen u. Prestigefragen getrübte Zusammenarbeit von StAschaft u. Gestapo in einer typischen Kleinstadt wie Schneidemühl geben die ausführlichen Ber. des GStA Marienwerder an den RJM v. 2.8.37, 15. u. 25.6 .38 (a.a.O., Sign. R 22/1462).

42 Schr. des Leiters der Stapostelle Klagenfurt an den LGPräs. Klagenfurt v. 30.4 .38 (a.a.O.).

43 RGBI. I, S. 262.

${ }^{44}$ Ber. des Beauftragten des RJM in Österreich (Minister Hueber) an das RJM v. 30.5 .38 (Akten des RJM, a.a.O.).

45 Schr. des RJM an den Beauftragten des RJM in Wien v. 18.6.38 (a.a.O.). 
„diejenigen Anzeigesachen, in denen der Verdacht einer hoch- und landesverräterischen Tat in Frage kam, nicht wie im Altreich üblich, den örtlich zuständigen Staatsanwaltschaften zuzuleiten, sondern sie dem Geheimen Staatspolizeiamt in Berlin unmittelbar zur Entscheidung darüber vorzulegen, ob eine Abgabe an den Oberreichsanwalt beim Volksgerichtshof angezeigt sei““46

Gesetzlich wurde eine solche Vorentscheidung der Gestapo mit Kriegsbeginn nur in einem Fall festgelegt: die Strafverfolgung wegen Abhörens ausländischer Sender und Verbreitung der abgehörten Nachrichten fand nur auf Antrag der Staatspolizeistellen statt. $^{47}$

Im Kriege verstärkte sich mit zunehmender Radikalisierung und Unzufriedenheit der politischen Führung mit der Justiz auch das Bestreben der Gestapo, die Staatsanwaltschaft von der Verfolgung strafbarer Handlungen nach Gutdünken auszuschließen. Dazu trug bei, daß die Polizei nach dem Willen der politischen Führung zur Ahndung strafbarer Handlungen - teils durch geheime Erlasse des Reichsführers-SS, die der Justiz erst nachträglich zur Kenntnis kamen, teils durch öffentlich verkündete Rechtsverordnungen - ermächtigt wurde: so durfte sie z.B. alle Straftaten von Juden und bestimmte Straftaten polnischer und sowjetrussischer Zivilarbeiter im Reich durch Einweisung in Arbeitserziehungs- bzw. Konzentrationslager und sogar durch staatspolizeiliche Hinrichtungen („Sonderbehandlung") bestrafen, die vom Reichssicherheitshauptamt angeordnet bzw. genehmigt wurden. ${ }^{48}$ Die Maßnahmen gegen polnische und sowjetrussische Arbeitskräfte, die gegen die Bestimmung des $\S 163$ StPO verstießen, beruhten offenbar auf einem mündlichen Auftrag Hitlers an den Reichsführer-SS, bei den Polen auf einer Ermächtigung Görings in seiner Eigenschaft als Beauftragter für den Vierjahresplan und Vorsitzender des Ministerrats für die Reichsverteidigung aus dem Jahre $1940 .^{49}$

Die Schwierigkeiten, die die Justiz in den Vorkriegsjahren bei der Ermittlungstätigkeit und der Abgabe der Straftaten hatte, sollten sich nur als Vorspiel zu dem Ziel erweisen, das Himmler in der zweiten Kriegshälfte offen verfolgte: der völligen Übernahme der Funktion der Staatsanwaltschaft durch die Polizei. Bereits im Januar 1939 hatte Heydrich über den Chef der Reichskanzlei bei Hitler angeregt, daß die Polizei das Recht erhalten sollte, den Täter „bis zur restlosen Klärung der gegen ihn vorliegenden oder sich ergebenden Verdachtsmomente im eigenen Gewahrsam zu halten“ und "selbständig eidliche Vernehmungen durchzuführen“, d.h. sogar richterliche Funktion zu übernehmen. Die „Tatsache, daß der kriminalpolizeiliche Schlußbericht

46 Ber. Pareys an das RJM v. 29.7.38 (Akten des RJM, BA, Sign. R 22/20040). Diese Praxis der Gestapo verstieß gegen die ausdrückliche Bestimmung des $\S 5$ der VO über die Einführung der Vorschriften über Hochverrat und Landesverrat im Lande Österreich v. 20.6.38 (RGBl. I, S. 640), wonach die Sicherheitsbehörden den OReiA unverzüglich in Kenntnis zu setzen hatten.

47 Vgl, dazu Kapitel VII.3.e., S. 904 f.

48 Vgl. dazu Kap. VI.6, ferner die 13. VO zum ReichsbürgerG v. 1.7.43 (RGBl. I, S. 372) u. geh. RdErl. des RSHA betr. Verfolgung der Kriminalität unter den polnischen und sowjetrussischen Zivilarbeitern $v$. 30.6.43 (Allg. Erl.Samml. des RSHA 2 A IIIf, S. 131, Arch. des IfZ, Sign. Dc 15.21): „An die Justiz sind nur die Fälle weiterzuleiten, in denen aus stimmungspolitischen Gründen eine gerichtliche Aburteilung wünschenswert erscheint und durch vorherige Fühlungnahme sichergestellt ist, daß das Gericht die Todesstrafe verhängen wird.“ Ähnlich schon RdErl. des RFSSuChdDtPol. im RMdI v. 20.2.42 hinsichtl. krimineller Verfehlungen von Arbeitskräften aus dem Osten (Nicht-Polen) (a.a.O., S. 15) u. v. 19.1.42 (poln. Arbeiter im Reich) (a.a.O., S. 4).

49 Zu Görings Erl. v. 8.3.40 u. den darauf fußenden Geheimerl. Himmlers, die schon 1940 zur "Polizeijustiz“ gegen poln. Zivilarbeiter im Reich führten, vgl. Kapitel VI.6.b., S.689f.; laut Erl. des RSHA v. 4.9.40 VA 1 Nr. 4177/40 - waren die polizeil. Ermittlungsvorgänge betr. strafbare Handlungen poln. Zivilarbeiter nicht an die StAschaft, sondern an die zuständige Stapostelle zu geben. 
oftmals von der Staatsanwaltschaft wörtlich in die Anklageschrift übernommen“ werde, beweise, mit welcher Sorgfalt die Polizei das Beweismaterial zusammenstelle; durch die Erfüllung der beiden Forderungen könne die Beweisführung so erschöpfend vorbereitet werden, ,daß nach Überstellung des Täters an die Justiz entsprechend dem Willen des Führers das Urteil und die Vollstreckung ohne weiteren Verzug erfolgen können". ${ }^{\text {so }}$ Theoretisch untermauert wurde das Ziel der UUbernahme der Staatsanwaltschaft durch Best, der in einer Veröffentlichung 1940 die Meinung vertrat, daß die Bestimmung der StPO, die den Polizeibeamten zum abhängigen „Hilfsbeamten“ der Staatsanwaltschaft machte, völlig veraltet sei: unterdessen seien umfangreiche, mit allen Mitteln kriminalistischer Technik und einheitlich ausgebildeten Beamten ausgestattete Polizeibehörden geschaffen worden, die den Staatsanwaltschaften in der Verbrechensverfolgung weit überlegen seien. Daraus zog Best den Schluß:

„Die Umkehrung des früheren Verhältnisses zwischen der Polizei und der Staatsanwaltschaft ist bereits so weit gediehen, daß mit guten Gründen die Frage ernsthaft erwogen wird, ob nicht die Polizei, deren Kriminalbehörden bereits die Verbrechensverfolgung bis zu dem Augenblick, in dem die Anklage formuliert werden kann, durchführen, auch noch die Erhebung und Vertretung der Anklage übernehmen soll." 51

Diese Forderung Himmlers wurde zwar selbst von eingefleischten NS-Juristen wie Freisler und dem Reichsjustizminister Thierack „rundweg“ abgelehnt ${ }^{52}$; die Ablehnung änderte aber nichts an der Tatsache, daß die Polizeiführung die Angehörigen ihrer Organisation nicht mehr als Hilfsbeamte der Staatsanwaltschaft angesehen wissen wollte und die Befugnisse bei der Ermittlungstätigkeit nicht mehr aus dieser Eigenschaft ${ }^{53}$, sondern als eigenständige Befugnisse aus dem institutionellen Gesamtauftrag der Polizei herleitete. ${ }^{54}$ Als Konsequenz erklärte der stellvertretende Leiter der Kriminalpolizeistelle Magdeburg dem dortigen Oberstaatsanwalt offen, „daß er die Staatsanwaltschaft in ihrer jetzigen Form nicht mehr für zeitgemäß halte und daß nach dem gegenwärtigen Rechtszustand eine weitgehende Ausschaltung der Staatsanwaltschaft durch die Polizei zulässig [!] sei“". 55

Unter den Verhältnissen des Krieges brach die von der politischen Führung unterstützte Haltung der Polizei gegenüber der Justiz offen durch. Sie war jedoch bei der Polizei als einem der wichtigsten Herrschaftsinstrumente des Regimes schon seit 1933 verdeckt vorhanden gewesen und bewirkte, daß die Justiz ihren Anspruch zur alleinigen Verfolgung von Straftaten in der Praxis nicht durchzusetzen vermochte. Sie konnte nie erreichen, daß die Gestapo alle ermittelten Straftaten an sie abgab, und nie

so Schr. Heydrichs an Lammers v. 4. 1.39 (Akten der RK, BA, Sign. R 43 II/1553 a).

31 W. Best, Die Deutsche Polizei, Darmstadt 1940, S. 27 f.

52 Aufz. Thieracks über eine Bespr. mit Himmler am 18.9.42 (Nümbg. Dok. PS-654). Zu Bests Vorschlägen hatte Freisler bereits auf einer Arbeitstagung der OLGPräs. und GStAe am 23./24.4.41 in Berlin (vgl. Freislers Manuskript in den Akten des RJM, BA, Sign. R 22/246) erklärt: „Wir sind wieder wachsam! Meine Herren, da wird nichts draus."

53 Vgl. noch $\S 12$ der AusfVO zum GestapoG v. 10.2.36 (Preuß. GS, S. 22): Soweit Gestapobeamte die der Polizei „nach den Bestimmungen der Strafprozeßordnung obliegenden Aufgaben übernehmen, handeln sie als Hilfsbeamte des Oberreichsanwalts oder des örtlich zuständigen Oberstaatsanwalts“.

54 Vgl. RdErl. des RFSSuChdDtPol im RMdI v. 28. 10.42 (MBliV 1942, S. 2087): „Kraft der ihr gestellten Aufgabe, die deutsche Volksordnung zu sichern, ist die Pol. verpflichtet und befugt alle die Maßnahmen zu treffen, die zur Erfüllung ihrer Aufgaben erforderlich sind. Aus dieser Ermächtigung ergibt sich, daß die Bestellung von Angehörigen der Pol. zu Hilfsbeamten der Staatsanwaltschaft überflüssig ist, da sie ... alle die Maßnahmen treffen können, zu denen die Reichsstrafprozeßordnung ... ermächtigt."

s5 Ber. des GStA Naumburg an das RJM v. 12.6.44 (Akten des RJM, BA, Sign. R 22/1462). 
verhindern, daß Beschuldigte statt in gerichtliche Untersuchungshaft in Schutzhaft genommen wurden.

\section{b. Schutzhaft nach gerichtlichem Freispruch}

Als besonders mißlich mußten es die Gerichte empfinden, wenn Angeklagte, die freigesprochen wurden, oder Verurteilte, bei denen die erkannte Strafe durch die erlittene Untersuchungshaft als verbüßt erklärt wurde, unmittelbar nach der Urteilsverkündung im Gerichtsgebäude in Schutzhaft genommen wurden. ${ }^{56}$ Dem Richter mußte seine Arbeit sinnlos erscheinen, wenn sein nach eingehender Verhandlung und sorgfältiger Abwägung gefälltes Urteil auf diese Weise ignoriert wurde. In ihren Berichten über derartige Vorfälle gaben die Gerichtsvorsitzenden ihrem Unwillen gegen diese Maßnahmen, die sie als Kritik der Gestapo an ihrer Rechtsprechung ansahen, offen Ausdruck. Der Oberlandesgerichtspräsident von Braunschweig, in dessen Bezirk ein sogar auf Antrag des Generalstaatsanwalts vom Strafsenat Freigesprochener verhaftet worden war, äußerte im Oktober 1935 dem Justizministerium gegenüber die nicht unberechtigte Meinung, „daß in den meisten Fällen der Schade, den das Ansehen des Gerichts erleidet, denjenigen, den ein freigesprochener Angeklagter - zumal bei den sonstigen Überwachungsmöglichkeiten - ausrichten könnte, bei weitem überwiegt“'. Deshalb sollten solche Schritte der Gestapo möglichst unterbleiben. ${ }^{57}$ Sosehr das Ministerium diese Maßnahmen der Gestapo als Korrektur richterlicher Urteile und grundsätzlichen Eingriff in den Tätigkeitsbereich der Justiz empfand, konnte es gegen eine als staatspolizeiliche Präventivmaßnahme deklarierte Schutzhaft nichts unternehmen, da die Justiz zur Nachprüfung der Schutzhaftgründe nicht befugt war. Um diese Ohnmacht nicht unnötig vor den nachgeordneten Justizbehörden zu offenbaren, entschied Staatssekretär Freisler, das vom Oberlandesgerichtspräsidenten aufgeworfene Problem auf der Ende November 1935 stattfindenden Tagung der Generalstaatsanwälte und Oberstaatsanwälte im Reichsjustizministerium nicht allgemein zu erörtern. Die Angelegenheit wurde vielmehr mit dem Vertreter des Generalstaatsanwalts Braunschweig gesondert besprochen und der Oberlandesgerichtspräsident aufgefordert, zukünftig besonders krasse Fälle mit Einzelheiten zu berichten, um im Ministerium Material zu sammeln. ${ }^{58}$

Die erwähnten Verhaftungen nahmen zu, als die Gestapo im Jahre 1937 der Internationalen Bibelforscher-Vereinigung verstärkt den Kampf ansagte. So berichtete z. B. der Oberlandesgerichtspräsident Frankfurt a. M. über die jeweils unmittelbar nach der Urteilsverkündung erfolgte Festnahme von 62 Bibelforschern, bei denen vom dortigen Sondergericht die Gefängnisstrafen von zwei bis sieben Monaten durch Schutz- und Untersuchungshaft als verbüßt erklärt worden waren. Der Vorsitzende des Sondergerichts erklärte hierzu, das Gericht erblicke

36 Fälle aus den Jahren 1933-36 finden sich z.B. in den Akten der Bayer.StKanzlei (BayerHStArch., Sign. MA 106 301), über die die Ber. der BPP liefen, die der RuPrMdI nach Eingang von Schutzhaftbeschwerden anforderte. Ein bekannter Fall war der Pfarrer Niemöllers, dessen Freiheitsstrafe laut Urt. des SG II Berlin v. 2.3.38 durch die U-Haft als verbüßt galt, der aber nach Aufhebung des Haftbefehls ins KZ Sachsenhausen überführt wurde.

37 Schr. des OLGPräs. Braunschweig an das RJM v. 23.10.35 (Akten des RJM, BA, Sign. R 22/1467).

58 Verm. v. 2.12.35 (a.a.O.). 
„in diesem Vorgehen eine Schädigung des Ansehens der Justiz und eine Erschütterung des Vertrauens in die Rechtspflege. Es wird dadurch der Anschein der Korrektur eines unmittelbar vorangegangenen Richterspruches erweckt. Insbesondere wird durch dieses Verfahren die nach sorgfältiger Beratung erfolgte Abwägung und Abstufung des Strafmaßes zunichte gemacht. ${ }^{459}$

Auch als sich das Sondergericht Hamburg in einem Bibelforscherfall, bei dem die achtmonatige Gefängnisstrafe ebenfalls durch Schutz- und Untersuchungshaft als verbüßt erklärt wurde, ausdrücklich für die sofortige Freilassung des Verurteilten aussprach, damit er „so dem Gericht sein als glaubwürdig erscheinendes Bekenntnis zum Nationalsozialismus durch die Tat" erhärten könne, verzichtete die Gestapo nicht auf die Verhaftung. ${ }^{60}$

Die Gestapo schreckte mit ihrer Praxis selbst vor dem höchsten deutschen Strafgericht nicht zurück. Als der Volksgerichtshof am 3. März 1937 eine wegen Vorbereitung zum Hochverrat angeklagte Frau mangels Beweisen freisprach, spielte sich folgende Szene ab:

„Als sich nunmehr nach der Urteilsverkündigung [sic] durch den Vorsitzenden des 2. Senats des Volksgerichtshofes zwei vom Geheimen Staatspolizeiamt zur Gerichtsverhandlung entsandte Beamte zu dem Anklagevertreter begaben, um sich von ihm das Urteil bestätigen zu lassen, wurden sie von einem der Beisitzer angesprochen, der ihnen erklärte, nun Frau M. nicht etwa in Schutzhaft zu nehmen. Als die Beamten erklärten, daß die Inschutzhaftnahme der Frau M. beabsichtigt sei, begab sich der Beisitzer in das Beratungszimmer. Kurze Zeit später wurden die Beamten gleichfalls dorthin gerufen, wo ihnen der Vorsitzende eröffnete, daß es nicht angängig sei, Personen in Schutzhaft zu nehmen, die von dem Gericht freigesprochen wurden. Der Vorsitzende äußerte weiter, daß der Volksgerichtshof vom Führer und Reichskanzler eingesetzt und demnach als höchstes Gericht des Deutschen Reiches völlig souverän [!] sei. Er müsse es als einen unhaltbaren Zustand betrachten, wenn nach der Urteilsverkündung freigesprochene Personen in Schutzhaft genommen würden. Eine derartige Maßnahme sei als Kritik einer Verwaltungsbehörde an dem gerichtlichen Urteil zu bewerten. “61

Daraufhin sahen die beiden Beamten zwar von der sofortigen Festnahme der Frau ab, sie wurde jedoch zwei Tage später zu Hause verhaftet. Das Geheime Staatspolizeiamt begründete das Vorgehen gegenüber dem Reichsjustizministerium damit, daß die Frau eine marxistisch geschulte SPD-Anhängerin sei, von der mit Bestimmtheit eine erneute staatsfeindliche Betätigung erwartet werden könne. Da es sich bei der Verhängung von Schutzhaft „stets um eine vorbeugende Maßnahme zur Gewährleistung der öffentlichen Ordnung und Sicherheit" handele, könne die Gestapo darin keinen Eingriff in die Zuständigkeit eines Gerichts und schon gar nicht eine Kritik gegen das gefällte Urteil erblicken. Das Geheime Staatspolizeiamt bat, „zur Vermeidung derartiger Zwischenfälle ... die in Frage kommenden Gerichtsbehörden entsprechend zu verständigen" ${ }^{62}$ Da die Gestapo den Fall auf das Gleis der staatspolizeilichen Präventivmaßnahmen geschoben hatte, blieb dem Justizministerium nichts anderes übrig, als dem Präsidenten des Volksgerichtshofs die Ansicht der Gestapoführung über den Vorfall mitzuteilen und zuzugeben, daß in solchen Ausnahmefällen auch Schutzhaft "gegen solche Staatsfeinde geboten sein kann, die in einem gerichtlichen

s9 Ber. des SG-Vors. v. 10.5.37, zit. im Ber. des OLGPräs. Frankfurt a. M. an das RJM v. 21. 5.37 (a.a.O.).

60 Urt. aus dem Jahre 1937, Az. 11 Js Sond. 646/37; Unterlagen des OLGPräs. Hamburg für die Bespr. im RJM am 24.1.39 (Forschungsstelle f. d. Gesch. des NS in Hamburg, Sign. Best 3305). Dort heißt es: „Was unter diesen Umständen eine Strafzumessung und ihre Begründung für einen Sinn haben soll, ist unklar.“

61 Ber. des Gestapa an das RJM v. 9.3.37 (Akten des RJM, BA, Sign. R 22/1467).

62 a.a.O. 
Verfahren mangels Beweises freigesprochen" wurden. ${ }^{63}$ Diese auch dem Geheimen Staatspolizeiamt übermittelte Äußerung des Justizministeriums wurde von der Gestapoführung sofort ausgenutzt und ,wegen der grundsätzlichen Bedeutung“ allen Gestapostellen übermittelt. ${ }^{64}$ Das geschah offenbar mit der Absicht, den Gestapobeamten durch die Aushändigung einer Art von der Justiz anerkannten „Freibriefs“ die Durchführung des Runderlasses vom 22. April 1937 zu erleichtern, mit dem die Gestapoführung befohlen hatte, grundsätzlich alle Bibelforscher nach Freispruch oder Strafverbüßung in Schutzhaft zu nehmen. Den Wortlaut dieses Gestapo-Erlasses erhielt das Justizministerium erst Anfang Juni durch den Generalstaatsanwalt Stettin, der ihn anläßlich eines konkreten Verhaftungsfalles von der dortigen Staatspolizeileitstelle angefordert und auch erhalten hatte. ${ }^{65}$ Auf einer Besprechung mit den Oberlandesgerichtspräsidenten und Generalstaatsanwälten am 18.Juni 1937 in Berlin wurde der Erlaß vom Leiter der Strafrechtspflegeabteilung Ministerialdirektor Crohne mit der Bitte um Vertraulichkeit verlesen. Crohne führte dazu aus:

„Wir haben uns sofort mit der Gestapo in Verbindung gesetzt und sind zu folgendem Ergebnis gekommen: Wir können, nachdem die allgemeine Anordnung nun einmal besteht, hiergegen nichts unternehmen, ... da es sich bei den in der genannten Anordnung behandelten Maßnahmen lediglich um solche polizeilicher Art handelt.“

Das Ministerium hatte bei der Gestapoführung lediglich erreichen können, daß die Wiederverhaftung künftig nicht unter Begleitumständen geschehen sollte, die dem Ansehen der Justiz abträglich waren, d.h. nicht unmittelbar im Gerichtssaal vorgenommen werden sollte. Crohne ermahnte die Besprechungsteilnehmer, bei Verstößen gegen diese Abmachung sofort vorstellig zu werden.$^{66}$ Obwohl das Geheime Staatspolizeiamt seine Dienststellen entsprechend anwies ${ }^{67}$, hielten sie sich nicht immer an die Abmachung: so berichtete z. B. der Oberlandesgerichtspräsident Darmstadt auf der Berliner Tagung im Januar 1939 abermals von einer Inschutzhaftnahme nach Freispruch im Sitzungssaal. Gürtner forderte die versammelten Chefpräsidenten erneut auf, durch Kontakt mit den regionalen Gestapostellen dafür zu sorgen, daß derartige Fälle vermieden würden. ${ }^{68}$

Hatte sich die Justizleitung mit der Verhaftung von Personen abfinden müssen, die mangels Beweises freigesprochen worden waren, so erhob sie doch entschieden Einspruch, als ein am 9. Dezember 1938 vom Volksgerichtshof wegen erwiesener Unschuld Freigesprochener am nächsten Tag in Schutzhaft überführt wurde, obwohl gegen ihn keinerlei Verdachtsgrund bestehengeblieben war. Die Verhaftung stellte sich heraus,

63 Schr. des RJM an den VGHPräs v. 21.4.37 (a.a.O.).

${ }^{64}$ Schr. des RJM an das Gestapa, abgeg. am 26.4.37 (a.a.O.), u. RdErl. des Gestapa v. 8.5.37 „zur Weitergabe an die Kreis- u. Ortspolizeibehörden nicht geeignet“ (Akten des RSHA, BA, Sign. R 58/264, Bl. 279).

65 Schr. des GStA Stettin an das RJM v. 4.6.37 (Akten des RJM, BA, Sign. R 22/1467).

66 Prot. der Bespr. mit den OLGPräs. und GStAen im RJM am 18.6.37, Vormittag (Akten des RJM, BA, Sign. R 22/4277).

${ }^{67}$ Vgl. RdErl. des Gestapa v. 5.8.37 an alle Stapostellen, Ober- u. RegPräs. in Preußen u. die MdI der anderen Länder (StArch. Düsseldorf, Sign. Best RW 18).

68 Bespr. mit den OLGPräs. am 24.1.39 (Akten des RJM, BA, Sign. R 22/1467). Als 1942 unter Thierack die Komplizenschaft mit der Gestapoführung enger wurde, vereinbarte dieser mit Himmler, daß zur Vermeidung spektakulärer Peinlichkeiten der der Verhandl. beiwohnende Pol.Beamte beauftragt wurde, „den Richter in unauffälliger Form auf eine beabsichtigte Inhaftnahme hinzuweisen, so daß der Richter auf die sofortige Aussprache der Haftentlassung verzichten“ könne. Vorläufige Niederschr. der Bespr. zwischen RFSS und Thierack am 18.9.42 (a.a.O., Sign. R 22/5029). 
als ihm die Gewährung einer Entschädigung für unschuldig erlittene Haft mitgeteilt werden sollte. Der Vorsitzende und sämtliche Mitglieder des erkennenden Senats fanden die Schutzhaft in diesem Fall „unerträglich“; sie sei nur dann zu rechtfertigen, wenn der Gestapo neues Belastungsmaterial bekannt geworden sei, das das Gericht nicht gekannt habe. Sie baten den Präsidenten des Gerichtshofs Thierack, über das Justizministerium eine grundsätzliche Klärung dieser Frage mit der Gestapo zu erreichen. Da Schutzhaft häufig ohne Wissen der obersten Gestapoführung erfolge ${ }^{69}$, könne sich die groteske Lage ergeben, daß untergeordnete Organe der Polizei das Urteil des höchsten deutschen Strafgerichts auf ihre Weise korrigierten. ${ }^{70}$ Auch das Ministerium stellte sich der Gestapoführung gegenüber auf den Standpunkt, daß im Falle einer Freisprechung wegen erwiesener Unschuld keine erneute Schutzhaft verhängt werden dürfe, es sei denn, daß sie durch völlig neue Gründe gerechtfertigt werden könne. $^{71} \mathrm{Wie}$ der zuständige Referent vermerkte, bestand zu diesem Zeitpunkt sogar bereits eine entsprechende Vereinbarung mit der Gestapo, die „vom Herrn Minister und dem Reichsführer-SS gebilligt worden" war. ${ }^{72}$ Die Gestapoführung antwortete, daß im vorliegenden Fall die Rückübernahme des Angeklagten bereits bei seiner Überstellung an den Ermittlungsrichter im April 1938 beantragt worden und ohne neuen Antrag erfolgt sei; allerdings habe es der Oberreichsanwalt unterlassen, dabei auf den Freispruch wegen erwiesener Unschuld besonders hinzuweisen. Überdies habe das Geheime Staatspolizeiamt nach zwei Wochen, als ihm das freisprechende Urteil bekannt geworden sei, trotz Bedenken die Freilassung des Gefangenen verfügt. ${ }^{73} \mathrm{Da}$ offenbar ein Versäumnis des Oberreichsanwalts vorgelegen hatte und das Urteil von der Gestapo letztlich respektiert worden war, gab sich das Justizministerium damit zufrieden. Es wies aber den Oberreichsanwalt an, künftig in solchen Fällen vor der Erfüllung bestehender Rückführungsersuchen ausdrücklich auf den Freispruch wegen erwiesener Unschuld hinzuweisen und gleichzeitig anzufragen, ob sich die Rücküberstellung dadurch erledigt habe. ${ }^{74}$ Tatsächlich sind dem Ministerium daraufhin Schutzhaftfälle nach gerichtlich erwiesener Unschuld nicht mehr bekannt geworden. ${ }^{75}$

Im Juli 1940 schlug Oberreichsanwalt Lautz im Einvernehmen mit Präsident Thierack vor, grundsätzlich alle durch den Volksgerichtshof von einer Anklage wegen staatsfeindlicher Tätigkeit Freigesprochenen - auch diejenigen, um deren Rückführung die Gestapo nicht ersucht hatte - der Gestapo zur weiteren Entscheidung zu überstellen, soweit diese nicht schon vorher ausdrücklich auf die Rückführung verzichtet habe. Bei Freisprechung wegen erwiesener Unschuld wolle er wie bisher vor der Überstellung anfragen, ob sie sich damit erübrige, bei Freisprechung aus sonstigen Gründen die Gestapo jedoch bei der Überstellung lediglich von den Gründen unterrichten. Sollte er eine anschließend verhängte Schutzhaft für unbegründet halten,

69 Nach den Schutzhaftbestimmungen v. 25.1.38 konnte eine vorläufige Festnahme ohne Beteiligung des Gestapa allerdings nur bis zu einer Dauer von 10 Tagen erfolgen (vgl. Kapitel VI.2.a., S. 561 f.).

70 Zit im Schr. Thieracks an das RJM v. 21.1.39 (a.a.O., Sign. R 22/1467).

71 Schr. des RJM an den RFSSuChdDtPol v. 30.1 .39 (a.a.O.).

72 Der Verm. v. 23.1.39 (a.a.O.) fährt fort: „Wenn sofort uns Mitteilung gemacht worden wäre, hätte die sofortige Wiederfreilassung alsbald erwirkt werden können.“

73 Schr. des RFSSuChdDtPol an das RJM v. 21.2.39 (a.a.O.).

74 Schr. des RJM an den OReiA beim VGH v. 31.3.39 (a.a.O.).

75 Verm. Crohnes für Sts Rothenberger v. 10.9.42 (a.a.O., Sign. R 22/5029). 
werde er von der Gestapo nach der Überstellung Informationen einholen und an das Ministerium berichten. ${ }^{76}$ Dieser Vorschlag ging jedoch dem Ministerium zu weit. Da das Überstellungsverfahren bei Aufhebung gerichtlicher Haft in politischen Strafsachen von den Generalstaatsanwälten regional unterschiedlich gehandhabt wurde - teils erfolgte die Überstellung in jedem Fall, teils nur nach ausdrücklichem Ersuchen der Gestapo, teils nur dann, wenn ein Verdacht staatsfeindlicher Betätigung zurückblieb -, wollte das Ministerium eine generelle Regelung der Materie vermeiden, um der Gestapo nicht unnötig ein Maximum an Entgegenkommen einräumen zu müssen. Der Oberreichsanwalt wurde daher mündlich vom Standpunkt des Ministeriums unterrichtet und angewiesen, wegen erwiesener Unschuld Freigesprochene auf jeden Fall von einer automatischen Überstellung auszunehmen. ${ }^{77}$

Grundsätzlich mußte also die Justiz auch die Korrektur ihrer freisprechenden Urteile durch Schutzhaft hinnehmen, es sei denn, daß sie wegen erwiesener Unschuld des Angeklagten erfolgten. Aber auch diese Ausnahmeregelung konnte die Gestapo umgehen, indem sie die erneute Verhaftung mit neuen, für die Justiz unkontrollierbaren Gründen motivierte: „souverän“ war keineswegs die Justiz und ihr höchster Gerichtshof, sondern die Gestapo.

\section{c. Anrechnung der Schutzhaft auf die Freibeitsstrafe}

Da die Schutzhaft von der Gestapo auch bei der Strafverfolgung angeordnet wurde, ergab sich für die Justiz die Frage, ob die in Schutzhaft verbrachte Zeit wie eine Untersuchungshaft gemäß $\S 60 \mathrm{StGB}$ auf die gerichtlich erkannte Strafe angerechnet werden müsse. Anfangs lehnten die Gerichte eine Anrechnung mit der Begründung ab, daß eine Freiheitsentziehung zum Schutze der eigenen Person oder wegen staatsgefährdender Betätigung - die nach den Bestimmungen Fricks vom April 1934 formell die einzigen Schutzhaftgründe darstellten - „nach ihrem Wesen und Zwecke nicht als Untersuchungshaft“ angesehen werden könne; ihre Anrechnung müsse „durch eine ausdrückliche gesetzliche Vorschr. zugelassen“ werden. ${ }^{78}$ Auf eine gesetzliche Regelung des Problems bestanden jedoch nicht die geringsten Aussichten: sie hätte das Eingeständnis der Gestapo bedeutet, daß sie die Schutzhaft gegen Strafverdächtige einsetzte. Während das preußische Justizministerium gegen eine Anrechnung der Schutzhaft als Untersuchungshaft aus Billigkeitsgründen keine Bedenken hatte, wurde sie von der Gestapo abgelehnt, da sie die Vorstellung von einer Gleichstellung beider Haftarten aufkommen lasse. Gerade die bisherige scharfe Trennung müsse ,analog der Trennung zwischen Justiz und Verwaltung im Allgemeinen ... unter allen Umständen, insbesondere im Interesse des Justizwesens [?] gewahrt bleiben" 79

Als jedoch immer deutlicher wurde, daß die Gestapo die Schutzhaft zur Strafverfolgung anwandte, setzte sich bei den Gerichten die Praxis durch, die Schutzhaft auf die

76 Schr. des OReiA an das RJM v. 29.7.40 (a.a.O., Sign. R 22/1467).

7 Vgl. Aktenvermerke v. August-November 1940 (a.a.O.). Der GStA beim KG z.B. überstellte alle wegen Hochverrats Angeklagten nach Aufhebung des Haftbefehls, nahm jedoch wegen erwiesener Unschuld Freigesprochene gleichfalls davon aus.

78 Urt. des Bayer. Obersten LandesG v. 30.4.34 (JW 1934, S. 2167).

$79 \mathrm{Vgl}$. Schr. des Gestapa an den preußJM v. 22.8.34 u. Schr. Freislers an den preußMinPräs/Chef der Gestapo v. 23.5.34 (GehStArch. Berlin, Sign. Rep. 84 a/7953). 
Strafe dann anzurechnen, wenn sie zur Sicherung der Strafverfolgung oder zur Untersuchung der Straftat angeordnet worden war. Laut einer Entscheidung des Oberlandesgerichts Kassel vom Oktober 1934 war unter dem Begriff der Untersuchungshaft nicht nur die vom Richter verhängte Haft nach $\S 112 \mathrm{ff}$. StPO zu verstehen, „sondern jede Freiheitsentziehung durch eine Amtsperson zur Sicherung der Strafverfolgung“, also auch eine nach $\S 127$ StPO verhängte Polizeihaft, selbst wenn die Polizei den Festgenommenen nicht dem Richter nach $\S 128$ StPO vorführte. Die Bezeichnung der Haft durch die Polizei sei dabei nicht maßgebend. Nur eine „Verwahrung aus rein polizeilichem Interesse, z. B. lediglich im Interesse der allgemeinen Staatssicherheit“, könne nicht angerechnet werden. Die Gerichte müßten daher im Einzelfall prüfen, ob die Festhaltung zugleich den Ermittlungen und der Vorbereitung eines Strafverfahrens wegen einer bestimmten Straftat diene. Im Zweifelsfalle sei nach dem Grundsatz in dubio pro reo zugunsten des Verurteilten zu entscheiden. ${ }^{80}$ Der Strafrechtsreferent im Reichs- und Preußischen Justizministerium, Ministerialrat Rietzsch, kommentierte die veröffentlichte Entscheidung mit dem Wunsch, „daß diese billigenswerte Auffassung sich in der Praxis durchsetzen möchte“. Seiner Ermutigung wurde entsprochen: sowohl der Volksgerichtshof wie das Reichsgericht schlossen sich dieser Auffassung an. ${ }^{81}$

Erleichtert wurde den Gerichten die Entscheidung dadurch, daß der Schutzhaftbefehl, den Fricks Bestimmungen vom April 1934 generell vorschrieben, zumindest die Gründe der Verhängung angeben mußte. Einige der - nach Ländern verschiedenen Schutzhaftformulare enthielten auch Angaben, wann die Betreffenden festgenommen und ob Ermittlungen wegen einer Straftat eingeleitet wurden ${ }^{82}$ In Hamburg bat der Vorsitzende des Strafsenats im dortigen Oberlandesgericht den Generalstaatsanwalt, an die Staatspolizei mit der Bitte heranzutreten, daß der Grund für die Verhaftung ausführlich aktenkundig gemacht würde. ${ }^{83}$ Der Leiter der Staatspolizei Hamburg, SS-Standartenführer Streckenbach, sicherte zwar die Aufnahme entsprechender Vermerke in die Schutzhaftbefehle zu, äußerte sich jedoch als "grundsätzlicher Gegner“ zu der Anrechnungspraxis des Strafsenats, die er „bereits seit einiger Zeit“ beobachte. „Rein rechtlich gesehen“ sei gegen die Anrechnung zwar nichts einzuwenden, sie dürfe jedoch nicht generell, sondern nur in besonderen Einzelfällen angewendet werden. Er sei der Meinung,

„daß rein rechtspolitisch gesehen eine Anrechnung gegenüber Hochverrätern nicht in Betracht kommen kann, sondern daß die gegen sie erkannten Strafen vollen Umfanges zu vollstrecken sind ... Kommunistische Funktionäre, die eben durchweg unverbesserlich und unbelehrbar sind, müssen solange wie möglich festgehalten werden“.

${ }^{80}$ Entsch. des OLG Kassel v. 7.10.34 (DJ 1934, S. 1647); im Ergebnis ebenso die dort erwähnten Erkenntnisse des KG und des OLG Hamm.

${ }^{81}$ Urt. des VGH v. 17. 10.34 (DJ 1935, S. 300) u. Entsch. des RG v. 30.9.35 (a.a.O., S. 1635).

82 Vgl. z. B. das durch die RdEntschl. des bayerStMdI v. 2.5.34 vorgeschr. Formular (Arch. des IfZ, Sign. Fa $183 / 1, \mathrm{Bl} .322 \mathrm{f}$.).

${ }^{83}$ Schr. des Senatspräs. Roth an den GStA Hamburg v. 31.1.35 (Forschungsstelle f. d. Gesch. des NS in Hamburg, Sign. Best 3305). Der Vorschlag ging auf ein Rechtsgutsachten des OLG-Rats Hansen v. 19.1.35 zurück, das die Möglichkeit der Anrechnung bejahte. Zum Problem der Anrechnung der Schutzhaft in Hamburg s. W. Johe, Die gleichgeschaltete Justiz. Organisation des Rechtswesens und Politisierung der Rechtsprechung 1933-1945 dargestellt am Beispiel des Oberlandesgerichtsbezirks Hamburg, Frankfurt a.M. 1967, S. $137 \mathrm{f}$ 
In einem Fall sei ein Verurteilter vom Strafsenat „als ein an Gefährlichkeit nicht zu überbietender Kommunist geschildert und dann die Schutzhaft als Milderungsgrund anerkannt" worden. Streckenbach forderte den Generalstaatsanwalt auf, darauf hinzuwirken, daß eine Anrechnung bei Kommunisten grundsätzlich nicht mehr erfolgen solle. $^{84}$

Den besonderen Unwillen der Gestapoführung mußten diejenigen Fälle erregen, bei denen gerichtliche Freiheitsstrafen durch eine längere vorausgegangene Schutzhaft als verbüßt angesehen und der Verurteilte vom Gericht aus auf freien Fuß gesetzt wurde. Im April 1935 forderte Heydrich daher das Reichsjustizministerium auf, die Anrechnung der erlittenen Schutzhaft auf die Strafe durch die Gerichte generell zu unterbinden. Das Ministerium antwortete, daß es "die neuere Praxis der Gerichte“ nicht zu beanstanden vermöge, wenn die Schutzhaft wegen der abgeurteilten Tat verhängt worden sei, da sie in diesen Fällen ,ausschließlich oder mindestens zugleich den Zwecken der Strafverfolgung gedient" habe. Da die Gestapo die Beschuldigten teilweise in Schutzhaft behalte, statt sie in Untersuchungshaft zu überführen, sei die Forderung der Gestapoführung mit dem Grundsatz einer gleichmäßigen Behandlung aller Rechtsbrecher nicht zu vereinbaren:

„Wenn z. B. ein Teil der Täter, deren Vergehen bereits einwandfrei geklärt ist, in gerichtliche Untersuchungshaft verbracht, ein anderer Teil der Beteiligten aber in Schutzhaft verbleibt, so würde die Anwendung der dort vertretenen Auffassung das Ergebnis haben, daß die Gruppe der Mittäter, die in Schutzhaft überführt sind, wegen der vielleicht ganz gleichen strafbaren Betätigung praktisch eine längere Freiheitsentziehung auf sich nehmen müßte, als diejenigen Mittäter, die sogleich in gerichtliche Untersuchungshaft überführt worden sind. Diese Folge würde aber dem gesunden Rechtsempfinden zuwiderlaufen."

Die Praxis der Gerichte zu ändern habe der Justizminister um so weniger Anlaß, als sogar

„der Führer und Reichskanzler, wie ich bei der Vorlage zahlreicher Gnadengesuche an ihn festgestellt habe, ausnahmslos, in Einzelfällen sogar gegen meinen ablehnenden Vorschlag Gnadenerweise in Höhe der nicht angerechneten Schutzhaft an solche Verurteilte erteilt hat, die wegen der zur Aburteilung gelangten Tat oder in gewissem Zusammenhang mit ihr in Schutzhaft eingesessen haben" 85

Eine grundsätzliche Äußerung Hitlers wurde schließlich am 7.Juni 1935 vom Chef der Präsidialkanzlei, Staatssekretär Meissner, als Erlaß formuliert,

„daß in der Regel die Schutzhaft auf die Strafzeit angerechnet werden soll, es sei denn, daß es sich um führende kommunistische Funktionäre handelt, bei denen die Schutzhaft als allgemeine Abwehrmaßnahme selbständig und ohne Zusammenhang mit einer einzelnen Straftat verfügt worden ist" ${ }^{\mathbf{8 5 a}}$

Das Reichsjustizministerium gab diese Entscheidung zehn Tage später den Generalstaatsanwälten bekannt und ersuchte sie, dafür zu sorgen, daß die unterstellten Staatsanwaltschaften diese Gesichtspunkte bei Strafanträgen und Stellungnahmen zu Gnadengesuchen berücksichtigten. ${ }^{86}$

84 Schr. Streckenbachs an den GStA Hamburg v. 28.2.35 (a.a.O., Sign. Best 3305).

85 Antw.Schr. des RJM (I.A. Crohne) an den Stellv. Chef u. Inspekteur der Gestapo v. 14.5.35 auf dessen Schr. v. 24.4.35 (StArch. Düsseldorf, Gestapa-Erlasse, Sign. Best. RW 18, Nr. 2).

${ }^{85 a}$ Erl. v. 7.6.35 - RP 2695/35 - (Akten des RJM, BA, Sign. R 22/931).

86 RV des RJM an die GStAe v. 17.6.35 (a.a.O., Sign. R 22/847). Der Grundsatz, daß das Gericht über die Anrechnung der Schutzhaft entscheidet, wurde auch als $\S 23$ Abs. 2 in die Strafvollstreckungsordnung v. 7.12.35 (AV des RJM, DJ 1935, S. 1800) aufgenommen. 
Unterdessen instruierte Heydrich am 15.Juli - offenbar noch in Unkenntnis von Hitlers Erlaß - als Reaktion auf die Äußerung des Justizministeriums alle Staatspolizeistellen, daß es trotz der rechtlichen Würdigung des Problems durch die Justizleitung „unbedingt erforderlich“ sei, „die staatspolizeilichen Interessen gegenüber den politischen Delikten auch weiterhin durch die der politischen Polizei zur Verfügung stehenden Mittel“ zu wahren: erforderlichenfalls sei „daher von der Verhängung der Schutzhaft gegen zur Entlassung kommende Strafgefangene [!] Gebrauch zu machen“. Seine weiteren Ausführungen stellten ein Grundsatzprogramm der Gestapo für die Korrektur der Rechtsprechung dar:

„Die strafrechtliche Erledigung einer politischen Straftat bedeutet daher durchaus nicht, daß nunmehr Maßnahmen der politischen Polizei nicht mehr erforderlich seien. Es ist vielmehr nach wie vor darauf zu achten, daß auch strafrechtlich abgeurteilte Personen nicht mehr die Möglichkeit haben, ihr politisches Treiben gegen den nationalsozialistischen Staat erneut aufzunehmen."87

Von Hitlers Erlaß gab die Gestapoführung ihren nachgeordneten Dienststellen erst am 1. September 1935 Kenntnis. ${ }^{88}$ Er änderte nichts an der Befugnis der Gestapo, auch in diesem Punkte die Tätigkeit der Justiz zu korrigieren.

Die Gestapo konnte diese Korrektur in der Form durchführen, daß sie den Verurteilten nach Verbüßung der Strafhaft erneut in Schutzhaft nahm. Dieses Verfahren wird in einem späteren Abschnitt behandelt werden. Sie konnte den Verurteilten aber auch nach Eintritt der Rechtskraft des Urteils weiter in Schutzhaft behalten, statt sie zu beenden oder zum Zwecke der Strafvollstreckung zu unterbrechen ${ }^{89}$, um ihn in die Strafhaft der Justiz zu überführen. Um diesen „unerwünschten, den Interessen einer geordneten Strafrechtspflege abträglichen Verzögerungen "90 zu entgegnen, gingen die Gerichte dazu über, nicht nur die bis zum Erlaß des Urteils bereits erlittene Schutzhaft, sondern darüber hinaus auch eine $z u$ erwartende Schutzhaft bis zu einer gewissen Höchstdauer auf die Strafe anzurechnen.

Anfänglich schien dieses Verfahren selbst der Staatsanwaltschaft bedenklich. Als das Schöffengericht beim Amtsgericht München am 3. September 1935 ein solches Urteil fällte, führte der Staatsanwalt über die Berechnung der Strafe eine gerichtliche Entscheidung gemäß $\S 458$ StPO herbei. Das Amtsgericht München (Strafgericht) verwarf jedoch den Antrag der Staatsanwaltschaft, als Strafbeginn erst den Zeitpunkt der Unterbrechung der Schutzhaft zu bestimmen, und setzte den Beginn der Strafzeit wiederum auf den Zeitpunkt der Rechtskraft des Urteils fest. Auch die Beschwerde der Staatsanwaltschaft gegen diesen Beschluß beim Landgericht München I wurde als unbegründet abgelehnt. Daraufhin unterbreitete der Oberstaatsanwalt das Problem dem Reichsjustizministerium. ${ }^{91}$ Das Ministerium antwortete, daß diese Form der Anrechnung durchaus möglich sei, „wenn die bereits vor Erlaß des Urteils zur Durchführung des Strafverfahrens verhängte Schutzhaft einfach automatisch über den Zeitpunkt der Urteilsrechtskraft hinaus fortgedauert hat", da sie dann ihren ursprünglichen Zweck

${ }^{87}$ RdErl. des stellv. Chefs u. Inspekteurs der Gestapo an die Stapostellen v. 15.7.35 (StArch. Düsseldorf, Gestapa-Erlasse, Sign. Best RW 18, Nr. 2).

88 RdErl. des stellv. Chefs u. Inspekteurs der Gestapo v. 1.9.35 mit Abschr. der RV des RJM v. 17.6.35 (a.a.O.).

89 Dazu vgl. Kapitel VI.3.d., S.610 ff.

90 Vgl. AGRat im RJM Kelz, Zur Anrechnung von Schutzhaft auf die Strafe (DJ 1936, S. 1609).

91 Schr. des OStA beim LG München I an das RJM v. 12.10.35 nebst Beschl. des AG München v. 7.10.35 u. der 4. Strafkammer des LG München I v. 10.10.35 (Akten des RJM, BA, Sign. R 22/1467). 
beibehalten habe. Werde hingegen nach der Urteilsrechtskraft die Schutzhaft erneut angeordnet, so werde eine zusätzliche Haft angenommen werden müssen, „die zwecks Sicherung der Allgemeinheit oder zwecks Erziehung des Betroffenen neben die gerichtlich erkannte Strafe treten soll“. Im vorliegenden Fall läge jedoch eine automatische Fortdauer des bisherigen Schutzhaftzwecks vor und die Art der Anrechnung sei daher unbedenklich. ${ }^{92}$

Da die Gestapo gegen Hitlers Entscheidung über die Anrechnung der Schutzhaft nicht angehen konnte, verfiel sie darauf, von der Justiz die Übernahme der Kosten für die angerechnete Schutzhaft auf den Reichsjustizhaushalt zu fordern. Sie begründete ihre Forderung damit, daß die Justiz die Schutzhaft durch die Anrechnung selbst als einen Teil der gerichtlichen Strafe ansehe und die Schutzhaftkosten nach dem Fortfall der Reichszuschüsse für Schutzhäftlinge am 1.April 1936 vor allem für die kleineren Länder eine erhebliche Belastung darstellten. ${ }^{93}$ Als Gegenmaßnahme versicherte sich das Justizministerium zunächst der Unterstützung durch den Reichsfinanzminister: es teilte ihm mit, daß es das Ansinnen des Reichsführers-SS abzulehnen gedenke, da die daraus für die Justiz entstehenden Lasten ,recht beträchtlich“ seien. Die Forderung sei aber auch sachlich nicht berechtigt, denn für die Justiz sei es gerade „eine Notwendigkeit, den Straffälligen, sei es zur Strafverfolgung (Untersuchungshaft), sei es zur Strafvollstreckung, möglichst bald in ihre alleinige Verfügungsgewalt $\mathrm{zu}$ bekommen“. Wenn die Gestapo das verhindere und „auf dem Gebiet der Strafrechtspflege in weitem Umfang von sich aus tätig“ werde, so müsse sie auch die dadurch anfallenden Kosten selbst tragen. Es sei ein allgemeiner haushaltsrechtlicher Grundsatz, daß jede Verwaltung für die innerhalb ihres Aufgabenbereichs erwachsenden Ausgaben selbst aufkomme, und höchst unzweckmäßig, „daß mittelbar einer Verwaltung die Verfügungsbefugnis über den Haushalt der anderen eingeräumt“ werde. Bei den Kosten der Schutzhaft, an deren Verhängung die Justiz ,in keiner Weise beteiligt“ sei, wäre diese Folge gerade aus dem Aspekt heraus, daß „die Justiz Wert darauf legen muß, die Beschuldigten möglichst bald in ihre alleinige Verfügungsgewalt zu bekommen, besonders mißlich“. Nachdem das Reichsfinanzministerium dieser Stellungnahme zugestimmt hatte, lehnte der Justizminister die Forderung Himmlers ab. ${ }^{94}$

Die Gestapoführung schreckte selbst vor bewußter Irreführung nicht zurück, um die Anrechnungspraxis der Justiz zu bekämpfen. Im April 1936 rügte Heydrich ein Urteil des Oberlandesgerichts München vom 23. November 1935, das einen zurückgekehrten Emigranten wegen eines minder schweren Falles von Vorbereitung zum Hochverrat zu einer Gefängnisstrafe von einem Jahr und zwei Monaten verurteilt, dabei aber acht Monate durch Schutz- und Untersuchungshaft als verbüßt angerechnet hatte: die Anrechnung sei in diesem Falle rechtlich unzulässig, da es sich nicht um Schutzhaft, sondern um eine „Schulungshaft" gehandelt habe. Diese Schulungshaft sei „auf Weisung des Herrn Reichs- und Preußischen Ministers des Innern ausnahmslos“ für alle Rückwanderer eingeführt worden, da sie wegen ihrer staatsfeindlichen Einstellung eine Gefahrenquelle bildeten und durch Verbreitung unsinniger Auslandsgerüchte bei noch nicht gefestigten Volksgenossen Unsicherheit verursachten. Andererseits befinde sich unter ihnen „Menschenmaterial, das bei geeigneter Anleitung und

92 Schr. des RJM (l.A. Crohne) an den GStA München v. 21.11.35 (a.a.O.).

93 Schr. des RFSSuChdDtPol. im RMdI v. 26.11.36 (a.a.O.).

94 Schr. des RJM an den RFinanzM v. 15.12.36 u. an den RFSSuChdDtPol im RMdI v. 18.1.37 (a.a.O.). 
Schulung wieder in den Volkskörper einzureihen“ sei. Diese Schulung, die dem „Verständnis der neuen Verhältnisse in Deutschland“ diene, werde „aus Zweckmäßigkeitsgründen in Gemeinschaftslagern vorgenommen“. Da zwischen dieser Schulungshaft und der Schutzhaft "ein Zusammenhang nicht" bestehe, solle das Justizministerium dafür Sorge tragen, daß zukünftig die Anrechnung dieser Haftart auf eine Kriminalstrafe nicht mehr erfolge..$^{95}$

Was Heydrich dabei bewußt verschwieg, war die Tatsache, daß die Rückkehrer - angeblich mangels geeigneter Lager - in normale Konzentrationslager verbracht wurden und dort ihre Vergangenheit „einer eingehenden Nachprüfung in politischer und krimineller [!] Beziehung“ unterzogen wurde ${ }^{96}$, und daß auch jene von Heydrich erwähnte „Weisung“ des Reichsinnenministeriums - es handelte sich um einen Runderlaß vom 9. Februar 1935, der der Justiz gleichfalls unbekannt war - schlechthin von „Schutzhaft“ sprach, die „in dem für die jeweilige Landesregierung zuständigen Schutzhaftlager zu vollstrecken“ war, und als Zweck ebenfalls „eingehende polizeiliche Ermittlungen über die Tätigkeit und das politische Verhalten“ der Rückkehrer im Ausland bezeichnete. ${ }^{97}$

Freisler wies die Strafrechtspflegeabteilung des Ministeriums (Abteilung III) an, „der Gestapo unter Bezugnahme auf den Willen des Führers“, d.h. unter Hinweis auf Hitlers Erlaß vom 7.Juni $1935 \mathrm{zu}$ antworten. ${ }^{98}$ Weder dieser Abteilung noch der von ihr befragten Abteilung V (Öffentliches Recht) war über die Einrichtung einer Schulungshaft etwas bekannt. Der Referent für Verwaltungsrecht Ministerialrat Kritzinger vertrat die Ansicht, daß das Ersuchen der Gestapo nur dann erfüllt werden könne, wenn „es sich dabei tatsächlich um eine von der gewöhnlichen Schutzhaft unterschiedene und unterscheidbare Haft handelt": im beanstandeten Münchener Urteil habe das Gericht lediglich von angerechneter „Schutzhaft“ gesprochen. Er schlug vor, bei der Gestapo nähere Angaben darüber einzuholen, „ob bei der Verhängung und Vollziehung der Schulungshaft klar zum Ausdruck kommt, daß es sich nicht um eine ,Schutzhaft ${ }^{\circ}$ handelt", da andernfalls die Gerichte mit der Unterscheidung nichts anfangen könnten. ${ }^{99}$ Die Gestapo wurde daher um Auskunft über die Möglichkeit einer klaren Abgrenzung dieser besonderen Haft von der Schutzhaft gebeten, ferner darüber, „wer in Schulungshaft genommen wird (nur zurückkehrende Emigranten oder auch andere Personen?), wie die Schulungshaft angeordnet wird und wie ihr Vollzug erfolgt". Vom Reichsinnenministerium wurde eine Abschrift der in Heydrichs Brief erwähnten Weisung über die Schulungshaft erbeten. ${ }^{100}$

In seiner Antwort vom 8.Juli 1936 hielt Heydrich seine Behauptung aufrecht, daß sich die Schulungshaft von "der Schutzhaft im üblichen Sinne“ wesentlich unter-

95 Schr. des Gestapa (I.V. Heydrich) an das RJM v. 4.4.36 (a.a.O.), vgl. auch Diensttageb. des RJM, Bd. 8, Eintr. v. 17.4.36 (BA, Sign. R 22/929).

96 Vgl. RdErl. des Gestapa v. 28.1.35 (Akten des RSHA, BA, Sign. R 58/259), ferner RdEntschl. der BPP v. 28. 2., 7.3. u. 21.3.35 (Arch. des IfZ, Sign. Fa 183/1, Bl. 363), wonach männl. Emigranten ins KZ Dachau, weibliche ins Frauenschutzhaftlager Moringen verbracht wurden.

${ }^{7}$ Geh. RdErl. des RuPrMdI an die Landesreg. v. 9.2.35 (a.a.O., Bl. 335). Entgegen Heydrichs Darstellung war nicht dieser nachträgliche u. ergänzende Erl., sondern der Gestapo-Erl. v. 28.1.35 Grundlage für die Maßnahme.

${ }^{98}$ Verm. des persönl. Ref. Freislers für Crohne v. 22.4.36 (Akten des RJM, BA, Sign. R 22/1467).

99 Verm. Kritzingers v. 12.5.36 (a.a.O.).

${ }^{100}$ Schr. des RJM an das Gestapa v. 25.5.36, Schr. an das RuPrMdI v. gleichen Datum (a.a.O.). 
scheide. Sie werde nur gegen zurückkehrende Emigranten, und zwar aus den in seinem Schreiben vom April bereits dargelegten Gründen angeordnet, die mit den Schutzhaftgründen gemäß den Bestimmungen Fricks vom April 1934 nichts zu tun hätten. Die Schulungshaft werde allerdings ,in Ermangelung geeigneter Schulungslager ... z.Zt. [?] in den Konzentrationslagern vorgenommen“. Heydrich stellte die Einlieferung der Emigranten ins Konzentrationslager nur als Folge vorübergehender Unterbringungsschwierigkeiten dar, obwohl seit dem Inhaftierungserlaß vom Januar 1935 nicht der geringste Versuch zur Änderung dieser Tatsache unternommen worden und auch gar nicht beabsichtigt war. Eine krasse Lüge aber stellte seine Behauptung dar, „daß die Emigrantenschulung eine individuelle Note [?]“ trage ,und die Behandlung der Schulungshäftlinge eine andere" sei als die normaler Schutzhäftlinge: tatsächlich wurden die Emigrantenhäftlinge im Konzentrationslager in keiner Hinsicht abweichend behandelt, außer daß sie mit einem besonderen blauen Dreieck gekennzeichnet wurden. ${ }^{101}$ Auch das von Heydrich angegebene Ziel der Verwahrung - daß die Häftlinge entlassen würden, sobald bei ihnen „das nötige Verständnis für die Verhältnisse des nationalsozialistischen Deutschlands geweckt" sei $^{102}$ - unterschied sich in nichts von dem propagierten Schutzhaftzweck der politischen „Erziehung“, „Besserung“ und „Eingliederung in die Volksgemeinschaft“, der angeblich auch für andere Kategorien von Konzentrationslagerhäftlingen galt. In Wirklichkeit konnte von „Schulung“ keine Rede sein; Zweck der Verhaftung war lediglich, den unerwünschten Rückwanderern den „weiteren Aufenthalt im Reichsgebiet zu verleiden“ und die Wiederausreise nahezulegen ${ }^{103}$, zugleich aber durch polizeiliche Ermittlungen diejenigen auszusieben, denen eine politische Straftat angehängt werden konnte. Da die Existenz des GestapoErlasses vom 28. Januar 1935, der diese Ermittlungen vorschrieb, der Justizleitung vorenthalten wurde ${ }^{104}$, waren Heydrichs Mitteilungen für sie die einzige Information über die „Schulungshaft“, die sie als authentisch ansehen mußte und die für sie nicht nachprüfbar war. Freisler, der ursprünglich die Anrechnung auch in diesen Fällen unter Berufung auf Hitler verteidigen wollte, gab nunmehr klein bei. Nachdem das Ministerium auf Rückfrage beim Geheimen Staatspolizeiamt noch unterrichtet worden war, daß die Dauer dieser Haft „in der Regel 3 Monate“ betrage, benachrichtigte Crohne die Generalstaatsanwälte durch eine Rundverfügung vom 22. September 1936 von der Einrichtung der "Schulungshaft“ und wies sie an, diese Haftart auf eine erkannte Strafhaft nicht anzurechnen, da sie „ohne Zusammenhang mit etwaigen strafbaren Handlungen“ erfolge. Die Polizeibehörden würden angewiesen werden, bei Überführung eines Häftlings in Untersuchungshaft oder bei Vorführung vor das Gericht „der Staatsanwaltschaft eine etwa vollstreckte Schulungshaft anzuzeigen“. ${ }^{105}$ Die

${ }^{101}$ Vgl. dazu H. E. Tutas, Nationalsozialismus und Exil. Die Politik des Dritten Reiches gegenüber der deutschen politischen Emigration 1933-1939, München-Wien 1975, S. 124 mit Belegen. S. 119 ff. geht T. auf die „Schulungshaft" u. das hier behandelte Problem ihrer Anrechnung ein.

${ }^{102}$ Schr. Heydrichs an das RJM v. 8.7.35 (a.a.O.).

${ }^{103}$ Vgl. RdErl. des Gestapa v. 13.6.35 (Akten des RSHA, BA, Sign. R 58/269).

${ }^{104}$ Aus den Akten geht nicht hervor, ob das RJM den Geh. RdErl. des RuPrMdI v. 9.2.35 abschriftlich erhielt. $\mathrm{Da}$ in ihm nur von Ermittlungen über die politische Tätigkeit der Emigrantenhäftlinge die Rede war, wäre jedoch für die Justiz daraus nicht ersichtlich gewesen, daß die Schutzhaft in diesen Fällen zugleich der Strafverfolgung diente.

${ }^{105}$ RV des RJM v. 22.9.36 (Akten des RJM, BA, Sign. R 22/1467). Die Verzögerung ergab sich daraus, daß der Entw. vorher der Gestapoführung m.d. B. um Einverständnis u. um Herausgabe entspr. Weisungen an die Stapostellen übersandt wurde. 
Gestapoführung gab einige Zeit später den Staatspolizeistellen entsprechende Weisung. ${ }^{106}$

Während sich die Justiz dadurch des Rechts begab, die Schutzhaft bei zurückgekehrten Emigranten anzurechnen, hielt sie in allen übrigen Fällen an der Auffassung fest, „daß jede aus Anlaß des Strafverfahrens vorgenommene Schutzhaft wie eine richterliche oder polizeiliche Vorhaft auf die Strafe angerechnet werden" konnte. ${ }^{107}$

\section{d. Unterbrechung der Schutzhaft zur Strafvollstreckung und Inschutzhaftnabme nach verbüßter Freibeitsstrafe}

Die Justiz vollstreckte die von ihr ausgesprochenen Strafen selbst. Wurde ein Angeklagter rechtskräftig zu einer Freiheitsstrafe verurteilt, so gebot "das Interesse von Volk und Staat an wirksamer Bekämpfung des Verbrechens wie auch das Ansehen der Strafrechtspflege“, daß die Vollstreckung dem Urteil auf dem Fuße folgte und der Verurteilte so schnell wie möglich in die Strafhaft überführt wurde. ${ }^{108}$ Soweit sich der Verurteilte in Untersuchungshaft befand, bereitete die Durchführung dieser Maxime keine Schwierigkeit. Bestand aber gegen ihn ein Schutzhaftbefehl von seiten der Gestapo, so mußte die Vollstreckungsbehörde die Kommandantur des Konzentrationslagers, in dem der Betreffende einsaß, oder - soweit bekannt - die einweisende Staatspolizeistelle um Genehmigung für die Aufhebung oder zumindest Unterbrechung der Schutzhaft zum Zwecke des Strafvollzugs ersuchen. Die Gestapo sah diese Unterbrechung als lästige Störung an: die Häftlinge wurden ihrer Verfügungsgewalt entrissen, ihre Überführung erforderte zusätzliches Wachpersonal, beeinträchtigte den ,planmäBigen Lagerdienst“ und erhöhte die Fluchtgefahr. „Um solche Unzuträglichkeiten zu vermeiden“, wies das preußische Justizministerium - noch unter Leitung Kerrls, der der Gestapo entgegenkam - die Staatsanwaltschaften und Amtsgerichte in einer Rundverfügung an,

„die Vollstreckung von Freiheits- (Ersatzfreiheits-)strafen gegen in polizeilicher Schutzhaft befindliche Personen grundsätzlich bis zur Aufhebung der Schutzaufsicht aufzuschieben, es sei denn, daß ausnahmsweise, insbesondere mit Rücksicht auf die Höhe der erkannten Strafe, im Interesse der Strafrechtspflege die alsbaldige Vollstreckung der Strafe geboten erscheint".

Die Vollstreckungsbehörden sollten die Kommandantur des betreffenden Konzentrationslagers von der Aufschiebung benachrichtigen und sie ersuchen, eine bevorstehende Entlassung des Verurteilten so rechtzeitig mitzuteilen, daß er anschließend in Strafhaft überführt werden konnte. ${ }^{109}$

Nach der Verreichlichung der Justizverwaltung wurde diese Rundverfügung durch die Strafvollstreckungsordnung des Reichsjustizministeriums vom 7. Dezember 1935 zugunsten der eingangs erwähnten Maxime aufgehoben: ${ }^{110}$ als noch im Januar 1939 (!)

\footnotetext{
${ }^{106}$ RdErl. des Gestapa v. 17. 10.36, dem RJM am 16. 12.36 übersandt (a.a.O.).

${ }^{107} \mathrm{Vgl.} \mathrm{RV} \mathrm{des} \mathrm{RJM} \mathrm{an} \mathrm{die} \mathrm{OLGPräs.} \mathrm{u.} \mathrm{GStAe} \mathrm{Linz,} \mathrm{Wien,} \mathrm{Graz} \mathrm{u.} \mathrm{Innsbruck} \mathrm{v.} \mathrm{7.8.} 42$ (a.a.O.).

${ }^{108} \mathrm{Vgl}$. $\S 1$ der StrafvollstreckungsO v. 7.12.35 (DJ 1936, S. 1800).

${ }^{109} \mathrm{RV}$ des preußJM v. 8.9.33 (Akten des preußJM, GehStArch. Berlin, Sign. Rep. 84a/3715). In den Schutzhaft-Vorschriften des bayerMdI für die BPP v. 2.5.34 hieß es demgegenüber eindeutig: „Dem Ersuchen der Strafvollstreckungsbehörden um Unterbrechung der Schutzhaft zur Strafverbüßung ist grundsätzlich zu entsprechen" (Arch. des IfZ, Sign. Fa 183/1, Bl. 320).

${ }^{110} \S 72$ der StrafvollstreckungsO v. 7.12.35 (DJ 1935, S. 1800).
} 
die Kommandantur des Konzentrationslagers Buchenwald eine Abschrift der preußischen Rundverfügung anforderte, um sich gegenüber Justizbehörden auf sie berufen zu können, wurde sie entsprechend belehrt. Der Generalreferent für Strafverfahrensrecht vermerkte dazu, das Ministerium vertrete „schon seit längerer Zeit die Auffassung, daß Untersuchungs- und Strafhaft der Schutzhaft grundsätzlich vorgehen


Schutzhäftlingen in Justizgewahrsam im allgemeinen - wenn auch verschiedentlich mit absichtlichen oder durch den Geschäftsgang bedingten Verzögerungen - für die Justiz zufriedenstellend gehandhabt worden zu sein. ${ }^{112}$ Erst im Juli 1940 trat der Chef der Sicherheitspolizei an das Reichsjustizministerium mit der Absicht heran, die mit der Überführung verbundenen Häftlingstransporte insbesondere dann zu vermeiden, wenn es sich um die Verbüßung kleinerer Strafen handelte. Da sich in solchen Fällen die Staatsanwaltschaften unter den Kriegsverhältnissen "teilweise“ schon mit dem Aufschub der Vollstreckung auf die Zeit nach Beendigung der Schutzhaft einverstanden erklärt hätten, schlug er als einheitliche Regelung vor, daß Schutzhäftlinge, die eine Strafe bis zu sechs Monaten zu verbüßen hatten, im Konzentrationslager verbleiben und den Strafvollstreckungsbehörden erst nach Aufhebung der Schutzhaft zugeführt werden sollten. Nur bei längeren Freiheitsstrafen sollte es wie bisher bei der Überführung auf Antrag der Vollstreckungsbehörde bleiben, die nach Strafverbüßung für die Rücküberstellung zu sorgen hatte. Der Leiter der Strafrechtspflegeabteilung, Ministerialdirektor Crohne, hielt diese Regelung für „unmöglich“, da sie den Grundsatz des Ministeriums von der nachdrücklichen Strafvollstreckung "völlig umstoßen“ würde und auch beim Verurteilten die Vorstellung erwecken müsse, „daß die gerichtliche Strafe von der Polizei vollstreckt werde“. ${ }^{113}$ Nach Vortrag forderte auch Staatssekretär Freisler, es müsse auf jeden Fall ,sichergestellt werden, daß auch die Strafen bis zu 6 Monaten innerhalb einer bestimmten kurzen Frist zur Vollstreckung gelangen“. Bei den folgenden Verhandlungen mit dem zuständigen Referenten des Reichssicherheitshauptamtes schlug der Justizvertreter als Kompromiß vor, „daß diese Strafen 3 Monate nach dem Urteil auf jeden Fall zur Vollstreckung kommen " sollten. ${ }^{114}$ Aber die Gestapoführung blieb hart. Unter Hinweis „auf den erheblichen Schriftwechsel, der mit der fortlaufenden Abstellung von Schutzhäftlingen zur kurzfristigen Strafverbüßung verbunden" sei, sowie auf knappe Transportmittel, verursachte Kosten und die "Störung in den Arbeitsvorhaben der Konzentrationslager" lehnte sie den Vorschlag der Justiz ab, da er diese Schwierigkeiten nicht beseitige, sondern lediglich zeitlich hinausschiebe. Die von der Justiz geäußerten Bedenken, daß die von der Gestapo vorgeschlagene Regelung einer vollkommenen Aussetzung der unter sechs Monaten Dauer liegenden Strafen gleichkomme, teile die Gestapoführung nicht: auch nach längerer Schutzhaft werde die Strafe noch vollstreckt werden können, ohne daß der Betreffende dann nicht mehr wisse, weshalb er die Strafe erhalten habe; daher brauche der Bestrafte in einem solchen Fall keineswegs einen Gnadenerweis für die noch zu

\footnotetext{
${ }^{11}$ Verm. v. 22.2. 39; Korresp. zwischen RJM u. GStA Naumburg v. 10.2./25.3.39 (Akten des RJM, BA, Sign. R 22/1467).

${ }^{112}$ Vgl. RdErl. der BPP an ihre Dienststellen v. 25.11.35, es bestehe „Veranlassung, erneut darauf hinzuweisen“, daß entsprechende Ersuchen der Strafvollstreckungsbehörden zu erfüllen seien (Arch. des IIZ, Sign. Fa 183/1, Bl. 346).

${ }^{113}$ Schr. des Chefs Sipo/SD an das RJM v. 30.7.40 mit Verm. Crohnes (Akten des RJM, BA, Sign. R 22/1467).

${ }^{114}$ Verm. des Referenten v. 16. u. 24.8.40 (a.a.O.).
} 
verbüßende Strafhaft zu erhalten. Angesichts der genannten Mißstände der bisherigen Regelung halte sie es für durchaus „tragbar, in den betreffenden Fällen von dem Grundsatz abzuweichen, nach dem die Strafe unmittelbar im Anschluß an das Urteil vollstreckt werden müsse", zumal auch der Vermittlungsvorschlag des Justizministeriums auf eine Verschiebung hinauslaufe. ${ }^{115}$ Nunmehr entschied Freisler, die Bedenken der Justiz gegen den Vorschlag der Gestapo „für die Dauer des Krieges“ zurückzustellen; nur sollten Häftlinge mit einer Freiheitsstrafe von genau sechs Monaten in die Überstellung einbezogen und der beabsichtigte Gestapo-Erlaß „als vorläufige Regelung " gekennzeichnet werden. ${ }^{16}$ Nachdem Heydrich diese Wünsche in einem übersandten Erlaßentwurf berücksichtigt hatte, ließ auch Crohne seine Bedenken mit dem Argument fallen, daß die Delikte, die zu einer Strafe unter sechs Monaten führten, regelmäßig leichter sein würden als diejenigen, die zur Schutzhaft geführt hätten: daher leide hier das Sühnebedürfnis bei der Zurückstellung hinter die Vollziehung der Schutzhaft nicht. In dieser Form sei - zumal in der Kriegszeit - die Durchbrechung des Grundsatzes sofortiger Strafvollstreckung tragbar. ${ }^{17}$ Nachdem Freisler Heydrich seine Zustimmung mitgeteilt hatte, wurde der Runderlaß des Reichssicherheitshauptamtes vom 12. Mai 1941 den Justizbehörden mit der Weisung bekanntgegeben, nach der vereinbarten Regelung zu verfahren. ${ }^{118}$ Wenn jedoch einzelne Justizbehörden daraufhin glaubten, daß durch diesen Erlaß eine generelle Genehmigung zur Haftunterbrechung für Strafen von sechs Monaten und mehr erteilt worden und die Einholung der Genehmigung im Einzelfall dafür nicht mehr erforderlich sei, sollten sie eines anderen belehrt werden: die Gestapo hielt daran fest, daß die zuständige Staatspolizeistelle den Unterbrechungsantrag in jedem einzelnen Falle genehmigen müsse, folglich in Ausnahmefällen wohl auch ablehnen könne. ${ }^{119}$

Neben der Strafvollstreckung an Schutzhäftlingen bedurfte auch die Praxis der Gestapo einer Regelung, bestimmte Kategorien von Justizgefangenen, die ihre gerichtliche Freiheitsstrafe verbüßt hatten und entlassen werden sollten, in Schutzhaft zu nehmen. Die Schutzhaft im Anschluß an die Strafhaft sollte sich als ein wesentliches Mittel zur „Korrektur“ gerichtlicher Urteile herausstellen. Dabei war die Gestapo jedoch auf Informationen seitens der Justiz angewiesen. Der preußische Justizminister hatte daher schon in seiner Rundverfügung vom 6. Mai 1933 angeordnet, daß die Justizbehörden vor der Entlassung „staatsfeindlicher Personen“ aus der Strafhaft mit der zuständigen Polizeibehörde rechtzeitig Fühlung nehmen sollten. ${ }^{120}$ Das preußische Innenministerium hatte diese Rundverfügung den Dienststellen der Polizei mitgeteilt und sie ersucht, sich in derartigen Fällen mit den Oberstaatsanwälten in Verbindung zu setzen. ${ }^{121} \mathrm{Zu}$ einer konkreten Regelung kam es zunächst hinsichtlich der wegen Landesverrats Verurteilten. Am 24. November 1933 teilte das Geheime Staatspoli-

\footnotetext{
${ }^{115}$ Schr. des Chefs Sipo/SD an das RJM v. 14.11 .40 (a.a.O.).

116 Schr. des RJM an den Chef Sipo/SD v. 29.11. 40 (a.a.O.).

${ }^{117}$ Schr. Heydrichs an das RJM v. 11.3.41 mit Erl.Entw., Verm. Crohnes v. 25.3.41 (a.a.O.).

${ }^{118} \mathrm{RV}$ des RJM v. 6.6.41 u. Zustimmungsschr. Freislers v. 2.4.41 (a.a.O.).

119 Vgl. die irrtüml. Annahme des AG Stuttgart, das vom KZ Dachau daraufhin an die Stapoleitstelle Stuttgart verwiesen wurde. Korresp. RSHA mit dem RJM v. 10.11./26.11.41 (a.a.O.).

${ }^{120}$ RV des preuß. JM v. 6.5.33 (s. Anm. 12). Der Entw. war dem preuß. MdI am 19.4.33 zwecks Einvernehmen zugegangen. Zur analogen Regelung durch Justizsenator Rothenberger in Hamburg vgl. W. Johe, a.a.O., (s. Anm. 83), S. 138.

${ }^{121}$ RdErl. des preußMdI an das Gestapa u. die Pol.Dienststellen v. 16.5.33 (Arch. des IfZ, Sign. Fa 183/1, Bl. 272).
} 
zeiamt dem preußischen Justizminister mit, daß es am Vortage alle Staatspolizeistellen angewiesen habe, „durch Vereinbarung mit den örtlich zuständigen Justizbehörden ... sicherzustellen, daß Landesverräter im Anschluß an die Verbüßung ihrer Freiheitsstrafe in Schutzhaft überführt werden können “ ${ }^{122}$ Der Bitte um einen ergänzenden Erlaß kam der preußische Justizminister mit der Rundverfügung vom 20. Dezember nach, in der er die Provinzialjustizbehörden ersuchte, den Wünschen der Gestapo zu entsprechen und im Benehmen mit den Präsidenten der Strafvollzugsämter die erforderlichen Ausführungsbestimmungen zu erlassen. ${ }^{23}$ Daraufhin gaben z.B. der Oberlandesgerichtspräsident und der Generalstaatsanwalt Naumburg im Einvernehmen mit den Leitern der Staatspolizeistellen in Halle, Magdeburg und Erfurt für ihren Bezirk genaue Vorschriften heraus, nach denen Amtsgerichte oder Staatsanwaltschaften als Strafvollstreckungsbehörden schon bei Beginn der Vollstreckung der Gestapo die Personalien jedes wegen Landesverrats Verurteilten, seine Tat und Strafe sowie das Strafende mitzuteilen hatten. Von der bevorstehenden Entlassung war die Staatspolizeistelle nochmals rechtzeitig zu benachrichtigen und die Gefängnisverwaltung von der Beteiligung der Gestapo zu informieren. Die Gestapo ihrerseits unterrichtete die Justizbehörden, ob der Verurteilte zum Zeitpunkt der Entlassung in Polizeigewahrsam genommen oder darauf verzichtet werde. Die erfolgte Inschutzhaftnahme meldete die Gefängnisverwaltung der Strafvollstreckungsbehörde. Jede Änderung des Strafendes, z. B. durch Strafunterbrechung, sollte der Staatspolizeistelle unter Angabe des neu errechneten Termins mitgeteilt werden. Mußte eine Entlassung unerwartet erfolgen, so hatte die Strafvollstreckungsbehörde „dafür zu sorgen, daß der Verurteilte der Staatspolizeistelle zugeführt" wurde. Das preußische Justizministerium war mit diesen Vorschriften einverstanden ${ }^{124}$, bemühte sich aber beim Reichsjustizministerium um eine einheitliche Regelung. ${ }^{125}$ Sie erfolgte im Rahmen der geheimen Rundverfügung betr. die Behandlung wichtiger Strafsachen, die das Reichsjustizministerium im Zuge der Verreichlichung der Justizverwaltung am 18. Dezember 1934 erließ. Danach sollte die Mitteilung von der bevorstehenden Strafentlassung von Landesverrätern ergehen „an die zuständige Landespolizeistelle 1 Monat vor dem Entlassungsdatum unter Bezeichnung des zu Entlassenden, seiner Tat, der Strafanstalt, aus der die Entlassung erfolgt, sowie des genauen Entlassungsdatums“. Im Gegensatz zur nunmehr aufgehobenen preußischen Regelung vom Mai 1933 war für sonstige „Staatsfeinde“, insbesondere die wegen Hochverrats Verurteilten, keine derartige Mitteilungspflicht mehr vorgesehen. Da bei Hochverratssachen - ebenso wie bei Landesverratssachen - eine Abschrift der Anklageschrift sowie des Urteils mit Gründen bzw. der sonstigen das Verfahren abschließenden Entscheidung an das Geheime Staatspolizeiamt und an das Zentralbüro des politischen Polizeikommandeurs der Länder gegeben wurde ${ }^{126}$, mußte sich die

${ }^{122}$ Geh. Schr. des Gestapa an den preußJM v. 24.11 .33 (Akten des preußJM, GehStArch. Berlin, Sign. Rep. $84 \mathrm{a} / 3715$ ).

${ }^{123} \mathrm{RV}$ des preußJM v. 20.12.33 (s. S. 588, Anm. 13).

${ }^{124}$ GehRV des OLGPräs./GStA Naumburg (Saale) an die nachgeordneten JBehörden v. 5.1.34, dem preußJM am 25.1.34 zugeleitet; Aktenverm. v. 6./8.2.34 (Akten des preußJM, a.a.O.)

${ }^{125}$ Vgl. die Wiedervorlagevermerke bis Sept. 1934, d. h. bis kurz vor Vereinigung beider Ministerien (a.a.O.).

${ }^{126}$ Vgl. GehRV des RJM v. 18.12.34 an die nichtpreuß. LJVerwaltungen u. die preuß. Provinzialjustizbehörden, nachrichtlich an andere beteiligte Stellen (BayerHStArch., MJu 12003); dazu Berichtig. v. 8.1.35 (Akten des RJM, BA, Sign. R 22/953). Später wurde auf Bitten der Gestapoführung die Ubersendung der Abschriften auf die örtl. zuständige Gestapostelle ausgedehnt (Schr. Bests v. 7.11.35 u. RV des RJM v. 6.2.36, a.a.O.). 
Gestapo in Hochverratsfällen auf Grund dieser Unterlagen von sich aus bei den Justizbehörden über den Zeitpunkt der Strafentlassung informieren. ${ }^{127}$

Als dieses Verfahren nicht immer zur Zufriedenheit der Gestapoführung funktionierte, bemühte sie sich unter Hinweis auf die frühere preußische Regelung darum, daß das Reichsjustizministerium auch eine Mitteilungspflicht für die Entlassung aller Hochverräter einführte. ${ }^{128}$ Das Ministerium lehnte diese Forderung mit dem Argument ab, daß der Preußische Ministerpräsident als Chef der Gestapo dem Entwurf der Rundverfügung vom Dezember 1934 in der vorliegenden Fassung zugestimmt und die getroffene Neuregelung gerade „das Ziel einer Verminderung der nicht mehr erträglichen Arbeitsbelastung“ der Justizbehörden verfolgt habe, das durch den neuerlichen Anspruch der Gestapo wieder in Frage gestellt werde. Bei denjenigen, die in einer Hochverratssache vom Strafsenat eines Oberlandesgerichts abgeurteilt würden ${ }^{129}$, handele es sich „regelmäßig um Persönlichkeiten, an denen sich die Bestrafung und die Strafvollstreckung günstig, mindestens in der Richtung einer wirksamen Abschreckung vor weiterem staatsfeindlichen Verhalten" auswirke; an ihnen dürfte die Gestapo daher „kaum ein besonderes Interesse haben“. Diejenigen aber, die „wegen ihrer früheren besonders intensiven oder gemeingefährlichen Tätigkeit“" regelmäßig vom Volksgerichtshof abgeurteilt würden und bei denen „eine weitere Überwachung, vielleicht auch Freiheitsentziehung, angezeigt" erscheine, seien der Gestapo ausnahmslos bekannt. Bei diesen nicht so zahlreichen Personen könne die Gestapo die Staatsanwaltschaft beim Oberlandesgericht entweder schon bei Einreichung der von ihr eingeleiteten Ermittlungen oder aber nach der Verurteilung um Mitteilung des Entlassungstages ersuchen. ${ }^{130}$ Die Gestapoführung gab sich damit zunächst zufrieden: In einem Runderlaß an die preußischen Staatspolizeistellen und die Politischen Polizeien der Länder vom August 1935 stellte Best mißbilligend fest, in letzter Zeit seien "mehrfach staatsfeindliche Personen, die wegen Hocbverrats in Strafhaft einsaßen, nach Strafverbüßung aus der Anstalt entlassen worden, ohne daß ihre weitere Überwachung oder Inschutzhaftnahme zwecks Überführung in ein Konzentrationslager erfolgte“. Entsprechend der Anregung des Justizministeriums ordnete er für seine Dienststellen Anfragen über den Entlassungstermin bei den Staatsanwaltschaften der Oberlandesgerichte an, um alle vom Volksgerichtshof wegen Hochverrats Verurteilten anschließend in Schutzhaft nehmen zu können. Bei den von den Oberlandesgerichten

${ }^{127}$ Zahlreiche bayer. Fälle, bei denen wegen Vorbereitung des HVs zu 1-2 Jahren Gefängnis verurteilte Kommunisten nach Verbüßung 1935 ins KZ Dachau gebracht wurden, da ihre erneute kommunistische Betätigung „mit Bestimmtheit angenommen werden“ mußte, finden sich in den Ber. des Polit.Pol.Kommandeurs Bayerns an die Bayer.StKanzlei v. Frühjahr 1936 (BayerHStArch., Sign. MA 106 301). Nach dem Ber. des GStA Karlsruhe v. 15.5.35 wurden in Baden seit dem 1.4.35 alle Strafgefangenen, die wegen HVs verurteilt waren, nach Verbüßung ins KZ Kislau überführt (Akten des RJM, BA, Sign. R 22/1467).

${ }^{128}$ Schr. des stellv. Chefs u. Inspekteurs der preuß. Gestapo an das RJM v. 28.5.35 (Akten des RJM, BA, Sign. R 22/953).

${ }^{129}$ Minderschwere Fälle von Verabredung u. Vorbereitung des Hochverrats konnten vom OReiA u. dem VGH an das zuständige OLG abgegeben werden; vgl. Art. III $\S 4$ des G. zur Änderung des Strafrechts und des Strafverfahrens v. 24.4.34 (RGBI. I, S. 341).

${ }^{130}$ Schr. des Leiters der Strafrechtspflegeabteilung, MinDir. Crohne, an das Gestapa v. 14.6.35 (Akten des RJM, a.a.O.). 
Abgeurteilten „müßte von Fall zu Fall geprüft werden, ob mit Rücksicht auf ihre frühere Tätigkeit die Rückführung nach Strafverbüßung in die Wege zu leiten wäre“. ${ }^{131}$

Auf seiten der Gestapo wurde sogar der Gedanke erwogen, wegen Hochverrats einsitzende Gefangene schon einige Zeit vor ihrer Strafentlassung in Schutzhaft zu nehmen. Anfang März 1935 berichtete der Leiter des Badischen Geheimen Staatspolizeiarhtes an die Gestapoführung, „daß in den Gefängnissen die Behandlung der wegen Hochverrats abgeurteilten Marxisten aller Schattierungen nicht dazu angetan" sei, sie „von ihrer staatsfeindlichen Einstellung zu bessern oder gar zu heilen“. Daher müßten Wege gesucht werden, „um möglichst noch während der Strafhaft sich dieser Häftlinge besonders anzunehmen". ${ }^{132}$ Er übersandte der Berliner Gestapozentrale seinen Vorschlag an den Badischen Innenminister, die Gefangenen zwei Monate vor Beendigung ihrer Strafhaft in das Konzentrationslager Kislau zu überführen. Dort sollten sie "durch geeignete Lehrkräfte“ ideologisch umgeschult und gleichzeitig durch individuelle Beobachtung beurteilt werden, ob sie nach Beendigung ihrer Strafzeit freigelassen werden könnten. ${ }^{133}$ Der Generalstaatsanwalt Karlsruhe, dem der badische Innenminister diesen Vorschlag unterbreitete, leitete ihn den Vorständen der drei badischen Strafanstalten zur Stellungnahme zu. Die drei Direktoren maßen einer solchen Umschulung von acht Wochen - noch dazu in einem Schutzhaftlager - keine großen Chancen zu; außerdem würden dabei diejenigen, von denen vielleicht eine Abkehr von der marxistischen Gedankenwelt erwartet werden könne, durch die gemeinsame Unterbringung mit unverbesserlichen Funktionären wiederum im kommunistischen Sinne beeinflußt werden. Erfolgversprechender seien Unterricht durch den Anstaltslehrer und zwanglose Unterhaltung bei Zellenbesuchen während der Strafhaft, durch die der Gefangene zum Nachdenken angeregt werde. Wenn aber Schutzhaft vorgesehen werde, hielten sie eine Verhängung vor Strafende für weitaus günstiger als nach der Verbüßung, weil sie dem Gefangenen dann als Verlängerung der Strafhaft, „als ein Strafübel erscheinen und ihn gegen eine Belehrung störrischer und unempfindlicher machen" würde. ${ }^{134}$

Nach Eingang dieser Stellungnahmen legte der Generalstaatsanwalt den GestapoVorschlag dem Reichsjustizministerium zur Entscheidung vor, wobei er sich der Meinung der Strafanstaltsleiter im wesentlichen anschloß. Den Bemühungen der Strafanstalten um einen Gesinnungswandel der Hochverratsgefangenen sprach er angesichts der arbeitsmäßigen Belastung der Anstaltsbeamten und -lehrer allerdings wenig Erfolg zu. Andererseits lehnte auch er für diesen $Z$ weck eine Schutzhaft nach verbüßter Strafe ab. Es bleibe nur die Möglichkeit, den Gefangenen vor Ende der Strafhaft bedingte Strafaussetzung zu gewähren, wobei der Strafrest so bemessen werden müsse, „daß der Aufenthalt im Lager möglichst vor dem Zeitpunkt des Strafendes, spätestens aber mit diesem enden würde“. Zur praktischen Durchführung schlug er vor, daß die Strafanstalten in bestimmten Abständen diejenigen politischen Häftlinge melden soll-

${ }^{131}$ RdErl. des stellv. Chefs u. Inspekteurs der preuß. Gestapo v. 27.8.35, Hervorheb. im Original (StArch. Düsseldorf, Sign. Best. RW 18, Nr.2), u. Mitteilung an das RJM v. selben Datum (Akten des RJM, BA, Sign. R 22/953).

${ }^{132}$ Schr. des Leiters des Bad. Gestapa an das Gestapa/Zentralbüro Berlin v. 1.3.35 (a.a.O.).

${ }^{133}$ Schr. des Leiters des Bad. Gestapa an den badMdI v. 23.2.35 (a.a.O.).

${ }^{134}$ Schr. des Dir. der Strafanstalt Freiburg i. Br. an den GStA Karlsruhe v. 19.3.35, vgl. ferner Schr. der Dir. der Anstalten Mannheim-Heidelberg v. 14.3.35 u. Bruchsal v. 30.3.35 (a.a.O.). 
ten, bei denen der Strafrest noch etwa drei Monate betrage, und sich dabei darüber äuBern sollten, bei welchen Gefangenen eine Belehrung Erfolg verspreche.

„Darnach hätte sich der Generalstaatsanwalt als Gnadenbehörde zu entschließen, ob er höherenorts die Aussetzung der Strafvollstreckung unter der Bedingung vorschlagen will, daß der Strafgefangene noch für eine bestimmte Zeitdauer in einem Schutzhaftlager untergebracht wird. Die Entschließung über die bedingte Strafaussetzung, die sich der Führer und Reichskanzler vorbehalten hat, ... müßte naturgemäß für die Maßnahmen des Geheimen Staatspolizeiamts bindend sein. Ganz abgesehen von der Person des Führers und Reichskanzlers müßte es dem Ansehen der Justizbehörden allgemein abträglich sein, wenn das Geheime Staatspolizeiamt die Schutzhaft über die von irgend einer Gnadeninstanz bezeichnete Frist hinaus verlängern [würde] ... Soweit die Gnadenbehörde von ihrem Gnadenrecht keinen Gebrauch machen wollte, stände nach völliger Strafverbüßung die Entscheidung über weitere Schutzhaftmaßnahmen frei im Ermessen des Geheimen Staatspolizeiamts.“

Der Generalstaatsanwalt betonte, eine Entscheidung des Reichsjustizministeriums über diesen Vorschlag sei um so notwendiger, als die seit 1. April in Baden durchgeführte Gestapopraxis einer ausnahmslosen Überführung der in Frage kommenden Strafgefangenen ins Konzentrationslager nach Beendigung des Strafvollzugs „wegen der Mißstimmung, die sie bei den Betroffenen vielfach zur Folge haben dürfte“, und "wegen der Gefahr der negativen Beeinflussung der im Strafvollzug zur Einsicht Gelangten" auf die Dauer nicht wünschenswert sein könne. Da aber der badische Innenminister an diesem Verfahren festhalte, solange die vorgeschlagene Neuregelung nicht verwirklicht werde, habe er das Ersuchen des Innenministers erfült und die drei ihm unterstellten Strafanstalten angewiesen, die zur Entlassung kommenden Hochverratsgefangenen der Gestapo einen Monat vorher zu benennen. ${ }^{135}$

Das Reichsjustizministerium lehnte diesen Vorschlag der „Begnadigung zu Konzentrationslager" rundweg ab: Die Zeit, die ein Häftling nach seiner vorzeitigen Entlassung aus der Strafanstalt im Konzentrationslager verbringe, könne nicht als Strafhaft angesehen und daher keinesfalls auf die Strafzeit angerechnet werden. Über den nichtverbüßten Strafrest könne aber unmöglich in der Weise entschieden werden, daß ausnahmslos allen wegen Hochverrats Verurteilten vor der Überführung in das Schutzhaftlager ein Gnadenerweis bewilligt werde, weil damit auch solche Verurteilte diese Vergünstigung erhielten, die ihrer von vornherein unwürdig seien. Die Entscheidung könnte nur davon abhängig gemacht werden, welchen Erfolg der Aufenthalt im Konzentrationslager beim Verurteilten gehabt habe. Werde er aber dort als ein unverbesserlicher Staatsfeind angesehen, der weiter in Schutzhaft bleiben müsse, so müsse auch von einem Gnadenerweis für den Strafrest abgesehen werden: der Verurteilte müßte dann zunächst zur Verbüßung des Strafrestes in die Haftanstalt zurückverlegt werden, um danach abermals in Schutzhaft überführt zu werden. Im positiven Falle aber würde ihm auf dem Gnadenweg entweder der Strafrest mit Rücksicht auf die nachträglich erlittene Schutzhaft erlassen oder eine mehrjährige Bewährungsfrist bewilligt werden.

„Ein solches Verfahren, d.h. die Erteilung von Gnadenerweisen an die meisten wegen Hochverrats Verurteilten, würde aber dem heutigen Rechtsempfinden, das den Hochverrat als eine der schwersten Verfehlungen gegen Volksgemeinschaft und Staat ansieht, widersprechen und wäre mit der strengen Gnadenpraxis, wie sie sich seit der nationalsozialistischen Erhebung entwickelt hat, nicht in Einklang zu bringen."

${ }^{135}$ Schr. des GStA Karlsruhe an das RJM v. 15.5.35 (a.a.O.). 
Das Ministerium könne den Vorschlag - abgesehen von der erwachsenen Mehrarbeit für die Justizbehörden - vor allem deswegen nicht unterstützen, da er eine erhebliche Arbeitsbelastung für den Führer bedeuten würde, der sich in Hoch- und Landesverratssachen die Entscheidung über Gnadenerweise vorbehalten hatte. ${ }^{136}$ Unter Anführung der erwähnten Argumente äußerte das Justizministerium ferner Zweifel, daß „die Unterbringung und Schulung in einem Schutzhaftlager der richtige Weg ist, die wegen Hochverrats Verurteilten für den neuen Staat zu gewinnen“. Weit besser dafür geeignet sei der Strafvollzug, „der wegen seiner längeren Dauer ${ }^{137}$, wegen der Isolierung der einzelnen Gefangenen und der damit verbundenen Fernhaltung schädlicher Einflüsse weitaus mehr Einwirkungsmöglichkeiten" biete.

In diesem Schreiben brachte das Justizministerium auch seine Abneigung gegen das Verfahren der Gestapo zum Ausdruck, Schutzhaft nach Strafverbüßung zu verhängen, das in Baden offensichtlich auf die ganze Gruppe der wegen Hochverrats Verurteilten angewendet wurde:

„Eine solche unterschiedslos durchgeführt Maßnahme läuft im Ergebnis darauf hinaus, daß die in ihrer Dauer bestimmte Strafe durch eine Freiheitsentziehung von unbestimmter Dauer ersetzt wird. Es wird also der Richterspruch in aller Regel durch eine Verwaltungsmaßnahme ergänzt und korrigiert, eine Tatsache, die ich im Interesse der Rechtssicherheit und der Achtung vor der Autorität der richterlichen Entscheidung unbedingt vermieden wissen möchte.“

Die sicher notwendige weitere Verwahrung einzelner unbelehrbarer Staatsfeinde lasse sich auch durchführen, ohne sämtliche wegen Hochverrats Verurteilte ins Konzentrationslager zu überführen: entweder seien sie der Gestapo von ihrer früheren Betätigung her bekannt oder sie würden ihre staatsfeindliche Einstellung im Strafvollzug hinreichend zu erkennen geben. Nach den Beobachtungen des Ministeriums handele es sich jedoch bei der Mehrzahl dieser Verurteilten um Leute, die - selbst wenn sie die Strafanstalt nicht innerlich gewandelt verließen - durch die erlittene Freiheitsstrafe wirksam gewarnt und von erneuter staatsfeindlicher Betätigung ein für allemal abgeschreckt worden seien. Gerade dieser Erfolg werde aber durch die anschließende Schutzhaft zunichte gemacht, denn auch der zu innerer Umstellung Bereite werde in seiner Enttäuschung und Verbitterung dem erneuten Einfluß von Hetzern unter seinen Mitgefangenen zugänglich sein. ${ }^{138}$

Gegen die getroffene Anordnung des Generalstaatsanwalts über eine regelmäßige Mitteilung der Entlassungstermine auch von Hocbverrätern an das Badische Geheime Staatspolizeiamt erhob das Reichsjustizministerium - falls sie die Justizbehörden nicht zu sehr belaste - „einstweilen“ keine Bedenken, obwohl es fünf Tage vorher der Gestapoführung eine generelle Einführung dieser Regelung verweigert hatte. Die Versuche anderer Staatspolizeistellen, die regionalen Justizbehörden zur Herausgabe entsprechender Weisungen zu veranlassen, wurden jedoch in der Folgezeit mit Unterstützung des Ministeriums abgewehrt. ${ }^{139}$ Erst nachdem die Gestapoführung durch das Gestapo-

\footnotetext{
${ }^{136}$ Vgl. Erl. des Führers u. Reichskanzlers über die Ausübung des Gnadenrechts v. 1.2.35 (RGBl. I, S. 74).

${ }^{137}$ Die hier im Entwurf folgenden Worte: „wegen seiner größeren Strenge“ wurden nach der bezeichnenden Anmerkung des Referenten: „ob ,Schutzhaft' oder ,Strafhaft' strenger ist, ist nicht ohne weiteres allgemein zu beantworten", gestrichen.

${ }^{138}$ Schr. des RJM (I.A. Crohne) an den GStA Karlsruhe v. 19.6.35 mit Zweitschr. für den badMdI (Akten des RJM, a.a.O.)

${ }^{139}$ Vgl. z. B. Korresp. zwischen Stapostelle u. GStA Königsberg u. dem RJM vom Sept./Okt. 1935 (a.a.O.). Eine weitere Ausnahme machte hier der Bezirk des GStAs Dresden, vgl. im folgenden S.620 und Anm. 151.
} 
Gesetz vom Februar und die Ernennung Himmlers zum Chef der Deutschen Polizei im Juni 1936 ihre Machtstellung ausgebaut hatte, konnte sich die Justizleitung dieser Forderung nicht länger entziehen. Nachdem das Geheime Staatspolizeiamt Ende November 1936 seinen Vorstoß erneuert und dabei darauf hingewiesen hatte, „daß zur Zeit im Reichsgebiet 21 verschiedene Abmachungen der Staatspolizei“ mit Justizbehörden über die Unterrichtung bei Entlassungen von Hochverrätern bestanden ${ }^{140}$, gab das Reichsjustizministerium am 18. Januar 1937 eine entsprechende Rundverfügung heraus. Sie hob die Bestimmungen vom Dezember 1934 auf und ordnete die Mitteilung über die Entlassung aller wegen Hoch- und Landesverrats Verurteilten einen Monat vor dem Entlassungstermin an, und zwar nur an diejenige Staatspolizei(leit)stelle, die die polizeilichen Ermittlungen geführt und die Akten mit Schlußbericht an das Gericht oder die Staatsanwaltschaft abgegeben hatte. Die Mitteilung erfolgte nunmehr direkt durch die Strafanstalten, denen die Strafvollstreckungsbehörde schon bei Einleitung der Vollstreckung die zuständige Staatspolizeistelle und deren Aktenzeichen angab. Die Strafanstalt verwendete dazu einen Vordruck, in dem außer den Personalien das erkennende Gericht, Datum und Aktenzeichen des Urteils, Tat, Strafe, Entlassungstag und künftiger Aufenthaltsort sowie ein „kurzer Bericht über die Führung während der Strafhaft, insbesondere Beobachtung über die politische Einstellung" eingetragen wurden. ${ }^{141}$ Nach Weisung der Gestapoführung sollte diese Beurteilung durch die Strafanstalt allerdings nicht die Grundlage für die Entscheidung über die anschlieBende Schutzhaft abgeben: vor allem das tadellose Verhalten kommunistischer Funktionäre in der Strafanstalt sollte „nicht als Zeichen innerer Umstellung gewertet werden ..., weil bekanntlich gerade die Funktionäre bemüht sind, durch einwandreie Führung Gnadenerweise oder günstige Beurteilungen zu erhalten“. ${ }^{142}$ In einer Besprechung am 1. Februar 1938 einigten sich der Hochverratsreferent und der stellvertretende Generalreferent für politische Strafsachen mit einem Vertreter des Geheimen Staatspolizeiamts, daß diesem Amt in denjenigen Fällen die Vorgänge zur nochmaligen Prüfung zugeleitet werden sollten, in denen das Justizministerium „mit Rücksicht auf eine besonders günstige Äußerung der Strafanstalt oder aus sonstigen Gründen Bedenken gegen die von der Stapo beabsichtigte Verhängung von Schutzhaft nach Strafverbüßung " habe. ${ }^{143}$ Bei Übersendung der Besprechungsniederschrift an die Gestapo äußerte der Leiter der Strafrechtspflegeabteilung nochmals schriftlich die Bitte, in allen Fällen „stets eingehend zu prüfen, ob die Maßnahme der Verhängung von Schutzhaft, die von dem Verurteilten und seinen Angehörigen als Zusatzstrafe aufgefaßt wird, vom dortigen Standpunkt als vorbeugende Maßnahme unbedingt erforderlich" sei. ${ }^{144}$ Darauf antwortete Heydrich, für die Entscheidung der Gestapo sei „nicht die irrige Auffassung des Verurteilten oder seiner Angehörigen“, sondern allein „die Art des

${ }^{140} \mathrm{Schr}$. des Gestapa an das RJM v. 24.11 .36 (Diensttageb. des RJM, Bd. 9, Eintr. v. 27.11.36, BA, Sign. R 22/930).

${ }^{141} \mathrm{RV}$ des RJM (mit Vordruckmuster) v. 18.1.37 an den ReiA beim VGH u. die GStAe zur Weitergabe an die OStAe u. Leiter der Vollz.Anstalten (a.a.O., Sign. R 22/1337).

${ }^{142}$ RdErl. des Gestapa v. 18. 2.37 (Arch. des IfZ, Sign. MA 443). So wurden nach Beginn des Krieges gegen die Sowjetunion aus der Strafhaft entlassene kommunistische Hochverräter pauschal in Schutzhaft genommen, vgl. Schr. des Chef Sipo/SD an den RJM v. 27.11.41 u. Mitteil. des RJM an den OReiA und die GStAe bei den zuständigen OLGen v. 24.12.41 (Akten des RJM, BA, Sign. R 22/1467).

${ }^{143} \mathrm{Vgl}$. Ergebnisprotokoll der Referentenbespr. am 1.2.38 (a.a.O., Sign. R 22/1467).

${ }^{144}$ Schr. Crohnes an das Gestapa v. 13.4.38 (a.a.O.). 
begangenen Deliktes und die politische Vergangenheit des Täters" maßgebend; auch die Führung während der Strafhaft oder die persönlichen Verhältnisse würden dabei „erst in zweiter Linie“ berücksichtigt. Entgegen der - vor allem intern - häufig offen geäußerten Motivation für die anschließende Inschutzhaftnahme ${ }^{145}$ behauptete Heydrich, daß die Schutzhaft „in keinem Falle als Zusatz- oder Ersatzstrafe gedacht" sei, sondern „in allen Fällen eine vorbeugende Maßnahme“ darstelle, „die von dem Wunsch diktiert ist, die der Geheimen Staatspolizei zufallenden Aufgaben zur Sicherung des Staates und Aufrechterhaltung der öffentlichen Ordnung restlos zu erfüllen“. ${ }^{146}$ Mit dieser Prärogative der Gestapo mußte sich die Justizleitung abfinden. Resigniert vermerkte der Generalreferent für politische Strafsachen nach Vortrag bei Abteilungsleiter Crohne zu den Akten:

„Soweit ... die Polizei entgegen unserer Auffassung den Standpunkt vertritt, daß bei der Prüfung der Schutzhaftfrage der Führung des Verurteilten in der Strafanstalt (und einer sich aus ihr gegebenenfalls ergebenden offenbaren inneren Umstellung) gegenüber der objektiven Staatsgefährlichkeit der begangenen Handlung und der politischen Vergangenheit des Täters nur nebensāchliche Bedeutung zukommt, ist von weiteren Schritten abzusehen, da es sich bei der Frage, ob nach Strafverbüßung als vorbeugende Maßnahme die Verhängung der Schutzhaft gegen einen Hoch- oder Landesverräter angezeigt ist, um eine rein polizeiliche Angelegenheit handelt.“

Er empfahl jedoch, in geeigneten Fällen dem Geheimen Staatspolizeiamt nach wie vor die Vorgänge entsprechend der getroffenen Vereinbarung zu nochmaliger Prüfung vorzulegen. ${ }^{147}$

Das Justizministerium achtete streng darauf, daß sich die Strafanstalten bei ihrer Beurteilung der Häftlinge, die sie in der Mitteilung über die Entlassung zu geben hatten, auf die Führung des Verurteilten beschränkten und sich jedes empfehlenden Kommentars enthielten. Als der Vorstand der Strafanstalt Bernau (Chiemsee), dem das Frauenzuchthaus Laufen angeschlossen war, die Beurteilung einer Gefangenen mit der Bemerkung schloß: „Ich erachte daher weitere Maßnahmen für angezeigt“, wurde die Verurteilte von der Gestapo anschließend prompt ins Frauenkonzentrationslager Ravensbrück gebracht. Das Justizministerium rügte diese Mitteilung mit der ausdrücklichen Feststellung, daß „eine Stellungnahme der Strafanstalt zur Schutzhaftfrage ... nicht vorgesehen und aus allgemeinen Erwägungen unerwünscht" sei. ${ }^{148}$

War mit der Rundverfügung vom 18. Januar 1937 „eine der wichtigsten Voraussetzungen für eine lückenlose Erfassung und Nachüberwachung der verurteilten Hochund Landesverräter gegeben“, so sah sich die Gestapo bei den anderen politischen Strafgefangenen ${ }^{149}$, die meist von den Sondergerichten und unteren Gerichten abgeurteilt worden waren, nach wie vor gezwungen, sich „die Kenntnis ihrer Entlassung

${ }^{145}$ Vgl. z. B. den GehRdErl. des RSHA v. 2.7.40 an alle Stapo(leit)stellen (Arch. des IfZ, Sign. MA 444/3, Bl. 953868): „Es ist in letzter Zeit die Erfahrung gemacht worden, daß die Gerichte in steigendem Maße Landesverräter nach $\S 90 \mathrm{c}$ RStGB zu geringen Freiheitsstrafen verurteilen ...“, daher sei die Frage anschließender Schutzhaft in jedem Falle zu prüfen. Vgl. auch die Beispiele im Kapitel VI.3.d., S.620f., 625.

${ }^{146}$ Schr. des Chefs der Sipo (gez. Heydrich) an das RJM v. 20.7.38 (a.a.O.).

${ }^{147}$ Verm. OStA Klemm v. 20.9.38 (a.a.O.).

${ }^{148}$ Schr. des RJM an den GStA München v. 21.2.41 mit der Bitte, den Anstaltsleiter zu instruieren (a.a.O.).

149 Nach dem RdErl. des Gestapa v. 29.7.35 waren z. B. alle Funktionäre marxist. Organisationen nach Strafverbüßung in Schutzhaft zu überführen, sofern sie besonders fanatisch eingestellt oder aktiv gewesen waren oder sich voraussichtlich erneut betätigen; vgl. RdErl. der BPP v. 13.8.35 (Arch. des IfZ, Sign. Fa 183/1, Bl. 338). 
zur Erreichung des gleichen Zieles wie bisher durch geeignete Vormerkungen oder Anfragen zu verschaffen “. ${ }^{150}$ Eine abweichende Regelung, die der Generalstaatsanwalt Dresden mit dem Geheimen Staatspolizeiamt Sachsen im Oktober 1935 getroffen hatte und die eine Benachrichtigung über die bevorstehende Entlassung bei allen politischen Strafgefangenen vorsah, durfte auf Bitten der Staatspolizeileitstelle Dresden zunächst noch beibehalten werden. ${ }^{151}$ Nachdem es aber auf der Tagung der Oberlandesgerichtspräsidenten und Generalstaatsanwälte im Reichsjustizministerium im Juni 1937 zu einer grundsätzlichen Erörterung des Gesamtproblems gekommen war, wurde der Generalstaatsanwalt Dresden angewiesen, ab 1. Oktober ausschließlich nach der Rundverfügung vom Januar zu verfahren, um damit eine einheitliche Regelung in ganz Deutschland herzustellen. ${ }^{152}$ Diese generelle Regelung blieb bis zum Ende des Regimes bestehen. Sie wurde jedoch von den Justizbehörden nicht immer genügend beachtet, so daß sie nach Beschwerden der Gestapoführung durch das Ministerium in Erinnerung gebracht werden mußte. ${ }^{153}$

Im Laufe der folgenden Jahre sollten neben den Hoch- und den Landesverrätern noch andere Häftlingsgruppen in die Mitteilungspflicht an die Gestapo über bevorstehende Strafentlassung einbezogen werden. Noch 1937 folgten die wegen Betätigung für die Internationale Bibelforschervereinigung Verurteilten, deren Inschutzhaftnahme nach verbüßter Strafe die Gestapo am 22. April 1937 anordnete. ${ }^{154}$ Als sich daraufhin die Staatspolizeileitstelle Stettin mit der Forderung nach Kooperation an den dortigen Generalstaatsanwalt wandte, zeigte das Reichsjustizministerium - das dadurch erstmals von dem Gestapo-Erlaß Kenntnis bekam - zunächst keine Bereitschaft, seine Rundverfügung vom Januar entsprechend zu ergänzen: der Generalstaatsanwalt mußte die notwendigen Anordnungen für seinen Geschäftsbereich allein treffen. ${ }^{155}$ Nachdem aber weitere Berichte auch aus anderen Oberlandesgerichtsbezirken eintrafen, konnte das Ministerium den Kopf nicht länger in den Sand stecken. Auf der bereits erwähnten Tagung aller Oberlandesgerichtspräsidenten und Generalstaatsanwälte am 18. Juni 1937 in Berlin äußerte Gürtner, daß die Schutzhaft nach Strafverbüßung ,zur Zeit eine mißliche Rolle auf dem Gebiet der Internationalen Bibelforscher" spiele. Aus dieser Besprechung geht deutlich hervor, welchen konkreten Druck die Gestapo durch ihre Praxis der Urteilskorrektur auf die Rechtsprechung ausübte. Nachdem der Leiter der Strafrechtspflegeabteilung Ministerialdirektor Crohne den fraglichen Gestapo-Erlaß den Anwesenden zur vertraulichen Kenntnisnahme verlesen hatte, führte

${ }^{150}$ So der Chef der Sipo in den geh. Richtlinien über die Nachüberwachung v. 17.2.38 (Arch. des IfZ, Sign. Fa 183/1, Bl. 386).

${ }^{151}$ Die Regelung wies zwei weitere Abweichungen auf: die Benachrichtigung erfolgte seit 20.4.36 zwei Monate vor der Entlassung und seit 17.10.36 zusätzlich an den SD, Oberabschnitt Elbe; vgl. Ber. des GStA Dresden an das RJM v. 22. 2.38 u. Genehmigungsschr. des RJM v. 2.3.37 (Akten des RJM, BA, Sign. R 22/954).

${ }^{152} \mathrm{Vgl}$. Verf. des RJM an den GStA Dresden v. 25.6.37 u. Vollzugsber. des GStA vom 24.7.37 (a.a.O.).

${ }^{153}$ Vgl. z. B. Beschwerdeschr. des Chef/Sipo an das RJM v. 30.6.41 u. die RV des RJM an den OReiA beim VGH u. die GStAe v. 16.7./4.8.41 (Akten des RJM, BA, Sign. R 22/956).

${ }^{154}$ Es handelt sich um denselben RdErl. des Gestapa, in dem auch die Inschutzhaftnahme von Bibelforschern nach Aufhebung der U-Haft und nach Freispruch angeordnet wurde (s. Kapitel VI.3.b., S.601); vgl. auch RdEntschl. der Stapoleitstelle München v. 19.5.37 (Arch. des IfZ, Sign. Fa 183/1, Bl. 374).

${ }^{155}$ Schr. der Gestapoleitstelle Stettin an den dortigen GStA v. 13.5.37, Schr. des GStA an das RJM v. 4.6.37 mit Ber. über seine Bespr. mit dem Generalref. für polit. Strafsachen am 2.6.37 (Akten des RJM, BA, Sign. R 22/1467). 
er aus, Himmler habe "geltend gemacht, daß die Strafen gegen die Bibelforscher zu gering seien. Das Gesetz sieht Geldstrafe und Gefängnis von 1 Monat bis zu 5 Jahren vor. Der Reichsführer-SS schlägt vor, in einer Novelle Zuchthaus anzudrohen". Die Bibelforscher, deren Zahl nach Angaben der Gestapo fünf bis sechs Millionen betrage - er, Crohne, „rechne mit 1 bis 2 Millionen“ -, seien nicht lediglich als religiöse Sekte oder ,alte Trottel“ anzusehen: indem sie den Wehrdienst und jede Tätigkeit in den für die Wehrmacht arbeitenden Betrieben, im Kriegsfall auch bei der Eisenbahn und Post verweigerten, ferner die Eidespflicht und den Führergedanken ablehnten, hätten sie sich zu einer staatsgefährdenden Vereinigung entwickelt. Da die von Himmler geforderte Novelle vor der Inkraftsetzung des vom Reichskabinett nahezu fertigberatenen neuen Strafgesetzbuches - das für aktive Bibelforscher wegen Teilnahme an einer wehrfeindlichen Verbindung die Zuchthausstrafe vorsah - nicht mehr in Frage komme, sei tunlichst die Möglichkeit der gegenwärtig bestehenden Höchststrafe auszuschöpfen, von der allerdings bisher „wenig Gebrauch gemacht" werde:

„Nur wenig Bezirke sind überhaupt bis zu 5 Jahren Gefängnis hinaufgegangen. Es sind dies die folgenden vier: Darmstadt, Dresden, Jena, Königsberg. Andere Bezirke sind auffällig milde; teilweise finden sich hier Geldstrafen. Daß eine Geldstrafe nicht mehr am Platze ist, brauche ich wohl nicht mehr hervorzuheben. Es handelt sich bei den milden Bezirken um folgende, wobei ich keine Anprangerung erreichen [!], sondern nur einen Hinweis geben will: Breslau, Celle, Düsseldorf, Naumburg, Stettin und Zweibrücken ... Ich bitte, darauf hinzuwirken, daß die Weichheit in dem Vorgehen gegen die Internationalen Bibelforscher zurückgestellt wird."

Dieser Schritt zur „Lenkung der Rechtsprechung“, der gegenüber den späteren Maßnahmen im Kriege noch als zahm bezeichnet werden kann, wurde durch die Ausführungen Staatssekretär Freislers ergänzt, der das im Hintergrund lauernde Schreckgespenst der „Polizeijustiz“ beschwor, die nur auf ein „Versagen“ der Justiz warte, um deren Funktion zu übernehmen. Freisler erklärte, ein uneinheitliches Strafmaß und eine „aus dem Rahmen fallende“ Milde erzeugten

„die Gefahr, daß die Aufgabe der Justiz, Rechtspflege zu üben, von anderen Stellen mitergriffen wird [!]. Es ist nicht gut, wenn jemand wegen einer Tat, für die er verurteilt worden ist, nach Verbüßung der gerichtlichen Strafe, ohne daß irgendetwas anderes hinzugekommen ist, weiter in einer Haft bleibt, die ihm als verlängerte Strafhaft erscheint ... Wenn die staatlichen Organe über das Strafmaß und den Erfolg des Strafvollzuges verschiedener Ansicht sind, liegt es nahe, daß dann das andere Sicherheitsorgan sagt, es habe auch das Seinige zu tun ... Diese Gefahr wird erhöht, wenn es nicht glückt, eine Strafzumessungspraxis herbeizuführen, die den Meinungen der beteiligten Stellen entspricht. Man könnte sagen, es sei auch nicht gut, wenn Stellen außerhalb der Justiz gewissermaßen die Strafzumessungsgründe vorschreiben. Ich meine, daß die richterliche Aufgabe der Strafzumessung viel stärker in unerfreulicher Weise dadurch eingeengt wird, daß der Täter ... in einer gleichsam verlängerten Strafhaft bleibt, als dadurch, daß man sich das richtige Strafmaß überlegt ... Wir können und dürfen von uns aus nirgends den Anschein erwekken, als wären wir nicht der Meinung, daß wir in der Lage sind, gegenüber dem Verbrechertum das Schlußwort des Staates zu sprechen und zu vollziehen."

Gleichzeitig sprach sich Freisler aber auch für eine klare Trennung der Funktionen von Justiz und Gestapo aus. Er bezeichnete es als "ganz unmöglich“, daß Schutzhaft im Anschluß an die Strafverbüßung - und sei es auch nur für kürzeste Zeit - in einem Justizgefängnis vollzogen werde. Alle Fälle, in denen die Gestapo dies etwa verlange, seien sofort zu melden:

„Die Verantwortlichkeit muß absolut klargestellt sein. Für politische Präventivhaft, die sich an eine Strafhaft anschließt, ... muß die dafür zuständige Stelle auch allein in Frage kommen. Sonst 
sieht es im Volke so aus, als ob in der Justiz selbst der Strafvollzug sich die Aufgabe gestellt hätte, die Urteile der Gerichte zu ändern. Eine solche Meinung dürfen wir nicht aufkommen lassen." ${ }^{156}$

Als das Justizministerium kurz nach dieser Besprechung das Ersuchen der Gestapoführung erfüllte und anordnete, die wegen Betätigung für die Internationale Bibelforschervereinigung Verurteilten in die Mitteilungspflicht über bevorstehende Strafentlassungen einzubeziehen ${ }^{157}$, setzte sie die Forderung Freislers bei der Gestapo durch: in einer zusätzlichen Rundverfügung wurde bestimmt, daß eine anschließende Schutzhaft der Bibelforscher „nicht, und zwar auch nicht vorübergehend, in einer Justizvollzugsanstalt" vollstreckt werden dürfte. ${ }^{158}$

Eine weitere Mitteilungspflicht erwuchs der Justiz, als die Gestapoführung zur Inschutzhaftnahme von „Rassenschändern“ - d.h. wegen unerlaubten Geschlechtsverkehrs zwischen Juden und „Staatsangehörigen deutschen und artverwandten Blutes“ Verurteilter ${ }^{159}$ - schritt und deshalb die Gestapostellen geheim anwies, jeden einzelnen Fall vier Wochen vor der Strafentlassung unter Beifügung des Urteils zur Entscheidung vorzulegen. ${ }^{160}$ Das Justizministerium erfuhr auch von diesem Geheimerlaß nicht durch die Gestapoführung, sondern Mitte Juli 1937 durch den Generalstaatsanwalt Celle, an den die Staatspolizeistelle in Bielefeld mit der Bitte herangetreten war, ihr u.a. nach rechtskräftigem Abschluß eines Rasseschandeverfahrens zwei Urteilsabschriften zu übersenden und den Tag der Entlassung des Verurteilten aus der Strafhaft sechs Wochen vorher mitzuteilen. ${ }^{161}$ Daraufhin fragte das Ministerium beim Reichsführer-SS an, ob die bisher getroffene Regelung, die doch nach den beiderseitigen Absprachen ,als eine erschöpfende anzusehen war“, tatsächlich abermals erweitert werden sollte und welche Gründe dafür vorlägen. Heydrich antwortete, die Erfahrungen seit dem Inkrafttreten des Blutschutzgesetzes hätten ergeben, daß selbst hohe Strafen nicht ausreichten, um „die Reinerhaltung des deutschen Blutes zu sichern“: die Rassenschandefälle hätten in letzter Zeit zugenommen, insbesondere seien wiederholt Rückfälle vorgekommen. „Bei der großen Bedeutung, die dieser Frage für die Zukunft des Deutschen Volkes“ zukomme, halte er „daher neben der strafgerichtlichen Verfolgung der einzelnen Fälle weitgehende sicherheitspolizeiliche Maßnahmen“, vor allem eine ausreichende Nachüberwachung, für geboten. Er bitte daher, den Staatsanwälten eine entsprechende Weisung mit einer Sechs-Wochen-Frist zu erteilen. In die früheren Erörterungen hätte dieses Problem noch nicht eingeschlossen werden können, da sich die Notwendigkeit zu derartigen Maßnahmen erst in letzter Zeit ergeben hätte. ${ }^{162}$

${ }^{136}$ Prot. der Bespr. mit den OLGPräs. u. GStAen im RJM am 18.6.37 vormittags (a.a.O., Sign. R 22/4277).

${ }^{157}$ Die RV des RJM v. 2.7.37 (a.a.O., Sign. R 22/1337) dehnte die Regelung der RV v. 18.1.37 „mit sofortiger Wirkung" auf diese Gruppe aus.

${ }^{158}$ RV des RJM v. 7.7.37 (a.a.O., Sign. R 22/1421) u. entspr. RdErl. des Gestapa v. 5.8. 37 (StArch. Düsseldorf, Sign. Best. RW 18). Der Grundsatz wurde generell für alle Häftlingsgruppen nochmals festgelegt in der RV des RJM v. 7.7.39 (Akten des RJM, a.a.O.), vgl. Kapitel VI.2.c., S. 582.

${ }^{159} \mathrm{Vgl}$. $\$ \S 2$ u. 5 Abs. 2 des G. zum Schutze des deutschen Blutes und der deutschen Ehre (BlutschutzG) v. 15.9.35 (RGBl. I, S. 1146).

${ }^{160}$ Vgl. geh. RdErl. des Chefs der Sipo (gez. Heydrich) an alle Stapo- u. Kripo(leit)stellen v. 12.6.37 (Akten des RJM, BA, Sign. R 22/50); da sich nach dem BlutschutzG jeweils nur der Mann strafbar machte, sollte sofort nach rechtskräftigem Abschluß des Verfahrens gegen einen Deutschblütigen die beteiligte Jüdin in Schutzhaft genommen werden.

${ }^{161}$ Vertraul. Schr. des GStA Celle an das RJM v. 14.7.37 nebst Schr. der Stapostelle für den RegBez. Minden u. die Länder Lippe u. Schaumburg-Lippe an ihn v. 29.6.37 (a.a.O.). Eine Abschr. des geh. Heydrich-Erl. v. 12.6.37 hatte ihm der OStA Detmold vertraulich überlassen.

${ }^{162}$ Schr. des RJM an den RFSSuChdDtPol. im RMdI v. 21.8.37 u. Antwort (I.V. Heydrich) v. 4. 1. 38 (a.a.O.). 
Das Justizministerium entsprach dem Ersuchen und ordnete am 8. März 1938 an, daß der zuständigen Staatspolizei(leit)stelle schon bei Abschluß des Verfahrens eine Abschrift des rechtskräftigen Urteils zu übersenden und ihr der Entlassungstag - abweichend von der bisherigen Fristenregelung - bereits sechs Wochen vorher mitzuteilen war. ${ }^{163}$ Die Mitteilungspflicht an die Gestapo über die Strafentlassung von Landesverrätern, Hochverrätern, Bibelforschern und „Rassenschändern“" wurde später unter Aufhebung der entsprechenden Einzelverfügungen in den „Mitteilungen in Vollzugssachen" zusammengefaßt und dabei eine einheitliche Frist von sechs Wochen festgesetzt. ${ }^{164}$

Hatte sich die Justiz bis Frühjahr 1938 durch Anzeige der bevorstehenden Entlassung von Angehörigen der genannten Häftlingsgruppen zur technischen „Mitwirkung“ bei der Schutzhaftverhängung nach Strafverbüßung bewegen lassen, so empfand sie diese Maßnahme trotzdem als Urteilskorrektur und suchte sie in Einzelfällen abzuwenden. $\mathrm{Zu}$ den Kritikern dieser Gestapopraxis gehörte der Hamburger Oberlandesgerichtspräsident Rothenberger. Anläßlich einiger Bibelforscherfälle wandte er sich im April 1938 an den Hamburger Gestapochef Streckenbach, „daß derartig widersprechende Entscheidungen der Gerichte und der Staatspolizeistellen im Interesse der Sache besser vermieden werden sollten" ${ }^{165}$ Nachdem ihn Streckenbach auf die Anordnung des Geheimen Staatspolizeiamtes verwiesen hatte, Bibelforscher nach Entlassung grundsätzlich in Schutzhaft zu nehmen, ließ Rothenberger einen Bericht mit folgendem Vorschlag an das Reichsjustizministerium senden: da „derartige Vorfälle dem Ansehen der Justiz außerordentlich abträglich" seien, wollte er die in Sondergerichtssachen tätigen Richter seines Bezirks von der grundsätzlichen Entscheidung der Gestapo - die das Ministerium bisher nur den Oberlandesgerichtspräsidenten und Generalstaatsanwälten auf der Berliner Tagung mündlich und vertraulich mitgeteilt hatte informieren,

„damit sie bei der Findung ihrer Entscheidung und der Abfassung der Urteilsgründe darüber unterrichtet sind, daß der Verurteilte nicht in Freiheit kommen wird. Nur auf diesem Wege scheint es mir möglich, Begründungen ..., die angesichts der Praxis der Geheimen Staatspolizei und der für sie bestehenden Anweisungen utopisch sind, zu verhindern. ${ }^{166}$

In diesem Vorschlag kommt die Ambivalenz der damaligen Politik der Justizverwaltung deutlich zum Ausdruck. Einerseits sollte das „Ansehen“ der Justiz durch die Verhängung höherer Freiheitsstrafen, die die „herabsetzende" Urteilskorrektur vermied oder zumindest hinausschob, gewahrt werden. Andererseits wurde dadurch der

${ }^{163}$ RV des RJM an die GStAe v. 8.3.38 (a.a.O.). Im Übersendungsschr. an den RFSSuChdDtPol. wurde Einverständnis unterstellt, daß die Angelegenheit künftig nicht mehr als „geheim“ behandelt werde.

${ }^{164} \mathrm{Vgl}$. Ziff. 16 Abs. 2 der AV des RJM v. 25.3.41 (DJ, S. 399). Ergänzend sei erwähnt, daß im Kriege weitere Häftlingsgruppen in die Mitteilungspflicht einbezogen wurden: z. B. alle Juden (AV des RJM v. 20.11.41, DJ S. 1091), ferner Polen, die eine Freiheitsstrafe von mehr als 6 Monaten verbüßt hatten (geh. RV des RJM an die GStAe v. 21.4.43, Arch. des IfZ, Sign. Fa 506/11). Gemäß Erl. des RSHA v. 11.3.43 (a.a.O.) sollten die Juden nach Auschwitz bzw. Lublin, die Polen auf Kriegsdauer ins KZ überführt werden.

${ }^{165}$ Schr. Rothenbergers an den Leiter der Stapoleitstelle Hamburg, ORegRat u. SS-Oberführer Streckenbach, v. 25.4.38 (Akten des OLG Hamburg, Arch. der Forschungsstelle für die Geschichte des NS in Hamburg, Sign. Best. 330). Zum folgenden vgl. auch die aus Material der Hamburger Justizbehörden erarbeitete Darstellung von W. Johe, a.a.O. (s. Anm. 83), S. $155 \mathrm{ff}$.

${ }^{166}$ Schr. des Vizepräs. des OLG Hamburg Letz an das RJM v. 12.10.38 nach Eingang der Antw. Streckenbachs v. 7.10.38 (Akten des OLG Hamburg, a.a.O.). 
Weg eröffnet, Bibelforscher für Jahre im Justizgefängnis zu behalten und vor dem Konzentrationslager zu bewahren.

Das Reichsjustizministerium nahm den Hamburger Bericht zum Anlaß, ähnlich wie früher bei den Hochverrätern an die Gestapoführung mit der Frage heranzutreten, ob es wirklich angebracht sei, jeden Bibelforscher nach Strafverbüßung in Schutzhaft zu nehmen. Als Beispiel führte es u.a. einen der von Rothenberger beanstandeten Fälle an, in dem eine Bibelforscherin, Mutter von zwei Kindern, nach Verbüßung ihrer als „hart genug“ angesehenen Strafe von einem Jahr und drei Monaten Gefängnis erneut verhaftet worden war. In einem solchen Fall sei zu befürchten, daß auch die übrigen Familienmitglieder - denen keine Bibelforschertätigkeit nachgewiesen wurde - „so verbittert werden, daß in Zukunft mit einer staatsfeindlichen Einstellung zu rechnen“ sei. Das Ministerium halte es demgegenüber für angebracht, daß Leute, die sich von der Bibelforscherlehre abkehrten, nach Verbüßung ihrer Strafe freigelassen werden sollten, „damit sie allein schon durch das Beispiel weiterhin in ihrem ehemaligen Sektiererkreis zersetzend wirken “. ${ }^{167}$ In ihrer Antwort behauptete die Gestapoführung, daß Bibelforscher „nur dann in Schutzhaft genommen bezw. in ein Konzentrationslager verbracht" würden, wenn sie trotz verbüßter Strafe an ihrer Irrlehre festhielten, daher würden sie ,in jedem Einzelfall einer eingehenden Prüfung“ unterzogen. Das konnte angesichts der angeordneten Pauschalverhaftung ${ }^{168}$ jedoch nur heißen, daß die Entscheidung darüber während der bereits realisierten Schutzhaft getroffen wurde. Die erwähnte Bibelforscherin, schrieb die Gestapo, sei jedenfalls immer noch eine eingefleischte Vertreterin ihrer Lehre, während sich in einem anderen der monierten Fälle der Betroffene ,inzwischen im Lager umgestellt" habe und nach fast sechzehnmonatiger Schutzhaft entlassen worden sei. ${ }^{169}$ Damit mußte sich das Justizministerium zufriedengeben; es teilte Rothenberger mit, es müsse „der pflichtgemäßen Prüfung der mit Handhabung vorbeugender Maßnahmen betrauten Stellen überlassen bleiben, ob sie von den ihnen obliegenden Mitteln" Gebrauch machten. Die berichteten Fälle seien „daher nicht geeignet, bei dem RFSS. weitere Vorstellungen zu erheben“. Auf den Vorschlag, die beteiligten Richter von der grundsätzlichen Entscheidung der Gestapo zu unterrichten, ging das Ministerium in dem Schreiben nicht ein. ${ }^{170}$

Das Reichsjustizministerium behielt trotz allem die Korrekturmaßnahmen der Gestapo ständig im Auge. Auf einer Berliner Arbeitstagung ließ Gürtner am 23. Januar 1939 die Generalstaatsanwälte und am nächsten Tag die Oberlandesgerichtspräsidenten über dieses Problem ausführlich Bericht erstatten, um sich „über die Erfahrungen der Außenbehörden zu unterrichten “. ${ }^{171}$ Die Generalstaatsanwälte trugen vor, daß

${ }^{167}$ Schr. des RJM (Generalref. für polit. Strafsachen, OStA Klemm) an den Chef der Sipo v. 13.12.38 (Akten des RJM, BA, Sign. R 22/1467).

${ }^{168} \mathrm{Vgl}$. Wiedergabe des RdErl. des Gestapa v. 22.4.37 in der RdEntschl. der Stapoleitstelle München v. 19.5.37 (Arch. des IfZ, Sign. Fa 183/1, Bl. 374): „Sämtliche Anhänger der I.B.V., die nach Beendigung der Strafhaft aus den Gefängnissen entlassen werden, sind unverzüglich in Schutzhaft zu nehmen; ihre Überführung in ein Konzentrationslager ist unter Darlegung des Sachverhalts zu beantragen."

${ }^{169}$ Schr. des RFSSuChdDtPol an das RJM v. 8.2.39 (Akten des RJM, BA, R 22/1467). Hervorheb. im Original.

${ }^{170}$ Schr. des RJM (Crohne) an den OLGPräs. Hamburg v. 27.3.39 (a.a.O.). Die persönl. Information der Richter scheint über den LGPräs. dennoch erfolgt zu sein, da Rothenberger schon Anfang Dezember nicht mehr mit einer Antw. des RJM rechnete, vgl. Verm. Letz' v. 2.12.38 (Akten des OLG Hamburg, a.a.O., Sign. Best. 330).

${ }^{171} \mathrm{Vgl}$. RV des RJM v. 14.1.39 mit Tagesordnung für die Zusammenkunft (Akten des RJM, BA, Sign. R 22/1263). 
Schutzhaft nach Strafverbüßung weiterhin erfolge - im Oberlandesgerichtsbezirk München waren es unterdessen ,insgesamt nach Strafhaft 359“ Fälle -, daß aber im letzten Jahr „hinsichtlich der abträglichen Fälle Besserung“ eingetreten sei. Die Generalstaatsanwälte von Braunschweig und Naumburg berichteten von „peinlichen“ Einzelfällen, bei denen die „Kritik an der Justiz durch Schutzhaftmaßnahmen nicht ganz unberechtigt" gewesen sei. Gürtner schloß die Aussprache der Generalstaatsanwälte mit der Feststellung, daß diese Fälle im Interesse der Justiz zu bedauern seien, im übrigen aber gegen die Maßnahmen der Gestapo, soweit sie präventiver Natur seien, nichts eingewendet werden könne. Während die meisten Oberlandesgerichtspräsidenten erklärten, daß es sich in den überwiegenden Schutzhaftfällen um Präventivmaßnahmen gehandelt habe - teilweise auch, daß die Zahl der Fälle, die einer Justizentscheidung entgegenstanden, überhaupt zurückgegangen sei -, berichtete Rothenberger über eine Zunahme der Schutzhaftfälle in seinem Bezirk, seit über den Schutzhaftbefehl bei der Gestapozentrale in Berlin entschieden würde. Dabei habe die Gestapo teilweise Haftgründe zu den Akten vermerkt, die eindeutig zeigten, daß sie sich den Gerichten gegenüber als berufene Korrekturinstanz betrachte: in einigen Fällen habe sie offen angegeben, daß die Schutzhaft erfolge, „um die verbüßte Strafe noch wirksamer zu gestalten" ${ }^{.172}$ In einer Ausarbeitung, die sich Rothenberger für diese Tagung hatte anfertigen lassen, finden sich Bemerkungen über die negativen Auswirkungen der polizeilichen Korrekturmaßnahmen. Obwohl nicht sicher ist, ob er sie auf der Tagung vortrug ${ }^{173}$, seien sie in diesem Zusammenhang erwähnt, da sie nicht nur mit den Ansichten Rothenbergers, sondern der meisten leitenden Justizbeamten im Einklang gestanden haben dürften. Darin wurde ausgeführt, daß die Urteilskorrektur beim Richter das Gefühl der Sinnlosigkeit seiner Tätigkeit sowie seelische Spannungen erzeugen müsse und letztlich seine Unabhängigkeit gefährde. Noch schlimmer aber sei der Verlust der Autorität der Justiz und des Staates überhaupt beim einfachen Volksgenossen: er müsse

„den Eindruck des Gegeneinanderarbeitens der verschiedenen staatlichen Organe gewinnen, und das Bild des einheitlichen und geschlossenen nationalsozialistischen Staatsgefüges muß bei ihm aufs schwerste erschüttert werden. Schließlich wird von dem Volksgenossen die Respektierung staatlicher Akte verlangt; wie wird der Volksgenosse darüber denken, wenn er sieht, daß die von ihm verlangte Respektierung staatlicher Akte von Organen des Staates selbst nicht betrieben wird? ... Grundsätzlich ist aber noch zu bedenken, daß der Richter kraft Auftrags des Führers entscheidet, also der Angriff auf ihn letzten Endes ein Angriff auf den Führer selbst ist. Gerade dieses Argument wird ja von den Behörden der polizeilichen Verwaltung ihrerseits stets ins Feld geführt.."174

${ }^{172}$ Niederschr. v. 25.1 .39 (unterz. von Klemm) über die Bespr. mit den GStAen am 23. u. die Bespr. mit den OLGPräs. am 24.1.39 (a.a.O., Sign. R 22/1467).

${ }^{173}$ Während laut Niederschr. die in der Ausarbeitung enthaltenen Fälle von Rothenberger auf der Bespr. vorgetragen wurden, sind die folgenden Bemerkungen in der Niederschr. nicht erwähnt: entweder hat $R$. diese kritischen Bemerkungen unterlassen oder sie wurden aus internen Gründen nicht in die Niederschr. aufgenommen. Bei seinem Vortrag zu einem anderen Tagesordnungspunkt (vgl. Johe, a.a.O., S. 163) hat R. die Ausarbeitung wiederum benutzt. Vgl. dazu auch Anm. 179).

${ }^{174}$ Undat. Ausarbeitung für die Bespr. am 24.1.39, laut Johe, a.a.O., S. 159, vermutl. vom Mitarbeiter Rothenbergers AGRat Bepler (Akten des OLG Hamburg, Archiv der Forschungsstelle für die Geschichte des NS in Hamburg, Sign. Best. 3305). Im letzten Argument klingen bereits Gedankenzüge wie in Rothenbergers spãteren Vorstellungen einer Justizreform an: wenige, mit unmittelbar vom Führer abgeleiteter Autorität ausgestattete Richter, die von Staats- u. Parteistellen unabhängig und ohne starre Bindung an das Gesetz nach dem Willen des Führers Recht sprechen, folglich aber an dessen Willen absolut gebunden sind. 
Nach Hamburg zurückgekehrt, berichtete Rothenberger seinen Gerichtspräsidenten von der Berliner Besprechung und ersuchte sie, ihm Fälle von Urteilskorrekturen sofort zu melden. ${ }^{175}$ Ferner reichte er an Gürtner persönlich und vertraulich die Akten zu einigen der auf der Tagung mündlich vorgetragenen Fälle ein. ${ }^{176}$ Das Generalreferat für politische Strafsachen erörterte diese Fälle mit dem Sachbearbeiter für Schutzhaftfragen beim Reichsführer-SS anläßlich einer Besprechung über andere Angelegenheiten am 17. August 1939. Der Gestapo-Vertreter erklärte, „daß die für die Inschutzhaftnahme gegebene Begründung [offensichtlich aber nicht die Inschutzhaftnahme selbst!] von seiner Dienststelle in keiner Weise gebilligt würde und untragbar sei““. ${ }^{177}$ Nach Vortrag bei Gürtner und Freisler teilte Ministerialdirektor Crohne Rothenberger dieses Ergebnis unter Rückgabe der Akten mit und äußerte dabei die wenig realistische Annahme, daß auf Grund dieser Erklärung "gleichartige unsachgemäße Maßnahmen künftig unterbleiben werden ". ${ }^{178}$

Bei seiner grundsätzlichen Ohnmacht gegen die Urteilskorrekturen durch anschlieBende Schutzhaft blieb dem Reichsjustizministerium schließlich nur der Weg übrig, bei der Gestapoführung immer wieder in geeigneten Einzelfällen vorstellig zu werden, um zu versuchen, die Praxis der Gestapo dadurch vielleicht doch zu beeinflussen. Im Mai 1939 schlug der Hochverratsreferent des Ministeriums dem Leiter der Strafrechtspflegeabteilung vor, diese Methode der Gestapo gegenüber zum Prinzip zu erheben. Er führte aus, bei der letzten Berliner Arbeitstagung mit den höheren Behördenchefs im Januar sei „erneut zum Ausdruck gekommen“, daß Schutzhaft nach verbüßter Freiheitsstrafe "grundsätzlich unerwünscht" sei ${ }^{179}$ :

„Aus diesem Grunde habe ich in Einzelfällen, in denen Gnadengesuche hier durchgegangen sind, aus welchen hervorging, daß ein Verurteilter in Schutzhaft genommen worden ist, oder in denen eine Besorgnis [besteht], der VU. [Verurteilte] könnte im Anschluß an die Strafhaft in Schutzhaft genommen werden, ... Ermittlungen über die Führung des VU. angestellt und bin, wenn die Führung gut war, an die Geh. Staatspolizei herangetreten ... Ich hoffe auf diesem Wege eine Lockerung von Inschutzhaftnahmen nach Strafverbüßung zu erreichen, was ja in unserem Sinne liegt."

Der Referent bat Ministerialdirektor Crohne, diese Art der Sachbehandlung grundsätzlich zu genehmigen. Crohne setzte unter diesen Vorschlag den vielsagenden Vermerk: „Einverstanden! Durch diese Methode wird die Gestapo sich an unsere Auffassung gewöhnen, sodaß sie später von selbst nach unseren Grundsätzen handeln wird." "180

Diese Hoffnung sollte sich allerdings nicht erfüllen. Die Schutzhaft nach VerbüBung der gerichtlichen Strafe blieb bis zum Ende des Regimes eine ständige Reibungsfläche zwischen Justiz und Gestapo.

\footnotetext{
${ }^{175}$ Ber. über die Präsidentenbespr. am 1.2.39 (Nürnbg. Dok. NG-629).

${ }^{176} \mathrm{Vgl}$. persönl. Schr. Rothenbergers an Gürtner v. 30.1.39 (Akten des RJM, BA, Sign. R 22/1467).

${ }^{177}$ Aktenverm. v. 30.8.39 (a.a.O.).

178 Vertraul. Schr. des RJM (I.A. Crohne) an den OLGPräs. Hamburg v. 7.9.39 (a.a.O.).

179 Daraus ergibt sich, daß diese Frage auf der Berliner Bespr. (neben den in der Niederschr. Klemms festgehaltenen Berichten der GStAe u. OLGPräs. über aufgetretene Fälle) auch grundsätzlich erörtert worden sein muß. Das erhöht die Wahrscheinlichkeit, daß Rothenberger die angeführte Kritik vorgebracht hat.

${ }^{180}$ Vgl. Aktenverm. des Hochverratsref. und Crohnes v. 10.5.39 (a.a.O.).
} 


\section{e. Schutzhaft gegen begnadigte Strafgefangene und Beteiligung der Gestapo bei Gnadenerweisen}

Ein besonderes Problem bildete die Schutzhaftverhängung gegen Strafgefangene, die aufgrund eines Gnadenerweises vor der Verbüßung ihrer Freiheitsstrafe aus der Haft entlassen wurden. „Da die Begnadigungen im Namen des Führers ausgesprochen werden“, schrieb der Leiter der Politischen Polizei im Geheimen Staatspolizeiamt, SSHauptsturmführer Müller, am 25. März 1936 an das Reichsjustizministerium, „könnte leicht der Eindruck erweckt werden, daß durch eine auf die Amnestierung folgende Inschutzhaftnahme der Gnadenerweis des Führers illusorisch gemacht" werde. Um dieses Dilemma zu vermeiden, schlug Müller vor, bei politischen Strafgefangenen die zuständige Staatspolizeistelle oder das Geheime Staatspolizeiamt schon in die Bearbeitung der Gnadensachen - d.h. bevor ein Gnadenvorschlag an Hitler erging - einzuschalten. ${ }^{181}$ Der zuständige Referent des Justizministeriums klärte Müller telefonisch darüber auf, daß sich dieses Problem und daher auch der geäußerte Wunsch nicht auf alle „politischen Strafhäftlinge“, sondern nur auf die wegen Hoch- und Landesverrats verurteilten Gefangenen beziehen könnte, für die sich Hitler die Ausübung des Begnadigungsrechts vorbehalten hatte. ${ }^{182}$ Müller teilte ihm mit, daß es sich nach den Erfahrungen der Gestapo auch bei begnadigten Hochverrätern „vereinzelt um absolut staatsfeindliche Elemente handele, die vermutlich alsbald rückfällig würden und deshalb in Schutzhaft genommen werden sollten" ${ }^{183}$ Das Justizministerium wies daraufhin am 7. April 1936 den Oberreichsanwalt und die Generalstaatsanwälte an, bei dem abschließenden Bericht zur Gnadenfrage in Hochverratssachen regelmäßig eine Stellungnahme der zuständigen Staatspolizeistelle beizuziehen. In allen Fällen, in denen nicht von vornherein eine Vergünstigung im Gnadenwege ausgeschlossen erscheine, sollten sie daher zur Vermeidung von Verzögerungen bei der Staatspolizeistelle schon rechtzeitig eine rasche Stellungnahme anfordern. Das Justizministerium bat die Gestapoführung, ihre Dienststellen zu veranlassen, daß sie den Staatsanwaltschaften „mit allergrößter Beschleunigung“ anworteten: da es sich bei Hochverratssachen meist nur um einen Gnadenerweis für einen kurzen Strafrest handele, würde er sonst ,aus zeitlichen Gründen gegenstandslos werden“ “ ${ }^{184}$ Das Geheime Staatspolizeiamt wies seine Dienststellen entsprechend zu schneller Erledigung an. ${ }^{185}$

Durch diese Regelung konnte die Gestapo auf Gnadenerweise in Hochverratssachen erheblichen Einfluß nehmen, da auch die Justizbehörden in der Regel die Ablehnung des Gnadengesuchs vorschlugen, wenn die Gestapo die politische Wandlung des Verurteilten verneint und dem Gesuch widersprochen hatte. Dennoch war das eigentliche Problem damit noch nicht gelöst: es kam zuweilen vor, daß Hitler selbst entgegen dem Vorschlag der Justiz Gnadenerweise bewilligte. So gewährte er am 21. Oktober 1936 einem vom Oberlandesgericht Hamburg wegen Vorbereitung des Hochverrats

\footnotetext{
${ }^{181}$ Schr. des Gestapa (I.A. Müller) an das RJM v. 35.3.36 (Akten des RJM, BA, Sign. R 22/1467).

${ }^{182} \mathrm{Vgl}$ § 1 der GnadenO v. 6.2 .35 (DJ 1935, S. 203). Das dem RJM durch Erl. Hitlers v. 1.2.35 (RGB1. I, S.74) übertragene Recht zu ablebnenden Entschließungen übertrug der RJM durch die RV v. 6.5.35 (Strafrechtliche Verwaltungsvorschriften, zusammengest. von K. Krug, K. Schäfer u. a., 3. Aufl. Berlin 1943, S. 805) auf den OReiA und die zuständigen GStAe weiter in den Fällen, in denen keine der nach der GnadenO anzuhörenden Stellen einen Gnadenerweis befürwortete.

${ }^{183}$ Aktenverm. v. 3.4.36 (Akten des RJM, BA, Sign. R 22/953).

${ }^{184}$ Schr. des RJM an das Gestapa v. 7.4.36 nebst Abdruck der RV v. selben Tag (a.a.O., Sign. R 22/1467).

${ }^{185} \mathrm{RdErl}$. des Polit.Pol.Kommandeurs/Gestapa an die Stapostellen u. Polit. Pol. der Länder v. 25.4.36 (a.a.O.).
} 
zu einem Jahr Gefängnis verurteilten Arbeiter für einen Strafrest von drei Monaten und elf Tagen bedingte Strafaussetzung mit einer vierjährigen Bewährungsfrist. Die Hamburger Gestapo hatte jedoch schon in ihrer Stellungnahme zur Gnadenfrage am 15. August erklärt, daß sie den Verurteilten nach Strafverbüßung in Schutzhaft nehmen werde. Acht Wochen vor dem Entlassungstermin schrieb daher das Reichsjustizministerium an den Chef der Sicherheitspolizei, der Gnadenerweis des Führers bringe zum Ausdruck, „daß der Strafzweck erfüllt und die vorzeitige Rückkehr des Verurteilten zu seinen Angehörigen gerechtfertigt" sei; bei Verwirklichung ihrer Absicht würde die Gestapo diesen Gnadenerweis zunichte machen. Es sei aber

„mit dem Führerprinzip unvereinbar, wenn dem ausdrücklich erklärten Führerwillen zuwider auf Grund des gleichen Sachverhalts, der der Entscheidung des Führers zu Grunde gelegen hat, von einer Stapostelle Schutzhaft angeordnet wird“.

Eine Schutzhaft käme hier im höchsten Falle nur dann in Betracht, „wenn gegen den zu Entlassenden neue, seine politische Unzuverlässigkeit beweisende Gesichtspunkte" vorlägen. ${ }^{186}$ Daraufhin wies das Geheime Staatspolizeiamt die Hamburger Staatspolizeistelle tatsächlich an, von der Verhaftung des Arbeiters Abstand zu nehmen, und untersagte seinen nachgeordneten Behörden, von Hitler begnadigte Strafgefangene - auch dann, wenn der Gnadenerweis entgegen der Stellungnahme der Gestapo ergangen war - in Schutzhaft zu nehmen, „da sonst dem ausdrücklich erklärten Willen des Führers, dessen Entscheidung auf Grund desselben Sachverhalts erfolgt ist, zuwidergehandelt werden würde“. Die vorherige Befürwortung des Gnadengesuchs durch die Gestapo schließe natürlich eine Inschutzhaftnahme nach der Begnadigung erst recht aus. Dennoch sollte auch ein Gnadenerweis durch Hitler für den Betreffenden keinen unverbrüchlichen Freibrief darstellen: würden nach Abgabe einer befürwortenden Stellungnahme nachteilige Aspekte bekannt, so sei darüber schnellstens ein Nachtrag zum Gnadenvorgang anzufertigen; Schutzhaft sei gegen einen zur Entlassung kommenden Begnadigten aber ,nur dann anzuordnen, wenn neue, seine politische Unzuverlässigkeit beweisende Gesichtspunkte vorliegen “ ${ }^{187}$ Trotz der einschränkenden Formulierung hatte sich die Gestapo mit diesem Satz die Möglichkeit offengehalten, auch von Hitler begnadigte Strafgefangene wieder zu verhaften.

Es stellte sich heraus, daß die Gnadenäußerungen der einzelnen Staatspolizeistellen bei Hochverratsfällen erheblich voneinander abwichen und sich in ihrer grundsätzlichen Auffassung unterschieden. Das Justizministerium gab der Gestapoführung - die ihrerseits stets die uneinheitliche Rechtsprechung in Hochverratssachen kritisierte und zum Anlaß für „Korrekturen“ nahm - davon nicht ohne innere Genugtuung Kenntnis. ${ }^{188}$ Als auch auf internen Gestapobesprechungen gegebene Richtlinien das Problem nicht lösten, erließ Heydrich am 23. November 1937 die Weisung, daß nur noch das Geheime Staatspolizeiamt berechtigt sei, in Hoch- und Landesverratssachen Stellungnahmen gegenüber den Gnadenbehörden abzugeben: wenn die Staatspolizei(leit)stellen darum ersucht würden, sollten sie die Vorgänge mit einem Bericht an

\footnotetext{
${ }^{186}$ Schr. des RJM (I.A. Crohne) an den RFSSuChdDtPol im RMdI/Chef der Sipo v. 4.11.36 (a.a.O., Sign. R 22/ 954), Hervorheb. im Original.

${ }^{187}$ Schr. des Gestapa an das RJM v. 17.11.36 u. RdErl. an alle Stapo(leit)stellen v. 15.12.36 (a.a.O.).

${ }^{188}$ Verm. des Ref. über telef. Bespr. mit Müller v. 13.1.37 (a.a.O.).
} 
die Zentrale übersenden. Auf Heydrichs Wunsch hin sollten aber die Justizbehörden ihre Ersuchen auch weiterhin an die örtlichen Gestapostellen richten. ${ }^{189}$

Am 1. Februar 1938 einigten sich die Hochverratsreferenten des Justizministerums mit dem zuständigen Vertreter des Geheimen Staatspolizeiamts über folgende Grundsätze:

1. Eine Verhängung von Schutzhaft gegen begnadigte und entlassene Hochverräter sollte auch dann nicht effolgen, wenn der Gnadenerweis - statt durch Hitler - „auf Grund der bevorstehenden Delegation des Gnadenrechts für Reststrafen bis zu drei Monaten" durch den Reichsjustizminister gewährt werde. Das bisherige Verfahren, vor Erteilung eines Gnadenerweises eine Äußerung der Gestapo einzuholen, sollte auch in diesen Fällen angewendet werden.

2. Eine ablehnende Stellungnahme der Gestapo werde bei der Entschließung des Reichsjustizministeriums zur Gnadenfrage besonders berücksichtigt werden. Dabei werde aber davon ausgegangen, daß sich diese Stellungnahme „auch mit etwaigen zu Gunsten des Verurteilten sprechenden Umständen, insbesondere einer günstigen Äußerung der Strafanstalt auseinandersetzt“. Sie sollte u.a. in Fällen, in denen die hochverräterische Tat erst verhältnismäßig spät entdeckt wurde - z. B. unmittelbar nach der Machtübernahme begangen, aber erst Jahre später bekannt wurde -, auch das Verhalten des Verurteilten in der Zwischenzeit bis zur Festnahme berücksichtigen.

3. Damit sich die Gestapo in diesem Sinne erschöpfend zur Gnadenfrage äußern könne, sollten ihr die Äußerungen der anderen Gnadenstellen, insbesondere der Strafanstalt, durch den Oberreichsanwalt beim Volksgerichtshof und die Generalstaatsanwälte abschriftlich mitgeteilt werden, falls nicht der Bitte um Stellungnahme überhaupt gleich das Gnadenheft beigefügt werden könne.

4. Da verschiedentlich nach Erteilung eines Gnadenerweises verhängte Schutzhaft darauf zurückzuführen war, daß die Gestapo von der Begnadigung nichts wußte, wollte das Justizministerium künftig für eine rechtzeitige Mitteilung durch die Staatsanwaltschaft sorgen. ${ }^{190}$

Am 20. Juli 1938 äußerte sich Heydrich schriftlich zu dieser Referentenvereinbarung, die ihm in Form des Besprechungsprotokolls vom Justizministerium übersandt worden war. Er legte die Grundsätze dar, nach denen die Gestapo prüfte, „ob die Begnadigung vom Standpunkt der Staatssicherheit verantwortet werden" konnte; sie unterschieden sich von denen der Justiz erheblich. Die zuständige Staatspolizeistelle - d.h. diejenige, die die Strafsache schon vor Abgabe an die Justiz bearbeitet hatte - habe dabei folgendes zu berücksichtigen:

„a) nicht nur die objektive Staatsgefährlichkeit der begangenen Handlung (Sprengstoffverbrechen und sonstige Leben Einzelner oder Mehrerer gefährdende Anschläge und dergleichen) sondern auch die Intensität des staatsfeindlichen Willens,

b) ob der Täter ein gefährlicher politischer Verbrecher ist, dessen Rückfälligkeit vermutet werden muß (Funktionär usw.),

${ }^{189}$ RdErl. des Chefs der Sipo an das Gestapa u. die Stapo(leit)stellen v. 23.11.37 (a.a.O.) u. RV des RJM an die GStAe v. 15.12.37 (a.a.O., Sign. R 22/1462).

${ }^{190} \mathrm{Vgl}$. Ergebnisprot. der Referentenbespr. am 1.2.38 u. Ubersendungsschr. des RJM an das Gestapa v. 13.4.38 (a.a.O., Sign. R 22/1462). 
c) oder ob es sich um einen Mitläufer handelt, von dem angenommen werden kann, daß er sich in Zukunft weiterer staatsfeindlicher Betätigung enthalten wird“.

In den ersten beiden Fällen könne einem Gnadenerweis auch dann nicht zugestimmt werden, wenn sich die Strafanstalt günstig äußere oder der Verurteilte zwischen Tat und Festnahme lange Zeit politisch nicht mehr aufgefallen sei, „da weder das eine noch das andere für die milde Behandlung eines Sprengstoffattentäters oder eines langjährigen Funktionärs sprechen" könne. Im dritten Fall würden die persönlichen Verhältnisse des Strafgefangenen dagegen eingehend geprüft und seine gute Führung sowie die Möglichkeit berücksichtigt, ihn durch vorzeitige Entlassung in den Arbeitsprozeß einzugliedern und ihn vor ungünstigen wirtschaftlichen Verhältnissen zu bewahren. Heydrich begrüßte daher die Anregung der Justiz, der Gestapo die Äußerungen der anderen beteiligten Gnadenstellen mitzuteilen. ${ }^{191}$ Eine Weisung an die Generalstaatsanwälte, die Staatspolizeistellen von der erfolgten Begnadigung zu unterrichten, hielt er jedoch für überflüssig, da diese Unterrichtung nunmehr erfahrungsgemäß erfolge, „so daß künftighin Inschutzhaftnahmen begnadigter Strafgefangener nicht mehr angeordnet" würden. Diese eindeutige, für die Justiz erfreuliche Feststellung machte Heydrich durch folgende Information wieder zunichte, die in der Tat eine Mitteilung durch die Generalstaatsanwälte überflüssig machte: um unnötige Rückfragen zu erübrigen, habe er die Staatspolizei(leit)stellen am 3. März angewiesen, den Rücküberstellungsantrag durch eine der beiden folgenden Zusätze zu ergänzen: „a) Von der Rücksistierung ist abzusehen, wenn Gnadenerweis erfolgt ist“, oder: „b) Rücksistierung hat trotz Erlaß eines Gnadenerweises zu erfolgen, da in neuer Strafsache Festnahme notwendig ist“" ${ }^{192}$

Da der Häftling die hier angesprochene neue Straftat ohne Wissen der Justiz kaum im Gefängnis begangen haben konnte, die Entdeckung einer weiteren, vor seiner ersten Verurteilung liegenden Tat aber äußerst selten gewesen sein dürfte, konnte es sich bei der Begründung der Schutzhaft - will man die „Korrektur“ des vorliegenden Urteils und des Gnadenerweises dafür ausschließen - normalerweise nur um die politische Einstellung des Gefangenen handeln, die er vor seiner ersten Festnahme bekundet hatte. Offensichtlich wählte Heydrich hier den Ausdruck „Strafsache“, um die Justiz von der Notwendigkeit der erneuten Verhaftung zu überzeugen und ihr zugleich die beruhigende Gewißheit zu vermitteln, daß sie in die künftige Behandlung des Falles abermals eingeschaltet werden würde. Jedenfalls gab Heydrich seinen Dienststellen damit ausdrücklich auch weiterhin die Handhabe, jeden - auch durch Hitler - begnadigten Strafgefangenen bei seiner Entlassung in Schutzhaft zu nehmen: sie mußten die Verhaftung nur mit einem anderen Sachverhalt begründen. Daran änderte auch die Tatsache nichts, daß sich das Reichsinnenministerium in der Folge ein-

${ }^{191}$ Durch RV des RJM v. 24.10.38 (a.a.O.) wurden der OReiA beim VGH u. die GStAe der für Hochverratssachen zuständigen OLGe entsprechend angewiesen.

${ }^{192}$ Schr. des Chefs der Sipo (gez. Heydrich) an das RJM v. 20.7.38 (a.a.O.). Der RdErl. des Gestapa an alle Stapo(leit)stellen v. 5.3.38 (Arch. des IfZ, Sign. MA 443), I.V. Best, spiegelt die schizophrene Zielsetzung besonders deutlich wider. Eingangs heißt es: „Einige Sonderfälle geben mir Veranlassung, nochmals eindringlich darauf hinzuweisen, daß wegen politischer Straftaten Verurteilte unter keinen Umständen [?] in Schutzhaft genommen werden dürfen, wenn sie auf Grund eines Gnadenerweises vorzeitig aus der Strafhaft entlassen werden“, am Schluß aber steht der von Heydrich unter b) zitierte Satz mit den Hervorheb. im Original. 
deutig der Ansicht des Reichsjustizministeriums anschloß, daß im Falle eines Gnadenerweises keine Schutzhaft erfolgen sollte. ${ }^{193}$

Wie aus den Akten hervorgeht, gelang es dem Reichsjustizministerium durch Intervention bei der Gestapoführung in Einzelfällen, die Schutzhaft von Begnadigten abzuwenden. Andererseits vereitelte die Gestapo eine vorzeitige Entlassung aus der Strafhaft auf dem Gnadenwege häufig allein durch die Verzögerung ihrer Stellungnahme: da die örtlichen Staatspolizeistellen bis zur Vorlage ihrer Berichte an das Geheime Staatspolizeiamt teilweise zwei Monate brauchten, war oftmals das Gnadengesuch durch Ablauf der Strafzeit gegenstandslos geworden. Das Justizministerium forderte daher die Generalstaatsanwälte schließlich auf, in aussichtsreichen Fällen zur Herbeiführung einer vorläufigen Strafunterbrechung schon vor dem Vorliegen der Äußerung der Gestapo zu berichten und sie dann nachzureichen. ${ }^{194}$ Aus Gründen kriegsbedingter Arbeitsersparnis wurden die Staatspolizei(leit)stellen im September 1940 befugt, Stellungnahmen zu Gnadengesuchen um vorzeitige Strafentlassung oder Strafunterbrechung in Hoch- und Landesverratssachen wieder in eigener Zuständigkeit abzugeben. ${ }^{195}$

Abschließend sei bemerkt, daß die Gestapo die Bewilligung von Gnadenerweisen im Laufe des Krieges immer stärker einschränkte, vor allem nach Beginn des Feldzuges gegen die Sowjetunion, als sie verschärft gegen Personen vorging, die sich als Kommunisten verdächtig oder strafbar gemacht hatten. Ende Juni 1941 teilte der Chef der Sicherheitspolizei dem Justizministerium mit, daß alle befürwortenden Gnadenäußerungen, die die Staatspolizei(leit)stellen vor dieser außenpolitischen Wende abgegeben hatten, „durch die jetzige Sachlage überholt“ seien. ${ }^{196}$ Als Leiter der Gestapo-Abteilung im Reichssicherheitshauptamt ergänzte SS-Gruppenführer Müller diese Information durch die Mitteilung, daß nunmehr alle Personen, die eine Freiheitsstrafe wegen kommunistischer oder marxistischer Betätigung verbüßt hatten, nach der Entlassung in Schutzhaft genommen würden: eine Bearbeitung von Gesuchen für diese Personen um vorzeitige Entlassung auf dem Gnadenwege sei „deshalb augenblicklich wegen Aussichtslosigkeit überflüssig“. Um die Dienststellen der Gestapo „angesichts des starken Personalmangels und anderer dringender Aufgaben zu entlasten“, bat er, die Gnadenbehörden anzuweisen, mit derartigen Anliegen an die Gestapo nur noch in berechtigten Ausnahmefällen heranzutreten. Die zuständigen Justizstellen wurden durch Freisler darüber instruiert. ${ }^{197}$

Wie bei allen entscheidenden Fragen saß die Gestapo gegenüber der Justiz auch hinsichtlich der Mitwirkung bei Gnadenerweisen und in der Frage der Schutzhaft gegen begnadigte Strafgefangene am längeren Hebelarm. Zwar konnte die Justiz unter Berufung auf die Autorität Hitlers erreichen, daß die Gestapo die grundsätzliche Unzulässigkeit der Verhängung von Schutzhaft gegen Personen anerkannte, die wegen

${ }^{193}$ Vgl. Referentenbespr. mit dem RMdI am 16.8.39, erwähnt im Verm. v. 12.2.42 (Akten des RJM, BA, Sign. R 22/1467).

${ }^{194}$ Vgl. z. B. Schr. des RJM an den GStA Hamm v. 31.3.38 u. Verm. des Hochverratsref. vom selben Tag (a.a.O., Sign. R 22/955).

${ }^{195}$ Schr. des Chefs Sipo/SD an das RJM v. 9.9.40, dem OReiA beim VGH u. den zuständigen GStAen am 20.9. 40 vom RJM mitgeteilt (a.a.O.).

${ }^{196}$ Schr. des Chefs Sipo/SD an das RJM v. 30.6.41 (a.a.O., Sign. R 22/956).

${ }^{197}$ Schr. des Chefs Sipo/SD an das RJM v. 27.11.41 u. Erl. Freislers an den OReiA/VGH u. die zuständigen GStAe v. 24.12.41 (a.a.O., Sign. R 22/1467). 
Hochverrats verurteilt, aber auf dem Gnadenwege vorzeitig aus der Strafhaft entlassen wurden; auch konnte sie in solchen Einzelfällen Schutzhaft gegen Begnadigte verhindern. Aber auch auf diesem Gebiet gelang es ihr nicht, die Omnipotenz der Gestapo für Präventivmaßnahmen zu brechen.

\section{Die Justiz und das Konzentrationslagersystem}

\section{a. Gesetzliche Zuständigkeit der Justiz für Straftaten im Konzentrationslager und ibre Sabotierung durch die SS}

Von den gesetzlichen Bestimmungen her gesehen, endete die Zuständigkeit der Justiz an den Toren der Konzentrationslager zunächst keineswegs. Zur Verfolgung von Straftaten, die die SS-Bewacher an den Lagerinsassen und die Gefangenen untereinander verübten, blieb die Justiz gesetzlich weiterhin befugt; noch symbolisierten die Mauern und Stacheldrähte keine rechtliche „Exterritorialität“ der Lager. Ein Vorstoß, den die Gestapoführung im Februar 1935 in diese Richtung unternahm, wurde von der Justiz mit Erfolg abgewehrt: Am 14. Februar informierte der stellvertretende Gestapochef das Reichsinnenministerium, er halte es ,aus naheliegenden Gründen weder für tunlich noch für unbedingt notwendig“, daß Beauftragte der Verwaltung und Justiz Zutritt zu den Lagern erhielten, um sich dort „unter dem Deckmantel [!] von Besichtigungen an Ort und Stelle Einblick in die näheren Lagerverhältnisse“ zu verschaffen. ${ }^{1}$ Vom Innenministerium zur Stellungnahme aufgefordert, lehnte Gürtner diese Auffassung strikt ab: die Beamten der Justizverwaltung hätten

„das Recht und die Pflicht, zur Durchführung der ihnen kraft Gesetzes obliegenden Aufgaben auch Zutritt zu einem Konzentrationslager zu verlangen und dort die erforderlichen Amtshandlungen vorzunehmen. Ein Verzicht auf die Ausübung staatlicher Gerichtsbarkeit innerhalb der Konzentrationslager wäre mit der Rechtslage nicht vereinbar; die Lager genießen auch nicht das Recht der ,Exterritorialität'“.

Er sei lediglich bereit, „die erforderlichen Maßnahmen, soweit irgend angängig, im Einvernehmen mit der Lagerordnung und unter Berücksichtigung der besonderen Lagerverhältnisse durchführen zu lassen".2

War schon die gerichtliche Verfolgung jener Verbrechen äußerst schwierig gewesen, die in den „wilden“ Konzentrationslagern begangen worden waren ${ }^{3}$, so mußten sich die Schwierigkeiten gegenüber dem organisierten Konzentrationslagersystem Himmlers noch vergrößern. Mißhandlungen oder ähnliche an den Lagerinsassen verübte Straftaten kamen schon deshalb höchst selten vor den Staatsanwalt, weil die Schutzhäftlinge keine Möglichkeit zu einer Anzeige hatten. Da sie bei der Entlassung eine Erklärung unterschreiben mußten, mit der sie sich zu absolutem Schweigen über die Verhältnisse im Lager verpflichteten ${ }^{4}$, wurden auch nachträgliche Anzeigen aus

1 Schr. des Gestapa/Stellv. Chef u. Inspekteur an den RuPrMdI v. 14.2.35 (Akten des RJM, BA, Sign. R 22/1467). Konkreter Anlaß war die Weigerung des Kommandanten des KZ Esterwegen, die gesetzlich vorgeschriebene feuerpolizeiliche Brandschau vornehmen zu lassen.

2 Schr. Gürtners an den RuPrMdI v. 12.3.35 (a.a.O.).

3 Vgl. dazu Kap. IV.2.b. u. 3.

4 Zu der Erklärung mit 9 Punkten vgl. E. Kogon, Der SS-Staat. Das System der deutschen Konzentrationslager, München 1974, S. 284 f. 
Furcht vor Repressalien und erneuter Schutzhaft unterlassen. Nur die Toten sprachen für sich: da die personenstandsrechtlichen Vorschriften über Anzeige und Registrierung von Todesfällen, vor allem die Pflicht der Polizei- und Gemeindebehörden zur Anzeige aller Fälle nicht natürlichen Todes bei der Staatsanwaltschaft oder dem Amtsrichter ( $\S 159 \mathrm{StPO})$ auch für die Lagerleitungen galten, waren es überwiegend Todesfälle im Lager, mit denen sich die Justiz zu befassen hatte. Dagegen kamen ihr Fälle von Mißhandlungen meist nur dann zur Kenntnis, wenn ehemalige KZ-Häftlinge ihre Erlebnisse ausplauderten und daraufhin wegen Verstoßes gegen die Heimtücke-Bestimmungen ${ }^{5}$ - d.h. wegen "unwahrer" Behauptungen, die das Ansehen von Regierung oder Partei schädigten, oder wegen hetzerischer Äußerungen über deren Einrichtungen, die das Vertrauen zur Führung untergruben - angezeigt wurden. In solchen Fällen stieß die Justiz bei ihren Ermittlungen über Vorgänge im Lager auf erhebliche Schwierigkeiten: auf die Unmöglichkeit, Zeugen unter den Häftlingen zu finden, die aus verständlichen Gründen schwiegen, auf die Abschirmung beschuldigter Bewacher durch ihre Vorgesetzten und das dichte Geflecht der Kameraderie unter den SSWachmannschaften, die durch besonderes Treuegelöbnis an die Befehle ihrer Vorgesetzten gebunden waren und nach außen eine festgefügte Gemeinschaft bildeten, und nicht zuletzt auf die Passivität der Polizei, die mit der SS organisatorisch verbunden war. Als ein ehemaliger Dachauer Häftling im Dezember 1934 über Mißhandlungen im Lager berichtete und das Amtsgericht Dachau daraufhin einen Wachkompanieführer vernehmen wollte, lehnte der Kommandant die Vernehmung zunächst mit der Begründung ab, daß hierzu die Genehmigung des Reichsführers-SS erforderlich sei. Nachdem die Erlaubnis durch Einschaltung der Justizleitung offenbar erwirkt worden war, bestätigten die Ermittlungen zwar allgemein die Behauptungen über „mehrfach vorgekommene" Mißhandlungen im Lager, aber der Aufenthaltsort des betroffenen Kompanieführers war angeblich nicht mehr festzustellen: auch die Bayerische Politische Polizei konnte ,in der Angelegenheit Sachdienliches nicht ermitteln“.6 In einem ähnlichen Dachauer Fall lehnte die politische Polizei das Ersuchen der Staatsanwaltschaft ab, den ehemaligen Häftling über seine Behauptungen überhaupt zu vernehmen, und veranlaßte entgegen den Bestimmungen der Strafprozeßordnung seine Vernehmung durch das Amtsgericht. Die Lagerkommandantur verweigerte aber eine Untersuchung der Beschuldigungen mit der Erklärung: „Die Angaben sind unwahr. Es wird im Konzentrationslager Dachau nicht wild geprügelt, sondern rechtmäßig gestraft. $\mathrm{K}$... ist deswegen wegen Verbreitung von Greuelnachrichten zu bestrafen. Jede weitere

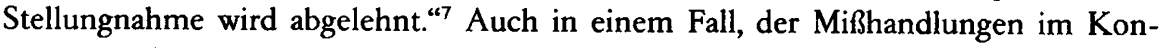
zentrationslager Esterwegen betraf, behauptete das Geheime Staatspolizeiamt gegenüber dem Reichsjustizministerium, daß die „erörterten Vorfälle aus dem KZ Esterwe-

5 VO zur Abwehr heimtückischer Angriffe gegen die Regierung der nationalen Erhebung v. 21.3.33 (RGBl. I, S. 135), ersetzt durch das G. gegen heimtückische Angriffe auf Staat und Partei und zum Schutz der Parteiuniformen v. 20.12.34 (RGB1. I, S. 1269).

6 Vgl. die Ber. des zuständigen OStA u. GStA an das RJM (Diensttageb. des RJM, Bd. 1, Eintr. v. 4. 1.35, BA, Sign. R 22/131; v. 24.5.35, Bd.3, BA, Sign. R 22/1056; v. 14.9.35, Bd. 5, BA, Sign. R 22/1088). Das Strafverfahren gegen den ehemal. Häftling wegen Verstoßes gegen die HeimtückeVO v. 21.3.33 (RGB1. I, S. 135) wurde daraufhin eingestellt.

7 Ber. des OStA beim LG München I (a.a.O., Eintr. v. 14.10.35, Bd. 5, BA, Sign. R 22/1088). Auch in diesem Fall wurde das Heimtückeverfahren gegen den Exhäftling eingestellt, da aufgrund dieser bloßen Erklärung der Kommandantur ein Nachweis der Unwahrheit der Behauptung nicht zu führen war. 
gen nicht den Tatsachen entsprächen" und "die Wachmannschaften laufend über ihre Pflichten und über die Strafen unterrichtet würden, die ihnen bei Gefangenenmißhandlung bevorstünden“. ${ }^{8}$ Die vernommenen Häftlinge aber verweigerten „unter Berufung auf das Schweigegebot der Gestapo“ jegliche Angaben, weil sie „im Falle der Aussage Schwierigkeiten“ befürchteten.?

Bei den Todesfällen, die von den Kommandanturen nach wie vor gemeldet werden mußten, war die Feststellung eines Verbrechens für die Justiz leichter als bei Mißhandlungen, weil sie hierbei weniger auf die Aussagen Beteiligter angewiesen war, sondern sich auf die „Aussagen“ der Toten stützen konnte: dann nämlich, wenn der Obduktionsbefund der Leiche mit der Ursache oder den näheren Umständen beim Tode, die die Bewacher angaben, nicht übereinstimmte. Daß selbst bei einwandfreiem Nachweis einer Tötung die Ermittlung und Verurteilung der Täter auf Schwierigkeiten stieß, zeigen die Versuche der Justiz, die ersten Mordfälle im Konzentrationslager Dachau zu verfolgen. Obwohl Himmler zu dieser Zeit als Kommandeur der Bayerischen Politischen Polizei noch nicht die spätere Machtfülle besaß, sollte er schon damals der Justiz unüberwindliche Hindernisse in den Weg legen.

Mit den Tötungen im Lager Dachau wurden die Justizbehörden erstmals befaßt, als am 12. April 1933 drei Häftlinge von SS-Posten - angeblich auf der Flucht - erschossen wurden; ein vierter, der ,ihnen in das Feuer gelaufen“ war, wurde schwer verletzt und starb vier Tage später. Die für Dachau zuständige Staatsanwaltschaft beim Landgericht München II, die offenbar durch die Polizeidirektion München von den Todesfällen benachrichtigt wurde, sandte am nächsten Tag eine Gerichtskommission ins Lager. Da der Gerichtsarzt den Befund der Leichen mit den Angaben der Wachposten über den Hergang der Tat in Einklang stehen sah, wurde auf eine Obduktion verzichtet und die Ermittlung eingestellt: die Behauptungen des Lagerpersonals hatten nicht widerlegt werden können. ${ }^{10}$

Bei weiteren Todesfällen, die sich im Mai ereigneten ${ }^{11}$, erhob die Staatsanwaltschaft hingegen in vier Fällen öffentliche Klage und beantragte gerichtliche Voruntersuchung. Diese Fälle sollten einen bezeichnenden Verlauf nehmen.

8 Schr. des Gestapa (I.A. Best) an das RJM v. 24.10.35 (a.a.O., Eintr. v. 29.10.35, Bd.6, BA, Sign. R 22/1089).

9 Ber. des OStA Hannover (a.a.O., Eintr. v. 27.7.35, Bd.8, BA, Sign. R 22/929). Auch in einem Fall von Mißhandlungen im KZ Columbia-Haus mußte das Ermittlungsverfahren gegen Unbekannt „wegen Nichtermittlung der Täter" eingestellt werden (Ber. des GStA beim LG Berlin v. 7.5.35 u. des GStA beim KG v. 25.5.35, a.a.O., Eintr. v. 3.6.35, Bd.3, BA, Sign. R 22/1056).

10 Undat. zeitgenöss. Notiz des damaligen EStA beim LG München II und seine Zeugenaussage v. 27.3.51 im Untersuchungsverfahren gegen Steinbrenner (StArch. München, Sign. Staatsanw. 7014). Es handelte sich um die Häftlinge Dr. Benario, Goldmann, Arthur Kahn. Die Namen aller in Dachau Getöteten sind aufgeführt in dem Gedenkwerk: Die Toten von Dachau, Deutsche und Österreicher, herausg. v. Staatskommissariat für rassisch, religiös u. politisch Verfolgte in Bayern, München 1947, und können daher ohne persönlichkeitsschutzrechtliche Bedenken genannt werden.

11 In folgenden, hier nicht näher behandelten Fällen kam es nicht zur Anklageerhebung: am 7.5.33 wurde der frühere kommunistische Landtagsabgeordnete Dressel mit geöffneter Pulsader aufgefunden; die Leiche wies bei der Untersuchung Prügelspuren auf. Einen Tag später wurde der Schlosser Götz aus München von einem SS-Mann im Gang des Zellenbaus „aus Notwehr“ durch Kopfschuß getötet; die Leichenschau v. 9.5. stellte zusätzlich Verletzungen und auch schon in der Zelle des Getöteten Blutspuren fest (Verm. des EStA der StAschaft München II v. 30.5.33 u. undat. Verm.; ferner Zeugenaussage des damaligen leitenden OStA dieser StAschaft v. 7.3.51 im Untersuchungsverfahren gegen Steinbrenner; a.a.O.). Am 19.5.33 starb der jüdische Gerichtsreferendar Aron aus Bamberg an den Folgen von Mißhandlungen (Urteil d. LG München II v. 10.3.52, Arch. d. IfZ, Sign. Gm 07.19). 
Am 16. Mai übersandte der Lagerkommandant, SS-Oberführer Wäckerle, der Staatsanwaltschaft einen Bericht, daß sich der Nürnberger Kaufmann Schloß in einer Einzelhaftzelle mit seinem Hosenträger erhängt habe. Die diesmal sofort an den Tatort eilende Gerichtskommission stellte jedoch fest, daß die Leiche ausgedehnte Blutunterlaufungen aufwies, der Tod wahrscheinlich durch eine Fettembolie - hervorgerufen durch die Zertrümmerung des Gewebes - eingetreten war und der Tote erst nachträglich aufgehängt wurde, um einen Selbstmord vorzutäuschen. Als sich der Verdacht durch die am nächsten Tag vorgenommene Leichenöffnung verstärkte, erhob der Erste Staatsanwalt beim Landgericht München II am 1. Juni Klage beim zuständigen Untersuchungsrichter gegen unbekannte Täter wegen Verbrechens der Körperverletzung mit Todesfolge, ferner gegen Wäckerle, den Lagerarzt und einen Angehörigen der Lagerkanzlei wegen Begünstigung. Er beantragte die Durchführung der gerichtlichen Voruntersuchung und einen Haftbefehl gegen die bekannten Beschuldigten wegen Verdunkelungsgefahr. ${ }^{12}$

Bereits einen Tag nach der Tötung Schloß' wurde am 17. Mai der Hilfsarbeiter Hausmann aus Augsburg von einem SS-Scharführer bei Außenarbeiten in einer Fichtenschonung ,auf der Flucht“ erschossen. Da die noch am selben Tage tätig werdende Gerichtskommission feststellte, daß der Schuß nicht auf die angegebene Entfernung von 10 bis 12 Meter abgegeben worden war, sondern daß es sich um einen Nahschuß aus weniger als einem Meter handelte, wurde eine genauere gerichtsmedizinische Untersuchung angeordnet. Als sie ergab, daß die Entfernung sogar weniger als 30 Zentimeter betrug, wurde auch in diesem Falle am 1. Juni gerichtliche Voruntersuchung und Haftbefehl beantragt. ${ }^{13}$

Als Dritter in dieser Serie wurde der Münchener Rechtsanwalt Dr. Strauß am 24. Mai „auf einem Spaziergang, der ihm vom Lagerarzt verordnet worden war“, von dem begleitenden SS-Mann durch zwei Schüsse in den Hinterkopf getötet, da er angeblich flüchten wollte. Die Untersuchung der Gerichtskommission vom selben Tag ergab, daß der mit Pantoffeln bekleidete Tote außer den Einschüssen am Körper Striemen und Blutunterlaufungen, eine offene Wunde am Gesäß und eine Fußverletzung aufwies. Da es äußerst zweifelhaft war, daß der Getötete in diesem körperlichen Zustand, mit dieser Fußbekleidung und angesichts der Begleitung durch einen besonderen Wächter einen Fluchtversuch unternehmen konnte, wurde auch hier gegen den SSMann Klage wegen Mordes erhoben und gerichtliche Voruntersuchung beantragt. ${ }^{14}$

Schon der nächste Tag brachte ein neues Opfer: der Kaufmann Lehrburger aus Nürnberg wurde in einer Einzelhaftzelle von einem SS-Mann durch einen Schuß in die Stirn getötet, weil er eine Bewegung machte, die dieser „als Angriff auffaßte“. Da

12 Schr. Wäckerles u. Prot. der Gerichtskommission v. 16.5.33; Verm. des EStA v. 30. 5. 33 (a.a.O.); Prot. über die Leichenöffnung v. 17.5.33 (Nürnbg. Dok. PS-644, IMG Bd.XXVI, S. 178); Klageerhebung des EStA v. 1.6.33 (StArch. München, Sign. Staatsanwaltschaft 7014).

13 Ber. der polit. Abt. des Lagers v. 17.5.33, über die Kommandantur der StAschaft München II zugeleitet; Prot. der Gerichtskommission v. 17.5.33 u. ihrer Vernehmung des Scharführers v. 18.5.33; Klage des EStA v. 1.6 .33 (a.a.O.).

14 Verm. des EStA v. 30.5.33, sein undat. zeitgenöss. Ber. und seine Aussage v. 13.7.33; Aussage des leitenden OStA v. 7.3 .51 (a.a.O.) sowie dessen Ber. an den GStA v. 1.6.33 (Nürnbg. Dok. PS-641, IMG Bd. XXVI, S. 171). 
das Vorbringen des Wachmannes durch die Leichenschau nicht widerlegt werden konnte, stellte die Staatsanwaltschaft in diesem Falle das Verfahren ein. ${ }^{15}$

Der vierte Fall, der bis zum Antrag auf gerichtliche Voruntersuchung gedieh, betraf den Tod des Kaufmanns Nefzger aus München in der Nacht zum 26. Mai. Um die Einschaltung der Justiz zu umgehen, setzte die Lagerverwaltung ein Protokoll auf, wonach sich Nefzger in seiner Arrestzelle zuerst mit dem Riemen seiner Beinprothese zu erhängen versucht und, als dieser riß, die Pulsadern aufgeschnitten habe. „Da nach Feststellung des Lager- und Leichenschauarztes Dr. N.“, so endete das Protokoll, „die Todesursache einwandfrei feststeht, wurde von einer Verständigung der Gerichtskommission abgesehen. ${ }^{16}$ Das Amtsgericht Dachau erhielt von der politischen Abteilung des Lagers lediglich eine Bescheinigung des Lagerarztes, „daß eine Tötung durch Einwirkung fremder Personen auszuschließen ist. Der Tod ist ohne Zweifel ein Verblutungstod durch Öffnung der Pulsader der linken Hand “. ${ }^{17}$ Die vom Amtsgericht verständigte Staatsanwaltschaft München II ordnete für den 27. Mai dennoch die gerichtliche Leichenschau an. Da der Landgerichtsarzt den Tod durch Verbluten für zweifelhaft hielt, wurde zwei Tage später die Obduktion vorgenommen, die die Schnittwunde als Selbstverletzung und als Todesursache ausschloß. Als Todesursache wurde vielmehr Erwürgen und Erdrosseln angenommen, da der Verlauf der Strangmarke am Hals nicht den beim Erhängungstod beobachteten Befunden entsprach. Daraufhin beantragte die Staatsanwaltschaft am 1. Juni auch hier gerichtliche Voruntersuchung und Haftbefehl gegen die drei bereits erwähnten Personen. ${ }^{18}$

Unter welchen Bedingungen die Justiz derartige Fälle bearbeiten mußte, geht aus dem Bericht des damaligen Ersten Staatsanwalts über die Einreichung seiner vier Anträge auf Voruntersuchung und Haftbefehl hervor:

„Da mir einige mittlere und untere Beamte der Staatsanwaltschaft nicht zuverlässig erschienen, hielt ich eine Schreibkraft, die ich als einwandfrei betrachtete, für die Zeit nach Büroschluß am Abend zurück und diktierte ihr meine Anträge. Ich brachte die Akten am nächsten Morgen unter Umgehung des sonst üblichen Weges persönlich dem Untersuchungsrichter Dr. K., mit dem ich die Angelegenheit bereits vorher besprochen hatte."

Dieser Untersuchungsrichter beim Landgericht München II begab sich am 1. Juni zur Münchener Polizeidirektion, um die Verhaftung der Angeschuldigten mit Hilfe der Mordkommission durchzuführen. Die Mordkommission lehnte jedoch ihre Mitwirkung ab, weil es sich um eine politische Strafsache handelte, für die allein die politische Polizei zuständig sei. Dort wurde der Richter „mit einem Lächeln abgewiesen“. ${ }^{19}$

Am selben 1. Juni berichtete der leitende Oberstaatsanwalt beim Landgericht München II über die vier Anträge dem Generalstaatsanwalt München, der die Berichte so-

15 Verm. des EStA v. 30.5.33 (a.a.O.) u. Ber. des leitenden OStA an den GStA v. 1.6.33 (Akten des RJM, BA, Sign. R 22/20383). Wie die Nachkriegsermittlungen ergaben, war L. auf Befehl des Lagerkommandanten Wäckerle (als angeblicher, für den Bakterienkrieg ausgebildeter sowjetrussischer Agent) erschossen worden, weil er "verheimlicht“ hatte, daß er Jude war (Urteil des LG München II v. 10.3.52, Arch. d. IfZ, Sign. Gm 07.19).

16 Prot. der Lagerkanzlei v. 26.5.33 (StArch. München, Sign. Staatsanw. 7014).

17 Schr. v. 27.5.33 (a.a.O.).

18 Prot. der Gerichtskommission v. 29.5.33 u. Anklageerhebung des EStA v. 1.6.33 (a.a.O.).

19 Schr. des früheren EStA bei der StAschaft München II v. 13.7.49 an den LGPräs. Amberg auf Anfrage der StAschaft München I (a.a.O.). 
fort an das bayerische Justizministerium weiterleitete. ${ }^{20}$ Der Generalstaatsanwalt hatte bereits einen Bericht des Oberstaatsanwalts vom 22. Mai zum Fall Schloß weitergereicht und dadurch die Aktivität des Ministeriums ausgelöst. Am 29. Mai wurde der Oberstaatsanwalt zum mündlichen Vortrag ins Justizministerium gebeten und übergab dabei dem Strafrechtsreferenten Ministerialrat Döbig neben einem schriftlichen Bericht Abschriften der „Lagerordnung“ von Dachau, die ihm Wäckerle auf sein Verlangen mit der Erläuterung übergeben hatte, „daß er [Wäckerle] diese Bestimmungen auf Befehl seiner vorgesetzten Stelle selbst verfaßt habe und daß diese Bestimmungen vom Herrn Polizeikommandeur genehmigt seien". ${ }^{21}$ Diese "Sonderbestimmungen" besagten nichts weniger, als daß über das Lager Dachau "das Standrecht verhängt“ sei, daß die Wachmannschaft bei Fluchtversuchen „ohne Anruf von der Schußwaffe Gebrauch machen" dürfe und daß als Lagerstrafen außer abgestuftem Einzelarrest die „Todesstrafe“ verhängt werden dürfe. Mit Arrest bis zu drei Monaten Dunkelzelle konnte u.a. bestraft werden, wer einen Angehörigen der Wachtruppe „beleidigt oder verleumdet“ oder „eine Beschwerde auf unwahre Behauptungen stützt oder [!] unter Abweichung von dem vorgeschriebenen Dienstweg ... vorzubringen versucht", mit der Todesstrafe, wer tätlichen Widerstand leistete oder auch nur den Gehorsam verweigerte oder dazu verleitete. Strafen sollten generell durch den Lagerkommandanten verhängt, die Todesstrafe aber durch ein Lagergericht ausgesprochen werden, dem der Kommandant, ein oder zwei von diesem bestimmte Offiziere und ein SS-Mann der Wachtruppe angehörten; die Anklage wurde gleichfalls von einem SS-Mann übernommen. ${ }^{22}$

Döbig informierte noch am selben Tage den bayerischen Justizminister Hans Frank. ${ }^{23}$ Frank rief sofort Ministerpräsident Siebert an und erreichte, daß die Angelegenheit auf die Tagesordnung der nächsten Ministerratssitzung vom 31. Mai gesetzt wurde, da derart schwerwiegende Anordnungen über Leben und Tod nur von der Regierung getroffen werden könnten. Döbig wurde beauftragt, noch vorher am 30. Mai Innenminister Wagner sowohl über die vier Straffälle, deren Ermittlung ,im Interesse des Staates gelegen" sei, als auch über die rechtliche Problematik der Lagerordnung zu berichten. Bei dieser Unterredung am nächsten Tag erklärte Wagner, „daß der Sachverhalt noch zu wenig geklärt sei, um die Angelegenheit zum Gegenstand einer Beratung im Ministerrat zu machen, und daß zunächst der Herr Politische Polizeikommandeur Bayerns, der z.Zt. erkrankt sei, sowie der Lagerkommandant gehört werden müßten“. Wagner rief nun ebenfalls Siebert an und setzte durch, daß dieser Punkt von der Tagesordnung des Ministerrats wieder abgesetzt wurde. Dafür schlug er vor, daß "unverzüglich“ eine Besprechung zwischen einem Vertreter seines Ministeriums, Himmler, dem Lagerkommandanten, dem Lagerarzt, zwei Vertretern des Justizministeriums, dem zuständigen Oberstaatsanwalt und dem Landgerichtsarzt stattfinden sollte.

Döbig berichtete am nächsten Tag Frank über dieses Ergebnis der Unterredung mit Wagner und erhielt die Weisung, bei der in Aussicht genommenen Besprechung ins-

20 Nürnbg. Dok. PS-641 (Schloß), PS-642 (Hausmann), PS-641 (Strauß) u. PS-645 (Nefzger), sämtl. IMG Bd.XXVI.

${ }^{21}$ Ber. des leitenden OStA an das bayer. JM v. 29.5.33 (Akten des RJM, BA, Sign. R 22/4209).

22 a.a.O. (auch Nürnbg. Dok. D-922, IMG Bd. XXXVI, S.6).

${ }^{23}$ Zum folgenden vgl. Verm. MinRat Döbig v. 1.6.33 (Akten des RJM, a.a.O.). 
besondere „auf die aus $\S 346$ StGB sich ergebende Verpflichtung der StAschaft und der Polizeibehörde zur Ermittlung des Sachverhalts hinzuweisen“. Am Nachmittag desselben Tages, während Frank in der Ministerratssitzung weilte, teilte der Polizeireferent des Innenministeriums dem Justizministerium im Auftrag Wagners mit, „daß die in Aussicht genommene Besprechung unterbleibe, weil jeder Anschein des Eingreifens in das schwebende Verfahren vermieden [!] werden solle“. Wegen der strafrechtlichen Behandlung der Einzelfälle sollte sich der leitende Oberstaatsanwalt mit Himmler direkt ,ins Benehmen setzen“. ${ }^{24}$ Am gleichen Tage schickte das Innenministerium als einzige Reaktion auf den am 29. Mai vom Justizministerium übersandten Bericht einschließlich Protokoll der Leichenschau im Falle Schloß eine schriftliche Beschwerde Wagners, „daß die Zuschrift mit den in offenem Umschlag befindlichen Lichtbildern durch die Post" zugegangen und damit einer Reihe von Personen bekannt geworden war, da sie "den normalen Geschäftsgang durchlief, bis sie in die Hände des zuständigen Referenten gelangte“. ${ }^{25}$

Der Oberstaatsanwalt war bereits nach seinem Bericht im Falle Schloß angewiesen worden, „die Frage der Weiterbehandlung der Sache mit dem Herrn Polizeikommandeur persönlich zu besprechen ${ }^{\text {“26; }}$, er bekam nun den erweiterten Auftrag, auch die anderen drei Fälle in die Besprechung einzubeziehen. In dieser Unterredung, die am Mittag des 1. Juni mit dem angeblich erkrankten Himmler in der Polizeidirektion München stattfand, betonte nunmehr der Oberstaatsanwalt weisungsgemäß, daß die Staatsanwaltschaft und übrigens auch die Polizeibehörden „bei Meidung schwerer Strafandrohung verpflichtet seien, ohne Rücksicht auf irgendwelche Personen die strafrechtliche Verfolgung der genannten Vorkommnisse durchzuführen“, und daß er daher in den vier Fällen gerichtliche Voruntersuchung und Haftbefehle beantragen werde. $\mathrm{Zu}$ den Ermittlungen werde er "die allein geeigneten Beamten der Kriminalabteilung der Polizeidirektion“ heranziehen. Auf seine Bitte um Unterstützung sagte Himmler erstaunlicherweise zu, daß dem Untersuchungsrichter bei den notwendigen Erhebungen im Lager Dachau keine Schwierigkeiten bereitet würden. ${ }^{27}$ Himmler vermied die offene Konfrontation, wahrscheinlich hatte er längst einen anderen Ausweg im Auge, um die Sache in seinem Sinne aus der Welt zu schaffen.

Am nächsten Tag bekam die Staatsanwaltschaft vom Justizministerium fernmündlich den Auftrag, die vier Ermittlungsakten einzureichen, weil sie für eine am Nachmittag stattfindende Besprechung mit Reichsstatthalter von Epp benötigt würden. Da Wagner eine Diskussion der Angelegenheit im Ministerrat verhindert hatte, wählte Frank offenbar diesen Weg, um die Sache auf oberster bayerischer Ebene zur Sprache zu bringen. Als Ergebnis dieser Besprechung, an der außer Siebert, Frank und Wagner auch die Minister Schemm und Esser sowie Himmler teilnahmen, mußte sich Himmler bequemen, im Lager Dachau „personelle Veränderungen“ zuzugestehen, d.h. den unhaltbar gewordenen Wäckerle als Kommandanten abzulösen. ${ }^{28}$ Die vorgelegten Ermittlungsakten sollten zunächst dem Innenministerium „zur Stellungnahme“ überge-

24 a.a.O.

25 Schr. Wagners an das bayer. JM v. 31.5 .33 (Nürnbg. Dok. PS-644, IMG Bd.XXVI, S. 186).

26 Erwähnt im Schr. des bayer. JM an das bayer. MdI v. 29.5.33 (a.a.O.).

27 Ber. des OStA an das bayer. JM v. 2.6.33 (Akten des RJM, BA, Sign. R 22/20383).

28 Wäckerle wurde am Monatsende durch SS-Oberführer Eicke ersetzt, der anstelle der erwähnten Lagerordnung neue Dienstvorschriften erließ, die zum Modell für die Konzentrationslager der SS wurden; vgl. M. Broszat, Nationalsozialistische Konzentrationslager 1933-1945, Olten u. Freiburg i. Br. 1965, S. 53 ff. Broszat 
ben werden. ${ }^{29}$ Das Justizministerium rechnete dabei mit einer baldigen Rückgabe, denn die Staatsanwaltschaft wurde angewiesen, die Ermittlungen fortzuführen, „sobald sie die Akten zurückerhalten habe, was in Kürze zu erwarten sei““ ${ }^{30} \mathrm{Da}$ die Fälle ohne Akten nicht weiterbearbeitet werden konnten, bat der Oberstaatsanwalt in der Folge nach wiederholten vergeblichen Rückfragen beim Ministerium den Generalstaatsanwalt um Intervention, dem Frank am 13. Juni zunächst versicherte, daß die Akten vom Innenministerium zurückverlangt wurden, um ihn zehn Tage später auf eine „demnächst" stattfindende Besprechung hinzuweisen. ${ }^{31}$ Eine persönliche Rücksprache des Generalstaatsanwalts bei Himmler brachte lediglich dasselbe Ergebnis. ${ }^{32}$ Als die angekündigte Besprechung zwischen Himmler, dem Generalstaatsanwalt und den Vorständen der Staatsanwaltschaften München I und II am 24. Juli endlich stattfand, erklärte Himmler, daß er die Akten vom Innenministerium erhalten und „inzwischen weitere Ermittlungen gepflogen habe, die noch nicht abgeschlossen seien"; danach würden die Akten der Staatsanwaltschaft wieder zugehen. Voraussichtlich aber ,werde in Bälde eine weitere Amnestie kommen, die zur Niederschlagung der einschlägig. Verfahren führen werde “. ${ }^{33}$ Nachdem die Staatsanwaltschaft die Akten drei Wochen später erneut angemahnt hatte, um die Anwendung der unterdessen ergangenen bayerischen Amnestieverordnung vom 2. August 1933 auf die Fälle prüfen zu können ${ }^{34}$, forderte Staatsrat Spangenberger Ende August die Akten abermals schriftlich vom Innenministerium zurück. ${ }^{35}$ Mehrmals sagten Vertreter der politischen Polizei die Rückgabe auch zu; am 9. Oktober versprach Heydrich in einem persönlichen Gespräch Döbig, er werde „sich bemühen, die Akten beizuschaffen“ ${ }^{36}$ Am 12. Oktober ging jedoch ein Schreiben Heydrichs im Justizministerium ein, daß die vier Ermittlungsakten beim Politischen Polizeikommandeur/Staatsministerium des Innern „nicht im Einlauf gebucht" seien und „trotz eingehender Nachforschungen ... über den Verbleib der Akten hier nichts ermittelt werden“ konnte. Er „werde jedoch die Nachforschungen fortsetzen und gegebenenfalls sofort Mitteilung machen“ ${ }^{37}$ Diese "Nachforschungen“ sollten auch nach Einschaltung des Verbindungsmannes der Justiz bei der politischen Polizei Dr. Stepp ${ }^{38}$ erfolglos bleiben ${ }^{39}$ : Um dem Risiko zu entgehen, daß die Morde von der Justiz etwa als „aus niedrigen Beweggründen begangen“ beurteilt und daher nicht amnestiert werden könnten, hatte Himmlers Polizei das Problem auf ihre Weise gelöst.

Während der Zeit, in der die Verfolgung der genannten Fälle zur Diskussion stand, wurden aus Dachau keine neuen Fälle gewaltsamen Todes gemeldet. Offensichtlich hatte Himmler das Wachpersonal zur Vorsicht gemahnt. Nachdem sich Innenminister

bezeichnet es als unbekannt, aber wohl mit Recht als fraglich, ob das von Wäckerle niedergelegte Verfahren zur Verhängung von Todesurteilen in Dachau tatsächlich angewendet wurde (a.a.O., S. 55).

29 Verm. Döbigs über die Ergebnisse der Bespr. v. 2.6.33 (Akten des RJM, BA, Sign. R 22/4209); die Teilnehmer gehen aus dem Itinerar Epps hervor (BayerHStArch., Sign. Reichsstatthalter 63).

30 Unterredung des leit. OStA mit Döbig v. 3.6.33, Verm. des OStA v. 21.6.33 (Akten des RJM, a.a.O.).

${ }_{31}$ Verm. des OStA v. 21. u. 23.6 .33 (a.a.O.).

32 Verm. des OStA v. 14.7.33 (a.a.O.).

${ }^{33}$ Verm. des OStA v. 24.7.33 (a.a.O.).

${ }^{34}$ Schr. des OStA an das bayer. JM v. 11.8.33 (Akten des RJM, BA, Sign. R 22/20383).

${ }^{35}$ Schr. v. 28.8 .33 (a.a.O.).

${ }^{36}$ Verm. Döbigs v. 23.9. u. 9.10 .33 (a.a.O.).

${ }^{37}$ Schr. datiert v. 6.10 .33 (a.a.O.).

${ }^{38} \mathrm{Zu}$ Stepp vgl. Kap. IV.4.d., S. 406 f., u. dortige Anm.114.

39 Die Wiedervorlageverm. reichen durch das Jahr 1934 hindurch bis zum Januar 1935 (a.a.O.). 
Wagner in den Ministerratssitzungen verschiedentlich Klagen seitens des Reichsstatthalters und des Ministerpräsidenten über das eigenmächtige Vorgehen der politischen Polizei hatte anhören müssen, ohne daß er selbst von den entsprechenden Maßnahmen Himmlers unterrichtet worden war $^{40}$, hatte er „bestimmten Befehl gegeben, ... $\mathrm{da} ß \mathrm{ihm}$ tägliche Rapporte über die wesentlichen Ereignisse und über geplante gröBere Maßnahmen vorgelegt würden“. ${ }^{11}$ Obwohl Wagner die Schritte Himmlers im allgemeinen deckte, wollte er die Dinge besser in den Griff bekommen. Als sich am 22. August der nächste Fall einer Tötung in Dachau ereignete, wurde Wagner nicht erst auf dem Umweg über die Justiz, sondern durch ein Schreiben Himmlers direkt informiert, von dem er sofort auch von Epp und Siebert Kenntnis gab ${ }^{42}$ : der Bahnarbeiter Stenzer aus Pasing war ,auf einem Spaziergang in der Nähe des Lagers von dem ihn begleitenden SS-Scharführer" - angeblich bei einem Fluchtversuch - durch einen Genickschuß getötet worden. Die sofort verständigte Staatsanwaltschaft ordnete die Einholung eines gerichtsmedizinischen Gutachtens an. Obwohl sich hinsichtlich der Entfernung, aus der der Schuß angeblich abgefeuert worden war, Unklarheiten ergaben, stellte der leitende Oberstaatsanwalt das Verfahren im Dezember ein, da dem Scharführer nicht widerlegt werden konnte, daß er den Häftling auf der Flucht erschossen hatte, "wozu er nach den für ihn geltenden Dienstvorschriften berechtigt war". ${ }^{43}$

Die nächste Serie von drei Fällen, die zur entscheidenden Kraftprobe zwischen Justiz und politischer Polizei führen sollte, ereignete sich im September und Oktober 1933 - wobei der erste Fall nicht einmal dem Konto der Dachauer Lagermannschaft zugerechnet werden kann. Die Mutter des Kunstgewerblers Handschuch aus München erhielt vom Lager die Nachricht, daß ihr Sohn am 2. September in Dachau verstorben sei; auf dem Totenschein war als Todesursache „Herzschwäche nach vorausgegangener Gehirnerschütterung“ angegeben worden. Der Wunsch, den Toten noch einmal zu sehen, wurde den Angehörigen ausdrücklich verweigert, vielmehr wurde der Sarg vernagelt vom Lager auf den Friedhof Dachau überführt, wo die Beerdigung stattfand. Am 18. September erstattete die Mutter bei der Staatsanwaltschaft München II Anzeige und begehrte gerichtliche Leichenschau, um Identität und Todesursache feststellen zu lassen. Die Einvernahme der Braut des Verstorbenen, die zusammen mit ihrem Verlobten am 23. August verhaftet, nach sechs Tagen aber wieder entlassen worden war, ergab, daß Handschuch nach seiner Verhaftung im Braunen Haus in der Briennerstraße derartig mißhandelt worden war, daß er bereits nach seiner Überführung in die Polizeidirektion in der Ettstraße leblos zusammenbrach. ${ }^{44}$ Daraufhin wurde von der Staatsanwaltschaft Exhumierung der Leiche angeordnet. Die gerichtliche Leichenschau vom 23. September ergab, daß der Tod durch Gehirnlähmung infolge von Blutungen eingetreten war, die von einer Schädelverletzung herrührten. Obwohl auf Forderung der SS diesmal ein Arzt ihres Vertrauens zusätzlich hinzugezogen

40 Vgl. z. B. Prot. der MinRatssitzungen v. 16.5.33; 4.7.33; 26. 7.33 (BayerHStArch., Akten der bayer. Staatskanzlei, Sign. MA 99526$)$.

4! Sitzung v. 26.7 .33 (a.a.O.).

42 Schr. Himmlers an Wagner v. 23.8.33 (StArch. München, Sign. Staatsanw. 7014).

43 Ber. des OStA an den GStA v. 21.12.33 mit Weitergabeverm. v. 23.12 .33 (a.a.O.).

44 Niederschrift der Vernehmung v. 21.9.33 (Nürnbg. Dok. D-926, IMG Bd.XXXVI, S.45). 
worden war, war der Befund unbestritten. Die Staatsanwaltschaft ersuchte die Bayerische Politische Polizei um die Vornahme der notwendigen Ermittlungen. ${ }^{45}$

Die beiden weiteren Todesfälle dieser Serie wurden der Staatsanwaltschaft am 19. Oktober telefonisch mitgeteilt: am 17. Oktober nachmittags hätten sich der kaufmännische Angestellte Franz aus München und in der Nacht zum 18. Oktober der praktische Arzt Dr. Katz aus Nürnberg in ihren Einzelhaftzellen erhängt. Wie der von Himmler unterzeichnete Tagesrapport an Siebert ergänzend berichtete, sei am 17. Oktober in Dachau ein Kassiberschmuggel mit Nachrichten aufgedeckt worden, die angeblich dazu dienten, in der Tschechoslowakei „einen Greuelpropagandafilm über die angeblichen Vorkommnisse" im Lager herzustellen. Franz, dessen in einer Konservenbüchse verwahrtes und im Lagergelände vergrabenes - aber noch nicht aufgefundenes - Tagebuch die Grundlage für die Nachrichten abgegeben haben sollte, wurde daraufhin in eine Einzelhaftzelle gebracht, wobei er heftigen Widerstand leistete und „in gehöriger Weise zurechtgewiesen werden mußte“. Eine halbe Stunde später habe man ihn an seinem Leibriemen erhängt aufgefunden. Da sich der ,jüdische Kommunist“ Katz als "geistiger Urheber“ der Greuelpropaganda entpuppt habe, der die Nachrichten für das Tagebuch geliefert habe, wurde auch er in Einzelhaft gebracht, wo man ihn gegen Morgen „mit seinem Hosenträger an der Zugvorrichtung zur Oberlichtöffnung aufgehängt" entdeckt habe. ${ }^{46} \mathrm{Da}$ der neue Lagerkommandant Eicke am 1. Oktober 1933 eine „Disziplinar- und Strafordnung“ erlassen hatte, wonach „kraft revolutionären Rechts als Aufwiegler gehängt“ werden sollte, wer „wahre [!] oder unwahre Nachrichten zum Zwecke der gegnerischen Greuelpropaganda über das Konzentrationslager oder dessen Einrichtungen ... hinausschmuggelt ${ }^{\text {“47 }}$, ist es sehr wahrscheinlich, daß diese Vorschriften gegen Franz und Katz tatsächlich angewendet, die Vorgänge jedoch nach außen hin als Selbstmord getarnt worden waren. ${ }^{48}$ Die am 18 . Oktober vorgenommene Leichenschau und die daraufhin zwei Tage später erfolgte Obduktion - bei der diesmal bezeichnenderweise auch der Lagerarzt und der Lageradjutant zugegen waren - stellten in beiden Fällen „Erstickungstod durch Erwürgen und Erdrosseln" von fremder Hand fest; im Falle Franz wurde als konkurrierende Todesursache auch Fettembolie durch ausgedehnte Zertrümmerung des Gewebes nicht ausgeschlossen. Vergeblich hatte die Staatsanwaltschaft schon am 18. Oktober die Aushändigung des Leibriemens bzw. Hosenträgers verlangt, mit denen sich die beiden Gefangenen angeblich aufgehängt hatten; auch eine Beschlagnahmeverfügung durch das Landgericht Dachau konnte eine Übergabe dieser Beweisstücke nicht bewirken. ${ }^{49}$

45 Zum Voranstehenden s. Ber. des OStA an das bayer. JM v. 26.9.33 (Nürnbg. Dok. D-926); Bericht Franks an Siebert v. 2.12 .33 (BayerHStArch., Sign. MA 107200 ); undat. zeitgenöss. Notiz des EStA bei der StAschaft München II u. seine Zeugenaussage v. 27.3.51; ferner Zeugenaussage des leitenden OStA v. 7.3.51 (StArch. München, Sign. Staatsanw. 7014).

46 Ber. Himmlers an Min Präs. Siebert v. 19.10.33 (BayerHStArch., Sign. MA 105 490), er wurde ergänzt durch den Ber. v. 20.10.33, daß bis zur Klärung des Kassiberschmuggels „zunächst auf die Dauer von 6 Wochen keine Entlassungen“" aus Dachau erfolgten (a.a.O.).

47 Siehe folgende Anm.67, dazu auch Kap. VI.4.b., S.645f.

48 Der Häftling Altmann, der lt. Himmlers Rapport den Kassiber aus dem Lager zu schmuggeln versucht hatte, wurde am 12.2.34 gleichfalls ,erhängt aufgefunden“; die Obduktion ergab diesmal „keine Anhaltspunkte für ein fremdes Verschulden“, ebensowenig in einem weiteren Fall (Hutzelmann) v. 25.2.34 (undat. zeitgenöss. Notiz des EStA, StArch. München, Sign. Staatsanw. 7014).

49 Undat. zeitgenöss. Notiz des EStA (a.a.O.); Schr. Franks an Siebert v. 2.12.33 (BayerHStArch., Sign. MA 107200 ). 
Himmler stellte am 18. November im bayerischen Innenministerium den Antrag, die Ermittlungsverfahren in Sachen Handschuch, Franz und Katz "aus staatspolitischen Gründen" niederzuschlagen. In einem Schreiben an Frank vom 29. November schloß sich Wagner diesem Antrag an, da

„durch die Durchführung der Ermittlungsverfahren dem Ansehen des nationalsozialitstischen Staates großer Abbruch deswegen getan würde, weil diese Verfahren sich gegen Angehörige der SA. und SS. richten und somit die SA. und SS., also Hauptträger des nationalsozialistischen Staates, unmittelbar betroffen würden“. Zur Beruhigung fügte er hinzu, er hoffe, „daß dies die letzten Fälle sind, die den Herrn Reichsstatthalter und den Ministerrat zum Eingreifen im Staatsinteresse zwingen. Den Organen der Politischen Polizei gegenüber habe ich eindeutigst zum Ausdruck gebracht, daß ich mich künftig in ähnlichen Fällen nicht mehr zur Antragstellung auf Niederschlagung der Ermittlungsverfahren bereit erklären kann. “so

Frank wollte jedoch diesmal fest bleiben, zumal er im Ministerrat mit den anderen Vertretern des Staatsapparats als Verbündeten rechnen konnte. Formelle Handhabe, die Sache im Kabinett zu behandeln, bot ihm der Beschluß des Ministerrats vom 10. Oktober, daß der Justizminister Niederschlagungsfälle, die nicht mehr unter die bayerische Amnestieverordnung vom 2. August 1933 fielen, diesem Gremium zur vorbereitenden Beschlußfassung unterbreiten konnte. ${ }^{51}$ Frank legte dem Ministerpräsidenten am 2. Dezember einen detaillierten und ungeschminkten Bericht über die drei Fälle vor. Er bat, den Antrag Wagners in die Tagesordnung der nächsten Ministerratssitzung aufzunehmen, betonte aber, daß er "davon ausgehe, daß der Herr Staatsminister des Innern den Antrag im Ministerrat selbst vertreten“ werde. Zur Vorbereitung der Sitzung erhielten die anderen Kabinettsmitglieder und über Siebert auch von Epp Abdrucke des Schreibens. ${ }^{52}$ Als Wagner am 5. Dezember 1933 dem Ministerrat seinen Antrag unterbreitete, erwiderte ihm Frank, er halte in den vorliegenden Fällen eine Niederschlagung für „rechtspolitisch äußerst gefährlich; er müsse als Justizminister auf den Ernst der Situation hinweisen “. Er könne daher die Verantwortung für einen entsprechenden Antrag an den Reichsstatthalter „nicht allein übernehmen und lege deshalb entsprechend früheren Ministerratsbeschlüssen die Verhandlungen vor“. Daraufhin erklärte von Epp,

„ein Begnadigungsakt komme gegenwärtig deshalb nicht in Frage, weil die Täter nicht festgestellt, Tatbestand und Motive der Handlungen nicht untersucht seien. Bei dieser Sachlage werde die Niederschlagung nicht Nutzen, sondern Schaden stiften. Auch für die Staatsregierung müsse es erwünscht sein, ihre Beschlüsse nur auf Grund genauer Unterlagen zu fassen, da dies die Verantwortung verringere. Notwendig sei, die dem Antrag zugrunde liegenden tatsächlichen Verhältnisse zu bessern und die Autorität des Staates nach allen Seiten zu wahren. Wenn ein Gnadenakt geschehe, müsse Sicherheit bestehen, daß sich ähnliche Vorfälle nicht wiederholten; auch müsse man wissen, wie mit den Leuten verfahren werde, die an den Taten beteiligt waren.“

Nach weiterer Aussprache stimmte schließlich auch Wagner dem Beschluß zu, „daß die schwebenden Untersuchungsverfahren mit Beschleunigung weiterzuführen seien“.

so Schr. Wagners an Frank v. 29.11 .33 (BayerHStArch., Sign. MA 105 487). Am Vortag hatte sich ein neuer Fall ereignet: der Häftling Bürk war auf der Lagerlatrine von einem SS-Scharführer durch 3 Schüsse getötet worden, angeblich weil er ihn tätlich angriff. Da die Ermittlungen die Behauptung des Täters nicht widerlegen konnten, wurde das Verfahren Mitte Dezember eingestellt (Schr. d. OStA beim LG München II an den GStA v. 2. u. 16.12.33, StArch. München, Sign. MInn 73690; undat. zeitgen. Notiz des EStA beim LG München II u. seine Zeugenaussage v. 27.3.51 im Untersuchungsverfahren gegen Steinbrenner, StArch. München, Sign. Staatsanw. 7014).

51 Vgl. Kap. IV.1.c., S.333f., u. dortige Anm.63.

52 Schr. Franks an Siebert v. 2.12.33 (BayerHStArch., Sign. MA 107 200). 
Nach ihrem Abschluß sollte die Angelegenheit nochmals aufgegriffen werden, „wenn feststeht, welche Garantien gegen die Wiederholung der Vorfälle gegeben sind und was mit den beteiligten Personen geschehen ist" ${ }^{53}$ Das war eine deutliche Warnung für die politische Polizei. Offensichtlich hatte Frank diesmal einen Sieg für die Justiz errungen. Er sollte sich als Pyrrhussieg erweisen.

Am nächsten Tag wies Frank seinen Strafrechtsreferenten an, daß die drei Verfahren „mit aller Entschiedenheit“ und „größter Beschleunigung“ weitergeführt werden sollten und gegebenenfalls „zur Unterstützung die Landespolizei heranzuziehen“ sei. $^{54}$ Der leitende Oberstaatsanwalt beim Landgericht München II wurde durch Ministerialrat Döbig von der Entscheidung unterrichtet und angewiesen, daß er ,in den Fällen Franz und Katz sofort und im Fall Handschuch nach Eintreffen der von der politischen Polizei zurückgeforderten Akten gerichtliche Voruntersuchung beantragen“ und das Ministerium über den Gang der Verfahren laufend informieren solle. ${ }^{55}$ Als jedoch der Verbindungsmann des Ministeriums zur Bayerischen Politischen Polizei, Staatsanwalt Stepp, den Beschluß des Ministerrats am 6. Dezember weisungsgemäß Himmler vortrug, erklärte dieser, seine Meinung erst nach Rücksprache mit seinem Vorgesetzten, dem Stabchef der SA Röhm, äußern zu können. Beide fuhren daher zur Reichsstatthalterei, in der Röhm nominell als „Staatssekretär“ residierte; dort mußte der Oberstaatsanwalt im Vorzimmer Röhms warten, bis ihn Himmler hereinrief. Röhm, der einige Tage vorher zum Reichsminister ohne Geschäftsbereich ernannt worden war, ersuchte ihn, Frank in seinem Namen folgende Antwort zu übermitteln:

„Das Lager Dachau ist ein Lager für Schutzhaftgefangene, die aus politischen Gründen festgenommen wurden. Die in Frage stehenden Vorgänge sind politischer Natur und müssen unter allen Umständen zunächst von den politischen Stellen entschieden werden. Sie scheinen mir für eine Behandlung durch die Justizbehörden vorerst nicht geeignet. ${ }^{56}$ Das ist meine Ansicht als Stabschef und als Reichsminister, der ein Interesse daran hat, daß das Reich nicht politisch durch die in Frage stehenden Verfahren geschädigt [!] wird. Ich werde durch den Reichsführer SS anordnen lassen, daß zunächst irgendwelche Untersuchungsbehörden das Lager nicht betreten dürfen und auch Angehörige des Lagers zunächst nicht einvernommen werden dürfen. Morgen werde ich mit dem Führer die Angelegenheit besprechen und ihn um seine Entscheidung bitten. ${ }^{457}$

In Erfüllung seines Auftrages rief am 7. Dezember der leitende Oberstaatsanwalt, der von diesem Vorgang nichts ahnte, Heydrich an, um wegen der Fortsetzung der Ermittlungsverfahren eine Besprechung zu vereinbaren. Heydrich teilte ihm mit, daß Himmler und Röhm am Morgen „aus Anlaß des Min.Ratsbeschlusses“ zu Hitler nach Berlin gefahren seien. Bis zu deren Rückkunft habe er Befehl, ,jede Besprechung und jede Auskunft in den fraglichen Dachauer Fällen abzulehnen und das Betreten des Lagers Dachau durch einen Richter oder Staatsanwalt in diesen Fällen zu verhindern“. Der Oberstaatsanwalt setzte sich sofort mit dem Generalstaatsanwalt und dem Justizministerium in Verbindung und erhielt die Weisung, „von dem Antrag auf Eröffnung

53 Prot. der MinRatssitzung v. 5.12 .33 (BayerHStArch., Sign. MA 99526).

34 Verm. Döbigs v. 6.12.33 (Nürnbg. Dok. D-926, IMG Bd.XXXVI, S. 53).

ss Verm. Döbigs v. 6.12.33 (a.a.O.), übereinstimmend Verm. des OStA v. 6.12.33 (StArch. München, Sign. Staatsanw. 7014).

s6 Da die politischen Stellen auch entschieden, was als „politisch“ anzusehen war, wird an dieser Stelle ganz deutlich, daß die nur noch unter dem „Vorbehalt des Politischen“ arbeitende Justiz de facto willkürlich ausgeschaltet werden konnte.

57 So durch Stepp im Verm. v. 6.12.33 festgehalten (Nürnbg. Dok. D-926, a.a.O., S. 54 f.). 
der Voruntersuchung bis auf weiteres abzusehen" und sich darauf zu beschränken, die seit Ende September bei der politischen Polizei liegenden Ermittlungsakten zum Fall Handschuch zurückzufordern. ${ }^{58}$ Eine klare Stellungnahme hatte aber wohl auch Röhm von Hitler nicht erhalten: das Jahr ging zu Ende, ohne daß eine Entscheidung über Weiterführung oder Niederschlagung fiel. ${ }^{59}$ Ende Februar 1934 wurde dem Oberstaatsanwalt von Döbig mitgeteilt, daß die Akten mit Bericht an das Reichsjustizministerium gingen; Mitte April erfuhr er, die Akten würden dem Reichsstatthalter zur Entscheidung über eine Niederschlagung zugeleitet. ${ }^{60}$ Aber der General in der Reichsstatthalterei, der bereits über einen neuen Fall zweifelhaften Selbstmordes durch Erhängen verärgert war ${ }^{61}$, blieb starrköpfig. Die Beseitigung Röhms brachte eine Wende: am 11. Juli 1934 erhielt der Oberstaatsanwalt die Akten mit dem Auftrag zurück, die Ermittlungen in den Fällen Franz und Katz mit Hilfe der politischen Polizei fortzusetzen und die Akten Handschuch zuständigkeitshalber an die Staatsanwaltschaft München I abzugeben, da offensichtlich nunmehr feststand, daß Handschuch nicht in Dachau, sondern in der Polizeidirektion München zu Tode gekommen war. ${ }^{62}$ Der Oberstaatsanwalt sollte jedoch sofort belehrt werden, wie die „Mitwirkung" der politischen Polizei bei der Aufklärung der beiden Fälle aussah: Auf die Übersendung der Akten und sein Ersuchen, die als Täter verdächtigen Personen und die gerichtlich beschlagnahmten „Selbstmordwerkzeuge“ (Leibriemen und Hosenträger) auffinden zu helfen, bekam er ein Schreiben der politischen Abteilung des Lagers, das mit folgenden Sätzen begann:

„Der neuerliche Beweiserhebungsantrag durch die Staatsanwaltschaft München II zeigt, mit welchen an den Haaren herbeigezogenen Mitteln gearbeitet wird, um dem Konzentrationslager Dachau angeblich ausgeführte Verbrechen in die Schuhe zu schieben.“

Nach dem Bedauern, daß sich die beiden Häftlinge ihrer zu erwartenden Bestrafung wegen Kassiberschmuggels durch Selbstmord hätten entziehen (!) können, nahm das Schreiben mit folgenden Worten auf die beschlagnahmten Beweisstücke Bezug:

„Nachdem nun nach durchgeführter gerichtlicher Sektion der Leichen die Beiden freigegeben waren, bestand für die Kommandantur kein Interesse mehr, die Gegenstände mit denen sich die Beiden aufhängten, noch aufzuheben. Die Kommandantur zählt nicht zu jenen widerlichen Kulturmenschen, die derartige Gegenstände, wie es in letzter Zeit in Amerika sich bei dem Fall Dillinger gezeigt hat, als Amulett in Verwahrung nehmen." ${ }^{\text {" } 3}$

58 Verm. des leitenden OStA v. 7.12.33 (StArch. München, Sign. Staatsanw. 7014) u. Verm. Döbigs v. 7.12.33 (Dok. D-926, IMG Bd.XXXVI, S. 55).

s9 Vgl. Verm. des OStA v. 9.12., 14.12., 23.12.33 (a.a.O.).

${ }^{60}$ Verm. des OStA v. 26. 2. u. 12.4.34 (a.a.O.). Die Akten waren offensichtlich deswegen zunächst nach Berlin geschickt worden, da mit dem G. v. 16.2.34 (RGB. I, S.91; vgl. dazu Kap. IV.1.d., S. 334) das Niederschlagungsrecht auf den Reichspräs. übergegangen war. Da dieser das Recht am 21.3.34 für alle vor diesem Stichtag aufgetretenen Straftaten den Reichsstatthaltern wieder übertrug, blieb v. Epp für die hier behandelten Fälle zuständig.

${ }^{61}$ Am 9.4.34 (Fall Stiebel); die Obduktion ergab den „Verdacht, daß der festgestellte Erstickungstod durch Einwirkung Dritter hervorgerufen wurde“. Anläßl. dieses Falles folgende undatierte Notiz (offenbar für eine MinRatssitzung) in Epps Akten: „Mit Mißhandlungen und sonstigen des national. Staates unwürdigen Dingen in Konzentrationslagern ... ist immer noch nicht Schluß [ursprüngl.: muß endgültig Schluß gemacht werden]“, es müsse „darauf hingearbeitet werden, daß die Berichterstattung der Polizeibehörden ein Bild der wahren Sachlage geben, daß die Erhebungen der Polizei der Erforschung der Wahrheit dienen“ (BayerHStArch., Sign. Reichsstatthalter 446).

${ }^{62}$ Verm. des OStA v. 11.7.34 (StArch. München, Sign. Staatsanw. 7014).

${ }^{63}$ Schr. v. 25.7.34, i.V. des Lagerkommandanten unterzeichnet v. SS-Obersturmbannführer Lippert, zit. im Ber. des leitenden OStA v. 30.7.34 an das bayer. JM über den GStA (Nürnbg. Dok. D-926, IMG 
Da ihm die Bayerische Politische Polizei die Akten mit diesem Schreiben der Lagerkommandantur ohne weitere Äußerung wieder zustellte, hielt es der Oberstaatsanwalt für notwendig, daß SS und Polizei „von höherer Stelle“ Weisung erteilt werden müßte, wenn die Ermittlungen fortgesetzt werden sollten; ebenso sollten wegen der in dem Schreiben enthaltenen „unerhörten Anwürfe“ gegen die Justiz höheren Orts Verfügungen getroffen werden ${ }^{64} \mathrm{Z}$ war wurde der fragliche Brief nach Intervention Franks von der Lagerkommandantur „zurückgenommen “65, aber Weisungen der obersten Führung, die einen Fortgang der Verfahren ermöglicht hätten, blieben aus. Andererseits erfolgte aber auch keine Niederschlagung, zu der das am 7. August 1934 erlassene Straffreiheitsgesetz bei entsprechender Interpretation seiner einschränkenden Bestimmung formell eine Handhabe geboten hätte. Um diesen Schwebezustand, bei dem die Polizei ohnehin faktisch Sieger blieb, zu beenden, stellte der Anfang August zum Leiter der Staatsanwaltschaft München II berufene Oberstaatsanwalt Barnickel schließlich am 27. September 1934 das Verfahren ein, „da die Erhebungen keine ausreichenden Anhaltspunkte für die Annahme eines fremden Verschuldens am Ableben der beiden Schutzhaftgefangenen ergeben" hätten. ${ }^{66}$ Die Kraftprobe war zum Nachteil der Justiz ausgegangen; da sie am „Modellfall Dachau“ ausgetragen worden war, der für den Ausbau von Himmlers Konzentrationslagersystem als Muster diente, kam ihrem Ausgang zugleich überregionale Bedeutung zu.

\section{b. Bemübungen der Justiz um eine Änderung der Straf- und Dienstvorscbriften in den} Konzentrationslagern 1934-1938

Nachdem Himmler bis Frühjahr 1934 die politischen Polizeien aller Länder unter seine Befehlsgewalt gebracht hatte, Heydrich als Chef in das Geheime Staatspolizeiamt in Berlin eingezogen war und der im Juli 1934 zum „Inspekteur der KL und Führer der SS-Wachverbände“ und zum SS-Gruppenführer ernannte Theodor Eicke alle Konzentrationslager übernommen und einheitlich organisiert hatte, verlagerte sich die Auseinandersetzung in KZ-Angelegenheiten mit der unterdessen gleichfalls "verreichlichten“ Justiz auf die Reichsebene. Das Reichsjustizministerium versuchte vor allem auf die von Eicke erlassene Strafordnung für die Häftlinge und die Dienstvorschriften für die Bewacher Einfluß zu nehmen, die ohne gesetzliche Basis kraft usurpierter Befugnis nicht-,,staatlicher" Stellen für die Konzentrationslager eigenes „Recht" schufen und nicht ohne Grund als Ursachen für die zahlreichen gewaltsamen Todesfälle in diesen Lagern angesehen wurden.

Noch als Kommandant von Dachau hatte Eicke am 1. Oktober 1933 eine „Disziplinar- und Strafordnung “67 erlassen, die ihn selbst mit der „vollziehenden Strafgewalt“ ausstattete, bei deren Ausübung er lediglich Himmler persönlich verantwortlich war.

Bd.XXXVI, S. 55 ff.). Der amerikanische Gangsterboss John H. Dillinger, dessen Bande 1933/34 zahlreiche Morde und Raubüberfälle beging, war am 22.7.34 bei seiner Festnahme in Chicago erschossen worden.

64 Ber. des OStA v. 30.7.34 (a.a.O.).

65 Verm. Stepps v. 7.9 .34 (a.a.O., S. 55).

66 Ber. an den GStA v. 27.9 .34 (a.a.O., S. 57 f.). B. wurde 1938 ReiA beim VGH und im Nürnbg. Juristenprozeß angeklagt, aber freigesprochen.

67 In Auszügen als Nürnbg. Dok. PS-778, IMG Bd.XXVI, S. $291 \mathrm{ff}$. Vgl. dazu M. Broszat, Nationalsozialistische Konzentrationslager 1933-1945 (Anatomie des SS-Staates, Bd. II, Olten u. Freiburg i. Br. 1965, S. 58 ff.). 
Sie sah u.a. neben „strengem Arrest“ von 8, 14, 21 oder 42 Tagen und dauernder Einzelhaft - beide "in einer Zelle, bei hartem Lager, bei Wasser und Brot“" (warmes Essen nur jeden 4. Tag) vollzogen - die Prügelstrafe vor, die auch zusätzlich zu Beginn und am Ende der Arreststrafe „mit je 25 Stockhieben ${ }^{\text {" } 68}$ angeordnet werden konnte. Als „Nebenstrafen“ standen u. a. Postsperre, Kostentzug, Strafexerzieren, Prügelstrafe und Pfahlbinden zur Verfügung. Die Todesstrafe war für denjenigen vorgesehen, der „zum Zwecke der Aufwiegelung politisiert, aufreizende Reden hält, sich mit anderen zu diesem Zweck zusammenfindet ..., wahre [!] oder unwahre Nachrichten zum Zwecke gegnerischer Greuelpropaganda über das Konzentrationslager" sammelt oder weitergibt: er sollte „kraft revolutionären Rechts als Aufwiegler gehängt“" werden (§ 11). "Wer einen Posten oder SS-Mann tätlich angreift" oder den Gehorsam verweigerte, sollte „als Meuterer auf der Stelle erschossen oder nachträglich gehängt“ werden (§ 12). Ebenso wurde vorsätzliche Sabotage an den Einrichtungen des Lagers „mit dem Tode bestraft" $(\S 13)$. Diese Disziplinar- und Strafordnung führte Eicke auch in den anderen Konzentrationslagern ein, so z. B. am 1. August 1934 in Esterwegen, wo sie im September bei einer Untersuchung von Mißhandlungen in die Hände der Staatsanwaltschaft Osnabrück geriet. ${ }^{69}$

Das Reichs- und Preußische Justizministerium reichte diese ungesetzliche Lagerordnung an das für die Schutzhaftangelegenheiten zuständige Preußische Staatsministerium Görings weiter - dem sie bis dahin unbekannt war - und forderte eine Aufhebung der drakonischen Strafen. Der Versuch des Staatsministeriums, die Gestapo „in die gesetzlich vorgesehene Abhängigkeit von der Aufsichtsbehörde zu bringen" und zu einer zwar strengen, aber den staatlichen Gefängnisordnungen angeglichenen Strafordnung zu veranlassen, scheiterte: das Geheime Staatspolizeiamt verhinderte und verschleppte die Sache, indem es die angeforderten Unterlagen über die innere Organisation der Konzentrationslager trotz mehrfacher Erinnerung nicht vorlegte. Göring, der versprochen hatte, die Angelegenheit mit Hitler zu erörtern, tat nichts ${ }^{70}$; im Gegenteil entschloß er sich, das Staatsministerium durch seinen Erlaß vom 20. November 1934 von der Verantwortung für alle Maßnahmen der Gestapo zu entlasten ${ }^{71}$ und ihm dadurch auch die Zuständigkeit für die KZ-Strafordnung zu entziehen. Damit war der erste Versuch der Justiz fehlgeschlagen, eine Änderung der Lagerordnung Eickes zu erreichen.

Obwohl diese Strafordnung für Konzentrationslager weiterhin in Kraft blieb, wurden die vorgesehene Verhängung und Vollzug der ungesetzlichen Todesstrafe - zumindest während der Friedensjahre ${ }^{72}$ - stets als Selbstmord, Erschießung „bei Widerstand“ oder „auf der Flucht“" getarnt, um eine offene Auseinandersetzung mit der Justiz zu vermeiden; Beispiele dafür sind die bereits geschilderten Dachauer Fälle

68 Diese Zahl der Schläge entsprach der Höchstzahl, die auch bei der „verschärften Vernehmung a angeordnet werden sollte (vgl. Kap. VI.7.b., S. 716).

69 Vgl. dazu Kap. IV.2.b., S.365. Im März 1935 unterstanden Eicke außer Dachau u. Esterwegen schließlich die KZ Lichtenburg, Sachsenburg, Oranienburg, Columbia-Haus (Berlin) u. Hamburg-Fuhlsbüttel.

70 Zum Voranstehenden vgl. Verm. des zuständigen Beamten in Görings Preuß.StMin. v. 20.11.34 (Akten des Preuß.StMin., Abt. Polizei, GehStArch. Berlin, Sign. Rep. 90) u. S. Aronson, Reinhard Heydrich und die Frühgeschichte von Gestapo und SD, Stuttgart 1971, S. 223 f.).

71 Vgl. dazu Kap. Vl.2.a., S. 553.

72 Zur Erhängung zweier Schutzhäftlinge in Mauthausen, die im November 1939 einen Posten niederschlugen, und der öffentlichen Bekanntgabe im "Schwarzen Korps“ v. 21.12.39 vgi. Kap. VI.6.a., S.682. 
Franz und Katz vom Oktober 1933. Im April 1935 erklärte Eicke gegenüber der Justiz, „daß zur Zeit eine geheime Gegenorder an die Lagerkommandanten ergangen sei, wonach diese scharfen Bestimmungen in Wirklichkeit nicht zur Anwendung gelangen“, sondern lediglich zur „Einschüchterung“ der Häftlinge dienen sollten; bezeichnenderweise konnte er aber nicht sicher sagen, „ob die Vorschriften den Schutzhäftlingen wirklich bekannt" gemacht wurden, da jedenfalls ein Aushang im Lager nicht erfolgte. $^{73}$

Nachdem somit wenigstens die Vorschriften über die Verhängung der Todesstrafe in der Strafordnung suspendiert schienen - was natürlich Tötungen aus Straf- und Rachemotiven nicht ausschloß -, wandte sich Gürtner am 14. Mai 1935 mit einem Schreiben an den für das polizeiliche Schutzhaftwesen zuständigen Reichsinnenminister Frick auch gegen die derzeitige Handhabung der „Prügel als Hausstrafe in Konzentrationslagern“. Er führte aus, daß die Untersuchungsgefängnisse und Haftanstalten der Justiz ohne Prügelstrafe auskämen: es sei erwiesen, daß ein gutgeschultes und zuverlässiges Wachpersonal auch ohne diese Strafart eine mustergültige Disziplin aufrechterhalten könne.

„Wenn man aber entgegen diesen Feststellungen annehmen will, daß in den Konzentrationslagern ein Bedürfnis zur Einführung der Prügelstrafe bestehen sollte, so erscheint es unerläßlich, daß diese Hausstrafe und die Art ihrer Vollstreckung für das gesamte Reichsgebiet einheitlich und unmißverständlich geregelt wird."

Die Lagerordnungen der Konzentrationslager enthielten über die Prügelstrafe und über den Waffengebrauch „ungewöhnlich scharfe Bestimmungen ..., die den Häftlingen zur Abschreckung bekanntgegeben wurden, während den Wachmannschaften dienstlich erklärt wurde, daß diese meist aus dem Jahre 1933 stammenden Bestimmungen nicht mehr anwendbar seien". Dieser Zustand sei für die Wächter und die Häftlinge gleichermaßen gefährlich. Nachdem die Frage der Schutzhaftverhängung durch den Erlaß des Reichsinnenministers vom 12./26. April $1934^{74}$ einheitlich geregelt worden sei, sei es nunmehr

„im Interesse aller Beteiligten und zur Herbeiführung einer klaren Verantwortlichkeit und Rechtslage dringend geboten, daß dieselbe verantwortliche Stelle auch in einer allgemein gültigen Lagerordnung die z.Zt. noch völlig unklare Frage der Prügelstrafe als Hausstrafe wie übrigens auch die Frage des Waffengebrauchs seitens der Wachmannschaften regelt " ${ }^{75}$

Doch auch dieser Vorstoß der Justizleitung zugunsten einer humanen Lagerordnung scheiterte am Kompetenzschwund der staatlichen Verwaltung gegenüber der sich verselbständigenden SS- und Polizeiführung, die die Lagerordnung auch weiterhin allein regelte. Die Verhängung der Prügelstrafe wurde von ihr analog der späteren Bestimmungen über die „verschärfte Vernehmung “76 und die „Sonderbehandlung" ${ }^{\text {"77 }}$ geordnet: sie mußte bei der Zentrale - in diesem Falle beim Inspekteur der KL - beantragt und von dort genehmigt werden; vollzogen wurde sie im Lager vor einer angetretenen Abteilung der Wachtruppe und versammelten Häftlingen in Anwesenheit des Lagerarztes auf dem „Prügelbock“. Diese zentrale Reglementierung schloß jedoch

73 Vgl. Diensttageb. des RJM, Eintr. v. 18.4.35, Bd. 1 (BA, Sign. R 22/603) u. v. 29.5.35 (BA, Sign. R 22/1056).

74 An den sich die Gestapopraxis aber schon längst nicht mehr hielt, vgl. Kap. VI.2.a., S. $550 \mathrm{ff}$.

75 Schr. Gürtners an Frick v. 14.5.35 (Nürnbg. Dok. PS-3751, IMG Bd.XXXIII, S. 56 ff.).

76 Vgl. dazu Kap. VI.7.b., S. 716.

77 Vgl. dazu Kap. VI.6, S.676f., 690. 
weder aus, daß die Lagerführung bei „kleineren“ Vergehen die Prügelstrafe von sich aus verfügte ${ }^{78}$, noch verhinderte sie überhaupt willkürliche Mißhandlungen von Häftlingen.

Wie Gürtner in dem erwähnten Schreiben an Frick ausgeführt hatte, gaben nicht nur die Strafvorschriften, sondern auch die KZ-Wachvorschriften Anlaß zu rechtlichen Beanstandungen, da sie nicht zu unrecht als eine der Ursachen für die häufigen Todesfälle in den Lagern angesehen wurden. Zusammen mit der Strafordnung hatte Eicke am 1. Oktober 1933 auch „Dienstvorschriften für die Begleitposten und die Gefangenenbewachung ${ }^{\text {“79 }}$ erlassen. Danach war an sich ,jede Mißhandlung und Schikane" als Mittel, träge Gefangene zur Arbeit anzuhalten, streng untersagt; auch Disziplinlosigkeit wie nachlässiges Arbeiten und freche Antworten sollten nach dem Grundsatz: „Selbsthilfe bedeutet Mangel an Disziplin“ zur Ahndung gemeldet werden. Punkt „6. Postenpflicht" der Vorschriften aber enthielt jene rigorosen Bestimmungen, auf die sich die Bewacher in den Fällen von Tötungen üblicherweise beriefen:

„Versucht ein Gefangener zu entfliehen, dann ist ohne Anruf auf ihn zu schießen. Der Posten, der in Ausübung seiner Pflicht einen fliehenden Gefangenen erschossen hat, geht straffrei aus. Wird ein Posten von einem Gefangenen tätlich angegriffen, dann ist der Angriff nicht mit körperlicher Gewalt, sondern unter Anwendung der Schußwaffe zu brechen ...

Meutert oder revoltiert eine Gefangenenabteilung, dann wird sie von allen aufsichtsführenden Posten beschossen. Schreckschüsse sind grundsätzlich untersagt.“

Diese drakonischen Bestimmungen wurden noch durch die weitere verschärft, daß jeder Wachposten, der einen Gefangenen entweichen ließ, selbst sofort festgenommen und der politischen Polizei übergeben werden sollte.

Auf diese in allen Konzentrationslagern eingeführten Dienstvorschriften beriefen sich auch die beteiligten SS-Leute, die im Lager Columbia-Haus in Berlin in der Nacht zum 22. März und am 4. April 1935 zwei Schutzhäftlinge erschossen. Bei ihrer Vernehmung gaben sie im ersten Fall an, der Häftling habe sie bei einer ärztlichen Untersuchung, ob seine weitere Fesselung zu verantworten sei, tätlich angegriffen, sei von ihnen durch einen Schuß verletzt und in seine Zelle zurückgebracht worden. Als sie vier Stunden später (!) nach ihm sehen wollten, sei er aufgestanden und „mit erhobenen Händen und Schimpfworte ausstoßend auf einen der SS-Leute zugekommen, worauf dieser ihn erschossen" habe. Nach dem Ermittlungsergebnis nahm der Generalstaatsanwalt beim Landgericht Berlin Notwehrexzeß an und beabsichtigte Anklage wegen Totschlags.

Im zweiten Fall wurde nach Darstellung der Bewacher der tobende Häftling in die Dunkelzelle gelegt, wo er auf einen SS-Mann, der ihn zur Ruhe mahnen wollte, mit dem „Anschein“ (!) losgegangen sei, ihm an den Hals zu springen. Daraufhin habe ihn

${ }^{78}$ Zur Handhabung der Prügelstrafe im KZ vgl. E. Kogon, a.a.O., S. 108 ff.; Kommandant in Auschwitz. Autobiographische Aufzeichnungen von Rudolf Höss, eingel. u. komment. v. M. Broszat, Stuttgart 1961, S.54f. Aus einem Schr. des Kommandanten des KZ Columbia-Haus an den RFSS v. 8.5.35 (Diensttageb. des RJM, Bd.3, Eintr. v. 24.6.35, BA, Sign. R 22/1056) geht hervor, daß schon zu dieser Zeit die Prügelstrafe vom Inspekt. der $\mathrm{KL}$ genehmigt und vor versammelten Häftlingen vollzogen werden mußte. $\mathrm{Zahl}$ und $\mathrm{Zu}$ sammensetzung der ,als Zeugen“ teilnehmenden SS-Truppe regelte genauer Eickes Befehi Nr.29 im Befehlsbl. SS-TV/IKL Nr. 2 v. 1.3.37 (Arch. des IfZ, Sign. MA-283).

79 Nürnbg. Dok. PS-1216; Punkt 6 der Dienstvorschriften auch als Nürnbg. Dok. PS-778 abgedruckt in IMG Bd.XXVI, S. $296 \mathrm{f}$. 
der SS-Mann durch zwei Schüsse getötet. Als Zeuge für diesen Vorgang boten die Bewacher einen Schutzhäftling an, dessen Name sich jedoch als falsch herausstellte und von dem die Staatsanwaltschaft daraufhin vermutete, „daß es sich bei ihm um einen Spitzel der SS“ handelte. Die Ermittlungen ergaben, daß der Erschossene kurz vor seinem Tode mißhandelt und zehn bis fünfzehn Stockhiebe auf das Gesäß als Hausstrafe erhalten hatte. Obwohl der Lagerkommandant seine Untergebenen durch allgemeine Äußerungen wie „die Bande müßte erschossen werden“ scharf gemacht hatte, konnte ihm nicht nachgewiesen werden, daß er die Erschießung der beiden befohlen hatte; derartige Reden, die er als „schwerer Alkoholiker“ führte, seien von seinen Leuten nie ernst genommen worden.

Aufgrund seiner Ermittlungen bestätigte der Generalstaatsanwalt, daß zwar verschiedene Strafvorschriften für Schutzhäftlinge durch einen geheimen Gegenbefehl aufgehoben worden seien, die „Dienstvorschriften“ dagegen seien nach wie vor in Geltung und ihre Befolgung den Beschuldigten "bis in die neueste Zeit wiederholt“ zur Pflicht gemacht worden. Zur rechtlichen Beurteilung dieser Dienstvorschrift führte er aus, daß sie

„die Beschuldigten strafrechtlich nicht entlasten könne. Da sie sich nicht als gesetzliche Bestimmung darstellt, kann sie die Rechtswidrigkeit des Handelns der Beschuldigten nicht beseitgen. Es handelt sich hier um ein bedauerliches Auseinanderklaffen von Dienstanweisungen und rechtlich Zulässigem.“

Der Generalstaatsanwalt beantragte daher gegen einen SS-Oberscharführer und einen Unterscharführer Voruntersuchung wegen vollendeten Totschlags. ${ }^{80}$

Als die Fälle gewaltsamen Todes in den Konzentrationslagern - Erschießungen „bei Widerstand“, „auf der Flucht" und Selbstmorde - in den folgenden Monaten weiter anhielten $^{81}$, machte Gürtner erneut einen Vorstoß, diesmal unmittelbar bei Himmler: am 16. Oktober 1935 übersandte er ihm eine Liste der gemeldeten Todesfälle und forderte offenbar Maßnahmen, um die Ursachen abzustellen. Aber Himmler wehrte auch diesen Versuch unter Berufung auf Hitler ab. Am 6. November teilte er dem Reichsjustizminister mit, er habe Gürtners Aufstellung vor fünf Tagen Hitler selbst vorgelegt; der Führer habe jedoch „besondere Maßnahmen ... bei der ohnehin gewissenhaftesten Leitung der Konzentrationslager [!] nicht als notwendig erachtet" ${ }^{\text {“ }}{ }^{82}$ Doch Gürtner ließ sich nicht entmutigen. Am 2. März 1936 erörterte er in einem persönlichen Gespräch mit Himmler anhand der geschilderten Vorfälle im ColumbiaHaus die Frage des Waffengebrauchs durch die KZ-Mannschaften. Um die Unvereinbarkeit der KZ-Dienstvorschriften mit den Strafgesetzen zu beseitigen, legte er ihm nahe, diese Frage ähnlich zu regeln, wie es die Wehrmacht durch die Verordnung vom 17. Januar für den Einsatz des Militärs bei inneren Unruhen getan hatte. Dort war bestimmt worden, daß die Waffe ,nur insoweit gebraucht werden [durfte], als es für die

80 Vgl. Ber. des GStA beim LG Berlin an das RJM v. 18.5.35 (Diensttageb. des RJM, Bd. 3, Eintr. v. 29.5.35, BA, Sign. R 22/1056), ferner v. 12.4.35 (a.a.O., Eintr. v. 18.4.35, Bd. 2, Sign. R 22/603) u. Eintr. v. 5.7.35 (Bd. 4, BA, Sign. R 22/1059).

81 Vgl. dazu die zahlreichen Eintr. im Diensttageb. des RJM v. 18.4. bis 14.10.35 betr. die KZ ColumbiaHaus, Esterwegen, Hamburg-Fuhlsbüttel, Dachau u. Sachsenburg (Bde. 2, 3, 4, BA, Sign. R 22/603, 1056, 1059).

82 Antwortschr. Himmlers an Gürtner v. 6.11.35, Abschr. ließ Himmler an Göring u. Frick gehen (Akten des persönl. Stabes RFSS, Arch. d. IfZ, Sign. MA 193; vgl. auch Diensttageb. des RJM, Bd.6, Eintr. v. 9.11.35, BA, Sign. R 22/1089). Gürtners Schr. v. 16.10.35 nebst Anl. war in den Akten nicht auffindbar. 
zu erreichenden Zwecke erforderlich“ war, und zwar die Schußwaffe nur dann, „wenn die blanke Waffe nicht ausreicht" oder mit Waffen Widerstand geleistet wurde. Beim Fluchtversuch eines Gefangenen hatte vor Gebrauch der Schußwaffe Anruf oder Warnschuß zu erfolgen; auch gegenüber Menschenansammlungen hatte eine Warnung vorherzugehen. ${ }^{83}$ Obwohl Himmler in der Unterredung Gürtner den Erlaß einer solchen Verordnung zusagte und versprach, das Justizministerium bei den Vorarbeiten zu beteiligen, unternahm die SS-Führung in dieser Richtung nichts. ${ }^{84}$ Als das Reichsund Preußische Innenministerium im Juli 1936 eine Vorschrift für den Waffengebrauch der Polizeibeamten erlassen hatte, dessen Bestimmungen der Wehrmachtsverordnung angeglichen waren ${ }^{85}$, wurden die Dienstvorschriften der SS-Wachverbände anscheinend wenigstens dahingehend geändert, daß bei Fluchtversuch „nach dreimaligem Anruf" geschossen werden sollte, im Falle eines tätlichen Angriffs dagegen blieb es bei einer Abwehr nur mit der Schußwaffe und "ohne Warnungsruf“" ${ }^{86}$

Immerhin scheinen die dauernden Einwirkungen von Justizseite insofern nicht ohne Wirkung geblieben zu sein, als die SS-Führung in der Folgezeit willkürliche Mißhandlungen und Tötungen, die ohne Anordnung der Lagerkommandantur erfolgten, abzustellen suchte bzw. gegenüber der Justiz nicht mehr in jedem Fall deckte. Als die Bewacher eines Konzentrationslagers bei der Ankunft eines Gefangenentransportes eigenmächtig Prügel austeilten, rügte Eicke dieses Verhalten in seinem Befehlsblatt vom 1. März 1937 mit folgender vielsagender Begründung: „So sehr ich als Nationalsozialist für ein solches Vorgehen Verständnis habe, kann und darf ich dieses Verhalten nicht dulden, wenn wir nicht Gefahr laufen sollen, vom Innenministerium des Deutschen Reiches als unfähig zur Behandlung von Gefangenen bezeichnet zu werden" (!). Himmler habe daher für willkürliche Mißhandlungen den Ausschluß aus der SS angedroht, „um die SS vor Angriffen zu schützen“. ${ }^{87}$ Tatsächlich wurde ein SSOberscharführer, der in Sachsenhausen ,infolge sadistischer Anwandlungen“ einen inhaftierten jüdischen Landgerichtsdirektor i. R. erdrosselte, zum SS-Mann degradiert, aus der SS ausgeschlossen und der Justiz zur Verurteilung übergeben. ${ }^{88}$ Dagegen wurden Häftlinge, deren ungesetzliche Tötung die SS- und Polizeiführung selbst anordnete, in den Konzentrationslagern auch weiterhin erschossen - und zwar „auf der Flucht", weil eben die von Hitler indirekt gebilligten Dienstvorschriften die einzige "normative“ Grundlage waren, auf die sich die SS der Justiz gegenüber berufen konnte. Himmler selbst machte dieses Prinzip im Februar 1937 im engen Kreise seiner Gruppenführer deutlich, als er auf die Bekämpfung der Homosexualität innerhalb

83 Vgl. VO über den Waffengebrauch der Wehrmacht v. 17.1.36 (RGBl. I, S. 39).

84 Vgl. Verm. Gürtners v. 9.3.36 über sein Gespräch mit Himmler u. Mahnschr. Dohnanyis an SS-Brigadef. Wolff v. 23.3.36 sowie Wiedervorlagevermerke (Nürnbg. Dok. PS-781).

85 RdErl. des RuPrMdI v. 27.7.36, den Gestapo- u. Kripo(leit)stellen durch einen RdErl. des Chefs der Sipo u. SD v. 9.1.37 übersandt (Allg. Erl. Sammlung des RSHA 2 F VII S. 1, Arch. d. IfZ, Sign. Dc 15.21); er sollte „im Falle eines Krieges u. einer ihm vorausgehenden Spannungszeit“" in Kraft gesetzt werden u. wurde ersetzt durch den RdErl. des RMdI v. 2.8.39 (a.a.O., S.3).

86 Wann diese Änderung erfolgte, die aus einem Schr. Himmlers an Gürtner v. 16.5.38 (Nürnbg. Dok. PS782) hervorgeht, konnte der Verf. nicht ermitteln.

87 Vgl. Befehlsbl. SS-TV/IKL Nr.2 v. 1.3.37, S.10 (Arch. d. IfZ, Sign. MA 293).

${ }^{88}$ Eicke gab diesen Fall als „warnendes Beispiel“ im Befehlsbl. SS-TV/IKL Nr.5 v. 4.6 .37 (a.a.O.) bekannt, sprach dabei allerdings nur von "gemeinster" Mißhandlung, nicht von Tötung. Zum Vorgang vgl. Ber. des GStA beim LG Berlin an das RJM v. 11.3.37 (Diensttageb. des RJM, Bd. 10, Eintr. v. 13.3.37, BA, Sign. R 22/706). Der Lagerarzt hatte offenbar anfangs versucht, den Oberscharführer durch die Feststellung von "Selbstmord“ zu decken. 
der SS zu sprechen kam. Nachdem er erwähnt hatte, daß die Germanen dieses ,anomale Leben“ dadurch ausgelöscht hätten, daß sie solche Menschen im Sumpf versenkten, führte er folgendes aus:

„Ich betone ausdrücklich, daß ich genau weiß, was ich sage. Dies ist selbstverständlich nicht für Führerbesprechungen bestimmt, sondern das können Sie in einzelnen Unterhaltungen erzählen: ... Diese Leute werden selbstverständlich in jedem Fall öffentlich degradiert und ausgestoßen und werden dem Gericht übergeben. Nach Abbüßung der vom Gericht festgesetzten Strafe werden sie auf meine Anordnung in ein Konzentrationslager gebracht und werden im Konzentrationslager auf der Flucht [!] erschossen. ${ }^{\text {(89 }}$

Gerade weil aber die häufigen „Erschießungen auf der Flucht" - obwohl der SS die wahren Ursachen so gut wie nie eindeutig nachgewiesen werden konnten - unglaubwürdig waren, lag Gürtner dem Reichsführer-SS auch weiterhin wegen einer Änderung der Dienstvorschriften, die den Bewachern als Alibi dienten, in den Ohren. Das Reichsjustizministerium beobachtete diesen Komplex aufmerksam: zwar wurden die eingehenden Berichte über Fälle gewaltsamen Todes in den Konzentrationslagern von den jeweils gebietsmäßig zuständigen politischen Referenten des Ministeriums bearbeitet, jedoch war der Generalreferent für politische Strafsachen von jedem Fall zu informieren, um eine zentrale Übersicht zu behalten. ${ }^{90}$ Im März 1938 hielt Gürtner dem Reichsführer-SS vor, daß die übliche Behauptung der Wachmannschaften, daß sie auf Flüchtende geschossen hätten, häufig schon deshalb angezweifelt werden müsse, weil die Schüsse aus nächster Entfernung abgegeben worden waren. Obwohl Himmler diese Tatsache ableugnete und behauptete, in allen vorliegenden Fällen sei aus 30-80 Meter Entfernung geschossen worden, teilte er Gürtner schließlich mit, er habe SSGruppenführer Eicke befohlen, den Totenkopfverbänden „einzuschärfen“, daß nur im äußersten Notfall geschossen werden“ dürfe. Falls er damit nicht nur Gürtner zu beruhigen versucht, sondern diesen restriktiven Befehl tatsächlich erteilt haben sollte, fand er zwei Monate später jedenfalls einen willkommenen Anlaß, ihn wieder aufzuheben. Am 16. Mai schrieb er an Gürtner, „der Erfolg“ dieses Befehls sei ein „erschütternder“ gewesen: vor drei Tagen hätten zwei Häftlinge in Buchenwald einen SS-Rottenführer erschlagen und seien geflüchtet; er sei daher

„tief betrübt bei dem Gedanken, daß durch zu große Milde, die immer in einem Bremsen bezüglich der Dienstvorschriften des Schießens bei Fluchtversuchen liegt, nun einer meiner anständigen Männer das Leben lassen mußte.

Ich darf Sie davon unterrichten, daß ich meinen Befehl, nur im äußersten Notfall zu schießen, aufgehoben habe und die alte Anordnung, daß streng nach der Dienstvorschrift nach dreimaligem Anruf oder bei tätlichem Angriff ohne Warnungsruf geschossen wird, wieder in Kraft getreten ist."

In Wirklichkeit war der Tod des Rottenführers keineswegs auf die Einhaltung der Dienstvorschriften, sondern darauf zurückzuführen, daß er den vorgeschriebenen Abstand zu den Gefangenen nicht eingehalten hatte und deshalb nicht sofort hatte schießen können. ${ }^{91}$ Himmler teilte in seinem Schreiben außerdem mit, daß nach dem Vor-

89 Rede Himmlers anläßlich der Gruppenführer-Besprechung in Tölz am 18.2.37 (Arch. des IfZ, Sign. MA 311 ).

$90 \mathrm{Vgl}$. den geheimen, von Crohne gezeichneten Umlauf für die Referenten für polit. Strafsachen v. 18. 10.37, der anschließend im verschlossenen Umschlag zu den Generalakten Gestapo zu nehmen war (Akten des RJM, BA, Sign. R 22/1462).

91 Vgl. Schr. Eickes an Himmler v. 5.7.38 (Akten persönl. Stab RFSS, Arch. d. IfZ, Sign. MA 465) u. Schilderung des Hergangs im „Schwarzen Korps“ v. 26.5.38, Folge 21, S.3. 
fall zwei weitere Häftlinge „auf dem Heimweg ins Lager in der Entfernung von 50 oder $60 \mathrm{~m}$ auf der Flucht erschossen" worden seien. ${ }^{92}$ Hierbei dürfte es sich wahrscheinlich um einen reinen Vergeltungsakt der SS gehandelt haben. Eicke benutzte seinen im "Völkischen Beobachter" veröffentlichten Nachruf für den getöteten Rottenführer zu der Ankündigung, nunmehr ,stahlhart mit den uns zur Überwachung übergebenen Staatsfeinden zu verfahren “. ${ }^{93}$

In seiner Antwort an Himmler widersprach Gürtner - dem Himmler indirekt die Schuld am Tod des SS-Angehörigen zugeschoben hatte - der Behauptung, daß der Tod des Rottenführers auf die Änderung der Dienstvorschriften zurückzuführen sei; auch wenn sie nicht geändert worden wären, hätte sich nach den Ermittlungen der Vorgang nicht anders abgespielt. Gürtner machte bei dieser Gelegenheit überaus deutlich, daß eine wirksame Abhilfe auch nicht durch Abänderung einzelner Vorschriften, sondern nur durch eine grundlegende Wandlung im System der Konzentrationslager geschaffen werden könne: wie er in Gesprächen mit Himmler wiederholt betont habe, sei allein entscheidend, daß der Wille „zur Flucht durch eine entsprechende Verwahrung [!] vermindert wird. Denn von Menschen, die nichts zu verlieren haben, durch eine Gewalttat aber hoffen, die Freiheit gewinnen zu können, muß man jede Selbstbefreiungshandlung erwarten". ${ }^{94}$ Gürtners Meinung über die Verhältnisse in den Konzentrationslagern dürfte auch im Juli 1938 bei der Ablehnung von Himmlers Gesuch eine Rolle gespielt haben, einen Teil der Sicherungsverwahrten in diese Lager zu überführen, wenngleich die Ablehnung damit begründet wurde, daß diese Justizgefangenen dringende Arbeiten für den Eigenbedarf der Vollzugsanstalten und solche im Sinne des Vierjahresplans ausführten. ${ }^{95}$ Bei einem zweiten Vorstoß Himmlers im August 1939, bei dem sich dieser sogar auf eine Entscheidung Hitlers berief, gelang es Gürtner mit der Unterstützung durch den Chef der Reichskanzlei Lammers abermals, diese Forderung geschickt abzuwenden. ${ }^{95 a}$ Auch Himmlers mehrmals praktizierter Versuch, die Konzentrationslager durch Einladungen zur Besichtigung bei den Juristen „salonfähig“ zu machen, stieß auf wenig Gegenliebe: als ein Ministerialbeamter im Anschluß an seinen vertraulichen Bericht über die Besichtigung des Konzentrationslagers Dachau durch eine Arbeitsgemeinschaft der Akademie für Deutsches Recht, an der er teilgenommen hatte, im April 1938 vorschlug, den Referenten der Strafvollzugsabteilung "mit Rücksicht auf die Gestaltung des Vollzugs der [gerichtlich angeordneten] Sicherungsverwahrung " derartige Besichtigungen zu ermöglichen, lehnte Freisler diesen Vorschlag ab. ${ }^{66} \mathrm{Da}$ es der Justizleitung nicht gelungen war, die Verhältnisse in den Lagern durch die Einführung entsprechender Straf- und Dienstvorschriften zu ändern, wollte sie sich von der Art des dortigen Haftvollzugs deutlich distanzieren.

92 Schr. Himmlers an Gürtner v. 16.5.38 (Nürnb. Dok. PS-782). Himmler erhielt Hitlers Zustimmung, den gefaßten und von einem ordentl. Gericht zum Tode verurteilten Täter in Buchenwald vor den angetretenen Häftlingen zu hängen (Verm. v. 27.5.38 in den Akten des RJM, a.a.O.).

93 VB v. 17.5.38 (Zeitungsausschnitt, a.a.O.).

94 Schr. Gürtners an Himmler v. 28.5.38 (Akten persönl. Stab RFSS, Arch. d. IfZ, Sign. MA 465).

$95 \mathrm{Vgl}$. Schr. Himmlers v. 28.6.38 u. Antwortschr. Gürtners v. 14.7.38 (Akten des RJM. BA, Sign. R 22/1437).

95a Vgl. dazu mit Hinweis auf die Einzelkorrespondenzen: Möhler, Strafvollzug (1996), S. 97 ff., ferner Nürnbg. Dok. NG-340.

96 Vgl. vertraul. Ber. des Ref. v. 8.4.38 u. Verm. über die Entsch. Freislers v. 25.4.38 (Akten des RJM, BA, Sign. R 22/1333). Wenn dagegen einzelne Beamte gelegentlich die Möglichkeit zu einem KZ-Besuch erhielten, sei dagegen „nichts einzuwenden“. 
c. Schwierigkeiten der Justiz bei KZ-Ermittlungen und Einengung ibrer Zuständigkeit zugunsten der SS-Gerichte 1938/39

Bei ihrer Handhabung der Schutzhaft im Konzentrationslager war es der SS- und Polizeiführung ein ständiger Dorn im Auge, daß die Justiz für die Untersuchung der Fälle nicht natürlichen Todes in den Lagern zuständig blieb. In ihren Richtlinien für Todesfälle von Schutzhäftlingen, die das Geheime Staatspolizeiamt auch dem Reichsjustizministerium im Oktober 1935 zur Kenntnis brachte, hatte sie aufgrund der Gesetzeslage festlegen müssen, daß beim Ableben eines Häftlings infolge Krankheit also bei natürlichem Tode - außer dem Lagerarzt noch der zuständige Kreisarzt zuzuziehen war. Stimmten beide in ihrem Befund nicht überein, mußte der Staatsanwaltschaft Anzeige erstattet werden. Fälle gewaltsamen Todes durch Selbstmord, Erschießung „bei Widerstand“ oder „auf der Flucht“ waren dem Staatsanwalt „wie bisher" sofort anzuzeigen. ${ }^{97}$ Eine teilweise Aufhebung der Justizzuständigkeit - nämlich dann, wenn SS-Wachmänner der Tötung dringend verdächtig waren sollte die SS-Führung erst nach Kriegsausbruch erreichen. Es war daher nicht verwunderlich, daß bis zu diesem Zeitpunkt den Justizbehörden bei ihren Ermittlungen in den Lagern, insbesondere bei Leichenschau, Leichenöffnung und Ortsbesichtigung, Schwierigkeiten bereitet wurden. Im Konzentrationslager Sachsenhausen, bei dem der Generalstaatsanwalt beim Landgericht Berlin grundsätzlich in jedem Fall eines unnatürlichen Todes die gerichtliche Obduktion beantragte, kam es im Juli 1938 zu einem ernsten Zwischenfall. Bereits bei zwei Obduktionen am 14. und 17. Juli waren zwischen dem zuständigen Richter des Amtsgerichts Oranienburg und der Lagerführung Spannungen aufgetreten: da sich der Richter dagegen verwahrte, daß die Leichenöffnung gestört und die Herausgabe von Sektionsunterlagen gefordert wurde, wurde er indirekt als „Staatsfeind“ angesprochen. Als er bei der nächsten Obduktion am 25. Juli die geforderte Teilnahme des Lagerarztes verweigerte, drang ein SS-Führer in den Sektionsraum ein und teilte ihm mit, SS-Gruppenführer Eicke habe telefonisch seine Inschutzhaftnahme befohlen, falls er der Forderung nicht nachkäme. Für diese Forderung gab es jedoch keine Rechtsgrundlage; nach $\S 87$ Abs. 1 der StPO stand es im freien Ermessen des Richters, den „behandelnden Arzt“ zusätzlich beizuziehen; im vorliegenden Fall hatte jedoch der Tote - ein erhängter Lagerinsasse - vorher nicht in ärztlicher Behandlung gestanden. Nachdem auch eine Unterredung mit dem Lagerkommandanten ergebnislos blieb, der Gerichtsarzt wegen des Zustandes der Leiche aber von einem Abbruch der Obduktion abriet, sah sich der Richter durch die erneut ausgesprochene Drohung mit Schutzhaft genötigt, die widerrechtliche Forderung zu erfüllen. In seinem Bericht über den Vorfall an das Reichsjustizministerium äußerte der Kammergerichtspräsident die dringende Bitte, Himmler zu veranlassen, die beteiligten SS-Führer zur Verantwortung zu ziehen und derartige Eingriffe in die Rechtspflege künftig auszuschließen. ${ }^{98}$ Im Auftrage des Leiters der Strafrechtspflegeabteilung wandte sich der Verbindungsmann des Ministeriums zur SS, Oberstaatsanwalt Joël,

97 Schr. des Gestapa (gez. Best) an das RJM (Diensttageb. des RJM, Eintr. v. 21.10.35, Bd.6, BA, Sign. R 22/1089).

98 Vgl. Ber. des KGPräs. an das RJM v. 27.7.38 nebst Ber. des AGPräs. Oranienburg u. des Amtsrichters vom Vortage (Akten des RJM, BA, Sign. R 22/1522). 
mit einer entsprechenden Bitte an Himmlers Chefadjutanten SS-Gruppenführer Wolff, um aus der „unmöglichen Drohung“ gegen den Richter, der durchaus „berechtigt und gesetzentsprechend“ gehandelt habe, nicht „einen ernsthaften Konflikt entstehen zu lassen“. In einer Aussprache mit Joël am 2. September 1938 behauptete Wolff, daß die Inschutzhaftnahme des Richters „von höherer Stelle“ nicht angeordnet worden sei, und stellte eine schriftliche Stellungnahme Himmlers in Aussicht. ${ }^{99}$ Trotz wiederholter telefonischer und schriftlicher Anmahnungen schrieb statt Himmler schließlich am 24. Dezember 1939 [!] Wolff, daß „solche und ähnliche Vorkommnisse“ durch eine ausdrückliche Weisung an die Lagerkommandanten künftig unterbunden seien. Außerdem würden sich derartige Fälle schon deshalb „kaum wiederholen, da in Zukunft bei den gerichtlichen Leichenöffnungen auf Grund der neuen SSGerichtsbarkeit die zuständigen Organe dieser SS-Gerichte beteiligt" seien. ${ }^{100}$

Durch diese globale Behauptung Wolffs veranlaßt, ließ Gürtner im Ministerium die Rechtsfrage prüfen, inwieweit die SS-Gerichte für gerichtliche Leichenöffnungen im Konzentrationslager tatsächlich zuständig seien. Auf Anregung Himmlers hatte nämlich Hitler Ende Juni 1939 befohlen, bestimmte Angehörige der SS und Polizei - darunter die SS-Totenkopfverbände, die die Konzentrationslager bewachten - von der allgemeinen Strafgerichtsbarkeit auszunehmen und für sie analog der Wehrmachtsgerichte „sofort“ eigene SS-Gerichte einzurichten. Was Röhm 1933/34 für die SA nicht gelungen war ${ }^{101}$, hatte Himmler für die SS erreicht. Auf einer Sitzung im Reichsjustizministerium am 6. Juli 1939 hatte SS-Chefrichter Gruppenführer Scharfe den Vertretern der Justiz die Entscheidung Hitlers „dahingehend erläutert“, daß diese Gerichte ihre Tätigkeit bereits am 1. August aufnehmen sollten. ${ }^{102}$ Durch die notwendigen Vorbereitungen, u.a. zur Eingliederung des Etats der neuen Gerichtsbarkeit in den Reichshaushalt, konnte jedoch die „Verordnung über eine Sondergerichtsbarkeit in Strafsachen für Angehörige der SS und für die Angehörigen der Polizeiverbände bei besonderem Einsatz" erst am 17. Oktober 1939 erlassen werden. ${ }^{103}$ Damit waren die ordentlichen Justizbehörden für die Verfolgung von Mißhandlungen und anderen Straftaten des KZ-Personals nicht mehr zuständig. Da nach $\S 3$ dieser Verordnung die Vorschriften der Militärstrafgerichtsordnung (MStGO) für die SS- und Polizeigerichte sinngemäß gelten sollten, waren deren Grundsätze auch für die Abgrenzung der $\mathrm{Zu}$ ständigkeit gegenüber der zivilen Justiz maßgebend. Nachdem Gürtner und Freisler das Ergebnis der Prüfung über die Zuständigkeit der SS-Gerichte bei der Obduktion

99 Vgl. Schr. des OStA u. SS-Untersturmf. Joël an Wolff v. 22.8.38 u. seinen Verm. v. 5.9.38 (a.a.O.). Statt Eicke direkt anzugehen, wie es OStA v. Haacke vorschlug, wurde dieser Weg gewählt, da Joël und Wolff „bisher alle die Konzentrationslager betreffenden Vorgänge in durchaus kameradschaftlichem gegenseitigem Entgegenkommen behandelt" hatten.

${ }^{100} \mathrm{Schr}$. Wolffs an Joël v. 24.12.39. Zu den vorangegangenen Mahnungen vgl. die Schr. Joëls an Wolff v. 19.1.39, 9.5.39 u. 22.6.39 sowie seine mehrfachen Verm. vom 7.12.38 bis 31.10.39 (a.a.O.).

${ }^{101}$ Vgl. dazu Kap. IV.5.

${ }^{102}$ Vgl. Schr. des Chefs des SS-Hauptamtes Haushalt u. Bauten, SS-Gruppenf. Pohl, an die RM der Finanzen, der Justiz, des Innern, OKW, OKH u.a. v. 22.7.39 (Akten des RJM, BA, Sign. R 22/27). Die eigene Strafgerichtsbarkeit der SS wurde schon seit Jahren vorbereitet: so referierte SS-Sturmbannführer Reinecke schon auf der Tagung der Arbeitsgemeinschaft der AkDR für Fragen der Strafgerichtsbarkeit der SS und des Reichsarbeitsdienstes in Dresden am 31.5.38 über den Entw. einer SS-Strafgerichtsordnung (Niederschr. über die Tagung und Wortlaut des Referats BayerHStArch., Sign. AkDR 10/11).

${ }^{103}$ RGBI. I, S. 2107. 
von $\mathrm{KZ}$-Häftlingen vorgetragen worden war ${ }^{104}$, ordnete der Minister an, daß Joël der SS-Führung „zur Vermeidung von Mißverständnissen“ die Rechtslage schriftlich erläutern sollte. Entsprechend teilte Joël Gruppenführer Wolff mit, daß die Leichenschau oder Leichenöffnung nur in den Fällen Sache der SS-Gerichtsbarkeit sei, ,in denen der dringende Verdacht besteht, daß ein SS-Angehöriger den Tod des Häftlings verursacht“ habe. „In anderen Fällen dagegen (Selbstmord, Tötung durch einen anderen Häftling)“ blieben nach wie vor die allgemeinen Gerichte allein zuständig. Bestehe „nur ein Verdacht, daß ein SS-Angehöriger an dem Tode eines Häftlings beteiligt war“, so hätten ebenfalls zunächst die Zivilbehörden zu ermitteln, jedoch einem zum Richteramt befähigten SS-Justizführer - nicht dagegen automatisch dem Lagerarzt - die Teilnahme an der Leichenschau, Leichenöffnung und Ortsbesichtigung zu gestatten. Joël äußerte abschließend die Annahme, daß Wolffs schriftliche Ausführungen „in diesem Sinne zu verstehen waren". 105

Die SS-Führung sollte jedoch die Abgrenzung der Zuständigkeiten keineswegs in diesem Sinne verstehen: Hatte die SS schon mit dieser Regelung die Möglichkeit, die Justiz beim Tod eines Häftlings in jedem beliebigen Falle von der Untersuchung auszuschließen, indem sie von vornherein zugab oder behauptete, daß der Tod durch einen SS-Wachmann verursacht worden sei, so stellte das Hauptamt SS-Gericht auch bei der Zuständigskeitsabgrenzung weitergehende Forderungen. ${ }^{106}$ Sein im Juni 1940 herausgebener Befehl regelte das Problem noch eindeutiger zugunsten der SS: beim gewaltsamen Tode eines Schutzhäftlings sollte nach $\S 39$ der Kriegsstrafverfahrensordnung vorgegangen, d.h. auch bei Selbstmord sämtliche Ermittlungen von der SS-Gerichtsbarkeit geführt werden. Nur wenn „sich der Verdacht einer strafbaren Handlung ausschließlich gegen eine Person richtet, die der SS- und Polizeigerichtsbarkeit nicht unterliegt“, sollte die allgemeine Justiz zuständig sein. ${ }^{107} \mathrm{Wie}$ der Chef des Hauptamts SS-Gericht an den Reichsführer-SS schrieb, war damit eine „für die SS sehr günstige Regelung getroffen“ worden: die allgemeine Justiz hatte "praktisch nur noch in dem einen Fall mitzuwirken, wenn ein Schutzhäftling von einem anderen Schutzhäftling ums Leben gebracht" wurde. ${ }^{108}$

Damit war es völlig in die Hand der SS gegeben, ob sie die Justiz an Vorgängen in den Konzentrationslagern beteiligen wollte. Bei der Staatsanwaltschaft Weiden z.B., die für das Konzentrationslager Flossenbürg zuständig war, blieben mit Einführung der SS- und Polizeigerichtsbarkeit im Oktober 1939 Meldungen über Erschießungen

${ }^{104} \mathrm{Vgl}$. die gutachtl. Äußerung des zuständigen Ref. der Strafgesetzgebungsabtl. (II) v. 15.1.40 (Akten des RJM, a.a.O.), die sich auf die $\$ \S 94$ bis 98 der MStGO i.d.F. der Bek. v. 29.9.36 (RGBI. I, S.751) stützte. Sie ging davon aus, daß diese Bestimmungen mangels anderslautender Vorschriften in der KStVO v. 17.8.38 (RGBl. 1939 I, S. 1457) auch im Kriege galten.

${ }^{105}$ Schr. Joëls (nunmehr SS-Hauptsturmführer) an Wolff v. 30.1.40 (Akten des RJM, a.a.O.), Hervorheb. im Original. In dem hier nicht zur Debatte stehenden Fall, daß beim Tode eines SS-Wächters ein Häftling der Tat verdächtig war, hätte demnach das zuständige SS-Gericht laut $\S 98$ Abs. 3 MStGO einem Richter der allgemeinen Justiz die Teilnahme an der Leichenschau etc. gestatten müssen.

${ }^{106}$ Nachdem Wolff Joëls Schr. an das Hauptamt SS-Gericht gegeben hatte, schlossen sich weitere Verhandlungen zwischen dem HA u. dem RJM an (vgl. Korresp. zwischen Wolff u. dem HA SS-Gericht v. 8.3. u. 27.3.40, Akten persönl. Stab RFSS, Arch. d. IfZ, Sign. MA 465).

${ }^{107}$ Befehl des RFSS, Hauptamt SS-Gericht betr. Verfahren bei unnatürlichem Tode eines Schutzhäftlings v. 7.6.40 (a.a.O.). Der entscheidende Abschnitt des Befehls wurde den Justizbeh. durch RV des RJM v. 24.6.40 abschriftl. z.K. gebracht (Akten des RJM, Hauptbüro, Arch. d. BJM).

${ }^{108}$ Schr. an den persönl. Stab des RFSS v. 11.6.40 (Akten persönl. Stab RFSS, a.a.O.). 
auf der Flucht schlagartig aus. ${ }^{109}$ Aufgrund des erwähnten Befehls der SS-Führung vom Juni 1940 wurden aber auch keine Selbstmorde mehr gemeldet: nachdem die Staatsanwaltschaft beim Landgericht Berlin im Konzentrationslager Sachsenhausen allein in der Zeit vom 1. März bis 15. Mai 1940 noch 37 Selbstmorde registriert und untersucht hatte ${ }^{110}$, wurden ihr in der Folgezeit keine Leichensachen mehr übergeben übrigens auch keine Anzeigen wegen widernatürlicher Unzucht von Häftlingen mehr, für deren Verfolgung die SS die Justiz noch verschiedentlich bemüht hatte. ${ }^{111} \mathrm{Um}$ zu verhindern, daß in den nunmehr von der SS selbst erledigten Fällen deren Untersuchungsergebnisse auch nicht etwa nachträglich auf Veranlassung von Angehörigen der im Konzentrationslager Umgekommenen nachgeprüft werden konnten, befahl Eicke im Einvernehmen mit der Gestapoführung, die Särge vor dem Abtransport aus dem Lager zu plombieren und bis zur Bestattung polizeilich zu überwachen; später wurde generell die Einäscherung angeordnet. ${ }^{12}$ Im Kriege bekamen die Lagerkommandanten sogar Weisung, daß auch in Fällen von Häftlingsmißhandlungen durch Mithäftlinge die Staatsanwaltschaft "nach Möglichkeit nicht mehr behelligt werden“ sollte, da sich solche Vorgänge "bei der Justiz für das Ansehen der Konzentrationslager in jedem Falle schädigend" auswirkten. ${ }^{113}$

Nachdem das Reichsjustizministerium die von Hitler befohlene Einführung der SSund Polizeigerichtsbarkeit hatte hinnehmen müssen, scheint es sich auch mit der von der SS erlassenen Regelung der Zuständigkeit für Todesfälle von KZ-Insassen ohne Widerstreben abgefunden zu haben. Nach den vorangegangenen Schwierigkeiten dürfte es den Verlust der Zuständigkeit für die Untersuchung der Selbstmorde eher als Erleichterung empfunden haben. Die Einstellung, die die Justiz diesem Komplex entgegenbrachte, wird treffend durch die Worte charakterisiert, mit denen jener bei seiner Tätigkeit im Konzentrationslager Sachsenhausen von der SS bedrängte Amtsrichter seine Vorgesetzten bat, ihn von der Bearbeitung der KZ-Sachen zu entbinden: durch das Verhalten der SS sei er gezwungen,

„in Lagersachen richterliche Handlungen in einer Form vorzunehmen, die nach meiner Überzeugung mit den bestehenden Gesetzesvorschriften nicht in Einklang zu bringen ist, und ich sehe keine Möglichkeit, in Zukunft selbst in Fällen, in denen ich es für unbedingt erforderlich halten würde, durchzugreifen. Ich unterliege somit bei der Erledigung der Lagersachen einer nicht geringen Befangenheit, und es besteht eine Belastung meines Gewissens, die für mich nicht tragbar ist. ${ }^{\circ 14}$

Wenn die Entscheidung des Justizministeriums unter den geschilderten Umständen auch verständlich war, so gab es damit doch die letzte Möglichkeit auf, den durch die Lagerverhältnisse verursachten Tod eines Häftlings zu untersuchen: insoweit jedenfalls waren Himmlers Konzentrationslager für die Justiz in der Tat „exterritorial“ geworden.

\footnotetext{
${ }^{109}$ Vgl. Ber. des GStA Nürnberg an das RJM v. 11.4.40 (Akten des RJM, BA, Sign. R 22/3381).

${ }^{110} \mathrm{Vgl}$. Ber. des GStA beim KG an das RJM v. 31.5.40 (a.a.O., Sign. R 22/3356).

${ }^{111}$ Ber. des GStA beim KG an das RJM v. 1.4.41 (a.a.O.).

${ }^{112}$ Schr. Eickes an Gestapa u. RKripoA v. 7.9.39, das den Polizeidienststellen z. K. gegeben wurde (StArch. Düsseldorf, Sign. Best. RW 18, Nr. 15). Zur Einäscherung, die in Einzelfällen auch schon früher erfolgte (vgl. Beispiel v. 17.9.34, Nürnbg. Dok. NG-2489), vgl. RdErl. des RFSSuChdDtPol v. 21. 5.42 (Allg. Erl.Sammlung des RSHA, 2 F VIIIf.).

${ }^{113}$ Bef. des SS-WVHA/Amtsgr. D an die Lagerkommandanten v. 19.8.42 (Arch. d. IfZ, Sign. Fa 183/1, Bl. 203).

${ }^{114}$ Ber. des AGRats beim AG Oranienburg v. 17.9.38 (Akten des RJM, BA, Sign. R 22/1522).
} 
Die Justiz blieb jedoch bemüht, wenigstens ihre gegenüber den KZ-Häftlingen verbliebenen Zuständigkeiten zu wahren. Der Lagerarzt des Konzentrationslagers Sachsenhausen hatte Anfang 1938 beim Erbgesundheitsgericht in Berlin die Unfruchtbarmachung eines Schutzhäftlings beantragt, war aber dann dem Ersuchen des Gerichts um Vorführung des Häftlings zum Verhandlungstermin ohne Angabe von Gründen nicht nachgekommen. Daraufhin hatte das Gericht die Sterilisation ohne persönliche Anhörung aufgrund des Akteninhalts angeordnet und dem Häftling den Beschluß am 31. März 1938 zu Händen des Lagerkommandanten zugestellt. Erst am 9. Juli (!), nachdem die Frist zur Einlegung der Beschwerde längst verstrichen und der Beschluß rechtskräftig geworden war, reichte der Lagerarzt die vom Häftling erhobene $\mathrm{Be}$ schwerde bei den Justizbehörden ein. Der Vorsitzende des Erbgesundheitsobergerichts untersagte daraufhin einstweilen die Durchführung der Operation; und das Gericht lehnte - nachdem es ihm gelungen war, den Häftling wenigstens im Konzentrationslager persönlich zu hören - am 6. Oktober 1938 die Sterilisation endgültig ab. Obwohl dieser Beschluß sowohl dem Häftling zu Händen des Lagerkommandanten wie auch dem Lagerarzt zugegangen war, ließ der Lagerarzt die Operation durchführen, ohne den Häftling von dem ablehnenden Entscheid zu informieren. Gegen diese Mißachtung einer richterlichen Entscheidung machte das Reichsjustizministerium beim Reichsführer-SS „schwerste Bedenken“ geltend und forderte, daß „Entscheidungen der Gerichte den Häftlingen, für die sie bestimmt sind, ... alsbald nach Zustellung ausgehändigt werden" sollten, was auch in zahlreichen anderen Fällen nicht geschehen sei, die nicht Erbgesundheitsangelegenheiten betrafen. Auch seien die KZ-Kommandanten „wie alle anderen Leiter von Gefängnissen und Anstalten verpflichtet ..., Vorführungsersuchen der Gerichte zu entsprechen“; durch das ungesetzliche Verhalten der Lagerkommandantur Sachsenhausen seien gegenwärtig allein fünfzig Verfahren unerledigt liegengeblieben. Der Reichsführer-SS wurde schließlich ersucht, die an „der zu Unrecht erfolgten Sterilisierung ... Schuldigen zur Rechenschaft zu ziehen". 115

In ihrer Antwort suchte die SS-Führung die Ungesetzlichkeit „auf das ungünstige Zusammentreffen von mißlichen Umständen infolge der durch die damaligen politischen Maßnahmen [Besetzung des Sudetenlandes] gegebenen besonderen Verhältnisse" zurückzuführen: den Tatsachen widersprechend behauptete sie, dem durch die Überbelegung des Lagers stark belasteten Lagerarzt sei nicht bekannt gewesen, daß der erste Gerichtsbeschluß aufgehoben worden sei. Die Aushändigung des zweiten $\mathrm{Be}$ schlusses an den Häftling sei aus „Lagersicherheitsgründen“ unterblieben, „weil gerade in dieser Zeit der Masseneinlieferungen ein großer Teil der Häftlinge mit den ihnen ausgehändigten Schreiben Mißbrauch trieben [!] und die Lagerdisziplin aufs Schwerste gefährdeten“. Im übrigen seien alle Lagerkommandanten nunmehr angewiesen worden, den Vorführungsersuchen der Erbgesundheitsgerichte in jedem Fall zu entsprechen und den Häftlingen Gerichtsbescheide „ohne Rücksicht auf besondere entgegenstehende Gründe sofort auszuhändigen“. Obwohl die SS-Führung meinte, damit dargelegt zu haben, „daß ein böswilliges und schuldhaftes Verhalten seitens einer SSDienststelle nicht vorliegt “116, ließ sich Gürtner damit nicht abspeisen. In einem

115 Schr. des RJM an den RFSSuChdDtPol. im RMdI v. 31.3.39 (Arch. d. IfZ, Sign. MA 293).

${ }^{116}$ Schr. des Chefs des persönl. Stabes RFSS, Gruppenf. Wolff, an AGRat u. SS-Untersturmf. Eckert im Min.Büro Gürtners v. 30.8 .39 (a.a.O.). 
Schreiben vom 18. Oktober 1939 machte er noch einmal deutlich, daß dieser Einzelfall dazu diene, um generell „auf die Gefahren hinzuweisen, die sich aus dem bisherigen Verhalten der zuständigen Stelle des Konzentrationslagers Sachsenhausen ergeben“. Im übrigen sei Himmler ,auch jetzt über den Sachverhalt noch nicht vollständig unterrichtet": aus den Akten des Erbgesundheitsgerichts gehe nämlich eindeutig hervor, daß der Lagerarzt bei der Anordnung der Sterilisation den ablehnenden Beschluß des Gerichts erwähnt und damit auch gekannt habe. Er bat daher um Stellungnahme, ob unter diesen Umständen das Verhalten des Lagerarztes nicht auch seitens der SSFührung anders beurteilt werden müsse. ${ }^{117}$ Die SS-Führung mußte daraufhin zugeben, daß den verantwortlichen Ärzten die gerichtliche Ablehnung der Unfruchtbarmachung bekannt gewesen sei; wie es trotzdem dazu gekommen sei, ließe sich jedoch „heute im einzelnen nicht mehr feststellen“ und könne nur mit den erwähnten außerordentlichen Verhältnissen erklärt werden, die seinerzeit in Sachsenhausen geherrscht hätten. ${ }^{118}$ Sie versicherte, aufgrund dieses Falles werde ,in Zukunft ganz von selbst eine besondere Vorsicht am Platze“ sein. Dann aber brach ihr Ärger über die - ihrer Denkweise nach völlig überflüssige - Auseinandersetzung um die „Rechte“ eines "minderwertigen“ KZ-Häftlings unverhohlen durch: da „letztlich durch die Unfruchtbarmachung des 24 mal vorbestraften Berufsverbrechers ... niemand geschädigt“" worden sei, schlage der Reichsführer-SS nunmehr vor, „diesen Fall als abgeschlossen zu betrachten ". ${ }^{119}$ Angesichts der Tatsache, daß die Verfolgung der Schuldigen inzwischen ohnehin auf die SS-Gerichte übergegangen war, fand sich das Justizministerium damit ab. Immerhin hatte es die SS noch für notwendig gehalten, ihr ungesetzliches Handeln der Justiz gegenüber zu rechtfertigen: die Methode der Justiz, die SS immer wieder auf die Übertretung gesetzlicher Schranken hinzuweisen, hielt auf SS-Seite wenigstens das Bewußtsein für die Existenz einer Rechtsordnung wach und löste bei Himmler die Mahnung an die KZ-Kommandanten aus, sich nicht "ganz offensichtlich ins Unrecht zu setzen". ${ }^{120}$ Dagegen hatte die Justiz keine Handhabe mehr, eine ungesetzliche Behandlung von KZ-Gefangenen zu verhindern oder zu ahnden: die Konzentrationslager waren für sie autonome „exterritoriale“ Inseln geworden.

\section{Die Kritik an Gerichtsurteilen durch SS und Polizei als Mittel der Korrektur der Rechtspflege}

\section{a. Urteilsschelte durch Himmler und Reaktion des Justizministeriums}

Neben der Schutzhaft bediente sich die Polizei der Kritik an Gerichtsurteilen als Handhabe, um auf die Rechtsprechung korrigierend einzuwirken. Sie erfolgte entweder öffentlich durch Angriffe in der Presse, vor allem im Organ der Reichsführung-SS

\footnotetext{
${ }^{117}$ Schr. Gürtners an den RFSS v. 18.10.39 (a.a.O.).

${ }^{118}$ In seiner an Wolff gerichteten Stellungnahme v. 2.12.39 (a.a.O.) führte der Inspekteur der KL Eicke die hohen Belegungszahlen des KZ Sachsenhausen „zwischen 8.000-14.000 Häftlinge“ $u$. ferner den Umstand an, daß die Vernehmung der beteiligten SS-Ärzte nicht möglich sei, da sie sich mit der SS-Totenkopfdivision auf dem Marsch befänden.

119 Schr. Wolffs an Gürtner v. 27.12.39 (a.a.O.).

${ }^{120}$ So Himmler in einem Schr. an den Inspekteur der KL Eicke v. 12.4.39 mit der Aufforderung, eine entspr. Anweisung zu geben.
} 
„Das Schwarze Korps“, oder intern durch Vorlage der beanstandeten Urteile beim Reichsjustizministerium, oftmals durch Himmler selbst.

Bereits im April 1935 beklagte sich Heydrich in einem Runderlaß an alle preußischen Staatspolizeistellen, „daß Staatsfeinde von einzelnen Gerichten nicht mit der notwendig erscheinenden Schärfe behandelt" würden. Da der Gestapo die Verantwortung für die Niederhaltung der Staatsfeinde „zugeschoben“ sei, sie selbst aber keine eigene Strafbefugnis besitze (!), habe sie ,von sich aus darauf zu achten, ob die von den Gerichten getroffenen Maßnahmen auch tatsächlich zur Niederkämpfung der Staatsfeinde geeignet" seien. Die Staatspolizeistellen sollten daher innerhalb von zwei Wochen eine Zusammenstellung bisher ergangener, ungenügender Gerichtsurteile einreichen und künftig solche Fälle sofort melden. Neben Angaben über Gericht, Täter, Tatbestand und gefällte Entscheidung sollte der Bericht auch die Feststellung enthalten, „ob eine zu milde gerichtliche Beurteilung etwa ihre Ursache in der negativen Einstellung des Richters oder Staatsanwaltes zum nat.soz. Staate“ habe. Wenn Heydrich seinen Erlaß mit der Ankündigung schloß, die Gestapoführung werde dann das Reichsjustizministerium ,veranlassen, Fälle mit offensichtlichen Fehlurteilen den erkennenden Gerichten [!] zur nochmaligen Überprüfung zurückzuleiten "1, so überschätzte er sowohl die verfahrensrechtlichen Möglichkeiten, die dem Ministerium zu dieser Zeit - d.h. vor Einführung der außerordentlichen Rechtsbehelfe - für eine Abänderung von Urteilen zur Verfügung standen, wie auch die Bereitschaft der Justizleitung, die geltenden Bestimmungen des Prozeßrechts zu ignorieren. Selbst bei Urteilen, die auch ihm bedenklich erschienen, schreckte das Ministerium damals vor direkten Eingriffen in die Unabhängigkeit der Richter zurück: wo prozeßrechtlich die Möglichkeit bestand, wurde in solchen Fällen die Staatsanwaltschaft angewiesen, Berufung oder Revision einzulegen. Allerdings wurden in wichtigen Fällen die Richter in der Form allgemeiner Rundverfügungen angehalten, zukünftig im Interesse einer einheitlichen Rechtsprechung bestimmte Gesichtspunkte zu beachten; allein die Tatsache, daß solche Verfügungen verschiedentlich in Erinnerung gerufen werden mußten, zeigt, daß sie nicht überall befolgt und ihre Einhaltung vom Ministerium im Einzelfall auch nicht erzwungen wurden.

Durch die laufende Beobachtung der Tätigkeit der Gerichte, die später der Sicherheitsdienst der SS (SD) mit seinen innenpolitischen Lagemeldungen auch auf dem Gebiet der Justiz übernehmen sollte ${ }^{2}$, war die Gestapoführung über die Rechtsprechung in politischen Strafsachen hinreichend informiert. Bei einer Besprechung mit Gürtner im Reichsjustizministerium am 2. März 1936 übergab Himmler eine vom Geheimen Staatspolizeiamt stammende Zusammenstellung beanstandeter Urteile. ${ }^{3}$ Sie betraf siebzehn Hochverratsfälle, von denen acht bereits im Frühjahr 1935 zu einem Schriftwechsel zwischen Himmler und dem Ministerium geführt hatten, sowie neun sonstige politische Strafsachen, von denen drei ebenfalls schon Gegenstand schriftlicher Beschwerden Himmlers bzw. des Geheimen Staatspolizeiamtes gewesen

1 RdErl. des Gestapa (gez. Heydrich) an alle preuß. Stapostellen v. 28.4.35 (StArch. Düsseldorf, Sign. Best. $\mathrm{RW}$ 18, Nr.4).

2 Vgl. H. Boberach (Herausg.), Meldungen aus dem Reich. Die geheimen Lageberichte des Sicherheitsdienstes der SS 1939-1945, Herrsching 1984, Band 1, S. 29 ff.

3 Vgl. zum folgenden die Zusammenstellung des Gestapa v. 25.4.35 u. 11.2.36, der Gestapo Hamburg v. 8. 2.36 sowie die Stellungnahmen der Ref. des RJM (Akten des RJM, BA, Sign. R 22/1462). Zur Kritik des Gestapa v. März 1936 an der Rechtsprechung zum BlutschutzG vgl. Kapitel VII.3.c., S.879. 
waren. ${ }^{4}$ Die von Himmler übergebenen Fälle wurden im Ministerium unter Beiziehung der Akten nochmals eingehend überprüft mit dem Ergebnis, daß die zuständigen Referenten in sieben Hochverratssachen den Bedenken der Gestapo zustimmten, während die anderen Hochverratsentscheidungen von ihnen ,für zutreffend oder vertretbar gehalten" wurden; bei den anderen politischen Strafsachen war das Verhältnis fünf zu vier.

Auch Freisler, dem die Prüfungsergebnisse vorgetragen wurden, scheint damit einverstanden gewesen zu sein. Die vom Ministerium gegenüber der Gestapo verteidigten Entscheidungen in den - meist kommunistischen - Hochverratssachen, die zu Einstellung der Verfahren, Freisprüchen und verhältnismäßig milden Strafen geführt hatten, waren nach den Gutachten aufgrund sachgemäßer Beweiswürdigung und Verneinung des subjektiven Tatbestandes durch die Gerichte zustandegekommen. Unter den für richtig befundenen Urteilen der übrigen politischen Strafsachen befanden sich allerdings einige, die in ihrer Argumentation stark an die Rechtsprechung erinnern, durch die Gerichte in der Weimarer Zeit der Republik den Ehrenschutz verweigert hatten. ${ }^{5}$ Hier zwei Beispiele: Im Oktober 1935 hatte das Landgericht Weimar ein Urteil des Schöffengerichts in Jena aufgehoben und einen Schlosser von der Anklage wegen öffentlicher Beleidigung freigesprochen, der Göring einen „Hund“ oder „elenden Hund“ genannt hatte. Der Freispruch wurde damit begründet, daß diese Äußerung „nach dem in Thüringen herrschenden Sprachgebrauch ... auch in anerkennendem Sinne gebraucht" werde; der aus dem Sudetenland stammende Belastungszeuge sei mit den thüringischen Sprachgewohnheiten nicht hinreichend vertraut gewesen. In ähnlicher Weise hatte das Schöffengericht in Dessau am 21. Dezember 1934 einen Ingenieur freigesprochen, der gegenüber Arbeitskollegen eine Standarte der SS mit dem Geßler-Hut verglichen und als „Fetzen Tuch“ bezeichnet hatte. Das Gericht hatte ausgeführt, „daß die Standarte der SS. nicht eine Fahne des Reiches sei und nicht denselben Schutz genieße, wie die Hakenkreuzfahne“. Das Ministerium beurteilte diese Entscheidung aus dem Grunde als völlig in Ordnung, weil die Standarten der SS erst durch den 1935 eingeführten $\S 134 \mathrm{~b} \mathrm{StGB}^{6}$ strafrechtlich geschützt worden seien.

Auch in den Fällen, in denen die Ministerialbeamten die Einwände der Gestapo anerkennen mußten, wird ihre kritische Einstellung zur Gestapo durch gelegentliche Randbemerkungen deutlich. Zu diesen Fällen gehörte das Urteil des Oberlandesgerichts Hamburg vom 23. November 1934 gegen einen belgischen Matrosen, der auf seinem Schiff ein Paket verbotener sozialistischer Druckschriften aus Antwerpen mitgebracht und zur Abholung bereitgehalten hatte. Da ihm nicht nachzuweisen war, daß er den Inhalt des Pakets kannte, wurde er wegen fahrlässigen Hochverrats zu acht Mo-

4 Vgl. die Erwähnung der Schr. Himmlers v. 21.11.34 (Diensttageb. des RJM, Bd. 1, Eintr. v. 5. 12.34, BA, Sign. R 22/131) u. v. 31.1 .35 (a.a.O., Bd. 2, Eintr. v. 13.2.35, BA, Sign. R 22/603), der Schr. des Gestapa v. 20.5. u. 11.11.35 und der Antwortschr. des RJM v. 5.9. u. 16.12.35 (Akten des RJM, BA, Sign. R 22/1462).

5 Vgl. G. Jasper, Der Schutz der Republik. Studien zur staatlichen Sicherung der Demokratie in der Weimarer Republik 1922-1930, Tübingen 1963. Die im folgenden erwähnten Beispiele sind den bei Jasper (a.a.O., S. $200 \mathrm{ff}$.) angeführten Urteilen zur Beschimpfung der Reichsflagge und -farben, insbes. den „Schwarz-rothühnereigelb“- bzw. „-hennadreckat"-Urteilen als durchaus ebenbürtig an die Seite zu stellen.

6 Eingefügt durch Art. 5 des G. zur Änderung des Strafgesetzbuchs v. 28.6.35 (RGBI. I, S. 839). Die Anklage hatte sich auf $\S 134$ a StGB gestützt, wonach die Beschimpfung der Farben und Flaggen des Reichs und der Länder strafbar war. Dieses Beispiel macht zugleich die gravierende Auswirkung der formalen Aufhebung des Analogieverbots (gleichfalls durch das G. v. 28.6.35) auf die Rechtsprechung deutlich: das Gericht hätte nach Einführung des Analogieprinzips eine derart formale Position kaum mehr vertreten können. 
naten Gefängnis verurteilt und die Strafe durch die Untersuchungshaft für verbüßt erklärt. Die Feststellung des Gestapoberichterstatters, das Urteil könne „nur ein Kopfschütteln auslösen“ und werde zur Folge haben, „daß Deutschland bei Bekanntwerdung [sic] dieser Tatsache von ausländischen Agitatoren geradezu überschwemmt“ werde, kommentierte der Sachbearbeiter des Justizministeriums trocken mit der Randbemerkung: „Weil es ein bes[onderes] Vergnügen ist, 8 Monate eingesperrt zu werden“. Dennoch mußte er zugeben, daß die Kritik der Gestapo „im wesentlichen begründet" sei, da das Leugnen des Angeklagten, wissentlich Kurierdienst geleistet zu haben, unglaubwürdig gewesen sei; er stellte aber fest, daß die Beurteilung der Glaubwürdigkeit eine Frage der Beweiswürdigung gewesen sei, die ausschließlich dem Gericht oblag.

Konnte in diesem Falle ohnehin nichts mehr bewirkt werden, da der Belgier nach Aufhebung des Haftbefehls polizeilich ausgewiesen worden war, so wurden aber auch jene anderen Urteile, bei denen die Kritik der Gestapo als berechtigt anerkannt wurde, keineswegs „revidiert“. Das sei an drei der von Himmler übergebenen Entscheidungen demonstriert:

1. Vor dem Sondergericht Altona war ein jüdischer Hausierer wegen unwahrer Behauptungen zum Schaden der Reichsregierung nach dem Heimtückegeset $z^{7}$ angeklagt worden, weil er im Juli 1935 einer Kundin erzählt hatte, daß viele Vorgänge nicht in die Zeitung kämen, so habe es in Bremen Zusammenstöße zwischen Demonstranten und der Polizei gegeben; in diesem Zusammenhang hatte er „etwas von einer Flagge“ geäußert. Das Gericht hatte ihn am 6. September 1935 freigesprochen, da dem nur gebrochen deutsch sprechenden Mann anscheinend nicht zu widerlegen gewesen war, daß er von dem tatsächlich stattgefundenen Flaggenzwischenfall auf dem deutschen Dampfer „Bremen“ in New York berichtet habe. ${ }^{8}$ Neun Wochen später hatte die Gestapo das Justizministerium auf die Unhaltbarkeit des Urteils hingewiesen, da sich der Flaggenzwischenfall im Hafen von New York erst kurz nach der Tat des Freigesprochenen ereignet hatte. Daraufhin hatte das Ministerium im Dezember zugegeben, daß der Freispruch "tatsächlich zu Unrecht erfolgt" sei, zugleich aber mitgeteilt, daß eine Wiederaufnahme des Verfahrens „aus Rechtsgründen nicht möglich“ sei." Bei dieser Entscheidung blieb es auch aufgrund der erneuten Prüfung nach Himmlers Eingabe: der Sachbearbeiter stellte darüber hinaus fest, „Maßnahmen gegen Richter und Staatsanwalt dürften nicht notwendig sein, weil die Schutzbehauptung außerordentlich plausibel klang, so daß die Nichtnachprüfung in zeitlicher Beziehung immerhin begreiflich und verzeihlich" gewesen sei.

2. Am 20. April 1934 war ein ehemaliger Reichsbannermann vom Amtsgericht Schmalkalden wegen Körperverletzung und Beleidigung zu vier Monaten und einer Woche Gefängnis unter Anrechnung der zweiwöchigen Untersuchungshaft verurteilt

$7 \S 1$ des G. gegen heimtückische Angriffe auf Staat und Partei und zum Schutz der Parteiuniformen v. 20.12.34 (RGBl. I, S. 1269).

8 Am 28.7.35 hatten Demonstranten im New Yorker Hafen als Reaktion auf antijüdische Ausschreitungen in Deutschland (u.a. Mitte Juli auf dem Kurfürstendamm in Berlin) die Hakenkreuzflagge vom Bug des deutschen Dampfers „Bremen“ heruntergeholt (vgl. Keesings Archiv der Gegenwart 1935, S. 2157).

9 Schr. des RJM an das Gestapa v. 16.12.35 (Akten des RJM, BA, Sign. R 22/1462). Dagegen wurde gegen den jüdischen Verteidiger ein ehrengerichtl. Verfahren eingeleitet, da er verdächtigt wurde, seinem Mandanten diese Schutzbehauptung beigebracht und den Freispruch durch eine bewußt falsche Sachdarstellung herbeigeführt zu haben. 
worden, weil er einen SA-Truppführer in einer Gastwirtschaft niedergeschlagen hatte. Der Referent des Ministeriums trat dem Einwand der Gestapo bei, daß das Urteil angesichts verschiedener Vorstrafen, der politischen Vergangenheit und des politischen Tatmotivs zu milde ausgefallen sei, führte aber gleichzeitig aus, die Verurteilung läge vor der Verreichlichung der Justiz und könne daher „zu nachträglichen Maßnahmen keinen Anlaß mehr bieten“.

3. Das Amtsgericht Luckenwalde hatte am 31. Oktober 1935 eine junge Frau wegen Beleidigung der SS zu 250 RM Geldstrafe verurteilt, weil sie in der Badeanstalt über anwesende SS-Männer geäußert hatte: „Die schwarze Pest ist auch da“. Auf Antrag hatte ihr das Gericht für die Geldstrafe eine Teilzahlung von monatlich 5 RM bewilligt. Vom Kreisleiter der NSDAP in Jüterbog darauf aufmerksam gemacht, schrieb der Gauleiter der Kurmark, Wilhelm Kube, am 26. Februar 1936 an seinen Duzfreund Freisler, daß damit „der Sinn des Urteils nämlich, die Tochter eines sozialdemokratischen Beamten wegen Beleidigung einer Formation des Führers zu strafen, hinfällig geworden“ sei, und bat ihn, „im Interesse des Ansehens der Bewegung“ einzugreifen. Einen Durchschlag dieses Schreibens hatte Himmler, der sich der Beschwerde anschloß, zusammen mit dem anderen Material Gürtner am 2. März übergeben. Der Sachbearbeiter trat der Ansicht bei, daß „der Strafzweck mit solchen Ratenzahlungen nicht erreicht" werde, führte aber zur Rechtfertigung des Gerichts an, daß die Verurteilte außer 10 RM monatlichem Taschengeld kein Einkommen hatte, daß sie die Tat nicht aus staatsfeindlicher Einstellung, sondern nur aus Unbedachtsamkeit begangen habe, und ihr Vater zwar ein aufgrund des Berufsbeamtengesetzes in den Ruhestand versetzter Polizeibeamter, aber kein Marxist gewesen sei. Falls die Strafe nicht überhaupt unter die zu erwartende Amnestie falle, sollte lediglich der Oberstaatsanwalt Potsdam angewiesen werden, „eine entsprechende Erhöhung der Ratenzahlung bei Gericht zu beantragen“. Nach dem Vortrag der Sache entschied Freisler, daß gegen den Amtsrichter wegen der geringen Bedeutung der Angelegenheit keine Maßnahmen ergriffen werden sollten.

Nach Vorlage bei Freisler und Gürtner wurden die Stellungnahmen des Ministeriums zu den gerügten Entscheidungen Himmler am 28. April 1936 übersandt. In seinem Begleitschreiben führte Gürtner aus, daß ihm die meisten Beanstandungen „zu Rügen keine Veranlassung gegeben" hätten. Von den Entscheidungen, bei denen sich die Beschwerden als berechtigt herausgestellt hätten, stammten die meisten allerdings „aus älterer Zeit (zum Teil sogar vor Erlaß des Heimtückegesetzes und vor der Verreichlichung der Justiz)“ und auch in anderen Fällen, die „grundsätzliche Fragen“ berührten, sei inzwischen "gegen die aufgetretenen Mängel durch Weisungen für die Zukunft Abhilfe geschaffen worden“. Da Himmlers Vorlagen immerhin Gelegenheit gegeben hätten, ,einzelnen Beanstandungen abzuhelfen oder Mißverständnisse aufzuklären, die bei der Geheimen Staatspolizei gegenüber einigen gerichtlichen Entscheidungen bestanden“, begrüße er eine derartige Fühlungnahme, die sich „für eine verständnisvolle Zusammenarbeit zwischen Staatspolizei und Justizverwaltung nur fruchtbar auswirken“ könne. Nur sollten ihm zukünftig Fälle, „die nach Auffassung der Geheimen Staatspolizei zu Bedenken Anlaß “ gäben, nicht erst nach so langer Zeit mitgeteilt werden, „damit noch rechtzeitig für Abhilfe im Einzelfall gesorgt ... und gleiche Fehler für die Zukunft abgestellt werden“ könnten. ${ }^{10}$

10 Schr. Gürtners an Himmler v. 28.4.36 (a.a.O.). 
Wie der ganze Vorgang zeigt, war es in den Jahren vor dem Kriege ${ }^{11}$ längst nicht soweit, daß die Justizverwaltung die Hacken zusammenschlug und in die Tätigkeit der Strafverfolgungsorgane eingriff, wenn Gestapo und SS in konkreten Fällen die Rechtsprechung rügten. Noch stand Himmler nicht auf dem Gipfel seiner Macht: der SS-Staat sollte den Höhepunkt seiner Entfaltung erst im Kriege erreichen. In seiner Antwort an Gürtner gab sich Himmler mit der geschilderten Reaktion des Justizministeriums zufrieden: schließlich hatte die Gestapo Mittel zur Verfügung, politische „Fehlurteile“ auf ihre Weise zu korrigieren. In seinem Antwortschreiben ${ }^{12}$ meinte Himmler, künftig werde eine „sofortige Fühlungnahme alle Meinungsverschiedenheiten ohne Verzögerung aus der Welt" schaffen. Die auch von Gürtner geäußerte Hoffnung auf „verständnisvolle Zusammenarbeit“ sollte sich aber nicht erfüllen. Es lag an der unterschiedlichen Funktion und der gegensätzlichen Arbeitsweise beider Apparate, daß sich die Kluft im Gegenteil noch vertiefte. Ein Instrument, das dem wachsenden Ressentiment von SS und Polizei gegen die Justiz öffentlich Ausdruck verlieh, war das 1935 gegründete Presseorgan der SS „Das Schwarze Korps“, das in den folgenden Jahren seine Angriffe auf die Rechtspflege verstärkte.

\section{b. Auseinandersetzung um die Angriffe auf die Justiz in dem Presseorgan der SS "Das Schwarze Korps"}

Gegen unberechtigte und polemische Angriffe auf die Tätigkeit der Rechtspflege in parteiamtlichen Zeitungen mußte sich das Reichsjustizministerium verschiedentlich zur Wehr setzen, da durch derartige Veröffentlichungen ausgelöste Zuschriften an die Justizbehörden deutlich machten, in welch starkem Maße unsachliche Kritik das Vertrauen zur Justiz untergrub. Das Ministerium suchte einer herabsetzenden Gerichtsberichterstattung im allgemeinen durch die dem Pressereferenten des Ministeriums unterstehenden Justizpressestellen in den Oberlandesgerichtsbezirken sowie durch die Pressedezernenten bei den Land- und Amtsgerichten entgegenzuwirken, die mit den Schriftleitungen Fühlung nahmen. In gravierenden Einzelfällen entgegnete der Pressereferent Anwürfen nach Prüfung der Akten im amtlichen Organ des Ministeriums, der „Deutschen Justiz“. ${ }^{13}$ Das antisemitische Hetzblatt „Der Stürmer“ tat sich mit derart unsachlichen Angriffen hervor, daß das Ministerium im Februar 1938 verbot, Nummern dieser Zeitung mit solchen Artikeln an oder in Justizbehörden auszuhängen oder in Leseräumen der Justizbüchereien auszulegen. ${ }^{14}$

Das Organ der Reichsführung-SS „Das Schwarze Korps“ begann schon bald nach seinem Erscheinen im März 1935 Gerichtsurteile zur kritisieren ${ }^{15}$, auch einzelne Richter und Staatsanwälte anzugreifen und den Juristenstand allgemein zu diffamieren. Mitunter gipfelten solche Kritiken in ausfallenden Bemerkungen wie z.B. anläßlich eines Freispruchs durch das Schöffengericht in Bielefeld:

11 Vgl. dazu auch einen Hamburger Fall vom Sommer 1938, bei dem der RFSS mit Schr. an das RJM v. 9.8.38 das freisprechende Hochverratsurteil des OLG rügte (Arch. des Hanseat. OLG, Sign. OLG 400 E - 1a/3).

12 Schr. Himmlers an Gürtner v. 23.5.36 (Akten des RJM, a.a.O.).

13 Vgl. z.B. ORegRat Dr. Doerner, Gegen unsachliche Angriffe auf die deutsche Rechtspflege! Eine notwendige Feststellung (DJ v. 21.6.1935, S.895 ff.)

14 RV des RJM an die Chefs der obersten Justizbehörden v. 21.2.38 (Akten des RJM, Hauptbüro, Arch. des BJM).

15 Vgl. Das Schwarze Korps v. 29.5.35, S.7; u.a. dagegen auch schon Doerner a.a.O. (Anm. 13). 
„Derartige Begründungen fordern das Volk ja geradezu zur Selbsthilfe gegen derartige Individuen heraus. Den Verantwortlichen, die solche hirnverbrannten, den nationalsozialistischen Staat beleidigenden Urteilsbegründungen auszuklügeln fähig sind, sprechen wir das Recht ab, künftig noch im Namen des deutschen Volkes zu Gericht zu sitzen."

Verschiedentlich griffen solche öffentlichen Brandmarkungen auch in schwebende Verfahren ein. ${ }^{17}$

Noch im November 1936 suchte Staatssekretär Freisler den Oberlandesgerichtspräsidenten und Generalstaatsanwälten, von denen einige persönlich angegriffen worden waren $^{18}$, auf einer Tagung die verhältnismäßig passive Haltung des Ministeriums gegenüber ehrenrührigen Attacken verständlich zu machen. Er räumte ein, daß es Aufgabe des Reichsjustizministeriums sei, die Ehre der deutschen Richter in der Öffentlichkeit zu wahren, wenn die Kritik das Wirken der Richter gegenüber Volk und Führung generell anzweifelte. Er gab auch zu, daß „an sich der Kränkung der einzelnen Betroffenen am meisten Gerechtigkeit widerfahren" würde, wenn bei der betreffenden Zeitung sofort eine Richtigstellung gefordert würde. Er bat aber auch zu bedenken, daß nicht jede Kritik unberechtigt sei und „daß wir mitten im Aufbau drin stehen, der erstmalig in einer revolutionären Zeit von der Führung der Revolution in einem Zuge mit der Revolution selbst versucht worden“ sei. Der nationalsozialistischen Führung, die „weder Gironde noch Jakobinertum sein"wolle, gehe es darum, die Revolution ohne Gefährdung ihrer Errungenschaften in ruhigere Bahnen zu lenken. Er bitte um Verständnis, daß dieser Gesichtspunkt stets mit beachtet werden müsse und „daß es deshalb in einer Reihe von Fällen viel richtiger und zweckmäßiger für die Gesamtheit der deutschen Rechtspflege ist, Wiederholungen von Vorfällen für die Zukunft zu verhindern als darauf zu bestehen, daß für einen vorgefallenen Einzelfall in der Öffentlichkeit die Antwort gegeben“" werde, die den Fall an sich am wirksamsten erledigen würde. Freisler mußte allerdings zugeben, daß hinsichtlich einer Vorbeugung gegen Presseangriffe bisher nur geringe Erfolge erzielt worden seien. Nichtsdestoweniger schloß er mit der Feststellung, daß jedenfalls „bei begründeter Kritik an Urteilen die Zentralbehörde nicht in der Lage sei, nur wegen der Form der Kritik Maßnahmen zum Schutz der Ehre der Richter zu ergreifen". ${ }^{19}$

Nur wenige Wochen später wurde das Justizministerium gezwungen, aktiv zu werden und sogar Hitler zu bemühen, um der Kritik des „Schwarzen Korps“ an dem Urteil des Reichsgerichts vom 14. November 1936 entgegenzutreten. Es handelte sich um einen der bedeutsamsten Zivilprozesse jener Jahre, bei dem eine Schallplattenfirma die Reichsrundfunkgesellschaft auf Schadenersatz und Unterlassung verklagte, weil sie Schallplatten ohne Zahlung von Lizenzgebühren sendete. Die Reichs-Rundfunk $\mathrm{GmbH}$, deren Anteile sich sämtlich in der Hand des - durch den Reichsminister für Volksaufklärung und Propaganda vertretenen - Deutschen Reiches befanden, berief sich darauf, daß sie „als Werkzeug der Reichsregierung kraft deren Kultur- und Funkhoheit staatliche Hoheitsaufgaben erfülle“ und der Rechtsweg daher unzulässig

16 Der Freispruch von Bielefeld (Das Schwarze Korps v. 5.3.36, S. 14).

17 Vgl. z. B. Strafsache 3.K.Ls. 26/35 (Das Schwarze Korps v. 19.3.36, S.6).

18 Vgl. Das Schwarze Korps v. 9.4.36, S.17 (OLGPräs. Frankfurt a.M.), u. 23.7.36, S. 17 (GStA Darmstadt), dazu die Eintr. im Diensttageb. des RJM, Bd.8, v. 17.4.36 u. 27.7.36 (BA, Sign. R 22/929).

19 Freisler, Das Ringen um Richterfreiheit und Schutz der Richterehre (Niederschr. über die Tagung der OLGPräs. u. GStAe im RJM v. 13.11.36, Akten des RJM, BA, Sign. R 22/51). 
sei. Das Reichsgericht als Revisionsinstanz entschied jedoch, daß die Beschaffung urheberrechtlich geschützten Sendegutes ein privatrechtlicher Vorgang sei und sich beide Streitparteien daher als Gesetzesunterworfene gleichberechtigt gegenüberstünden. Es entschied zugunsten der Schallplattenfirma, weil die Rundfunkübertragung von Werken gegen den Willen des Urheberberechtigten aufgrund eines Staatshoheitsrechtes eine entschädigungslose Enteignung sei, für die bei der gegenwärtigen Rechtslage jede Grundlage fehle. ${ }^{20}$ Diese Entscheidung wurde vom „Schwarzen Korps“ angegriffen:

„Nun sind für uns aber Paragraphen keine anbetungswürdigen Knochensplitter, vor denen wir bedingungslos auf dem Bauche herumkriechen ... Oberstes Gesetz ist uns vor allem der Interessenschutz des Staates und mit ihm der des deutschen Volkes. An dieser Auffassung rütteln, heißt, an die Fundamente des Staates zu rühren. Wir leben nicht mehr im Jahre 1932, wo man den Staat und die ihn vertretende Regierung einfach verdonnern kann, weil ... irgendein Paragraph hier passend schien. Seither sind viereinhalb Jahre vergangen, in denen Zeit genug gewesen sein dürfte, um- und neuzulernen."21

Gegen diese Kritik, die das Reichsgericht der staatsfeindlichen Betätigung zieh, verfaßte der Reichsgerichtspräsident ein Beschwerdeschreiben, das vom Justizministerium an die Reichskanzlei geschickt und Hitler vorgelegt wurde. Hitler erkannte, daß er diese Entscheidung nicht kritisieren und das höchste deutsche Gericht nicht bloßstellen konnte, ohne damit die auf der Anerkennung des Privateigentums aufbauende Wirtschaftsordnung des Regimes zu erschüttern ${ }^{22}$ : er erklärte, „daß er das in Rede stehende Urteil des RG für richtig und den Aufsatz ... des Schwarzen Korps vom 26.11. für unangebracht und unnationalsozialistisch" (!) halte. Die Auffassung Hitlers wurde von Lammers außer dem Justizministerium auch der Schriftleitung des „Schwarzen Korps“, ferner Himmler und Goebbels übermittelt. ${ }^{23}$ Zwar mußte das Schwarze Korps daraufhin seine Meinung über das Reichsgerichtsurteil, dessen grundsätzliche Bedeutung für den Schutz geistigen Eigentums es nunmehr anerkannte, öffentlich berichtigen ${ }^{24}$; aber die erlittene Schlappe hinderte das Blatt keineswegs daran, die Justiz auch weiterhin anzugreifen. Während es sich in den folgenden Monaten zunächst relativ gemäßigt zeigte, ging es Anfang November 1938 zum Generalangriff über: seit dieser Zeit erschien fast keine Nummer, in der die Justiz nicht in einem oder gar mehreren Artikeln kritisiert und verächtlich gemacht wurde. ${ }^{25}$ Das Ziel dieser Kampagne war offensichtlich, einerseits die Justiz zu verunsichern und nach Möglichkeit gefügig zu machen, andererseits durch das Herausstellen ihrer „reaktionären Unfähigkeit“, so-

20 Urt. des RG, I. Ziv.Sen., v. 14.11.36 (JW 1937, S.690ff.).

21 Zum Schallplattenkrieg: Bitte, neue Nadeln nehmen! (Das Schwarze Korps v. 26.11.36, S.6).

$22 \mathrm{Vgl}$. dazu die Ausführungen im Urteil des RG: „Auch im Urheberrecht geht Gemeinnutz vor Eigennutz. Der Einzelne genügt jedoch seiner Pflicht der Gesamtheit gegenüber dann am besten, wenn die ihm dafür gewährten Bedingungen die Erfüllung der Pflicht begünstigen und fördern" (JW 1937, S.690). E. Fraenkel (Der Doppelstaat, a.a.O., S.111) bemerkt treffend, daß „gerade im Bereich dieser Rechtsmaterien [Urheberrecht, Patentrecht, Verlagsrecht, Warenzeichenrecht etc.] die kapitalistische Wirtschaftsordnung eine Erschütterung der Grundsätze des überlieferten Privatrechts noch am wenigsten vertragen“ konnte.

${ }^{23}$ Schr. Lammers' an das RJM v. 15.12.36 (Diensttageb. des RJM, Bd.9, Eintr. v. 18.12.36, BA, Sign. R 22/930).

24 Grundsätzliche Rechtsbegriffe (Das Schwarze Korps v. 18.3.37, S.11).

25 Vgl. Das Schwarze Korps v. 3.11.38 (AGe Berlin, Nürnberg, Spandau, Hindenburg, Bütow u. LGPräs. Berlin), 24.11.38 (LG Leipzig), 1.12.38 (AG Mainz, StAschaft Tübingen), 8.12.38 (LG Berlin), 29.12.38 (AG Düren), 12.1.39 (AG Berlin-Wedding), 19.1.39 (AG Düren, Werne, KG Berlin): „Das ist ein Zustand, der nach Selbsthilfe schreit ... Es gibt auch Konzentrationslager!“. 
gar durch die Unterstellung absichtlicher Sabotage, die polizeilichen Korrekturmaßnahmen öffentlich zu rechtfertigen. Dabei verband das Blatt die Urteilskritik teilweise mit unwahren persönlichen Anwürfen gegen Richter und Staatsanwälte, die nunmehr sogar Freisler auf den Plan riefen: So behauptete Himmlers Organ, in einem Steuerhinterziehungsprozeß gegen einen Geschäftsführer der württembergischen Sekte „Möttlinger Bewegung“ - bei dem ohnehin nur eine „lächerliche Bestrafung“ herausgekommen sei - hätten nacheinander zwei Tübinger Staatsanwälte die Bearbeitung des Falles wegen Befangenheit niedergelegt, weil „diese beiden Leuchten der deutschen Justiz" selbst Anhänger der Sekte seien. In diesem Zusammenhang wurden die beiden Beamten als „geistige Untermenschen“ beschimpft, die auf dem „Niveau eines Zulukaffern“ stünden, und daran die Folgerung geknüpft: „Wer wagt es, einem deutschen Reichsbürger und Nationalsozialisten zuzumuten, daß er eines Tages von solch einem Exemplar angeklagt oder verurteilt wird?"26 Auf die Schreiben des Generalstaatsanwalts Stuttgart und des Pressereferenten des Reichsjustizministeriums, die die unrichtigen Behauptungen über die Vorgänge und die beiden Staatsanwälte widerlegten und die Veröffentlichung einer Berichtigung forderten, reagierte die Schriftleitung zunächst nicht. Auf eine nochmalige Aufforderung des Pressereferenten erkannte die Redaktion in einem Schreiben vom 20. Dezember 1938 die Beschwerde „insofern als durchaus berechtigt an“, als sich die Behauptungen nach Rückfrage bei ,jener amtlichen Stelle", von der das verwertete Material stammte, als nicht stichhaltig erwiesen hätten. Dem Ersuchen, diese Dienststelle - wahrscheinlich der SD - zu nennen, könne jedoch nicht entsprochen werden. Nach Rücksprache mit Gürtner schickte der Pressereferent der Zeitung am 22. Dezember den Wortlaut einer Berichtigung mit der Bitte um Veröffentlichung zu, um die Ehre der beiden Beamten wiederherzustellen. Das „Schwarze Korps“ publizierte jedoch einen eigenen Artikel, in dem es den Irrtum zwar eingestand, die Berichtigung aber indirekt mit einer neuen Kritik an der Staatsanwaltschaft verband: sie erklärte den Irrtum völlig unlogisch damit, „daß eine derartig zum Himmel stinkende Eiterbeule“ wie die genannte Sekte lange Zeit „ungestraft gedeihen konnte, ohne daß sich jemand fand [warum nicht die Polizei?], der bereit gewesen wäre, sie aufzustechen “. ${ }^{27} \mathrm{Da}$ dieser Artikel hinsichtlich der Wiederherstellung der Ehre der beiden Beamten ungenügend war, griff nunmehr Freisler selbst zur Feder, veröffentlichte den angefallenen Schriftwechsel in der „Deutschen Justiz“ und schloß mit der Feststellung, daß „eine Zurücknahme der persönlich verunglimpfenden Charakterisierung der beiden angegriffenen Beamten der Staatsanwaltschaft, die pflichttreu ihre Aufgabe erfüllen“, noch immer nicht erfolgt sei. ${ }^{28}$ Mit dieser ,in höchst unfreundlicher Tendenz" verfaßten Veröffentlichung Freislers beschäftigte sich das "Schwarze Korps" wiederum in seiner Nummer vom 19. Januar 1939 und griff die Schriftleitung der „Deutschen Justiz“ - de facto Freisler - an, sie hätte besser getan, sich bei der in erster Linie betroffenen Generalstaatsanwaltschaft Stuttgart zu informieren, und „somit den peinlichen Eindruck vermeiden können, daß nunmehr ihrer Veröffentlichung vom 4. Januar die Erklärung der Stuttgarter Staatsanwaltschaft vom

26 Die „Rettungsarche“ gestrandet (Das Schwarze Korps v. 1.12.38, S.15).

27 Nicht mitgestrandet (Das Schwarze Korps v. 5.1.39, S. 14).

28 DJ v. 4.1.1939, S.58f. Am 8.12.38 hatte das Schwarze Korps (S.15) einige Bilder jüdischer Ärzte gebracht, darunter ausgerechnet das eines Dr. Freißler. Es ist möglich, daß sich Freisler durch diese Anzüglichkeit besonders getroffen fühlte. 
14. Januar gegenübersteht, in der diese uns bestätigt, daß sie unsere Klarstellung dankbar und freudig begrüßt". ${ }^{29}$

Den Angehörigen der Justiz ging diese herabsetzende Kritik erheblich an den Nerv. Der Hamburger Oberlandesgerichtspräsident Rothenberger, der sich gerade in dieser Zeit gegen die zunehmenden Korrekturmaßnahmen seitens der SS- und Polizeiführung durch Schutzhaftverhängung in seinem Bezirk wandte ${ }^{30}$, ließ von seiner Behörde die hauptsächlichsten Urteilskritiken des "Schwarzen Korps“ seit Sommer 1938 mit kurzen Inhaltsangaben zusammenstellen. Gleichzeitig ließ er Beobachtungen über ihre Auswirkung, ferner Überlegungen über mögliche Gegenmaßnahmen aufzeichnen, da er vom Reichsjustizministerium aufgefordert worden war, auf einer für Ende Januar 1939 geplanten Zusammenkunft der Chefpräsidenten in Berlin ein Referat über den „Ehrenschutz der Richter und Staatsanwälte“ zu halten. Diese Aufzeichnung gewährt einen anschaulichen Einblick in die Haltung und Gefühle der Justizangehörigen gegenüber der Kampagne des „Schwarzen Korps“. Sie konstatierte zunächst, daß von der Kritik dieser Zeitung an staatlichen Behörden die Kritik an der Justiz bei weitem den größten Raum einnehme, während bezeichnenderweise über Mißgriffe und Irrtümer der Polizei nicht ein einziges Wort zu finden sei. Angesichts der Tatsache, „daß diesen wöchentlich ein oder zwei nach Ansicht des Schw. K. unrichtigen Urteilen hunderte und tausende von richtigen Urteilen gegenüberstehen“, die - mit Ausnahme einer Entscheidung des Amtsgerichts Lüneburg über die Nichtanwendung des Abtreibungsparagraphen ( $\S 218 \mathrm{StGB}$ ) auf Juden ${ }^{31}$ - nicht erwähnt würden, stellte die Ausarbeitung die berechtigte Frage nach dem Zweck dieser Art Berichterstattung ohne sie allerdings expressis verbis zu beantworten. Ob die vorgebrachte Kritik sachlich berechtigt sei, lasse sich für die meisten Urteile von Hamburg aus nicht feststellen; in den nachgeprüften Hamburger Fällen habe sie sich jedenfalls als ungerechtfertigt erwiesen. Wesentlicher als eine mögliche Berechtigung der Kritik im Einzelfall, die in der Aufzeichnung durchaus nicht bestritten wurde, sei aber, „daß fast in jedem Fall verallgemeinernde Schlußfolgerungen gezogen“ würden, die beim Leser notwendigerweise die Vorstellung hervorriefen, ,daß es nur in der Justiz stinkt, und daß in der Justiz Saboteure sitzen“. Die Folge sei ein Vertrauensverlust gegenüber der Justiz, ein „Aufreißen einer unüberbrückbaren Kluft zwischen Volk und Justiz“ und die Unterhöhlung der Autorität einer Sparte der staatlichen Verwaltung, die sich auf die Dauer auch auf die Autorität weiterer Dienststellen von Staat und Partei auswirken werde. Schon sei ein Fall bekannt geworden, in dem ein Mann nach Verlust eines Prozesses die Richter aufs übelste beleidigt hatte, ein Strafantrag gegen ihn aber hatte zurückgenommen werden müssen, da er sich auf ähnlich formulierte Äußerungen im „Schwarzen Korps" berief. Ferner ermögliche eine derartige parteiamtliche Berichterstattung der ausländischen Presse die Behauptung, daß die Richterschaft pauschal den nationalsozialistischen Staat ablehne und seine Ziele sabotiere. Besonders gravierend aber sei die Auswirkung auf die Richter: sie würden, „wie das in Berichten an uns schon zum

29 Was den Juristen interessiert (Das Schwarze Korps v. 19.1.39, S. 14). Die GStAschaft Stuttgart hatte sich in dem erwähnten Schreiben mit der ungenügenden Berichtigung vom 5.1.39 offenbar zufriedengegeben.

30 Vgl. dazu Kap. VI.3.d., S.623 ff.

31 Vgl. Sie dürfen? Sie sollen! (Das Schwarze Korps v. 24.11.38, S.16); Wir haben wirklich nichts dagegen! (a.a.O., v. 22.12.38, S.11). 
Ausdruck gekommen ist, sich vollkommen schutzlos vorkommen, ... selbst gegenüber eklatant unrichtigen Vorwürfen“. Die amtliche „Deutsche Justiz“ habe

„erst in allerletzter Zeit in einer viel zu feinen und vornehmen Weise sich für die Richter eingesetzt. Die Berufsfreude der Richter muß gegenüber derartigen dauernden Angriffen völlig verloren gehen. Außerdem leidet die Unbeeinflußbarkeit der Richter, die dauernd unter dem Druck einer sie persönlich über das ganze Reich defamierenden [sic] Veröffentlichung, möglichst noch unter Namensnennung, stehen."

Vor allem dann werde der Richter "vollkommen verwirrt in der Findung dessen, was nun eigentlich nationalsozialistisch" sei, wenn er die angegriffene Entscheidung im Einklang mit den Richtlinien des Reichsjustizministeriums getroffen habe. Das wurde am Komplex der Behandlung von Räumungsklagen gegen Juden verdeutlicht, zu dem Göring als Beauftragter für den Vierjahresplan den Reichsministerien in einem geheimen Schnellbrief vom 23. Dezember 1938 die Entscheidung Hitlers mitgeteilt hatte, daß der Mieterschutz für Juden zunächst nicht generell aufzuheben $\operatorname{sei}^{32}$ eine Entscheidung, die den Justizbehörden vom Ministerium gleichfalls geheim bekanntgegeben worden war.

„Wenn das amtliche Organ des Reichsführers SS ,hü‘ sagt und ein Geheimerlaß des Reichsjustizministeriums behauptet, daß laut Mitteilung von Generalfeldmarschall Göring der Führer ,hott' sage, dann ist schlechterdings unerfindlich, wie der Richter aus diesem Dilemma nun erkennen soll, was wirklich der Wille des Führers ist und wer sozusagen die besseren Beziehungen zum Führer hat."

Unter diesen Verhältnissen verliere der Richter das Vertrauen zu seinen Vorgesetzten sowie den beamtenrechtlich zugesicherten besonderen Schutz des Führers und wandere bei nächster Gelegenheit aus der Justiz in die Wirtschaft ab; viele befähigte Assessoren schlügen daher von vornherein gar nicht erst die Richterlaufbahn ein.

Die Ausarbeitung hielt eine solche öffentliche Kritik schon deshalb für überflüssig, da es bessere Wege gebe, wirkliche Mißstände zu beseitigen, nämlich Disziplinar- und Dienststrafverfahren und vor allem die prozessualen Rechtsmittel. Auf diesem Wege sei eine sachverständige Kritik gewährleistet, der alle Beurteilungsunterlagen zur Verfügung stünden, und es sei daher nicht einzusehen, daß die Kritik an der Justiz ausgerechnet von inkompetenter Seite ohne genaue Kenntnis der Fälle und der juristischen Problematik ausgeübt werde.

Als Gegenmaßnahmen wurden in der Aufzeichnung folgende Schritte der Justizverwaltung vorgeschlagen:

1. Die Richterschaft sei mit äußerstem Nachdruck anzuhalten, daß sie „sich persönlich in jeder Hinsicht [d.h. aber auch in politischer] unangreifbar" verhalte.

2. Hinsichtlich der Rechtsprechung sei eine noch intensivere Schulung anzustreben, um keinen Anlaß zu berechtigter Kritik zu bieten.

Die Tendenz dieser beiden Vorschläge, den von der SS ausgeübten Druck innerhalb der Justiz weiterzugeben, zeigt, daß die Kampagne des "Schwarzen Korps“ durchaus nicht wirkungslos war. Die weiteren Vorschläge betrafen hingegen echte Abwehrmaßnahmen:

32 Vgl. Nürnb. Dok. NG-4821 (Arch. d. IfZ). Die Materie wurde erst durch das G. über Mietverhältnisse mit Juden v. 30.4.39 (RGBl. I, S.864) zu ungunsten der Juden geregelt. 
3. „Allgemein gesehen dürfte es notwendig werden, daß der Führer vom Minister auf die Bedenklichkeit dieser Berichterstattung hingewiesen wird unter besonderer Klarlegung der Ansehensminderung“, die sich aus einem Autoritätsverlust mit den erwähnten Folgen ergebe. Man dürfe davon ausgehen, daß Hitler den Richter vor unberechtigter Kritik schützen werde, nachdem er ihn in der Ernennungsurkunde seines besonderen Schutzes versichert habe.

4. Bis zu einer grundlegenden Änderung, d.h. Einstellung der Angriffe, müßte die Kritik im Einzelfall nachgeprüft werden und das Resultat gegebenenfalls - wenn das Schwarze Korps keine zufriedenstellende Berichtigung bringe - ,in der ,Deutschen Justiz', und zwar nicht an versteckter Stelle, sondern groß aufgemacht am Eingang des Heftes, mitgeteilt" werden.

5. Durch ein Verbot des direkten Verkehrs mit dem Schwarzen Korps sollten gegenüber dem SS-Organ eine einheitliche Linie eingehalten und solche Pannen vermieden werden, wie sie durch die unterschiedlichen Stellungnahmen Freislers und der Stuttgarter Staatsanwaltschaft zur „Berichtigung“ des „Schwarzen Korps“ im Falle der „Möttlinger Bewegung“ aufgetreten seien.

6. Am wünschenswertesten sei der Erlaß eines Gesetzes nach englischem Vorbild, das die öffentliche Kritik an Urteilen unter Strafe stelle; die Möglichkeit dafür wurde jedoch unter den herrschenden Umständen als „außerordentlich fraglich“ bezeichnet. $^{33}$

In seinem Vortrag vor den Chefpräsidenten am 25. Januar im Reichsjustizministerium über den Ehrenschutz der Richter und Staatsanwälte stellte Rothenberger "die seit Monaten zu beobachtende Ehrenkränkung der deutschen Richter durch das Schwarze Korps" in den Mittelpunkt seiner Ausführungen und trug dazu wesentliche Punkte der Aufzeichnung vor. ${ }^{34} \mathrm{Z}$ war lehnte er eine Stellungnahme zu den kritisierten Urteilen und Personen ab, da er die Verhältnisse in den anderen Bezirken nicht kannte, wandte sich aber entschieden gegen die Form und die Verallgemeinerung der Kritik, „die darin gipfelt, daß die deutschen Richter Saboteure am Werk des Führers seien". Anders als in England, wo selbst berechtigte Angriffe auf den Richter verboten seien, müsse in Deutschland gegenwärtig Pressekritik zugelassen werden, da hier die Justiz ,in der Umgruppierung begriffen“ sei. Wenn aber der gesamte Richterstand jede Woche in der parteiamtlichen Presse „als reaktionärer Zopf und Saboteur“ bezeichnet werde, müsse er „entweder resignieren und eingeschüchtert werden, oder er muß dick- und starrköpfig" werden. Ein solcher Richter könne nicht die Wahrheit er'mitteln, nicht Recht finden und gestalten.

„Die Wirkung auf das Volk zeigt sich darin, daß die Leute den Richtern und den Chefs schon im Laufe des Prozesses Zeitungsausschnitte aus dem ,Schwarzen Korps‘ zusenden mit dem Bemerken: Mein Fall liegt ebenso wie der im ,Schwarzen Korps' besprochene oder der Richter ist ebensoeiner, wie der im ,Schwarzen Korps' angegriffene. Ein ganz allgemeines Mißtrauen gegen die Justiz ist erzeugt worden. Es handelt sich um eine Vertrauenskrise der Justiz und damit des

33 Undat. Ausarbeitung für die Bespr. im RJM am 24.1.39 (Akten des OLG Hamburg, Arch. der Forschungsstelle für die Geschichte des NS in Hamburg, Sign. Best. 3305).

${ }^{34} \mathrm{Zu}$ den Ausführungen Rothenbergers im folgenden vgl. Aufzeichn. des Vizepräs. des OLG München v. 6.2.39 (Akten des OLG München 313 Bd.I, StArch. München) u. Ber. Rothenbergers (der sein Referat auf den 26.1. datiert) an den Hamburger Gauleiter/RStH Kaufmann v. 8.2.39 (Akten des OLG Hamburg, StArch. Hamburg, Best. 213-1, Wiedergabe des Inhalts auch bei Johe, Die gleichgeschaltete Justiz, a.a.O., S. $163 \mathrm{f}$.), die inhaltlich weitgehend übereinstimmen. 
Staates. Die Wirkung auf den Nachwuchs besteht darin, daß es sehr schwer ist, die wirklich tüchtigen aktiven Leute für die Justiz zu bekommen. Man kann mit gutem Gewissen keinem Assessor mehr sagen, daß der Richterberuf ein idealer Beruf ist.“

Auch das Ausland müsse entweder annehmen, daß die deutsche Richterschaft gegen den nationalsozialistischen Staat eingestellt sei, oder daß „nach bolschewistischer Manier die ganze deutsche Rechtsprechung eine Farce“ sei.

Rothenberger nutzte die Situation zu dem Versuch aus, bei dem bedrängten Justizminister seine schon damals entwickelten Reformideen durchzusetzen. ${ }^{35}$ Er führte aus, daß den öffentlichen Angriffen nur dann erfolgreich begegnet werden könne, wenn die Justiz selbst keine Schwächen und Angriffsflächen für berechtigte Kritik aufwies:

„Voraussetzung für eine wirksame Abhilfe sei daher eine durch und durch nationalsozialistische Personalpolitik. Dazu gehörte z. B. ständige Fühlungnahme der Justizbehördenchefs mit allen politischen Stellen, engster organisatorischer Anschluß an diese politische Stellen, Politisierung und Aktivierung des Richterstandes, Aufklärung der Öffentlichkeit über Justizfragen durch Vorträge, taktvolle Dienstaufsicht und Besprechung von grundsätzlichen Fehlern in Urteilssprüchen mit den jeweiligen Richtern, Menschenführung in größtem Ausmaß und alles, was damit zusammenhänge."

Zur Abwehr unberechtigter Angriffe schlug Rothenberger vor, Anzeige gegen die betreffende Zeitung beim zuständigen Bezirksgericht der Presse zu stellen, um ein Ehrenverfahren gegen den Schriftleiter durchzuführen. Er wies auf eine kürzlich erlassene Anordnung des Stellvertreters des Führers hin ${ }^{36}$, die allen Parteizeitschriften öffentliche Angriffe gegen Parteigenossen unter Androhung von Maßregeln gegen die Redakteure verbot und verfügte, belastendes Material statt dessen dem zuständigen Hoheitsträger oder dem Parteigericht zuzuleiten. Diese Bestimmung könnte zumindest auf Attacken gegen diejenigen Richter angewendet werden, die Parteigenossen seien. Rothenberger kritisierte in diesem Zusammenhang das Vorgehen des Ministeriums im Falle der „Möttlinger Bewegung“: der Pressereferent hätte sich nicht schriftlich an das "Schwarze Korps“ wenden dürfen, sondern „persönlich dorthin gehen müssen und eine für beide Teile tragbare Berichtigung vereinbaren sollen“. Es sei aber überhaupt fraglich, ob Berichtigungen das richtige Gegenmittel darstellten: „Die Richter wären schon erheblich beruhigt, wenn in der Deutschen Justiz an ganz sichtbarer Stelle gebracht würde, daß der Reichsminister der Justiz das Verhalten des betreffenden Richters deckt“. So aber "stehe der deutsche Richter seit Monaten schutz- und wehrlos da. Das Ministerium müsse, wenn nicht unendlicher Schaden weiter angerichtet werden solle, eine sofortige Entscheidung herbeiführen“.

Den anwesenden Chefpräsidenten hatte Rothenberger aus der Seele gesprochen. In der anschließenden Erörterung bestätigten sie die starke Erregung, die die Angriffe

35 In einer Aufzeichn. vom 19.1.44 schrieb Rothenberger rückblickend: „Ich war mir klar darüber, daß die Justiz selbst durch eine grundlegende Reform das notwendige Vertrauensverhältnis ... schaffen mußte ... Meine mehrfachen Versuche - veranlaßt durch die schweren Angriffe, die in der Öffentlichkeit gegen die Justiz erhoben wurden -, den verstorbenen Minister Gürtner zu einer Reform zu veranlassen, [waren] erfolglos“ (Beiakten zu den Personalakten Rothenberger, Bd.V, Blattsammlung, BA Berlin). Zu Rothenbergers Reformplänen als Staatssekretär $1942 / 43$ vgl. H. Weinkauff, Die deutsche Justiz und der Nationalsozialismus, a.a.O., S. $150 \mathrm{ff}$.

36 Es handelt sich um die Anordnung des Stellv. des Führers 12/39 v. 10.1.39 (vgl. Verfügungen/Anordnungen/ Bekanntgaben, herausg. von der Partei-Kanzlei, München, Bd. I, S. 454). 
unter den Richtern ihrer Bezirke verursacht hatten, und nahmen dem Ministerium gegenüber bei ihren Unmutsäußerungen kein Blatt vor den Mund. Der Kammergerichtspräsident führte aus, seine in besonders starkem Maße angegriffenen Richter seien „nicht gesonnen, die Beleidigung auf sich sitzen zu lassen. Sie bitten den Herrn Reichsminister um Schutz und werden sich selbst Genugtuung verschaffen, wenn sie ihnen nicht gegeben wird“. Der Kieler Chefpräsident verstieg sich zu der Äußerung: „Man muß sich überlegen, ob man selber noch Richter bleiben will, wenn es so weitergeht.“ Reichsgerichtspräsident Bumke erklärte, die Richter erhöben „keinen Anspruch auf Beliebtheit, aber auf Achtung“, deshalb müsse Hitler selbst mit der Sache befaßt werden. Der Oberlandesgerichtspräsident Frankfurt meinte, daß Erklärungen in der „Deutschen Justiz“ keinesfalls genügten, sondern eine „parteiamtliche Zurückweisung" erforderlich sei. Der Chefpräsident Karlsruhe, der selbst Vorsitzender des dortigen Bezirksgerichts der Presse war, hielt Rothenbergers Vorschlag einer Anrufung dieser Gerichte für ungeeignet, da die Einleitung eines solchen Verfahrens vom Antrag des Reichspropagandaministeriums abhing: „Ob ein solcher Antrag gestellt wird, möchte ich bezweifeln."

Von seiten des Ministeriums nahm zunächst Freisler zu den Vorwürfen Rothenbergers Stellung: Im Falle der „Möttlinger Bewegung“ habe er selbst angeordnet, den schriftlichen Weg zu beschreiten, weil die Sache lange genug mit dem „Schwarzen Korps" verhandelt worden sei. Aufgrund der Angriffe die funktionsbedingte, eigene Stellung des Richters aufzugeben, komme „nicht in Betracht, weil der Kapitän und seine Leute ein Schiff in Not nicht verlassen dürfen. Die Sache ist heute die ernsteste seit Jahren. Die Gründe der Angriffe erblicke ich darin, daß es Leute gibt, die die Rechtsordnung nicht für notwendig halten". Diese Ansicht stamme daher, daß die Partei noch aus der Kampfzeit "unangenehme Erinnerungen an die Rechtspflege“ habe. Die Attacken gegen die Justiz auf Gauebene, die sich nicht auf die Presse beschränkten, seien „allgemein gut abgeschlagen worden“. Auf Reichsebene könnten die Angriffe im „Stürmer“, im „Rechtsspiegel“ - die deswegen bemerkenswert gewesen seien, weil sie von Juristen stammten - und im „SA-Mann“ gegenwärtig als erledigt angesehen werden; anders als die Offensive im „Schwarzen Korps“ seit Oktober 1938 seien sie auch nie als System aufzufassen gewesen. Den Vorwurf ungenügender Aktivität des Ministeriums wies Freisler mit den Worten zurück, daß der Pressereferent dieser Angelegenheit stets besondere Aufmerksamkeit zugewendet und eine bereits Ende 1937 anhebende Welle der Kritik des „Schwarzen Korps“ durch Bemühungen um sachliche Aufklärung für fünfeinhalb Monate zum Stillstand gebracht habe. Gegenwärtig schwebten mit dem „Schwarzen Korps“ Verhandlungen über sechzehn Fälle, deren Ausgang abgewartet werden müsse. Wenn keine Einigung erzielt werde, werde die Klärung jedoch nicht gerichtlich oder ehrengerichtlich, „sondern auf andere Weise" herbeigeführt werden.

Zum Abschluß machte Gürtner einige grundsätzliche Ausführungen zu dem ausgebrochenen Konflikt: bei den gegenwärtigen Angriffen des "Schwarzen Korps“ handele es sich keineswegs nur „um die Hetze einer wildgewordenen Zeitung, sondern um eine periphäre [sic] Erscheinung des Kampfes gegen die Justiz überhaupt". Da im heutigen Staat jeder Staatsdiener ganz selbstverständlich Weisungen zu befolgen habe, verstehe der juristische Laie nicht, warum das nicht auch auf den Richter zutreffe, warum nicht auch der Richter wie jeder Verwaltungsbeamte oder Offizier ohne weite- 
res versetzt werden könne. Über den Sinn der richterlichen Unabhängigkeit habe er daher immer wieder aufklärend zu wirken versucht. Gewiß hätten die Gerichte bei der Auslegung der Gesetze verschiedentlich Anlaß zu Kritik gegeben, und auch darüber, was zur Wiederherstellung der angegriffenen Ehre notwendig sei, könne man verschiedener Auffassung sein. Aber alle Bemühungen zur Klärung von Einzelfällen könnten den Konflikt nicht beheben, da „sich der Kampf nicht gegen die Richter, sondern gegen das Richteramt richtet". Durch das massive Drängen der Chefpräsidenten wurde Gürtner offenbar in seinem Entschluß bestärkt, zur Beseitigung des Konflikts grundsätzliche Schritte zu unternehmen. Den Oberlandesgerichtspräsidenten gegenüber bekräftigte er: „Ich bin entschlossen wegen dieser Angriffe nicht mehr mit dem ,Schwarzen Korps' zu verhandeln. Ich frage: Wer ist denn für diese Artikel verantwortlich? Ich werde die Verhandlungen auf einer anderen Ebene fortsetzen." ${ }^{\text {"37 }}$

Die Reaktion des Ministeriums ließ nicht lange auf sich warten. Die laufenden Verhandlungen mit dem „Schwarzen Korps“ über eine berichtigte Darstellung der strittigen Fälle in dieser Zeitung wurden abgebrochen. Das Ministerium veröffentlichte nun seinerseits schon in der nächsten Nummer der Deutschen Justiz - am 27. Januar eine vierseitige Zurückweisung und Berichtigung der dreizehn eklatantesten Kritiken des „Schwarzen Korps“ vom Juni 1937 bis Januar 1939, diesmal im Abschnitt „Amtliche Erlasse und Verordnungen ${ }^{\text {“ } 38}$, der sozusagen zur Pflichtlektüre jedes Justizbeamten gehörte. Es handelte sich offensichtlich um jene Fälle, deren Klärung mit dem „Schwarzen Korps“ Freisler den Tagungsteilnehmern gegenüber immerhin noch als möglich bezeichnet hatte.

Rothenberger, der offenbar glaubte, dem Ministerium weiter zusetzen zu müssen, berichtete am 28. Januar an Gürtner, daß er die Hamburger Richter, Staatsanwälte und Assessoren zusammengerufen und sie vom Ergebnis der Berliner Tagung informiert habe. Er sei der Ansicht, daß die Justizbeamten Hamburgs zwar weiterhin unbeirrt ihre Pflicht tun würden, aber „dem Ernst der Lage um so mehr gewachsen sein werden, je mehr sie die Gewißheit haben, daß ihr Minister und ihre Dienstvorgesetzten sich unter Einsatz ihrer ganzen Persönlichkeit vor sie stellen “ ${ }^{39}$ Seine Vorwürfe gegen das Ministerium hatte er in dieser Versammlung allerdings nicht erwähnt aber betont, daß ihm selbst ,jedes Mittel recht sei, um einen hanseatischen Richter, dessen Ehre zu Unrecht angegriffen würde, zu schützen “. ${ }^{40}$ Auf einer Besprechung am 1. Februar berichteten ihm die Hamburger Gerichtspräsidenten, daß die Richterschaft durch die Angriffe des „Schwarzen Korps“ stark beunruhigt gewesen sei, seine Ansprache vom 28. Januar aber Hoffnung auf Besserung verbreitet habe. „Allerdings würden Zweifel geäußert, ob es dem Reichsjustizminister gelingen würde, sich gegenüber dem Schwarzen Korps bzw. der SS. durchzusetzen. Diese Zweifel beruhten insbesondere auf der früheren passiven Haltung des Ministeriums. “ 41

Wie er auf der erwähnten Tagung angekündigt hatte, blieb Gürtner jedoch durchaus nicht untätig: die „andere Ebene“, auf der er nunmehr verhandelte, war Himmler.

${ }^{37} \mathrm{Zu}$ den Ausführungen der Tagungsteilnehmer, Freislers u. Gürtners vgl. Aufzeichn. des Vizepräs. des OLG München, a.a.O. (Anm. 34).

${ }^{38}$ Überschrift: Veröffentlichungen der Zeitschrift „Das Schwarze Korps“ (DJ v. 27.1.39, S. 175 ff.).

39 Schr. Rothenbergers an Gürtner v. 28.1.39 (Akten des RJM, BA, Sign. R 22/245).

40 Ber. Rothenbergers an Kaufmann v. 8. 2.39 (Akten des OLG Hamburg, Arch. der Forschungsstelle für die Geschichte des NS in Hamburg, Sign. Best. 3305).

41 Ber. über die Präsidentenbespr. v. 1.2.39 (Nürnbg. Dok. NG-629, Arch. d. IfZ). 
Schon am 1. Februar hatte er mit dem Reichsführer-SS eine Unterredung, auf der Himmler erklärte, zu den in der letzten Nummer der "Deutschen Justiz“ aufgerollten Fällen erst Stellung beziehen zu können, wenn er „die andere Seite gehört" habe. Die Besprechung endete jedoch mit einem „Burgfrieden“: beide Partner vereinbarten, die Pressefehde einzustellen. ${ }^{42}$ Um so erstaunter war Gürtner, als das „Schwarze Korps“ in seiner Ausgabe vom 9. Februar die Richtigstellung der dreizehn Kritiken durch die „Deutsche Justiz“ als „Sammelsurium“ und „sachlich durch nichts begründete Unfreundlichkeiten" abtat und erklärte, nach wie vor zu seinen Veröffentlichungen zu stehen und auch weiterhin „notwendige Kritik“ ohne Rücksicht auf die Meinung derjenigen zu üben, die sie mit Recht auf sich bezögen. ${ }^{43}$ Gürtner übersandte Himmler diesen Artikel umgehend und beschwerte sich, daß er in keiner Weise dem Geist ihrer Vereinbarung entsprach. Er nehme daher an, daß Himmler davon keine Kenntnis gehabt habe, und drückte erneut die Hoffnung aus, „daß nunmehr weitere Angriffe unterbleiben. Ich will darauf öffentlich nicht erwidern. Sie werden aber verstehen, daß ich den Aushang der Folge 6 des ,Schwarzen Korps' wegen dieses Angriffes in und an Gebäuden der Reichsjustizverwaltung nicht zulassen kann" “. ${ }^{44}$ Drei Tage später antwortete Himmler, daß er den Artikel „selbstverständlich" nicht veranlaßt habe - für seine persönliche Stellungnahme zu dem umstrittenen Fällen würden die „Beweisstücke ... gerade gesammelt“. Sein Befehl an das „Schwarze Korps“ sei jedoch zu spät gekommen, um in dieser Ausgabe noch berücksichtigt zu werden. Andererseits möge der Minister bedenken, daß die letzte Veröffentlichung der „Deutschen Justiz“ „nicht ohne Widerspruch entgegengenommen werden“ könne: auch Gürtner habe ihm in der Unterredung erklärt, daß er bei neuerlichen Angriffen seine Beamten nicht an einer Erwiderung hindern werde. Offenbar war es Himmler aber nur darum zu tun, daß sein Presseorgan vor Eintritt des Burgfriedens das letzte Wort behielt, denn am Schluß seines Schreibens bekräftigte er schließlich, daß er es für gut halte, „wenn weder die Zeitschrift ,Deutsche Justiz' noch das ,Schwarze Korps' in dieser Richtung weitere Dinge veröffentlichen. Für das ,Schwarze Korps' habe ich es selbstverständlich abgestellt" ${ }^{\text {. }}$.

Tatsächlich vollzog das Blatt am 23. Februar eine überraschende Wendung: Plötzlich fand sich ein Volksgenosse, der der Schriftleitung einen Beschluß des Amtsgerichts Berlin-Schöneberg mit der Bitte einsandte, ihn doch „mit einem netten Kommentar" zu veröffentlichen. Die Zeitung lobte den Beschluß wegen seiner Übereinstimmung mit dem gesunden Volksempfinden und knüpfte daran die Behauptung, sie habe der Justiz niemals feindlich gegenübergestanden, sondern durch die Kritik stets nur positive Wirkungen für sie erzielen wollen. Lediglich diejenigen, die die Zeitung nicht verstehen wollten, ,verallgemeinerten nur unsere kritische Einstellung zu manchen Richtern und ihren Urteilen" ${ }^{4}{ }^{6}$

Den Chefs der obersten Justizbehörden, die eine öffentliche Zurücknahme der vorangegangenen beleidigenden Angriffe auf verschiedene ihrer Beamten erwartet hatten,

42 Vgl. Himmlers Schr. an Gürtner v. 12.2.39 (Akten persönl. Stab RFSS, Arch. des IfZ, Sign. MA 3/7, folder 47), dort auch der Ausdruck „Burgfrieden“.

43 Wir stellen fest! (Das Schwarze Korps v. 9.2.39, 6. Folge, S. 16).

44 Schr. Gürtners an Himmler v. 8.2.39 (Akten persönl. Stab RFSS, Arch. d. IfZ, Sign. MA 3/7, folder 47).

43 Schr. Himmlers an Gürtner v. 12.2.39 (a.a.O.).

46 Ein netter Kommentar (Das Schwarze Korps v. 23.2.39, S.9). 
stellte Gürtner Anfang März eine erneute Kontaktaufnahme wegen dieser Frage mit dem Reichsführer-SS in Aussicht. Mitte März wies er Himmler in einem Gespräch auf die Empörung hin, die seinerzeit „durch die ehrverletzenden Angriffe in der Richterschaft ausgelöst worden" waren. Himmler beteuerte, daß er eine ehrverletzende Kritik im „Schwarzen Korps“ grundsätzlich mißbillige. Am 23. März - nachdem er offensichtlich die Einzelfälle geprüft hatte - bekräftigte er gegenüber Gürtner nochmals schriftlich, daß er „die Form, die menschlich und beruflich kränkend war" und die von ihm „, keiner Weise gutgeheißen und gebilligt“ wurde, „sehr bedauert" habe. Die Stellungnahme Himmlers berichtete Gürtner vertraulich den Behördenchefs und ersuchte sie, diejenigen Richter, die im "Schwarzen Korps“ beleidigt worden waren, in geeigneter Weise davon zu unterrichten. Er bat aber zugleich - nachdem ihm der Reichsführer-SS über die verletzenden Veröffentlichtungen mündlich und schriftlich sein Bedauern ausgesprochen habe -, „die Angelegenheit nunmehr als abgeschlossen zu betrachten “ 47 : Gürtner war nicht gewillt, den gerade erzielten „Burgfrieden“ durch das Anfachen einer neuen öffentlichen Polemik zu gefährden.

Mit Gürtners Initiative bei Himmler schien das Justizministerium einen Erfolg errungen zu haben. In den folgenden Monaten fand das „Schwarze Korps“ verschiedentlich sogar lobende Worte über Gerichtsurteile. ${ }^{48}$ Selbst wenn die Zeitung Entscheidungen unbefriedigend fand, griff sie die beteiligten Gerichte nicht mehr direkt an. ${ }^{49}$ Dieser „Burgfrieden“ hielt bis in die ersten Kriegswochen hinein an. Aber abgesehen davon, daß die nicht-öffentliche Urteilskritik der Polizeiführung fortdauerte, wurde auch der Öffentlichkeit in dieser Phase die Unzulänglichkeit der Justiz durch zunehmende Meldungen über Korrekturmaßnahmen - darunter sogar über polizeiliche Exekutionen ${ }^{50}$ - weiter vor Augen geführt, wobei die Wiedergabe dieser Nachrichten allerdings nicht auf das "Schwarze Korps“ beschränkt blieb. Schon Anfang 1940 fiel die Zeitung aber in das alte Fahrwasser der Urteilskritik zurück, da die Gerichte verschiedentlich hinter der Forderung nach scharfer und abschreckender Rechtsprechung mit generalpräventiven Zielen zurückblieben ${ }^{51}$; dabei enthielt sie sich allerdings nunmehr persönlicher Angriffe gegen Richter und Staatsanwälte, nicht dagegen gegen Rechtsanwälte. ${ }^{52}$ Eine noch unter Gürtner oder auch erst unter Schlegelberger getroffene Absprache, vor der Veröffentlichung einer negativen Urteilskritik mit dem Reichsjustizministerium Fühlung zu nehmen, wurde vom „Schwarzen Korps“ häufig nicht eingehalten. ${ }^{53}$ Auch die im September 1942 von dem neuen Justizminister und Vertrauensmann der Partei Thierack mit Himmler getroffene Vereinbarung, daß das

47 Zum Voranstehenden vgl. vertraul. RV des RJM an die Chefpräs., den OReiA u. die GStAe v. 26.3.39 (Akten des RJM, Hauptbüro, Arch. des BJM).

48 Vgl. z. B. Das Schwarze Korps v. 13.4.39, S. 18 (AG Königsberg), 27.4.39, S. 12 (AG Suhl), 8.6.39, S. 16 (AG Stettin), 27.7.39, S.7 (AG Lesum, LG Verden), 16.11.39 (Berlin).

49 Vgl. z. B. Das Schwarze Korps v. 27.4.39, S.7 (OLG Celle u. LG Hannover, die den § 218 auf Juden anwendeten im Gegensatz zu dem vom Schw. Korps im Vorjahr gelobten Urt. des LG Lüneburg), v. 22.6.39, S. 2 (AG Wilhelmshaven).

so Vgl. z. B. Das Schwarze Korps v. 14.9.39, S. 1. Zu Erschießungen als Urteilskorrekturen vgl. Kap. VI.6.a.

51 Vgl. z. B. Das Schwarze Korps v. 25.1.40, S.12, Unangebrachte Milde (LG Darmstadt), 15.2.40, S.6 (RG; „Einem Feinde nähert man sich nicht mit der Allongeperücke weltentrückter Objektivität. Im Kriege wird scharf geschossen."), 21.3.40, S.4 (AG Berlin), 11.4.40, S.6 (AG Hamburg-Harburg), 2.5.40, S.6 (Köln).

52 Vgl. dazu Kap. VI.2.b., S. 572 , und dortige Anm. 116.

53 Vgl. Verm. der Abt. I des RJM v. 14.9.42 für die bevorstehende Bespr. Sts. Rothenbergers mit Himmler (Akten des RJM, BA, R 22/5029). 
„Schwarze Korps“ seine Angriffe gegen die Justiz einstellen, auf Anregung der Justiz auch positive Urteile, negative aber nur „nach vorheriger Ưbereinstimmung mit der Justiz“ bringen sollte ${ }^{54}$, löste das Problem nicht engültig und schloß gelegentliche Auseinandersetzungen in dieser Frage nicht aus: die SS- und Polizeiführung sollte auf das Mittel der öffentlichen Kritik an der Justiz nie ganz verzichten.

\section{Die polizeiliche Exekution als Mittel der „Polizeijustiz“ und der Korrektur der Strafrechtspflege}

\section{a. „Legalisierung" der Exekutionen durch Hitler bei Kriegsbeginn 1939 und die Reaktion der Justiz}

Das schärfste Mittel, das SS und Polizei zur Korrektur der Justiz anwandten, waren verfahrenslose Exekutionen. Mit Ausnahme der Erschießungen anläßlich der RöhmAffäre wurde die Tötung von politischen Gegnern - aber auch Straffälligen und vorbestraften Kriminellen - während der Friedensjahre noch verborgen durchgeführt und auch gegenüber der Justiz als Selbstmord, Erschießung ,auf der Flucht“ oder „bei Wi-

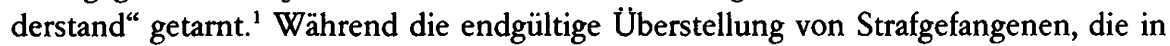
Justizgefängnissen einsaßen, vor Beendigung ihrer Strafverbüßung an die Polizei in den Vorkriegsjahren selten gewesen zu sein scheint, kamen aber z. B. Personen, deren Unterbringung in einem Arbeitshaus gerichtlich angeordnet worden war, verschiedentlich als „Arbeitszwangshäftlinge“ in die Konzentrationslager und waren damit einer möglichen Exekution ausgesetzt. ${ }^{2}$ Sonst dürften „Korrekturen“ von Gerichtsurteilen durch Tötung von Strafgefangenen in den ersten Jahren nur aus politischen Motiven und aus Rache, nicht aber zur schärferen Bekämpfung der Kriminalität erfolgt sein. So wurde z. B. der Mörder von Horst Wessel, Ali Höhler, von Beamten des Geheimen Staatspolizeiamtes aus der schlesischen Strafanstalt Wohlau, wo er seine Zuchthausstrafe verbüßte, zur Vernehmung nach Berlin abgeholt und am 20. September 1933 auf dem Rücktransport bei Frankfurt (Oder) ermordet. Dem Direktor der Strafanstalt wurde telefonisch mitgeteilt, daß Höhler in Berlin verstorben sei. An Ministerpräsident Göring berichtete das Geheime Staatspolizeiamt, Höhler sei von unbekannten SA-Männern umgebracht worden, die den Polizeitransport überfallen hätten und trotz aller Bemühungen nicht ermittelt werden könnten; um eine Einmischung der Justiz zu vermeiden, wurde Göring gebeten, den preußischen Justizminister Kerrl zu veranlassen, daß ein Ermittlungsverfahren gegen Unbekannt unterblieb. ${ }^{3}$ Obwohl sich derartige Aktionen bei einem ausgebauten KZ-System später weniger umständ-

\footnotetext{
54 Vgl. vorläuf. Niederschr. v. 21.9.42 der zwischen RFSS u. RJM Thierack am 18.9.42 erörterten Punkte (a.a.O.) u. erste Reaktion des „Schwarzen Korps“ im Artikel: Das starke Recht (29.10.42, S.4).

1 Vgl. dazu Kap. VI.4.a., S. $634 \mathrm{ff}$.

2 Vgl. z.B. die Erschießung eines Arbeitszwangsgefangenen „auf der Flucht“ im KZ Dachau am 1.3.37 (Diensttageb. des RJM, Bd.10, Eintr. v. 24.3.37, BA, Sign. R 22/706).

${ }_{3}$ Vgl. Diensttageb. des RJM, Bd. 1, Eintr. v. 14.11.34 (BA, Sign. R 22/131).
} 
lich erledigen ließen, mußte es vom Standpunkt der SS- und Polizeiführung aus erstrebenswert bleiben, die lästige Notwendigkeit einer Rechtfertigung von Tötungen durch vorgeschobene Gründe gegenüber der Justiz loszuwerden und für besondere Fälle zur Exekution ermächtigt zu werden. Darauf mußte sie allerdings warten, bis das NS-Regime mit dem Ausbruch des Krieges in eine neue Phase der Radikalisierung eintrat. Am 25. Mai 1939 brachte das Organ der Reichsführung-SS, das „Schwarze Korps“, einen groß aufgemachten Bericht über die Erschießung eines mehrerer Sittlichkeitsdelikte beschuldigten Priesters in Bolivien, die ohne Gerichtsverfahren auf Befehl des bolivianischen Staatspräsidenten erfolgt war. Das Blatt kommentierte diese Tatsache mit dem Ausruf: „Bolivien, du hast es besser!“ und setzte hinzu, solange in Deutschland nach Gesetzen verfahren werde, die aus der liberalistischen Ära stammten, nütze es „nur wenig, daß die Rechtsauffassung des [bolivianischen] Staatspräsidenten Busch unserem Empfinden weitaus näher steht. Aber was nicht ist, kann noch werden “ (!). ${ }^{4}$ Nur drei Monate später sollte es tatsächlich auch in Deutschland soweit sein: der als "völkischer Ausnahmezustand"s angesehene Krieg verhalf der Gestapoführung zu der lang ersehnten Vollmacht, nun mehr oder weniger unverhüllt exekutieren zu dürfen.

Bevor Hitler am 3. September 1939 nach Polen an die Front fuhr, wies er Himmler an, die Ordnung im Innern „mit allen Mitteln“ aufrechtzuerhalten. ${ }^{6}$ Aufgrund dieser Weisung gab Heydrich als Chef der Sicherheitspolizei an die Dienststellen der Gestapo einen geheimen Runderlaß über „Grundsätze der inneren Staatssicherung während des Krieges“ heraus. Danach war ,jeder Versuch, die Geschlossenheit und den Kampfwillen des deutschen Volkes zu zersetzen, ... rücksichtslos zu unterdrücken“". Personen, die sich in dieser Hinsicht vergingen, waren sofort festzunehmen; nach eingehenden Ermittlungen über ihre Einstellung und Beweggründe war unverzüglich an den Chef der Sicherheitspolizei zu berichten, „da gegebenenfalls auf höhere Weisung brutale Liquidierung solcher Elemente erfolgen" werde. ${ }^{7}$ In einem Durchführungserlaß präzisierte Heydrich, daß die Betreffenden in Fällen, „die hinsichtlich ihrer Verwerflichkeit, ihrer Gefährlichkeit oder ihrer propagandistischen Auswirkung“ hervorstächen, „ohne Ansehung der Personen durch rücksichtslosestes Vorgehen (nämlich durch Exekution) ausgemerzt" werden sollten. Als Beispiel für solche Fälle wurden „Sabotageversuche, Aufwiegelung oder Zersetzung von Heeresangehörigen [sic] oder eines größeren Personenkreises, Hamsterei in großen Mengen, aktive kommunistische oder marxistische Betätigung usw." genannt. Halte eine Staatspolizeistelle aus solchen Gründen die „Sonderbehandlung“, d.h. die Exekution, für angebracht, habe sie „sofort Schutzhaft zu verhängen und schnellstens (Blitz-FS) anher zu berichten“. Um eine Einschaltung der Justiz von vornherein zu verhindern, sollten die Kreis- und Ortspolizeibehörden angewiesen werden, solche Fälle sofort der zuständigen Staatspolizeistelle zu melden, damit durch deren Anordnung „die Überstellung der festgenommenen

4 Ohne Verfahren erschossen! (Das Schwarze Korps, Folge 21 v. 25.5.39, S. 1).

5 So treffend M. Broszat in der Dokumentation: Zur Perversion der Strafjustiz im Dritten Reich (VfZ 1958 , S. 390 ff.), in der die im folgenden erwähnten Nürnbg. Dok. NG-190, NG-287, NG-540, NG-3278, NO-905, NO-2263 u. PS-3813 im Wortlaut abgedruckt sind.

6 Vgl. dazu Anm. 12 u. 14.

7 Geh.RdErl. des Chefs der Sipo (Heydrich) v. 3.9.39 an die Leiter aller Stapo(leit)stellen, nachrichtl. an die HSSPF, IdS u.a. (Arch. des IfZ, Sign. Fa 183/1). 
Personen an den Ermittlungsrichter bis zum Eintreffen der Endentscheidung vermieden wird" (!). ${ }^{8}$ Aus internen Richtlinien des Geheimen Staatspolizeiamtes, die die Zuständigkeiten bei der Bearbeitung der eingegangenen Berichte betr. „Sonderbehandlung" regelten, geht hervor, daß die Vorschläge für Exekutionen Himmler persönlich zu unterbreiten waren. ${ }^{9}$ Bei Genehmigung sollten sie „im nächstliegenden $\mathrm{KL}^{\text {“ durch- }}$ geführt werden. ${ }^{10}$

Das Reichsjustizministerium erfuhr die neue Praxis der Gestapo - die ihre geheimen Anordnungen sofort in die Tat umsetzte - bezeichnenderweise nur durch Meldungen in der Presse. Am 8. September wurde in den Zeitungen folgende DNB-Meldung vom Vortage veröffentlicht:

„Der Reichsführer SS und Chef der Deutschen Polizei teilt mit, daß wegen Verweigerung der Mitarbeit an Sicherungsschutzaufgaben für die Landesverteidigung Johann Heinen, Dessau, am 7. September 1939 erschossen worden ist. Heinen war außerdem ein wegen Diebstahls vorbestrafter Verbrecher. ${ }^{\text {"11 }}$

Noch am selben Tag fragte das Justizministerium wegen dieses Vorgangs bei der Polizeiführung an und erhielt von SS-Brigadeführer Best die Auskunft, die Hinrichtung beruhe auf einer Anordnung Hitlers, der den Reichsführer-SS beauftragt habe, „mit allen Mitteln die Sicherheit im Reichsgebiet aufrechtzuerhalten, und dieser Auftrag schließe bei Handlungen gegen die Kriegsgesetze auch die sofortige Exekution“ ein. Das Ersuchen des Ministeriums, über Hitlers Anordnung genauer unterrichtet zu werden, wurde von Heydrich mit dem Rat beantwortet, „der Justizminister möge sich wegen der Erschießungen unmittelbar mit dem Führer in Verbindung setzen ". ${ }^{12}$

Nur diese recht unbefriedigende Auskunft konnte das Reichsministerium am Abend des 9. September der Rechtsabteilung des OKH erteilen, die sich aufgrund der Pressemeldung im Auftrag des Generalquartiermeisters telefonisch an das Ministerium gewandt hatte. Das OKH war hinsichtlich Himmlers Polizeimethoden in diesen Tagen besonders hellhörig, weil sich gerade die Auseinandersetzung mit der Sicherheitspolizei über die vollziehende Gewalt im rückwärtigen Frontgebiet in Polen entspann. ${ }^{13}$ Der Generalquartiermeister war der Ansicht, daß eine derartige Pressemeldung „nach Willkür aussieht, aber nicht nach Recht“, und daß in solchen Fällen eine Meldung über die Verurteilung durch ein Sondergericht und die sofortige Vollstrekkung des Todesurteils wesentlich wirksamer sei; im übrigen sei „die Vollstreckung der Todesstrafe durch Erschießen ein Vorrecht der Feldkriegsgerichte“. Noch am selben

8 FS des Chefs der Sipo (Heydrich) v. 20.9.39 an die Stapo(leit)stellen, nachrichtl. an die IdS (Nürnbg. Dok. NO-2263).

9 Verm. v. 26.9.39 über die in der Ref.Bespr. vom Leiter der Abt.II des Gestapa gegebenen Richtlinien (Nürnbg. Dok. NO-905). Über die anfangs noch erforderliche Zustimmung Hitlers vgl. das folgende.

10 Vgl. Kommandant in Auschwitz. Autobiographische Aufzeichnungen von Rudolf Höß. Eingel. u. komment. v. M. Broszat, Stuttgart 1961, S.70. Höß spricht in diesem Zusammenhang von einem regelrechten "geheimen Mobilmachungs-Befehl“".

"Vgl. u. a. VB, Münchener Ausg. v. 8.9.39, S. 2, unter der Überschrift: „Ein Saboteur der Landesverteidigung erschossen." Wie die Nachforschungen des RJM später ergaben, hatte sich $\mathrm{H}$. an einem Fliegerunterstand mitzuarbeiten geweigert mit der Begründung, daß er staatenlos sei. $\mathrm{H}$. wurde im $\mathrm{KZ}$ Sachsenhausen erschossen; die Exekution leitete der damalige Adjutant u. Führer des Kommandanturstabes, der spätere Kommandant von Auschwitz, Rudolf Höß (vgl. Kommandant in Auschwitz, a.a.O., S.69f.).

12 Vgl. Aufz. Gürtners v. 28.9.39 (Akten des RJM, BA, Sign. R 22/5019, auch als Nürnbg. Dok. NG-190 u. PS-3813 vorhanden).

13 Vgl. dazu K.-J. Müller, Das Heer und Hitler. Armee und nationalsozialistisches Regime 1933-1940, Stuttgart 1969, S. $426 \mathrm{ff}$. 
Tage unterbreitete der Chef der Wehrmachtrechtsabteilung anläßlich einer Sitzung des Reichsverteidigungsausschusses Göring den Vorgang, und obwohl Heydrich anschließend auch hier die Auffassung vertrat, „der Reichsführer SS sei befugt, in derartigen Fällen Deutsche ohne weiteres erschießen zu lassen“, erklärte Göring, „daß Todesstrafen niemals ohne Urteil vollstreckt werden könnten “. ${ }^{14}$ Diese Kontroverse mußte den Verdacht erregen, daß Himmler und Heydrich eine allgemein gehaltene Vollmacht Hitlers in ihrem Sinne ausgelegt und erweitert hatten.

Das Reichsjustizministerium mußte jedenfalls durch die Ausübung einer offenen „Polizeijustiz“, die eigenmächtig Todesurteile verhängte und deren Vollstreckung öffentlich verkündete, die Grundlagen der Rechtspflege bedroht sehen. Die Beunruhigung in der Justiz über diese Vorgänge war allgemein. ${ }^{15}$ Nachdem in der Presse Meldungen über zwei weitere polizeiliche Exekutionen - über eine Erschießung am 11. September "wegen vorsätzlicher Brandstiftung und Sabotage" und über die ErschieBung eines Bibelforschers am 15. September wegen Wehrdienstverweigerung - erschienen waren, trat Gürtner über den Chef der Reichskanzlei an Hitler heran, um eine Klärung zu erreichen. „Wenn die Unterrichtung des Justizministeriums richtig“ sei, führte er in seiner Aufzeichnung für Lammers aus, bestehe ,jetzt im nichtbesetzten Gebiet des Reiches, also außerhalb des Kampf- und Operationsgebiets, eine konkurrierende Zuständigkeit zwischen dem Volksgerichtshof, den Kriegsgerichten und Sondergerichten einerseits und der Polizei andererseits für die Ahndung von Kriegsverbrechen“. Dabei sei gegenwärtig völlig ungeklärt - d.h. der Entscheidung der Gestapo überlassen -, „nach welchen Gesichtspunkten ... diese Konkurrenz im einzelnen Falle entschieden werden" solle. Um zu demonstrieren, daß außerordentliche Polizeimaßnahmen im nichtbesetzten (Heimat-)Gebiet überflüssig seien, wies er darauf hin, daß dort sichere Zustände herrschten und „keine Behörde in ihrer Wirksamkeit gehindert oder gestört" werde. Die bestehenden Zuständigkeits- und Verfahrensregelungen einschließlich der seit Kriegsbeginn in Kraft getretenen Neuerungen ${ }^{16}$ ermöglichten den Sondergerichten ein derart beschleunigtes Verfahren, daß es "praktisch dem der Standgerichte völlig gleich kommt“; sie seien „nur nicht als Standgerichte bezeichnet worden". In der Tat entsprach das Verfahren bei den Sondergerichten, das keine gerichtliche Voruntersuchung, kein Eröffnungsverfahren, eine Ladungsfrist von 24 Stunden, sofortige Rechtskraft und Vollstreckbarkeit des Urteils vorsah, sachlich dem von Standgerichten. ${ }^{17}$ Als Beispiel für das energische Vorgehen der Sondergerichte führte Gürtner einen ähnlichen Fall von Brandstiftung und Sabotage an, wie ihn

14 Zum Voranstehenden vgl. die beiden Aktenverm. des Leiters der Gruppe III (Rechtswesen) beim OKH v. 9.9.39 (Arch. d. IfZ, Sign. MA-261).

15 So bat z. B. der Vizepräs. des VGH Engert einen Offizier der Abwehr - Abt. III im OKW - zu sich und eröffnete ihm, die Erschießung des Dessauer Arbeiters H. könne sich „als verhängnisvolle Maßnahme erweisen. Die Wehrmacht dürfte nicht dulden, daß in die Gerechtsame der Justiz und der obersten Gerichte eingegriffen werde“ (vgl. H. Groscurth, Tagebücher eines Abwehroffiziers 1938-1940, herausg. v. H. Krausnick u. H. C. Deutsch, Stuttgart 1970, S.364, Vortragsnotiz [ca. 23.9.39]).

16 Insbesondere $\S 5$ der VO gegen Volksschädlinge v. 5.9.39 (RGBI. I, S. 1679). Über Zuständigkeit u. Verfahren der SGe vgl. Kap. VIII.1.b., S. $946 \mathrm{ff}$.

17 Am 20.11.38 war Hitlers Befehl vom Vortage, für „Gangsterverbrechen“ (Raubüberfälle auf Kraftwagen) ein standgerichtliches Verfahren einzuführen, kurz nach der Unterzeichnung der VO über die Erweiterung der Zuständigkeit der Sondergerichte (RGBI. I, S. 1632) durch Gürtner und Frick im RJM eingegangen. Daraufhin hatte Gürtner bereits in seinem Schr. an Hitler v. 20.11.38 ausgeführt, daß diese VO dem Befehl voll gerecht werde: „Nur die Bezeichnung ,Standgericht' habe ich vermieden, weil sich damit Vorstellungen von Kriegs- oder Ausnahmezustand verbinden“ (Akten des RK, BA, Sign. R 43 II/1553a). 
laut Pressemeldung die Polizei durch Erschießen geahndet hatte: ein Bauer in Obersleben bei Weimar, der in der Nacht zum 18. September seinen Getreidespeicher angezündet und dadurch 100 Zentner Getreide vernichtet hatte, sei noch an diesem Tage vom Sondergericht zum Tode verurteilt worden. Am Schluß seiner Aufzeichnung betonte Gürtner, er halte „eine allgemeine Klärung der Frage, ob Verbrechen im nichtbesetzten Gebiet nach den Kriegsgesetzen oder von der Polizei ohne Verfahren und Urteil zu ahnden“ seien, „für dringend geboten“. Die Aufzeichnung übergab er noch am Tage ihrer Niederschrift, am 28. September, Lammers. ${ }^{18}$

In der Reichskanzlei wurde Gürtners Schritt von Ministerialdirektor Kritzinger unterstützt, der bis Anfang 1938 Referent für staatsrechtliche Fragen im Reichsjustizministerium gewesen war und die langjährige Auseinandersetzung der Justiz mit der Gestapo aus eigener Anschauung kannte: um die Schlagkraft der Sondergerichte bei der Aburteilung jener Straftaten zu unterstreichen, „die mit dem Kriege in unmittelbarem Zusammenhang“ standen, stellte Kritzinger in einem Vermerk die gesetzlichen Maßnahmen zusammen, die zur Stärkung ihrer Effektivität getroffen worden waren, und erläuterte sie. ${ }^{19}$ Beide Aufzeichnungen trug Lammers am 13. Oktober Hitler in Berlin vor. Am nächsten Vormittag besuchte er Gürtner im Auftrag Hitlers und teilte ihm das Ergebnis der Unterredung mit: Hitler habe erklärt, „eine allgemeine Anweisung habe er nicht gegeben. Die 3 Erschießungen habe er angeordnet. Er könne im Einzelfall auch darauf nicht verzichten, weil die Gerichte (Militär- und Civil-) den besonderen Verhältnissen des Krieges sich nicht gewachsen zeigten“. ${ }^{20}$

Gegenüber Lammers und Gürtner hielt Hitler somit daran fest, daß er Himmler keine generelle Vollmacht zur Strafverfolgung durch Exekutionen in eigener Regie gegeben habe, sondern sich dafür selbst die letzte Entscheidung vorbehalte - wobei durchaus möglich ist, daß er die drei nun einmal erfolgten Erschießungen nachträglich „übernommen“ hatte. Dennoch sollte die Polizei nur ein knappes halbes Jahr später - auch für das Reichsgebiet - in dieser Hinsicht eine allgemeine Ermächtigung gegenüber polnischen Zivilarbeitern und im weiteren Verlauf auch gegenüber sowjetrussischen Arbeitern und Juden erlangen. ${ }^{21} \mathrm{Ob}$ jedoch die Polizeiführung bei ihren auch in den folgenden Monaten nachweisbaren verfahrenslosen Exekutionen von Reichsdeutschen tatsächlich jedesmal die Entscheidung Hitlers einholte ${ }^{22}$, ist fraglich. Aber abgesehen von dieser Frage verdeutlichte Hitlers Mitteilung an Gürtner erneut, daß sich der Führerwille auch dann ungehindert über bestehende Gesetze hinwegsetzen konnte, wenn es sich um das Leben eines Volksgenossen handelte. Noch in der erwähnten Unterredung teilte Lammers dem Justizminister mit, daß Hitler nunmehr auch die Erschießung der am Vortage vom Sondergericht Berlin verurteilten „Teltower Bankräuber" befohlen habe. Es handelte sich um zwei Täter, die mit je zehn Jah-

18 Vgl. Aufz. Gürtners v. 28.9.39 mit Übergabeverm. (a.a.O., Anm.12).

19 Verm. Kritzingers v. 9.10.39 (Nürnbg. Dok. PS-3813).

20 Vgl. handschriftl. Verm. Gürtners v. 14.10.39 (a.a.O., Anm. 12).

21 Vgl. dazu das folgende u. Kap. VI.6.b., S.689ff.

22 Es geschah regelmäßig dann, wenn die Exekution eines Reichsdeutschen zur Korrektur eines Gerichtsurteils erfolgte, d.h. der Betroffene aus Justizgewahrsam geholt werden mußte (vgl. dazu das folgende). Bei Exekutionen, die unter völliger Ausschaltung der Justiz stattfanden, genügte im Kriege die Entscheidung Himmlers, der sie Anfang November 1944 für "Fremdvölkische“ im Reichsgebiet sogar auf den Chef der Sipo im RSHA delegierte (Befehl Himmlers v. 1.11.44 in der Sammlung der Zentralen Stelle Ludwigsburg, s. G. Kimmel, Das Konzentrationslager Dachau, in: Bayern in der NS-Zeit, Bd. II, herausg. v. M. Broszat u.

E. Fröhlich, München 1979, S.378, Anm.127). 
ren Zuchthaus bestraft worden waren, weil sie Ende September versucht hatten, die Kreissparkasse in Berlin-Teltow zu berauben, und dabei einen verfolgenden Sparkassenangestellten durch Schüsse verletzt hatten. Lammers unterrichtete Gürtner davon, daß sich Himmler deshalb ,noch heute “ an den Justizminister wenden werde. ${ }^{23}$

Während bei den vorangegangenen Exekutionen kein Richterspruch vorgelegen hatte, d.h. die Justiz völlig ausgeschaltet geblieben war, sollten nunmehr zwei rechtskräftig zu Freiheitsstrafen Verurteilte eben wegen der abgeurteilten Tat erschossen werden. Empfand die Justiz schon eine Verhängung von Schutzhaft nach einem Freispruch oder nach der Strafverbüßung in politisch gefärbten Fällen als korrigierenden Eingriff ${ }^{24}$, so mußte sie sich durch diese unmittelbare und massive Korrektur eines rechtskräftigen Urteils gegen rein kriminelle Täter brüskiert fühlen. Den Richtern mußte ihre - theoretisch „kraft Auftrag des Führers“ ausgeübte - Tätigkeit sinnlos erscheinen, wenn ihre Entscheidungen jederzeit mit Hilfe der Polizei umgestoßen werden konnten, und die ständig drohende Möglichkeit einer solchen Korrektur mußte schließlich die Unabhängigkeit der Rechtspflege gefährden. Viel stärker als durch die Schutzhaftpraxis mußte auch in der Öffentlichkeit der Eindruck entstehen, daß die staatlichen Organe gegeneinander arbeiteten, mußten Autorität des Richterspruchs und Rechtssicherheit erschüttert werden.

Im Nürnberger Juristenprozeß sagte Schlegelberger 1947 aus, „daß diese Entscheidung Hitlers wohl das schwerste war, was ... Gürtner im Amte erlebt hat ${ }^{\text {“ }}{ }^{25}$ Nun hatte Gürtner in seiner damals bereits über sechseinhalbjährigen Amtszeit unter Hitler schon einiges erlebt, das seiner Vorstellung von Justiz sicher nicht entsprach; dennoch dürfte die Beurteilung nicht falsch sein, daß dieses verfahrenslose Umstoßen eines rechtskräftigen Gerichtsurteils in derart massiver Form den Nerv seines juristischen Denken traf. Jedenfalls sah er die Situation als so ernst an, daß er sich nunmehr mit einem Brief direkt an Hitler wandte, um Himmler zuvorzukommen. Darin bat er, gegen das Urteil des Sondergerichts gegen die beiden Sparkassenräuber den vier Wochen vorher eingeführten ,außerordentlichen Einspruch“ einlegen zu dürfen: bei der gegenwärtigen Gesetzeslage werde die neue Verhandlung vor dem besonderen Senat des Reichsgerichts „nach menschlichem Ermessen dazu führen, daß die beiden Bankräuber zu Sicherheitsverwahrung verurteilt werden " würden. ${ }^{26}$ Es war der verzweifelte Versuch, die gewünschte Korrektur wenigstens im Rahmen justizmäßigen Verfahrens und des rechtlich noch Möglichen zu halten. Daß aber Gürtner trotz seiner Bedenken stets kapitulierte und gehorchte, wenn seine Gegenvorstellungen erfolglos blieben und ein Führerentscheid vorlag, sollte sich an jenem 14. Oktober abermals erweisen. Die Ereignisse am Abend jenes Tages werden durch eine handschriftliche Notiz Gürtners anschaulich wiedergegeben, die er zur Unterrichtung Freislers und Crohnes, des Lei-

23 Handschriftl. Verm. Gürtners v. 14.10 .39 (a.a.O., Anm. 12).

24 Vgl. dazu Kap. VI.3.b., S. 599 ff., VI.3.d., S. 612 ff., 623 ff.

25 Zeugenaussage Schlegelbergers v. 30.6.47 im Juristenprozeß vor dem amerikanischen Militärgerichtshof III in Nürnberg. Protokoll (d), S. 4395.

26 Schr. Gürtners an Hitler v. 14.10.39 (Akten der Reichskanzlei, BA, Sign. R 43 II/1513 a). Um jeder Person - wie z. B. dem Bankkassierer - bei der Verfolgung von Verbrechern den gleichen strafrechtlichen Schutz zu gewähren wie Polizei-, Justizbeamten oder Mitgliedern von NSDAP-Gliederungen (nach § 1 des G. zur Gewährleistung des Rechtsfriedens v. 13.10.33, RGBI. I, S.723 wäre dann Todesstrafe zulässig gewesen), schlug Gürtner in dem Schr. die Einbringung eines entspr. Gesetzentwurfs - die spätere GewaltverbrecherVO - vor. 
ters der Strafrechtspflegeabteilung, anfertigte, und die zugleich Bemerkenswertes über den Regierungsstil im Dritten Reich aussagt:

„20h Anruf Himmler: der Führer habe ihm soeben den Befehl gegeben, die beiden Täter (Teltow) heute noch erschießen zu lassen. Ich fragte, ob der Führer meinen Brief schon bekommen habe. Himmler meinte, daß dies der Fall sei. Ich bat ihn, sich dessen beim Führer selbst zu vergewissern $u$. teilte ihm den Inhalt des Briefes mit. Himmler sagte das zu.

20h20' Anruf Himmler: Er habe den Führer befragt. Der Führer habe meinen Brief noch nicht bekommen. Himmler habe ihn über den Inhalt unterrichtet. Der Führer erwiderte: das sei alles gut, aber die beiden Täter müßten heute noch erschossen werden. Er (Himmler) bitte um sofortige Überstellung ,zu einer Vernehmung.

Weiter teilte Himmler folgendes mit. Der Führer habe von einem Münchener Fall gelesen ${ }^{27}$, in dem ebenfalls $10 \mathrm{~J}$. Zuchthaus ausgesprochen worden seien wegen eines Raubes, in der Dunkelheit begangen. Auch dieser Täter müsse erschossen werden. (Name und näherer Sachverhalt nicht bekannt.)

Die Überstellung der beiden Berliner Täter wurde veranlaßt.“" ${ }^{“ 28}$

Die beiden Berliner Sparkassenräuber wurden noch in der Nacht erschossen. Mit Rücksicht auf die Justiz wurde die Pressemeldung so formuliert, daß die Exekution nicht als Korrektur des Gerichtsurteils in Erscheinung trat; sie lautete, die Verurteilten „versuchten bei ihrer Überführung in die Strafanstalt erneut, tätlich Widerstand zu leisten. Die beiden Verbrecher wurden sofort erschossen“. ${ }^{29}$ Bei dem weiteren Opfer, dessen Herausgabe Himmler im Auftrag Hitlers gefordert hatte, handelte es sich um einen vom Sondergericht München am 6. Oktober aufgrund $\S 2$ der Volksschädlingsverordnung $^{30} \mathrm{zu}$ zehn Jahren Zuchthaus verurteilten Täter, der einem Mädchen unter Ausnutzung der Verdunkelung die Handtasche unter dem Arm weggerissen und dabei etwas über vier Mark erbeutet hatte. Er wurde am 16. Oktober erschossen ${ }^{31}$, laut Pressemeldung bei einem Fluchtversuch.

Während die Exekutionen aufgrund der Entscheidung der obersten Führung anliefen, versuchten die nachgeordneten Polizeibehörden, im Sinne des erwähnten Runderlasses Heydrichs vom 3. September auf ihre Weise aktiv zu werden. Der Höhere SSund Polizeiführer für die Wehrkreise München und Nürnberg wandte sich am 25. Oktober mit einem ausgefallenen Vorschlag an den Generalstaatsanwalt Nürnberg: Da die Staatsanwaltschaft bei verschiedenen Prozessen vor dem Sondergericht mangels gesetzlicher Handhabe nicht die Todesstrafe habe beantragen können, „die in Anbetracht des gegenwärtigen Kriegszustandes das gesunde Volksempfinden“ an sich gefordert hätte, halte er es

„für notwendig, daß vor Erhebung der öffentlichen Anklage die Staatsanwaltschaft mit mir die Frage der Exekution erörtert, falls sie zu der Auffassung gelangt ist, die maßgeblichen gesetzlichen Bestimmungen gestatten nicht eine vom Volk geforderte Todesstrafe“.

27 Offensichtl. in der Münchener Ausg. des VB v. 14.10.39, S. 10.

28 Handschriftl. Aufzeichn. Gürtners v. 14.10.39 (Akten des RJM, BA, Sign. R 22/5019).

29 Ausschnitt aus dem VB [Berliner Ausg.] Nr. 289 v. 16.10.39, S.6, in den Akten des RJM (a.a.O.). In der Süddt. Ausg. wurde die Meldung nicht gebracht.

30 § 2 der VO gegen Volksschädlinge v. 5.9.39 (RGBl. I, S. 1679) lautete: „Wer unter Ausnutzung der zur Abwehr von Fliegergefahr getroffenen Maßnahmen [u.a. Verdunkelung] ein Verbrechen oder Vergehen gegen Leib, Leben oder Eigentum begeht, wird mit Zuchthaus bis zu 15 Jahren oder mit lebenslangem Zuchthaus, in besonders schweren Fällen mit dem Tode bestraft."

31 Handschriftl. Verm. Gürtners v. 23.10.39 (Akten des RJM, a.a.O.). Die schriftl. Benachrichtigung über Hitlers Exekutionsbefehl erfolgte durch den RFSS „versehentlich“ erst am 29.11.39. 
Nur auf diese Weise lasse sich die von der Justiz als belastend empfundene nachträgliche Korrektur durch Exekution vermeiden. Er bat daher, in allen derartigen Fällen mit ihm in Verbindung zu treten. ${ }^{32}$ Der Vorschlag bedeutete nichts weniger, als daß die Justiz nunmehr selbst ihre Hand dazu leihen sollte, die Vorentscheidung für die Exekution durch die Polizei zu treffen. Der Generalstaatsanwalt berichtete daher auch an Gürtner, daß er nicht beabsichtige, ,in die gewünschte Erörterung über die Frage der Exekution einzutreten oder die Oberstaatsanwälte meines Bezirks entsprechend anzuweisen". ${ }^{33}$ Er bekam vom Justizminister den Auftrag, dem Höheren SSund Polizeiführer zu antworten, daß die Anregung ,nicht mit der Gesetzeslage in Einklang" stehe und derartige Erörterungen „die Zuständigkeit einer Provinzialbehörde“ bei weitem überschritten. Nachdem die Strafbestimmungen weitgehend verschärft worden seien, würden im übrigen derartige Fälle kaum mehr auftreten. ${ }^{34}$ Den Gestapobehörden blieb daher auch weiterhin nur übrig, zur "Sonderbehandlung“ vorgeschlagene Fälle von vornherein der Justiz fernzuhalten oder nach dem richterlichen Urteilsspruch tätig $\mathrm{zu}$ werden.

Vom Tage des Kriegsbeginns bis zum 20. Januar 1940 registrierte das Reichsjustizministerium 18 Exekutionen $^{35}$, von denen die Hälfte ohne vorherige Einschaltung der Justiz erfolgt war, während die anderen Urteilskorrekturen darstellten. Von den ersteren neun Exekutionen erfuhr das Ministerium sieben Fälle nur durch Zeitungsmeldungen, zwei Fälle nachträglich durch Schnellbrief des Reichsführers-SS. Bei diesen beiden handelte es sich um vorbestrafte Schutzhäftlinge, die im Konzentrationslager Mauthausen angeblich „nach einem vorgefaßten Plan“ einen SS-Wachposten niedergeschlagen hatten, auf der Flucht festgenommen und „am 9. Dezember im Konzentrationslager erhängt" worden waren. ${ }^{36}$ Von den anderen ohne Gerichtsverfahren Getöteten wurde einer beschuldigt, sich in Marineoffiziersuniform als Angehöriger eines siegreichen U-Bootes ausgegeben und zahlreiche Schwindeleien verübt zu haben, einer sollte die Arbeit in einem kriegswichtigen Betrieb verweigert, einer ein Sittlichkeitsverbrechen an einer Halbjüdin verübt und ein weiterer - ein Jude - sich gewaltsam an einem „arischen“ Mädchen vergangen haben. Die Begründungen für die restlichen drei Erschießungen dieser Art wurden schon erwähnt. Während die Staatsanwaltschaft über die ersten verfahrens- und gesetzlosen Erschießungen im September deshalb keine Ermittlungen anstellte, da sie von Hitler befohlen bzw. gedeckt wurden, war sie bei den weiteren - Anfang November beginnenden - Exekutionen dieses Dilemmas bereits dadurch enthoben, daß die am 27. Oktober eingeführte SS- und Polizeigerichtsbarkeit der Justiz die Zuständigkeit für Straftaten u. a. der Wachmannschaften in den Konzentrationslagern entzogen hatte. Damit war der Justiz aber auch die

32 Schr. des HSSPF in den Wehrkreisen VII u. XIII an den GStA Nürnberg v. 25.10.39 (Akten des RJM, BA, Sign. R 22/5020).

33 Der Ber. des GStA Nürnberg v. 7.11.39 ging unter geh. u. persönlich an den Dir. des Min.Büros Gürtners (a.a.O.).

34 Schr. des RJM (I.A. Crohne) an den GStA Nürnberg v. 25.11.39 (a.a.O.).

35 Zum folgenden vgl. die Aufstellung in den Akten des RJM (BA, Sign. R 22/5019, auch als Nürnbg. Dok. NG-190 vorhanden).

${ }^{36}$ Kriegsgebiet KZ (Das Schwarze Korps v. 21.12.39, S.9f.). Die Nachricht wurde zum Anlaß genommen, der Bevölkerung darzulegen, daß die SS-Wachmannschaften an der „inneren Front “ genauso eine gefährliche und wichtige Aufgabe erfülten wie die Frontsoldaten. 
Möglichkeit einer Kontrolle darüber genommen worden, ob die Exekutionen im Einzelfall auf Weisung Hitlers oder in eigener Regie der SS- und Polizeiführung erfolgten.

Den neun Erschießungen, die bis zum 20. Januar 1940 als Urteilskorrekturen vorgenommen wurden, lag hingegen stets eine ausdrückliche Anordnung Hitlers zu Grunde. ${ }^{37}$ Wie bereits erwähnt, wurde Hitlers Weisung einer Überstellung an die Gestapo in den ersten drei Fällen Gürtner mündlich durch Lammers bzw. telefonisch durch Himmler übermittelt; im nächsten Fall erfolgte die Übermittlung durch ein Schreiben Bormanns vom 25. Oktober 1939. Es handelte sich um einen Juden, der zwei Tage zuvor vom Sondergericht Berlin wegen Sittlichkeitsverbrechens in Tateinheit mit „Rassenschande“ zu sechs Jahren Zuchthaus verurteilt worden war und noch am 25. Oktober erschossen wurde. Von der Korrektur eines weiteren Urteils durch Exekution am 18. November erfuhr das Justizministerium zuerst durch die Presse. Betroffen war ein fast 18jähriger Schlosserlehrling, der am Vortage vom Sondergericht Berlin zu zehn Jahren Gefängnis verurteilt worden war, sich aber offenbar zur Einlieferung in die Strafanstalt noch in Polizeigewahrsam befunden hatte. Er hatte im Laufe des Sommers in der Nähe von Potsdam aus Geltungsbedürfnis mehrere Brände gelegt, „um hinterher als besonders tüchtiger Feuerwehrmann glänzen zu können“. Der gerichtsärztliche Gutachter hatte festgestellt, daß der Täter sich noch in der Pubertät befand und auf der Entwicklungsstufe eines Sechzehneinhalbjährigen stand. Als SSBrigadeführer Müller vom Geheimen Staatspolizeiamt dem Ministerium Hitlers Anordnung nachträglich mitteilte, behauptete er, Hitler habe sie ,in Kenntnis des ärztlichen Gutachtens getroffen“, er habe aber geäußert, „es sei sinnlos, einen derart gemeingefährlichen Menschen für weitere Schandtaten aufzusparen“ ${ }^{38}{ }^{38}$ Einen weiteren Überstellungsbefehl Hitlers bekam das Justizministerium am 1. Dezember über Himmler vom Reichskriminalpolizeiamt; in diesem Falle war der Täter von der Strafkammer Naumburg am 25. Oktober wegen Straßenraubs und versuchter Notzucht zu zehn Jahren Zuchthaus verurteilt worden. Die nächsten drei Anordnungen übermittelte Hitlers persönlicher Adjutant SS-Gruppenführer Schaub telefonisch dem Verbindungsmann des Ministeriums zur Gestapo, Oberstaatsanwalt und SS-Hauptsturmführer Joë ${ }^{39}$, und bestätigte sie nachträglich schriftlich. Im ersten Falle handelte es sich um einen Mann, der Angehörige von in Polen gefallenen Soldaten aufgesucht und ihnen aus Briefen - die angeblich von seinem an der Ostfront stehenden Neffen, in Wahrheit jedoch von ihm selbst geschrieben waren - über nähere Umstände beim Tod berichtet hatte; dafür hatte er „Fahrkosten und sonstige Auslagen“ erbeten und erhalten. Er war dafür vom Sondergericht Breslau strafverschärfend wegen „Ausnutzung des Kriegszustandes“ ( $\$ 4$ der Volksschädlingsverordnung) zu fünfzehn Jahren Zuchthaus verurteilt worden. Er wurde am 21. Dezember erschossen. Der zweite Fall betraf einen neunzehnjährigen Postfacharbeiter, der einen dreieinhalbjährigen Knaben unter Verabreichung einer Ohrfeige mit sich genommen hatte, um sich an ihm sexuell

37 Vgl. die Rede des Chefs des Amtes III im RSHA, SS-Brigadef. Ohlendorf, vor dem SD am 27.7.42 (VfZ 1956, S. $416 \mathrm{f}$.): „Es ist festzustellen, daß diese Erschießungen [zur Korrektur unzulänglicher Strafurteile] in jedem Fall durch einen Führerbefehl ausgelöst werden, daß es sich hierbei also nicht etwa um sogenannte ,Willkürakte“ der SS handelt."

${ }^{38}$ Verm. Crohnes v. 7.3.41 (Akten des RJM, a.a.O.).

39 Nach Auflösung der ZStAschaft (vgl. Kap. IV.2.b., S.367) wurde OStA Joël im Dezember 1937 zum Verbindungsmann des RJM zur SS einschl. SD und zur Gestapo bestellt, mit Wirkung v. 30.1.38 in die SS aufgenommen u. sofort zum Untersturmf. befördert (vgl. Nürnbg. Dok. NG-587 u. 747). 
zu vergehen; die Ausführung der Tat wurde durch das Auftreten der Mutter des Kindes verhindert. Da sich der Jugendliche schon einmal als Sechzehnjähriger in ähnlicher Weise strafbar gemacht hatte, wurde er vom Landgericht München I am 5. Januar 1940 wegen Vergehens der Nötigung in Tateinheit mit dem Vergehen der Körperverletzung zu einer Gefängnisstrafe von sechs Monaten verurteilt. Durch eine Meldung in den „Münchner Neuesten Nachrichten“ vom folgenden Tag auf das Urteil aufmerksam geworden, sandte Heydrich einen eingehenden Bericht an Schaub mit der „Bitte um telef. Mitteilung d. Führerentscheidung ". ${ }^{40}$ Als sich Schaub deswegen mit Joël in Verbindung setzte, wollte Gürtner diesmal das Feld nicht widerstandslos räumen: er ließ Schaub nähere Ausführungen zu dem Fall übersenden, die er glaubte „dem Führer zur Kenntnis bringen zu müssen“. Darin wurde mitgeteilt, daß der festgestellte Sachverhalt auch nach Meinung des Ministeriums wenigstens zu einer Zuchthausstrafe hätte führen müssen; deshalb sei der Oberreichsanwalt veranlaßt worden, gegen das bereits rechtskräftige Urteil beim Besonderen Senat des Reichsgerichts außerordentlichen Einspruch einlegen zu lassen, so daß nunmehr mit einer Zuchthausstrafe zu rechnen sei. „Bei einer über eine Zuchthausstrafe hinausgehenden Ahndung der Tat dürfte aber zu bedenken sein, daß gleichartige Straftaten in verhältnismäßig großer Zahl vorgekommen sind. Diese Fälle liegen zumeist schwerer. ${ }^{\text {“41 }}$ Das Vorbringen dieser rechtlichen Bedenken war völlig vergebens: der Verurteilte wurde auf Befehl Hitlers am Abend des 20. Januar 1940 im Konzentrationslager Dachau erschossen. Zwei Stunden vorher war in Sachsenhausen der dritte Verurteilte exekutiert worden ${ }^{42}$, dessen Auslieferung an die Gestapo Hitler dem Justizministerium durch Schaub hatte befehlen lassen. Ihn hatte das Sondergericht Berlin am Vortage wegen Rückfalldiebstahls und Raubes in Tateinheit mit Körperverletzung zu zwölf Jahren Zuchthaus verurteilt.

In allen diesen Fällen der Korrektur rechtskräftiger Urteile, bei denen das Reichsjustizministerium ausdrücklich auf einer - wenigstens nachträglichen - schriftlichen Bestätigung über das Vorliegen eines Führerbefehls bestand ${ }^{43}$, erfolgte durch den Reichsführer-SS eine öffentliche Bekanntgabe der Exekution in der Form, daß die Verurteilten während der Einlieferung in die zuständige Strafanstalt entweder „auf der Flucht“ oder „bei Widerstandshandlungen“" von der Polizei erschossen wurden. Diese Pressenotizen gaben nicht nur in Juristenkreisen „dem Verdacht Nahrung, dieses Erschießen könnte eine Art politischer Urteilskorrektur darstellen “44, - zumal dann, wenn die Richtigkeit dieser Meldungen aus konkreten Gründen angezweifelt werden konnte. In dem Entwurf eines Schreibens Gürtners an Himmler vom 30. November 1939 wurde denn auch darauf hingewiesen, „daß diese in ihrem Wortlaut jeweils übereinstimmenden Veröffentlichungen zu mindestens bei den an der Durchführung der

40 Ber. an Schaub mit handschriftl. Verm. Heydrichs v. 8.1.40 (Akten der Adjutantur des Führers, BA, Sign. NS 10/137).

41 Schr. Joëls an Schaub v. 18.1.40 (a.a.O.).

42 Vgl. geh. Schnellbrief Heydrichs an Schaub v. 20.1.40 mit der Exekutionsmeldung betr. beide Täter für Hitler (a.a.O.).

43 In den Schr. Schaubs an Joël hieß es stereotyp: „Auf Ihren ausdrücklichen Wunsch hin gebe ich Ihnen nachträglich schriftlich den Befehl des Führers durch, und zwar, daß der ..." usw. (a.a.O.).

44 Vgl. z. B. Zusammenstellung in den Akten des OLG Hamburg v. 30.11 .39 betr. „Material für die Tagung der Gaurechtsamtsleiter [des NSRB] am 2./3. Dezember 1939 in Berlin“ (Arch. der Forschungsstelle f. d. Geschichte des NS in Hamburg, Sign. Best. 3305). 
Strafverfahren beteiligt gewesenen Personen Aufsehen ${ }^{45}$ zu erregen geeignet" seien. Bei der Erschießung der Teltower Sparkassenräuber, von denen einer

„vor seinem Abtransport im Streckverband im Gefängnislazarett lag, war auch die breite Öffentlichkeit durch die am Tage vorher erfolgte Presseberichterstattung über die im Lazarett des Untersuchungsgefängnisses stattgefundene Hauptverhandlung über diesen einen Widerstand schwerlich ermöglichenden körperlichen Zustand des Verurteilten unterrichtet“ ${ }^{46}$

In dieser Situation war es nicht weiter verwunderlich, daß in der Bevölkerung mancherlei Gerüchte über Erschießungen durch die Polizei umgingen und das Ministerium auch entsprechende Meldungen nachgeordneter Behörden erhielt, die sich bei einer Nachprüfung - die von der Justizleitung stets angestellt wurde - als falsch erwiesen. So gab z. B. der Oberlandesgerichtspräsident Naumburg am 23. Oktober 1939 den Bericht eines Amtsgerichtsrats in Stolberg (Landgerichtsbezirk Nordhausen) an das Reichsjustizministerium weiter, der auf gesprächsweisen Mitteilungen des Landrats beruhte: in zwei verschiedenen Orten seien „ein Arbeiter wegen herabsetzender Kritik an den Maßnahmen des Führers“ und ein Evakuierter aus der Saar - „wegen Aufzeichnung militärischer Vorgänge“ auf dem Nordhausener Flugplatz - von der Gestapo verhaftet und erschossen worden. Im Ministerium wurde der Sache immerhin soviel Bedeutung zugemessen, daß außer beiden Staatssekretären auch Gürtner mit der Sache befaßt wurde. Durch die Einschaltung des Oberlandesgerichtspräsidenten, des Gauleiters in Halle, des Reichssicherheitshauptamts, des Regierungspräsidenten in Merseburg und der Staatspolizeistelle Halle, die den Landrat und den Amtsgerichtsrat vernahm - letzterer wurde sogar zur Rücksprache ins Ministerium bestellt - konnte der Bericht als bloßes Gerücht zu den Akten gelegt werden: der „erschossene“ Arbeiter saß wegen Verstoßes gegen das Heimtückegesetz in Untersuchungshaft und der Saarländer war längst dem zuständigen Amtsgericht in Halle zugeführt worden. ${ }^{47}$ Was dagegen nicht ohne weiteres beiseitegeschoben werden konnte, war die in dem $\mathrm{Be}$ richt des Amtsgerichtsrats festgehaltene einhellige Ablehnung der vermeintlichen Vorgänge durch die Bevölkerung:

„Es wurde darauf hingewiesen, daß der Täter einer jeden geringfügigen Übertretung die Möglichkeit des Gehörs und die Verurteilung durch den Richter habe. Das müsse umsomehr bei solchen Verbrechern gelten. Gerade wenn die Tat klar liege, sei eine Verurteilung zum Tode gerechter und abschreckender. Die Verurteilung durch die Gestapo wurde außerdem als offenes Mißtrauen gegen die Justizverwaltung gewertet. “48

Die nicht zuletzt wegen dieser Stimmung in der Bevölkerung - ähnlich wie bei der Euthanasie - beibehaltene Tarnung zumindest der Urteilskorrekturen sollte der Polizeiführung nur für eine begrenzte Zeit gelingen: bald stellten die Justizbehörden fest,

45 Die folgenden Worte: „und Mißtrauen“ wurden handschriftl. gestrichen.

46 Der v. Crohne am 28.11. paraphierte Entw. trägt das Datum v. 30.11.39 und den Verm. Gürtners zur Wiedervorlage vom selben Tage. Da der Abgangsverm. fehlt, wurde das Schr. offensichtlich nicht abgeschickt (Akten des RJM, BA, Sign. R 22/5019, u. Nürnbg. Dok. NG-190).

47 Vgl. Ber. des OLGPräs. Naumburg an das RJM v. 23.10.39 mit teilweiser Abschr. aus dem Ber. des AG Stolberg (Harz) an den LGPräs. Nordhausen v. 13.10.39; ferner Aktenvermerke des RJM u. Korrespondenz der im Text genannten Dienststellen bis zum 7.11.39 (Akten des RJM, BA, Sign. R 22/5020). Bei der Vernehmung des AGRats durch die Stapostelle Halle erklärte der Gestapobeamte bezeichnenderweise: „Wenn Erschießungen durch die Gestapo erfolgten, dann würden diese, wie z. B. im Falle Heine-Dessau und ... -Halle nur auf Grund sorgfältiger Ermittlungen und stets erst im Lager vorgenommen“(Verm. des AGRats v. 25.10.39 über seine Vernehmung, a.a.O.).

48 Ber. des AGRats aus Stolberg (Harz) an den LGPräs. Nordhausen v. 13.10.39 (a.a.O.). 
„daß es in der Öffentlichkeit kaum mehr unbekannt ist, daß die ,wegen Widerstandes" erfolgenden Erschießungen aus anderen Erwägungen stattfinden".99

Nachdem sich die Justizleitung von dem betäubenden Schlag der ersten ErschieBungsbefehle Hitlers erholt hatte, übernahm sie den verzweifelten Versuch, dieser Maßnahme wenigstens im Einzelfall entgegenzuwirken und damit indirekt die ergangenen Urteile der Gerichte zu verteidigen. Da immer deutlicher wurde, daß Hitlers Entscheidungen hauptsächlich auf ungenügenden Pressemeldungen und einseitigen Informationen beruhten, versuchte sie, Hitler wenigstens die genauen Urteilsgründe mitzuteilen, um ihn zu einer Änderung seiner Entscheidung zu bewegen. Abgesehen von der geringen Aussicht, Hitler mit rechtlichen Argumenten beeindrucken zu können, war dieser Versuch stets auch ein Wettlauf mit der Zeit. Schlegelberger schilderte im Nürnberger Juristenprozeß den Vorgang wie folgt:

„Ging nun ein solcher Befehl ein, so setzte eine rastlose Arbeit ein. Zunächst mußte versucht werden, bei der Polizei die Verlängerung der Frist zu erreichen ... Gleichzeitig wurden die Akten des Falles auf schnellstem Wege nach Berlin beordert und die Zeitungsausschnitte herbeigeholt, die vermutlich Hitler zu diesen Überstellungsbefehlen veranlaßt hatten. Dann wurde ein ausführlicher Bericht über die Tat und den Täter selbst gemacht und damit das Urteil gerechtfertigt, und zur Unterstützung fanden noch Telefonate mit verschiedenen Stellen statt, weil man sich von dieser Verbindung einen Erfolg versprechen konnte. Einige Erfolge wurden erzielt. Gelang es aber nicht, die Rücknahme des der Polizei erteilten Befehls zu erreichen, obwohl alle Möglichkeiten erschöpft waren, so blieb gar nichts anderes übrig, als der Vollstreckungsbehörde die Weisung zu geben, ... der Polizei auf Verlangen den Mann herauszugeben." ${ }^{\text {"so }}$

Ging der häufig auch für die Polizei auf 24 Stunden befristete Exekutionsbefehl spontan von Hitler selbst aus, so war auch dann nichts mehr zu retten, wenn er auf zweifelhaften Informationen beruhte. So erfolgte von zwei Exekutionen, die Hitler durch Schaub am 23. September 1940 aufgrund von Meldungen im „Völkischen Beobachter" und in den „Münchner Neuesten Nachrichten“ vom selben Tage befahl - soweit das Justizministerium feststellen konnte -, mindestens eine auf unrichtige Presseberichte hin. ${ }^{51}$ In dem bereits geschilderten Fall des neunzehnjährigen Münchener Postfacharbeiters war zu einer, wenn auch fehlgeschlagenen, Intervention des Ministeriums nur deswegen Zeit und Gelegenheit gewesen, weil der Exekutionsbefehl von Heydrich erst bei Hitler eingeholt worden war und das Ministerium rechtzeitig davon erfahren hatte. Nur in ähnlich gelagerten Fällen war ein solcher Versuch überhaupt möglich und gelegentlich auch erfolgreich. Am 9. Dezember 1940 gab Hitler aufgrund einer falschen Darstellung in der „Berliner illustrierten Nachtausgabe“ "durch SS-Gruppenführer Schaub fernmündlich seiner Verwunderung Ausdruck“, daß ein Melker, der in Breslau einer Frau auf der Straße die Handtasche weggezogen hatte, zu zehn Jahren Zuchthaus statt zum Tode verurteilt worden war. Der Artikel hatte jedoch nicht erkennen lassen, daß es sich lediglich um eine Gelegenheitstat handelte: der Melker kam verschiedentlich ohne einen Pfennig nach Breslau, um von

49 So z. B. im Lageber. des GStA beim KG an das RJM v. 27.1.42 (Akten des RJM, BA, Sign. R 22/3356); ähnlich schon im Ber. des OLGPräs. Darmstadt v. 10.5.41 (a.a.O., Sign. R 22/3361), der daran die Frage knüpfte, ob die Veröffentlichung der Erschießungen nicht besser unterbleibe.

so Zeugenaussage v. 30.6.47 im Nürnbg. Juristenprozeß, Protokoll (d), S. $4395 \mathrm{f}$.

51 Vgl. Schr. Schaubs an Meissner v. 23.9.40 (Nürnbg. Dok. NG-3278) u. Aufzeichn. Crohnes für Schlegelberger v. 7.3.41 betr. „Exekutionen auf Grund zweifelhafter Informationen“ (Nürnbg. Dok. NG-190). Es handelte sich um einen zu $6 \mathrm{~J}$. Zuchthaus verurteilten Berliner „Volksschädling“; der andere Betroffene war vom LG München I zu $5 \mathrm{~J}$. Gefängnis verurteilt worden. 
seinem Guthaben aus Arbeitsersparnissen Geld abzuheben; da die Kasse an diesem Tage bereits geschlossen hatte, kam er auf den Gedanken, sich auf diese Weise Geld für die Rückfahrt zu verschaffen. Nachdem hier noch kein definitiver Exekutionsbefehl Hitlers vorlag und Freisler daher Schaub die näheren Umstände der Tat mündlich auseinandersetzen konnte, wurde „die Sache damit als erledigt“ angesehen. ${ }^{52}$

Es gab allerdings Fälle, bei denen die Justiz gegenüber Hitlers Exekutionsbefehl kein anderes Rechtfertigungsargument vorbringen konnte, als daß sie selbst bereits ihr Möglichstes getan hatte, bei der gerichtlichen Verurteilung des Betroffenen aber an die Grenzen der gesetzlichen Bestimmungen gestoßen war. So forderte Hitler aufgrund einer Meldung im „Völkischen Beobachter“ am 13. August 1940 die Überstellung eines fünf Tage vorher vom Volksgerichtshof zu lebenslangem Zuchthaus verurteilten Stickereizeichners an die Gestapo, der im Januar 1939 in der Schweiz die Nachricht von einem unmittelbar bevorstehenden deutschen Einmarsch verbreitet und dafür bis ins einzelne gehende Berichte und Meldungen gefälscht hatte. Der Volksgerichtshof hatte ihn wegen des Verbrechens der landesverräterischen Fälschung und der landesverräterischen Volksverleumdung ( $\$ \S 90$ a Abs. 2, 90 f StGB) zu der genannten Höchststrafe verurteilt, da das geltene Recht die Verhängung der Todesstrafe nicht ermöglichte. Nach einer Pressemeldung wurde er „wegen Widerstandes“ erschossen. Gürtner nahm diesen Fall bezeichnenderweise zum Anlaß, bei Lammers auf die Verabschiedung einer Strafrechtsänderungsverordnung durch den Ministerrat für Reichsverteidigung zu dringen, die er schon Monate vorher eingebracht hatte und deren Bestimmungen ein Todesurteil im vorliegenden Fall ermöglicht hätten. ${ }^{53}$

Wenige Wochen nach Gürtners Tod versuchte der die Geschäfte des Reichsjustizministeriums führende Staatssekretär Schlegelberger über den Chef der Präsidialkanzlei Meissner noch einmal zu erreichen, daß grundsätzlich keine Überstellung von Strafgefangenen zur Gestapo erfolgen sollte, bevor Hitler nicht ein Bericht des Justizministeriums vorgelegen habe. ${ }^{54}$ Aber Hitler ließ durch Bormann antworten, daß er „die Beiziehung von Stellungnahmen des Reichsjustizministeriums zu Urteilen, die ihm zur Nachprüfung vorgelegt werden, nicht für notwendig“ halte. Wie Meissner an Schlegelberger berichtete, war dabei die Frage offengeblieben, ob Hitler in den Fällen, in denen ihm das Urteil überhaupt nicht vorlag, den Spruch anfordern wollte. Meissner stellte aber dem Chef der Justizverwaltung anheim, ihm in den Fällen, in denen er es für notwendig hielt, „vor Übergabe des Gefangenen an die Geheime Staatspolizei den Sach- und Rechtsstand mit größter Beschleunigung kurz zu unterbreiten“; er werde die berichteten Umstände - „soweit der Fall dazu angetan“ sei - Hitler mitteilen. In diesen Fällen könne die Übergabe an die Gestapo „kurzfristig solange aufgeschoben werden, bis ich Ihnen erneute Mitteilung gebe“.55 Damit war zwar eine Mög-

52 Vgl. Aufzeichn. Crohnes für Schlegelberger v. 7.3.41 (a.a.O.).

${ }_{53} \mathrm{Zu}$ diesem Fall vgl. Schr. Gürtners an Lammers v. 12.9.40 (Akten des RJM, BA, Sign. R 22/856). Bei der erwähnten ErgänzungsVO handelte es sich um die „Staatsverbrecherverordnung“, deren Erlaß Hitler im November 1940 schließlich ablehnte (vgl. Kap. VII.3.f., S. 918 ff.).

54 Gegen den Mißstand, daß Hitler Urteile aufgrund unvollständiger Pressenotizen kritisierte, war Gürtner bei der Reichskanzlei schon in den vorangegangenen Jahren wiederholt vorstellig geworden; Lammers hatte diesen Gesichtspunkt Hitler mehrmals vorgetragen. Vgl. Verm. Kritzingers v. 22.10.38 u. Lammers' v. 28.10.39 (Akten der Reichskanzlei, BA, Sign. R 43 II/1508).

5s Schr. Meissners an Schlegelberger v. 22.4.41 (Akten des RJM, BA, Sign. R 22/5019, auch Nürnbg. Dok. NG-540). 
lichkeit eröffnet, bei weitem aber keine Garantie dafür gegeben, daß Hitler vor dem Vollzug des Exekutionsbefehls wenigstens vom Urteil und seiner rechtlichen Begründung Kenntnis bekam. Die Justizleitung sollte auch weiterhin Schwierigkeiten haben, sachliche Argumente an Hitler heranzutragen: als er z. B. auf Anregung des Münchener Gauleiters Wagner die Vollstreckung eines Todesurteils anordnete, das drei Monate vorher mit seiner Zustimmung und in seinem Namen auf dem Gnadenwege in eine Zuchthausstrafe von zehn Jahren umgewandelt worden war, scheiterte die Unterrichtung Hitlers über diese Tatsache daran, daß „Herr Schaub es für ausgeschlossen hielt, den Führer noch einmal mit der Sache zu befassen". ${ }^{56}$

Die Zahl der Fälle, bei denen auf diesem Wege Urteile der Justiz durch polizeiliche Exekutionen korrigiert wurden, ist nicht mehr exakt feststellbar. Nach den übereinstimmenden Aussagen des persönlichen Referenten Schlegelbergers und eines in der Präsidialkanzlei tätigen damaligen Oberregierungsrats waren es bis zum Ausscheiden Schlegelbergers aus seinem $\mathrm{Amt}^{57}$, d. h. bis zum 20. August 1942, mindestens dreißig Fälle. ${ }^{58}$ Sie betrafen aber nur Reichsdeutsche; die Zahl der Überstellungen von gerichtlich verurteilten „fremdvölkischen“ Arbeitskräften im Altreich an die Polizei zu diesem Zweck dürfte im gleichen Zeitraum ein mehrfaches betragen haben: Die Anlage zu einer Rundverfügung Schlegelbergers vom Juli 1941, in der er zu milde Urteile gegen Polen als „eine unverständliche, nachsichtige Einstellung gegenüber dem uns unversöhnlich gegenüberstehenden polnischen Volkstum“ rügte, enthält allein acht Fälle, in denen Verurteilte ab November 1940 der Gestapo überstellt und „wegen Widerstandes erschossen“ wurden; diese zwischen dem 16. Juli 1940 und dem 4. April 1941 gefällten Urteile wegen Sittlichkeitsverbrechen und Einbrüchen hatten immerhin Strafen zwischen eineinviertel und zehn Jahren Zuchthaus mit anschließender Sicherungsverwahrung beinhaltet. ${ }^{59}$ Für die Überstellung dieser „Fremdvölkischen“ ist Hitler im Einzelfall nicht bemüht worden, sie wurde von Himmler in eigener Regie gefordert und von der Justizverwaltung offensichtlich ohne große Gegenvorstellungen zugelassen. Als der Oberlandesgerichtspräsident von $Z$ weibrücken auf Schlegelbergers

56 Schr. Schlegelbergers an Lammers v. 20.2.42 (Akten der RK, BA, Sign. R 43 II/1544). Darin hieß es u.a.: „Die Herren der Umgebung des Führers sollten sich aber der schweren Verantwortung bewußt sein, die sie damit übernehmen, wenn sie den Führer unter Ausschaltung des von ihm mit der Führung der Geschäfte des Reichsministeriums der Justiz beauftragten Beamten zu derartigen Entscheidungen veranlassen."

57 Thierack einigte sich nach seinem Amtsantritt mit Himmler, in solchen Fällen Hitler nicht mehr zu befassen; nur wenn beider Ansichten nicht übereinstimmten, sollte "die Meinung des Reichsleiters Bormann, der evtl. [?] den Führer unterrichten wird, beigezogen“ werden (Aufz. Thieracks über seine Bespr. mit Himmler am 18.9.42, Nürnbg. Dok. PS-651, abgedr. in IMG Bd.XXVI, S. 200 ff.).

58 Vgl. eidesstattl. Erkl. Gramm v. 12.2.48 (Nürnbg. Dok. NG-4798), Lüdtke v. 4.2.48 (Nürnbg. Dok. NG4744) u. Schaub v. 30.4.48 (Nürnbg. Dok. NG-5263), der erklärte, daß allein 12-18 Fälle durch seine Hand gelaufen seien. Am bekanntesten wurde der im Nürnbg. Juristenprozeß behandelte Fall des Juden Luftglass, der im Oktober 1941 wegen Eierhamsterns vom SG Kattowitz zu 21/2 J. Gefängnis verurteilt worden war (Nürnbg. Dok. NG-287). Weitere Hinweise auf Exekutionen von Reichsdeutschen (nicht „Fremdvölkischen") nach rechtskräftiger Verurteilung zu Freiheitsstrafen in der Zeit bis 20.8.42 vgl. Lageber. GStA Köln v. 2.1.40 u. 31.1.40 (BA, Sign. R 22/3374), GStA München v. 26.1.40 (R 22/3379), OLGPräs. Bamberg v. 30.4 .40 u. 2.9.40, GStA Bamberg v. 30.5.40 (R 22/3355), GStA Naumburg v. 4.8 .40 (R 22/3380), GStA Königsberg v. 2.4.41 (R 22/3375), OLGPräs. Braunschweig v. 5.5.41 u. 10.3.42 (R 22/3357), GStA Darmstadt v. 17.10.41, OLGPräs. Darmstadt v. 10.11.41 (R 22/3361) u. GStA beim KG v. 27.1.42 u. 31.3.42 (R 22/3356).

39 Vgl. RV des RJM an die OLGPräs. u. GStAe betr. „Milde Urteile gegen Polen“ v. 24.7.41 (Nürnbg. Dok. NG-505). Weitere Hinweise auf Exekutionen von Polen, gegen die vorher Verfahren vor SGen stattgefunden hatten, u.a. in den Lageber. des GStA beim KG v. 27.1.42 (BA, Sign. R 22/3356) u. des OLGPräs. Danzig v. 10.7 .42 (R 22/3360). 
Rundverfügung hin Bedenken äußerte, daß diese Maßnahmen „entgegen der bisherigen Stellungnahme des Reichsjustizministeriums das Anerkennen einer über den Gerichten stehenden polizeilichen Instanz" bedeuteten, falls sie „mit dem Willen der Reichsjustizverwaltung getroffen worden" seien, wurde er von Freisler aufgeklärt, daß über die Exekutionen ohne Anhörung und ohne den Willen des Ministeriums „von höchster Stelle" entschieden wurde. ${ }^{60}$

Auch die Zahl derjenigen, die unter Umgehung der Justiz - also nicht anläßlich einer "Urteilskorrektur", sondern in eigener „Polizeijustiz“ - exekutiert wurden, kann nicht mehr exakt bestimmt werden. Bei den davon betroffenen Reichsdeutschen, die nach den erwähnten geheimen „Grundsätzen der inneren Staatssicherung“ vom September 1939 exekutiert wurden ${ }^{61}$, dürfte die Zahl bei weitem die Ziffer derjenigen überstiegen haben, die zur Korrektur rechtskräftiger Urteile erschossen wurden. Am umfangreichsten aber war die Zahl der ohne Gerichtsurteil exekutierten „Fremdvölkischen" - meist polnischer Zivilarbeiter - im Reich.

\section{b. Exekution als Mittel der Strafverfolgung gegen polnische Zivilarbeiter im Reich ab 1940}

Die polizeilichen Exekutionen von polnischen Zivilarbeitern im Reich, die von den noch zahlreicheren Erschießungen als „Säuberungs“- und Vergeltungsmaßnahmen gegen Widerstands- und Sabotagehandlungen in den eingegliederten Ostgebieten unterschieden werden müssen, erfolgten wegen angeblicher Straftaten wie Notzucht, Brandstiftung u.a., aber auch wegen eigenmächtigen Verlassens des Arbeitsplatzes, schweren Verstößen gegen die Arbeitsdisziplin und - am häufigsten - wegen Geschlechtsverkehrs mit Deutschen. Auch diese Polizeijustiz gegen "fremdvölkische“ Zivilarbeiter beruhte auf geheimen Anweisungen des Reichsführers-SS, über die die Justiz nicht informiert wurde: Am 8. März 1940 teilte Göring als Beauftragter für den Vierjahresplan und Vorsitzender des Ministerrats für die Reichsverteidigung den obersten Reichsbehörden lediglich mit, daß er Himmler ermächtige, die „einwandfreie Lebensführung" der ins Reich verpflichteten polnischen Zivilarbeiter durch Rechts- und Verwaltungsvorschriften sowie staatspolizeiliche Maßnahmen sicherzustellen. Aufgrund dieser Generalermächtigung erließ Himmler noch am selben Tage eine Reihe von Vorschriften, die auch an andere Behörden gingen ${ }^{62}$, daneben aber auch geheime

${ }^{60}$ Lageber. des OLGPräs. Zweibrücken v. 11.11 .41 (R 22/3389) u. Schr. Freislers v. 10.1.42 (BA, Sign. $\mathrm{R} 22 / 849$ ).

${ }^{61}$ Es handelte sich meist um „Berufs-“ oder „V:-dunkelungsverbrecher“. Hinweise z. B. in den Lageberichten OLGPräs. München v. 3.1.40 (BA, Sign. R 22/3379), GStA Celle v. 31.7.40 (R 22/3359), Naumburg v. 6.10.40 (R 22/3380), GStA Stuttgart v. 31.5 .41 (R 22/3387), GStA Königsberg v. 19.2.42 (R 22/3375), OLGPräs. Hamm v. 27.2.42 (R 22/3367), OLGPräs. Nürnberg v. 5.3.42 (R 22/3381), danach allein am 10. 2. 42 „10 Verdunkelungsverbrecher“, GStA Darmstadt v. 9.4.42 (R 22/3361) u. OLGPräs. Köln v. 2.7.42 (R 22/3374).

${ }^{62}$ Vgl. Erl. Görings betr. Behandlung von Zivilarbeitern und -arbeiterinnen polnischen Volkstums v. 8.3.40 an die Obersten Reichsbehörden mit „Erläuterungen“; Pol.VO über die Kenntlichmachung der poln. Zivilarbeiter, Schnellbrief Himmlers als RFSSuChdDtPol im RMdI an die Behörden der inneren Verw., seine Schr. an den Reichsarbeitsminister, den RM f. d. kirchl. Angelegenheiten u. den Stellvertr. d. F., sämtlich vom 8.3.40 (Arch. d. IfZ, Sign. Fa 506/11). Zum Gesamtkomplex der Behandlung „Fremdvölkischer“ s. D. Majer, „Fremdvölkische“ im Dritten Reich. Ein Beitrag zur nationalsozialistischen Rechtssetzung und Rechtspraxis in Verwaltung und Justiz unter besonderer Berücksichtigung der eingegliederten Ostgebiete und des Generalgouvernements, Boppard a. Rh. 1981. 
Anweisungen für die Staatspolizeistellen. Den polnischen Arbeitern wurde beim Eintreffen am Arbeitsort von der Polizei ein Merkblatt des Reichssicherheitshauptamtes in deutscher und polnischer Sprache verlesen, das weder den Polen noch den deutschen Arbeitgebern ausgehändigt werden durfte. Darin wurde den Arbeitern bei schweren Verstößen gegen die Arbeitsdisziplin mindestens Arbeitserziehungslager (Konzentrationslager), bei Geschlechtsverkehr mit Deutschen aber als Regel die Todesstrafe angedroht, die für dieses „Delikt“ somit ohne Gesetz, auf dem Verwaltungswege eingeführt wurde. Die Staatspolizeistellen wurden geheim angewiesen, Verstöße gegen die aufgeführten „Pflichten“ zu ahnden und außer in Fällen des verbotenen Geschlechtsverkehrs auch in schwereren Fällen von Arbeitsunlust eine „Sonderbehandlung " zu beantragen, über die der Chef der Sicherheitspolizei entschied ${ }^{63}$ Bald sollte sich die Strafgewalt der Gestapo aber nicht nur auf die erwähnten „Delikte“ beschränken: am 4. September 1940 wies das Reichssicherheitshauptamt die Dienststellen der Kriminalpolizei an, in allen Fällen, in denen polnische Zivilarbeiter „strafbare Handlungen, insbesondere auf sittlichem Gebiet begangen haben, die Vorgänge nach Abschluß der Vorermittlungen nicht der Staatsanwaltschaft, sondern sofort der zuständigen Staatspolizeistelle zu übergeben"64, die darüber entscheiden konnte, ob sie die Tat selbst ahnden oder an die Justiz abgeben wollte.

Das Reichsjustizministerium erfuhr von den ersten Exekutionen polnischer Zivilarbeiter durch die Berichte verschiedener Oberlandesgerichtspräsidenten und Generalstaatsanwälte vom Sommer und Herbst 1940, die diese polizeiliche „Strafjustiz“ - die jeder erkennbaren gesetzlichen Grundlage entbehrte - ablehnten und auch von der Mißbilligung durch die Bevölkerung berichteten. Das von der Gestapo betriebene Versteckspiel gegenüber der Justiz geht deutlich aus dem Bericht des Generalstaatsanwalts Jena vom 30. September 1940 hervor, der mit zu den ersten nachweisbaren Informationen des Ministeriums über diese Vorgänge gehört ${ }^{65}$ : Am 24. August wurde ein siebzehnjähriger polnischer Arbeiter, der wegen Geschlechtsverkehrs mit einer deutschen Dirne im Gerichtsgefängnis Gotha in Polizeihaft saß, von der Gestapo mit dem Bemerken abgeholt, daß er ins Konzentrationslager Buchenwald komme. Drei Tage später teilte die Gestapo der Gefängnisverwaltung ,zur Vervollständigung der Akten" mit, daß der Pole noch am 24. August verstorben sei. Der Generalstaatsanwalt, dem das merkwürdig vorkam, ging der Sache nach und erfuhr, daß der Gefangene auf Befehl des Reichsführers-SS in freiem Gelände vor den Augen von etwa fünfzig polnischen Zivilarbeitern gehängt worden war. „Ob und welches Verfahren vorausgegangen

${ }^{63}$ Vgl. RdErl. Himmlers an die Stapo(leit)stellen v. 8.3.40, der den Kreis- und Ortspolizeibehörden nicht mitgeteilt werden durfte, sowie Merkblatt I des RSHA (Akten des RFSSuChdDtPol., a.a.O., MA 444/3).

64 RdErl. des RSHA v. 4.9.40 - V A 1 Nr. 4177/40 - (zit. im Ber. des GStA Hamm v. 25.7.41, BA, Sign. R 22/ 3367). Er beruhte auf dem RdErl. des RFSSuChdDtPol. im RMdI v. 3.9.40 - S IV D $23382 / 40-$, der offensichtlich den RdErl. v. 8.3.40 in dieser Hinsicht ergänzte.

${ }^{65}$ Akten des RJM, BA, Sign. R 22/3369; auf einen ersten Fall hatte er bereits in seinem Ber. v. 31.5.40 hingewiesen. Der OLGPrās. Braunschweig kommentierte am 11.7.40 (BA, Sign. R 22/3357) den ersten aus seinem Bezirk berichteten Fall: „An amtlichen Stellen wird darüber augenscheinlich strenges Stillschweigen bewahrt“, die Bevölkerung aber würde „diese Art Justiz als mit der deutschen Rechtsauffassung nicht vereinbar ablehnen und als einen Eingriff in die Rechtspflege ansehen“. Zum Ber. des GStA Celle v. 31.7.40 vgl. die folgende Anm. Auch der OLGPräs. Königsberg begleitete am 4.11.40 seinen Ber. (BA, Sign. $\mathrm{R}$ 22/3375) mit den Worten, es habe „sich ein aufsehenerregender Fall behördlichen Eingreifens in den Zuständigkeitsbereich der Reichsjustizverwaltung zugetragen“. 
ist und auf welche Gesetzesbestimmung sich die Todesstrafe stützt“, schrieb der Generalstaatsanwalt, habe er nicht feststellen können. Es gelang ihm lediglich, des erwähnten Merkblattes habhaft zu werden, zu dem er bemerkte: „Das scheint die Grundlage für das Erhängen zu sein. Eine Aufklärung wäre erwünscht, damit nicht ein Staatsanwalt einmal auf den Gedanken kommt, Ermittlungen einzuleiten“. Er forderte eine gesetzliche Regelung der Straftatbestände für die ausländischen Arbeiter, um einer eigenmächtig handelnden Polizeijustiz zu begegnen. Daß die Justizbehörden hinsichtlich der Hintergründe der beobachteten Vorgänge völlig im Dunkeln tappten, geht auch aus dem Lagebericht des Generalstaatsanwalts Hamm vom November 1940 hervor, der die Erhängung eines polnischen Zivilarbeiters durch die Polizei „wegen Erregung öffentlichen Ärgernisses“ vom 29. Juli meldete. Grundlage für die Exekution sei „angeblich ein Erlaß des Reichsführers-SS“, dessen Wortlaut - wie ihm wissentlich falsch mitgeteilt worden war - mit dem Text des auch ihm ausgehändigten Merkblattes identisch sei. Nach seinen Beobachtungen beschränkten sich die Gestapobehörden

„aber nicht etwa auf die Verfolgung solcher Vorkommnisse, die einer Strafbestimmung nicht unterliegen, sie erledigen vielmehr auch strafbare Handlungen, die von Angehörigen polnischen Volkstums begangen werden ... Wenn derartige Vorkommnisse Schule machen, so muß naturnotwendig in weitesten Kreisen der Bevölkerung das Gefühl der Rechtssicherheit schwinden. Ich befürchte aber auch, daß das Ansehen der Justiz Schaden nimmt, wenn die Staatspolizeistellen und die ihnen übergeordneten Behörden Aufgaben der Justiz nach Belieben an sich ziehen.“

Auch er forderte die „Einführung klarer gesetzlicher Bestimmungen“. 66 Bald berichteten auch andere Generalstaatsanwälte, daß die Gestapo dazu übergegangen war, polnische Zivilarbeiter nicht nur wegen Geschlechtsverkehrs mit Deutschen, sondern auch wegen gesetzlich normierter Straftaten zu exekutieren. ${ }^{67}$

In Bayern wurde die Konfusion noch dadurch vergrößert, daß Innenminister Wagner am 11. März 1940 eine Verordnung erlassen hatte, die alle einengenden Regelungen für die polnischen Zivilarbeiter einschließlich des Verbots der „Aufnahme von Geschlechtsbeziehungen zu Deutschen und die Annäherung an Deutsche zu diesem Zweck" enthielt und Zuwiderhandlungen der Verfolgung durch die Justiz unterwarf: sie sollten nach $\S 8$ der Verordnung über die Behandlung von Ausländern vom 5. September 1939 (RGBl. I, S. 1667) bestraft werden, der Gefängnis- und Geldstrafen vorsah. ${ }^{68}$ Damit war in Bayern eine Rechtsgrundlage für die Bestrafung wegen Geschlechtsverkehrs mit Deutschen gegeben. Der ahnungslose Generalstaatsanwalt Bamberg beklagte sich am 30. Mai beim Reichsjustizministerium, daß diese Materie nicht reichseinheitlich geregelt sei; es ergebe sich daraus „der Mißstand, daß wegen Verstoßes gegen diese Bestimmungen z. B. wegen Geschlechtsverkehrs zwischen polnischen Landarbeitern und Deutschen in Bayern verhältnismäßig hohe Strafen ausgesprochen werden können, während solche Verstöße im übrigen Reichsgebiet überhaupt nicht

${ }^{66}$ Lageber. des GStA Hamm v. 29.11.40 (BA, Sign. R 22/3367). Der GStA Celle war schon laut Ber. v. 31.7.40 (Sign. R 22/3359) anläßlich der Erhängung eines Polen "wegen unzüchtiger Handlungen“" in den Besitz des Merkblattes gelangt, darüber hinaus aber wenigstens mit den nicht geh. Erlassen Görings $u$. Himmlers v. 8.3.40 bekannt gemacht worden.

67 Vgl. z. B. Lageber. des GStA Celle v. 27.1.41 (BA, Sign. R 22/3359) u. GStA Oldenburg v. 30.1.41 (BA, Sign. $R$ 22/3382), in beiden Fällen wegen Brandstiftung.

68 VO des bayer. StMdI über die Behandlung von polnischen Arbeitskräften v. 11.3.40 (bayer. GVB1. 1940, S.37). Sie beruhte auf den $\S \S 3$ u. 6 der erwähnten AusländerVO. 
strafbar sind“ (!) ${ }^{69}$ Dieser „Mißstand“ regulierte sich in der Folge offenbar dadurch, daß auch in Bayern die Polizei den Justizbehörden einschlägige Fälle einfach vorenthielt, weil die dafür vorgesehenen Strafen ihr zu niedrig waren. ${ }^{70}$

Da die einschlägigen Geheimerlasse Himmlers dem Reichsjustizministerium nicht mitgeteilt wurden - sie waren der Justizleitung selbst noch einige Zeit nach dem Amtsantritt Thieracks im August 1942 unbekannt $^{71}$-, wurden die Eingriffe der Gestapo in die Verfolgung von Straftaten polnischer Zivilarbeiter im Reich von der Justiz als Eigenmächtigkeiten angesehen, wie sie sie bis dahin sattsam erfahren hatte. Deshalb konnte auch den nachgeordneten Justizbehörden nicht die gewünschte Aufklärung gegeben werden. Auf einer Arbeitstagung am 20. März 1941 in Berlin konnten die Generalstaatsanwälte daher lediglich über die - aus dem Merkblatt bekannte - Tatsache informiert werden, daß der Geschlechtsverkehr polnischer Zivilarbeiter mit Deutschen und Arbeitsvertragsbrüche durch die Polizei geahndet würden. ${ }^{72} \mathrm{Da}$ die Justiz jedoch den Anspruch auf die Verfolgung aller „normalen“ Straftaten der polnischen Zivilarbeiter im Reich aufrechterhielt, kam es immer dann zu Reibereien, wenn z. B. ein Landjäger die Anweisungen des Reichssicherheitshauptamtes nicht beachtete und einen straffälligen Polen den zuständigen Justizbehörden zuführte. In einem solchen Falle, wo sich ein Pole der Verführung eines minderjährigen deutschen Mädchens $(\S 182 \mathrm{StGB})$ schuldig gemacht hatte, verweigerte der Generalstaatsanwalt Celle die Herausgabe an die Gestapo und berichtete über die bestehende „Zweispurigkeit“ der Strafverfolgung treffend:

„Es kann sich also demnächst das geradezu als grotesk anmutende, als höchst unerwünscht zu bezeichnende Bild ergeben, daß Polen im Altreich im Regelfalle wegen Geschlechtsverkehrs mit deutschen Frauen ohne - soweit mir bekannt - entsprechende Strafvorschrift und ohne ordentliches Strafverfahren gehenkt werden, der Pole dagegen in den seltenen Fällen, wo er - gewissermaßen zufällig - zur Strafverfolgung im Wege der ordentlichen Strafjustiz gelangt, im Falle der

69 Vgl. Lagebericht des GStA Bamberg v. 30.5.40 (BA, Sign. R 22/3355), er zit. aus dem Ber. eines OStA seines Bezirks.

70 Beim SG München z.B. sind einschlägige Fälle erst nach Erlaß der PolenstrafrechtspflegeVO v. 4.12.41 (RGBl. I, S. 759) nachweisbar, als die Gerichte gegen Polen drakonische Strafen verhängen konnten, vgl. die Urteile aus dem Jahre 1942 gegen poln. Zivilarbeiter wegen Verfehlung ,gegen die Geschlechtsehre eines deutschen Mädchens“ (Todesstrafe), wegen „unsittlicher Belästigungen“" (Todesstrafe, 7 Jahre verschärftes Straflager), wegen „unsittlicher Annäherungsversuche“ (3 Jahre verschärftes Straflager), wegen „sexueller Zudringlichkeiten“ (2 Jahre Straflager) (StArch. München, Best. Staatsanwaltschaft/SG, Nr. 10 870, 10976 , $10984,10988,10973,10979$ ).

7 Auf der Arbeitsbespr. der OLGPräs. u. GStAe am 10.2.43 in Berlin (Akten des RJM, BA, Sign. R 22/4200) führte Thierack aus: „Dieses Problem war für mich eines der schwersten, weil ich überhaupt nicht wußte, was los war; auch das Ministerium wußte es nicht ... Ich kannte nur immer wieder jene aus der Front heraufkommenden Schreiben, die Sorgen und die tatsächlichen Fälle ... Ich hatte keine Unterlagen. Nun haben wir des Schlüssels Lösung gefunden [sic] ... Nachdem wir die Erlasse bekommen haben, sehen wir jetzt klar.“ Der MinDirig. der Gesetzgebungsabt. ergänzte: „Die Justiz hatte von diesen Anweisungen keine offizielle Kenntnis und versuchte deshalb, nach den Vorschriften der Strafprozeßordnung ... einzuschreiten. Dies mußte zu ständigen Reibungen zwischen den Dienststellen der Justiz und der Polizei führen... Zahllose Berichte von Ihnen sind uns dieserhalb zugegangen ... Wir haben uns auch den Wortlaut der einzelnen Anweisungen des Reichsführers-SS beschafft, bis jetzt [?] aber noch nicht in der Lage gesehen, diese Anweisungen den Außenstellen mitzuteilen, weil wir erst durch [noch bevorstehende] Verhandlungen mit dem Reichsführer zu einer sowohl für die Justiz wie die Polizei tragbaren Regelung gelangen wollten."

72 Das geht aus dem Lagebericht des GStA Celle v. 31.5.41 (BA, Sign. R 22/3359) hervor. Eine Aufzeichn. über die Berliner Tagung war in den Akten nicht auffindbar. 
Verurteilung wegen einer strafbaren Handlung mit einer Freiheitsstrafe davonkommt. Größer kann m. E. die Verwirrung auf diesem Gebiet nicht mehr werden. Daß der Rechtswahrer diesen unerfreulichen Zustand wegen unzureichender Unterrichtung über die Grundlagen des polizeilichen Vorgehens mit Befremden betrachtet, bedarf keiner Erörterung. Darüber hinaus geben diese Vorfälle aber auch der Bevölkerung, der sie nicht unbekannt geblieben sind, ... Anlaß zu Betrachtungen mancherlei Art, insbesondere über die Gesetzlichkeit der polizeilichen Maßnahmen und über die völlige Ausschaltung der ordentlichen Organe der Strafrechtspflege. ${ }^{173}$

Die ständigen Reibereien auf diesem Gebiet machten schließlich eine Aussprache auf höherer Ebene notwendig: Am Tage des Angriffs auf die Sowjetunion, am 22. Juni 1941, bat Himmler Schlegelberger „zu einer dringenden Unterredung“ zu sich und teilte ihm mit, „ihm sei vom Führer der Auftrag erteilt, im Verwaltungswege alle Angriffe von Polen gegen deutsche Frauen und Mädchen durch Erhängen der Täter zu ahnden". Aus diesem Anlaß würde ihm von der Justiz immer wieder vorgeworfen, daß er in ihre Befugnisse eingriffe. Er wünsche daher „in diesem Punkt endlich einmal Klarheit zu schaffen“. Schlegelberger erwiderte,

„die Justiz nehme für sich ausschließlich die Ahndung strafbarer Handlungen in Anspruch und sie sei nicht in der Lage, auf diese Strafverfolgung zu verzichten, da sie insoweit ebenso einen bindenden Auftrag des Führers habe wie der Reichsführer für die Fälle, in denen eine strafbare Handlung nicht vorliege. Der Reichsführer könne sich auch wohl kaum darüber beklagen, daß die Justiz auf ihrem Wirkungsgebiet nicht mit der erforderlichen Strenge vorgehe. Nach längerer Aussprache erkannte der Reichsführer die Zuständigkeit der Justizverwaltung, soweit es sich um strafbare Handlungen handele, an."

Nachdem Himmler anhand zweier Beispiele darauf hingewiesen hatte, daß die Rechtsprechung gegen die polnischen Zivilarbeiter keineswegs befriedige, versicherte er, „er habe nur den Wunsch, mit der Justiz in Frieden zur Erreichung des gemeinsamen Zieles zusammenzuarbeiten". Schlegelberger bestätigte seinerseits diesen Wunsch und bat, doch den Weg zu beschreiten, ihn zu unterrichten, falls Himmler von seinem Standpunkt aus Gerichtsurteile für unzureichend halte. Er würde dann selbst „das hiernach etwa Erforderliche veranlassen".76 Um polnische Sittlichkeitsverbrecher mit dem Tode bestrafen zu können, nahmen die Gerichte schließlich eine „Ausnutzung der durch den Kriegszustand verursachten außergewöhnlichen Verhält-


die Ergänzung des Strafgesetzbuchs vom September 1941 heran, wonach die Todesstrafe bei Sittlichkeitsverbrechen zulässig war, „wenn es der Schutz der Volksgemeinschaft oder das Bedürfnis nach gerechter Sühne" erforderte. ${ }^{76}$

Trotz Himmlers verbaler Anerkennung der Zuständigkeit der Justiz hielten die Exekutionen polnischer Zivilarbeiter auch wegen gesetzlich bestimmter Straftaten in

${ }^{73}$ Lageber. des GStA Celle v. 27.1.41 (a.a.O.).

${ }^{74}$ Verm. Schlegelbergers o.D. (Akten des RJM, BA, Sign. R 22/849). Außer auf die Rüge eines Urteils gegen einen poln. Landarbeiter durch Hitler selbst (vgl. Nürnbg. Dok. NG-280) ist Schlegelbergers scharfmacherische RV v. 24.7.41 (s. Anm. 59) wohl darauf zurückzuführen.

75 Vgl. § 4 der VO gegen Volksschädlinge v. 5.9.39 (RGBl. I, S. 1679) u. Urt. des RG v. 23.10.41 (DJ 1942, S. 19).

76 Vgl. § 1 des G. zur Änderung des RStGB v. 4.9.41 (RGBl. I, S. 549) u. Urt. des RG v. 20.11.41 (DJ 1942, S. 265). 
der Folgezeit an. ${ }^{77}$ Es erwies sich, daß sich durch Hitlers grundsätzliche Entscheidung vom September/Oktober 1939 die polizeiliche Exekution als Mittel der Korrektur der Rechtspflege generell durchgesetzt hatte.

\section{Die Einwirkung der Gestapo auf schwebende Verfahren}

\section{a. Drobungen und Schutzhaft gegen Rechtsanwälte und Prozeßbeteiligte}

Außer den geschilderten Korrekturmaßnahmen sah sich die Justiz noch anderen Methoden ausgesetzt, mit denen die Gestapo auf die Rechtsprechung einwirkte. Das Verfahren, von Angeklagten und Zeugen gewaltsame Geständnisse und Aussagen zu erpressen, wird in einem eigenen Abschnitt behandelt werden. Eine weitere Art der Einwirkung, die wohl überwiegend bei Zivilprozessen angewendet werden konnte, war die Methode, durch Schutzhaft oder Androhung von Schutzhaft Prozeßbeteiligte zur Änderung oder Unterlassung unerwünschter Klagen sowie Rechtsanwälte zur Beratung ihrer Mandanten in einem bestimmten Sinne zu zwingen. Daß die Gestapo hierbei auch auf Veranlassung der NSDAP oder ihrer Verbände tätig wurde, macht ihre Funktion als eigentliches Exekutivorgan der nationalsozialistischen Bewegung besonders deutlich. Zahlreiche Beispiele für derartige Eingriffe in die Zivilrechtspflege aus der Zeit vor der Überleitung der Justizverwaltung auf das Reich finden sich in den einschlägigen bayerischen Akten der Jahre 1933 und 1934. ${ }^{1}$ Einige Fälle aus den folgenden Jahren, mit denen sich das Reichsjustizministerium befassen mußte, seien hier angeführt.

Im Oktober 1935 wurde in München ein Gläubiger, der ein Zwangsversteigerungsverfahren gegen den Ehemann einer Altparteigenossin erwirkt hatte, auf Betreiben dieser Frau von der politischen Polizei wegen "unsozialen Verhaltens" in Schutzhaft genommen und erst wieder ehtlassen, nachdem er sich verpflichtet hatte, auf die Zwangsvollstreckung zu verzichten. Der Anwalt des Verhafteten wandte sich über die Rechtsanwaltskammer München an Gürtner, der beim Reichsinnenministerium gegen diesen Eingriff protestierte, den er ,im Interesse der Rechtssicherheit nicht zulas-

77 Bis zum Ende der Amtszeit Schlegelbergers im August 1942 sind Exekutionen poln. Zivilarbeiter im Reich (d.h. ohne eingegliederte Ostgebiete) außer den schon genannten Fällen nachweisbar in den Lageberichten: GStA Celle v. 31.5.41 (Arbeitsvertragsbrüche), 1.8.41, 27.9.41, 1.12.41, 28.7.42 (BA, Sign. R 22/3359); GStA Dresden v. 10.8.40, 12.6.41 (R 22/3362); GStA Düsseldorf v. 1.12.41 (R 22/3363); GStA Hamm v. 29.1.41 (R 22/3367); GStA Innsbruck v. 29.3.41, 29.7.42 (Diebstahl) (R 22/3368); GStA Jena v. 31.1 .41 (R 22/3369); GStA Karlsruhe v. 3.6.41 (R 22/3370); GStA Kassel v. 30.1.42 (Mord) (R 22/3371); GStA Leitmeritz v. 30.9.41 (R 22/3376); GStA Linz v. 22.4.42 (u.a. Mißhandlung) (R 22/3377); GStA Naumburg v. 3.12.40 (R 22/3380); GStA Nürnberg v. 1.8.41, 11.8.42 (R 22/3381); GStA Stuttgart v. 1.8.41 (R 22/3387); OLGPräs. Bamberg v. 29.10.42 (Tätlichkeiten gegen Deutschen) (R 22/3355); OLGPräs. Braunschweig v. 5. 5.41 (R 22/3357); OLGPräs. Düsseldorf v. 3.1.42 (R 22/3363); OLGPräs. Frankfurt a. M. v. 29.4.42 (R 22/ 3364); OLGPräs. Kassel v. 5.3.42 (Mord) (R 22/3371); OLGPräs. Kiel v. 17.5.41 (R 22/3373); OLGPräs. Königsberg v. 4.1.41 (R 22/3375); OLGPräs. Nürnberg v. 1.7.41, 4.11.41, 4.9.42 (R 22/3381). Die Lageberichte aus den OLG-Bezirken, die eingegliederte Ostgebiete betreffen, wurden nicht einbezogen, weil darin polizeil. Strafverfolgungs- von "Säuberungs“- u. Vergeltungsmaßnahmen nicht immer unterscheidbar waren.

1 Vgl. die Aufstellung Hans Franks aus diesen Jahren in den Akten des bayer. StMdJ (BayerHStArch., Sign. MJu 12003), ferner seine Schr. an das bayer. StMdI v. 23.10., 29.11.33 (Akten der bayer. StKanzlei, a.a.O., Sign. MA 105 448), 10.11.33, 3.2. u. 28.8.34 (a.a.O., Sign. MA 105491). 
sen“ könne. Seine Forderung, die Maßnahme der politischen Polizei rückgängig zu machen und das Versteigerungsverfahren zu ermöglichen, wurde vom Innenministerium mit Hinweis auf die vollendeten Tatsachen und die Stellungnahme der Polizeidirektion München abgelehnt. ${ }^{2}$

In einem Zivilrechtsstreit, an dem die „Deutsche Arbeitsfront“ (DAF) und die Gauleitung der NSDAP München interessiert waren, dessen gerichtliche Austragung für sie jedoch keinerlei Aussicht auf Erfolg besaß, wurde im März 1936 einer Grundstücksbesitzerin und einem Bauunternehmer vom DAF-Fachgruppenwalter angedroht, daß sie „nach Dachau kämen“, wenn sie nicht einen Grundstücksverkauf rückgängig machten bzw. eine Entschädigungssumme an den Käufer zahlten. Während die Frau aus Furcht eine entsprechende Erklärung unterschrieb, weigerte sich der Unternehmer und verwies auf den Rechtsweg. Als daraufhin der Rechtsanwalt der beiden die Willenserklärung der Frau als unter widerrechtlicher Drohung abgegeben $(\S 123$ BGB) anfocht, griff die politische Polizei ein und nahm seine beiden Klienten als „Volksschädlinge“ in Schutzhaft. Sie wurden erst freigelassen, nachdem sie sich unterschriftlich verpflichtet hatten, die Forderung durch notariellen Vertrag zu erfüllen und ihren Anwalt - der bei der politischen Polizei gegen das Vorgehen protestiert hatte nicht mehr zu konsultieren. Nach einem entsprechenden Bericht des Anwalts wandte sich der Präsident der Reichs-Rechtsanwaltskammer am 22. Mai 1936 an das Reichsjustizministerium mit der Bitte, „gegen diese schweren Eingriffe in die Rechtspflege und in die anwaltliche Berufsausübung mit geeigneten Maßnahmen vorzugehen". ${ }^{3}$ Während die Reaktion des Ministeriums gegenüber der Gestapo aus den Akten nicht ersichtlich ist, wurde der Gaufachgruppenwalter, der auch noch in anderen Fällen Zivilrechtsgegner von Angehörigen der DAF durch Drohung mit Schutzhaft zu Zugeständnissen veranlaßt hatte, wegen Nötigung und Erpressung angeklagt. ${ }^{4}$

Es kam vor, daß die Gestapo einzelnen Rechtsanwälten verbot, in bestimmten Sachbereichen Prozesse zu übernehmen, oder ihnen vorschrieb, sie nur unter Beachtung bestimmter Auflagen zu führen. ${ }^{5}$ Ein bezeichnender Fall, in dem die beteiligten Rechtsanwälte von der Gestapo unter massiven Druck gesetzt wurden, ereignete sich anläßlich der „Arisierung“ der Vereinigten Schlesischen Granitwerke GmbH in Breslau. Nachdem die jüdischen Gesellschafter in Schutzhaft genommen worden waren, wurde Ende März 1937 durch Verfügung Görings ein Treuhänder eingesetzt und - auch von den im Konzentrationslager sitzenden Teilhabern - ermächtigt, alle zur Überführung in arischen Besitz notwendigen Verkaufsverhandlungen zu führen. Als dieser Treuhänder auch die interne Aufteilung des Verkaufserlöses unter den jüdischen Gesellschaftern festlegte, strengte eine Mitgesellschafterin, die im Juli 1937 aus der Schutzhaft wieder entlassen worden war, eine gerichtliche Klärung ihrer ungenü-

2 Schr. Gürtners an den RuPrMdI v. 12.12.35 mit Anl.; Antwortschr. des RuPrMdI (gez. Grauert) v. 11.2.36 (Akten des RJM, BA, Sign. R 22/1467).

3 Vgl. Schr. des Präs. der RRAK an das RJM v. 22.5.36 (Diensttageb. des RJM, Bd. 8, Eintr. v. 27. 5. 36, BA, Sign. R 22/929).

4 Schr. des OStA beim LG München I v. 13.7.36 (a.a.O., Eintr. v. 14.7.36) u. v. 9. 3.37 nebst Anklage (a.a.O., Bd. 10, Eintr. v. 15.3.37, BA, Sign. R 22/706).

5 So z. B. im Mai 1935 einem Berliner RA hinsichtlich Prozessen gegen die Preußisch-Süddeutsche Staatslotterie, vgl. Korresp. zwischen BNSDJ, RJM u. Gestapa (Diensttageb. des RJM, Bd.4, Eintr. v. 16.7.35, BA, Sign. R 22/1059; Bd. 5, Eintr. v. 11.9.35, BA, Sign. R 22/1088). 
gend befriedigten Ansprüche an. Daraufhin teilte der Treuhänder ihrem Anwalt mit, daß eine prozessuale Geltendmachung der Ansprüche „staatlicherseits keinesfalls gewünscht" werde. Als der Anwalt erwiderte, daß er gegen seine Pflichten als Rechtsanwalt verstoßen würde, wenn er seiner Mandantin ohne vorherige Prüfung der Unterlagen durch einen unparteiischen Sachverständigen und damit wider seine eigene Überzeugung zur Annahme der Entscheidung des Treuhänders raten würde, bekam er zur Antwort, daß er dann „als staatsfeindlich gelten“ müsse. Am 7.Oktober 1937 wurde der Rechtsanwalt vom Leiter der Staatspolizeistelle Breslau, SS-Sturmbannführer Stahlecker, vorgeladen und informiert, daß es sich bei der vorliegenden Arisierung „um einen eindeutig politisch bestimmten“ Vorgang im Interesse des Staates handele. Ein Anwalt, der diesen Gesichtspunkt bei der Vertretung seines Klienten nicht berücksichtigen könne, beweise „damit seine Unfähigkeit, im nationalsozialistischen Sinne Rechtsvertreter bei politisch-wirtschaftlichen Maßnahmen sein zu können“. Als der Anwalt erklärte, daß ihm dann nur die Niederlegung des Mandats übrigbleibe - da er sich sonst an seiner Klientin des Parteiverrats schuldig mache -, wurde ihm das ausdrücklich untersagt und erklärt, daß auch darin ein staatsfeindlicher Akt gesehen werde, weil den staatlichen Stellen dadurch Ungelegenheiten bereitet würden. Ebenso wurde die Hinzuziehung weiterer Anwälte verboten, um nicht etwa „auf diesem Umweg eine indirekte Mandatsniederlegung zu erreichen“. Ferner wurde ihm „strikt untersagt, auch nur andeutungsweise etwa dem jüdischen Auftraggeber" oder diesem nahestehenden Personen von diesen Auflagen zu berichten; ein gegenteiliges Verhalten müsse ,als böswillige Stellungnahme wider Staatsinteressen und gleichzeitig als Versuch angesprochen werden, das deutsche Recht vor dem Ausland herabzusetzen [!] und zweifelhaft erscheinen zu lassen". Vielmehr wünsche der Staat, der Anwalt solle mit dem Treuhänder ,zusammenwirken, um den beschleunigten Abschluß der Angelegenheit umgehend zu ermöglichen“. Die Bitte des Anwalts, ihm diese Eröffnung schriftlich zu geben, lehnte Stahlecker ab und erklärte sich lediglich bereit, sie nochmals vorzulesen. Der Anwalt wurde darüber hinaus angewiesen, der Gestapo seine Handakten zum vorliegenden Fall vorübergehend auszuhändigen. ${ }^{6}$

Der derart bedrängte Rechtsanwalt erbat vom Präsidenten der Anwaltskammer Breslau Bescheid, wie er sich bei dieser Pflichtenkollision verhalten sollte. Der Präsident riet ihm, „sich vorläufig in dieser Angelegenheit untätig zu verhalten“, und sandte den Bericht des Anwalts an den Präsidenten der Reichs-Rechtsanwaltskammer nach Berlin, der das Reichsjustizministerium um Intervention bat, da die Forderungen der Gestapo mit „einer verantwortungsbewußten Rechtsberatung nicht verträglich“ seien. $^{7}$

Unterdessen waren einem Berliner Anwalt, der den Schwiegersohn der jüdischen Anteilseignerin bei der Sicherung des Pflichtteils für dessen Ehefrau vertrat, von der Berliner Gestapo die gleichen Eröffnungen gemacht worden. Wie aus dem Bericht dieses Anwalts an das Reichsjustizministerium hervorging, hatte die Berliner Staatspolizei dabei verlauten lassen, daß die massiven Drohungen der Gestapo gegen beide

6 Vgl. dazu die Schr. des Breslauer RA an den Präs. der Anwaltskammer Breslau v. 5. u. 8.10.37, sowie Notiz des schles. Gauleiters v. 6.10.37 über die Eröffnung der Gestapo an den RA (Akten des RJM, BA, Sign. R 22/2050).

7 Schr. des Präs. der Anwaltskammer Breslau an den Präs. der RRAK v. 12.10.37 u. Schr. des Präs. der RRAK an das RJM (z.H. Freislers) v. 13.10.37 (a.a.O.). 
Anwälte auf Anregung des schlesischen Gauleiters Josef Wagner erfolgten. ${ }^{8}$ Den Gegenschritten des Reichsjustizministers kam dabei der Umstand zu Hilfe, daß es sich bei dem erwähnten Schwiegersohn um den diplomatischen Vertreter Rumäniens in Ägypten und darüber hinaus um einen Duzfreund des rumänischen Königs handelte. Das ermöglichte Gürtner, beim Auswärtigen Amt Schützenhilfe zu suchen und auch $\mathrm{zu}$ finden. Aus Altenberg im Erzgebirge, wo er eine Tagung der Strafprozeßkommission leitete, schrieb Gürtner am 23. Oktober an Gauleiter Wagner, durch die Maßnahmen der Gestapo werde „den Rechtsanwälten ein Verhalten angesonnen, das, wenn nicht eine strafbare Handlung, so doch mindestens eine schwere ehrengerichtlich zu ahndende Berufsverfehlung darstellen würde“. Er bat daher dringend, daß Wagner „die polizeilichen Auflagen unverzüglich zurückziehen“ solle. Er halte diesen Schritt für ,außerordentlich eilbedürftig“, da nach seiner Unterrichtung „sonst mit diplomatischen Schritten in allernächster Zeit zu rechnen" sei. ${ }^{9}$ Abschriften des Briefes ließ Gürtner an Himmler und das Auswärtige Amt gehen. Das Auswärtige Amt, bei dem die rumänische Gesandtschaft in dieser Sache vorstellig wurde, forderte die beteiligten deutschen Stellen auf, „bei der weiteren Behandlung der Angelegenheit auch den außenpolitischen Interessen des Reichs Rechnung zu tragen". ${ }^{10}$

Gegenüber Gürtner verteidigte Wagner die Schritte der Gestapo gegen die Rechtsanwälte damit, daß sie „zur Vermeidung einer Greuelhetze und einer weiteren falschen Beratung [!] und Unterrichtung von Ausländern notwendig“ gewesen seien. Deshalb halte er es „nicht für tunlich, die erteilte Auflage im jetzigen Zeitpunkt zurückzunehmen“. Auch eine Drohung mit diplomatischen Schritten könne „die beteiligten Behörden nicht von ihren pflichtgemäßen Maßnahmen abschrecken"." dieser starken Worte gab Wagner in der Sache nach und machte bereits in seiner Antwort Vorschläge, die wenige Tage später eine Zurücknahme der erteilten Auflagen ermöglichen sollten. In einer mehrstündigen Unterredung zwischen Wagner und den beiden Rechtsanwälten am 29. Oktober 1937 wurde der Konflikt beigelegt: um den Verkauf des Unternehmens in „arische“ Hände durch die umstrittene Verteilung des Erlöses unter die jüdischen Anteileigner nicht weiter zu verzögern, sollte der Treuhänder die Verkaufssumme hinterlegen; den streitenden Gesellschaftern sollte danach gestattet werden, intern um die Verteilungsquoten zu prozessieren. ${ }^{12}$

Als der Berliner Anwalt das Justizministerium am 2. November telefonisch von der Behebung des staatspolizeilichen Eingriffs informierte, sprach er ,seinen besonderen Dank für den wirksamen Schutz des RJM aus“, der zur Lösung des Konflikts entscheidend beigetragen hätte. ${ }^{13}$ Dem Ministerium, zu dessen Aufgaben die Beaufsichtigung und Betreuung der Anwaltschaft gehörte, gelang es verschiedentlich, Rechtsanwälte, die in ihren Schriftsätzen Angriffe auf Parteistellen und Kritik an Maßnahmen der Ge-

8 Schr. des Berliner RA an das RJM v. 15.10 .37 (a.a.O.).

9 Schr. Gürtners an Wagner v. 23.10 .37 (a.a.O.).

10 Ber. des AA an das RJM v. 12.11.37 über die im Oktober erfolgten rumän. Schritte; Abschr. gingen an Himmler und Wagner (a.a.O.).

11 Schr. Wagners an Gürtner v. 26.10.37 (a.a.O.).

12 a.a.O. u. Bericht des Berliner Anwalts an das RJM v. 2.11.37 (a.a.O.). Daraufhin unterblieb die Absendung eines bereits entworfenen Schr. Freislers an Wagner über die grundsätzl. Erörterung der Frage, „ob es zweckmäßig ist, Mitgliedern der Anwaltschaft ... für ihre Berufsausübung staatspolizeiliche Auflagen machen zu lassen, ohne daß meine Vermittlung zur aufsichtlichen Bereinigung in Anspruch genommen ist“ (a.a.O.).

13 Ref. Verm. v. 2.11 .37 (a.a.O.). 
stapo ausgedrückt hatten, vor angedrohter Schutzhaft zu bewahren, indem es der Gestapo seinerseits ehrengerichtliche Verfahren gegen die betreffenden Anwälte ankündigte. Da die Einleitung solcher Verfahren nur durch schwere Pflichtverletzung gerechtfertigt war, der von den Anwälten angeschlagene Ton zwar als unerwünscht, aber „einer eingerissenen Übung“ entsprechend angesehen wurde, wurden die Ehrenverfahren dann jedoch meist nicht durchgeführt. ${ }^{14}$ Die Gestapo bevorzugte daher die Praxis, sich mit den Justizbehörden nicht erst in eine Diskussion einzulassen, sondern sie vor vollzogene Tatsachen zu stellen. Daher konnte das Ministerium in zahlreichen Fällen die Inschutzhaftnahme von Rechtsanwälten - auch soweit sie nur mit ihrer Berufsausübung zusammenhing - nicht verhindern. Entsprechende Fälle aus Bayern berichtete Hans Frank schon im Januar 1934 an das Reichsjustizministerium. ${ }^{15}$ Auf die Verhaftung der Berliner Rechtsanwälte Pünder und Wedell, die ein Entschädigungsverfahren im Fall des am 30. Juni 1934 ermordeten Klausener verhindern sollte, ist bereits eingegangen worden. ${ }^{16}$ Weitere Gründe für die Schutzhaft gegen Rechtsanwälte waren: vorwiegende Vertretung „asozial eingestellter"17 oder „staatsfeindlicher Elemente“, „unsachliche Prozeßführung“18, „mittelbare reaktionäre Bestrebungen“, ungebührliche Beschwerde gegen eine Untersagung der Sprecherlaubnis für vertretene Schutzhäftling $\mathrm{e}^{19}$, „Gefährdung staatspolitischer Belange ${ }^{\text {“20, }}$, Beratung von "gewohnheitsmäßigen Rasseschändern“, Entgegennahme von „Greuelnachrichten über das KZL Dachau“21 u.a.

Die Kompetenz, Rechtsanwälte aus diesen - in ihrer Berufsausübung liegenden Gründen zu verhaften, hatte Hans Frank als bayerischer Justizminister der politischen Polizei schon im September 1933 abgesprochen: vom bayerischen Innenminister hatte er gefordert, die Inschutzhaftnahme in diesen Fällen von seiner Genehmigung abhängig zu machen. ${ }^{22} \mathrm{Da}$ die Praxis der politischen Polizei jedoch unverändert anhielt, wandte er sich im Januar 1934 an das Reichsjustizministerium mit der Bitte, gegen diese "unerträgliche Störung des Rechtslebens“ einzuschreiten. ${ }^{23}$ Auch das preuBische Justizministerium hatte schon vor der Verreichlichung versucht, für die Schutzhaft von Rechtsanwälten die gleiche Regelung zu erreichen, wie sie das preußische Innenministerium für aktive Beamte durchzusetzen bemüht war. Beide Komplexe waren dadurch eng miteinander verknüpft worden. In einem Erlaß vom 10. November 1933 hatte das Innenministerium bestimmt, daß Staatsbeamte nur mit seiner vorherigen Genehmigung in Schutzhaft genommen werden dürften. War bei Gefahr im Verzuge eine sofortige Festnahme erforderlich, so sollte die Genehmigung unter einge-

14 Vgl. die Fälle dreier Berliner RAe und eines Dresdener RAs im Diensttageb. des RJM, Bde. 3, 4 u. 6, Eintr. v. 6.5.35, 14.8.35, 16.8.35, 19.8.35, 16.10.35 u. 17.10.35 (BA, Sign. R 22/1056, 1059, 1089).

15 Schr. des bayer. JM (gez. Frank) an das RJM v. 24.1.34 (BayerHStArch., Sign. MJu 12003).

16 Vgl. Kap. V. 1.f., S. 483.

17 Fall eines RA in Königsberg (Diensttageb. des RJM, Bd.3, Eintr. v. 8.6.35, BA, Sign. R 22/1056).

18 Fall eines RA in Koblenz (a.a.O., Eintr. v. 17.5.35).

19 Fall eines RA in Wittenberg (a.a.O., Bd.2, Eintr. v. 18.4.35, BA, Sign. R 22/603; Bd. 3, Eintr. v. 6. 5. 35, BA, Sign. R 22/1056). Vgl. dazu auch Kap. VI.2.b., S. 566, und dortige Anm. 88.

20 Fall eines RA in München, der u.a. dem Bistum Berlin angeboten hatte, die Verteidigung in Devisenstrafsachen der kathol. Kirche zu übernehmen (a.a.O., Bd.4, Eintr. v. 30.8.35, BA, Sign. R 22/1059; Bd. 5, Eintr. v. 10.9.35, BA, Sign. R 22/1088).

21 Fall eines RA in Würzburg (a.a.O., Bd.6, Eintr. v. 28. u. 29.10.35, BA, Sign. R 22/1089).

22 Schr. Franks an Wagner v. 28.9.33 (Akten des bayer. JM, BayerHStArch., Sign. MJu 12003).

${ }^{23}$ Schr. Franks an den RJM v. 24.1.34 (a.a.O.). 
hender Begründung des Vorgriffs sofort nachträglich eingeholt werden. ${ }^{24}$ In einem Begleitschreiben an die anderen preußischen Ministerien führte das Innenministerium aus, das praktizierte Vorgehen untergeordneter Behörden gegen Staatsbeamte sei ,im Interesse des Ansehens des Staates“ untragbar, weil damit „unter Umständen der Entscheidung des Fachministers über die nach dem Gesetz zur Wiederherstellung des Berufsbeamtentums zu treffenden Maßnahmen“ vorgegriffen würde. Deshalb werde es auch „den jeweils zuständigen Fachminister vorber um Stellungnahme bitten“, wenn es sich um einen Beamten aus dessen Geschäftsbereich handelte. ${ }^{25}$ Am 15. Dezember bat nun das preußische Justizministerium, den Runderlaß auch auf Rechtsanwälte auszudehnen. Es begründete die Bitte damit,

„daß den Prozeßparteien und den Angeklagten durch den plötzlichen Wegfall ihrer Vertreter oder Verteidiger schwere Nachteile erwachsen können, aber auch das Ansehen der Justiz und damit des Staates selbst wird gefährdet, wenn die erörterte Maßnahme ohne Rücksicht auf die Interessen der Rechtspflege und insbesondere auf die Notwendigkeit der Durchführung gerichtlicher Verfahren angeordnet wird". ${ }^{26}$

Als das Justizministerium darauf keine Antwort bekam und nach einigen Wochen mahnte, weil inzwischen wieder mehrere Rechtsanwälte verhaftet worden waren, erhielt es Ende Februar 1934 vom preußischen Innenministerium lediglich den $\mathrm{Be}$ scheid, daß dieses Ministerium seit dem Gestapo-Gesetz vom 30. November 1933 für die Angelegenheit nicht mehr zuständig sei. ${ }^{27}$ Erkundigungen beim Geheimen Staatspolizeiamt - in das unterdessen Himmler und Heydrich eingezogen waren - anläßlich der Verhaftung eines Berliner Anwalts führten schließlich Ende Mai zu der Auskunft der Gestapo, daß z.Z. Ausführungsbestimmungen zu den neuen Schutzhaftbestimmungen vom 12. April 1934 vorbereitet würden, bei denen die Anregung des Justizministeriums bezüglich der Rechtsanwälte berücksichtigt würde. ${ }^{28}$ In diese April-Bestimmungen hatte das Reichsinnenministerium auf Veranlassung des Reichsjustizministeriums den Passus eingefügt, daß Schutzhaft gegen Rechtsanwälte „wegen Vertretung von Interessen ihrer Klienten“ allein nicht zulässig sein sollte. ${ }^{29}$ Die Forderung der Justizverwaltung, künftig bei der Inhaftierung von Rechtsanwälten eingeschaltet zu werden, zielte darauf ab, die Tätigkeit der Gestapo auf Einhaltung dieser Bestimmung zu kontrollieren. Trotz ihrer Hoffnung erweckenden Zusagen dachte die Gestapoführung aber nicht daran, sich Fesseln anlegen zu lassen. Im Juli mußte sich das preußische Innenministerium beschweren, daß auch bei der Verhaftung von Beamten die Bestimmung über die Beteiligung der vorgesetzten Dienststellen nicht eingehalten wurde; es forderte erneut, die Gestapobehörden anzuweisen, sich vorher mit den zuständigen Dienstvorgesetzten des Beamten ins Benehmen zu setzen. ${ }^{30}$ Heydrich sah sich schließlich genötigt, Schutzhaftmaßnahmen gegen Beamte kommunaler, staatlicher und Reichsbehörden durch Erlaß vom 1. Dezember 1934 von der Genehmigung

24 RdErl. des preuß. MdI (I.V. Grauert) an die preuß. Polizeistellen und das Gestapa v. 10.11.33 (Akten des preuß. JM, GehStArch. Berlin, Sign. Rep. 84a/3715). Für Kommunalbeamte war entspr. die Genehmigung der Oberpräs. oder RegPräs. einzuholen.

${ }^{25}$ Schr. des preuß. MdI an den preuß. MinPräs. und die übrigen preuß. StMinister v. 10.11.33 (a.a.O.). Hervorheb. im Original.

26 Schr. des preuß. JM (I. V. Nadler) an den preuß. MdI v. 15.12.33 (a.a.O.).

${ }^{27} \mathrm{Vgl}$. Erinnerungsschr. des preuß. JM v. 21.2. und Antwortschr. des preuß. MdI v. 24.2.34 (a.a.O.).

${ }^{28}$ Schr. des preuß. JM an das Gestapa v. 17.5. u. Antwortschr. des Gestapa v. 30.5 .34 (a.a.O.).

29 Vgl. Kap. VI.2.a., S. 549.

30 Schr. des preuß. MdI an den preuß. MinPräs./Gestapa v. 31.7.34 (Arch. des IfZ, Sign. MA 198/2, Bl. 34 R). 
des Leiters des Geheimen Staatspolizeiamtes abhängig zu machen. Die Vorschrift wurde am 1. Februar 1935 dadurch abgeschwächt, daß die Genehmigung nicht erforderlich sei, wenn es sich „um vorläufige Festnahme im Sinne des $§ 127$ St.P.O.“ handelte, d.h. wenn Gefahr im Verzuge war. ${ }^{31}$ Immerhin lag es nun weitgehend in der Hand der Gestapozentrale selbst, wieweit sie die betreffende Verwaltung im konkreten Einzelfall an der Entscheidung beteiligen wollte. Die vorherige Zustimmung der vorgesetzten Dienststelle des betreffenden Beamten, die Frick in einem Erlaß vom 17. Juni 1935 nochmals angeordnet hatte ${ }^{32}$ und die zehn Tage später für Preußen vom preußischen Kabinett ausdrücklich beschlossen worden war $^{33}$, dürfte in der Praxis auf eine vorherige Benachrichtigung hinausgelaufen sein, wie auch aus internen GestapoErlassen ersichtlich wird. ${ }^{34}$ Notfalls konnte die Gestapo ihren Alleingang stets mit „Gefahr im Verzuge“ rechtfertigen, über deren Vorliegen sie autonom entschied. Das Reichsjustizministerium gab das vorgesehene Verfahren seinen Dienststellen jedenfalls in der vorsichtigen Formulierung bekannt, daß die Gestapo „in aller Regel“ die Zustimmung der vorgesetzten Behörde des Beamten einholen werde. ${ }^{35}$

Unter den geschilderten Umständen konnte 1934/35 dem Bestreben des Reichsjustizministeriums, die Schutzhaftverhängung gegen Rechtsanwälte von seiner vorherigen Stellungnahme abhängig zu machen, wenig Aussicht auf Erfolg beschieden sein. Nach mehrmaligem Bohren erhielt das Ministerium, das dieses Problem als Erbschaft der preußischen Justizverwaltung übernommen hatte, vom Geheimen Staatspolizeiamt am 20. Mai 1935 einen Runderlaß übersandt, in dem die Inschutzhaftnahme von nichtbeamteten Angehörigen der Justiz geregelt worden war. Danach bedurfte nun auch die Verhaftung von Rechtsanwälten, Notaren ${ }^{36}$, Konkursverwaltern und Zwangsverwaltern der vorherigen Genehmigung durch das Geheime Staatspolizeiamt selbst. War sie erteilt, so hatte die betreffende Staatspolizeistelle unverzüglich den zuständigen Oberlandesgerichtspräsidenten unter Übersendung einer Abschrift des Schutzhaftbefehls zu unterrichten. Auch hier war vorgesehen, daß bei Gefahr im Ver-

${ }^{31}$ Erl. des Gestapa (gez. Heydrich) an alle Stapostellen v. 1.12.34 u. 1.2.35 (StArch. Düsseldorf, Sign. Best. RW 18, Nr. 2). In Bayern, wo schon vorher analoge Bestimmungen erlassen worden waren, war entsprechend die Genehmigung der BPP einzuholen (vgl. die Zusammenfassung v. geitenden Schutzhaft-Vorschriften im Erl. des bayer. StMdI v. 2.5.34, Abschn. III. 7, Arch. des IfZ, Sign. Fa 119/1).

32 Erl. des RuPrMdI (gez. Frick) an die Landesregierungen (für Preußen: Preuß. MinPräs./Gestapo) v. 17.6.35, nachrichtl. dem RJM übersandt (Akten des RJM, BA, Sign. R 22/1467). Darin hieß es: „Ausnahmen ... sind in jedem Einzelfall nur mit meiner ausdrücklichen Zustimmung zulässig. Vorstehende Anordnung ersuche ich, den Beamten der Politischen Polizei nachweislich zu eröffnen. Zuwiderhandelnde werde ich dienststrafrechtlich zur Verantwortung ziehen."

${ }^{33}$ Vgl. dazu Kap. VI.2.a., S.554f. In Bayern wurde der Frick-Erl. den Dienststellen der politischen Polizei durch die RdEntschließung der BPP v. 27.6.35 bekanntgegeben (vgl. Zusammenstellung von geltenden Schutzhaftbestimmungen im Erl. der BPP v. 1.8.36, Arch. des IfZ, Sign. Fa 183/1), die ausdrücklich „die Zustimmungserklärung der vorgesetzten Dienststelle des Beamten“ forderte.

34 Vgl. schon den Erl. des Gestapa v. 5.9.34 (Arch. des IfZ, Sign. MA 443) trotz des erwähnten Erl. des preuß. MdI v. 30.11.33; ferner RdErl. des RSHA v. 22.8.42 (Befehlsbl. des Chefs Sipo/SD Nr. 38/42, S. 247). Auch in den vom RMdI selbst herausgegebenen SH-Bestimmungen v. 25.1 .38 hieß es lediglich, daß die vorgesetzte Dienststelle unverzüglich ,von der Inschutzhaftnahme des Beamten unter Angabe der Gründe in Kenntnis zu setzen" sei (Abdruck in der Allg. Erl.Sammlung des RSHA, 2 F VIII a, S. 4, Arch. des IfZ, Sign. Dc 15.21). Anders dagegen die RdEntschließung der BPP v. 27.6.35 (s. voranstehende Anm.).

35 Die Regelung wurde den Justizbehörden (den Vorständen der AGe nur mündlich) erst auf Bitten der Abt. III (Strafrechtspflege) durch die geh. RV v. 7.5 .37 bekanntgegeben, nachdem es in einem Fall Unzuträglichkeiten gegeben hatte (Akten des RJM, BA, Sign. R 22/5032, dort auch Ref. Verm. v. 19.4.37).

36 Soweit es sich um beamtete Notare handelte, sah das RJM das Problem durch die Bestimmungen betr. Schutzhaft von Beamten als geregelt an. 
zuge die Genehmigung der Gestapoführung nachträglich eingeholt werden konnte. Jedoch sollten „Rechtsanwälte und Notare nur dann vorläufig festgenommen werden, wenn unter den gegebenen Umständen mit der Verhängung der Schutzhaft nicht ohne erhebliche Nachteile für die Öffentlichkeit gewartet werden" konnte. Dagegen sollten Vormünder und Pfleger jederzeit ohne vorherige Genehmigung verhaftet werden können; auch hiervon war aber der Oberlandesgerichtspräsident zu informieren. Die Benachrichtigung des Reichsjustizministers über einschlägige Schutzhaftfälle, die dessen Geschäftsbereich „erheblich berührten“, behielt sich das Geheime Staatspolizeiamt selbst vor. ${ }^{37}$

Dieser Gestapo-Erlaß, der eine bloße Information über vollzogene Tatsachen vorsah, entsprach in keiner Weise den Wünschen der Justiz. Der zuständige Referent des Ministeriums bestand auf einer vorherigen Beteiligung der Justizverwaltung, weil es sich häufig um Schutzhaftgründe handelte, „zu deren Beurteilung und Aufklärung der zuständige Oberlandesgerichtspräsident oder das Reichsjustizministerium (ev. in $\mathrm{Zu}$ sammenarbeit mit der zust[ändigen] Anwaltskammer) entscheidend beitragen" und damit eine Schutzhaft vermeidbar machen konnte. Denn abgesehen von den erheblichen Gefahren für die Klientel errege jede Verhaftung eines Rechtsanwalts ,in der Bevölkerung und beim Zulassungsgericht wohl mindestens das gleiche Aufsehen wie die Inschutzhaftnahme eines Beamten “ ${ }^{38}$ Nach Vortrag ordnete Gürtner an, der zuständige Referent solle in einer persönlichen Rücksprache mit dem Sachbearbeiter des Geheimen Staatspolizeiamts zu erreichen suchen,

„daß die Gestapo vor Anordnung der Schutzhaft möglichst in allen Fällen, zum mindesten aber in den Fällen, in denen die Schutzhaft allein wegen der Ausübung des Rechtsanwaltsberufes (z. B. Erhebung von Klagen gegen prominente Persönlichkeiten oder in politisch unerwünschten Fällen) oder wegen eines Verhaltens erfolge, das mit der Berufsausübung in Zusammenhang steht (z.B. abfällige Bemerkungen in Schriftsätzen, kritische Bemerkungen über Art und Dauer der Schutzhaft), die Stellungnahme des RJM zur Frage der Schutzhaft einhole“.

Bei der Unterredung, die am 10. September 1935 stattfand, begründete der Leiter der Schutzhaftdienststelle des Geheimen Staatspolizeiamts die Maßnahmen gegen Rechtsanwälte damit, daß sie „häufig recht anmaßend aufträten und Rechte für sich in Anspruch nähmen, die ihnen vielleicht nach der StPO. in einem Strafverfahren, nicht aber gegenüber der Polizei zustünden“. Eine Unterrichtung des Justizministeriums vor der Inschutzhaftnahme könne meist schon deshalb nicht erfolgen, „weil sofortiges $\mathrm{Zu}$ greifen erforderlich" sei. Anhand konkreter Einzelfälle wies ihm jedoch der Vertreter der Justiz nach, daß eine telefonische Rückfrage beim Ministerium keinerlei abträgliche Auswirkungen gehabt hätte. Er benannte diejenigen Beamten im Ministerium, die für eine fernmündliche Rücksprache in eiligen Fällen zur Verfügung standen; notfalls seien die Adjutanten Gürtners und Freislers jederzeit erreichbar. Der Gestapovertreter sagte zu, die Wünsche der Justizleitung dem Reichsführer-SS vorzutragen. ${ }^{39}$

37 RdErl. des stellv. Chefs und Inspekt. der Preuß. Gestapo (I. A. Best) an alle Stapostellen v. 20.5.35 nebst Übersendungsschr. an das RJM v. gleichen Datum (Akten des RJM, BA, Sign. R 22/1467). Zur analogen Regelung in Bayern vgl. schon den zusammenfassenden Erl. des bayer. StMdI v. 2.5.34, Abschn. III.8 (Arch. des IfZ, Sign. Fa 119/1).

38 Vgl. Verm. der Ref. der Abt. V (öffentl. Recht) und I (Personal u. Organisation) v. 27.6. u. 5.7.35 (Akten des RJM, a.a.O.).

39 Vgl. Ref.Verm. v. 12.9.35 über die Unterredung am 10.9.35 (a.a.O.). Hervorheb. im Original. 
Der Vorstoß der Justiz war erfolglos. Das Schreiben, mit dem Best die Entscheidung Himmlers am 25. September mitteilte, war ein Meisterwerk der Verdrehungskunst und enthielt glatte Unwahrheiten. Best verwies zunächst auf die bereits getroffene Regelung durch den erwähnten Erlaß vom 20. Mai 1935. Um die Unmöglichkeit einer vorherigen Beteiligung der Justizbehörden zu begründen, berief sich Best auf die Schutzhaftbestimmungen Fricks vom 12./26. April 1934, an die sich jedoch die Gestapo in ihrer Praxis selbst längst nicht mehr hielt ${ }^{40}$ : eine Beteiligung sei deshalb nicht möglich, da nach diesen Bestimmungen die Schutzhaft außer zum Schutze des Betroffenen nur bei unmittelbarer Gefährdung der öffentlichen Sicherheit durch staatsfeindliche Betätigung zulässig sei (!) und gerade diese Fälle zwangsläufig größter Eile bedürften. Er räumte ein, daß in Fällen, in denen die Schutzhaft von Rechtsanwälten mit ihrer Berufsausübung zusammenhing - und bei denen das Ministerium unter allen Umständen eine vorherige Einholung seiner Stellungnahme gefordert habe -, die dienststrafrechtliche Zuständigkeit des Justizministeriums „in erheblichem Maße“ berührt werde, behauptete aber unter glatter Leugnung der tatsächlichen Gestapo-Praxis, daß gerade in diesen Fällen eine Schutzhaft nach den gültigen Bestimmungen vom April 1934 ,als nachträgliche Maßnahme im allgemeinen nicht in Erwägung gezogen werden“ könne. Für die Gestapo seien diese Fälle nur „insofern von Interesse, als sie ein Bild von der politischen Einstellung und Zuverlässigkeit des Betreffenden“ gäben. Er schlage daher vor, es bei „der bisher geübten Praxis“" zu belassen und dem Ministerium „bei der Inschutzhaftnahme von Organen der Rechtspflege ... schnellstmöglich Kenntnis zu geben“. Nur in nichteiligen Fällen - sofern dann ,überhaupt Schutzhaft zulässig sein sollte" - sei das Geheime Staatspolizeiamt bereit, auf sofortige Schritte zu verzichten und das Ministerium vorher zu benachrichtigen."

Obwohl die sophistische Argumentation der Gestapoführung im Reichsjustizministerium als „bemerkenswert“ und ihre Entscheidung als „unbefriedigend“ angesehen wurden, hielt die Justizleitung eine Fortsetzung der Verhandlungen in dieser Frage für zwecklos. Ihre Hoffnung, „weitere Vorstellungen in anderem Zusammenhang“ - offenbar bei der angestrebten Ausarbeitung neuer Schutzhaftbestimmungen - erheben zu können ${ }^{42}$, zerschlug sich jedoch gleichfalls. Die Gestapo blieb bei der Regelung, wonach die zuständige Justizbehörde und Rechtsanwaltskammer erst nach der erfolgten Verhaftung zu unterrichten waren. In einem Punkt sollte später allerdings eine Änderung getroffen werden: nachdem der Reichsjustizminister im Kriege ermächtigt worden war, einem Rechtsanwalt die Berufsausübung zu versagen, der „durch Verletzung der ihm obliegenden Pflichten staatswichtige Belange“ gefährdete ${ }^{43}$, ordnete die Gestapoführung im August 1942 an, „von der Festnahme eines Rechtsanwalts dann abzusehen, wenn sie lediglich zu dem Zweck erfolgen soll, ihn an einer weiteren Berufsausübung zu hindern". In diesem Fall sollte die Staatspolizeistelle schleunigst dem Reichssicherheitshauptamt berichten, damit von dort aus der notwendige Schritt durch das Justizministerium bewirkt werden konnte. Bei der kurz zuvor erfolgten

40 Vgl. dazu Kap. VI.2.a., S. $550 \mathrm{ff}$

41 Schr. des stellv. Chefs u. Inspekteurs der preuß. Gestapo (I. A. gez. Best) an das RJM v. 25.9.35 (Akten des RJM, a.a.O.).

42 Vgl. Ref.Vermerke v. Okt. 35 bis Juni 36 in den Akten des RJM (a.a.O.). Zum Bestreben des RJM, die durch die Praxis überholten SH-Bestimmungen von 1934 durch eindeutige neue zu ersetzen, vgl. Kap. VI.2.a., S. $560 \mathrm{f}$.

${ }^{43}$ Durch $\S 4$ der VO zur weiteren Ergänzung der Reichs-Rechtsanwaltsordnung v. 24.6.41 (RGBI. I, S.333). 
Übernahme des Ministeriums durch Thierack erwartete die Gestapo offenbar, daß die Justiz künftig von sich aus schärfer durchgreifen werde. Da jedoch auch in dieser neuen Regelung eine Verhaftung bei Gefahr im Verzuge vorgesehen war $^{44}$, konnte die Gestapo eine eventuelle gegenteilige Entscheidung des Reichsjustizministeriums stets ignorieren. Wie in anderen Bereichen gab die Gestapo auch bei der Schutzhaftverhängung gegen Rechtsanwälte als Mittel korrigierenden Eingriffs in die Rechtspflege ihre Prärogative nicht aus der Hand.

Im Gegensatz zur Verhaftung von Rechtsanwälten und anderen Prozeßbeteiligten sind Fälle der Anwendung von Schutzhaft gegen Richter wegen ibrer Sprucbtätigkeit nicht bekannt geworden.

\section{b. Auseinandersetzung um die "verschärfte Vernebmung" von Beschuldigten durch die Polizei}

Die Methode, politische Gefangene durch Anwendung körperlicher Gewalt gefügig zu machen und zu belastenden Aussagen zu veranlassen, wurde durch die als improvisierte Hilfspolizei tätige SA und SS schon in der ersten Phase der ,nationalsozialistischen Revolution" mit Erfolg angewendet. Der Erlaß des Staatssekretärs im preußischen Innenministerium Grauert vom 29. Mai 1933 an alle Regierungspräsidenten, die Vernehmung politischer Straftaten Verdächtiger statt den ordentlichen Polizeibehörden besser diesen Hilfspolizeibeamten zu überlassen ${ }^{45}$, legt dafür ein beredtes Zeugnis ab. Auch Himmlers und Heydrichs wohlorganisierte politische Polizei sollte auf diese Methode in den folgenden Jahren nicht verzichten. Für die Justiz erwiesen sich solche erpreßten Aussagen als Beweismittel jedoch praktisch wertlos, wenn sie von den Angeklagten vor Gericht widerrufen wurden. Sie führten im Gegenteil verschiedentlich zu Ermittlungen gegen die vernehmenden Gestapobeamten - meist wegen Mißbrauchs der Amtsgewalt, Körperverletzung im Amt und Aussageerpressung (§§ 339, 340 und $343 \mathrm{StGB}$ ) - und damit zur Auseinandersetzung mit der Gestapoführung. So sprach das Landgericht Berlin Anfang 1934 in einer politischen Strafsache Angeklagte frei, weil sie behaupteten, zu ihren Geständnissen erpreßt worden zu sein, während der darüber befragte verantwortliche Kriminalsekretär eine Aussage „aus dienstlichen Gründen" verweigerte. Der Kriminalsekretär suchte daraufhin die Staatsanwaltschaft beim Kammergericht auf und berichtete, daß sich bei einem vor diesem Gericht noch anstehenden Hochverratsprozeß „dasselbe Bild ergeben“ werde: die Beschuldigten seien auch ,in dieser Sache sehr verstockt gewesen, so daß Geständnisse auf ordnungsmäßigem Wege nicht hätten herbeigeführt werden können“. Tatsächlich sprach das Kammergericht am 25. August auch in dieser Sache jene Angeklagten frei, deren Aussagen - auf denen die Anklage beruhte - durch Mißhandlungen erzwungen worden waren. Der Generalstaatsanwalt beim Landgericht Berlin ordnete daraufhin gegen die Polizeibeamten Ermittlungen an. ${ }^{46}$ Nach seinem ersten unvollständigen Bericht handelte es sich um sechs Ermittlungsverfahren mit insgesamt 39 Verletzten; die ermit-

\footnotetext{
44 Vgl. RdErl. des RSHA v. 22.8.42 Abschn. II: Maßnahmen gegen Notare, Rechtsanwälte, Nachlaß-, Konkurs-, Zwangsverwalter, Pfleger und Vormünder (Befehlsbl. des Chefs Sipo/SD Nr. 38/42, S. 247).

45 Zum „Grauert'schen Erlaß" vgl. Kap. IV. 2. b., S. 359, Anm. 104.

46 Ber. des GStA beim KG an das RJM v. 30.11. u. 27.12.34 (Diensttageb. des RJM, Bd. 1, Eintr. v. 8. 12.34 u. 4.1.35, BA, Sign. R 22/131).
} 
telten Täter waren auf Weisung der Gestapoführung ,in Schutzhaft genommen“ worden, offenbar um einer Untersuchungshaft vorzubeugen. Der Generalstaatsanwalt beim Kammergericht ersuchte die Staatsanwaltschaft beim Landgericht, einen Beamten ausschließlich für die beschleunigte Durchführung der Verfahren abzustellen. ${ }^{47}$ Bei diesem Oberstaatsanwalt erschien am 25. April 1935 der Leiter der zuständigen Staatspolizeistelle und trug ihm die Bedenken vor, die gegen die Verfahren sprachen: „Nachrichten über die beanstandeten Vernehmungsmethoden würden an die Öffentlichkeit dringen und dem Wohl des Reiches schaden“, ferner würde die „Autorität der Staatspolizei“ leiden. Deshalb werde er „bei seinen vorgesetzten Dienststellen die Herbeiführung einer Niederschlagung“ anregen. In seinem Bericht über diesen Vorgang betonte der Generalstaatsanwalt beim Kammergericht, „daß es sich bei den Ausschreitungen um systematische, durch lange Zeit ständig angewandte Vernehmungsmethoden" handele, und verglich die Art der Mißhandlungen mit denjenigen im Lager Bredow, die im Frühjahr 1934 durch das Stettiner Verfahren gesühnt worden waren. Gegen die von der Gestapo vorgebrachten Argumente führte er an, daß ein Bekanntwerden der polizeilichen Mißhandlungen doch nicht verhindert werden könne, dem Reich aber gerade dann Schaden zugefügt werde, wenn die Öffentlichkeit erfahre, daß die schuldigen Beamten nicht bestraft würden: dadurch werde die kommunistische Hetze erst recht verstärkt werden. Eine Bestrafung werde keineswegs die Autorität der Gestapo, sondern nur das persönliche Ansehen der betroffenen Polizeibeamten gefährden. Er beabsichtige daher, die Verfahren beschleunigt durchzuführen, falls er nicht gegenteilige Weisung erhalte. ${ }^{48}$

Ende März 1935 hatte auch der Generalstaatsanwalt Düsseldorf an das Justizministerium berichtet, daß in den Polizeigefängnissen von Elberfeld, Düsseldorf, Duisburg, Remscheid und Wuppertal erheblich mißhandelt wurde: von den Gestapostellen seien „dienstliche Weisungen ergangen, bei gewissen Gefangenen Aussagen mit allen Mitteln herbeizuführen“. Seit Jahresanfang hätten sich in seinem Bezirk neun Selbstmorde und ein Selbstmordversuch von politischen Häftlingen ereignet, die höchstwahrscheinlich darauf zurückzuführen seien. Ermittlungen würden dadurch erschwert, daß der Leiter der Staatspolizeistelle Düsseldorf vermutliche Täter nicht zur verantwortlichen Vernehmung überstelle. Der Generalstaatsanwalt hielt jedoch ein energisches Vorgehen deshalb für notwendig, weil sonst auch die Verfolgung der Mißhandlungen im Lager Kemna ${ }^{49}$ gefährdet sei: die im Kemna-Komplex Beschuldigten könnten sich sonst mit Recht auf die milde Behandlung der hier in Frage stehenden Mißhandlungen durch die politische Polizei berufen. Auch er betonte, daß die erprügelten Geständnisse vor Gericht jeder Beweiskraft entbehrten. ${ }^{50}$ Die Staatspolizeistelle Düsseldorf wiederum, die in ihren Berichten an das Innenministerium die Bekämpfung des angeblich wieder auflebenden Kommunismus „unter dem Gesichtspunkt eines Staatsnotrechts" betrachtet wissen wollte, beschwerte sich über den Generalstaatsanwalt: er habe „neuerlich bei jedem kommunistischen Selbstmörder die Vornahme richterlicher Leichenschau angeordnet, um feststellen zu lassen, ob der Tote

47 Ber. des GStA beim KG an das RJM v. 26.4.35 (a.a.O., Bd.3, Eintr. v. 2. 5.35, BA, Sign. R 22/1056).

. ${ }^{48}$ Ber. des GStA beim LG Berlin v. 2.5.35, vom GStA beim KG am 4.5.35 an das RJM gegeben (a.a.O., Eintr. v. 10.5.35)

49 Vgl. dazu Kap. IV.2.b., S. 353 ff.

so Ber. des GStA Düsseldorf an das RJM v. 29.3.35 (a.a.O., Bd. 2, Eintr. v. 2.4.35, BA, Sign. R 22/603). 
etwa vorher ,hart' angefaßt worden" sei. Die Justizbehörden, die immer noch den „starren Standpunkt der bestehenden Gesetze“ verträten, stärkten dadurch dem Kommunismus den Rücken. ${ }^{51}$

Berichte über polizeiliche Mißhandlungen erhielt das Reichsjustizministerium auch aus dem Bezirk Hamburg ${ }^{52}$, wo das Oberlandesgericht im Hochverratsverfahren gegen den ehemaligen Leiter des Rotfrontkämpferbundes im Gau Wasserkante, Fritz (Fiete) Schulze, das im März 1935 mit einem Todesurteil endete, die erprügelten Zeugenaussagen nur soweit wertete, als sie mit anderen Beweiserhebungen übereinstimmten. ${ }^{53}$ Als das ehemalige Mitglied der Hamburger kommunistischen Bürgerschaftsfraktion Westermann nach einem fünfzehnstündigen Verhör im Hamburger Stadthaus - bei dem es gezwungen wurde, nach und nach die kommunistischen Gruppenleiter der Hafen- und Werftarbeiter preiszugeben - erkrankte und am 16. März 1935 im Konzentrationslager starb, forderte Justizsenator Rothenberger von der Gestapo einen genauen Bericht über die Art des Verhörs, da die Leiche Spuren von Mißhandlungen aufwies. Erst nach nochmaliger Mahnung erhielt Rothenberger am 29. März kurzerhand die Mitteilung, ein Bericht brauche nicht mehr erstattet zu werden, da Hamburgs Gauleiter Kaufmann die Angelegenheit mit Gürtner in Berlin besprochen habe. Dazu findet sich jedoch im Diensttagebuch des Reichsjustizministeriums der bezeichnende Vermerk: „Nach Mitteilung des Herrn Ministers muß hier ein Mißverständnis vorliegen. Herrn Statthalter Kaufmann gegenüber hat Herr Min. auf den Bericht in der Sache Westermann nicht verzichtet." ${ }^{\text {"54 }}$ Die Hamburger Staatsanwaltschaft stellte jedenfalls am 25.April in einem Schreiben an die Staatspolizeistelle warnend fest, daß es sich bei den aufgetretenen Mißhandlungen „offenbar nicht um einzelne Übergriffe im Affekt, sondern um systematische Aussageerpressung handele, die mit politischem Übereifer nicht entschuldigt werden" könnten und folglich auch nicht unter das Straffreiheitsgesetz vom August 1934 fielen. $^{55}$

In dieser Lage forderte Himmler in einem Schreiben vom 28. März 1935 vom Reichsjustizministerium die Anerkennung der Rechtmäßigkeit der gewaltsamen Vernehmungsmethoden seiner Polizeiorgane und deren strafrechtliche Nichtverfolgung. Himmler gab eine Übersicht über den bezirksweisen Wiederaufbau und das ständige Anwachsen der illegalen kommunistischen Bewegung in Deutschland, deren Ursache er , ,in erster Linie in den unzulänglichen Mitteln der Verfolgung“ sah. Schon im Weimarer Staat seien „die auflösenden Wirkungen der unzulänglichen formellen und materiellen Gesetzesbestimmungen durch einsichtige und verantwortungsbewußte Kräfte erkannt worden": so habe auch das Reichsgericht übergesetzliche Staatsnot-

51 Im Diensttageb. des RJM zit. aus den Lageber. der Stapostelle Düsseldorf, die vom RMdI übersandt worden waren (Eintr. v. 24.4.35, a.a.O.).

52 Vgl. Ber. des GStA Hamburg v. 14.3. u. 27.4.35 (a.a.O., Eintr. v. 21.3. u. 30.4.35); vgl. auch Nürnbg. Dok. NG-656, Bl. 16 (Arch. des IfZ).

53 Vgl. Eintr. im Diensttageb. des RJM v. 18.4.35 (a.a.O.), gestützt auf Abschriften aus dem Urt. v. 18. 3.35, die vom GStA Hamburg übersandt wurden. Als am 18.6.35 die dänische Zeitung „Politiken“ über einen ähnlichen Fall vor dem OLG berichtete, empfahl der OLGPräs. dem Senatsvorsitzenden, in solchen Situationen die Öffentlichkeit auszuschließen (a.a.O., Eintr. v. 1.7.35, BA, Sign. R 22/1059).

54 Ber. des GStA Hamburg an das RJM v. 4.4.35 (a.a.O., Bd.3, Eintr. v. 16.5.35, BA, Sign. R 22/1056).

5s Zit. im späteren Schr. Heydrichs an das RJM (a.a.O., Bd.4, Eintr. v. 27.7.35, BA, Sign. R 22/1059). Im Diensttageb. des RJM sind Fälle auch aus anderen Bezirken vermerkt, so aus dem LG-Bez. Halle (OLG-Bez. Naumburg), vgl. Eintr. v. 8. 6.; 12.6.; 27.6.; 19.8.; 2.10. u. 11. 10.35; und aus dem LG-Bez. Chemnitz (OLGBez. Dresden), vgl. Eintr. v. 12.10; 15.11.35. 
wehr und Staatsnotstand anerkannt. Wer den Staat bekämpfe, habe keinen Anspruch auf den Schutz der Strafgesetze; vielmehr habe der Staat „die Pflicht, seinen Vollzugsorganen Mittel in die Hand zu geben, die es ermöglichen, staatliche Autorität dem Verbrecher gegenüber durchzusetzen“. Insbesondere müßten sie den Rechtsbrecher „schon im polizeilichen Ermittlungsverfahren in gehöriger Weise anfassen können“. ${ }^{56}$

Der Reichsjustizminister beantwortete dieses Schreiben am 14. Mai an die Adresse des 1935 noch für die Polizei zuständigen Reichs- und Preußischen Ministers des Innern. Gürtner lehnte die Aussageerpressung durch körperliche Mißhandlungen als polizeiliches Mittel rundweg ab und forderte demgegenüber ein generelles Verbot dieser Maßnahme. Er verteidigte das Recht gegenüber den Vorstellungen der Gestapo mit folgenden Argumenten:

„Das z.Z. geltende Strafgesetz, dessen Durchführung meines Amtes ist, bedroht Beamte, die Mißhandlungen im Amte ausführen, besonders dann, wenn diese Mißhandlungen zur Herbeiführung von Geständnissen und Aussagen erfolgen, mit besonders schweren Strafen ... Bei dieser Rechtslage ist es nicht angängig, einem Teil der Polizeibeamtenschaft stillschweigend die Erlaubnis zur Erpressung von Aussagen durch körperliche Mißhandlung der Hättlinge zu erteilen. Eine derartige Maßnahme würde die Achtung vor den bestehenden Gesetzen auf das Empfindlichste erschüttern und damit notwendig zur Verwirrung und Demoralisierung der betreffenden Beamten führen."

Gürtner legte dar, daß erfahrungsgemäß Menschen, die mit Prügeln beauftragt würden, meist binnen kurzem das Gefühl für den eigentlichen Zweck ihrer Handlungen verlören und sich von Rachegefühlen oder sadistischen Neigungen leiten ließen. Er fuhr fort:

„Im übrigen sind derartig erpresste Aussagen insoweit als sie als Grundlagen für Hochverratsverfahren dienen sollen, praktisch bedeutungslos. Die Hochverratssenate erklären, nachdem sie aus zahlreichen Verfahren die Überzeugung gewonnen haben, daß die polizeilichen Aussagen und Geständnisse der Angeklagten durch Mißhandlungen erpreßt sind, in immer stärkerem Umfange die polizeilichen Aussagen der Angeklagten für wertlos und messen ihnen in ihren Urteilen keinerlei Beweiswert mehr bei."

Gürtner stützte dabei die Behauptung, daß die bestehende gesetzliche Regelung auch dem Willen Hitlers entspräche, mit dem Hinweis, daß Hitler anläßlich der Röhm-Affäre die Erschießung dreier SS-Angehöriger angeordnet hätte, die in Stettin Gefangene mißhandelt hatten - sicher eine fragwürdige und verzweifelte Methode, als Beweis für die Anerkennung der Rechtsnormen durch Hitler die rechtswidrige Erschießung von drei Strafhäftlingen heranzuziehen, die ihre gerichtlich zugesprochene Zuchthausstrafe verbüßten. ${ }^{57}$ Gürtner argumentierte weiter, daß durch die von der Gestapo angewendeten Vernehmungsmethoden wohl Teilerfolge, „niemals aber die auf die Dauer allein wertvolle Gesamterfassung und Vernichtung eines illegalen revolutionären Apparates erreicht" werden könnten: wie die Ausführungen der Gestapo zeigten, gelinge es gewiegten Revolutionären sehr bald, „durch geschickte Tarnung aller wichtigen Funktionäre, die Möglichkeit des Verrates als Folge von Mißhandlungen praktisch im wesentlichen auszuschalten“. Gürtner schloß, es sei daher „erforderlich, daß der zuständige Ressortminister an alle Polizeibehörden jeder Art ein einschrän-

56 Schr. Himmlers als stellv. Inspekteur der Gestapo an das RJM v. 28.3.35 (a.a.O., Bd. 2, Eintr. v. 2.4.35, BA, Sign. R 22/603).

57 Vgl. Kapitel IV.2.b., S. 352, und V.1.d., S.458. 
kungsloses Verbot der Mißhandlung von Häftlingen zum Zwecke der Aussageerzwingung erläßt". ${ }^{58}$

Doch Frick, dem um diese Zeit die Zuständigkeit über die Gestapoangelegenheiten immer mehr entglitt ${ }^{59}$, konnte oder wollte ${ }^{60}$ sich in dieser Sache nicht engagieren, so daß sie zwischen Justizministerium und Gestapoführung ausgetragen werden mußte. Im Juli übersandte Heydrich dem Ministerium mehrere Strafakten der Hamburger Staatsanwaltschaft gegen Polizeibeamte, die ihm von der Staatspolizei Hamburg übermittelt worden waren. Ähnlich wie Himmler führte er dazu aus, das „Vordringen des Kommunismus sei darauf zurückzuführen, daß es mit den der politischen Polizei zur Verfügung stehenden absolut unzulänglichen Mitteln nicht gelungen sei, entscheidend in den illegalen Funktionärapparat der KPD. einzudringen". Aus einer beigelegten illegalen Broschüre über Abwehrmaßnahmen gegen die Arbeitsmethoden der Gestapo ergebe „sich wieder der Beweis für die in letzter Zeit fast ausnahmslos festgestellte Aussageverweigerung". Aus der Haltung der Hamburger Justizbehörden spreche „eine Verkennung der politischen Lage, welche bei einer Verallgemeinerung katastrophale Folgen haben“ könne. Heydrich behauptete, „daß den anzeigeerstattenden Kommunisten bereits wieder mehr geglaubt werde als den Organen des Staates“, die Tag und Nacht ihre Kraft und ihre Gesundheit zum Wohle des nationalsozialistischen Staates einsetzten. „Wenn es der KPD. gelinge, einige Verfahren gegen politische Kriminalbeamte mit Erfolg durchzuführen, werde diese Tatsache in allen illegalen Schriften entsprechend propagiert werden mit dem Erfolg, daß der Funktionärkörper einen neuen Auftrieb erhalte." Aus diesem Grunde bat er, die von der Hamburger Staatsanwaltschaft eingeleiteten Verfahren „bis zur grundsätzlichen Entscheidung durch den Führer auszusetzen". 61

Eine grundsätzliche Entscheidung Hitlers, die diese Methoden der Gestapo entweder untersagt oder aber formell-rechtlich geregelt hätte, sollte allerdings auf sich warten lassen. Der Schwebezustand blieb bestehen und schlug sich deutlich in der Behandlung der Berliner Fälle nieder. Hier waren einige Verfahren gegen Gestapobeamte aufgrund des Amnestiegesetzes vom 7. August 1934 eingestellt worden, in anderen Fällen waren die Täter dank der Haltung der Polizeibehörden nicht zu ermitteln gewesen $^{62}$ : erneut zeigte sich die Ohnmacht der Justiz, wenn es galt, gegen Angehörige jener Organisation vorzugehen, auf deren Ermittlungen sie dabei angewiesen war. In einem Verfahren gegen zwei Gestapobeamte und einen Hauptmann der Schutzpolizei, die in gerichtliche Untersuchungshaft genommen werden konnten, sollte es zu einem regelrechten Tauziehen kommen. Die beiden Gestapobeamten konnten in 6 bzw. 22 Fällen, der Polizeihauptmann in zwei Fällen einwandfrei der Aussageerpressung und Mißhandlung im Amt überführt werden, wobei sich die Ermittlungsergeb-

${ }^{8}$ Schr. Gürtners an Frick betr. Mißhandlungen von kommunistischen Häftlingen durch Polizeibeamte v. 14.5.35 (Nürnbg. Dok. PS-3751, IMG Bd.XXXIII, S. 56 ff.).

59 Vgl. dazu Kap. VI.2.a., S.551 ff.

${ }^{60} \mathrm{H}$. Frank berichtet, daß sich Gürtner über Fricks Schwäche empört geäußert habe: „Frick ist ein guter und braver Mann, aber als Innenminister zu feige. Daß er erklärt, es schade nichts, wenn Himmler die Juden und Staatsfeinde fest anpacke', ist ein furchtbarer Freibrief für Heydrich und Konsorten " (Im Angesicht des Galgens, München-Gräfelfing, 1953, S. 161).

61 Vgl. Diensttageb. des RJM, Bd.4, Eintr. v. 27.7.35 (BA, Sign. R 22/1059).

62 Vgl. die Ber. des GStA beim LG Berlin v. 6.4.35 (Diensttageb. des RJM, Bd. 2, Eintr. v. 17.4.35, BA, Sign. R 22/603) u. v. 8. 5.35, des GStA beim KG v. 18. u. 25.5.35 (a.a.O., Bd. 3, Eintr. v. 23.5. u. 3.6.35, BA, Sign. R 22/1056). 
nisse nicht nur auf Angaben der Mißhandelten, sondern auch auf Zeugenaussagen beteiligter Kriminalbeamter und teilweise sogar auf Geständnisse der Beschuldigten selbst stützten. Die teils im Berliner Polizeipräsidium, teils in verschiedenen Polizeirevieren begangenen Untaten zeugten von solcher Brutalität, daß die Justiz auf Durchführung des Strafverfahrens bestand. Ein Mißhandelter war von einem der Gestapobeamten vierzigmal mit Jiu-Jitsu-Griff zu Boden geworfen worden, und zwar so, daß er mit dem Hinterkopf aufschlug, und anschließend jedesmal gewürgt worden. Schließlich wurden ihm die Beine auseinandergedrückt und mit einem Kabelstück zwischen die Beine geschlagen. Nachdem ihm der Polizeihauptmann gedroht hatte, ihn in Lichterfelde erschießen zu lassen, wurde ihm das Ehrenwort abgenommen, daß er auch vor Gericht "richtig aussagen“ werde. Ein anderes Opfer erhielt derartige Faustschläge, daß ihm der Unterkiefer brach. Unter den Mißhandelten befanden sich sechs Frauen, die mit Fäusten und Gummiknüppeln bearbeitet und anschließend an den Haaren oder an einem um den Hals geschlungenen Handtuch auf dem Boden durchs Zimmer geschleift wurden, wobei sie zu ersticken drohten. Eine Anzahl der Mißhandelten war in den anschließenden Gerichtsverfahren freigesprochen worden, weil ihnen die Behauptung über eine gewaltsame Geständniserpressung nicht widerlegt werden konnte. $^{63}$

$\mathrm{Da}$ es sich bei den beiden Gestapobeamten „um in hohem Maße verdiente Vorkämpfer der nat.soz. Bewegung" handelte, schaltete das Geheime Staatspolizeiamt - wo SS-Standartenführer Best für eine sofortige Haftentlassung und Niederschlagung eintrat - die Kanzlei des Führers ein, die sich bei der Präsidialkanzlei zunächst um die Haftentlassung zumindest eines der Gestapobeamten bemühte, da der Gesundheitszustand beider Untersuchungsgefangener „besorgniserregend“ sei. In ihrem Schreiben kündigte die Kanzlei des Führers gleichzeitig an, daß sie sich bei Hitler für eine Niederschlagung des Verfahrens einsetzen werde. Ferner wurde darin ausgeführt, daß die beiden Beamten ,ihre Aufgabe nur erfüllen konnten, wenn sie von Fall zu Fall die ihnen geeignet erscheinenden und bei den jeweils gegebenen Umständen erforderlichen Maßnahmen ergriffen“ hätten. Es sei „ein groteskes Bild, daß Zuchthäusler [!] als Ankläger gegen Beamte des Dritten Reiches“ aufträten. Die Kanzlei des Führers versäumte darüber hinaus auch nicht, den untersuchungsführenden Staatsanwalt darauf hinzuweisen, daß „der gesamte Fragenkomplex in nächster Zeit Gegenstand einer Besprechung beim Führer" sein werde. ${ }^{64}$ Doch die Staatsanwaltschaft blieb fest: als der Haftbefehl gegen den erwähnten Gestapobeamten am 15. August vom zuständigen Berliner Amtsgericht aufgehoben wurde, weil Fluchtverdacht und Verdunkelungsgefahr nicht bestünden, wurde dieser Beschluß aufgrund ihrer Beschwerde revidiert. ${ }^{65}$

Wie bereits angekündigt, wandte sich der Chef der Kanzlei des Führers, Reichsleiter Bouhler, am 23. August 1935 mit der Bitte an die Präsidialkanzlei, das Verfahren niederzuschlagen, da ein Prozeß das „Staatsinteresse gefährden und der ausländischen Hetzkampagne gegen das Dritte Reich neuen Stoff zuführen“ werde. Disziplinarmaß-

${ }^{63}$ Vgl. die Ber. des GStA beim LG Berlin v. Juli 35 (a.a.O., Bd.4, Eintr. v. 29.7.35, BA, Sign. R 22/1059), v. 27.8. u. 27.9 .35 (a.a.O., Bd. 5, Eintr. v. 3.9. u. 3.10.35, BA, Sign. R 22/1088).

64 Diensttageb. des RJM, Bd. 4, Eintr. v. 16.8.35 (BA, Sign. R 22/1059). Das Schr. der Kanzlei d. F. wurde am 13.8.35 von Meissner dem RJM übersandt.

65 Ber. des GStA beim LG Berlin v. 21.8.35 (a.a.O., Eintr. v. 30.8.35). 
nahmen gegen die Polizeibeamten genügten als Sühne völlig. ${ }^{66}$ Drei Tage später rief Stabsleiter Brack von der Kanzlei des Führers den Sachbearbeiter der Staatsanwaltschaft an und teilte ihm mit, daß er bei Hitler einen förmlichen Antrag auf Niederschlagung einreichen werde. Vergebens versuchte er dabei, für die beiden in Untersuchungshaft befindlichen Gestapobeamten einen dringend notwendigen „Kuraufenthalt" durchzusetzen. ${ }^{67}$ Für den am 24. August gleichfalls verhafteten Polizeihauptmann verwandte sich der Berliner Polizeipräsident Graf Helldorf beim Oberstaatsanwalt: die Untersuchungshaft des Polizeioffiziers sei „aus staatspolitischen Gründen untragbar“, da er sich um die Bekämpfung des Kommunismus besonders verdient gemacht habe. Der Beamte trage ,infolge einer schweren Schädelverletzung, die er im Kampf mit Kommunisten erhalten habe, einen besonderen Haß gegen den Kommunismus mit sich“; schon triumphiere aber die Kommune über seine Verhaftung. Im Falle einer Haftentlassung sei Verdunkelungsgefahr ausgeschlossen, wenn dem Beschuldigten „das dienstliche Verbot erteilt werde, mit irgend jemand über den Gegenstand des gegen ihn schwebenden Ermittlungsverfahrens zu sprechen“. Helldorfs Argumente überzeugten jedoch nicht: der Generalstaatsanwalt beim Kammergericht wies den Oberstaatsanwalt an, Helldorf zu erklären, daß eine Haftentlassung nicht vertreten werden könne - es sei denn, der Beschuldigte werde dafür in Schutzhaft genommen. ${ }^{68}$

Am 6. September sprach Bouhler bei Gürtner vor und bat, die Verfahren gegen die drei Polizeibeamten einzustellen und sie „zwecks Klärung des Falles auf disziplinärem Wege ihren vorgesetzten Dienststellen zuzuweisen“. Gürtner sagte jedoch lediglich zu, die Frage der Entlassung eines der Gestapobeamten und des Polizeioffiziers aus der Untersuchungshaft zu prüfen. ${ }^{69}$ Nunmehr reichte Brack einen förmlichen Antrag auf Niederschlagung bei der Präsidialkanzlei ein, den der Leiter der Polizeiabteilung im Innenministerium, SS-Obergruppenführer Daluege, am 25.September dem Reichsjustizministerium abschriftlich mitteilte. Es enthielt die bereits erwähnten Argumente, die Daluege voll unterstützte. ${ }^{70}$

Nachdem sich der Generalstaatsanwalt beim Landgericht Berlin in seinem abschlieBenden Bericht über das Ermittlungsverfahren vom 27. September 1935 nochmals ausdrücklich gegen eine Aufhebung des Haftbefehls für die drei Beschuldigten ausgesprochen hatte ${ }^{71}$, meldete sich Bouhler am 11. Oktober mit einem Schreiben beim Justizministerium: da er seit seinem Besuch bei Gürtner vor fünf Wochen nichts mehr gehört habe, habe er heute die Angelegenheit Hitler unterbreitet. Hitler habe ihn daraufhin beauftragt, dem Justizminister mitzuteilen, „daß die Genannten sofort aus der Haft zu entlassen und daß die gegen sie schwebenden Verfahren einzustellen" seien. ${ }^{72}$

Diese Entscheidung sowie die kurze Zeit später verfügte Erlassung der Reststrafen für die im Hohnstein-Prozeß Verurteilten machten der Justiz deutlich, daß Hitler ungesetzliche Gewaltmethoden in Einzelfällen billigte. In dem Kriminalfall des Knabenmörders Seefeld, der am 22. Februar 1936 vom Landgericht Schwerin zum Tode ver-

66 a.a.O., Eintr. v. 30.8.35.

${ }^{67}$ a.a.O., Bd. 5, Eintr. v. 3.9.35 (BA, Sign. R 22/1088).

68 Bericht des GStA beim KG v. 31.8 .35 (a.a.O.).

69 Diensttageb. des RJM, Eintr. v. 12.10.35 (a.a.O.).

70 a.a.O., Eintr. v. 30.9.35.

71 a.a.O., Eintr. v. 3.10.35.

72 a.a.O., Eintr. v. 12.10.35. 
urteilt wurde, ordnete Hitler sogar persönlich die „verschärfte Vernehmung“ an. Hitler selbst berichtete darüber: „Gürtner zögerte. Ich sagte ihm, ich möchte, daß der Mann vernommen wird von der Gestapo; es wird ihm nichts passieren, er kriegt vielleicht Prügel. ${ }^{\text {"73 } 3}$ Bezeichnenderweise wurde hierbei die vorübergehende Übergabe an die Gestapo offiziell damit begründet, daß „sich bei Seefeld Zweifel aufgetan hatten über eine mögliche Identität mit einem kommunistischen Geheimagenten gleichen $\mathrm{Na}$ mens“. Wie zu erwarten, war das Ergebnis des Verhörs ,in bezug auf seine politische Tätigkeit negativ“, in anderer Hinsicht dagegen „ein umfassendes und eingehendes Geständnis" ${ }^{.74}$ Auch mit dieser eindeutigen, fast persönlichen Niederlage, die Gürtner bei seinem Bestreben um die Abschaffung der gewaltsamen Vernehmungsmethoden erlitten hatte, war immer noch keine Entscheidung darüber gefallen, ob die Justiz "verschärfte Vernehmungen" durch Polizeibeamte grundsätzlich nicht mehr verfolgen sollte. Die Ermittlungen der Staatsanwaltschaften und die Auseinandersetzung zwischen Justiz und Gestapo über diese Fälle hielten deshalb auch in den folgenden Monaten an. ${ }^{75}$ Betroffene Staatanwaltschaften reagierten zum Teil durch Anordnungen, daß wenigstens Häftlinge aus den Gefangenenanstalten ihres Bezirks bis auf weiteres nicht mehr zu Vernehmungen oder Gegenüberstellungen ins Polizeigefängnis überführt werden durften. ${ }^{76}$ Immerhin war aber die Justiz durch Hitlers Verhalten verunsichert. Als der Oberstaatsanwalt Duisburg im Januar 1936 in einem Fall, der mit Selbstmord des Gefangenen geendet hatte, ein Strafverfahren einleitete, sollte - im Hinblick auf die erwähnten Entscheidungen Hitlers - wegen einer Durchführung des Prozesses vorher an Hitler berichtet werden. ${ }^{77}$ Himmler nahm diese Angelegenheit zum Anlaß, um in einem Schreiben vom 30. März zu dem ganzen Problem abermals grundsätzliche Ausführungen zu machen. Er erklärte zunächst, daß der im vorliegenden Fall verstorbene Gefangene „5 Stockhiebe“ bekommen habe, weil er sich bei seiner Vernehmung "gemäß den kommunistischen Anweisungen" verhalten habe. Die Genehmigung zu diesen Stockhieben habe er (Himmler) ,nachträglich erteilt“. Daraus geht hervor, daß die Anwendung der „verschärften Vernehmung“ gegen mutmaßliche Hochverräter innerdienstlich bereits in irgendeiner Form - etwa auf der Linie des noch zu behandelnden Erlasses von 1937 - zentral geregelt war ${ }^{78}$, wobei die Gestapoführung auch auf diesem Gebiet als selbstverständlich für sich in Anspruch nahm, sich über bestehende Gesetze hinwegsetzen zu können. Zu den Ermittlungsverfahren der

73 Vgl. L. Gruchmann, Hitler über die Justiz. Das Tischgespräch vom 20. August 1942 (VfZ 1964, S. 97 f.), dort auch Einzelheiten zum Fall Seefeld.

74 VB, Münchener Ausgabe v. 25. 2.36, S. 2 .

75 Vgl. außer dem folgenden die Eintr. im Diensttageb. des RJM v. 6.1.; 12. 3.; 24.3.36; 14.1.; 24.2. u. 15. 3.37.

76 So z. B. der OStA Düsseldorf (Ber. des GStA Düsseldorf v. 8. 8.35, a.a.O., Bd.4, Eintr. v. 14. 8.35, BA, Sign. R 22/1059). Später wurde die Úberführung von Straf- und Untersuchungsgefangenen durch die RV des RJM v. 13.5.37 betr. Vernehmung von Gefangenen durch andere Behörden (Akten des RJM, BA, Sign. $R$ 22/1462) von der Genehmigung durch den zuständigen GStA abhängig gemacht, der aus den angeführten Gründen häufig eine Überführung verweigerte (vgl. Ber. des GStA Düsseldorf v. 14.11. 38, Bl. 17, a.a.O., Sign. R 22 Gr. 5/A 10).

7 Ber. des GStA Düsseldorf v. 1.2.36 (Diensttageb. des RJM, Bd. 7, Eintr. v. 8. 2.36 mit entspr. Vermerk, BA, Sign. R 22/928).

78 Das ergibt sich aus einem Erl. Heydrichs v. 28.5.36 (Best. RSHA, BA, Sign. R 58/243), daß „der gesamte Schriftverkehr, der sich durch die Einholung der Genehmigung verschärfter Vernehmungsmethoden beim Geheimen Staatspolizeiamt ergibt“, vom Leiter der betr. Stapostelle „persönlich unter Verschluß aufzubewahren“" war. Das Verfahren dürfte etwa dem der Genehmigung von „Prügelstrafen“ in den KZ entsprochen haben, vgl. dazu Kap. VI.4.b., S.647f. 
Justiz generell schrieb Himmler, daß natürlich „Mißhandlungen aus unlauteren Beweggründen" verfolgt und nicht vertuscht werden dürften. Andererseits müsse die Polizei ein Mittel in der Hand haben, um kommunistischen Staatsfeinden „den Mund zu öffnen“:

„Die Behandlung gefährlicher Staatsverbrecher nach liberalistischen Grundsätzen und die Strafverfolgung von Beamten wie im vorliegenden Fall müsse jedoch zu einer Verwirrung der Beamten in ihrem nat.soz. Empfinden und damit zu einer Minderung ihrer Arbeitsfreudigkeit führen ... Zwar sei die Geltung des $\S 343$ [Verbot der Aussageerpressung] auch im nat.soz. Staate nicht anzuzweifeln. Es sei aber auch seines Erachtens die rechtliche Úberlegung nicht zu bestreiten, daß durch den sog. Staatsnotstand jede andere gesetzliche Bestimmung aufgehoben werde... Grundsatz sei selbstverständlich, daß die härteren Zwangsmittel nur bei maßgebenden Funktionären zu dem bereits erwähnten Zweck angewandt würden.“

Aufgrund dieser Darlegungen bat Himmler, das Duisburger Verfahren einzustellen und durch eine generelle Anordnung sicherzustellen, daß „gleichartige, das Ansehen der Staatspolizei im In- und Ausland schädigende Verfahren gegen Beamte in Zukunft - und zwar nach genauer Prüfung der Begleitumstände - nicht angestrengt oder gar durchgeführt werden". 79

Da die Justiz von sich aus nicht entscheiden konnte, ob der betreffende Gestapobeamte eigenmächtig und aus unlauteren Motiven oder im Einklang mit den Intentionen - oder gar auf ausdrückliche Weisung - der Gestapoführung handelte, bedeutete Himmlers Forderung nichts weniger, als daß die Justiz künftig diese Fälle grundsätzlich nur unter dem Vorbehalt der Zustimmung der Gestapo bestrafen durfte. Bald sollte die Justiz die Erfahrung machen, daß eine einmal außerhalb der Gesetzlichkeit - nur für die Bekämpfung des Hochverrats - eingeräumte Ermächtigung zur ,verschärften Vernehmung“ nur zu leicht ausufern und auch auf andere Fälle angewendet werden konnte: Am 29. September 1936 gab der Generalstaatsanwalt Düsseldorf Berichte der Staatsanwaltschaften aus Düsseldorf und Duisburg an das Reichsjustizministerium, daß von der Gestapo auch Untersuchungshäftlinge mißhandelt wurden, die im Verdacht homosexueller Verfehlungen ( $\S 175$ StGB) standen. Als in der Hauptverhandlung ein beteiligter Beamter über die entsprechende Behauptung eines Angeklagten aussagen sollte, erklärte er, „daß in einer anderen Stadt die Vernehmung eines Beamten der Gestapo über Vorgänge bei der Vernehmung eines Beschuldigten den betreffenden Richtern große Unannehmlichkeiten gebrachte habe“. Vom Vorsitzenden deswegen zurechtgewiesen, bestritt der Beamte die Mißhandlungen und gab lediglich die Fesselung der Gefangenen zu. Daraufhin verdächtigte ihn die Staatsanwaltschaft des Meineides. Der Generalstaatsanwalt bat das Ministerium um beschleunigte Klärung hinsichtlich einer Fortsetzung der Ermittlungen, da die Vorgänge bereits in weiten Kreisen bekannt geworden waren. ${ }^{80}$ Als sich das Reichsjustizministerium um Aufklärung an die Gestapoführung wandte, mußte Heydrich in einem Schreiben vom

79 Schreiben Himmlers an das RJM v. 30.3.36 (inhaltlich wiedergegeben im Diensttageb. des RJM, Bd.8, Eintr. v. 2.4.36, BA, Sign. R 22/929). Zum Argument der Staatsnotwehr heißt es in einem Schr. des Gestapa (gez. Meisinger) an das RJM v. 15.12.36 zu einem Ermittlungsverfahren gegen Kasseler Gestapobeamte: die verschärfte Vernehmung sei deshalb ein „Akt der Staatsnotwehr, weil derjenige, der sich vor der Polizei nach den Vorschriften der illegalen Organisationen einrichtet, noch während der Vernehmung das hochverräterische Unternehmen fördert und damit [einen] gegenwärtigen rechtswidrigen Angriff auf [den] Staat führt“ (a.a.O., Bd.9, Eintr. v. 21.12.36, BA, Sign. R 22/930).

80 Ber. des GStA Düsseldorf v. 29.9.36 (a.a.O., Eintr. v. 30.9.36). 
19. November zugeben, daß die Angaben der Gefangenen zuträfen. Dabei sei aber zu bedenken,

„daß nur vier [?] von annähernd 200 im Laufe dieser Aktion verhafteten Personen mißhandelt worden seien. Veranlassung dazu sei die der Gestapo bekannte Tatsache, daß unter den Homosexuellen in Duisburg ein Zusammenhang bestanden habe, der dem unter Kommunisten üblichen ähnlich [!] sei. Es sei deshalb zu befürchten, daß bei einer Verzögerung der Feststellung der $\mathrm{Zu}$ sammenhänge die übrigen Homosexuellen gewarnt worden wären. Die Beamten hätten deswegen geglaubt, auch in diesem Fall das Mittel der verschärften Vernehmung anwenden zu dürfen. Sie hätten sich dadurch einer Dienstverfehlung schuldig gemacht, wegen deren sie dienststrafrechtlich zur Verantwortung gezogen werden würden. Im übrigen müsse ihnen jedoch zugebilligt werden, daß sie glauben durften, nicht rechtswidrig zu handeln. Wenn er auch die Anwendung der verschärften Vernehmung auf den Bereich des Hochverrats zu beschränken bestrebt sei, so müsse er doch zugeben, daß angesichts der Lage in Duisburg der Gedanke, mit allen Mitteln das Scheitern der Aktion zu verhindern, sehr nahegelegen hätte. Er sei deshalb der Auffassung, daß sie [die Gestapobeamten] sich in einem strafausschließenden Irrtum über die Rechtswidrigkeit ihrer Maßnahmen befunden hätten und daß deswegen das Strafverfahren gegen sie eingestellt werden könne.."81

Offenbar konnte die Gestapoführung diese Forderung - ob mit oder ohne Einschaltung Hitlers, ist nicht ersichtlich - dann auch durchsetzen. ${ }^{82}$

Alle Hinweise, daß erzwungene Aussagen für die Justiz unbrauchbar und daher sinnlos waren, fruchteten bei der Gestapo nichts. Im Gegenteil: als dem Leiter der Staatspolizeistelle Hamburg, SS-Oberführer Streckenbach, vor Augen geführt wurde, daß das Hanseatische Oberlandesgericht durch Fesselung erzielte Geständnisse für wertlos befand, griff er zu einer regelrechten Erpressung. Er teilte Oberlandesgerichtspräsident Rothenberger mit, daß er daraufhin seine Dienststellen angewiesen habe, außer auf Transporten "vorläufig“ keine Fesselungen mehr vorzunehmen. Seine Anordnung werde aber „ein beträchtliches Anwachsen der Selbstmorde der Häftlinge zur Folge haben“, zu deren Verhinderung die Fesselungen lediglich erfolgt seien. Die bestürzten Chefs der Hamburger Justiz - Oberlandesgerichtspräsident und Generalstaatsanwalt - beeilten sich, Streckenbach mitzuteilen, daß sie zwar seine Anordnung zur Kenntnis genommen hätten, aber für deren Folgen bei der Polizeihaft keine Verantwortung tragen wollten und könnten. ${ }^{83}$ Damit war ihr Vorstoß von der Gestapo erfolgreich abgewehrt worden.

Für die Justiz war das Problem, das die mit ungesetzlichen Mitteln erzwungenen Aussagen bei der Feststellung des Tatbestandes aufwarfen, wesentlich zentraler und für ihre Tätigkeit von unmittelbarerer Bedeutung als die Strafverfolgung prügelnder Gestapobeamter. Da Heydrich ausdrücklich angeordnet hatte, „daß die Anwendung verschärfter Vernehmungsmethoden auf keinen Fall aktenkundig gemacht werden“ dürfe ${ }^{84}$, trat das Problem gewöhnlich in einem späteren Stadium des jeweiligen Strafverfahrens auf: meist erst in der Hauptverhandlung, wenn sich die Polizeibeamten

${ }_{82}$ Antwortschr. Heydrichs v. 19.11 .36 auf das Schr. des RJM v. 5.10.36 (a.a.O., Eintr. v. 24. 11.36).

82 Die beschuldigten Beamten befanden sich jedenfalls 1938 in gleicher Funktion im Amt; da gegen einen von ihnen wiederum wegen Aussageerpressung ermittelt wurde, schlug der GStA Düsseldorf vor, im Falle eines Verfahrens dessen Straftaten von 1936 mit abzuurteilen. Vgl. Ber. des OStA Düsseldorf u. Verm. des GStA v. 28.10 .38 (Akten des RJM, BA, Sign. R 22 Gr. 5/A 10).

${ }^{83}$ An die ZStA des RJM weitergegebenes Schr. Streckenbachs an Rothenberger v. 15.2.37 u. Verm. Joëls v. 24. 2.37 (a.a.O., BA, Sign. R 22/1467).

84 Erl. Heydrichs an alle Stapostellen v. 28.5.36 (Best. RSHA, BA, Sign. R 58/243). 
- die als Hilfsbeamte der Staatsanwaltschaft eigentlich zur Wahrheitsermittlung beizutragen verpflichtet waren - gegenüber den Behauptungen der Angeklagten auf ein ihnen erteiltes Aussageverbot beriefen ${ }^{85} \mathrm{Da}$ die Gerichte ihren Entscheidungen dann im Höchstfalle die eingeschränkten Geständnisse der Angeklagten zugrunde legen konnten, mußten die Urteile zwangsläufig im Sinne des Regimes zu milde ausfallen. Als das Reichsjustizministerium für eine im Herbst 1936 geplante Tagung über die Behandlung von Hochverratssachen bei den Präsidenten und Generalstaatsanwälten der für dieses Delikt zuständigen Oberlandesgerichte Anregungen einholte, welche Fragen zusätzlich erörtert werden sollten, waren dieses Problem und das verwandte Problem der Aussagen von geheimen Gestapo-Spitzeln (,V-Männern“) - die vom Gericht meist gleichfalls nicht vernommen werden durften - unter den vordringlich genannten Vorschlägen. ${ }^{86} \mathrm{Da}$ bei dieser Tagung auf Wunsch des Justizministeriums ohnehin Vertreter des Geheimen Staatspolizeiamts Informationsvorträge über die Tätigkeit verschiedener staatsfeindlicher Organisationen halten sollten, äußerte der zuständige Referent bei seiner vorbereitenden Besprechung mit SS-Sturmbannführer Müller („Gestapo-Müller") die Bitte, die beiden aktuellen Probleme mit zu behandeln. Müller erwiderte, daß er bezüglich der verschärften Vernehmung vorher ,höheren Orts Vortrag halten müsse“ ${ }^{87}$ Das Ergebnis dieser Initiative war, daß am Nachmittag des ersten Konferenztages Heydrich selbst einen halbstündigen Vortrag zu den Themen „Der Kommunist im polizeilichen Ermittlungsverfahren“ und „Die Stellung der Vertrauensmänner der Gestapo im Strafprozeß" hielt. ${ }^{88}$ Seine Ausführungen sind in den Justizakten nicht enthalten, wohl aber die Vorlage für den anschließenden Vortrag des Leiters der Strafrechtspflegeabteilung, Ministerialdirektor Crohne, der auf diese Probleme - wahrscheinlich aber nicht mehr in Gegenwart Heydrichs ${ }^{89}$ - einging. Crohne mahnte die Staatsanwaltschaft, daß sie sich nicht als eine bloße „Anklagefertigerin“ mit dem Schlußbericht der Gestapo begnügen dürfe, sich insbesondere die Geständnisse bei Widerrufungsgefahr wiederholen lassen und auch Entlastungsbeweise überprüfen müsse, um ein überraschendes Vorbringen durch den Angeklagten in der Hauptverhandlung zu vermeiden, das dann vom Gericht nicht übergangen werden

85 Typisch für die Problematik der Ber. des OLGPräs. Braunschweig v. 4.9.36 über eine Verhandlung des Strafsenats unter seinem Vorsitz gegen „einen an sich harmlosen, haltlosen, verbummelten jungen Menschen, dem die Wahrheit zweifellos auch mit anderen Mitteln abgerungen werden konnte“: „Ist das Verbot der Aussage im vorliegenden Fall aber nur ergangen, um den Kriminalsekretär ... vor dem bereits vorher aufgetretenen Verdacht des Verbrechens gegen den $\S 343$ RStGB. in Schutz zu nehmen, so liegt eine Begünstigung im Amt - $\S 346$ RStGB. - vor .... Größer jedoch erscheint mir der Schade, der entstehen muß, wenn die Öffentlichkeit von einer solchen Anordnung der Polizeibehörde Kenntnis erhält, die den Eindruck erwecken muß, daß die Bebörde als solche etwas zu verbergen habe“ (a.a.O., BA, Sign. R 22/1462).

${ }^{86} \mathrm{Vgl}$. Anschr. des RJM v. 13.6.36 u. Antw. der GStAe bzw. OLGPräs. u. des ReiA beim VGH. Letzterer schrieb am 14.9.36, die verschärfte Vernehmung sei „unbedingt abzulehnen. Sie ist kein zweckmäßiges und zuverlässiges Mittel zur Wahrheitsforschung, auch eines Kulturvolkes unwürdig“ (a.a.O., BA, Sign. R 22/5004).

${ }^{87}$ Ref.Verm. v. 12.8.36 (a.a.O.).

88 Die ursprüngl. für den 19./20.10.36 vorgesehene Tagung, an der auch die Vors. der mit Hochverrat befaßten Strafsenate sowie die entspr. Sachbearbeiter der StAschaften teilnahmen, mußte „wegen plötzlicher Verhinderung“ der Gestapo-Referenten auf den 11./12.11.36 verlegt werden, vgl. RdErl. des RJM v. 9.10.36 (a.a.O.).

89 In Abänderung der Tagesordnung sprach nach Heydrich zunächst Freisler über den Hochverratsbegriff im neuen StGB-Entwurf sowie über die Behandlung von Hochverrätern in der Strafhaft und ihre Wiedereingliederung in die Volksgemeinschaft. 
könne..$^{90}$ Aus seiner Bemerkung, daß mit der verschärften Vernehmung nunmehr „als gegeben gerechnet werden“ müsse, geht hervor, daß zu diesem Zeitpunkt die Hoffnung auf eine Wiederabschaffung dieses Mittels wohl schon begraben worden war. Crohne führte aus: behaupte ein Angeklagter, daß seine Angaben auf gewaltsame Maßnahmen zurückzuführen seien, so werde das Gericht „etwa angetretenen Beweisen nach der jetzigen Rechtslage nachgehen müssen“. Dabei sei jedoch vorher genau zu prüfen, ob auf die Vorgänge eingegangen werden müsse, bejahendenfalls müßten

„die Erörterungen mit dem nötigen Takt geführt werden. Das Ansehen der Polizeibeamten und damit des Staates darf nicht von Richtern und damit wieder vom Staat unnötig vor Leuten, gegen die immerhin hinreichender Hochverratsverdacht besteht, beeinträchtigt werden. Andererseits muß ... die Gestapo veranlassen, daß die Niederschriften unbedingt in Ordnung sind und tatsächlich das Vorbringen - sei es ent- oder belastend - des Beschuldigten ungefärbt wiedergeben."

Sei ein Polizeibeamter in diesem Zusammenhang als Zeuge zu vernehmen, so habe das Gericht unter Angabe des Ladungsgrundes von dessen vorgesetzter Behörde die Aussagegenehmigung einzuholen. Wenn die Beamten nicht sowieso nur mit einer beschränkten Aussagegenehmigung erschienen, seien sie auf $\S 55 \mathrm{StPO}^{91}$ aufmerksam zu machen. Lasse sich wegen einer teilweisen oder totalen Zeugnisverweigerung der Polizeibeamten „der Nachweis einer Straftat aus den anderen vorliegenden Beweisergebnissen nicht führen, mag es zum Freispruch kommen“. Die Staatsanwaltschaft sei dann nach $\S 160$ StPO verpflichtet zu prüfen, ob die getroffenen Feststellungen ein Strafverfahren gegen den betreffenden Polizeibeamten rechtfertigten. In diesem Falle sei jedoch die Zentralstaatsanwaltschaft mit der Sache zu befassen und von allen anderen Maßnahmen vorerst abzusehen: damit sollte die Möglichkeit geschaffen werden, die Angelegenheit auf alle Fälle vorher auf Ministerialebene mit der Gestapoführung zu besprechen.

In seinem Vortrag behandelte Crohne auch das weitere, ähnlich gelagerte Problem, das sich aus den speziellen Ermittlungsmethoden der Gestapo für die Justiz ergab: das Problem der gerichtlichen Nachprüfung von Angaben der Gestapo-Spitzel - insbesondere aus Täterkreisen -, deren Anonymität die Gestapo im Interesse ihrer erfolgreichen Weiterverwendung nicht durch Auftreten vor Gericht zerstört wissen wollte. $\mathrm{Da}$ auch durch Ausschluß der Öffentlichkeit bei der Verhandlung eine Aufdeckung nicht sicher verhindert werden konnte, sollte auch hier schon der Staatsanwalt klären, ob die Gestapo ihren Spitzel für die Hauptverhandlung zur Verfügung stellte. Geschehe das nicht, so dürfe er auch in den Akten keinesfalls auftauchen, und der Staatsanwalt müsse prüfen, ob eine Anklage überhaupt Aussicht habe; eventuell müsse dann die Gestapo ausreichende mittelbare Beweise ${ }^{92}$ beibringen. Wenn das nicht gelänge,

$90 \mathrm{Daß}$ die hier gegebenen Richtlinien an die unteren Behörden weitergegeben wurden, geht $z$. B. aus dem RdSchr des OLGPräs Düsseldorf v. 4.3.37 an die LGPräs. betr. richterliche Vernehmung des Beschuldigten hervor (Akten des RJM, BA, Sign. R 22/5004).

$91 \S 55$ StGB lautete: ,Jeder Zeuge kann die Auskunft auf solche Fragen verweigern, deren Beantwortung ihm selbst ... die Gefahr strafgerichtlicher Verfolgung zuziehen würde.“

92 Dieses Problem spielte in dem bekannten Fall Bullerjahn eine Rolle, der vom RG am 11.12.25 wegen angeblichen Verrats geheimer Waffenlager an die Alliierten aufgrund der Mitteilung eines ungenannt bleibenden Belastungszeugen, dessen Glaubwürdigkeit das Gericht nicht nachprüfen konnte (es wurden nur drei Kriminalbeamte als Zeugen vernommen, die die „Vertrauensperson“ verhört hatten), wegen Landesverrats zu $15 \mathrm{~J}$. Zuchthaus verurteilt worden war. Erst im Wiederaufnahmeverfahren hob das RG das Urt. auf und sprach B. im Herbst 1932 frei (vgl. M. Hirschberg, Das Fehlurteil im Strafprozeß, Stuttgart 1960, S. 162 f.). 
müsse der Staatsanwalt der Gestapo klarmachen, daß sie damit die Verantwortung für ein mögliches Fehlschlagen des Verfahrens trage.

„In keinem Falle geht es an, daß der Staatsanwalt den Vertrauensmann vernimmt, ihn mit 3 Kreuzen unterzeichnen läßt und diese Niederschrift zu den Akten bringt, oder daß eine Strafverfolgungsbehörde sich vertraulich von der Gestapo den Namen des Vertrauensmannes geben läßst, ihn dann niederschriftlich vernimmt und ihm zur Niederschrift Straffreiheit zusichert. Das greift in das Niederschlagungsrecht des Führers ein und führt zu ganz unmöglichen Folgerungen.“

Andererseits dürfe aber auch das Gericht im Falle der Nichtpreisgabe des „V-Mannes" eine Verurteilung - wie vielfach geschehen - zumindest dann nicht von vornherein ablehnen, wenn die durch den Spitzel gemachten Angaben in anderen Aussagen eine gewisse Stütze fänden, in sich schlüssig seien und so eindeutig in das Prozeßbild paßten, daß ihnen Glauben geschenkt werden könne. Das Gericht müsse ferner prüfen, „ob es sich auf die die Aussage vermittelnde Person, deren Kenntnis der Sache und deren Urteilsfähigkeit so weit verlassen darf, daß es die Glaubwürdigkeit der vermittelten Aussage annehmen kann. Alles das sind Fragen der richterlichen Urteilsfindung, auf die kein Einfluß genommen werden soll“. Werde aber der Vertrauensmann von der Gestapo für die Verhandlung gestellt, habe schon der Staatsanwalt dessen Glaubwürdigkeit nachzuprüfen, um in dieser Hinsicht Pannen und Freisprüche zu vermeiden. Auch hier sollte das Gericht auf die Belange der Gestapo Rücksicht nehmen ,und bei einem ungeeigneten V-Mann eine Bloßstellung der Polizeibeamten, die auf ihn hereingefallen sind“, vermeiden. Auf keinen Fall aber dürfe der Vertrauensmann als agent provocateur tätig gewesen sein, durch dessen Aktivität der Angeklagte überhaupt erst zu hochverräterischem Handeln gebracht worden sei: es könne „nicht Zweck der Übung sein, Hochverräter künstlich zu schaffen, sondern vorhandene zu ermitteln“. ${ }^{93}$ Crohne folgerte, daß die Gestapo auf alle in der Besprechung erörterten Probleme hingewiesen werden müsse, damit sich ihre Methoden im Rahmen der Erfordernisse einer geordneten Rechtspflege hielten. ${ }^{94}$

Hinsichtlich der „verschärften Vernehmung“ waren die Richtlinien, die auf der Tagung gegeben wurden, ein Versuch, in das knarrend arbeitende Getriebe der auch an dieser Stelle nicht „passend“ ineinandergreifenden Zahnräder von Normen- und Maßnahmenstaat wenigstens nicht zusätzlich Sand zu streuen. Auf diesem Gebiet sollte eine bessere technische Verzahnung zwischen den illegalen Methoden der Gestapo und der normativen Arbeit der Justiz erst durch eine Besprechung von Vertretern beider Seiten geschaffen werden, die ein halbes Jahr später im Reichsjustizministerium stattfand. Am 4.Juni 1937 trafen sich dort Ministerialdirektor Crohne sowie die beiden Oberstaatsanwälte der Zentralstaatsanwaltschaft Joël und von Haacke mit den SSStandartenführern Ministerialrat Best und Oberregierungsrat Möller. An der Besprechung nahmen ferner die beiden Generalstaatsanwälte beim Oberlandesgericht Hamm und beim Kammergericht sowie der Oberstaatsanwalt Düsseldorf teil. ${ }^{95}$ Nachdem Crohne einleitend betont hatte, daß die immer noch bestehenden Schwierigkei-

93 In einem Münchener Fall „hatte der V-Mann erst eine kommunistische Organisation aufgezogen, bis dahin Unbeteiligte mühselig überredet und geworben, um sie dann anzuzeigen und seine Tüchtigkeit unter Beweis zu stellen" (Unterlagen zum Vortrag Crohnes am 11.11.36, Akten des RJM, BA, Sign. R 22/5004).

$94 \mathrm{Vgl}$. Unterlagen und Konzept des Vortrags von Crohne am 11.11.36 (a.a.O.).

95 In Berlin und Düsseldorf waren offensichtlich die meisten Schwierigkeiten mit der verschärften Vernehmung aufgetreten. Da für die Düsseldorfer Hochverratsfälle das OLG Hamm zuständig war, nahm auch der dortige GStA teil. 
ten endlich ausgeräumt werden müßten, führte von Haacke folgendes aus: Da die verschärften Vernehmungen nun einmal „,on Seiten der höchsten Staatsführung ... für erforderlich und unerläßlich anerkannt" (!) worden seien, sei eine strafrechtliche Verfolgung der ausführenden Beamten folgewidrig geworden. Andererseits blieben den Staatsanwälten nur beschränkte gesetzliche Möglichkeiten, in diesen Fällen von Strafverfahren abzusehen, wenn sie sich nicht der Rechtsbeugung schuldig und damit selbst strafbar machen wollten. Eine Strafverfolgung nach § 153 StPO wegen Geringfügigkeit zu unterlassen, sei rechtlich nicht möglich, da es sich bei diesen Handlungen um den Tatbestand eines Verbrechens handele. Ebenso könne nicht jeder Einzelfall niedergeschlagen werden, da Hitler - dem das Niederschlagungsrecht allein zustand dadurch unerträglich belastet werden würde. Auch das von der Gestapo verschiedentlich vorgebrachte Argument des Staatsnotstandes sei „zu umstritten und daher zu gefährlich im Falle des $\S 172$ StPO“: wenn die Verletzten aufgrund dieses Paragraphen gegen den Einstellungsbeschluß Beschwerde einlegten und gegen einen daraufhin erfolgenden ablehnenden Bescheid der Staatsanwaltschaft eine gerichtliche Entscheidung beantragten, hielt das Ministerium angesichts der problematischen Feststellung des Staatsnotstandes eine Erzwingung der Anklage für möglich. Es bliebe daher nur die materielle Einstellung des Verfahrens mangels Rechswidrigkeit übrig; sie sei aber nur dann vertretbar, "wenn klare Regeln und Richtlinien für die Anwendung verschärfter Vernehmung vorliegen“: der Staatsanwalt müsse klar ersehen können, ob ein Fall zulässiger Einwirkung vorliege oder nicht. Gegenwärtig herrsche „ein völlig unhaltbarer Zustand“, der auf der einen Seite das Rechtsgefühl der Justizbeamten, auf der anderen Seite das Ehrgefühl der Polizeibeamten strapaziere, „die sich durch törichtes Bestreiten zu helfen“ suchten. Von Haacke trug anschließend sechs Fragen vor, die das Ministerium für die Erörterung ausgearbeitet hatte und die von den Besprechungsteilnehmern jeweils eingehend diskutiert wurden:

1. Die erste Frage bezog sich darauf, bei welchen Delikten die verschärfte Vernehmung zulässig sein sollte. Beide Partner stimmten überein, daß sie nur in Fällen, ,in denen der Sachverhalt unmittelbare Staatsinteressen berührt", angewendet werden dürfe, d.h. in erster Linie bei Hoch- und Landesverrat. Nach Ansicht Bests und Möllers konnten auch Sprengstoff- und Sabotagesachen in Frage kommen; eine endgültige Stellungnahme behielten sie sich nach Rücksprache mit Himmler vor. Keine Anwendung sollte die Maßnahme gegen Homosexuelle ( $\S 175 \mathrm{StGB}$ ) und Ausländer finden. Zweifelsfälle sollten von der Berliner Gestapozentrale entschieden werden.

2. Ủber die Art der körperlichen Einwirkung wurde festgestellt, daß „nur Stockhiebe auf das Gesäß, und zwar bis zu 25 Stück, zulässig“ sein sollten, wobei die Zahl vorher vom Geheimen Staatspolizeiamt bestimmt werden und vom 10. Stockhieb an ein Arzt zugegen sein sollte. Ferner sollte „ein ,Einheitsstock bestimmt werden, um jede Willkür auszuschalten“.

3. Die verschärfte Vernehmung sollte grundsätzlich nur vom Geheimen Staatspolizeiamt in Berlin angeordnet werden; die örtliche Staatspolizeistelle hatte vorher die Genehmigung von dort einzuholen.

4. Die körperliche Einwirkung sollte jeweils durch einen besonderen, von der einzelnen Staatspolizeistelle bestimmten Beamten vorgenommen werden, der mit dem vernehmenden Beamten nicht identisch sein durfte. 
5. Die Frage der Justiz, welche Sicherung gegen die Anwendung der verschärften Vernehmung bei Unschuldigen gegeben sei, wurde kurzerhand durch die Regelung „für erledigt erklärt“, daß sie künftig nur vom Geheimen Staatspolizeiamt angeordnet würde.

6. Über die technische Behandlung der Fälle von „verschärfter Vernehmung" durch die Justiz wurde folgendes vereinbart: wenn bei der Staatsanwaltschaft eine entsprechende Anzeige gegen einen Gestapobeamten einging, sollte sie sich von der betreffenden Staatspolizeistelle die Genehmigung zur Anwendung dieser Maßnahme durch das Geheime Staatspolizeiamt vorlegen lassen. ${ }^{96}$ Dem Verletzten war dann einfach der formelle Bescheid zu erteilen, daß nach den Ermittlungen keine strafbare Handlung vorliege. Stellte sich heraus, daß die Genehmigung fehlte, war beschleunigt zu ermitteln und an die Zentralstaatsanwaltschaft zu berichten; auch in Fällen zweifelhafter Zulässigkeit sollte ein Bericht an diese Stelle eingereicht werden.

Grundsätzlich bestand Einmütigkeit darüber, „daß die bisherige Art der Anwendung verschärfter Vernehmungen nicht mehr durchgeführt werden“ dürfe. Die noch offenstehenden Fälle strafrechtlicher Verfolgung von Polizeibeamten sollten durch Fühlungnahme zwischen Justizministerium und Geheimem Staatspolizeiamt geklärt werden. Ferner sollte die Gestapoführung auf der Grundlage der getroffenen Vereinbarung baldigst Anweisungen über die Durchführung der „verschärften Vernehmung“ an ihre Dienststellen erlassen. ${ }^{97}$

Mit dieser Vereinbarung hatte die Justiz zwar versucht, die von der politischen Führung gebilligten gewaltsamen Vernehmungsmethoden der Gestapo auf „erträgliche“ Maßnahmen zu reduzieren und ihre Anwendung in geregelte Formen zu bringen und sie damit gleichzeitig den Justizbehörden im konkreten Einzelfall als "sanktionierte“ oder „wilde“ Aktionen erkennbar zu machen: erneut hatte sie als „retardierendes“ Element gewirkt. Aber dieses mit dem Ziel der Beseitigung von Störungen ihrer normativen Funktion getroffene Arrangement war unter den gegebenen Machtverhältnissen abermals unter Aufgabe grundsätzlicher Positionen der Justiz zustande gekommen: die an sich ungesetzlichen Methoden zur Aussageerpressung durften von ihr nur dann verfolgt werden, wenn die Gestapo zustimmte, wobei es die Gestapoführung in der Hand hatte, auch „wilde“ Mißhandlungen untergeordneter Organe durch nachträgliche Genehmigung zu decken.

Die von der Gestapoführung in Aussicht gestellte Anweisung an ihre Dienststellen über die Handhabung der „verschärften Vernehmung“" wurde am 1.Juli 1937 herausgegeben. Obwohl der Wortlaut dieses geheimen Erlasses, den offensichtlich auch das Reichsjustizministerium nicht zu Gesicht bekam, nicht mehr vorliegt, kann davon ausgegangen werden, daß er im wesentlichen den dargestellten Vereinbarungen entsprach. In dem von Müller unterschriebenen Gestapo-Erlaß vom 12.Juni 1942, der

96 Später wurde die Regelung getroffen, daß die Gestapo jeweils gleich zu den Ermittlungsakten vermerkte, daß eine Aussage unter Anwendung „verschärfter Vernehmung zustandegekommen war (vgl. eidesstattl. Erkl. des Leitend. OStA Hamburg über eine Mitteilung v. Haackes vom 18.2.47, Nürnbg. Dok. NG-949, Arch. des IfZ).

97 Vgl. vertraul. Ber. des OStA Düsseldorf an den GStA Düsseldorf v. 8.6.37 über die Bespr. (Generalakten der StAschaft Düsseldorf, abgedruckt bei I. Staff, Justiz im Dritten Reich. Eine Dokumentation, Frankfurt a. M. 1964, S.118 ff. u. 124f.; 2. Aufl. 1978, S. 106 ff.) 
den Erlaß von 1937 wegen der notwendigen Anpassung an die Kriegssituation ersetzte $^{98}$, waren als Verschärfungen ,je nach Sachlage" vorgesehen: Beschränkung der Kost auf Wasser und Brot, Dunkelzelle, Schlafentzug, Ermüdungsübungen und Stockhiebe, wobei allerdings erst bei mehr als 20 Hieben die Anwesenheit eines Arztes gefordert wurde. Es ist anzunehmen, daß der erste Erlaß ganz ähnliches bestimmte. Der Kriegserlaß enthielt ferner die nicht unwesentliche Anordnung, daß die verschärfte Vernehmung nicht „zur Herbeiführung von Geständnissen über eigene Straftaten“ des Vernommenen gebraucht werden durfte, wobei allerdings das Geheime Staatspolizeiamt Ausnahmen bewilligen konnte. Best bestätigte nach dem Kriege, daß diese Regelung auch schon durch den Erlaß von 1937 getroffen worden war. ${ }^{99}$ Damit wäre immerhin schon ein Schritt zur Beseitigung der Schwierigkeiten für die Justiz getan gewesen. Die weitere Bestimmung, daß dieses Mittel ferner nicht ,gegenüber Personen, die zeitweilig von der Justiz zwecks weiterer Ermittlungen überstellt" wurden, angewendet werden durfte, scheint gleichfalls schon in dem früheren Erlaß enthalten gewesen zu sein: als der Generalreferent für politische Strafsachen im Justizministerium, Oberstaatsanwalt Klemm - der nach der Auflösung der Zentralstaatsanwaltschaft im Oktober 1937 für die Behandlung von Fällen „verschärfter Vernehmung“ zentral zuständig geworden war ${ }^{100}$-, sich bei Müller erkundigte, erhielt er jedenfalls die Zusicherung, „daß bei derartigen Vernehmungen völlig korrekt verfahren“ und "unter keinen Umständen geduldet [würde], daß bei derartigen Gefangenen durch besondere Behandlung das Ansehen der Justiz in irgendeiner Weise gefährdet" würde. Müller teilte bei dieser Gelegenheit ferner mit, daß der Erlaß über verschärfte Vernehmung den Gestapobeamten „alle Vierteljahre vorgelesen würde und sie die emeute Kenntnisnahme durch Unterschrift bestätigen müßten“. ${ }^{101}$

Während sich das Problem der Verfolgung von Gestapo- und Kriminalbeamten wegen Amtsverbrechen für die Justiz dadurch erledigte, daß der persönliche Geltungsbereich der SS- und Polizeigerichtsbarkeit im April 1940 auf die gesamte Sicherheitspolizei ausgedehnt wurde ${ }^{\mathbf{1 0 2}}$, blieb das Problem der Verwendung erzwungener Aussagen auch noch in den folgenden Jahren bestehen. ${ }^{103}$ Immer wieder sah sich das Reichsju-

98 Der geh. Erl. des Chefs der Sipo und des SD v. 1.7.37 - B. Nr. PP(II) 301/37 g.Rs. - ist laut Auskunft des BA an den Verfasser v. 24.7.80 nicht mehr erhalten. Er wurde durch den Erl. v. 12.6.42 (Nürnbg. Dok. PS1531, IMG Bd.XXVII, S.326f.) ersetzt und war dabei „unter Beachtung der Verschlußvorschriften zu vernichten“. Der Erl. von 1942 war auf die Kriegszeit zugeschnitten und sah die Anwendung der verschärften Vernehmung gegen „Kommunisten, Marxisten, Bibelforscher, Saboteure, Terroristen, Angehörige der Widerstandsbewegungen, Fallschirmagenten, Asoziale, polnische oder sowjetische Arbeitsverweigerer oder Bummelanten“ vor. Ein Erl. Heydrichs v. 6.10.41 betr. Geltung des Erl. v. 1.7.37 auch für Polen u. Sowjetrussen (Akten des RSHA, BA, Sign. R 58/243) hatte die Anwendung noch auf „kommunistische bzw. marxistische Funktionäre, Bibelforscher und Saboteure“ beschränkt.

99 Eidesstattl. Erkl. Bests v. 24.5.51 für die Verteidigung eines ehem. Sipo-Angehörigen in einem Verfahren vor dem Kriegsgericht in Brüssel (Arch. des IfZ, Sign. ZS 207/IV).

${ }^{100}$ Vgl. Umlauf (gez. Crohne) v. 18.10.37 bei den Ref. für polit. Strafsachen in der Abt. III des RJM (Akten des RJM, BA, Sign. R 22/1462).

${ }^{101}$ Verm. Klemms v. 26.1.38 über seine Bespr. mit Müller am 18.12.37 (a.a.O.). Die vierteljährl. Bekanntgabe wird bestätigt durch Heydrichs Erl. v. 6.10.41 (BA, Sign. R 58/243) u. die eidesstattl. Erkl. des stellv. Leiters der Stapoleitstelle München v. 22.9.54 in einem Strafverfahren vor dem LG München I (Arch. des IfZ, Sign. Gm 07.37).

${ }^{102}$ Erl. des RFSSuChdDtPol v. 9.4.40 betr. Sondergerichtsbarkeit der Polizeiverbände bei besonderem Einsatz (Mitteil. über die SS- u. Polizeigerichtsbarkeit, herausg. v. Hauptamt SS-Gericht, Heft 1, Juli 1940, S.19).

${ }^{103}$ Vgl. z. B. den Ber. des LGPräs. Hamburg an den OLGPräs. v. 22.7.41 (Akten des LG Hamburg 3130 E, Arch. der Forschungsstelle f. d. Gesch. des NS in Hamburg, Sign. Best. 3309). 
stizministerium der Kritik der Polizeiführung an der Haltung der Gerichte in dieser Frage sowie der Forderung ausgesetzt, bei den Justizbehörden „auf eine richtigere Würdigung der Mentalität und der Praxis der Staatsfeinde“ hinzuwirken. ${ }^{104}$

\section{Die „vorbeugende Verbrechensbekämpfung“ durch die Polizei als Korrektur der kriminellen Strafrechtspflege}

\section{a. Einfübrung der polizeilichen Vorbeugungshaft und die Haltung der Justiz 1933-1937}

Außer durch die Schutzhaft-Maßnahmen der Geheimen Staatspolizei wurde die Tätigkeit der Rechtspflege noch durch eine weitere Ermächtigung der Polizei zur Inhaftierung berührt: durch die „Vorbeugungshaft“, die die Kriminalpolizei gegen unpolitische Kriminelle und „Asoziale“ ohne Einschaltung der Justiz verhängen durfte. Während die Polizei durch die Schutzhaft bei der Ahndung von - durchaus nicht immer politisch motivierten - Straftaten mit der Justiz in Konkurrenz treten konnte, wirkte sich die Vorbeugungshaft vor allem als Instrument für die Korrektur der Entscheidung über unbefristete Sicherungsverwahrung aus, die die Gerichte seit Inkrafttreten des Gewohnheitsverbrechergesetzes am 1.Januar 1934 gegen "gefährliche Gewohnheitsverbrecher" neben der Strafe anordnen konnten und die nach der Strafverbüßung in Anstalten der Justizverwaltung vollzogen wurde, bis ihr Zweck erfüllt, d.h. der Betroffene für die Allgemeinheit nicht mehr gefährlich war.

Obwohl die Gerichte in diesem Gesetz ermächtigt wurden, die Sicherungsverwahrung auch gegen einen Verurteilten, der seine Freiheitsstrafe am 1.Januar 1934 noch nicht verbüßt hatte, nachträglich anzuordnen ${ }^{1}$, und die Strafanstaltsleiter daraufhin alle einschlägigen Fälle prüften und der Staatsanwaltschaft mitteilten ${ }^{2}$, wurde diese Maßnahme von der politischen und der Polizei-Führung für die „vorbeugende Verbrechensbekämpfung" nicht als ausreichend angesehen. Noch während das Gewohnheitsverbrechergesetz in Vorbereitung war, ordnete Göring in seiner Eigenschaft als preußischer Innenminister in einem geheimen Erlaß vom 13. November 1933 für Preußen die „vorbeugende Polizeihaft gegen Berufsverbrecher“ an. Er stützte sich dabei auf die Reichstagsbrandverordnung, die damit für Maßnahmen in Anspruch genommen wurde, die mit der Bekämpfung politischer Gegner nichts mehr zu tun hatten und über den Zuständigkeitsbereich der Gestapo hinausgriffen. Görings Erlaß trug zugleich programmatische Züge, die auf eine Desavouierung der Justiz hinausliefen. Darin hieß es, trotz der energischen Schritte der nationalsozialistischen Regierung seien „die Berufsverbrecher auch heute noch in nicht unerheblichem Maße tätig“ und verursachten Schäden, die „ganz besonders für den ärmeren Teil der Bevölkerung“ (!) mit geringer Habe empfindliche Verluste darstellten. Göring sei daher „nicht gewillt, dem Treiben

${ }^{104}$ Als eindringl. Beispiel vgl. Schr. des RFSSuChdDtPol im RMdI (gez. Best) an den RJM v. 9.8.38 (Akten des OLG Hamburg $400 \mathrm{E} 1 \mathrm{a} / 3$, Archiv des Hanseatischen OLG).

1 Zum G. gegen gefährliche Gewohnheitsverbrecher und über Maßregeln der Sicherung und Besserung v. 24. November 1933 (RGBI. I, S.995) vgl. Kap. VII.3.a., S.838ff., 841.

2 Vgl. dazu AV des Preuß. JM v. 29.11.33 (DJ 1933, S.770); Bek. des bayer. StMdJ v. 5.12 .33 (Staatsanz. Nr. 283 v. 7.12 .33 ). 
dieser Schädlinge länger untätig zuzusehen ". Zwar werde das in Aussicht genommene Gewohnheitsverbrechergesetz den Gerichten gegen Berufsverbrecher wesentlich schärfere Strafen und die Sicherungsverwahrung in die Hand geben, diese Maßnahmen würden die Verbrecher

„aber auch in Zukunft erst nach einer erneut begangenen Straftat treffen. Der gerichtlichen Aburteilung des Täters geht zudem stets ein oft schwieriges, meistens langwieriges und kostspieliges Ermittlungs- und Untersuchungsverfahren voraus. In der heutigen Zeit ist aber jede im Staatshaushalt erübrigte Mark segensreich als Arbeitsentlohnung für erwerbslose Volksgenossen zu verwenden. Ich betrachte es deshalb als mein vornehmstes Ziel, verbrecherische Angriffe auf Leben und Eigentum vorbeugend zu verhindern und damit zugleich die Kosten der Strafverfolgung herabzumindern".

Göring ordnete daher die Verhaftung derjenigen an, die der Kriminalpolizei als Berufsverbrecher bekannt waren und überwiegend vom Erlös aus ihren Straftaten lebten. Die Vorbeugungshaft sollte jedoch an die Voraussetzung gebunden sein, „daß der Betroffene dreimal wegen eines aus Gewinnsucht begangenen vorsätzlichen Verbrechens oder Vergehens zu Zuchthaus oder Gefängnis von mindestens sechs Monaten verurteilt worden ist und zwischen den einzelnen Straftaten ein Zeitraum von weniger als fünf Jahren“ lag. Die geschilderten Bestimmungen sollten ferner auch auf Sittlichkeitsverbrecher angewendet werden können, die wegen Blutschande, Unzucht mit Abhängigen, an Willenlosen oder Kindern ( $\S \S 173,174,176$ StGB) - später auch wegen Notzucht $(\S \S 177,178 \text { StGB })^{3}$ - bestraft waren. Da alle diese Personen keineswegs erneut straffällig geworden zu sein brauchten, sondern von der Kriminalpolizei nach eigenem Ermessen ausgesucht wurden, waren der Willkür Tür und Tor geöffnet. Die polizeiliche Willkür wurde noch durch eine zusätzliche Bestimmung verstärkt, die die Anwendung der Vorbeugungshaft über den Kreis der vorbestraften Berufsverbrecher hinaus ausdehnte. Laut Görings Erlaß sollten

„ausnabmsweise und nach eingehender gewissenhafter Prüfung auch Personen in polizeiliche Vorbeugungshaft genommen werden, die, ohne vorbestrafte Berufsverbrecher zu sein, künftig einen auf Mord, Raub, Einbruchsdiebstahl oder Brandstiftung abzielenden verbrecherischen Willen durch Handlungen offenbaren, welche die Voraussetzungen eines bestimmten strafbaren Tatbestandes noch nicht [?] erfüllen, den Begeher aber als eine Gefahr für die öffentliche Sicherheit kennzeichnen“.

Damit sollten Fälle wie die der Brüder Saß in Berlin zukünftig unmöglich gemacht werden, die mehrmals durch die Tat ihre Absicht zu einem Einbruchdiebstahl offenbart hatten, jedoch zum Spott für die Polizei jedesmal mangels Erfüllung eines strafrechtlichen Tatbestandsmerkmals hatten außer Verfolgung gesetzt werden müssen. Die Anwendung der Vorbeugungshaft sollte umfangmäßig zunächst auf von Göring festgesetzte "Quoten“ beschränkt werden: für den Bezirk jeder preußischen Landeskriminalpolizeistelle sollten zunächst fünf, für den Berliner Bezirk dreißig Personen festgenommen und analog der Schutzhaftpraxis ihre Überführung in ein Konzentrationslager beantragt werden. ${ }^{4}$ Jede Vorbeugungshaft war unter genauer Begründung dem Landeskriminalpolizeiamt beim Polizeipräsidium Berlin zu melden, das eine zen-

3 Zu dieser nachträglichen Ergänzung vgl. Schr. des preuß. MdI (gez. Daluege) an den preuß. JM v. 20.7.34 (Akten des preuß. JM, Geh. StArch. Berlin, Sign. Rep. 84a/3715).

4 Der gemäß RdErl. des preuß. MdI an die RegPräs. u. das Gestapa v. 14. 10. 34 (Arch. des IfZ, Sign. Fa 183/1, Bl. $284 \mathrm{ff}$ ) für die Schutzhaft vorgeschriebene Vordruck sollte lediglich mit dem roten Verm. „Berufsverbrecher" versehen werden. 
trale Kartei der Vorbeugungshäftlinge führte und ohne dessen Zustimmung keine Entlassung erfolgen durfte. ${ }^{5}$ Am 10 . Februar 1934 erweiterte das preußische Innenministerium die Anwendung der Vorbeugungshaft auf Personen, die ihren verbrecherischen Willen - ohne dabei schon strafbare Tatbestände zu erfüllen - durch vorbereitende Handlungen bekundeten, die auf Anfertigung von Falschgeld, falscher Schecks, Wechsel, Aktien oder Pässe abzielten, der Vorbereitung eines Kautions-, Darlehens-, Scheck-, Wechselschwindels oder der Gründung einer Firma dienten mit der Absicht, sich Geld- oder Warenkredite zu erschwindeln. Voraussetzung war, daß der Täter auBer einer Vorstrafe wegen Betrugs mindestens noch ein zusätzliches Mal aus Gewinnsucht bestraft worden war. Außerdem sollten noch Erwachsene, die gewohnheitsmäßig Jugendliche aus sexuellen Motiven belästigten, sowie gewohnheitsmäßige Exhibitionisten bei vorbereitenden Handlungen vorbeugend verhaftet werden können, soweit sie mindestens einmal wegen eines Sittlichkeitsdelikts vorbestraft waren. Entsprechend wurden auch die „Höchstquoten“ der Vorbeugungshäftlinge für die einzelnen Landeskriminalpolizeistellen auf je fünfzehn, für Berlin auf $120-\mathrm{d}$.h. für Preußen auf insgesamt 525 - heraufgesetzt. Schließlich wurde ausdrücklich bestimmt, daß gegen die Anordnung der polizeilichen Vorbeugungshaft - wie bei der Schutzhaft - nicht die Gerichte angerufen werden konnten, sondern nur die Beschwerde im Dienstaufsichtsweg zulässig war. ${ }^{6}$

In einem weiteren Erlaß vom selben Tage wurden die Kriminalpolizeistellen ferner ermächtigt, Berufsverbrecher und gewohnheitsmäßige Sittlichkeitsverbrecher, die sich auf freiem Fuß befanden, durch die Auferlegung besonderer Verbote und Verpflichtungen planmäßjig zu überwachen. Hatte bisher die Zulässigkeit einer Polizeiaufsicht nur durch ein Gericht festgestellt werden können ${ }^{7}$, so konnte sie nunmehr durch die Polizei auf dem Verwaltungswege angeordnet werden. $\mathrm{Zu}$ den vorgesehenen Auflagen gehörten die - auf die verschiedenen Verbrechensarten zugeschnittenen - Verbote, den Wohnort ohne polizeiliche Genehmigung zu verlassen, sich zur Nachtzeit außerhalb der Wohnung aufzuhalten, Kraftfahrzeuge aller Art zu führen und zu benutzen, bestimmte Örtlichkeiten wie Bahnhöfe, Wettannahmestellen, Schulen, Parks, Kinderspielplätze, Bedürfnisanstalten usw. zu betreten sowie - für Heiratsschwindler und andere Betrüger - in der Zeitung zu inserieren. Bei Verstoß gegen diese Auflagen war sofort die Vorbeugungshaft anzuwenden. Die Landeskriminalpolizeistellen konnten diese zunächst unbefristet verhängten Auflagen wieder aufheben, wenn der Betroffene seine Lebensführung geändert zu haben schien. ${ }^{8}$

Die drei geschilderten Erlasse, die auf die Anregung des Ministerialdirektors im preußischen Innenministerium SS-Gruppenführer Daluege zurückgingen, wurden Ende Februar 1934 vom preußischen Justizministerium - noch unter der Leitung Kerrls - den Staatsanwälten übermittelt. ${ }^{9}$ Im Reichsjustizministerium wurde die Verdrängung des Verfolgungsprinzips, das bisher im Vordergrund der kriminalpolizeili-

\footnotetext{
Geh.Erl. des preuß. MdI (gez. Göring) v. 13.11.33 an die RegPräs., den PolPräs. von Berlin und die LKPStellen (Akten des preuß. JM, GehStArch. Berlin, Sign. Rep. 84a/3715).

6 Erl. des preuß. MdI (gez. Grauert) v. 10.2.34 - II C II $22 \mathrm{Nr}$. $37 / 34$ - (a.a.O.).

7 Vgl. $\S 38$ StGB: erkannte das Gericht neben einer Freiheitsstrafe auf Zulässigkeit von Polizeiaufsicht, so erhielt die höhere Landespolizeibehörde die Befugnis, den Verurteilten nach Strafverbüßung für höchstens 5 Jahre unter Polizeiaufsicht zu stellen.

8 Erl. des preuß. MdI (gez. Grauert) v. 10.2.34 - II C II 22 Nr. 38/34 - (Akten des preuß. JM, a.a.O.).

9 RdSchr. des preuß. JM v. 26.2.34 an die GStAe (Akten des preuß. JM, a.a.O.).
} 
chen Tätigkeit gestanden hatte und auf enger Zusammenarbeit mit der Staatsanwaltschaft beruhte, durch das von der Polizei allein durchgeführte Verbütungsprinzip mit gemischten Gefühlen betrachtet, da sie die Gefahr einer Emanzipation der Polizei bei der Verbrechensbekämpfung heraufbeschwor ${ }^{10}$ - zumal die neuen Praktiken keineswegs auf Preußen beschränkt blieben, sondern auch in einigen außerpreußischen Ländern Einzug hielten: u.a. in Bayern, wo sie allerdings teilweise von der politischen Polizei in der Form von Schutzhaft ausgeübt wurden. ${ }^{11}$ Als Gürtner im Juni 1934 mit der Wahrnehmung der Geschäfte des preußischen Justizministers betraut wurde, ließ er schon in den ersten Tagen seiner Amtsführung beim preußischen Innenministerium anfragen, ob die bewußten Erlasse noch in Geltung seien, und erhielt von Daluege eine bejahende Antwort. ${ }^{12}$ Der Wortlaut der internen Ausführungsvorschriften zu den Erlassen wurde dem Reichsjustizministerium allerdings erst durch eine Veröffentlichung Dalueges im amtlichen Organ des Kameradschaftsbundes Deutscher Polizeibeamter im Herbst 1935 bekannt. ${ }^{13}$

Nun vertrat $z$ war auch Gürtner als Anhänger einer antiliberalen Strafrechtspflege eine wirksame Verbrechensbekämpfung, die „die Verteidigungslinie des Staates vorverlegen" und den Kampf schon mit dem verbrecherischen Willen aufnehmen sollte: nicht erst der vollendete Verstoß gegen das Strafgesetz sollte bestraft und dabei das Strafmaß durch den tatsächlich eingetretenen Erfolg bestimmt werden; vielmehr sollte schon der Beginn der Tat - d.h. die Handlung, durch die der Täter erkennen ließ, daß er seinen verbrecherischen Entschluß in die Wirklichkeit umsetzen wollte - mit Strafe bedroht werden. Indem der Richter ermächtigt werden sollte, dabei über den Buchstaben des Gesetzes hinaus nach dessen Geist und Grundgedanken zu entscheiden, sollte er jedes strafwürdige Verhalten gebührend bestrafen und verhindern können, daß ein Strafwürdiger durch die Maschen des unvollkommenen Gesetzes schlüpfte, indem er vom Gesetzgeber nicht vorausgesehene Methoden anwandte, die folglich keine der festumrissenen Tatbestände voll erfüllten. Damit sollte „um jede Strafvorschrift eine Gefahrenzone" gelegt werden, in die sich verbrecherische Naturen auf eigene Gefahr und mit dem Risiko begaben, bestraft zu werden. Gürtner hielt es daher „für richtiger, daß bei dem Verbrecher Hemmungen eingeschaltet, daß er zur Vorsicht, zum Verbleiben auf dem Boden des zweifellos Rechtmäßigen angehalten wird, als daß der Richter im Interesse der Erhaltung einer Rechtssicherheit gefesselt werde“. ${ }^{14}$ Der somit auch

10 Zur grundsätzl. Kontroverse vgl. ORegRat Böhme, Die Vorbeugungsaufgaben der Polizei (DR 1936, S. 142 ff.), der die „bis in die allerletzte Zeit herrschende Auffassung, daß die Kriminalpolizei ein Anhängsel der Staatsanwaltschaft und der Justiz“" sei, ablehnte: die Kripo erledige „Verwaltungsaufgaben, die weit über den Bereich der Justiz hinausgehen“.

11 Vgl. schon die Auseinandersetzung zwischen dem bayer. Innenminister und RStH Epp im März/April 1934 über die Anwendung der Schutzhaft für die vorbeugende Bekämpfung unpolitischer Verbrechen (Kap. VI.2.a., S. 550); ferner Entschl. des bayer. StMdI v. 19.1.35 betr. „Anordnung vorbeugender Polizeihaft gegen Berufs-, Gewohnheits- und Sittlichkeitsverbrecher und ihre Einschaffung in das Konzentrationslager Dachau“; vgl. RdErl. der BPP (I. V. Stepp) v. 1.8.36 betr. Zusammenstellung der zur Zeit in Bayern geltenden Schutzhaftbestimmungen (Arch. des IfZ, Sign. Fa 183/1, Bl.370).

12 Vgl. Antw.Schr. des PrMdI (I. A. Daluege) v. 20.7.34 an das preuß. JM auf die Anfrage v. 26.6.34 (Akten des preuß. JM, a.a.O.).

13 Vgl. Der Deutsche Polizeibeamte 1935, S.775; Verm. in den Akten des RJM v. 21.10.35 (BA, Sign. $\mathrm{R}$ 22/1469).

14 F. Gürtner, Der Gedanke der Gerechtigkeit in der deutschen Strafrechtserneuerung (DJ 1935, S. $1241 \mathrm{ff}$.). Dieser auf dem XI. Internationalen Strafrechts- und Gefängniskongreß in Berlin gehaltene Vortrag gibt Gürtners Anschauungen über die Gestaltung des Strafrechts komprimiert wieder; vgl. dazu ferner Kap. VII.3.b., S. 855 f. 
von Gürtner vertretene Gedanke der Vorbeugung hatte gerade im Gewohnheitsverbrechergesetz neben der Einführung der Sicherungsverwahrung insofern Ausdruck gefunden, als das Gesetz bei bestimmten Delikten die Grenze der Strafbarkeit in das Vorfeld der Vorbereitungshandlungen verlegt hatte: durch die Einfügung des $\S 245 \mathrm{a}$ in das StGB war allein der Besitz von Einbrecherwerkzeugen für Gewohnheitsverbrecher strafbar geworden, um geplante Straftaten zu unterbinden. So weit aber die Justiz die Grenzen ihrer Wirksamkeit auch vorverlegte, stets mußte eine erneute - wenn auch nur vorbereitende - Handlung des Verbrechers erkennbar werden, ehe sie einschreiten konnte; das unterschied sie von den vorbeugenden Maßnahmen der Polizei. Dennoch war die Justizleitung einschließlich Freislers der Ansicht, daß sich die polizeiliche Vorbeugungshaft erübrigen werde, sobald die Gerichte durch Anwendung der neuen gesetzlichen Bestimmungen einschließlich der Sicherungsverwahrung unter den Gewohnheitsverbrechern aufgeräumt haben würden ${ }^{15}$ : immerhin hatten die Gerichte allein vom 1.Januar bis 30. September 1934 gegen 3112 Gewohnheitsverbrecher die Sicherungsverwahrung angeordnet, davon gegen 1804 nachträglich. ${ }^{16}$ Die vorbeugende Verbrechensbekämpfung sollte mit den Mitteln der Justiz gemeistert werden, deren Methode, auch über den vorbeugenden Freiheitsentzug unabhängige Gerichte entscheiden zu lassen, jenes Maß an Willkür ausschloß, das den späteren Verhaftungsaktionen Himmlers innewohnte.

Solange die Vorbeugungshaft in der alleinigen Zuständigkeit der Polizei verblieb und ausschließlich durch (landes-)polizeiinterne Bestimmungen geregelt wurde, konnte die Justiz auf ihre rechtliche Ausgestaltung und Anwendung keinen Einfluß nehmen. Die Justizleitung unternahm daher beim Reichsinnenministerium wiederholt Vorstöße, um diese Materie gesetzlich auf Reichsebene zu regeln. Als z.B. am 15. Oktober 1935 das Nachrichtenbüro deutscher Zeitungsverleger in einem Bericht über Ausführungen Dalueges, der seit November 1934 die Polizeiabteilung im Reichsund Preußischen Innenministerium leitete, die Meldung von der Vorbereitung eines Reichsgesetzes über polizeiliche Vorbeugungshaft gegen Berufsverbrecher verbreitete, bat das Reichsjustizministerium sofort um Mitteilung über den Stand der Angelegenheit und um rechtzeitige Beteiligung. Es erhielt jedoch im Dezember 1935 lediglich zur Antwort, daß die Vorbereitungen für das Gesetz "noch nicht abgeschlossen“ seien. ${ }^{17}$ Der Entwurf wurde zwar im Innenministerium bis ins Frühjahr 1936 hinein beraten ${ }^{18}$, ein Gesetz sollte jedoch nie erlassen werden: die Emanzipation der Sicherheitspolizei einschließlich der Kriminalpolizei vom Innenressort und die Anwartschaft Himmlers, dem jede gesetzliche Bindung zuwider war, auf den Posten des Chefs der gesamten deutschen Polizei warfen ihre Schatten voraus.

Auf einer Tagung der Generalstaatsanwälte und Oberstaatsanwälte im Reichsjustizministerium am 29. November 1935 warb Daluege in einem Vortrag um das Verständnis der Justizbehörden für die „neue Art der Verbrechensbekämpfung durch die Polizei" und suchte aus den von der Justiz getrennt gehandhabten Vorbeugungsmaßnah-

15 Vgl. dazu das Folgende S. 736.

16 Vgl. Aufstellung in den Akten des RJM (BA, Sign. R 22/1334).

17 Vgl. Schr. des RJM (I. V. Schlegelberger) an den RMdI v. 23.10.35; Antwort des RuPrMdI v. 13. 12.35; das RJM hatte sich bereits am 30.3.35 wegen der Ausarbeitung eines Gesetzes an das RMdI gewandt (Akten des RJM, BA, Sign. R 22/1469). Ber. des Nachrichtenbüros deutscher Zeitungsverleger „Vor einem Reichsgesetz über polizeiliche Vorbeugungshaft“, Berliner Redaktionsdienst, Bl.4, in den Akten (a.a.O.).

18 Vgl. Verm. v. 24.1. bis 3.3.36 in den Akten des RJM (a.a.O.). 
men eine „Zusammenarbeit“ mit der Staatsanwaltschaft zu konstruieren, „weil die Tätigkeit beider Behörden ja auf dasselbe Ziel gerichtet ist und sich daher zwangsläufig ergänzt“". Er klärte die Staatsanwälte über die Grundsätze und Verfahren auf, nach denen die Polizei vorging, und teilte mit, daß sich in Preußen gegenwärtig 476 Personen - 215 Einbrecher, 144 Diebe, 66 Betrüger und Hehler, 38 Sittlichkeitsverbrecher und 13 Räuber - im Konzentrationslager Esterwegen in Vorbeugungshaft befänden und 740 Personen unter polizeilicher Überwachung ständen ${ }^{19}$; bei weiteren 220 hätten die polizeilichen Auflagen unterdessen aufgehoben werden können. Anhand von Zahlenmaterial unterstrich Daluege die positive Wirkung dieser Maßnahmen der preußischen Kriminalpolizei, denen sich eine ganze Reihe außerpreußischer Länder angeschlossen hätten. Es sei daher eine vordringliche Aufgabe, sie auf das ganze Reich auszudehnen. ${ }^{20}$

Instrument dieser Ausdehnung wurde nach Himmlers Ernennung zum Chef der deutschen Polizei das Preußische Landeskriminalpolizeiamt unter SS-Sturmbannführer Nebe, das die Kriminalpolizeien der Länder reichseinheitlich organisierte und am 16. Juli 1937 zum Reichskriminalpolizeiamt (RKPA) umgewandelt wurde. Die Ausdehnung der polizeilichen Vorbeugungsmaßnahmen auf das ganze Reich unter Himmler sollte jedoch zunächst keineswegs die Übertragung der preußischen Bestimmungen - die immerhin einige genaue Voraussetzungen für die Vorbeugungshaft aufgestellt hatten - oder ihre Ersetzung durch neue präzise Vorschriften bedeuten. Im Gegenteil führte Himmler zunächst unter dem Deckmantel der „Berufsverbrecherbekämpfung“ eine reichsweite umfangreiche Verhaftungsaktion durch, die das Maß polizeilicher Vorbeugung bei weitem überschritt. ${ }^{21}$ Ende Januar 1937 erhielten die Dienststellen der Kriminalpolizei im Reich von der Berliner Zentrale Weisung, eine Aufstellung aller Personen ihres Bezirks einzusenden, „die nach Auffassung der Kriminalpolizei [!] als Berufs- und Gewohnheitsverbrecher sowie als gewohnheitsmäßige Sittlichkeitsverbrecher anzusprechen" waren und zu einem bestimmten Zeitpunkt "unerwartet in vorbeugende Polizeihaft" genommen werden sollten. Die bisherigen von den Ländern erlassenen Bestimmungen, die diese Verbrecherkategorien näher definierten, sollten dabei ausdrücklich unberücksichtigt bleiben. ${ }^{22}$ Am 23. Februar befahl Himmler dem preußischen Landeskriminalpolizeiamt, aus den eingereichten Listen 2000 Personen auszuwählen und sie „schlagartig an einem Tage im ganzen Reichsgebiet festzunehmen und in den Konzentrationslagern unterbringen zu lassen“. Auch er

19 Bereits im April 1934 waren ca. 300 Personen in Vorbeugungshaft (damals im KZ Lichtenburg) u. ca. 100 unter Überwachung, vgl. die Ausführungen des Reg.Rats Liebermann von Sonnenberg auf der Führerstabstagung des Kameradschaftsbundes Deutscher Polizeibeamter am 18.4.34 (Der Deutsche Polizeibeamte 1934, S. 405 f.). Die von Daluege genannten Zahlen hatte L. als Reg.Dir. u. Leiter der Berliner Kripo bereits in einem Vortrag am 23.10.35 genannt (vgl. Berliner Börsen-Zeitung, Berliner Tageblatt v. 24.10.35, VB v. 25.10.35).

20 Vgl. auszugsweise Niederschr. aus der Tagung der GStAe u. OStAe im Festsaal des RJM am 29.11.35 (Akten des RJM, a.a.O.), ferner Daluege, Staatsanwaltschaft und Polizei in der Verbrechensbekämpfung (DJ 1935$, S. $1846 \mathrm{ff}$.$) .$

21 Zur Verhaftungsaktion im März 1937 vgl. M. Broszat, Nationalsozialistische Konzentrationslager (Anatomie des SS-Staates, Bd. II, Olten u. Freiburg i. Br. 1965, S. 80 ff.), der sie treffend als „eine uferlose Ausweitung und Strapazierung der geläufigen Grundsätze kriminalpolizeilicher Nachüberwachung und Vorbeugung" bezeichnet (S.82).

22 Vgl. RdSchr. des PrLKPA an die Kripo(leit)stellen v. 27.1.37 (Vertraul. Erl.Sammlung „Vorbeugende Verbrechensbekämpfung“, Schriftenreihe des Reichskriminalpolizeiamtes Berlin Nr. 15, Dezember 1941, Bl. 27), Hervorheb. im Original. 
bezeichnete als Rechtsgrundlage für diese polizeiliche Vorbeugungshaft nicht etwa die einschlägigen Länderbestimmungen, sondern berief sich ausschließlich auf die Reichstagsbrandverordnung vom Februar 1933. Als einzige - für die Verbrechensbekämpfung allerdings recht unspezifische - Richtlinie gab er an, daß Familienväter nur in Ausnahmefällen verhaftet werden sollten. ${ }^{23}$ Die Aktion erfolgte am 9. März 1937, und die Verhafteten wurden den Konzentrationslagern Sachsenhausen, Sachsenburg, Lichtenburg und Dachau - Frauen dem Schutzhaftlager Moringen - zugeführt. Bei der Meldung der Kriminalpolizeistellen nach Berlin über die Durchführung brauchten bezeichnenderweise die „beim Vollzug der vorbeugenden Polizeihaft sonst einzureichenden Unterlagen“ für die einzelnen Fälle gar nicht mitgeschickt zu werden. ${ }^{24}$ Erst nach Abschluß dieser Sonderaktion sollten bis zum Erlaß reichseinheitlicher Vorschriften gegen Berufsverbrecher wieder „nur die von den Ländern vorgesehenen Maßnahmen" getroffen werden. ${ }^{25}$

Die Justiz reagierte auf diese willkürliche Aktion mit Erstaunen, aber ohne Protest. Am 24. März 1937 bat z. B. der Generalstaatsanwalt in Hamburg die dortige Kriminalpolizei um Aufklärung, ob in seinem Bezirk tatsächlich 250 bis 300 als „Berufsverbrecher" bezeichnete Personen in Vorbeugungshaft genommen worden seien, und woher die Polizei ihre Kenntnis über die Einstufung der Verhafteten in diese Gruppe nehme. Das Preußische Landeskriminalpolizeiamt, dem die Anfrage zugeleitet worden war, ließ sich in seiner Erwiderung auf eine Diskussion über die angewendeten Kriterien nicht ein: es teilte dem Generalstaatsanwalt lediglich mit, die vorbeugende Verhaftung von 167 Hamburger Berufs- und gewohnheitsmäßigen Sittlichkeitsverbrechern sei am 9. März „aufgrund einer Geheimanweisung des Reichsführers SS und Chefs der Deutschen Polizei“" erfolgt. ${ }^{26}$

Da eine solche umfangreiche Aktion nicht ohne Billigung Hitlers hatte unternommen werden können ${ }^{27}$, sah sich auch die Justizleitung nicht veranlaßt, dagegen nachträglich zwecklosen Protest zu erheben. Um so dringlicher mußte es ihr erscheinen, die Vorbeugungshaft unter ihrer Mitwirkung durch präzise Bestimmungen für die $\mathrm{Zu}$ kunft reichseinheitlich zu regeln. Dennoch wurde der von Himmler schließlich vorgelegte grundsätzliche Erlaß über die „Vorbeugende Verbrechensbekämpfung durch die Polizei“" vom Reichsinnenministerium am 14. Dezember 1937 ohne jegliche Beteiligung des Reichsjustizministeriums herausgegeben. ${ }^{28}$ Das Justizministerium wurde auf diesen nichtveröffentlichten Erlaß bezeichnenderweise erst durch eine Meldung in der „Frankfurter Zeitung“ vom 16.Januar 1938 aufmerksam und forderte ihn daraufhin

${ }^{23}$ Schnellbrief des RFSSuChdDtPol. im RMdI an das PrLKPA v. 23.2.37 (a.a.O., BI. 28).

$24 \mathrm{Vgl}$. RdSchr. des PrLKPA an die Kripo(leit)stellen vom 27.2.37 (a.a.O., Bl. 29). Juden sollten grundsätzl. nur nach Dachau gebracht werden.

${ }^{25} \mathrm{Vgl}$. RdVerf. des RKPA an alle Kripo(leit)stellen v. 27.8.37 (a.a.O., Bl.31).

${ }^{26} \mathrm{Zu}$ dem Schriftwechsel u. den Hamburger Vorgängen vgl. W. Johe, Die gleichgeschaltete Justiz. Organisation des Rechtswesens und Politisierung der Rechtsprechung 1933-1945, dargestellt am Beispiel des Oberlandesgerichtsbezirks Hamburg, Frankfurt a. M. 1967, S. $142 \mathrm{f}$.

27 Hitler hatte in der Reichstagsrede vom 30.1.37 gerade die „Sicherung des Volkes vor jenen Elementen, die sich als Asoziale entweder den gemeinsamen Verpflichtungen zu entziehen trachten oder sich an diesen gemeinsamen Interessen versündigen“, zu einer Hauptaufgabe erklärt, bei deren Lösung auch die Justiz mithelfen müsse (VB Süddt. Sonderausgabe v. 31.1.37, S.3).

28 Nichtveröffentl. RdErl. des RuPrMdI (gez. Frick) v. 14.12.37 an die Landesreg., den preuß. MinPräs., die Ober- u. RegPräs., den PolPräs. Berlin u. die Kripo(leit)stellen (Akten des RJM, Hauptbüro. Arch. des BJM); mit den Abänderungen v. 23.1.41 u. 8.4.42, auch abgedruckt in der Vertraul. Erl.Sammlung „Vorbeugende Verbrechensbekämpfung“ (a.a.O.). Vgl. dazu ferner Broszat, a.a.O., S.82f. 
beim Innenministerium an. ${ }^{29}$ In diesem Erlaß, der sich ebenfalls auf die Reichstagsbrandverordnung als Rechtsgrundlage berief, war der Kreis derjenigen, auf die die polizeiliche Vorbeugungshaft angewendet werden konnte, wesentlich weiter gezogen als im Göring-Erlaß vom November 1933. Ebenso wie Berufsverbrecher sollten nicht nur gewohnheitsmäßige Sittlichkeitsverbrecher, sondern generell "Gewohnbeitsverbrecher", die aus verbrecherischen Trieben oder Neigungen wiederholt straffällig geworden waren, verhaftet werden können, wenn sie mindestens dreimal entweder zu Zuchthaus oder Gefängnis von mindestens sechs Monaten verurteilt worden waren und „damit zu rechnen" war, daß sie auch künftig strafbare Handlungen begingen, oder wenn sie die im Rahmen einer polizeilichen Überwachung erteilten Auflagen übertreten hatten. Ferner konnte jeder wegen einer schweren Straftat Vorbestrafte verhaftet werden, der „wegen der Möglichkeit der Wiederholung eine so große Gefahr für die Allgemeinheit bildet, daß seine Belassung auf freiem Fuß nicht zu verantworten ist“, ferner jeder auch nicht Vorbestrafte -, der „einen auf eine schwere Straftat abzielenden Willen durch Handlungen offenbart, welche die Voraussetzungen eines bestimmten strafbaren Tatbestandes noch nicht erfüllen“ (sogenannte "Gemeingefäbrliche"). Weiterhin konnte bis zu vier Wochen in Vorbeugungshaft genommen werden, wer keine oder falsche Angaben über seine Person machte und damit den Verdacht erweckte, begangene Straftaten decken oder neue begehen zu wollen. Außer auf Kriminelle und kriminell Verdächtige wurde die umfassende Ermächtigung der Polizei zur Vorbeugungshaft erstmals auf eine völlig neue Personenkategorie ausgedehnt: auf jeden, der „ohne Berufs- oder Gewohnheitsverbrecher zu sein, durch sein asoziales Verhalten die Allgemeinheit gefährdet“. Gegen diese „Asozialen“, die der preußische Erlaß vom November 1933 noch nicht erfaßt hatte, war allerdings in Bayern nach den Richtlinien der Bayerischen Politischen Polizei vom August 1936 schon die Verhängung der Schutzhaft möglich gewesen. ${ }^{30}$ Zuständig für die Vorbeugungshaft war nach dem Erlaß die jeweilige Kriminalpolizeistelle, die beim Reichskriminalpolizeiamt nachträglich die Bestätigung und die Überweisung in ein Konzentrationslager einholte. Während bei den Asozialen die Fortdauer der Vorbeugungshaft - wie bei der Schutzhaft vierteljährlich zu überprüfen war, erfolgte die Haftprüfung bei den Kriminellen nicht vor Ablauf eines Jahres, spätestens aber nach zwei Jahren; nach vier Jahren entschied über die Fortdauer der Reichsführer-SS. Der Erlaß regelte auch die polizeiliche Überwachung einheitlich und sah gegenüber dem Göring-Erlaß eine erweiterte und differenzierte Skala von Auflagen vor. Gegen die Vorbeugungshaft und die Überwachung war lediglich die Beschwerde an das Reichskriminalpolizeiamt, in zweiter Instanz beim Reichsführer-SS zugelassen.

Durch diesen Erlaß und den wenige Wochen später folgenden grundlegenden Erlaß

Vgl. Verm. v. 18.1. bis 3.2.38 nebst Zeitungsausschnitt in den Akten des RJM (BA, Sign. R 22/1469).

So gegen „Bettler, Landstreicher, Zigeuner, Landfahrer, Arbeitsscheue, Müßiggänger, Prostituierte, Querulanten, Psychopathen und Geisteskranke ... Gewohnheitstrinker, Raufbolde, Verkehrssünder usw.", wenn „die zur Bekämpfung dieser Personenkreise vorhandenen polizeilichen und gerichtlichen Sicherungsmaßnahmen“ nicht ausreichten (RdErl. der BPP v. 1.8.36, Arch. des IfZ, Sign. Fa 183/1, Bl. 369). Nach der Bek. des bayer. StMdI v. 16.12.35 (a.a.O., Bl.364) war auch gegen Preistreiber auf dem Lebensmittelmarkt „neben den Strafmöglichkeiten mit Schutzhaft vorzugehen ... wenn verwerflicher Egoismus die Triebfeder für dieses asoziale Handeln bildet“. 
über die Schutzhaft mit seinen gleichfalls dehnbaren Bestimmungen ${ }^{31}$ hatte sich Himmlers Polizei auch formal die Generalbefugnis geschaffen, unter völliger Ausschaltung der Gerichte Personen aus politischen und unpolitischen (kriminellen wie nichtkriminellen) Gründen der Freiheit zu berauben. Zwar sollte die Kriminalpolizei nach den Durchführungsbestimmungen des Reichskriminalpolizeiamts z. B. bei der Prüfung, ob eine Person als asozial vorbeugend zu verhaften war, keine politischen Gesichtspunkte einbeziehen ${ }^{32}$, dennoch wurde der Begriff des Asozialen - wie übrigens auch der des Berufs- und Gewohnheitsverbrechers - allein schon dadurch politisiert, daß in ihnen Feinde der Volksgemeinschaft gesehen wurden. So wurde die Vorbeugungshaft durch die Kriminalpolizei aus einer Schutzmaßnahme gegen die Kriminalität genauso zu einer politischen Kampfmaßnahme wie die Schutzhaft durch die Gestapo. Die Grenzen zwischen beiden Haftarten verwischten sich zusehends: als Himmler im März/April 1938 eine Verhaftungsaktion gegen „Arbeitsscheue“ durchführen ließ, bediente er sich des Instruments der Schutzhaft, obwohl dieser Personenkreis in der Weisung für die Aktion selbst eindeutig den Asozialen im Sinne des Erlasses vom Dezember 1937 zugerechnet wurde. ${ }^{33}$

\section{b. Verscbärfte Anwendung der gerichtlichen Sicherungsverwabrung als Reaktion auf die polizeiliche Vorbeugungshaft ab 1938}

Der Erlaß über die polizeiliche Vorbeugungshaft vom Dezember 1937 führte der Justiz deutlich vor Augen, daß die SS- und Polizeiführung nicht gewillt war, diese Maßnahme künftig wieder aus der Hand zu geben. Daß sich die Vorbeugungshaft gegen Berufs- und Gewohnheitsverbrecher als ein bleibendes Druckmittel auf die Rechtspflege auswirkte, wurde bereits auf der Arbeitstagung im Reichsjustizministerium am 7. März 1938 deutlich, als der Leiter der Strafrechtspflegeabteilung, Ministerialdirektor Crohne, die Generalstaatsanwälte vertraulich vom Dezember-Erlaß des Innenministeriums informierte und dabei ausführte:

"Diese Verfügung enthält einen Einbruch in das Reich der Justiz, weil sie für diejenigen Fälle, in denen das Gericht nach der Meinung der Polizei versagt, ein Eingreifen der Polizei vorsieht. Dieser Verfügung kann nur dadurch das Wasser abgegraben werden, daß in allen geeigneten Fällen der Antrag auf SV [Sicherungsverwahrung] gestellt wird.“34

Daraus geht hervor, daß der drohenden Korrekturtätigkeit der Polizei durch eine stärkere Anwendung der gerichtlichen Sicherungsverwahrung begegnet werden sollte. Da sich aber die Zahlen der Verhängung von Sicherungsverwahrung seit Jahren rückläufig entwickelten - 1934 wurde sie in 3935 Fällen angeordnet, 1935 in 1318, 1936 in

${ }^{31}$ Zum Schutzhaft-Erl. v. 25.1.38 vgl. Kap. VI.2.a., S. $561 \mathrm{f}$. Dem gummiartigen Vorbeugehaftgrund: „wer durch sein asoziales Verhalten die Allgemeinheit gefährdet" entsprach hier: Personen, „die durch ihr Verhalten den Bestand und die Sicherheit des Volkes und Staates gefährden“.

32 Richtlinien des RKPA zur Durchführung der vorbeugenden Verbrechensbekämpfung v. 4.4.38 (Vertraul. Erl.Sammlung „Vorbeugende Verbrechensbekämpfung“, a.a.O., Bl.65 ff.); dort nochmals die gummiartige Definition: „Als asozial gilt, wer durch gemeinschaftswidriges, wenn auch nicht verbrecherisches [!] Verhalten zeigt, daß er sich nicht in die Gemeinschaft einfügen will.“

${ }_{33} \mathrm{Zu}$ dieser Aktion und der Austauschbarkeit von Schutzhaft u. Vorbeugungshaft vgl. Broszat a.a.O., S.84 f.

$34 \mathrm{Vgl}$. Ber. des GStA Hamburg v. 18.3.38 an den Hamburger OLGPräs. Rothenberger über die Tagung der GStAe in Berlin am 7. u. 8.3.38 (Akten des OLG Hamburg, Arch. der Forschungsstelle f. d. Geschichte des NS in Hamburg, Sign. Best. 3308). 
907 und 1937 nur noch in 692 Fällen $^{35}$-, trat auf der erwähnten Tagung Staatssekretär Freisler als Scharfmacher auf. Er führte aus, die Rückläufigkeit könne keine ausreichende Erklärung darin finden, daß ein Großteil der Gewohnheitsverbrecher bereits unschädlich gemacht sei; vielmehr lasse die Anwendung der Sicherungsverwahrung - wie sich aus „unverständlichen“ Einzelfällen ergäbe - aus einer Reihe von Ursachen nach, denen Freisler im einzelnen entgegenzutreten suchte und deren Beseitigung durch künftige Maßnahmen er ankündigte. ${ }^{36} \mathrm{Er}$ forderte die Staatsanwälte auf, diesen Tendenzen energisch entgegenzutreten und die Sicherungsverwahrung „soviel als möglich zu beantragen und gut zu begründen“. Auch bei der gerichtlichen Entscheidung über die Entlassung aus der Sicherungsverwahrung, bei der die Staatsanwälte durch Stellungnahme mitwirkten, sollten sie strengste Maßstäbe anlegen. (Die Gerichte hatten im Jahre 1934 sieben Personen aus der Sicherungsverwahrung entlassen, 1935 waren es 72 und 1936 sogar 165 gewesen. ${ }^{37}$ ) Seine grundlegende Meinung zur Frage der Entlassung hatte Freisler den Generalstaatsanwälten bereits auf einer Arbeitstagung im November 1936 unmißverständlich dargelegt:

„Ich sehe die Sicherungsverwahrung als eine Dauermaßnahme an, bei der ich es grundsätzlich nicht verantworten kann, den Sicherungsverwahrten wieder der Freiheit zu übergeben. Ausnahmen erkenne ich nur in solchen Fällen an, wo infolge des Nachlassens der Kräfte oder des Trieblebens von dem Sicherungsverwahrten eine Wiederholung der von ihm begangenen Verbrechen nicht zu erwarten ist. In allen anderen Fällen bin ich deswegen gegen eine Entlassung der Sicherungsverwahrten, weil es kein Mittel gibt, um mit Sicherheit festzustellen, daß der Sicherungsverwahrte nicht wieder straffällig werden wird. ${ }^{\text {(38 }}$

Auch nunmehr auf der Tagung von 1938 erklärte Freisler, die Sicherungsverwahrung dürfe keinesfalls nur als eine automatische Strafverlängerung um drei Jahre - das war die Frist, die $\S 42 \mathrm{f}$ StGB für das Haftprüfungsverfahren vorschrieb - aufgefaßt werden. Auch erfordere die Entscheidung über ihre Verlängerung nicht etwa dieselbe Prüfung der Voraussetzungen, wie sie für die erstmalige Anordnung vorgeschrieben sei: zu entscheiden sei lediglich darüber, ob der Zweck der Unterbringung erreicht sei. Jeder verbleibende Zweifel, ob der Sicherungsverwahrte noch eine Gefahr für die Volksgemeinschaft bilde, müsse seine Entlassung ausschließen; hier gelte der Satz: in dubio contra reum. Freisler wiederholte seine Feststellung aus dem Jahre 1936, daß eine Entlassung eigentlich nur aus Altersgründen in Betracht käme. Anschließend schnitt er die Frage an, ob die Entscheidung über eine Entlassung aus der Sicherungsverwahrung nicht überhaupt den Gerichten genommen und in die Hände der Generalstaatsanwälte gelegt werden sollte - eine Frage, die später im Kriege tatsächlich zugunsten der Staatsanwaltschaft geregelt wurde. ${ }^{39}$ Zwar müsse sich auch der General-

35 Vgl. R. Freisler, Fragen zur Sicherungsverwahrung (DJ 1938, S.626ff.).

36 Auf die Gründe (einschränkende RG-Entscheidungen; überwiegende Veröffentlichung der die SV ablehnenden Revisionsentscheidungen im Schriftum; überdehnte Anwendung des Begriffs der fortgesetzten Handlung auf mehrere Straftaten; Abneigung des Richters gegen eine Verurteilung mit unbestimmtem Strafmaß; Einbeziehung der Prognose über die Strafwirkung in die Beurteilung, ob SV anzuordnen sei) und ihre Behandlung durch Freisler kann hier nicht eingegangen werden. Vgl. dazu u. zum folgenden den Ber. des GStA Hamburg v. 18.3.38 (a.a.O.), die Veröffentlichung über die Tagung in der DJ 1938, S. 385ff., sowie R. Freisler, Fragen der Sicherungsverwahrung (a.a.O.).

37 Vgl. LGDir. Stolzenburg (Ref. in der Strafrechtspflegeabt. des RJM), Die Entlassung aus der Sicherungsverwahrung (DJ 1938, S.219).

38 Niederschr. über die Erörterung von Strafvollzugsfragen in der Arbeitstagung der GStAe im RJM am 14.11.36 (Akten des RJM, BA, Sign. R 22/1263).

39 Vgl. G. zur Änderung des Reichsstrafgesetzbuchs v. 4.9.41 u. DurchfVO v. 24.9.41 (RGBI. I, S. 549 u. 581). 
staatsanwalt - nicht anders als das Gericht - bei dieser Entscheidung im wesentlichen auf den Akteninhalt und den Bericht des Leiters der Sicherungsanstalt über die Führung des Verwahrten stützen, dennoch stehe er als Vollstreckungsleiter und unmittelbarer Vorgesetzter des Anstaltsleiters dem Vollzug näher als das Gericht. Da aber dem Gericht und der Staatsanwaltschaft für die Entscheidung schließlich dieselben Erkenntnisquellen zur Verfügung standen, war Freislers Argumentation nicht überzeugend: hinter ihr steckte vielmehr der Gedanke, daß dem Staatsanwalt im Gegensatz zum Richter bindende Richtlinien für die Handhabung des Problems gegeben werden konnten.

Durch eine Allgemeinverfügung des Ministeriums wurden alle Justizbehörden im März $1938^{40}$ gleichfalls ermahnt, daß sie „die durch das [Gewohnheitsverbrecher-]Gesetz in ihre Hand gegebenen Abwehrmittel rücksichtslos einsetzen und ihre Befugnisse voll ausschöpfen" sollten. Die Gerichte wurden für die Handhabung der Sicherungsverwahrung mit Empfehlungen, die Staatsanwälte mit Richtlinien versehen. Die Staatsanwälte sollten bei einer Ablehnung ihres Antrags auf Sicherungsverwahrung durch das Gericht „grundsätzlich“ das zulässige Rechtsmittel einlegen und rechtskräftig gewordene Entscheidungen dieser Art zusammen mit den Akten dem Ministerium einreichen. ${ }^{40 a}$ Einer Entlassung aus der Sicherungsverwahrung sollten sie regelmäßig widersprechen, wenn sie von der Sicherungsanstalt nicht befürwortet worden war. Ordnete das Gericht entgegen ihrem Antrag aber die Entlassung an, sollten sie sofort Beschwerde beim nächsthöheren Gericht - in der Regel also beim Oberlandesgericht einlegen und beantragen, daß die Vollziehung der angefochtenen Entscheidung ausgesetzt wurde ${ }^{41}$, d.h. die Entlassung einstweilen unterblieb. Darüber hinaus sollten sie jede erfolgte Entlassung dem Ministerium melden, desgleichen ihren etwaigen Widerruf. Vor allem an zwei Bestimmungen wurde dabei erneut deutlich, daß hinter diesen Vorschriften das Bemühen stand, die gefürchtete Korrektur durch polizeiliche Vorbeugungshaft zu vermeiden: für die Entscheidung sowohl über die Anordnung wie über die Fortdauer der Sicherungsverwahrung sollte der Staatsanwalt eine Stellungnahme der Kriminalpolizei einholen, ob sie glaube, den Betroffenen durch polizeiliche Überwachung von weiteren Straftaten abhalten, d.h. allein durch dieses Mittel die Sicherheit der Volksgemeinschaft gewährleisten zu können. ${ }^{42}$ Da eine Verneinung dieser Frage unausgesprochen bedeuten mußte, daß die Polizei dann automatisch ihre schärfere Waffe der Vorbeugungshaft einsetzen werde - das Reichskriminalpolizeiamt hatte in einem Erlaß an seine Dienststellen vom Februar keinen Zweifel an dieser Be-

40 AV des RJM v. 3.3.38 betr. Strafsachen gegen gefährliche Gewohnheitsverbrecher (DJ 1938, S.323). Die $\mathrm{AV}$, die in der DJ v. 4.3.38 veröffentlicht wurde, dürfte den wenigsten der an der Tagung vom 7.3.38 teilnehmenden GStAen bereits bekannt gewesen sein. Ein Abdruck des Erl. des RMdI betr. Vorbeugende Verbrechensbekämpfung durch die Polizei v. 17.12.37 wurde ihnen von Gürtner auf der Tagung versprochen und am 11.3.38 zugesandt (Akten des RJM, BA, Sign. R 22/1469).

${ }^{\text {40a }}$ Die Berichtspflicht an das RJM fiel im Zuge der Vereinfachung des Geschäftsganges im Kriege wieder weg (AV des RJM v. 19.3.40, DJ 1940, S.395).

4 Gemäß $\S 307$ Abs. 2 StPO konnte „das Gericht, der Vorsitzende oder der Richter, dessen Entscheidung angefochten wird, sowie auch das Beschwerdegericht anordnen, daß die Vollziehung der angefochtenen Entscheidung auszusetzen sei“.

42 Die Entlassung des Sicherungsverwahrten war der zuständigen Kripostelle ohnehin vorher mitzuteilen (vgl. $\S 42$ der AV des RJM v. 21.5.35 betr. Mitteilungen in Strafsachen, Sonderveröffentlichung der DJ Nr. 8; Nr. 16 der AV des RJM v. 25.3.41 betr. Mitteilungen in Vollzugsachen, DJ 141, S.399). 
fugnis gelassen, falls die Justizbehörden die Entlassung nicht widerriefen ${ }^{43}$-, sollte der Staatsanwalt im verneinenden Falle grundsätzlich für die Sicherungsverwahrung eintreten. Die Richter erkannten sofort, daß der Polizei damit „ein ihr nicht zustehender Einfluß auf die Entschließung eingeräumt" wurde und „sich bei einer entgegen der Stellungnahme der Sicherheitspolizei erfolgenden Entlassung nur Schwierigkeiten ergeben" mußten. ${ }^{44}$ Obwohl sie sich an die Stellungnahme der Polizei, die der Staatsanwalt beibrachte, nicht zu halten brauchten, mußten sie diese Konsequenzen ihrer Entscheidung wohl oder übel in ihre Überlegungen einbeziehen: es war das gleiche Problem, vor dem die Richter bei drohender Schutzhaftverhängung durch die Gestapo im Falle eines Freispruchs oder der Verhängung einer „ungenügenden“ Freiheitsstrafe standen. Entweder nahmen sie hin, daß die Kriminalpolizei ihre richterliche Entscheidung mißachtete, durch Vorbeugungshaft korrigierte und damit jener Autoritätsverlust der Justiz und jene Rechtfertigung des Anspruchs der Polizei auf erweiterte Funktionen bei der Strafverfolgung eintraten, die die Justizleitung vermieden sehen wollte. Oder aber sie beugten sich den Umständen und verhängten oder verlängerten die $\mathrm{Si}$ cherungsverwahrung entgegen ihrer eigenen gewissenhaften Abwägung in den Fällen, in denen sonst die polizeiliche Vorbeugungshaft zu erwarten war. Damit wahrte die Justiz zwar ihr Gesicht, korrigierte sich aber im Grunde auf Geheiß der Polizei selbst. Von ausschlaggebender Bedeutung war diese Entscheidung allerdings für den Betroffenen: von ihr hing ab, ob er seine langjährige Haft in einer der Sicherungsanstalten der Justiz oder im Konzentrationslager verbringen mußte. Die Abwendung einer drohenden Vorbeugungshaft durch Sicherungsverwahrung mußte sich aber normalerweise auch auf das Strafmaß auswirken, denn als Voraussetzung dafür mußte der Betreffende zunächst als "gefährlicher Gewohnheitsverbrecher" nach $\S 20$ a StGB verurteilt werden, der - teils zwingend, teils fakultativ - erhebliche Strafverschärfungen vorschrieb. Wollte der Richter auf die zusätzliche Anordnung der Sicherungsverwahrung verzichten, aber den Täter dennoch dem Zugriff der Polizei längerfristig entziehen, konnte er nur von vornherein auf eine längere Freiheitsstrafe erkennen, als es dem Maß der Schuld und einer gerechten Vergeltung entsprach: er mußte selbst Unrecht tun, um den Verurteilten den Unrechtsmaßnahmen der Polizei zu entziehen. Auf jeden Fall erwies sich die polizeiliche Vorbeugungshaft - wie die Schutzhaft - als ein wirkungsvolles Mittel, der Justiz unter Drohung ihrer Ausschaltung den Willen der politischen Führung nach schärferen Strafen aufzuzwingen und sie so zum funktionierenden Werkzeug zu machen. Durch diese Entwicklung wurde das Institut der Siche-

${ }^{43} \mathrm{Vgl}$. RdErl. des RKPA an alle Kripo(leit)stellen v. 8.2.38 (Vertraul. Erl.Sammlung „Vorbeugende Verbrechensbekämpfung“, a.a.O. Bl.48). Danach sollten alle aus der SV Entlassenen unter polizeiliche Úberwachung gestellt werden. Bei Nichtbefolgung der Auflagen sollte vor Verhängung der Vorbeugungshaft den Justizbehörden Gelegenheit gegeben werden, die Entlassung gemäß $\S 42$ h StGB zu widerrufen. Aber auch ohne Übertretung der polizeilichen Auflagen konnten die Entlassenen in Vorbeugungshaft genommen werden, wenn die dafür festgesetzten ,allgemeinen Voraussetzungen“ zutrafen. Im Kriege wies das RSHA seine Dienststellen schließlich an, keiner Entlassung aus der Sicherungsverwahrung mehr zuzustimmen und im Falle einer trotzdem erfolgenden Entlassung Vorbeugungshaft zu verhängen. Daher mußte Freisler die StAe in einer RV v. 4.5.40 (Akten des RJM, Hauptbüro, Arch. des BJM) anweisen, „bis auf weiteres“ grundsätzlich jeder Entlassung bei den Gerichten zu widersprechen.

44 Vgl. Ber. des Vors. der Strafkammer II beim LG Hamburg an den LGPräs. v. 14.4.38 (Akten des OLG Hamburg, Arch. der Forschungsstelle für die Geschichte des NS in Hamburg, Sign. Best. 3305), veranlaßt durch die vertraul. Bitte des OLGPräs. Hamburg an die unterstellten Gerichtsprās. um Stellungnahme zu den Problemen, die mit der AV des RJM v. 3.3.38 zusammenhingen (vgl. dazu Johe, a.a.O., S. 149f.). 
rungsverwahrung - von Gürtner und den zuständigen Ministerialbeamten ursprünglich als rechtstechnische Ergänzung der Strafgesetze gedacht mit dem Ziel, unverbesserliche Kriminelle an der Begehung neuer Straftaten zu hindern und die Allgemeinheit vor ihnen zu schützen - aus politischen Gründen weitgehend deformiert. Als Gürtner am 17. November 1933 auf einem Presseempfang im Ministerium das angekündigte Gewohnheitsverbrechergesetz für die Öffentlichkeit erläuterte, beschränkte er die Anwendung der Sicherungsverwahrung ausdrücklich auf den engeren Kreis der unverbesserlichen Berufs- und Sittlichkeitsverbrecher: "nach verschiedenen Berechnungen, die aber alle zu dem gleichen verblüffenden Ergebnis gekommen seien“, werde ihre Zahl für das ganze Reich „etwa zwischen 800 und 1000 liegen“45 $\mathrm{Daß}$ es sich hierbei nicht lediglich um eine taktisch begründete maßvolle Äußerung handelte, geht aus den von den Referenten des Justizministeriums herausgegebenen offiziösen Publikationen und Kommentaren jener Jahre hervor, die diese Konzeption der Sicherungsverwahrung bestätigen. ${ }^{46}$ In ihrer Ansicht, daß es sich bei der Einführung der Sicherungsverwahrung lediglich um eine längst fällige rechtliche Maßnahme handelte, wurden die Juristen dadurch bestärkt, daß hierbei auf gesetzgeberische Vorarbeiten in der Weimarer Republik - auf die Vorlagen für den Reichsrat von 1925 und für den Reichstag von 1927 - zurückgegriffen wurde und diese Einrichtung auch in anderen Kulturstaaten bestand. ${ }^{47}$ Auch die amtliche Strafrechtskommission zeigte bei ihren Beratungen 1933/34 hinsichtlich der Sicherungsverwahrung eine einschränkende Tendenz: sie lehnte es ab, die formalen Voraussetzungen (Vortaten und Vorstrafen) für die Strafverschärfung im § 20a StGB durch eine allgemeine Vorschrift zu ersetzen, die lediglich auf die Persönlichkeit des Täters abstellte, weil eine solche Regelung „zu leicht zu einer allzu häufigen Verhängung der Sicherungsverwahrung führen“ könnte. ${ }^{48}$

Wie in zahlreichen anderen Fällen der nationalsozialistischen Praxis bot auch hier eine generalklauselartig formulierte Bestimmung die Möglichkeit, die Maßnahme über ihren ursprünglichen Sinn und Zweck hinaus auszuweiten: neben der Verurteilung als "gefährlicher Gewohnheitsverbrecher" gemäß $§ 20$ a StGB war die zweite Voraussetzung, die für eine Anordnung der Sicherungsverwahrung vorliegen mußte, daß „die öffentliche Sicherheit es erfordert““ ${ }^{49}$ Bei dem auslegungsfähigen Begriff der „öffentlichen Sicherheit" war die hier geforderte Entscheidung weniger eine Rechtsfrage als eine Ermessensfrage, die den Richtern von Anfang an erhebliche Schwierigkeiten bereitete und in den ersten Jahren nach 1934 zu einer recht unterschiedlichen Handhabung der Sicherungsverwahrung in an sich ähnlich oder gleichgelagerten Fällen

4s Vgl. VB v. 18.11.33, Süddt. Ausg. Nr. 322, S.4.

46 Vgl. MinRat L. Schäfer, ORegRat O. Wagner, RegRat J. Schafheutle: Gesetz gegen gefährliche Gewohnheitsverbrecher und über Maßregeln der Sicherung und Besserung mit dem dazugehörigen Ausführungsgesetz, Berlin 1934, S. 130.

47 Vgl. MinRat Rietzsch, Die Abwehr des Gewohnheitsverbrechertums. I. Deutsche Gesetze und Gesetzentwürfe bis zur Machtübernahme (DJ 1938, S. 139 ff.), AGRat Schönke, Einige Bemerkungen über die Sicherungsverwahrung im Ausland (a.a.O., S. $142 \mathrm{ff}$.).

48 Das kommende deutsche Strafrecht. Algemeiner Teil. Bericht über die Arbeit der amtlichen Strafrechtskommission, herausg. von F. Gürtner, 2. Aufl., Berlin 1935, S. 178. Zur Ablehnung von Freislers Vorschlag, kommunistische Straftäter automatisch als Gewohnheitsverbrecher anzusehen, vgl. Kapitel VII.2.b., S.778, und dortige Anm. 9

49 Vgl. dazu Kapitel VII.3.a., S.840f. 
führte. ${ }^{50}$ In ihrer Unsicherheit hatten einige erstinstanzliche untere Gerichte anfänglich einer vorschnellen Anordnung der Sicherungsverwahrung zugeneigt, so daß das Reichsgericht durch eine Reihe grundlegender Entscheidungen hemmend einwirkte. ${ }^{51}$ Als nun im Jahre 1938 die Justizleitung unter dem Druck der Ausübung der polizeilichen Vorbeugungshaft dazu überging, die Korrekturtätigkeit der Polizei durch eine verstärkte Anwendung der Sicherungsverwahrung einzudämmen, mußten diese Hemmnisse wieder beseitigt werden. Freisler als derjenige der beiden Staatssekretäre, dem die Strafrechtspflegeabteilung unterstand, nahm sich daher besonders intensiv der Aufgabe an, den Richtern klarzumachen, daß sie sich bei der Verhängung der Sicherungsverwahrung - anders als bei der Strafzumessung, bei der sie die Persönlichkeit des Täters gerecht beurteilen mußten - allein davon leiten lassen sollten,

„ob die Ausscheidung des Täters erforderlich ist, um das Volk vor weiterer Schädigung durch ihn zu bewahren. Hier gilt es eben, die Gewohnheit zu überwinden, überall den Blick auf den einzelnen zu richten; hier kommt alles darauf an, daß die Rechtsprechung ihren Blick bewußt auf das Ganze richte! (452 $^{\text {s }}$

Das bedeutete nichts anderes, als daß für die Beurteilung der Frage, ob der Täter eine Gefahr für die „öffentliche Sicherheit" darstellte, nicht mehr rechtliche, sondern ausschließlich Gesichtspunkte maßgebend sein sollten, die außerhalb des Täters und der Tat lagen - daß die Justiz nicht mehr nach der Rechtmäßigkeit, sondern wie die Polizei nach der Zweckmäßigkeit ihrer Entscheidungen fragen sollte. Damit war das Institut der Sicherungsverwahrung mit Hilfe der generalklauselartigen Bestimmungen von der "öffentlichen Sicherheit“ zumindest potentiell zu einem politischen Instrument geworden.

Als plastisches Beispiel dafür, daß die Richter der Aufforderung nach rigoroser Anwendung der Sicherungsverwahrung keineswegs generell folgten, zugleich aber auch dafür, daß die Beobachtung der Handhabung dieser Maßnahme durch die Justizverwaltung der Sorge um die zukünftige Stellung der Rechtspflege im nationalsozialistischen Staat entsprang, sei folgender Hamburger Fall vom Juli 1938 angeführt. In einem Urteil gegen drei Gewohnheitsverbrecher hatte eine Strafkammer des dortigen Landgerichts die Frage der Sicherungsverwahrung „nur unter Bedenken verneint ${ }^{\text {“ }}$ obwohl das Gericht vor allem bei dem Anführer der Diebesbande die Möglichkeit nicht ausschloß, „daß die erkannte Strafe nicht die genügende Wirkung ausüben“ werde, hielt es die Sicherungsverwahrung „diesmal ... noch nicht“ für erforderlich, da die Länge der verhängten Zuchthausstrafe immerhin erwarten lasse, daß ein Rückfall unterbleibe. Gegenüber dem Landgerichtspräsidenten kritisierte Oberlandesgerichtsprä-

so Die Unterschiede zeigten sich sogar innerhalb eines Gerichts: so ordnete z. B. die große Strafkammer A des LG Hamburg $1934 / 35$ in 25 von 50 Fällen (davon in 16 von 19 Fällen erstinstanzlich) die SV an, die große Strafkammer B dagegen in 33 von 40 Fällen (in 8 von 9 Fällen erstinstanzlich). Der Vors. der Strafkammer A war der Ansicht, daß die Gerichte "nach dem Willen des Gesetzgebers nur in den wirklich hoffnungslosen Fällen auf Sicherungsverwahrung erkennen dürften" (ungez. Stellungnahme zum Ber. über die Erfahrungen der großen Strafkammern des LG Hamburg mit der SV v. 24.2.36, Arch. der Forschungsstelle für die Geschichte des NS in Hamburg, Sign. Best. 3305). Hervorheb. im Original.

s1 Vgl. z. B. die in der JW 1934, S. 1662, 2057, 2912 u. vor allem S. 3062 veröffentlichten Urt. des RG. In der AV betr. Richtlinien für das Strafverfahren v. 13.4.35 (Sonderveröffentlichung der DJ Nr. 7) hatte das RJM die StAschaft angewiesen, in Fällen, in denen die Anwendung der SV zu erwarten war, die Eröffnung des Hauptverfahrens vor der großen Strafkammer zu beantragen, weil eine Revision dann vor das RG ging. Die Maßnahme sollte die Rechtseinheit fördern.

32 R. Freisler, Fragen zur Sicherungsverwahrung (DJ 1938, S.627). 
sident Rothenberger diese Urteilsbegründung, da sie die Polizei geradezu zum Eingreifen herausfordere. Wenn schon „dem Gericht die Anordnung der Sicherungsverwahrung nicht erforderlich erschien - ich betone, daß ich mich insoweit jeder Kritik enthalte -, so hätte das auf keinen Fall in einer Begründung niedergelegt werden dürfen, welche die $Z$ weifel besonders hervorhebt". Die Justiz müsse gegenwärtig alles vermeiden, was die Notwendigkeit einer polizeilichen Korrektur begründen könnte, denn seit dem Erlaß des Reichsinnenministers vom Dezember 1937 zeige die vorbeugende Verbrechensbekämpfung durch die Polizei „offenbar immer mehr die Tendenz, sich parallel neben die Strafjustiz zu schalten“. Fälle von Vorbeugungshaft nach Freispruch und Strafverbüßung seien auch bei unpolitischen Tatbeständen „nicht mehr Ausnahmen“. Der Landgerichtspräsident solle daher ,auf die große Verantwortung hinweisen, die gerade jetzt die in der Strafjustiz tätigen Vorsitzenden zu tragen" hätten. Derartige Urteilsbegründungen wie die von ihm beanstandete seien „für den Mangel an Verständnis für die Aufgaben der Strafjustiz unter den heutigen Verhältnissen" symptomatisch. Jeder Strafrichter sollte sich aber

„darüber klar sein, daß Urteile, die entweder jedes politische Fingerspitzengefühl oder jedes Verständnis für die nationalsozialistische Auffassung vom Primat des Schutzes der Volksgemeinschaft vor dem Einzelinteresse vermissen lassen, auch wenn es sich um seltene Ausnahmen handelt, dazu beitragen, daß das Bestreben um eine Abgrenzung der Funktionen durch die Justiz selbst erschwert, wenn nicht aussichtslos gemacht wird“" ${ }^{53}$

\section{c. Vergebliches Bemüben des Reichsjustizministeriums, die polizeiliche Vorbeugungshaft einschränkend zu regeln}

Trotz seiner Anpassung an die gegebenen Umstände gab das Reichsjustizministerium die Hoffnung nicht auf, durch eine grundlegende Neuregelung wenigstens die Mitwirkung der Justizbehörden an der polizeilichen Vorbeugungshaft zu erwirken. Das wird an folgenden Vorgängen deutlich. Im April $1938 \mathrm{nahm}$ die Kriminalpolizeistelle Wuppertal vier Strafgefangene nach Verbüßung ihrer Freiheitsstrafe in Vorbeugungshaft und bat den Oberstaatsanwalt beim dortigen Landgericht um Stellungnahme, ob auch von ihm „die Verhängung dieser Maßnahme für notwendig und zweckmäßig gehalten" werde. Sie wollte seine Stellungnahme mit dem Antrag beim Reichskriminalpolizeiamt zur Entschließung über die endgültige Haftverhängung einreichen. Wie der Oberstaatsanwalt an den Generalstaatsanwalt Düsseldorf berichtete, handelte es sich in einem Fall um einen vor dem Erlaß des Gewohnheitsverbrechergesetzes Verurteilten, bei dem eine Prüfung wegen nachträglicher Anordnung der Sicherungsverwahrung nicht erfolgt war, weil ihn schon die Strafanstalt gar nicht als einschlägigen Fall gemeldet hatte. Im zweiten Fall lagen die formellen Voraussetzungen des § 20a $\mathrm{StGB}$ von vornherein nicht vor. Bei den beiden anderen waren sie zwar gegeben; der Oberstaatsanwalt hielt es jedoch nach Prüfung in dem einen Fall für zweifelhaft, ob ein Antrag auf Anordnung erforderlich gewesen sei, im anderen bejahte er die Frage. Der Generalstaatsanwalt, der diesen Bericht an das Ministerium weitergab, äußerte dazu die Auffassung, „daß die Frage, ob und in welchen Fällen Vorbeugungshaft von

53 Schr. Rothenbergers an den LGPräs. Hamburg v. 26.7.38 nebst Auszug aus dem LG-Urteil (Arch. der Forschungsstelle für die Geschichte des NS in Hamburg, Sign. Best. 3305), auszugsweise wiedergegeben bei Johe, a.a.O., S. $147 \mathrm{f}$. 
der Polizei zu veranlassen sein wird, eine rein polizeiliche Angelegenheit ist, bei der irgendeine Mitwirkung der Staatsanwaltschaft nicht zweckmäßig“ sei. Er beabsichtige daher, alle Oberstaatsanwälte seines Bezirks anzuweisen, sich gegenüber der Polizei einer Stellungnahme zu dieser Frage zu enthalten. ${ }^{54}$ Das Reichsjustizministerium informierte ihn jedoch, diese Weisung zu unterlassen, da „die Frage, ob und wie die Justizbehörden an der polizeilichen Maßnahme der Vorbeugungshaft mitwirken sollen, von allgemeiner Bedeutung“ sei. Dafür werde „eine einheitliche Regelung für das gesamte Reichsgebiet in Aussicht zu nehmen sein, die nach Lage der Sache nur von mir im Zusammenwirken mit dem Herrn Reichs- und Preußischen Minister des Innern getroffen werden kann". Falls daher Kriminalpolizeistellen erneut mit solchen Ansuchen an die Staatsanwaltschaften oder an die Leiter von Vollzugsanstalten heranträten - was aus anderen Bezirken nicht bekannt geworden sei -, so sollte er sie ermuntern, bei ihrer Zentralbehörde eine solche einheitliche Grundsatzregelung anzuregen. ${ }^{55} \mathrm{Im}$ Juli 1938 bot sich dem Ministerium eine weitere Gelegenheit, die gleiche Empfehlung dem Generalstaatsanwalt Breslau zu geben: Im Rahmen einer neuen Verhaftungsaktion gegen Asoziale hatte die Kriminalpolizeistelle Gleiwitz den Oberstaatsanwalt in Neisse aufgefordert, „die in den dortigen Gefängnissen einsitzenden einschlägig Vorbestraften, die ... in den nächsten 3 Monaten zur Entlassung kämen“, auf dem Wege der Strafaussetzung oder der Unterbrechung der Strafvollstreckung an die Polizei zu überstellen, „um auch ihnen die Besserung[s]- und Erziehungsmöglichkeiten zuteil werden [!] zu lassen ". ${ }^{56}$ Das Justizministerium war mit dem Generalstaatsanwalt einer Meinung, daß die Forderung mangels jeglicher gesetzlicher Grundlage abgelehnt werden müsse, bat aber auch hier, der Kriminalpolizeistelle Gleiwitz und allen anderen Polizeidienststellen bei gleichartigen Ersuchen zu empfehlen, in Berlin eine grundsätzliche Regelung über die Mitwirkung der Justizbehörden an den polizeilichen Maßnahmen der vorbeugenden Verbrechensbekämpfung anzuregen. ${ }^{57}$ Aber die Bemühungen der Justizleitung, Verhandlungen über diesen Gegenstand auf dem Weg über die unteren Polizeidienststellen in Gang zu bringen, waren vergeblich: die Polizeiführung blieb auf diesem Ohr taub.

Bei der grundsätzlichen Entscheidung, die die politische Führung für die polizeiliche Vorbeugungshaft in der geschilderten Form getroffen hatte, konnte die Justizleitung ihre Ablehnung dieser Regelung nicht offen ausdrücken. Ihre unter der Decke erzwungener Anpassung schwelende Aversion gegen diese Maßnahme trat aber gelegentlich schlaglichtartig hervor. Das zeigte sich, als sich im Herbst 1938 für die Justizleitung unerwartet noch einmal ein Hoffnungsschimmer abzeichnete, die Institution der polizeilichen Vorbeugungshaft zurückdrängen zu können. Die Hoffnung wurde durch einen Schritt des Reichsfinanzministers Schwerin von Krosigk ausgelöst, der in dieser Sache unvermittelt zum Bundesgenossen der Justiz wurde. Am 1.September

s4 Vgl. Ber. des OStA beim LG Wuppertal v. 22.4.38 u. Randber. des GStA Düsseldorf v. 28.4.38 (Akten des RJM, BA, Sign. R 22/1469).

55 Schr. des RJM (I.A. gez. von Crohnes Vertreter) an den GStA Düsseldorf v. 5. 5. 38 (a.a.O.). Auch bei dieser Gelegenheit bat das RJM, die StAe auf die „nachdrückliche Bekämpfung des Berufsverbrechertums“ durch Anordnung der Sicherungsverwahrung hinzuweisen.

$56 \mathrm{Vgl}$. Schr. der Kripostelle Gleiwitz an den OStA in Neisse v. 15.6.38 u. Ber. des GStA Breslau an den RJM v. 17.6.38 (a.a.O., Sign. R 22/1238). Zur Verhaftungsaktion gegen Asoziale im Juni 1938 vgl. Broszat, a.a.O., S. $90 \mathrm{ff}$.

57 Schr. des RJM (I. A. Crohne) an den GStA Breslau v. 5.7.38 (a.a.O.). 
1938 führte von Krosigk in einem als geheim gekennzeichneten Schreiben an den Reichsjustizminister aus, im Erlaß über die vorbeugende Verbrechensbekämpfung durch die Polizei vom 14. Dezember 1937 seien „Maßnahmen vorgesehen, die der von den Justizbehörden auszusprechenden Sicherheitsverwahrung sehr ähnlich“ seien. Insbesondere scheine sich die polizeiliche Vorbeugungshaft mit der gerichtlichen Sicherungsverwahrung

„sehr stark zu überschneiden. Da außerdem der Entwurf des neuen Reichsstrafgesetzbuchs eine erhebliche Erweiterung der Sicherheitsverwahrung vorsieht, wäre ich für eine alsbaldige Stellungnahme zu dem Erlaß des Reichsministers des Innern dankbar. Ich bemerke noch, daß die Zahl der polizeilichen Vorbeugungshäftlinge von Monat zu Monat ansteigt und sowohl durch Vermehrung des Wachpersonals als auch insbesondere durch umfangreiche Bauten (Konzentrationslager) erhebliche Kosten verursacht. Bevor ich daher diesen erheblichen Mehrkosten zustimme, ist eine Klärung erforderlich, inwieweit durch die Verschärfung der Sicherheitsverwahrung Ihrer Behörde eine polizeiliche Sicherheitsverwahrung in größerem Umfange überflüssig wird. ${ }^{\text {s8 }}$

Die Beantwortung dieses Schreibens versetzte die Abteilungen II (Strafgesetzgebung), III (Strafrechtspflege) und die Unterabteilung III B (Strafvollzug) des Justizministeriums in rege Tätigkeit, aus der das Bemühen deutlich wird, den Reichsfinanzminister mit allen nur denkbaren Argumenten auszustatten, die gegen die polizeiliche Vorbeugungshaft sprachen. Von der Auffassung des Leiters der Abteilung II ausgehend, „daß die Bewachung in Konzentrationslagern die teuerste Form der Unterbringung überhaupt" darstelle, wurden auf Wunsch des federführenden Referenten zunächst auch finanzielle Argumente einbezogen: „Wenn der FM [Finanzminister] gegen den Erlaß v. 14.12.1937 vorgehen will, kann er es doch nur aus finanziellen Gesichtspunkten ... Dafür müssen wir Material schaffen ... Für die Asozialen sind doch bestimmt die hohen Kosten der Konzentrationslager völlig überflüssig." Hier sei der Punkt, „bei dem der FM einhaken“ müsse. ${ }^{59}$ Trotz anfänglicher Bedenken hinsichtlich der Einbeziehung finanzieller Gesichtspunkte stellte die Vollzugsabteilung ausführliche Unterlagen über die Unterhaltskosten, die Zahl des benötigten Aufsichtspersonals usw. pro Gefangener zusammen, um nachzuweisen, daß die Unterbringung in geschlossenen Anstalten grundsätzlich billiger sei als in Lagern: nach den Ist-Ausgaben für 1937 und nach Abzug der Einnahmen durch Gefangenenarbeit kostete sie pro Kopf und Tag in der Anstalt 1,32 RM, im Strafgefangenenlager dagegen 2,05 RM. Auch auf die Kosten bei der Neueinrichtung von Lagern wurde hingewiesen. So beliefen sich die Bau- und Einrichtungskosten für die 1935 errichteten Gefangenenlager der Justiz im Emsland auf 600,- RM pro Strafgefangenen. ${ }^{60}$ Der Generalreferent für den Vollzug führte aus, daß der vorhandene Gesamtbelegungsraum ausreichen würde, um noch eine erheblich höhere Zahl von Sicherungsverwahrten unterbringen zu können; ebenso stünden von den großen Provinzialanstalten und -arbeitshäusern bis hin zu den Wanderarbeitsstätten genügend Möglichkeiten zur Verfügung, um auch Asoziale in noch größerem Umfang aufzunehmen: „Hiernach würden die Kosten der Errichtung von Konzentrationslagern für pol[izeiliche] Vorbeugungshäftlinge überflüssigerweise aufgewendet werden", während vorhandene Einrichtungen unausgenutzt

58 Schr. des RMdF v. Krosigk an den RJM v. 1.9 .38 (a.a.O., Sign. R 22/1259).

$59 \mathrm{Vgl}$. die Verm. des Ref. für Strafrechtserneuerung in der Abt. II v. 21. u. 29.9.38, für den Gesamtvorgang die Verm. der verschiedenen Ref. sowie Crohnes u. Freislers v. 5.9. bis 22.11.38 (a.a.O.).

$60 \mathrm{Vgl}$. die Verm. der Mitarbeiter beim Generalreferat für die Verwaltung der Vollzugsanstalten u. beim Referat für Bauwesen-Vollzugsanstalten/Strafgefangenenlager Emsland (beide Abt. IIIB) v. 4. u. 5. 10.38 (a.a.O.). 
blieben. Obwohl auch er den Betrieb von Konzentrationslagern für wesentlich teuerer einschätzte als vor allem den von Arbeitshäusern, sprach er sich jedoch dagegen aus, das Argument des Kostenvergleichs gegenüber dem Finanzminister zu verwenden, solang nicht bekannt sei, wie hoch die Betriebskosten bei den Polizeilagern tatsächlich seien: „Der Reichsfinanzminister hat uns nach dieser Richtung hin doch auch gar nicht gefragt. ${ }^{\text {"61 }}$ Tatsächlich strich dann auch Freisler alle finanziellen Argumente aus dem Entwurf des Antwortschreibens heraus. Gestrichen wurden auch verschiedene Passagen, in denen die grundsätzlichen Vorbehalte der Justiz gegenüber dem Konzentrationslagerwesen und seiner Erweiterung mehr oder weniger offen zutage traten. ${ }^{62}$ Der Entwurf wurde in einem persönlichen Vortrag Freislers und der Leiter der Abteilungen II und III mit Gürtner abgestimmt.

In dem von Gürtner gezeichneten, als geheim deklarierten Schreiben, das schließlich unter dem Datum des 9.Januar 1939 an den Reichsfinanzminister abging, erhob die Justizleitung gegen den Dezember-Erlaß von 1937 insoweit keine Bedenken, als er die planmäßige polizeiliche Überwachung bestimmter Personen regelte und die sogenannte „Identitätshaft“ wegen falscher oder verweigerter Angaben zur Person ${ }^{63}$ vorsah. Bei der polizeilichen Vorbeugungshaft gelte es die Haft gegen Antisoziale (Berufsund Gewohnheitsverbrecher) und gegen Asoziale zu unterscheiden. Hinsichtlich der ersten Gruppe habe mit dem Gewohnheitsverbrechergesetz „die Gesetzgebung die Aufgabe des vorbeugenden Schutzes der Volksgemeinschaft gegen den gefährlichen Gewohnheitsverbrecher ... in die Hand der Justizbehörden gelegt", da sie den Richter ermächtigt habe, Maßregeln der Sicherung „neben die Strafe, nicht an ihre Stelle“ zu setzen. Bei der Ausarbeitung des Erlasses über die vorbeugende Verbrechensbekämpfung durch die Polizei, der "an sich dasselbe Ziel“" verfolge, sei - schrieb der Justizminister - sein „Ressort nicht beteiligt“ und ihm „keine Gelegenheit gegeben worden, die Gesichtspunkte der Justizverwaltung zur Geltung zu bringen“. Er habe dem Erlaß nachträglich nicht widersprochen, weil er „die ernste Sorge der Kriminalpolizei würdige, die Volksgemeinschaft vor voraussehbaren Straftaten“ zu bewahren, vor allem aber deshalb nicht, weil er der Auffassung sei,

„daß die polizeiliche Vorbeugungshaft gegen das gefährliche Gewohnheitsverbrechertum mit der fortschreitenden Aburteilung der Gewohnheitsverbrecher durch die Gerichte und ihrer Verbringung in die gerichtliche Sicherungsverwahrung sich von selbst mehr und mehr erübrigen wird [!]. Auf eine energische Anwendung des Gewohnheitsverbrechergesetzes durch die Justizbehörden wirke ich im Verwaltungswege mit allen Mitteln hin; die Anwendung des Gesetzes wird von mir ständig verfolgt und überwacht. Die Gerichte haben in der Zeit vom 1.1.1934 bis 30.6.1938 Sicherungsverwahrung in 7153 Fällen, Unterbringung im Arbeitshaus in 7469 Fällen, Unterbringung in der Heil- und Pflegeanstalt in 1920 Fällen, Unterbringung in der Trinkerheil- und Entziehungsanstalt in 641 Fällen und Entmannung in 1500 Fällen angeordnet. In dem Zeitraum von $4 \frac{1}{2}$ Jahren haben die Gerichte also über 17000 Antisozialen und Asozialen die Freiheit auf unbestimmte Zeit entzogen." ${ }^{\text {64 }}$

61 Verm. des Generalref. f. Vollzug (Sicherungsverwahrung u.a. Haftarten) in der Abt. IIIB v. 31 10. 38 (a.a.O.).

62 Sie werden z. T. im folgenden als Fußnoten angemerkt, vgl. den korrigierten Entw. v. Nov./Dez. 1938 u. das von Gürtner gez. Schr. an den RMdF v. 8.1.39 (a.a.O.).

63 Auch die amtl. Strafprozeßkommission hatte der Polizei die Zuständigkeit für die Feststellungshaft zugesprochen; die anderslautende Bestimmung des $§ 207$ StPOEntw. war bei der 2. Lesung gestrichen worden (vgl. auch Verm. des Ref. der Abt. II für Erneuerung des Strafverfahrensrechts v. 26.9.38, a.a.O.).

64 Im Entw. folgte der bezeichnende Satz, di€ Justizleitung rechne damit, daß sich die Justizbehörden durch die vom Ministerium ergriffenen Maßnahmen „daran gewöhnen werden, in der Handhabung des Gesetzes [über die Sicherungsverwahrung] an die äußerste Grenze des Möglichen [!] zu gehen“. 
Wie die Erfahrung lehre, würden die Gerichte durch gewisse Lücken im geltenden Recht gegenwärtig noch an einer maximalen Anwendung der Sicherungsverwahrung gehindert; diese Lücken würden aber im Entwurf des neuen Strafgesetzbuches geschlossen werden. ${ }^{65}$ Der Abschnitt endete mit der optimistisch formulierten Feststellung, die dem Finanzminister offensichtlich das gewünschte Argument gegen die SSund Polizeiführung in die Hand geben sollte: „Ein Bedürfnis für die Anwendung der polizeilichen Vorbeugungshaft gegen gefährliche Gewohnheitsverbrecher wird daher in absehbarer Zeit, wie ich glaube annehmen zu dürfen, nur noch in Ausnahmefällen [!] bestehen." Anders stehe es hingegen mit der Vorbeugungshaft gegen Asoziale. Hier gestatte $\S 42 \mathrm{~d}$ StGB die Unterbringung in ein Arbeitshaus nur bei Haftstrafen wegen bestimmter Verstöße - meist Landstreicherei und Betteln ${ }^{66}$ - sowie $\S 42 \mathrm{c} \mathrm{StGB}$ die Unterbringung von Trunk- und Rauschgiftsüchtigen in eine Trinkerheil- und Entziehungsanstalt nur bei Straftaten im Rausch. Da aber die Asozialen ,nur zum geringen Teile mit dem Strafrecht in Konflikt" gerieten, reichten diese Vorschriften nicht aus, um sie - wie Fachkreise meinten - „sowohl im Interesse der öffentlichen Ordnung wie auch zur Ausnutzung ihrer Arbeitskraft" für eine öffentliche Bewahrung zu erfassen. Der Justizminister versäumte jedoch nicht, darauf hinzuweisen, daß es auch hier Wege für ein gesetzlich geregeltes Verfahren gebe: so strebe der Ausschuß für Wohlfahrtsrecht an der Akademie für Deutsches Recht ein Bewahrungsgesetz an, „das für die Anordnung der Bewahrung und ihre Aufhebung ein geordnetes Rechtsverfahren" einführe und keine größere finanzielle Belastung darstelle als das polizeiliche Vorbeugehaftverfahren. ${ }^{67}$ Außerdem berge „eine Zusammenlegung so wesensverschiedener Gefangener, wie es die Antisozialen und die Asozialen sind“, im Konzentrationslager „erhebliche Gefahren in sich, wobei die für die Asozialen typische Willensschwäche und Beeinflußbarkeit eine wesentliche Rolle" spiele. ${ }^{68}$ Einerseits bedürfe es

„den Antisozialen gegenüber angesichts ihrer verbrecherischen Energie, Begabung und Gewandtheit weitgehender Vorkehrungen gegen Ausbruch und Meuterei, wie sie - ohne einen das Übliche wesentlich übersteigenden Personaleinsatz - am besten die feste Sicherungsanstalt zu bieten vermag. Andererseits geht das, was in den Konzentrationslagern in sicherheitlicher Beziehung geschieht, - insbesondere der Umfang des personellen Einsatzes - den Asozialen gegenüber über das notwendige Maß vielleicht hinaus, da die passiven Naturen der Asozialen, die in

65 Es handelte sich insbesondere um folgende Paragraphen im Entw. des neuen StGB i. d. F. v. Juni 1938 (vgl. Kabinettsvorlage des RJM an den Chef der Reichskanzlei v. 7.6.38, Akten des RJM, Hauptbüro, Arch. des BJM): $\S 49$ Abs. 2 (Bewertung der fortgesetzten Handlung bei der Charakterisierung als gefährlicher Gewohnheitsverbrecher), $\S \S 121,229,453 \mathrm{a}$ (Möglichkeit der Sicherungsverwahrung für Hoch- u. Landesverräter, entartete Sittlichkeitsverbrecher u. bei schwerem Raub), $\S 366$ (Freiheitsstrafe bei Verletzung polizeil. Auflagen).

${ }^{66}$ Voraussetzung waren Haftstrafen wegen Ubertretungen nach $\S 361 \mathrm{Nr}$. 3 bis 5,6 a bis 8 StGB, s. Kapitel VII.3.a., S.841.

67 Der folgende Satz mit der deutlichen Frage, ob somit „eine Erweiterung der Kapazität der Konzentrationslager" überhaupt erforderlich sei, um „die nicht in die Arbeitshäuser gelangenden Asozialen“ stärker zu erfassen, wurde von Freisler gestrichen.

68 Diesem Satz war die kritische Bemerkung vorausgegangen, daß die zu beanstandende Gleichbehandlung der Gewohnheitsverbrecher und der Asozialen bei der Regelung der Vorbeugungshaft durch den Erl. v. 14.12.37 vermuten lasse, „daß auch bei der Unterbringung im Konzentrationslager Unterschiede ... nicht gemacht werden. Die Regelung würde dann nicht nur vom kriminalpolitischen, sondern auch vom vollzugstechnischen Standpunkt aus zu bemängeln sein“. Freisler, der diese „Vermutung“ aus seiner Kenntnis heraus als Tatsache annahm, hatte diese beiden Sätze gestrichen. 
der Regel weder zu Gewalttätigkeiten noch zu Fluchtversuchen neigen, - wenn sie wirklich einmal entlaufen, werden sie in der Regel bald wieder aufgegriffen werden, ohne viel Schaden angerichtet zu haben -, solche Maßnahmen in viel geringerem Umfang notwendig machen. ${ }^{\text {"69 }}$

Abschließend wies der Justizminister darauf hin, daß der Gesamtbelegungsraum der Justiz ausreiche, noch weit mehr Sicherungsverwahrte aufzunehmen, als gegenwärtig vorhanden und nach Strafverbüßung noch zu erwarten seien. ${ }^{70}$

Auch dieses für die Einstellung der Justiz höchst aufschlußreiche Schreiben sollte jedoch lediglich eine fruchtlose Episode im Ringen um die Befugnisse der Polizei bleiben: die Politik der SS- und Polizeiführung, die die volle Rückendeckung Hitlers genoß, konnte von den beiden Reichsministern der Justiz und der Finanzen weder mit kriminalpolitischen und vollzugstechnischen noch mit finanziellen Argumenten beeinträchtigt werden. Es gelang ihnen nicht, die im Erlaß vom 14. Dezember 1937 niedergelegten Befugnisse auch nur im geringsten einzuschränken - jenes Erlasses, der - wie SS-Sturmbannführer Werner vom Reichskriminalpolizeiamt im Dezember 1938 offen konstatierte - lediglich eine polizeirechtliche „Reglementierung der ideenmäßig an sich unbeschränkten [!] Vorbeugungsbefugnis der Kriminalpolizei" darstellte, deren „Rechtsgrundlage ... allein der Auftrag des Führers an den Reichsführer SS [sei], auch die kriminellen Staatsfeinde vorbeugend zu bekämpfen ". ${ }^{71}$ Die Argumente des Justizministers trafen schon deswegen ins Leere, weil das Instrument der Vorbeugungshaft spätestens seit Frühjahr 1938 nicht mehr primär zur vorbeugenden Verbrechensbekämpfung und „Erziehung“ von Kriminellen, sondern zur Zwangsrekrutierung von Arbeitskräften eingesetzt wurde, um in den Konzentrationslagern SS-eigene Produktionsstätten vor allem zur Gewinnung von Natur- und Ziegelsteinen zu errichten: Himmler hatte Hitlers Unterstützung gewonnen, daß die Arbeitskraft der KZ-Häftlinge für die Großprojekte zur städtebaulichen Umgestaltung Berlins und anderer Großstädte ausgenutzt werden sollte. ${ }^{72}$ Die Zahl der polizeilichen Vorbeugungshäftlinge betrug Ende 1939 schließlich 12221, davon waren 4845 Kriminelle; bis Ende 1940 stieg diese Häftlingsgruppe auf 6530 an. $^{73}$

Die institutionalisierte Ohnmacht des Justizministeriums gegenüber der willkürlichen Handhabung der Vorbeugungshaft durch die Polizei trat gelegentlich nach auBen hin eindringlich in Erscheinung. Im November 1940 wandte sich ein Bremer An-

69 Hier unterblieb der im Entw. enthaltene Hinweis, daß dieses teils Zuwenig, teils Zuviel an Sicherheitsaufwand „auch vom finanziellen Standpunkt aus nicht gleichgültig“ sei; ferner, „daß den zur Unterbringung von Asozialen bestimmten Anstaiten - die sich bekanntlich im wesentlichen außerhalb des Bereichs der Justizverwaltung befinden [der Justiz unterstanden nur die Arbeitshäuser St. Georgen-Bayreuth im OLG-Bez. Bamberg, Kislau im OLG-Bez. Karlsruhe u. Vechta im OLG-Bez. Oldenburg] - eine besondere Billigkeit des Betriebes nachgerühmt“ werde.

70 Im letzten Abs. war die Bemerkung gestrichen, daß es sich nicht empfehle, „für bestimmte staatliche Maßnahmen Neueinrichtungen zu treffen, wenn für andere, bereits eingeführte Maßnahmen, die denselben Erfolg herbeizuführen in der Lage sind, vorhandene Einrichtungen in ausreichendem Umfang zur Verfügung stehen“, zumal die Betriebskosten einer Neueinrichtung stets höher seien als bei verstärkter Ausnutzung einer vorhandenen.

7 ORegRat u. Kriminalrat im RKPA Werner in der NS-Partei-Korrespondenz Folg. 306 v. 31.12.38, Bl.2.

?: Vyl. dazu Broszat, a.a.O., S. 91 ff.; ferner E. Georg, Die wirtschaftlichen Unternehmungen der SS, Stuttgart 1963, S. 42 ff. Zur Arbeitskräftebeschaffung gehörte auch Himmlers vergeblicher Versuch, 1938 und 1939 von der Justiz einen Teil der Sicherungsverwahrten ausgeliefert zu bekommen (s. Kap. VI.4.b., S.652).

${ }^{73} \mathrm{Zu}$ dieser Gruppe gehörten Einbrecher, Diebe, Hehler, Räuber, Betrüger, Sittlichkeitsverbrecher u. „Gemeingefährliche“, vgl. Jb. des Amtes V (RKPA) des RSHA 1939/40, S. 5, 44 (Arch. des IfZ, Sign. Dc 17.01). Das Jb. wurde dem RJM von Heydrich am 29.10.41 quasi als Tätigkeitsbericht des RKPA übersandt (Akten des RJM, BA, Sign. R 22/1457). 
walt wegen einiger Fälle an das Ministerium, in denen den Angehörigen die Gründe der Inhaftierung nicht bekannt waren. Die Häftlinge waren weder vorbestraft noch politisch belastet, befanden sich aber - offenbar als „Arbeitsscheue“ - bereits zweieinhalb bis drei Jahre in Vorbeugungshaft. Einer von ihnen hatte vor seiner Festnahme zwar nur Gelegenheitsarbeiten verrichtet, aber zu Hause den Haushalt geführt und sechs Kinder versorgt, während seine Frau erwerbstätig war. Der Anwalt hatte in diesen Fällen mehrmals durch Eingaben um Mitteilung der Haftgründe und um Entlassungen gebeten, da die lange Haftdauer ausgereicht haben dürfte, die Betreffenden zu geregelter Arbeit anzuhalten, und überdies teilweise konkrete Arbeitsplätze für sie nachgewiesen werden konnten. Er hatte aber in allen Fällen lediglich den Bescheid erhalten, daß „der mit der polizeilichen Maßnahme angestrebte Zweck noch nicht erreicht" sei, und war schließlich aufgefordert worden, weitere Eingaben zu unterlassen. Der Anwalt machte dem Ministerium die Auswirkungen dieses Zustandes nicht nur bei den unmittelbar Betroffenen, sondern in der Bevölkerung mit eindrucksvollen Worten deutlich: Da die Gründe der Inhaftierung nicht mitgeteilt würden, sei es dem Rechtsanwalt auch nicht möglich,

„die Gesuchsteller seiner Aufgabe entsprechend gegebenenfalls von der Rechtmäßigkeit der Festnahme zu überzeugen. So entsteht nicht nur bei den unmittelbar Beteiligten, sondern auch in weiteren Kreisen der Bevölkerung der Eindruck eines rein schicksalhaften, von menschlicher Schuld unabhängigen Geschehens, dessen Dauer unabsehbar ist und dessen Eintritt für jeden einzelnen unabwendbar zu sein scheint. Der Unterzeichnete kann aus seiner Erfahrung als Strafverteidiger bestätigen, daß durch diese Umstände das gesunde Rechtsgefühl gefährdet wird. Der Unterzeichnete empfindet daher das Bedürfnis, nicht nur die vorerwähnten beiden Fälle der Nachprüfung zu empfehlen, sondern die Bitte vorzutragen, aus rechtspolitischen Erwägungen ganz allgemein die Frage zu prüfen, ob nicht - außerhalb eines staatlichen Notstandes - ein gesundes Rechtsleben in jedem Falle die Möglichkeit begründen muß, die Berechtigung einer lang andauernden Freiheitsentziehung evtl. durch besonders dafür eingesetzte Gerichte nachprüfen zu lassen. Eine rechtmäßige polizeiliche Maßnahme braucht eine solche richterliche Nachprüfung nicht zu scheuen. Ein richterliches, die polizeiliche Maßnahme bestätigendes Urteil aber verschafft auch dem Volke das für ein gesundes Rechtsleben erforderliche Gefühl der RechtmäBigkeit. ${ }^{\text {774 }}$

Auf diesen eindringlichen Appell hin veranlaßte Gürtner die Prüfung der Fälle und erbat Rücksprache mit den zuständigen Beamten seines Ministeriums. Sein persönlicher Referent stellte eigens dafür die Grundlagen und Bestimmungen für die Schutzhaft und die polizeiliche Vorbeugungshaft nochmals zusammen. Die Strafrechtsabteilung mußte jedoch feststellen, daß ein Eingreifen des Ministeriums in den angeführten Fällen nicht möglich sei, weil die Betroffenen „nicht wegen strafrechtlich zu ahndender Handlungen" verhaftet worden waren. Die Gesetzgebungsabteilung aber mußte eine Verwirklichung des Vorschlags, für die polizeiliche Vorbeugungshaft eine gerichtliche Nachprüfung durchzusetzen, nach allen Erfahrungen, die in dieser Hinsicht auch schon bei der Regelung der Schutzhaft gemacht worden waren, von vornherein als aussichtslos ansehen. Am 22. Januar 1941 ging daher die von Freisler abgesegnete Bankrotterklärung des Justizministeriums an den Rechtsanwalt ab, in der es hieß: „Da die Angelegenheiten der polizeilichen Vorbeugungshaft wie auch der Schutzhaft nicht zu meinem Zuständigkeitsbereich gehören, vermag ich [im Entwurf: zu meinem Bedauern] in der Sache nichts zu veranlassen." Dem Anwalt wurde anheimgestellt, sich

74 Vgl. Schr. des Bremer RA an das RJM v. 18.11.40 (a.a.O.). 
an das Reichsinnenministerium zu wenden. Gürtner hatte den erbetenen Vortrag wegen seiner Erkrankung nicht mehr entgegennehmen können: er starb sieben Tage später, ohne mit dieser Manifestation der Ohnmacht der Justiz noch befaßt worden zu sein. $^{75}$

\section{d. Polizeiliche Vorbeugungshaft als Druckmittel gegen die Justiz im Kriege und ibr Vorrang vor gerichtlicher Sicherungsverwabrung}

Im Kriege erwies sich die polizeiliche Vorbeugungshaft als wirksames Mittel zur Korrektur der Rechtsprechung, das von der SS- und Polizeiführung nicht nur gegen „mangelhafte" richterliche Urteile und Entscheidungen über die Anordnung der Sicherungsverwahrung, sondern - wie die Schutzhaft - auch gegen gerichtliche Freisprüche angewendet wurde. Ein eklatanter Fall, der Freisler zu einem - wenn auch zahmen - Protest veranlaßte, ereignete sich im März 1940 in Heidelberg. Als die dortige Strafkammer einen Angeklagten von der Beschuldigung der Brandstiftung in drei Fällen mangels Beweises freisprach und aus der Untersuchungshaft entließ, nahm ihn die Kriminalpolizeistelle Karlsruhe als "Gemeingefährlichen" mit der simplen Begründung in Vorbeugungshaft, daß trotz des Freispruchs „für die Kriminalpolizei bezügl. der Täterschaft des X. kein Zweifel" bestehe. Freisler beschwerte sich daraufhin beim Reichsführer-SS, er halte ,im Interesse der Staatsautorität ... die Begründung für die polizeiliche Haftverfügung für bedauerlich", und bat um Stellungnahme. ${ }^{76}$

Das ständige „reagierende“ Defensivverhalten der Justiz gegen die konkurrierende Verbrechensbekämpfung durch die Polizei erschöpfte sich nicht nur in gelegentlichen Beschwerden und in Verwaltungsmaßnahmen zur Erzielung einer wirksamen Anwendung der geltenden Gesetze durch die Gerichte, sondern schlug sich auch in der $\mathrm{Ge}-$ setzgebungsarbeit nieder. Als z. B. die Polizei dazu überging, die Vorbeugungshaft auf Personen auszudehnen, die sich ihrer Unterhaltspflicht gegenüber Angehörigen böswillig entzogen, antwortete die Justiz mit gesetzgeberischen Schritten. Freisler schrieb im März 1940 ans Innenministerium, daß die geltende Strafvorschrift des $§ 361 \mathrm{Nr} .10$ StGB, die die Verletzung der Unterhaltspflicht nur als eine Übertretung einstufte, nicht ausreiche, um einen Unterhaltsverweigerer nachdrücklich zur Erfüllung seiner Pflicht zu bewegen. Daher sei bereits im $\S 206$ des neuen StGB-Entwurfs anstelle der Übertretungsstrafe eine kriminelle Strafe bis zu zwei Jahren Gefängnis vorgesehen und die Bestrafung nicht mehr von der Voraussetzung abhängig gemacht worden, daß die zuständige Behörde vorher den Verpflichteten zur Erfüllung seiner Unterhaltspflicht aufgefordert haben mußte und der Berechtigte gezwungen war, fremde Hilfe in Anspruch zu nehmen. Ferner habe der Richter nach $\S 60$ des Entwurfs neben der Gefängnisstrafe die Unterbringung des Täters in ein Arbeitshaus anzuordnen, wenn dies erforderlich sei, um ihn zur Arbeit anzuhalten und an ein ordentliches Leben zu gewöhnen. Beide Bestimmungen hätten seinerzeit bei der Beratung des StGB-Entwurfs bereits die Zustimmung des Reichskabinetts gefunden. Da die Justiz nunmehr eine wirksamere Strafvorschrift brauche, um mit ibren Mitteln „einen böswilligen Unter-

75 Vgl. Aktenverm. vom Nov. 1940 bis Jan. 1941 und Schr. an den Bremer RA v. 22.1.41 (a.a.O.).

76 Vgl. Schr. des RJM (I. V. Freisler) an den RFSSuChdDtPol. im RMdI v. 23.7.40 (Akten des RJM, a.a.O.)

Die Reaktion des RFSS ist aus den Akten nicht zu entnehmen. 
haltsverweigerer zu einer rechten Auffassung über seine Pflichten gegenüber Familie und Volksgemeinschaft zu erziehen“, kündigte Freisler die Vorlage einer entsprechenden Novelle zum StGB an. ${ }^{77}$ Die neue Strafvorschrift wurde schließlich im Zusammenhang mit der Verordnung zum Schutz von Ehe, Familie und Mutterschaft vom März 1943 ins StGB eingefügt. ${ }^{78}$

Unterdessen verfolgte die SS- und Polizeiführung längst das Ziel, die Justiz bei der vorbeugenden Verbrechensbekämpfung völlig auszuschalten und die Befugnis zur sichernden Verwahrung gänzlich an sich zu ziehen. Als auf Befehl Hitlers am 4.Oktober 1939 die Verordnung zum Schutz gegen jugendliche Schwerverbrecher erlassen worden war, beschwerte sich der von Frick offenbar nicht rechtzeitig beteiligte Himmler beim Reichsjustizminister, daß in diese Verordnung gerichtliche Maßregeln der Sicherung und Besserung gegen jugendliche Täter aufgenommen worden waren. $\mathrm{Er}$ habe die Justizverwaltung bereits wiederholt seine Auffassung wissen lassen, daß die Anordnung solcher Maßregeln „das ureigenste Aufgabengebiet der Polizei und nicht der Justiz“ sei; auf der Tagung der Strafprozeß-Kommission im Herbst 1938 habe er seinen Standpunkt durch seine Referenten eingehend vortragen lassen.

„Ich muß bei dieser Sachlage mein Befremden darüber ausdrücken, daß die zum Erlaß der vorerwähnten Verordnung führenden Umstände von dort aus dazu benutzt wurden, die Berechtigung der Justizbehörde zur Anordnung von Maßregeln der Sicherung und Besserung erneut festlegen zu lassen ..., zumal der vom Führer erteilte Befehl die Hineinnahme von Bestimmungen über Maßregeln der Sicherung und Besserung in die Verordnung nicht erforderlich machte.“

Er behalte sich daher vor, diese Zuständigkeitsfrage „Zu einem geeigneter erscheinenden Zeitpunkt nochmals aufzurollen".79

Dieser Zeitpunkt schien im Frühjahr 1940 gekommen, als es darum ging, das deutsche Gerichtsverfassungsrecht und Strafrecht in den eingegliederten (polnischen) Ostgebieten einzuführen. Die Polizeiführung forderte, daß die Zuständigkeit zur Verhängung von Maßregeln der Sicherung und Besserung in diesen Gebieten ausschließlich den Behörden der Sicherheitspolizei übertragen werden sollte. Aber das Reichsjustizministerium weigerte sich, in den Ostgebieten eine andere Regelung als im Reich einzuführen, und lehnte den Vorschlag des Reichsinnenministeriums ab, darüber mit dem Hauptamt Sicherheitspolizei unmittelbar zu verhandeln.$^{80} \mathrm{Um}$ die Einführung des deutschen Rechts durch diesen Konflikt nicht zu gefährden, zeichnete Frick schließlich die vom Justizministerium ausgearbeitete Einführungsverordnung unter der Bedingung, daß durch die Übertragung der bisherigen Bestimmungen auf die Ostgebiete eine künftige Neuregelung dieser Frage für das ganze Reich „nicht präjudiziert“ werde. Gürtner erklärte sich damit einverstanden, bemerkte jedoch, daß auch er seinen „bisherigen Standpunkt uneingeschränkt aufrechterhalte“ und „Erörterungen über die künftige Gestaltung der Maßregeln der Sicherung und Besserung ... vor der

77 Schr. Freislers an den RMdI v. 19.3.40 betr. Polizeiliche Vorbeugungshaft bei Verweigerung der Unterhaltspflicht (a.a.O., Sign. R 22/1469).

78 \$ DurchfVO zur VO zum Schutz von Ehe, Familie und Mutterschaft v. 18.3.43 (RGBl. I, S. 169). Werle, Justiz-Strafrecht, S.419ff. Der dadurch ins StGB eingefügte $\$ 170 \mathrm{~b}$ war mit dem Wortlaut des $\$ 206 \mathrm{StGB}$ Entw. fast identisch, sah aber keine Höchstgrenze von 2 Monaten Gefängnis vor. Vgl. Entw. des neuen StGB i.d.F. v. Dezember 1939. Schubert, Quellen II, Bd. 1.2, S.543.

79 Schr. Himmlers an den RJM v. 2.11 .39 (Akten der Reichskanzlei, BA, Sign. R 43 II/1513a). Zur VO v. 4. 10.39 (RGBl. I, S. 2000) vgl. Kapitel VII.3.e., S. 910 f.

${ }^{80}$ Vgl. Schr. des RMdl an das RJM v. 30.4.40 u. Antwortschr. des RJM v. 18.5.40 (Akten des RJM, BA, Sign. R 22/848). 
Beendigung des Krieges nicht für zweckmäßig" halte. ${ }^{81}$ Himmler hatte sich offenbar mit der Übertragung der reichsgesetzlichen Regelung auf die eingegliederten Ostgebiete in der Annahme abgefunden, daß seine Organe dort auch ferner weitgehend eigenmächtig handeln konnten.

In dieser Lage mußte die Justizleitung verstärkt darauf sehen, daß ihren Behörden bei der Handhabung der Sicherungsverwahrung während des Krieges kein „Versagen“ vorgeworfen werden konnte. Am 4. Mai 1940 schärfte Freisler den Staatsanwälten in einer Rundverfügung ein, die im März 1938 erteilten Richtlinien über die Entlassung aus der Sicherungsverwahrung strikt zu befolgen: wiederholt seien „Sicherungsverwahrte entlassen worden, ohne daß die Stellungnahme der Kriminalpolizei eingeholt" worden war. Demgegenüber habe das Reichssicherheitshauptamt die Polizeidienststellen angewiesen, „während des Krieges grundsätzlich gegen die Entlassung aus der Sicherungsverwahrung Stellung zu nehmen und für den Fall, daß es trotzdem zu Entlassungen kommen sollte, die Entlassenen unverzüglich in polizeiliche Vorbeugungshaft zu nehmen“. Da die Kriegsverhältnisse mit Verdunkelung, Rationierungsmaßnahmen usw. einen besonderen Anreiz zu neuen Straftaten böten, die polizeiliche Nachüberwachung aber gerade im Kriege mangels geeigneter Polizeibeamter nur unzureichend durchgeführt werden könne, stelle die Entlassung eines Sicherungsverwahrten gegenwärtig „regelmäßig eine Gefahr für die Volksgemeinschaft dar, deren Schutz oberste Pflicht aller Justizbehörden“ sei. Freisler ersuchte daher, „bis auf weiteres jeder Entlassung aus der Sicherungsverwahrung mit Nachdruck zu widersprechen und auch bei den Gerichten auf die Berücksichtigung der angeführten Gesichtspunkte hinzuwirken" ${ }^{82}$ Bei den Richtern schien diese Einwirkung der Staatsanwaltschaft jedoch offenbar nicht die erwünschte Resonanz zu finden, denn eineinhalb Jahre später wurde die Entscheidung über die Entlassung aus der Sicherungsverwahrung - wie schon erwähnt - in die Hände der Generalstaatsanwälte gelegt.

Im Herbst 1940 begann das Reichsjustizministerium eine bemerkenswerte Aktion, um systematisch festzustellen, welche Kategorien von Verurteilten die Kriminalpolizei nach Strafverbüßung eigentlich in Vorbeugungshaft nahm, und zugleich zu untersuchen, ob die Polizeimaßnahme in diesen Fällen durch eine mit dem Gerichtsurteil ausgesprochene Anordnung der Sicherungsverwahrung hätte vermieden werden können. Anfang Oktober wurden die Generalstaatsanwälte angewiesen, allmonatlich für jede Straf- und Haftanstalt ihres Bezirks „zu berichten, in welchen Fällen im Laufe des Vormonats für Strafgefangene dieser Anstalten anschließend polizeiliche Vorbeugungshaft entweder bereits angeordnet oder angekündigt worden“ war. Der erste Bericht sollte sich auch auf Fälle aus weiter zurückliegender Zeit erstrecken. Die Weisung ging gleichfalls an den Leiter der Strafgefangenenlager der Justiz im Emsland. In dem vorgeschriebenen Berichtsformular waren neben Vollzugsanstalt, Name und Alter des Betroffenen auch Zahl, Art und Grund seiner eventuellen Vorstrafen sowie Höhe, Art und Grund seiner im Vollzug befindlichen Strafe anzugeben. ${ }^{83}$ Die Analyse des im Laufe einiger Monate angesammelten Berichtsmaterials durch den zuständigen

${ }^{81}$ Schr. des RMdI (gez. Frick) an das RJM v. 6.6.40 u. Antwortschr. des RJM (gez. Gürtner) an das RMdI v. 13.6. 40 (a.a.O.).

82 RV des RJM an die GStAe und OStAe v. 4.5 .40 (a.a.O., Sign. R 22/1337).

83 RV des RJM v. 5.10.40 an die GStAe (außer Danzig, Posen, Prag) u. den Beauftr. des RJM für die Strafgefangenenlager im Emsland (a.a.O., Sign. R 22/1496). 
Referenten der Vollzugsabteilung ergab, daß sich die Polizei „anscheinend ohne Rücksicht auf die Vorstrafen [!] alle Sittlichkeitsverbrecher, politische Verbrecher, gewerbsmäßige Abtreiber, Münzfälscher, Arbeitsverweigerer, Prostituierte zur Prüfung der Frage, ob Vorbeugungshaft angeordnet werden soll, zuführen" ließ. Bei den dann in Vorbeugungshaft Genommenen handele es sich - den Vorstrafen nach zu urteilen offenbar meist „um asoziale Erscheinungen“. Genaueres über die polizeilichen Haftgründe ließe sich vor allem in Fällen mit keinen oder geringen Vorstrafen allerdings nur nach Studium der Akten sagen. Die Analyse legte aber auch die hauptsächlichen Gründe offen, aus denen die Gerichte selbst bei erheblich Vorbestraften keine Sicherungsverwahrung angeordnet hatten. Sie hatten davon abgesehen, weil

„a) die abgeurteilte Tat aus dem Rahmen der früheren Taten fällt (z. B. Verurteilung eines häufig wegen Diebstahls Vorbestraften wegen Verstoßes des Heimtückegesetz [sic] oder Erregung öffentlichen Ärgernisses),

b) die abgeurteilte Tat eine Bagatellsache ist, für die nur eine Strafe von 2 bis 3 Mon[aten] Gefängnis ausgeworfen wurde, so daß die Höhe dieser Strafe in keinem Verhältnis zu den früheren Verurteilungen steht und neben dieser geringfügigen Strafe die Anordnung der Sicherungsverwahrung nicht angebracht erschien,

c) das Gericht glaubte, trotz Vorliegens vieler Strafen durch die Verhängung einer langfristigen Zuchthausstrafe von der Anordnung der Sicherungsverwahrung absehen zu können,

d) bisher nur Gefängnisstrafen verhängt worden waren und das Gericht vor Anordnung der Sicherungsverwahrung die Wirkung einer Zuchthausstrafe erproben wollte“. ${ }^{84}$

Der zuständige Referent in der Strafgesetzgebungsabteilung, Ministerialrat Rietzsch, hielt die angeführten Erwägungen der Gerichte für "grundsätzlich falsch“ und verwies auf seinen veröffentlichten Kommentar zu $§$ 42a StGB. ${ }^{85}$ Inzwischen hatte sich das Ministerium direkt an die in den monatlichen Berichten der Generalstaatsanwälte genannten Gefängnisse bzw. Zuchthäuser gewandt und um Mitteilung gebeten, aufgrund welchen Urteils oder Gesamtstrafenbeschlusses der von der polizeilichen Vorbeugungshaft Betroffene dort einsaß, wobei jeweils das Gericht sowie Datum und Aktenzeichen des Urteils angegeben werden sollten ${ }^{86}$ Aus den eingegangenen Antworten wurden alle Angaben über Urteile, die nach dem 1.April 1938 - d.h. nach der Allgemeinverfügung des Ministeriums betr. Sicherungsverwahrung vom März 1938 - ergangen waren, nach den Bezirken der Generalstaatsanwälte zusammengestellt, in denen sich der Sitz des verurteilenden Gerichts befand. Diese einzelnen Zusammenstellungen - insgesamt handelte es sich um über 590 Urteile - erhielten die jeweiligen Generalstaatsanwälte am 26. März 1940 mit einer Rundverfügung zugesandt. In ihr wurde ausgeführt, daß ,in einer auffallend großen Zahl von Fällen, in de-

${ }^{84}$ Verm. des Ref. v. 2.4.41 und des MinRat Rietzsch v. 3.4.41 (a.a.O.).

${ }^{85} \mathrm{Vgl}$. Das neue Reichsrecht. Ergänzbare Sammlung des geltenden Rechts seit dem Ermächtigungsgesetz mit Erläuterungen. Herausg. v. H. Pfundtner u. R. Neubert unter Mitw. v. F. A. Medicus, Berlin $1933 \mathrm{ff}$., dort Abschn. II c 10. Gewohnheitsverbrecher. Dieser Abschnitt war von Rietzsch nach dem Stand v. 1.7.40 neu bearbeitet worden und ersetzte die alte Kommentierung. Auch $R$. betonte darin, daß die Sicherung des Volkes durch die vorgesehenen Maßregeln Aufgabe der Justiz und nicht der Verwaltung sei, da nur das Strafverfahren mit seinen mannigfachen Sicherungen gewährleiste, „daß bei der Entscheidung über die Maßregeln die körperliche, geistige und charakterliche Eigenart des Täters ... allseitig und erschöpfend geprüft ${ }^{\star}$ werde.

${ }^{86} \mathrm{Vgl}$. die formularmäßigen Schr. an die Vollzugsanstalten in den Akten des RJM (a.a.O.). 
nen polizeiliche Vorbeugungshaft angeordnet oder angekündigt worden“ sei, „die Täter erheblich einschlägig vorbestraft" seien. Es stelle sich die Frage, ob in diesen Fällen nicht von vornherein „Anlaß zu einer richterlichen Maßnahme der Sicherung und Besserung, insbesondere der Sicherungsverwahrung, bestanden hätte“. Die Generalstaatsanwälte wurden aufgefordert, ,zu prüfen, ob nicht die Behandlung der angeführten Einzelfälle Veranlassung gibt, die in meiner AV v. 3.3.1938 ... zur Anordnung der Sicherungsverwahrung gegebenen Richtlinien in Erinnerung zu bringen und auf einen nachdrücklichen Einsatz der den Justizbehörden durch das Gesetz gegen gefährliche Gewohnheitsverbrecher gegebenen Abwehrmittel hinzuwirken" ${ }^{87}$ Nachdem die Generalstaatsanwälte über die Ergebnisse ihrer Prüfung berichtet und fast alle mitgeteilt hatten, daß sie auf die Richtlinien vom März 1938 erneut hingewiesen hätten, wurde diese Aktion Mitte Mai 1941 abgeschlossen. ${ }^{88}$

Trotz derartiger Verwaltungsmaßnahmen konnte die Justiz schon ihrer Natur nach mit der Radikalität nicht Schritt halten, die Himmlers Polizei auf dem Gebiet der „vorbeugenden Verbrechensbekämpfung“ entwickelte. Abschließend sei ein Ausblick auf die weitere Entwicklung des Problems im Kriege gegeben, in deren Verlauf das Instrument gerichtlicher Sicherungsverwahrung gegenüber den konkurrierenden Polizeimaßnahmen immer weiter in den Hintergrund trat. Bezeichnend dafür ist z. B. die Antwort, die der Oberstaatsanwalt in Breslau von der dortigen Kriminalpolizeileitstelle im August 1942 erhielt, als er sie gemäß den Freislerschen Richtlinien zu einem Antrag auf Sicherungsverwahrung hören wollte: die Sicherungsverwahrung sei gar nicht erst erforderlich, da die Polizei den Angeklagten im Anschluß an die Verbüßung seiner zu erwartenden Freiheitsstrafe sowieso in Vorbeugungshaft nehmen und im Konzentrationslager unterbringen werde. ${ }^{89}$ Es muß schon als Ausdruck resignierender Verzweiflung angesehen werden, wenn der Oberlandesgerichtspräsident Darmstadt im Januar 1942 nach einem Fall, bei dem das Reichskriminalpolizeiamt schon vor dem Urteil eine Vorbeugungshaft von 20 Jahren [!] angekündigt hatte, dem Reichsjustizministerium vorschlug, der $§ 42 \mathrm{a}$ StGB solle doch gleich durch eine weitere Maßregel der Sicherung und Besserung ergänzt werden: durch „die Überweisung an die Geheime Staatspolizei (oder Sicherheitspolizei) zwecks Überführung in eine polizeiliche Korrekturnachhaft" unter Festlegung der genauen Voraussetzungen für diese Form der Unterbringung. Entsprechend sei in diesen Fällen statt dem Generalstaatsanwalt „die Entscheidung über die Entlassung und den Widerruf der Entlassung dem Reichsführer-SS und Chef der deutschen Polizei zu übertragen“. Wenn so der Richter selbst die polizeiliche Vorbeugungshaft anordnen könne, würde sich die ständige Desavouierung der Gerichtsurteile sowie die daraus folgende Untergrabung der richterlichen Autorität vermeiden lassen und „eine Zuständigkeitsüberschneidung nach außen hin sich nicht mehr bemerkbar machen ". ${ }^{90}$ Abgesehen davon, daß auch die SS- und Polizeiführung eine solche konkurrierende Zuständigkeit für die Einweisung in ihre Konzentrationslager abgelehnt haben dürfte, war für das Justizministerium eine solche Vermengung justizmäßiger und polizeilicher Verantwortlichkeiten von vornherein un-

87 Vgl. RV des RJM v. 26.3.41 an die GStAe (außer Danzig, Posen und Protektorat), nachrichtl. an die OReiAe u. Chefpräsidenten (a.a.O.).

${ }_{88}$ Vgl. Verm. des Leiters der Abt. II (Strafgesetzgebung) v. 15.5.41 (a.a.O.).

89 Vgl. Ber. des GStA Breslau an das RJM v. 25.8.42 (a.a.O., Sign. R 22/3358).

90 Vgl. Lageber. des OLGPräs. Darmstadt an das RJM v. 9.1 .42 (a.a.O., Sign. R 22/3361). 
annehmbar. Im Gegenteil ermahnte Freisler am 18. August 1942 alle Generalstaatsanwälte, daß eine Ankündigung der Vorbeugungshaft durch die Polizei die Justizbehörden keinesfalls von ihrer Pflicht entbinde, über die Anordnung gerichtlicher Sicherungsverwahrung oder Unterbringung im Arbeitshaus zu entscheiden. ${ }^{91}$ Diese Mahnung war ein ohnmächtiges Aufbäumen gegen die Entwicklung, die unaufhaltsam einer Verdrängung der Justiz aus diesem Bereich zutrieb: Nachdem Hitler zwei Tage später dem neuernannten Reichsjustizminister Thierack nahegelegt hatte, der kriegsbedingten „negativen Auslese“ im deutschen Volk entgegenzutreten - bei der die $\mathrm{Be}$ sten an der Front fielen und die Kriminellen und Asozialen in den Zuchthäusern „konserviert" würden -, vereinbarte Thierack mit Himmler am 18. September 1942 die schubweise Auslieferung aller Sicherungsverwahrten an die Polizei „zur Vernichtung durch Arbeit".92 Am 1.April 1943 waren von den 12658 überstellten Sicherungsverwahrten bereits 5935 in den Konzentrationslagern - die meisten von ihnen in Mauthausen/Gusen - an Entkräftung und Krankheit gestorben. ${ }^{93}$ Zwar bestand die formelle Zuständigkeit der Justiz zur Anordnung gerichtlicher Sicherungsverwahrung weiter, doch war es im Hinblick auf die geschilderte Entwicklung nur folgerichtig, daß die Leipziger Kriminalpolizei dem dortigen Oberstaatsanwalt, der wegen der Anordnung einer Sicherungsverwahrung mit ihr Fühlung nahm, im April 1943 erklärte, die Sache erübrige sich, da „ein besonderer Wert auf die Verhängung der Sicherungsverwahrung grundsätzlich bei solchen Personen nicht mehr gelegt wird, die die Voraussetzung zur polizeilichen Vorbeugungshaft erfüllen. Die Vorbeugungshaft ist ein wirksameres Mittel zur Ausrottung [!] gefährlicher Berufsverbrecher als die Sicherungsverwahrung. “94 Auch auf dem Gebiet der „vorbeugenden Verbrechensbekämpfung“ hatte somit Himmlers Polizei der Justiz den Rang abgelaufen.

91 Vgl. RV des RJM (gez. Freisler) v. 18.8.42 an die GStAe, nachrichtl. an die OReiAe und Chefpräsidenten (a.a.O., Sign. R 22/1469).

92 Vgl. dazu die Dokumentation von L. Gruchmann, Hitler über die Justiz. Das Tischgespräch vom 20. August 1942 (VfZ 1964, S.86ff.), S.91 f.; zur Vereinbarung Thierack - Himmler v. 18.9.42 die Aufz. Thieracks (Nürnbg. Dok. PS-654, abgedr. in IMG XXVI, S. 201).

93 Vgl. dazu das geh. Schr. des Chefs des WVHA, SS-Obergruppenf. u. General der Waffen-SS Pohl, an Himmler v. 18.3.43; Pohls undat. Entw. eines Schr. an den RJM mit Genehmigung Himmlers v. 14.4.43 (Arch. des IfZ, Sign. Fa 183 a, Bl.63ff.).

94 Vgl. Ber. des OStA in Leipzig v. 30.4.43 an das RJM, über den GStA Dresden (Akten des RJM, BA, Sign. R 22/1469). 